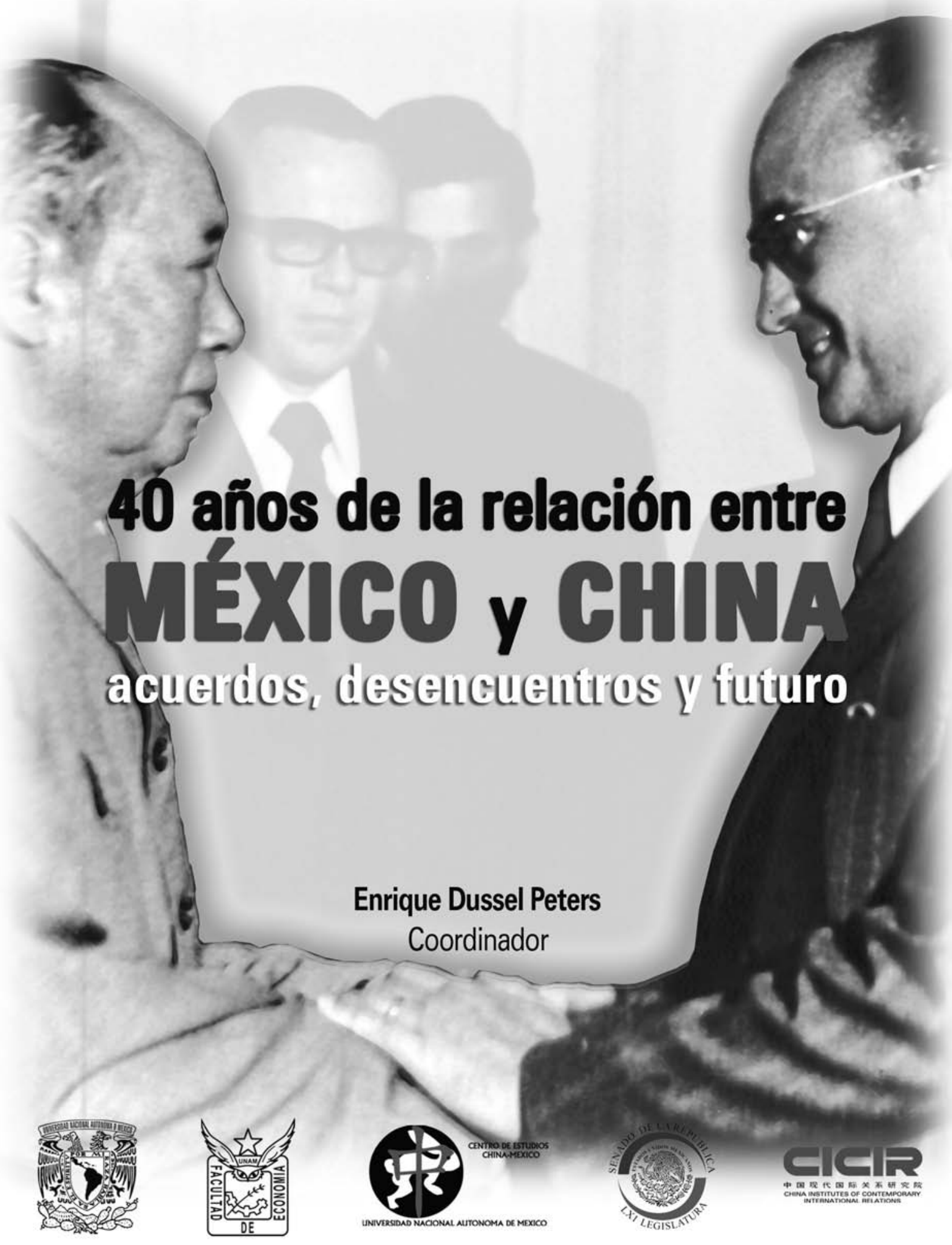


Cuarenta años de la relación entre México y China: acuerdos, desencuentros y futuro

Editores: Enrique Dussel Peters, Yolanda Trápaga Delfín

Diseño de portada e interiores: Wallys González Dorantes

$\begin{array}{ll}\text { Universidad Nacional Autónoma de México } \\ \text { Dr. José Narro Robles } & \text { Rector } \\ \text { Dr. Eduardo Bárzana García } & \text { Secretario General } \\ \text { Lic. Enrique del Val Blanco } & \text { Secretario Administrativo } \\ \text { Dr. Francisco José Trigo Tavera } & \text { Secretario de Desarrollo Institucional } \\ \text { Mtro. Miguel Robles Bárcena } & \text { Secretario de Servicios a la Comunidad } \\ \text { Lic. Luis Raúl González Pérez } & \text { Abogado General }\end{array}$

\title{
Facultad de Economía
}

Dr. Leonardo Lomelí Vanegas

Mtro. Eduardo Vega López

Lic. Javier Urbieta Zavala

Dr. Arturo Huerta González

Dr. Cesar Octavio Vargas López

Ing. Alejandro Pérez Pascual

Director

Secretario General

Secretario Administrativo

Jefe de la División de Estudios de Posgrado

Jefe de la División de Estudios Profesionales

Jefe de la División del Sistema Universidad Abierta

\section{Centro de Estudios China-México \\ Dr. Enrique Dussel Peters \\ Coordinador \\ Dra. Yolanda Trápaga Delfín \\ Responsable}

\section{China Institutes of Contemporary International Relations \\ Dr. Cui Liru \\ Presidente}

\section{Instituto de Estudios Latinoamericanos}
Dr. Yang Shuoguo
Director Ejecutivo

\author{
Senado de la República \\ LXI Legislatura \\ Mesa Directiva \\ Sen. José González Morfín Presidente \\ Sen. Francisco Agustín Arroyo Vieyra Vicepresidente \\ Sen. Ricardo Francisco García Cervantes Vicepresidente \\ Sen. Silvano Aureoles Conejo Vicepresidente
}

Comisión de Relaciones Exteriores, Asia Pacífico

Sen. Carlos Jiménez Macías Presidente

Sen. Javier Castelo Parada Secretario

Sen. Eugenio Govea Arcos Secretario

DRC

Universidad Nacional Autónoma de México

Facultad de Economía

Centro de Estudios China-México

Facultad de Economía-UNAM, edificio "B", segundo piso. Ciudad Universitaria. Cp. 04510.

México, DF. Tel. 56222195

Primera edición: 2012

ISBN: 978-607-02-2952-7

Impreso en México 
Introducción.

Patricia Espinosa Cantellano

40 años de la relación entre México y China

Zeng Gang......

Transmitiendo la amistad para abrir nuevas perspectivas en las relaciones entre

China y México

Carlos Jiménez Macías

40 años de relaciones diplomáticas entre México y China

Chen Yuming

Relaciones económicas y comerciales bilaterales entre China y México

Sección 1: La visión de los embajadores.

Eugenio Anguiano Roch

Sin sustento político, imposible construir relaciones económicas bilaterales sólidas

Cecilio Garza Limón

México ha dejado de soñar. No perdamos lo mejor que tiene su país: su juventud

Sergio Ley López

Algunas reflexiones sobre el futuro de la relación México-China

Omar Martínez Legorreta.

Intercambio cultural y asistencia técnica. Grupos de estudiantes chinos en otros países. La experiencia mexicana en los años 70

Jorge Eduardo Navarrete.

La relación bilateral China-México: una reflexión personal

Sección 2: Economía, comercio e inversión

Enrique Dussel Peters.

Aspectos comerciales y de inversión entre China y México: ¿colisión o acuerdo?

Jimmy Li

La Cámara (General) de Empresarios Chinos en México 
Rafael Valdez Mingramm

2012, año de oportunidad para renovar votos con China

Yang Zhimin.....

Cooperación económica y comercial entre China y México: elevando el nivel desde una óptica estratégica

Sección 3: Aspectos culturales.

Edgardo Bermejo Mora.

La fábrica 798 de Pekín, un ejemplo elocuente de arte público y una nueva plataforma para la cooperación cultural independiente entre México y China

Flora Botton Beja

Continuidad y fractura en la cultura china

Raúl Lomelí Rodríguez

Testimonios y pinceladas acerca de la realidad en 40 años de relaciones

diplomáticas entre China y México

Wu Yongheng. 153

Culturas: encuentro sí, confrontación no

Sección 4: Aprendizaje del chino

Jenny Acosta Trujillo

La enseñanza del idioma chino. La experiencia en la Universidad Nacional

Autónoma de México

Liljana Arsovska. 169

La enseñanza del chino en México: qué, cómo y para qué

Edmundo Borja Navarro

El idioma chino en el Centro de Enseñanza de Lenguas Extranjeras (CELE-UNAM)

María de Lourdes Cuéllar Valcárcel.

El aprendizaje de chino en México. Breve reflexión sobre cómo optimizar su aprendizaje

Lingyan Zhou Li.

El idioma chino, la lengua del futuro. Instituto Confucio el camino para llegar a él 
Simón Levy-Dabbah

La minería: el puente de plata estratégico entre México y China

Sergio E. Martínez Rivera

Lo urbano-ambiental en la relación México y China

María Teresa Rodríguez Rodríguez.

China. Políticas agrícolas antes y después de la crisis alimentaria de 2008

Yang Shouguo

Cuarenta años de las relaciones sino-mexicanas: evaluación, perspectiva y reflexión

Liu Sun Xuedong

Transformación de la propiedad colectiva a la privada en la tenencia de la tierra.

Yolanda Trápaga Delfín

La producción alimentaria en China y México. Dos historias contrapuestas

del subdesarrollo

Sección 6: La relación política binacional

Romer Cornejo

De la coincidencia diplomática a la competencia económica

Rafael Fernández de Castro y Diego Cándano Laris.

China: una relación prioritaria para México en el futuro inmediato

José Ignacio Martínez Cortés

La participación de China en la política internacional a través de su poder nacional

Jorge Nuño Jiménez

Cuarenta años de relaciones diplomáticas México-China. El nuevo diálogo de naciones amigas

Arturo Oropeza García .

La serpiente emplumada y el dragón chino: cuarenta años de un reencuentro ancestral

Sun Yanfeng

Mirada retrospectiva y reflexiones sobre la relación política entre China-México durante cuatro décadas 
Tatiana Alcázar Carrasco

La relación China-México. La experiencia de la Ciudad de México

Flor de María Cañaveral Pedrero

Puerto Chiapas. Puente logístico para China en México y Centroamérica

Gustavo Adrián Carrillo Jiménez y Misael López Vergara

La experiencia de la AMSDE con el programa de negocios México-China

Ricardo Román Chang Gamboa

Las acciones gubernamentales tejen las relaciones comerciales

Carlos Heredia Zubieta, Alexis Rivera y Jing Wang

Las relaciones internaciones de las entidades federativas mexicanas con las provincias chinas

Eloy Vargas Arreola

China: competencia global en los mercados locales. El caso de la guitarra

Paracho vs. "made in China"

Sección 8: Las experiencias de las empresas

ProMéxico

Oportunidades comerciales y de inversión entre México y China

Kuan Tai.

La experiencia de la Expo-China México 2009-2011 y Expo Asia-Pacífico 2011.

Misiones mexicanas a China

Enrique Tejeda Canobbio

El impulso de las empresas de pueblo y aldea (EPAs) al desarrollo económico de China

Oscar Eduardo Toulet Lazos y Rosalba Delgado Alvarado. 381 Huawei. Apoyo global y su participación en México 
Jorge Octavio Fernández Montes.

Encuentros y desencuentros. México y la República Popular China antes del establecimiento de relaciones diplomáticas (1949-1972)

Jorge Gómez Izquierdo 401

La hostilidad racista de México contra el ser chino

Natividad Gutiérrez Chong 411

Reflexiones sobre la etnicidad del estado-nación de China y de México

Sobre los autores 



\section{Introducción}

El 14 de febrero de 2012 la República Popular China y los Estados Unidos Mexicanos conmemoran los 40 años del establecimiento de relaciones diplomáticas en un espíritu de "respeto mutuo de su soberanía, independencia e integridad territorial, la no agresión, y la no intervención en sus asuntos internos o externos". El comunicado conjunto de entonces, sin lugar a dudas, constituyó un hito en la relación entre ambas naciones. Si bien otros dos países latinoamericanos habían avanzando ya en el reconocimiento diplomático de China, la profunda relación y agenda de trabajo entre China y México y la genuina cercanía política entre los funcionarios del más alto nivel permitieron realizar múltiples actividades conjuntas. Destacan, entre otras, el remarcable programa en el que fueron recibidos de manera permanente varias generaciones de estudiantes chinos entre 1974 y 1982, en el que se formaron los que años después serían importantes personalidades chinas del mundo diplomático especialista en América Latina. De la misma manera se dio curso a un diálogo ininterrumpido dentro del marco de los países no alineados que se coronó con acuerdos de alto nivel en temas internacionales y de América Latina, como el reconocimiento de una zona libre de armas nucleares, entre muchos otros temas.

En este marco, el presente documento busca lograr una profunda reflexión interdisciplinaria, crítica y constructiva sobre estos últimos cuarenta años de la relación bilateral, con una perspectiva propositiva y hacia el futuro. Con este objetivo se convocó a un grupo significativo de funcionarios, académicos, políticos, empresarios y expertos -probablemente uno de los más amplios en la historia de dichos cuarenta años de relación entre ambos países- para mejorar y profundizar el diálogo con base en un análisis compartido que resulte en un conocimiento más profundo y en mejores propuestas para una nueva etapa en la relación entre las dos naciones. Consideramos que la participación de casi cincuenta ponentes -unos mexicanos, otros chinos- con una diversidad de enfoques, proveniente de una enorme heterogeneidad disciplinara y de prácticas profesionales, será un verdadero aporte a un rico y necesario debate que dé un contenido sustantivamente superior a esta relación de tantos años. El conjunto de tales reflexiones las presentamos en este libro que se divide en 9 secciones que reflejan en buena medida la compleja diversidad de la relación entre China y México: la visión de los embajadores mexicanos en China, aspectos económicos y comerciales, aspectos culturales, el aprendizaje del mandarín, temas de minería, agricultura y medio ambiente, temas políticos binacionales, el creciente papel de las entidades federativas, la experiencia de las empresas y la larga historia compartida entre ambas naciones.

Existe un creciente consenso en México, así como entre los autores en este libro, sobre considerar que la relación entre México y China debiera no sólo ser político-estratégica -más allá de su establecimiento formal hace varias décadas-, sino que debiera 
también basarse en una agenda de trabajo para el corto, mediano y largo plazo, apoyada sólidamente por ambos gobiernos y el sector empresarial del más alto rango. De igual forma, también es evidente la necesidad de un acercamiento político entre ambos países, evocando particularmente que durante la década de los setenta se compartía una agenda política que incrementó la cooperación recíproca en todos los niveles y que contrasta con el claro deterioro que ha venido sufriendo la relación en los últimos tiempos hasta alcanzar su clímax en 2011.

Por otro lado, el documento refleja que China y México deben hacer un mayor esfuerzo para su mutuo conocimiento y sobrellevar importantes mitos que perjudican el buen entendimiento entre sus gobiernos. La larga e histórica relación en ámbitos como la cultura, la política y la academia, debieran fortalecerse con otras acciones que involucren a empresarios, legisladores y medios de comunicación, entre otros. Esta perspectiva pondría en su justa dimensión la relación entre dos países como México y China. Por el momento y desgraciadamente, estos aspectos no hacen justicia a la multifacética vinculación que se remonta claramente al siglo XVI y no es sólo de las últimas cuatro décadas.

Por último, parece también existir un especial potencial entre las dos economías en el ámbito institucional. Si bien existen la Comisión Binacional México-China y el Grupo de Alto Nivel (GAN) que funcionan desde hace más de un lustro, claramente ambas requieren de un apoyo administrativo, financiero y político para una mejor toma de decisiones y una gestión superior de los asuntos entre China y México. Por el momento, ambas instituciones no han recibido la debida atención por parte de los funcionarios y empresarios comprometidos en este rubro, ni en un país ni en el otro.

En este contexto la cooperación por parte de la Comisión de Relaciones Exteriores, Asia-Pacífico de la Cámara de Senadores, del Instituto de Estudios de América Latina del Instituto de China de Relaciones Contemporáneas Internacionales (CICIR, por sus siglas en inglés) y del Centro de Estudios China-México de la Facultad de Economía de la Universidad Nacional Autónoma de México es particularmente relevante y refleja los esfuerzos que se vienen realizando en ambos lados del Pacífico desde hace décadas. Las tres instituciones tienen ya varios años trabajando sobre la temática sino-mexicana.

No nos queda más que invitar a todos los interesados a comprometerse con el quehacer del análisis y la investigación crítica sobre China desde una perspectiva latinoamericana y mexicana y, particularmente, a participar en la difusión de sus resultados. Este horizonte, sin lugar a dudas, permitirá una creciente convergencia y asegurará el deseado reencuentro entre nuestros dos países.

\author{
Dr. Enrique Dussel Peters \\ Coordinador
}

Centro de Estudios China-México

Facultad de Economía
Dra. Yolanda Trápaga Delfín

Responsable

Centro de Estudios China-México

Facultad de Economía

\section{Universidad Nacional Autónoma de México}




\section{0 años de la relación entre México y China}

Patricia Espinosa Cantellano

Agradezco a la Universidad Nacional Autónoma de México, y en particular al doctor José Narro Robles, la gentil invitación que me permite participar en este evento conmemorativo del 40 aniversario del establecimiento de relaciones diplomáticas entre México y China. La amistad entre nuestros países es hoy más fuerte que nunca, y eso es precisamente lo que hoy celebramos.

Reconozco a la Comisión de Relaciones Exteriores Asia-Pacífico del Senado de la República, a la Facultad de Economía y al Centro de Estudios China-México de la UNAM, entre muchas otras instancias, la labor y el interés en desarrollar un mayor conocimiento de la República Popular China y su relación estratégica con nuestro país.

Permítanme felicitar muy calurosamente al embajador Zeng Gang, quien desde mucho antes de su llegada a México para encabezar la representación diplomática china trabajaba arduamente en promover un mayor conocimiento entre ambos países. Gracias a su gran labor, y por supuesto a la de nuestro representante en China, el embajador Jorge Eugenio Guajardo González, hoy es más fluido el diálogo político bilateral y multilateral entre nuestras naciones, así como mayores los intercambios económicos y la cooperación entre ambos países.

El día de mañana celebraremos el 40 aniversario del establecimiento de relaciones diplomáticas entre México y la República Popular China. No obstante, los contactos y la amistad entre ambos pueblos datan de mucho tiempo atrás.

Nuestra relación se remonta varios siglos en el pasado, al inicio de las travesías de la célebre Nao de China, que permitió establecer un comercio fructífero durante el periodo virreinal, antes del surgimiento de México como nación independiente. Posteriormente, a finales del diglo XIX, México suscribió con China el Tratado de Amistad, Comercio y Navegación que habría de sentar las bases para impulsar los vínculos de amistad y cooperación que hoy nos caracterizan.

Desde el establecimiento de relaciones diplomáticas, el 14 de febrero de 1972, la firme amistad entre nuestros pueblos y gobiernos se ha basado en el reconocimiento de la República Popular China como legítima representante de toda la nación china, en los términos acordados por la Asamblea General de la Organización de las Naciones Unidas, y reconociendo su indivisibilidad territorial.

A lo largo de cuatro décadas, China y México han construido un importante andamiaje jurídico e institucional para dar cauce a la relación bilateral y para tener un papel más activo en la escena internacional. Nuestros países trabajan juntos y construyen posiciones comunes respecto de algunos de los principales temas de las relaciones internacionales contemporáneas.

Hoy en día, en que el siglo XXI es ampliamente reconocido como el "Siglo del Pacífico", y dentro de un contexto de bajo crecimiento económico en Europa y Norteamérica, 
Asia-Pacífico y China en particular se han convertido en una de las mejores alternativas de los países en desarrollo para lograr un mejor equilibrio no sólo en sus relaciones económicas externas, sino, sobre todo, en el establecimiento de alianzas mutuamente benéficas.

Quiero subrayar que, como economías emergentes, México y China trabajan juntos para enfrentar y superar importantes retos de carácter global, como el cambio climático y la necesidad de alcanzar una sólida recuperación económica. Este esfuerzo está orientado no sólo a favorecer nuestros intereses, sino el de las naciones en desarrollo en su conjunto.

En el contexto de los acelerados cambios en el mundo y acorde con las transformaciones políticas y económicas que las sociedades mexicana y china han tenido en los últimos años, ambos países han profundizado y dinamizado sus relaciones con una visión estratégica, integral y de largo plazo.

La voluntad común de construir una relación sólida, bajo los principios de beneficio mutuo e intereses compartidos, ha marcado los lazos desarrollados en estos 40 años. Con esa determinación hemos logrado avances sustantivos en la relación, como es el establecimiento de la Asociación Estratégica en 2003; con ella dimos inicio a una nueva etapa en la relación entre México y China.

Gracias a la labor de la Comisión Binacional, establecida en 2004, y principal medio para instrumentar nuestra Asociación Estratégica, nos hemos convertido en socios cada vez más cercanos. La última reunión de la Comisión se realizó en esta ciudad en 2010. Aunque es un mecanismo de carácter gubernamental, desde su tercera edición incorporamos la participación de académicos y, desde la la cuarta, la de representantes del sector empresarial. China es hoy el único país de Asia con el que tenemos un mecanismo con un alcance tan amplio.

En el marco de la Comisión Binacional, adoptamos dos programas de acción conjunta (2006-2010 y 2011-2015), por medio de los cuales hemos dado un enfoque de planeación a futuro a nuestros vínculos, definiendo líneas de acción específicas para ampliar la interlocución a nivel bilateral y multilateral en los principales foros en que México y China son socios.

De igual forma, el interés por mantener una interlocución permanente con China se ha reflejado de manera especial con las visitas de todos los Presidentes de México a ese país desde hace cuatro décadas, y los que han realizado los presidentes y primeros ministros de China a nuestro país.

El presidente Felipe Calderón realizó una visita de Estado a China en 2008. Además, se ha reunido con el presidente $\mathrm{Hu}$ Jintao en el marco de los más importantes foros internacionales. Este año esperamos recibir nuevamente en México al presidente Hu, en ocasión de la Cumbre del Grupo de los 20, que se efectuará en Los Cabos, en junio.

A estas visitas se suman las de cancilleres, gobernadores, parlamentarios, empresarios y académicos, además de los contactos entre autoridades estatales y locales, que han tenido un papel cada vez más relevante para intensificar y dotar de un enfoque integral a la relación.

A nivel de cancillerías, mantenemos un diálogo fluido. Personalmente, me he reunido en múltiples ocasiones con el excelentísimo ministro Yang Jiechi, con quien he 
trabajado siempre de manera armónica y por demás fructífera. Contamos también con reuniones de diálogo estratégico, de consultas políticas bilaterales y planeación política, cuyas últimas ediciones se celebraron el año pasado.

Con todas estas acciones hemos logrado profundizar el intercambio de puntos de vista sobre temas globales de valor estratégico, y no sólo enfocarnos en la evaluación de la relación bilateral. Quiero destacar que el nivel y la intensidad del diálogo político con China, tal y como se desarrolla actualmente, no tiene precedente en la historia de la relación bilateral. Ello se debe a que ampliamos el marco jurídico, adecuándolo a las nuevas realidades en ambos países, así como a la prioridad de dar un enfoque integral a la relación. Desde el año 2001 hemos suscrito alrededor de 45 tratados y acuerdos interinstitucionales, a los que se suman los instrumentos que han formalizado las autoridades locales.

Quiero destacar, además, que la presencia institucional mexicana en China se ha fortalecido considerablemente. Después de Estados Unidos y Canadá, nuestros vecinos y socios en el TLCAN, China es el país en el que más oficinas consulares mantenemos. Eso dice mucho de la importancia que concedemos a esa gran nación asiática. Nuestra red de consulados podría ampliarse aún más en el futuro. También contamos con oficinas de ProMéxico en Beijing y Shanghai y una del Consejo de Promoción Turística de México en la capital china.

La presencia de China en México es también de la mayor importancia. México es, como todos saben, un país multiétnico y multicultural, en el cual está también presente la cultura china. Durante varios siglos, el contacto con China enriqueció a la cultura y la sociedad mexicanas, dejando una huella muy importante. Aún hoy lo hace, a través de su importante comunidad chino-mexicana, formada por mujeres y hombres muy trabajadores, de gran valía para nuestro país. México se siente muy orgulloso de contar con una gran comunidad de ascendencia china. Hace dos semanas, a un costado de la cancillería, en el barrio chino de este ciudad, celebramos con ella, con gran alegría y colorido, la llegada del nuevo Año Chino del Dragón.

México y China han desarrollado una intensa agenda de cooperación educativa y cultural, como reconocimiento a la riqueza del legado milenario de ambos países y también para contribuir a un mejor conocimiento mutuo entre nuestras sociedades. Entre las acciones que se inscriben en ese marco se incluye el otorgamiento de becas, la cooperación entre instituciones educativas de educación superior y el establecimiento de cinco institutos Confucio en nuestro país, uno de ellos en la UNAM.

A través de estos institutos se promueve el aprendizaje del idioma chino, uno de los principales retos en la estrategia de acercamiento con China.

Como parte de las acciones acordadas para conmemorar el 40 aniversario de relaciones diplomáticas, México y China han convenido en ampliar la oferta de becas existente. Un mayor intercambio de jóvenes significa un mayor conocimiento, un mayor aprecio entre ambos países construido desde el corazón de nuestras sociedades. Hoy ambos países reconocemos que debemos seguir sumando esfuerzos para que cada vez más jóvenes mexicanos y chinos se beneficien de este esquema.

De igual manera, como podrá confirmarnos el senador Carlos Jiménez Macías, el diálogo interparlamentario se ha acrecentado, contribuyendo a ampliar los contactos 
con China y el entendimiento mutuo. En 2010 se estableció y celebró su primera reunión en el Foro Permanente de Diálogo entre el Congreso Mexicano y la Asamblea Popular Nacional de China. Tengo conocimiento de que en abril próximo se realizará la segunda reunión de este Foro.

En el ámbito económico, Asia-Pacífico es, como región, nuestro segundo socio comercial después de los miembros del TLCAN. México tiene con dicha región tanto comercio como el que mantiene con Europa y América Latina juntas. Asia-Pacífico es también nuestro más importante competidor en nuestro principal mercado de exportación y nuestro principal competidor en materia de recepción de inversión extranjera directa. No obstante, China es y seguirá siendo un socio estratégico de la mayor envergadura.

China se afianza como nuestro segundo socio comercial a nivel internacional y el primero en Asia-Pacífico. El comercio bilateral ha crecido notablemente. En el periodo 2000-2010 se incrementó más de 15 veces. En 2010 sumó casi 50 mil (49 mil 805) millones de dólares estadounidenses, aunque debemos señalar que las exportaciones mexicanas representan sólo el 10 por ciento de este comercio mientras que nuestras importaciones representan el 90 por ciento. Deseo dejar muy en claro que México no busca reducir su comercio con China. Por el contrario, con China queremos más y mejor comercio; queremos lograr un intercambio más equilibrado.

La naturaleza de las importaciones chinas a nuestro país y su comportamiento inciden directamente en la industria nacional. De acuerdo con cifras de la Secretaría de Economía, 65\% de las importaciones son insumos que requiere la industria mexicana para manufacturar productos como teléfonos celulares, televisores, refrigeradores e incluso acero para fabricación de autos, que después son exportados o consumidos en México.

Tenemos que disipar la percepción de que China es una amenaza para México. No lo es. Al contrario, China representa una gran y creciente oportunidad tanto en términos económicos como en una gran multitud de rubros. Es necesario que consideremos todas las ventajas que China nos ofrece como socio económico-comercial y que nos enfoquemos en aprovechar el inmenso potencial de nuestra relación.

Considero que, ante el dinamismo de los vínculos bilaterales, es indispensable que el sector privado mexicano se involucre cada vez más en las acciones gubernamentales de acercamiento hacia China y busque aprovechar las oportunidades de mercado, de innovación tecnológica, de cooperación que nos ofrece ese país.

También debemos enfocar nuestros esfuerzos para aumentar el flujo de inversiones chinas a México. Numerosas empresas mexicanas y chinas han llevado a cabo inversiones en uno y otro país demostrando así su confianza en la seguridad y las oportunidades de negocios que ofrecen. En el caso de China, destacan las actividades de firmas como Huawei y Golden Dragon. En el de México, sobresalen empresas como Bimbo, Grupo Maseca, Nemak e Interceramic.

Como suele ocurrir entre individuos y entre naciones que mantienen muy intensos intercambios, las relaciones entre México y China no han estado exentas de ocasionales diferencias. No obstante, la buena voluntad de ambas partes y la solidez de la relación han permitido superarlas rápidamente y continuar avanzando en la profundización de nuestra asociación estratégica. 
Como grandes países emergentes con un creciente papel de liderazgo en el mundo, México y China han trabajado cercanamente en los foros multilaterales y regionales como la Organización de las Naciones Unidas, APEC y G20.

El respaldo de China fue decisivo para el éxito de la Decimosexta Conferencia de las Naciones Unidas sobre Cambio Climático, la COP16, que realizamos en Cancún a finales de 2010 y la cual permitió renovar la confianza en el sistema multilateral como espacio idóneo para llegar a acuerdos para atender problemáticas globales como el cambio climático. Esta estrecha coordinación también parte del deseo compartido de impulsar los intereses de las naciones en desarrollo para enfrentar los desafíos del siglo XXI.

Este año seguiremos trabajando cercanamente en el marco de la Presidencia Mexicana del G20 ante la coyuntura económica internacional. Este espacio nos permitirá incidir de manera positiva en la toma de decisiones para avanzar en la consolidación de una economía global con un crecimiento vigoroso, sostenible y equilibrado.

La conmemoración de 40 años de relaciones diplomáticas entre México y la República Popular China es así un marco idóneo no sólo para refrendar el compromiso de continuar colaborando estrechamente, sino también para identificar nuevas acciones que nos permitan avanzar en una agenda de cooperación cada vez más amplia, acorde con la asociación estratégica que tenemos.

Sin pretender abarcar todos los aspectos de la relación, me gustaría destacar que México y China están llamados a encauzar mayores esfuerzos conjuntos para:

- Continuar manteniendo un diálogo político al más alto nivel e involucrar a mayores actores de la sociedad.

- Fortalecer aún más la promoción y la defensa de los intereses de los países en desarrollo en los foros multilaterales.

- Alentar mayores sinergias entres sus sectores productivos y empresariales que permitan generar condiciones para el desarrollo de alianzas.

- Promover mayores flujos de inversión en nichos de oportunidad que correspondan al tamaño de sus economías.

- Lograr que la cooperación en ciencia y tecnología se convierta en un pilar de la relación bilateral.

- Fortalecer el ejercicio de difusión ante sus respectivas poblaciones sobre las acciones de cooperación que México y China desarrollan y las oportunidades que ofrece una relación más intensa.

- Profundizar la enseñanza de los idiomas chino y español entre los estudiantes de ambos países que incida favorablemente en el conocimiento de sus respectivas sociedades y pueda abrir oportunidades para el desarrollo de otras actividades, incluida la de hacer negocios. En manos de nuestros jóvenes está el futuro de la relación México-China. Son ellos los próximos funcionarios y empresarios, quienes nos representarán en los foros multilaterales y quienes dirigirán la relación bilateral.

Para el gobierno mexicano resulta prioritario seguir intensificando su asociación estratégica con China. En esta labor se requiere una colaboración más estrecha entre las dife- 
rentes instancias de gobierno, empresarios, instituciones educativas y sociedad civil. De esta forma podremos aprovechar las oportunidades que se deriven de nuestra relación con uno de los actores fundamentales del siglo XXI.

El 40 aniversario del establecimiento de relaciones diplomáticas entre México y China se conmemora, como señalé anteriormente, durante el Año del Dragón. Nos toca a nosotros que éste sea un año de logros y avances en la agenda nacional y bilateral. México y China tenemos aún muchas cosas por hacer.

Esta iniciativa de conmemoración es una oportunidad para reflexionar sobre el futuro de la relación entre nuestros países; sobre lo que México y China queremos lograr en el futuro, a partir de lo que hemos ya construido en estas cuatro décadas. Por ello reitero mi reconocimiento a la Universidad Nacional Autónoma de México, porque ha sido siempre un espacio para el intercambio libre de ideas y la reflexión que genera conocimiento, base de toda riqueza y, quizá también, de todo bienestar. 


\section{Transmitiendo la amistad para abrir nuevas perspectivas en las relaciones entre China y México}

Zeng Gang

\section{Introducción}

Para mí es un gran placer y honor tener la oportunidad de asistir a este simposio conmemorativo del cuadragésimo aniversario del establecimiento de relaciones diplomáticas entre China y México para refrescar, junto con todos los amigos aquí presentes, la profunda amistad entre China y México y ahondar en el desarrollo duradero de las relaciones entre nuestros dos países. Antes que nada, quisiera expresar mis más cordiales saludos a todos los amigos que han contribuido a la causa de la amistad sino-mexicana durante largo tiempo, y mis más sinceros agradecimientos al Centro de Estudios ChinaMéxico de la UNAM, el principal organizador de este simposio.

China y México son dos naciones antiguas con largas historias y esplendorosas civilizaciones. A lo largo de la historia de la humanidad, las civilizaciones china, azteca y maya se contrastaron y realzaron mutuamente. En los pasados dos años, celebramos sucesivamente el sexagésimo aniversario de la proclamación de la Nueva China y el bicentenario de la Independencia de México, y conmemoramos el centenario de la Revolución de 1911 de China y el de la Revolución Mexicana. Estos importantes acontecimientos históricos registraron las heroicas luchas libradas por las dos grandes naciones y sus pueblos en uno y otro lado del Pacífico con el fin de lograr la independencia y liberación nacional.

El 14 de febrero de 1972 es una importante efeméride de la historia de los intercambios sino-mexicanos. Ese mismo día, sus líderes, con la visión estratégica de futuro y la extraordinaria sabiduría, decidieron establecer relaciones diplomáticas entre nuestros dos países, abriendo así un nuevo capítulo en los anales de los lazos sino-mexicanos. Desde entonces, las dos grandes naciones del mundo se han estrechado aún más las manos. Durante las cuatro décadas, a pesar de los cambios radicales que se han operado en la situación nacional e internacional, las relaciones sino-mexicanas siempre han mantenido una positiva tendencia de desarrollo y han mostrado un dinamismo inagotable.

A lo largo de los 40 años, los lazos políticos entre China y México son cada día más estrechos. Los dirigentes de ambos países han manejado en todo momento la situación general de las relaciones bilaterales desde una perspectiva estratégica. Un importante número de dirigentes chinos, entre ellos los presidentes de Estado y primeros ministros, han realizado visitas a México. Entre tanto, los presidentes en turno de México, desde Luis Echeverría Álvarez hasta Felipe Calderón Hinojosa, han visitado China durante sus mandatos. Entrado el nuevo siglo, China y México han creado sucesivamente varios importantes mecanismos de diálogo y cooperación que abarcan la asociación estratégica, la Comisión Binacional Permanente, el Diálogo Estratégico y el Foro de Diálogo 
Permanente entre la Asamblea Popular Nacional de China y el Congreso de la Unión de México. Gracias a la eficiente conducción y garantía política, China y México han firmado cerca de 60 convenios de cooperación en los diversos sectores. Estos documentos han enriquecido enormemente el contenido de las relaciones binacionales.

Durante el mismo lapso, la cooperación práctica entre China y México ha resultado fructífera. En 1972, año en que los dos países oficializaron sus relaciones diplomáticas, el comercio bilateral fue menos de los 13 millones de dólares, mientras que en 2011 esta cifra alcanzó los 34 mil millones, es decir, 2,600 veces más que en 1972. Asimismo, las inversiones mutuas que no existían cuando se establecieron las relaciones diplomáticas han crecido notoriamente. Hasta el cierre de 2011, las inversiones chinas en México sumaron 614 millones de dólares. Cerca de 60 empresas chinas, entre ellas, Huawei ZTE, Sinatex y GD Copper, han invertido en México. Mientras tanto, las inversiones mexicanas en China también van en constante aumento. Ciertos productos mexicanos, como la cerveza Corona, el pan Bimbo, las tortillas de maíz Maseca y los equipos electrónicos y de comunicación, son cada día más populares entre los consumidores chinos.

En los últimos cuatro decenios, los intercambios culturales entre China y México son cada vez más frecuentes. A partir de la década de los 70 del siglo pasado, muchas películas y telenovelas mexicanas han cautivado a la audiencia china y han contribuido a que las espléndidas culturas y civilizaciones mexicanas hayan gozado de mayor prestigio en el país asiático. México ha sido el país latinoamericano más conocido y más querido por los chinos. Desde el establecimiento de relaciones diplomáticas hace 40 años, China y México han formado a varios cientos de estudiantes de manera recíproca, quienes se han convertido en mensajeros de la amistad para los intercambios no gubernamentales entre nuestros dos países, y yo tengo la suerte de ser uno de ellos. Ahora México cuenta con cinco institutos Confucio, siendo el país latinoamericano con el mayor número de este tipo de instituciones. Además, en 2005 México obtuvo el estatus de Destino Autorizado para que grupos de turistas chinos puedan visitar estas tierras maravillosas. Al entonces embajador de México en China, Sergio Ley López, y a mí nos tocó la oportunidad de participar y contribuir a que ambos países celebraran un acuerdo en esta materia.

Durante dicho periodo, la confianza estratégica mutua entre China y México se ha fortalecido incesantemente. En los asuntos internacionales, nuestros dos países siempre se respetan y se tratan en pie de igualdad y mantienen estrecha comunicación y coordinación, además de ofrecer su sincera y eficiente solidaridad y ayuda a la otra parte. En los años 70, China y México unieron sus esfuerzos para defender los intereses de los países del tercer mundo. Actualmente nuestras dos naciones se coordinan y cooperan en el seno de las Naciones Unidas, el Grupo de los 20 y otras organizaciones y mecanismos internacionales, con el propósito de enfrentar juntos los diversos retos globales, lo que ha permitido que los consensos y la confianza mutua entre ambas partes van ampliándose y profundizándose constantemente.

Al echar una mirada retrospectiva a los 40 años de relaciones diplomáticas entre China y México, estamos más conscientes de que el desarrollo de las mismas no puede separarse ni de la visión futurista de los fundadores y promotores de la amistad sinomexicana, ni de la conciencia histórica de nuestros dos pueblos de promover los lazos 
amistosos bilaterales y tampoco de los grandes esfuerzos realizados tanto por los gobiernos como por las personalidades de los más diversos sectores sociales de ambos países para impulsar un sano y estable desarrollo de los vínculos binacionales. A mi juicio, los grandes éxitos de la cooperación bilateral en los últimos 40 años se deben a las siguientes causas:

Primero, ambos países se han adaptado a las tendencias generales de desarrollo de nuestra era. Los últimos 40 años transcurridos desde el establecimiento de relaciones diplomáticas entre China y México han sido la época en que la democratización de las relaciones internacionales, la multipolarización mundial y la globalización económica se han desarrollado a un ritmo muy acelerado. A lo largo de los 40 años de contactos, en lo político China y México han persistido en todo momento en respetarse y tratarse en igualdad de condiciones y en respetar la soberanía y la realidad nacional de cada una. En lo económico, ambas partes se han adherido al principio de beneficio recíproco y ganancias compartidas para lograr un desarrollo conjunto, y en los intercambios culturales, los dos países han insistido en aprender mutuamente y aprovechar las ventajas de cada uno, para dar realce y difusión a los frutos de sus propias culturas y de las de toda la humanidad. Los hechos han corroborado que justamente debido a que nos hemos adaptado a la corriente de nuestra época, hemos logrado llevar adelante de manera estable y sana las relaciones sino-mexicanas.

Segundo, un mayor desarrollo de los dos países ha generado fuerzas endógenas para la exitosa cooperación bilateral. China y México son importantes países emergentes y, durante los pasados 40 años, han registrado el mayor crecimiento económico en sus historias y ahora se encuentran en un periodo inmejorable de oportunidades de desarrollo. Desde que China adoptó la política de reforma y apertura al exterior en 1978, su economía ha crecido en un promedio anual del 9.9\%, mientras tanto, la economía mexicana también ha logrado el milagro del despegue. El balance de las relaciones bilaterales nos ha permitido constatar que tenemos en común la aspiración de hacer que nuestros países sean más prósperos y poderosos, de forma que ambas partes valoramos cada vez más la cooperación binacional y prestamos mayor atención a la consecución de las ganancias compartidas a través de la colaboración, lo cual ha contribuido a abrir horizontes mucho más amplios para el ulterior desarrollo de las relaciones binacionales y también ha permitido que la cooperación práctica entre China y México alcance su nivel actual.

Tercero, nuestros dos pueblos se identifican mutuamente, se conocen el uno al otro y están cerca del corazón. Un antiguo dicho chino reza: “La amistad entre dos países se basa en los sentimientos de afecto y cariño entre sus pueblos". China y México celebran los 40 años de relaciones diplomáticas, pero los contactos entre los dos pueblos se remontan a los tiempos antiguos. En el siglo V, el monje chino Hui Seng cruzó el Pacífico y llegó al territorio que hoy es México. En el siglo XVI, la Nao de China arribó a Acapulco, quedando así abierta la Ruta Marítima de la Seda. En el siglo XIX, la moneda mexicana de plata empezó a circular en China. La amistad entre los dos pueblos forjada a lo largo de la historia es cada día más profunda y se vuelven cada vez más fuertes sus deseos de acercarse y conocerse aún más. Por lo tanto, el establecimiento de relaciones diplomáticas entre China y México y el desenvolvimiento de las mismas se apoyan en las firmes bases sociales y de la opinión pública. 
Cuarto y último, las personas perspicaces de China y México han promovido conjuntamente las relaciones bilaterales y las han cuidado con esmero. Los fructíferos resultados de los 40 años de relaciones diplomáticas entre China y México se deben a los esfuerzos mancomunados de los dos gobiernos y pueblos y cada avance de estas relaciones ha sido la cristalización de los esfuerzos de los numerosos amigos, incluidos todos los presentes. Durante varias décadas, las personalidades amistosas de los diversos estratos sociales de ambos países han dedicado entusiasmo, esfuerzo y tiempo para fortalecer la amistad y la cooperación bilateral. Gracias a sus esfuerzos, la amistad sino-mexicana es cada día más sólida. Aprovechando esta ocasión, quisiera reiterar mis más cordiales saludos y sinceros agradecimientos a todas las personas de los diversos círculos sociales de ambas naciones que han contribuido de una u otra manera al fomento de la amistad sino-mexicana.

Actualmente, la situación internacional está experimentando los ajustes más profundos y complicados desde el fin de la Guerra Fría. La dimensión, la profundidad y la rapidez de estos cambios superan mucho lo que esperaba la gente. La interdependencia entre los distintos países del mundo ha sido una tendencia más evidente. La búsqueda de la seguridad y el desarrollo por medio de la cooperación se ha convertido en la corriente principal del mundo de hoy día. Tras los 40 años de desarrollo y acumulación, las relaciones sino-mexicanas se encuentran ahora en una plataforma histórica totalmente nueva. Como grandes naciones de sus respectivas regiones e importantes economías emergentes, la profundización de la asociación estratégica entre China y México no sólo corresponde a los intereses fundamentales de los dos países y pueblos, sino que también reviste un significado de gran importancia y largo alcance para la salvaguarda de la paz y el desarrollo mundiales, razón por la cual debemos aprovechar la celebración del 40 aniversario de relaciones diplomáticas y aunar nuestros esfuerzos para llevar las relaciones de cooperación estratégica sino-mexicanas a un nivel más alto.

Tenemos que intensificar la coordinación estratégica y aumentar la confianza política mutua. Las dos partes deben mantener la tradición de realizar intercambios estrechos de alto nivel y respetarse, entenderse y apoyarse mutuamente en los asuntos que atañen a sus intereses importantes y fundamentales. Los gobiernos, parlamentos y partidos políticos de ambos países han de aumentar sus contactos para mejorar la comprensión mutua y consolidar la base política de los lazos bilaterales. En junio próximo, los líderes del G20 se reunirán en Los Cabos, México y la quinta reunión de la Comisión Binacional Permanente se llevará a cabo en de este año. Ambas partes deben aprovechar estas oportunidades para ampliar aún más su coordinación y cooperación en los asuntos internacionales y bilaterales y marcar el rumbo estratégico para el futuro desarrollo de los dos países.

Debemos expandir aún más la cooperación práctica. Es necesario promover un crecimiento estable del comercio bilateral y mejorar incesantemente su estructura. Actualmente la amplitud, la profundidad y el ritmo de desarrollo de la cooperación económica y comercial entre China y México superan las variantes registradas en cualquier otro periodo. Hemos de seguir manteniendo esta positiva tendencia. A pesar de que surja inevitablemente algún que otro problema en el comercio bilateral, no debemos dejar de hacer cosas necesarias. Ambas partes deben trabajar juntos para elevar el nivel y 
la calidad de las transacciones comerciales. China está dispuesta a aumentar las importaciones desde este país azteca y también da la bienvenida a que la parte mexicana promueva aún más sus productos para ampliar su cuota de participación en el mercado chino. En la actualidad, el gobierno chino está esforzándose por reajustar la estructura económica y ampliar la demanda interna, lo cual supone nuevas oportunidades para expandir el comercio bilateral. Tenemos que incrementar incesantemente las inversiones mutuas, que se han quedado rezagadas con respecto al comercio bilateral y a las inversiones entre China y las naciones sudamericanas por la falta de megaproyectos estratégicos. En momentos en que tanto China y México se encuentran en una etapa de desarrollo acelerado, son enormes las potencialidades de la cooperación bilateral en materia de inversiones. China y México son fuertemente complementarios en áreas como la energía, los recursos naturales y la construcción de infraestructuras, por ello debemos explotar conjuntamente esos recursos y aprovecharlos.

Debemos ampliar los intercambios culturales y profundizar la amistad tradicional. Las autoridades de los dos países tienen que satisfacer los crecientes deseos de sus pueblos de incrementar contactos, seguir promoviendo activamente los intercambios amistosos en ámbitos como la educación, la cultura, la salud, la ciencia y tecnología y la prensa, y ampliar los intercambios entre diferentes regiones de ambos países y los no gubernamentales, con miras a consolidar las bases sociales de la amistad sino-mexicana. Asimismo, debemos aprovechar la ola de entusiasmo generado por la celebración del 40 aniversario de relaciones diplomáticas entre sus pueblos, para promover visitas mutuas de las delegaciones de los gobiernos nacionales y regionales y de los grupos artísticos y académicos, ampliando así los intercambios a distintos niveles y en diversos terrenos.

Debemos estrechar la coordinación y colaboración para defender los intereses comunes. China y México son grandes naciones emergentes en vías de desarrollo y encaran situaciones y desafíos similares. $Y$ ambos países comparten las mismas posiciones o asumen las posturas similares en muchos asuntos internacionales y regionales. Tenemos que fortalecer aún más las consultas y coordinaciones en dichos asuntos y estrechar la cooperación en la ONU, el G20 y otros mecanismos internacionales, en aras de defender los intereses comunes tanto de China y México como de otros países en desarrollo y contribuir a la paz, la estabilidad y el desarrollo del mundo entero.

Una célebre frase del famoso poeta mexicano Octavio Paz reza: “Un caminar de río que se curva, avanza, retrocede, da un rodeo y llega siempre". El establecimiento de relaciones diplomáticas entre China y México y su rápido desarrollo durante las cuatro décadas se deben justamente a que ambos países se han adaptado a la corriente de nuestra época y a que hemos realizado esfuerzos conjuntos. En momentos en que celebramos los 40 años de lazos oficiales, las relaciones de amistad y cooperación entre ambos países encaran nuevos horizontes. Me asiste la firme convicción de que China y México tendrán un futuro más brillante siempre y cuando trabajemos codo con codo, nos comprendamos y nos apoyemos mutuamente. iViva la amistad entre China y México! 



\section{0 años de relaciones diplomáticas entre México y China}

Carlos Jiménez Macías

En la víspera de la celebración del 40 aniversario del establecimiento de relaciones diplomáticas entre México y la República Popular China (China en lo subsecuente), resulta conveniente realizar un ejercicio retrospectivo que nos permita visualizar nuestro accionar a lo largo de este periodo, pero sin duda es mucho más importante tener claras las líneas estratégicas que el gobierno de México deberá desplegar para vincularnos efectivamente con la economía más dinámica del mundo y uno de los actores políticos que se prevé tendrán mayor influencia en el siglo XXI.

En este reflexionar sobre la relación bilateral, resulta vital entender que la China de los últimos años de Mao Zedong, del Gran Salto Adelante, de la Revolución Cultural, del aislamiento del escenario internacional y de escasas relaciones con los países cercanos a su entorno, esa China con la que el entonces presidente Luis Echeverría estableció formalmente relaciones diplomáticas, cambió radicalmente con la llegada de Deng Xiao Ping al poder.

La China de Deng Xiao Ping se mantuvo ocupada en conservar el modelo socialista pero con un componente pragmático que derivó en una serie de reformas económicas, con elementos capitalistas, que le permitieran enfrentar su grave crisis socio-económica.

El resultado fue de tal magnitud que a finales de las décadas de los 60 y 80 , China manifestaba un crecimiento económico con tasas cercanas al $10 \%$ anual en su PIB. Por otro lado, la relación política de México con China, en este periodo se circunscribía básicamente en el liderazgo que nuestro país mantenía en el llamado "Tercer Mundo", exigiendo el respeto de los derechos de todos estos países para el acceso a mejores condiciones de vida.

Fue hasta la década de los 90, con la restructuración del mundo bipolar, que se dotó a la relación bilateral de un componente que dinamizó gradualmente sus intercambios. El país asiático continuó con su proceso de profundas reformas económicas con la expansión del comercio exterior como uno de sus principales objetivos, mientras que México también se envolvía en el paradigma comercial a través de la firma del tratado de libre comercio con los dos países norteamericanos.

Ya para ese entonces el caudal de productos chinos comenzaba a inundar el mercado mexicano en un hecho que sigue definiendo en mucho nuestra relación bilateral contemporánea. Hay que señalar que durante este periodo, China y México se mantuvieron ocupados en sus asuntos internos, por lo que el desarrollo de los vínculos políticos, posterior al apoyo que brindó México para que la República Popular China ocupara un asiento permanente en el Consejo de Seguridad de la ONU y del ulterior establecimiento de relaciones diplomáticas entre ambos países, nunca fue una prioridad para ninguno de los dos gobiernos. 
El punto de inflexión en la incipiente relación ocurre justamente cuando, por un lado, el déficit comercial que mantenía México con China crece de manera exponencial y, por el otro, en el momento en que el llamado Dragón Rojo comienza a evidenciar el capital político que le otorga la gran cantidad de divisas obtenidas de su comercio exterior con el mundo en proceso globalizador.

A diferencia de aquella China con la que México estableció relaciones diplomáticas, su dimensión actual en el contexto internacional no solamente está determinada por ser el país más poblado del mundo y por representar el tercer país con mayor extensión territorial del planeta.

Hoy su gran progreso económico, que destaca por ser la segunda economía del mundo (en 2001 era la 6 ${ }^{\mathrm{a}}$ ), el primer exportador (en 2001 era el $7^{\circ}$ ), el segundo importador global de bienes (en 2001 era el 12), y su posición como principal acreedor de los EU, posicionan a China como actor determinante para el sistema económico mundial.

Actualmente también es el $2^{\circ}$ receptor de las inversiones extranjeras directas, después de Estados Unidos. A su vez, es el $5^{\circ}$ país inversor en el exterior, superando a Japón y Gran Bretaña. La lista Fortune Global incluye 61 empresas chinas entre las 500 mayores del mundo. En 2001, eran sólo 16.

En 2010, el PIB de China representó el 9.5\% del producto mundial. Según el Fondo Monetario Internacional (FMI), la economía china crecerá un 9.5\% en 2012. A largo plazo, el Banco Mundial estima que si su crecimiento es ascendente al $8 \%$ anual, duplicaría el tamaño de la economía de Estados Unidos en 2030.

Asimismo, las instituciones y organismos internacionales señalan que en este año 2012, China seguirá siendo el principal motor económico mundial y que tendrá una presencia destacada en los organismos financieros internacionales como el FMI y el Banco Mundial como líder de los países emergentes.

El ranking Fortune 500, que analiza a las 500 principales empresas mundiales, señala que en 2011 las tres primeras empresas del ámbito energético son chinas (Sinopec Group; China National Petroleum; Corporation CNPC, posicionadas en los lugares 5, 6 y 7 a nivel mundial respectivamente), desplazando de esa posición a las grandes empresas automovilísticas de Japón (Toyota Motor Corporation y Japan Post Holdings). ${ }^{1}$

En cuanto a recursos naturales, en 2008-2009 China produjo más de 30\% del algodón y del arroz mundial y más de $20 \%$ del maíz. Su peso como productor de harina y aceite de soya también superó $20 \%$. $^{2}$ Sin embargo, a pesar de su producción, China requiere recursos naturales y productos primarios (como petróleo, minerales de hierro, cobre, níquel, soya) para abastecer y garantizar suficiente disponibilidad de alimentos a su población.

En términos de metales y petróleo y de acuerdo con reportes elaborados por la Comisión Económica para América Latina y el Caribe (CEPAL), China consumió un 10\% del petróleo crudo a nivel mundial en $2010 .^{3}$

1 CNNMoney, “Global 500" en: http://money.cnn.com/magazines/fortune/global500/2011/ full_list/index.html. Consultado el 13 de enero de 2012.

2 Panorama de la inserción internacional de América Latina y el Caribe, 2010-2011. La región en la década de las economías emergentes, p. 28.

3 Comisión Económica para América Latina y el Caribe (CEPAL). 
Todos estos elementos económicos traen consigo profundas implicaciones en el ámbito político que le otorgan a la República Popular China cada vez mayor influencia en el escenario internacional, y también en la definición de los asuntos multilaterales de la agenda global con la posibilidad de ejercer su capital político en las resoluciones tomadas tanto por los organismos internacionales como por las diversas cumbres y foros mundiales donde se estipulan los lineamientos estratégicos de la amplia agenda internacional.

La magnitud que ha alcanzado la República Popular China, como ya lo han analizado diversos especialistas en la materia, es resultante de una política de una escrupulosa planificación de corto, mediano y largo plazos, con un componente de certidumbre en la continuidad de los proyectos gubernamentales.

\section{Pocos resultados en la relación bilateral}

Por terrible que parezca, los cambios mayúsculos que ha experimentado China en las últimas décadas parecieran no haber generado un cambio de política en el Estado mexicano ni motivado la elaboración de una estrategia diferenciada e integral desde el gobierno que permita adaptarnos a las condiciones que impone el país asiático en el escenario internacional y que nos faculte para conseguir beneficios equilibrados de dicha relación en un esquema complementario que trascienda el plano meramente comercial.

El establecimiento de una Asociación Estratégica en el 2003 y su Comisión Binacional Permanente han traído acuerdos y programas de cooperación que, si bien abarcan varios aspectos de la relación, no parecen detonar el potencial que existe en la relación México-China ni tampoco han correspondido a la importancia que ambos países se atribuyeron al constituir la mencionada asociación.

En el diálogo político aunque fructífero en visitas protocolarias, reuniones entre funcionarios, legisladores, académicos y empresarios, y que siguen destacando en el papel, han mostrado resultados cortos en alcance y muy lejos de impactar positivamente en los principales retos que existen en la relación bilateral.

La sociedad política que México mantiene con China se reduce al discurso de la profundización de la confianza mutua y a la conveniencia de que ambos países se mantengan como puentes de interlocución regionales para que tanto China como México se acerquen a los países de la región opuesta. Ambas premisas, aunque ciertas, no han sido lo suficientemente fuertes, vigorosas ni determinantes para que se robustezca la supuesta sociedad estratégica firmada en 2003.

En materia comercial aún persiste el gigantesco déficit para México generado por la carencia de incentivos para que el mercado mexicano equilibre la balanza y por otra parte por el perverso círculo de dependencia y alta concentración hacia el mercado norteamericano, soslayándose las ventajas que la verdadera diversificación traería para el aparato productivo mexicano.

El comercio bilateral total sigue manteniéndose en aumento constante, las estadísticas de la Secretaría de Economía revelan que México es el segundo socio comercial y primer importador de China en América Latina, y aunque de enero a junio de 2011, 
el comercio total alcanzó 26 mil 586 millones de dólares, casi 5 mil millones más que lo registrado en el mismo periodo de 2010 (21 mil 607 millones de dólares), se sigue incrementando en la misma proporción el déficit comercial, comprando mucho más de lo que vendemos.

Al ver estos resultados es claro que México no está siendo eficiente para vincularse con China y contentarse con mantener el superávit comercial con EU para intentar equilibrar su balanza comercial con el mundo.

\section{La relación bilateral vista desde el Poder Legislativo}

El Poder Legislativo, particularmente la Cámara de Senadores por sus facultades constitucionales, ha insistido con especial énfasis en la necesidad para nuestro país de establecer una agenda de política exterior específica con China que asuma con mayor compromiso el significado de la asociación estratégica establecida y que lleve a buscar una verdadera complementariedad entre ambos países tanto en el ámbito político como en el económico agregándole el componente de cooperación con un nuevo enfoque que permita asumir nuestras fortalezas y explorarlas con China.

En la Comisión de Relaciones Exteriores Asia-Pacífico del Senado mexicano, preocupados por la falta de una estrategia integral con China y con el objetivo de construir un canal de diálogo adicional a la rigidez protocolaria que caracteriza a la diplomacia tradicional, decidimos impulsar la creación del Foro de Diálogo Permanente con nuestra contraparte china.

Este foro nace como respuesta al creciente interés mutuo entre el Senado mexicano y la Asamblea Popular Nacional de la República Popular China en los últimos tiempos, para construir un marco privilegiado para el diálogo, el intercambio y la cooperación parlamentaria.

Como ya se hizo referencia, las numerosas interacciones entre funcionarios de alto nivel durante los últimos años y las acciones manifestadas por el gobierno de México y su diplomacia en la búsqueda por el fortalecimiento de los vínculos políticos, hasta ahora no han correspondido totalmente al potencial de ambos países.

Para la Comisión de Relaciones Exteriores Asia-Pacífico de la Cámara de Senadores, el desarrollar la relación política con China es una de sus prioridades, por lo que el diálogo al más alto nivel sobre asuntos bilaterales y temas internacionales y regionales ha sido intenso y frecuente. Sin embargo, en la siguiente etapa de nuestras relaciones, se debía fortalecer dicho vínculo tomando en cuenta el peso específico que tienen México y China en sus respectivas regiones, para generar las condiciones adecuadas para la promoción de nuestros intereses en China.

En tal virtud, la Cámara de Senadores y la Asamblea Popular Nacional de la República Popular China, a iniciativa de la Comisión de Relaciones Exteriores Asia-Pacífico, acordaron formalizar el Foro Parlamentario México-China, el cual tiene como principal objetivo vigorizar el diálogo político para profundizar las convergencias sobre asuntos de interés mutuo, desde el ámbito parlamentario. Este foro pretende convertirse en un instrumento efectivo no sólo para el fortalecimiento de las relaciones bilaterales entre 
México y la República Popular China, sino como un instrumento para encontrar soluciones alternativas a los retos que persisten en la relación bilateral y, más aún, que sea un espacio adecuado para ventilar y defender con toda contundencia nuestros intereses, siempre buscando la concertación y la solución que beneficie a la relación bilateral en el largo plazo.

\section{Perspectivas de la relación bilateral}

China, en los próximos años cada vez jugará un papel más protagónico en el escenario internacional y ejercerá mayor presencia política internacional. Por lo tanto, China debe ser una oportunidad para México allende el discurso y empezar a comprender que podemos beneficiarnos de mejor manera con la segunda mayor economía del mundo.

Si bien es cierto que existe una feroz competencia por el mercado estadounidense, China no debe representar una amenaza competitiva para México; al contrario, se debe fortalecer la competitividad nacional para asumir un liderazgo en la competencia internacional, pues ambos países tienen el potencial y la oportunidad para desarrollar una mayor cooperación económica.

Efectivamente, México ha sido desplazado consistentemente por China en los mercados de manufacturas en lo general, y de la cadena metalmecánica en lo particular, de Estados Unidos, de América Latina y del resto del mundo, pero gran parte de ello generado por una frecuente visión cortoplacista que insiste en preocuparse más por la "amenaza china" que por la ocupación en encontrar medidas para asumir el contexto internacional y tener la capacidad de insertarse en la gran cadena productiva china, en donde parece que hay cabida para todos aquellos osados que buscan constantemente romper con los paradigmas tradicionales de una manera inteligente con altos niveles de eficiencia.

Desde el punto de vista político, ambas naciones han mantenido un diálogo cercano y del más alto nivel, pero falta extender su cooperación y desarrollo en los ámbitos de la ciencia y la tecnología, así como en la cultura y la educación. Urge a México aprovechar el vínculo con China para fortalecer nuestra capacidad de innovar con el objetivo de aumentar nuestra competitividad que hasta ahora se ha mantenido como uno de nuestras principales debilidades en la relación no sólo con China sino con el mundo.

México y China deben descubrir nuevas posibilidades, mejorando el mutuo conocimiento, acortando las distancias y ampliando el conocimiento, la cooperación y el entendimiento recíprocos.

China representa más del $20 \%$ de la población mundial (con 1 mil 354 millones de habitantes) y su clase media está en continuo aumento (157 millones de habitantes). Se trata de un mercado potencial crucial que México debería estar explorando con gran interés.

Siendo China el país más dinámico de la economía mundial, México debería esforzarse por definir una nueva relación con ella. China representa un mercado potencial cuya clase media tiene un creciente poder adquisitivo, que consume y demanda productos nuevos en los que México tiene interés exportador. China se ha convertido en 
un importante importador y consumidor de productos agroalimentarios. México podría convertirse en un exportador potencial de ciertas manufacturas de tecnología que actualmente exporta al mercado estadounidense.

En el aspecto geopolítico se puede encontrar un futuro esperanzador para las relaciones sino-mexicanas. Temas tales como la no proliferación de armas nucleares y desarrollo del recurso nuclear para fines pacíficos y la cooperación para el desarrollo ecológicamente sustentable son promisorios para la relación bilateral y la coordinación de acciones de carácter multilateral.

México, en los foros internacionales, debe seguir fomentando en conjunto con China la cooperación en materia ecológica, desarrollo de fuentes alternas de energía, conservación y racionalización del uso del agua y construcción de un nuevo sistema financiero internacional.

No cabe duda de que en los años por venir, la relación con China seguirá siendo marginal y altamente deficitaria para México de no cambiarse profundamente la visión de aproximación que hasta ahora se ha mantenido por nuestro país. México no puede permitirse continuar por esa senda de la indefinición o de las definiciones parciales motivadas por el desconocimiento, por el desdén o por la insana fijación de seguir dependiendo sólo de la economía de los Estados Unidos. De perdurar cualquiera de los tres casos, estaremos dejando escapar otra oportunidad más para hacer de la política exterior un medio para fortalecer nuestras capacidades internas y la posibilidad de retomar el rumbo de país que el interés nacional exige. 


\section{Relaciones económicas y comerciales bilaterales entre China y México}

Chen Yuming

De acuerdo con estadísticas de la Aduana de China, el volumen del comercio entre China y México en el año 2010 fue de 24,690 millones de dólares. Las exportaciones de China a México totalizaron 17,870 millones de dólares, mientras que las importaciones de China desde México sumaron 6,820 millones de dólares. Los principales productos de exportación de China para México son, entre otros, computadoras, productos de tecnologías de telecomunicación, instrumentos y medidores, equipos para procesamiento automático de datos y sus compuestos, tejidos e hilados y productos textiles terminados. Entre los productos que China importa desde México se destacan principalmente computadoras y productos de comunicación, cobre y condensados, circuitos integrados, automóviles (incluyendo autopartes), petróleo crudo, maquinarias y equipo, hierro y condensado.

De enero a noviembre de 2011, el comercio bilateral entre los dos países se ubicó en 30,450 millones de dólares, con un aumento de 37.2\% en comparación con el mismo periodo del año pasado. La exportación de China a México alcanzó los 21,915 millones de dólares, mientras que la importación desde México llegó a 8,535 millones de dólares, lo que representó respectivamente un aumento de 34.6\% y 44.3\% en relación con 2010 . Las estadísticas del año 2011 ponen en claro que México es el segundo socio comercial más importantes de China en América Latina, después de Brasil. Las exportaciones de China a México se posicionan en el segundo lugar en todas las exportaciones desde China a los países latinoamericanos, después de Brasil, en tanto que las importaciones chinas desde México ocupan el cuarto lugar después de Brasil, Chile y Venezuela.

En 2010, de la totalidad de las exportaciones de China hacia México, la exportación de equipo, maquinaria y productos electrónicos ocupó $71.6 \%$ con un valor de 12,800 millones de dólares la exportación de productos de industria ligera representó $10 \%$ con un monto total de 1,790 millones de dólares mientras que la de los productos textiles y de prendas de vestir registró una suma de 1,320 millones de dólares, con una participación de 7.4\% en todas las exportaciones chinas. Aunque México tiene un gran déficit comercial con China, viene comprando desde China gran cantidad de componentes y repuestos de computadoras y televisores, instrumentos y medidores electrónicos, así como autopartes con el fin de ensamblarlos en México y luego exportarlos como productos finales a EU y otros países vecinos. Por esa razón se puede afirmar que los productos exportados desde China a México no son, como se ha dicho, una inundación ni una realidad monstruosa. Al contrario, es un comercio con perfil de ganancia mutua para México y China, que facilita de la mejor manera el incremento de la productividad manufacturera de México y la ampliación de las exportaciones desde México a Estados Unidos y otros países. 
A partir de 2005, las importaciones de China desde México vienen creciendo notablemente, desde los 2,230 millones de dólares en 2005, 2,610 millones de dólares en 2006, 3,260 millones de dólares en 2007, 3,710 millones de dólares en 2008, 3,880 millones de dólares en 2009 hasta los 6,820 millones de dólares en 2010. En los primeros 11 meses de 2011, las importaciones desde México llegaron a los 8,535 millones de dólares. Es necesario señalar que en 2009, cuando las exportaciones de México a otros países disminuyeron, sólo las exportaciones a China lograron un aumento continuo.

En cuanto a las inversiones chinas en México, hasta el mes de noviembre de 2011, tenemos registradas 41 empresas chinas en México, con una inversión acumulada de 614 millones de dólares; dentro de estas empresas, están cuatro del sector petrolero y de contratación de construcción portuaria, dos de telecomunicación, diez de minería, dos del sector textiles y de prendas de vestir, una de fabricación de tubo de cobre, una de agricultura, una ensambladora de televisores, dos de planchas de impresión, dieciséis empresas comerciales, una de inspección de calidad para de los productos de exportación a China y una oficina representativa de un banco de China.

A la vez que las empresas chinas hacen inversiones en México, han asumido una responsabilidad social al pagar una suma considerable de impuestos tributarios al gobierno mexicano, generar plazas de trabajo, rehabilitar caminos y carreteras, proteger el medio ambiente, cuidar a los ancianos solitarios, financiar estudios de niños pobres e incluso prestar auxilio en la tormenta más reciente, lo cual demuestra que los empresarios chinos vienen a México no sólo en busca de mercados y oportunidades de negocio, sino también con un sentido de responsabilidad social que constituye uno de sus objetivos primordiales, y para ello realizan grandes esfuerzos y despliegan diversas acciones para profundizar en el entendimiento mutuo entre los dos pueblos y fomentar el desarrollo sostenible de las relaciones económico-comerciales bilaterales entre China y México.

En el futuro, como factor principal de las inversiones chinas en México, las empresas chinas seguirán desempeñando un papel central en el mejoramiento de las relaciones comerciales bilaterales y estoy convencido de que la experiencia exitosa que las empresas chinas han obtenido en sus operaciones en México motivará y atraerá a más empresas chinas.

De acuerdo con los estudios e investigaciones de la Oficina Comercial y sobre la base de beneficio mutuo y ganancia recíproca, creo necesario intensificar la cooperación entre China y México en los siguientes sectores:

1. Tecnología y equipos avanzados, así como recursos financieros de China; se debe buscar la cooperación entre las empresas de ambas partes en las industrias de confección, textiles y prendas de vestir, de calzado, juguetes y bicicletas, etc. Sobre todo será interesante establecer empresas de coinversión en México para elevar la productividad, la calidad de productos y ampliar las exportaciones desde México a Norteamérica, América Latina y el mercado europeo a través de la red de Tratados de Libre Comercio con los que cuenta México. 
2. Promover cooperaciones en la industria minera. México es un país con abundantes recursos minerales, en tanto que China tiene gran demanda de estas materias primarias debido al desarrollo económico. Las cooperaciones en minería entre los dos países permitirán el incremento de las exportaciones de México a China.

3. La cooperación agrícola. A través de la introducción de tecnología de alto nivel de China en la producción agrícola, ambas partes pueden hacer inversiones para establecer cadenas de cultivo, de crianza de ganado, procesamiento de cultivos y de venta. Los productos pueden destinarse principalmente al mercado mexicano, en beneficio de la estructura alimenticia de los mexicanos y, cuando sean suficientes, del mercado chino.

4. Cooperación en la producción y procesamiento de mariscos, aprovechando la amplia costa y recursos marítimos de México. Las inversiones y la cooperación en este sector puede mejorar la capacidad de producción y procesamiento de productos del mar en México y aumentar y diversificar la exportación a otros países.

5. Cooperación en recursos energéticos limpios. La fabricación y la tecnología de China en focos de ahorro tienen una calidad mundial. Las empresas en este rubro tienen interés de realizar inversiones en México para compartir el ahorro de energía y la reducción de emisiones. Otras áreas como la energía hidroeléctrica, la construcción de trenes de alta velocidad, la industria automotriz, la exploración de petróleo crudo, la perforación de pozos y las obras en campos petroleros constituyen también mercados de cooperación de enorme potencial.

En suma, existe gran potencial para incrementar inversiones chinas en México. Sin embargo, una de las mayores dificultades que encuentran las empresas chinas es la inseguridad en el ambiente de inversión, los robos frecuentes de productos de mucho valor en el transporte, la amenaza de la seguridad personal, las complicaciones en el otorgamiento de visas, etc.; todo ello implica impedimentos para ampliar las inversiones en México, por lo cual deseamos que el gobierno mexicano mejore aún más el ambiente de inversión, ofreciendo mayores facilidades para las inversiones chinas en México. 

Sección 1:

La visión de los embajadores 



\section{Sin sustento político, imposible construir relaciones económicas bilaterales sólidas}

Eugenio Anguiano Roch

\section{China en 1972-1975}

En agosto de 1972 llegamos mi familia y yo a lo que en esa época de la Guerra Fría se llamaba con frecuencia "China continental". Habían transcurrido casi seis meses desde que Alfonso García Robles y Huang Hua, representantes permanentes de sus respectivos países en Naciones Unidas, dieron a conocer al mundo el comunicado conjunto sobre el establecimiento de relaciones diplomáticas entre México y la República Popular China. Tuve el honor de ser nombrado el primer embajador mexicano en esta república, mas no el primero en China, con la que el México de la época del porfirismo había suscrito en 1899 un Tratado de Amistad, Navegación y Comercio, seguido de la apertura de una representación diplomática nuestra en Beijing (Capital del Norte), al comenzar el siglo pasado. Según los avatares, esta representación estuvo encabezada, indistintamente, por ministros plenipotenciarios, por encargados de negocios y por embajadores, en sedes alternadas, además de la citada, en las ciudades de Chongqing y Nanjing (capital del sur), que fueron las capitales de la República de China entre 1938 y 1949 (Pardinas, 1982).

Es decir, me tocaba abrir relaciones en la era de la "Nueva China", como solían Ilamar a su país los dirigentes comunistas, quienes después de una larga lucha política y guerrillera habían triunfado en 1949, e instalado la República Popular en octubre de ese mismo año. Esto sí que era nuevo, tanto en la diplomacia mexicana como en la china, y para tratar de asegurar que yo no iniciara mi misión con errores crasos -era entonces un novel embajador político con única experiencia previa en Costa Rica y economista de profesión, no un experto en China-, mi gobierno y su cancillería me facilitaron una preparación básica de dos meses antes de ir a China, durante la cual estudié los fundamentos de la lengua común china (普通话), convencionalmente llamada mandarín, y de la historia política de esa gran nación.

Mi primera experiencia como representante de México en China cubrió el periodo del 5 de agosto de 1972 al 1 de enero de 1976, contando desde mi llegada por la provincia de Guangdong hasta mi salida desde la ciudad de Beijing. En esos 3 años y 4 meses ocurrieron hechos políticos trascendentes para la vida de China y para sus relaciones con el resto del mundo. Este periodo corresponde a los últimos años del liderazgo de Mao Zedong, al de las pugnas internas por su sucesión, todo ello en un marco de apertura política al exterior, que se inició en octubre de 1971, cuando la República Popular recuperó el asiento de China en la Organización de las Naciones Unidas, que le había sido escamoteado por 22 años.

De esa experiencia quiero relatar los hechos que, en mi opinión, marcan el vínculo sino-mexicano como uno de índole fundamentalmente política, el cual se ha perdido en los últimos años, y lo complemento con aspectos de la segunda experiencia en la 
misma función y país, que corrió de abril de 1982 a junio de 1987, años del retorno de Deng Xiaoping al liderazgo de China y del inicio de la apertura comercial del país y su inserción en la globalidad financiera.

\section{Apertura política en un marco de desorden institucional}

La mencionada recuperación del asiento de China en las Naciones Unidas por el régimen comunista dominante se dio un mes después del fracasado golpe de Estado que supuestamente intentara el mariscal Lin Biao, quien apenas unos dos años antes había sido encumbrado como vicepresidente del partido comunista y como "el camarada de armas" más cercano a Mao Zhuxi (presidente o líder), por el $9^{\circ}$ Congreso Nacional. Se restauraba un cierto orden en el país después de los años más violentos de la Revolución Cultural en los que China se aisló del mundo y estuvo muy cerca de una nueva guerra civil y de una guerra con su otrora aliado principal, la Unión Soviética.

Entre mediados de 1970 y el primer semestre de 1971, el entonces asesor de seguridad del gobierno de Estados Unidos, Henry Kissinger, efectuó visitas secretas a Beijing para negociar un viaje de su jefe, el presidente Richard Nixon, que condujera a un insospechado acercamiento táctico sino-estadounidense. Para Nixon ese acercamiento era crucial a fin de negociar la salida de Estados Unidos de la Guerra de Vietnam, mientras que para los chinos sería vital como parte de su estrategia de disuasión a un posible ataque soviético de gran envergadura.

Cuando llegó el turno en la agenda de la XXVI Asamblea General de la ONU (AGO$\mathrm{NU}$ ) al debate anual sobre la representación de China en esa organización, las condiciones políticas habían cambiado a favor de China comunista y en contra de la nacionalista. El presidente Nixon había hecho público que viajaría a la República Popular China, y desde principios de 1972 había dejado de Ilamarla China roja; por su parte, el representante permanente estadounidense en la ONU, que a la sazón era George H. W. Bush (presidente de EU en el periodo 1989-1993), anticipaba que su país no se opondría al ingreso de dicha República a la ONU, con lo cual se ponía fin a 22 años de veto, con tal de que se respetara el derecho de la República de China en Taiwán a continuar en esa organización.

No obstante, el debate sobre la cuestión de la representación de China en la ONU, que se efectuó del 18 al 26 de octubre de 1971, resultó mucho más complicado de lo que se anticipaba porque Beijing no iba a aceptar la existencia de dos chinas en la ONU. Al comenzar la discusión había sobre la mesa tres proyectos de resolución: uno impulsado por EU y al final copatrocinado por otros 18 países, ${ }^{1}$ que pedía se considerara cualquier posibilidad de suspensión de la representación de Taiwán en la ONU como "cuestión importante", lo que de acuerdo con el Artículo 18, inciso 2 de la Carta de la ONU requeriría de dos tercios de los votos presentes y emitidos para validar tal suspensión; un segundo proyecto de resolución, también patrocinado por EU y algunos de sus aliados, que proponía el ingreso de la República Popular China a la ONU, y la obtención

1 Australia, Colombia, Costa Rica, El Salvador, Fiji, Filipinas, Gambia, Haití, Honduras, Japón, Lesoto, Liberia, Nicaragua, Nueva Zelanda, República Dominicana, Suazilandia, Tailandia y Uruguay. 
del asiento de miembro permanente en el Consejo de Seguridad, pero reafirmando al mismo tiempo "el derecho de continuación de la representación de la República de China" ("representación dual"); y una tercera propuesta, copatrocinada por Albania y otros 22 países, ${ }^{2}$ que pedía la admisión de la RPC a la ONU y simultáneamente la expulsión de "Ios representantes de Chiang Kai-shek". Debido a un error de procedimiento del representante de Arabia Saudí, quien presidía la sesión, el día 25 se puso primero a votación la resolución de la "cuestión importante", cuando los diplomáticos estadounidenses habían cabildeado para que primero se ventilara cualquiera de los otros dos proyectos resolutivos. El resultado fue la derrota de la propuesta de que cualquier resolución sobre la representación de China fuera tratada como "cuestión importante" por 59 votos en contra, 53 a favor (incluido el voto de México) y 19 abstenciones. El siguiente paso fue poner a votación el proyecto albanés, pese a los esfuerzos de Bush por retrasarlo para dar tiempo a que su gobierno presionara más en las capitales de "países amigos", a que votaran en contra de dicho proyecto o al menos se abstuvieran. En el alargue de los debates en la sede de la ONU en Nueva York, se hizo evidente que había mayoría simple a favor del ingreso de China Popular con la consecuente expulsión de Taiwán, por lo que los delegados de este último anunciaron dramáticamente que su país se saldría de la organización. La votación final fue la noche del 25 de octubre, con 76 votos a favor (incluido el de México y de otros países que habían apoyado la iniciativa estadounidense de la "cuestión importante"); 35 votos en contra y 17 abstenciones, de manera que se aprobó la Resolución 2758 de la XXVI AGONU (Keesing's, 1971-1972).

Algo que se supo después y que no ha tenido repercusión importante es que la delegación mexicana, encabezada por el entonces canciller Emilio O. Rabasa y con la participación del representante permanente en la ONU, Alfonso García Robles, recibió instrucciones de la presidencia de que se abstuvieran en la inminente votación del proyecto resolutivo de Albania y compañía, pero, con autorización de Rabasa, el embajador García Robles habló por teléfono a Los Pinos y convenció al presidente Luis Echeverría que México no podía abstenerse en ese momento crucial. Hasta la fecha se agradece en círculos oficiales y de prensa chinos al entonces presidente Luis Echeverría por el apoyo que dio para la recuperación del asiento de China que le pertenecía legítimamente a la República Popular. Poco después, Taiwán suspendería sus relaciones diplomáticas con México y el 14 de febrero de 1972 se anunció, como señalé al principio, el establecimiento de los vínculos diplomáticos entre nuestro país y la RPC. En el comunicado correspondiente se señaló que las relaciones bilaterales se abrían de acuerdo a los Ilamados cinco principios de coexistencia pacífica, que China e India habían concertado en $1954^{3}$ para ser abandonados por Beijing durante la etapa de su diplomacia revolucionaria, por la que se anteponían las relaciones de pueblo a pueblo (las ideológicas) a las de Estado a Estado. Al resucitar esa formulación de los cinco principios, en los meses que siguieron al ingreso de China Comunista a la ONU, decenas de gobiernos que como

2 Argelia, Birmania (Myanmar), Ceilán (Sri Lanka), Cuba, Guinea Ecuatorial, Guinea, Irak, Mali, Mauritania, Nepal, Pakistán, República Democrática Popular de Yemen (Sur), República Democrática Popular del Congo (Brazzaville), Rumania, Sierra Leona, Somalia, Siria, Sudán, Tanzania, Yemen (Norte), Yugoslavia y Zambia.

3 Los originales cinco principios de coexistencia pacífica o Panchsheel eran: respeto mutuo por la integridad territorial y soberanía de cada uno, no agresión mutua, no intervención mutua en asuntos internos de cada uno, igualdad y ventaja mutua y coexistencia pacífica. 
el mexicano tenían reservas respecto al cumplimiento de China de no intervenir en los asuntos internos de otros países, asumieron el riesgo de abrir las relaciones diplomáticas con un régimen revolucionario.

De todas formas, en su momento fui instruido por el propio presidente Echeverría, para que, al presentar las cartas credenciales como embajador de México, advirtiera de la manera más diplomática y clara posible que nuestro gobierno no toleraría la repetición de incidentes como el de que por territorio chino pasaran ciudadanos mexicanos a otros países vecinos para entrenarse como guerrilleros; eso había sucedido a fines de los años sesenta, cuando estudiantes de la universidad moscovita Patrice Lumumba viajaron a China y de allí a Corea del Norte y luego regresaron a México para formar parte de la Liga 23 de Septiembre. Cumplí con tal instrucción al presentarle credenciales a un “presidente provisional" de la RPC, que era el veterano Dong Biwu (董必武, 1886-1975), cofundador con Mao del Partido Comunista de China (PPC), quien no sólo no tomó a mal mi reclamo, sino que reiteró ampliamente las condiciones de la apertura política de su país: relaciones entre Estados.

La presidencia de la RPC había quedado vacante desde noviembre de 1968, cuando su titular, Liu Shaoqi, fue oficialmente expulsado de todos sus cargos en el partido y el gobierno. En los años setenta, no sólo el gobierno central chino tenía huecos institucionales importantes, sino que los provinciales y locales eran todos "gobiernos revolucionarios provisionales" y oficialmente el país vivía bajo la etapa de revolución cultural, que concluiría apenas después de la muerte de Mao, en septiembre de 1976. Más importante aún era que la política y estrategia económicas vigentes en todos esos años seguían el modelo de planificación compulsiva centralizada y el principio de la autosuficiencia económica. China estaba lejos de la apertura y reforma económicas que la convertirían en un imán mundial a partir de los años ochenta del siglo pasado.

\section{Acercamiento político a China}

Los primeros acercamientos político-diplomáticos que hicimos con China fueron al calor de un creciente involucramiento del gobierno del presidente Echeverría con dos temas multilaterales que entonces adquirían importancia creciente: la no proliferación de armas nucleares y la cooperación económica internacional ante la crisis monetaria causada por la inconvertibilidad del dólar en oro, decretada por Nixon en agosto de 1971.

En cuanto a lo primero, en octubre de 1972 llegó a China la primera misión oficial mexicana integrada por dos secretarios de Estado (Comercio y Recursos Hidráulicos), otros altos funcionarios, dirigentes empresariales y otras personas, y efectuó un extensa gira por el norte y la costa china, dividida en dos grupos; uno para observar centros fabriles urbanos y discutir asuntos comerciales con autoridades chinas, y el otro para conocer zonas rurales de irrigación y temporal, incluida la brigada Dazhai, paradigma entonces del colectivismo agrícola. En la ciudad de Shanghai se juntaron las dos partes de la delegación y durante el banquete oficial que ofrecieron las autoridades locales a los mexicanos y funcionarios del gobierno central chino que acompañaban a sus pares mexicanos en la gira, me tocó la responsabilidad de responder el discurso 
de los anfitriones. Aproveché para decir que China, como uno de los cinco miembros permanentes del Consejo de Seguridad y potencia nuclear, tenía la grave responsabilidad de suscribir el Protocolo Adicional II del Tratado para la Prescripción de las Armas Nucleares en la América Latina y el Caribe, más conocido como Tratado de Tlatelolco, cosa que las autoridades de Taiwán habían ignorado durante el tiempo que detentaron el lugar de China en la ONU, y Francia, otro miembro permanente del CS, había hecho lo mismo, razones por las cuales dicho tratado no había entrado en pleno vigor a pesar de que la mayoría de sus partes lo había suscrito desde abril de 1969. La Cancillería me instruyó para que presentara lo anterior en nota formal dirigida al ministro de Relaciones Exteriores de China, Ji Pengfei (姬鹏飞, 1910-20009) a nombre del gobierno mexicano， depositario del tratado mencionado; el ministro me respondió el 14 noviembre, ${ }^{4}$ y simultáneamente divulgó en la AGONU esa respuesta, que contenía la promesa solemne de que China "jamás usaría o amenazaría con usar armas nucleares contra los países no nucleares de América Latina ni contra la zona desnuclearizada", 5 pero al mismo tiempo China se rehusaba a firmar el protocolo citado porque el Tratado de Tlatelolco estaba vinculado jurídicamente con el más general de No Proliferación de Armas Nucleares ${ }^{6}$ o Tratado de Moscú, que Beijing repudiaba.

En abril de 1973 el presidente Echeverría llegó en visita oficial a China, como parte de una gira internacional que cubrió Canadá, Francia, Bélgica, Reino Unido, Unión Soviética y la República Popular. Fue recibido por Zhou Enlai, con quien Echeverría sostuvo pláticas formales, y por Mao Zedong; ello como muestra de la importancia política que Beijing le otorgaba a México. No era obligación protocolaria que Mao recibiera a todos los dignatarios extranjeros que Ilegaran a China, puesto que él no ostentaba ningún cargo oficial, era únicamente el presidente (Zhuxi) del Partido Comunista de China. La recepción que le brindaron a Echeverría a su llegada a Beijing y a su salida por Shanghai fue verdaderamente excepcional, y en la cena de bienvenida ofrecida por el premier Zhou apareció por segunda ocasión en público Deng Xiaoping. ${ }^{7}$ Este personaje había estado en la provincia de Jiangxi desde 1967, a donde había sido enviado en calidad de desterrado, y quien resurgía por decisión del propio Mao, el mismo que seis años antes había propiciado la caída del entonces secretario general del PCC, cargo abolido en 1969. Deng sería anfitrión de Echeverría durante la visita que éste hizo por unas horas a una comuna popular cercana a Beijing y que tenía dos nombres, según el tipo de visitantes: "amistad sino-norcoreana" o "siempre verde."

Antes de elucubrar sobre el significado de la rehabilitación de Deng Xiaoping, destaco los dos acuerdos más importantes que logró Echeverría con Zhou Enlai: el primero, que China suscribiría el Protocolo Adicional II (abierto a la firma de las cinco potencias nucleares a la vez que miembros permanentes del CS) del Tratado de Tlatelolco, lo cual obligó a Francia a seguir el mismo camino meses después y con ello entró en pleno vigor la primera zona desnuclearizada de la historia. Lo segundo fue el acuerdo de que

4 Texto completo en: http://www.nti.org/db/china/engdocs/mfa1172.htm

5 Un relato de esta acción se encuentra en Keesing's Contemporary Archives 1973.

6 Éste tiene establecido en sus funciones promover el establecimiento de zonas geográficas regionales libres de armas nucleares.

7 La primera aparición en público había sido unos días antes, en el banquete ofrecido al príncipe Norodom Sihanouk de Camboya, 12 de abril (Vogel, 2011:70) . 
China y México colaborarían en los trabajos multilaterales que se avecinaban en varios foros y que China apoyaría (más tarde formaría parte del grupo de redacción de 40 países) la formulación de una Carta de Derechos y Deberes Económicos de los Estados, que Echeverría promovía en el marco de la ONU. Echeverría había viajado a Chile en abril de 1972, coincidiendo con la celebración de la tercera Conferencia de las Naciones Unidas sobre Comercio y Desarrollo (UNCTAD), que se efectuó en Santiago, de la cual surgió la idea de la creación de un nuevo orden económico mundial; también entonces entabló un acuerdo de cooperación estrecha con Salvador Allende, ${ }^{8}$ sobre los temas económicos internacionales.

\section{Rehabilitación de Deng Xiaoping y la lucha por la sucesión en China}

Mao Zedong comenzó a desconfiar de Zhou Enlai desde los primeros meses de 1973, porque consideraba que era demasiado blando en las negociaciones que el premier tenía con Henry Kissinger sobre la contención de la Unión Soviética. Después de la visita de Brezhnev a Estados Unidos en julio del mismo año, Mao quedó convencido de que las dos superpotencias estaban forjando un acuerdo por el que Moscú se liberaría y podría amenazar con armas nucleares a China sin que Washington interviniera. “Mao acusó a Zhou Enlai y al ministro de relaciones exteriores de ser demasiado conciliadores con Estados Unidos, permitiendo que China fuera usada para mejorar las relaciones de aquel país con la Unión Soviética" (Vogel, 2011, p. 77).

Por otra parte, la decisión de Mao de revivir políticamente a Deng se derivó de que finalmente no tenía confianza en tres jóvenes y prometedores dirigentes que el "gran timonel" había ordenado llevar a Beijing entre 1971 y septiembre de 1972: Hua Guofeng, Wu De y Wang Hongwen (王洪文, 1935-1992). El interés de Mao cuando los seleccionó era preparar a posibles sucesores que salvaguardaran su imagen y herencia histórica, a la vez que mantuvieran una política exterior enérgica contra Moscú. En Wang en particular, Mao veía al sucesor de Zhou como jefe de gobierno -cuando el presidente Echeverría, Emilio Rabasa y el suscrito visitamos a Mao en su bungalow de Zhongnanhai, Wang estaba afuera y no participó en la reunión, pero luego recibiría a Echeverría en Shanghai-, sin embargo Mao pronto se dio cuenta de las limitaciones de ese exobrero y exguardia rojo, particularmente en su trato con dirigentes extranjeros. Simultáneamente, se manifestó el carácter terminal del cáncer de Zhou y Mao se vio en la necesidad de buscar un interino confiable: ese fue Deng, quien después del intento de golpe de Lin Biao en septiembre de 1971, le había escrito a Mao pidiéndole que le permitiera reincorporarse al trabajo del Estado en cualquier posición; incluso la más modesta.

Finalmente, el 27 de diciembre de 1972 Mao autorizó que se respondiera positivamente a Deng y se le llamara a Beijing. El 20 de febrero siguiente, Deng se despediría de los dirigentes locales y de los obreros de la fábrica rural de Jiangxi donde había trabajado durante los años del destierro, y al momento de abordar el tren para la ca-

8 Cuando el presidente fue derrocado y muerto por el golpe militar de septiembre de 1973, encabezado por el general Pinochet, se creía que China rechazaría al nuevo gobierno pero no fue así; le dio continuidad a las relaciones diplomáticas con Chile, ratificando que la diplomacia china no era más de pueblo a pueblo. 
pital dijo: "todavía puedo trabajar otros 20 años" (wo hai keiyi gao ershi nian). ${ }^{9}$ El 28 de marzo de 1973 Mao se encontró con Deng por primera vez después de 6 años y le dijo simplemente que trabajara fuerte y se mantuviera sano. En el décimo Congreso Nacional del PCC (24-28 de agosto de 1973), último de Mao, aunque sólo asistió por momentos porque sufría de anoxia (MacFarquhar y Schoenhals, 2006:360), Deng Xiaoping fue readmitido en el comité central pero no se le dio un papel central en el liderazgo, mientras que Wang Hongwen, quien entonces tenía 38 años, fue elevado a la posición de vicepresidente del partido y tercero en la jerarquía, después de Mao y de Zhou, a quien se le permitió presentar el informe político al Congreso, documento que redactarían dos estrechos colaboradores de la señora Jiang Qing; el ideólogo Zhang Chunqiao y el periodista Yao Wenyuan, quienes junto con la esposa de Mao y con Wang darían la pelea por la sucesión y quienes, en octubre de 1976, un mes después de la muerte de Mao, habrían de ser arrestados en un golpe palaciego y acusados de formar parte de la "banda o pandilla de los cuatro".

Para diciembre de 1973, Mao ya le había pasado las responsabilidades de Zhou a Deng, pese a la oposición de la señora Jiang y su grupo. Mientras tanto, la estrella política de Zhou decaía y la de Deng crecía, y la relación entre ellos se hacía compleja, aunque en el fondo compartían las ideas de moderación y restauración institucional de China. Los últimos dos años de mi actividad como embajador en China, 1974 y 1975, estuvieron marcados por la decadencia de un Mao enfermo y caprichoso y una lucha interna por el poder, entre radicales y veteranos. En medio de campañas nacionales, como la famosa批林批孔 (criticar a Lin Biao, 1907-1971, y a Confucio, 551-479 AC), de la que intuíamos los diplomáticos que estaba dirigida contra Zhou Enlai, y otras igual de esotéricas, dentro de Zhongnanhai y otros recintos del poder Mao manipulaba los hilos para evitar que su herencia política fuera rectificada después de su muerte, lo que lo llevó a primero castigar, pero sin dejarlo caer públicamente, a Zhou, y desde el otoño de 1975, nuevamente a impulsar la salida de Deng. Este drama interno, en sus detalles, no lo conocía la mayoría del publico chino, ni menos los extranjeros. Mucho después se divulgaría lo ocurrido entre 1972 y 1975, primero por académicos chinos y actores de la vida política china, y luego por sinólogos extranjeros. Entre éstos sobresale el trabajo de Ezra Vogel de la Universidad de Harvard, cuyo último libro, una biografía de Deng, salió a la luz en el otoño de 2011; en este libro, la parte segunda, intitulada Deng's Tortuos Road to the Top, 1969-1977 (capítulos 2 a 6) es el mejor recuento de la convulsa vida política de China durante ese periodo, además, desde luego, de los que existen en idioma chino.

\section{Segunda experiencia diplomática en China, 1982-1987}

Dejé China en 1976, año de profundas sacudidas para ese país: la muerte de Zhou Enlai y de Zhu De en enero; las manifestaciones populares espontáneas de simpatía por Zhou y de repudio a la esposa de Mao y al propio timonel, ocurridas en el mes de abril,

$9 \quad$ Citado por Vogel (2011, p. 69) con base en tres publicaciones chinas. 
que condujeron a una segunda caída de Deng; el catastrófico terremoto de Tangshan en julio; la muerte de Mao en septiembre; la designación de Hua Guofeng como su sucesor transitorio y, finalmente, el albazo a la "banda de los cuatro" en octubre. Entre 1977 y mediados de 1979 dejé el servicio exterior para incursionar en la academia, en El Colegio de México y en la Universidad de Harvard, donde seguí estudiando a China y Asia oriental.

En ese entonces llegué a la conclusión de que México había sido realmente considerado por el gobierno y el liderazgo chinos como su principal socio político en América en los años en que yo había estado allí como embajador. Desde luego que Estados Unidos era importantísimo para China por su posición de potencia mundial y por intereses compartidos y diferencias complejas, pero más que socio era un enemigo dialogante, con el que se establecerían relaciones diplomáticas apenas en enero de 1979. México era importante para China por varias razones, entre otras por nuestra cercanía con Estados Unidos y por el papel político-económico que jugaban nuestros gobiernos en el contexto de las negociaciones internacionales para crear un nuevo orden económico internacional, en un marco convulso por los dos choques petroleros mundiales (1973 y 1979), la formación de enormes masas de petrodólares; por la relevancia del llamado Tercer Mundo, y por una etapa de confrontación soviético-estadounidense en el prolongado ciclo de tensión-distensión de la Guerra Fría.

Tenía entonces, y ahora también, la certeza de que nuestra representación diplomática en China había desempeñado un activo papel durante los primeros cuatro años de la relación bilateral, que rebasaba el peso específico de nuestro país en el contexto mundial, gracias en gran parte a que el gobierno chino así lo quería y nos brindada acceso en Beijing a niveles políticos sólo comparables a los de países que históricamente han sido los principales interlocutores de China. En tales años, Estados Unidos y China habían convenido establecer en sus respectivas capitales sendas oficinas de enlace, cada una encabezada por personas importantes en el ámbito de sus respectivos países. La oficina estadounidense en Beijing tuvo como su segundo titular a George H. W. Bush, quien dejaría en su diario de China un testimonio sobre el activismo diplomático del embajador de México (Engel, 2008, pp. 81, 125, 385).

A mediados de 1979 me reincorporé a la Secretaría de Relaciones Exteriores en funciones principalmente de política económica -petróleo, GATT, nuevo orden económico internacional- y al concluir la Conferencia Cumbre sobre Cooperación Económica Internacional y Desarrollo de Cancún, de octubre de 1981 (última "Cumbre Norte-Sur" del siglo pasado), a la que acudieran varios jefes de Estado y de gobierno, entre ellos Margaret Thatcher y Ronald Reagan, ${ }^{10}$ quienes en esa década de los ochenta habrían de imponer en el mundo la lógica de los mercados y de la doctrina económica neoclásica en vez de la voluntad política colectiva para reformar, le pedí al canciller Jorge Castañeda y de la Rosa y al presidente José López Portillo volver a ser embajador en China. Para mi fortuna me aceptaron y el Congreso de la Unión ratificó mi designación.

Llegué a China en marzo de 1982 a una segunda experiencia diplomática y con la confianza de que los sólidos vínculos políticos bilaterales que se habían construido en

10 Entre los líderes del Sur (países en desarrollo) que asistieron estaba el primer ministro chino Zhao Ziyang (Keesing's, 1982). 
los años anteriores me abrirían nuevamente las principales puertas del gobierno chino. Pero entonces la República Popular comenzaba una nueva era, cuyos antecedentes inmediatos eran: la adopción de reformas económicas de fondo en diciembre de 1978; la apertura económica, que arrancaba con el ingreso de China al Banco Mundial y al Fondo Monetario Internacional en 1980 (instituciones a las que China no había querido ingresar antes, a pesar de que desde octubre de 1971 tenía derecho de entrada a ellas); Deng había triunfado en una lucha no violenta por el poder y desplazado a Hua Guofeng, y se iniciaba la restauración institucional del Estado chino (partido, gobierno, asamblea, etc.).

En los subsiguientes poco más de cinco años que duró mi segunda misión diplomática en China, percibí que la importancia política de México para ese país ya no era la de antes. No sólo tenían más de 10 años de existir las relaciones diplomáticas formales sino-estadounidenses, sino que, para ponerlo en la retórica china, la clave para Beijing era entonces "la lucha por el desarrollo económico". Estados Unidos, Japón, Australia y Nueva Zelanda y la Comunidad Económica Europea se volvían los focos de atención para la diplomacia de China y ella era fundamentalmente una diplomacia económica. Con los países del sudeste de Asia, China había establecido o restablecido relaciones -con excepción de Vietnam, con el que las relaciones no eran beligerantes pero sí fríasal igual que con Corea del Sur, y comenzaba a tejerse una red de intereses económicos que hoy en día es un verdadero foco regional de interrelaciones de crecimiento en todos sentidos. En fin, casi todos los países latinoamericanos, con excepción de los que tenían relaciones con Taiwán o no contaban con recursos o interés, habían abierto embajadas y aun consulados en China. El fomento del comercio exterior, las inversiones extranjeras, los contratos de co-inversión, incluidos contratos de riesgo para explorar y explotar petróleo en China y su plataforma continental, y en general la fiebre por el crecimiento dominaba sobre cualquier otra consideración.

En contraste, México vivía los efectos de la crisis financiera de 1982 que condujo a la nacionalización de la banca privada nacional y la introducción temporal de un control de cambios, para no mencionar la suspensión de pagos de la deuda pública y la devaluación del peso, factores que naturalmente limitaron enormemente cualquier posibilidad de que nuestro país aprovechara su capital político en China para empujar negocios e intercambios económicos bilaterales. Era tan grave la escasez de recursos en México, que todo el resto de 1982 y los primeros meses de 1983, mi principal actividad diplomática fue suplir a representantes mexicanos que debían participar en conferencias internacionales económicas o financieras en Asia, pero que por la falta de divisas no pudieron viajar a los países sede de esos eventos. El gobierno mexicano mandaba a su embajador en China, porque le salía más barato.

En otras palabras, cuando China iniciaba su inserción en la economía mundial y abría oportunidades de negocios a los extranjeros, México vivía lo que se ha dado en llamar la década perdida para el desarrollo. En el sexenio de Miguel de la Madrid (1983-1988), presidente que me había ratificado como embajador en China, el PIB total "creció" a una tasa media anual real de $0.3 \%$; la inflación promedio anual fue de $84.5 \%$ y en un año llegó a casi $100 \%$; se abandonó el tipo de cambio fijo por un sistema de flotación más o menos libre que significó una devaluación real de $67 \%$ en el sexenio; en suma, los intereses que el Gobierno Federal tenía que pagar por la enorme deuda pública acumulada 
representaron, en promedio, el $88 \%$ del total de los ingresos fiscales (cálculos del autor con base en datos del Banco de México).

En tales condiciones, resultó imposible para nuestro país el aprovechar el comienzo de la apertura económica de China para establecer ligas comerciales, financieras y aun tecnológicas de importancia relativa. No obstante, la relación política bilateral siguió siendo buena, en un contexto en el que China tenía numerosos socios. El presidente de la Madrid efectuó una visita de Estado en 1987, y se mantuvo la costumbre, ininterrumpida hasta ahora, de que todos los jefes de Estado mexicanos vayan a China en viaje oficial, eso desde el establecimiento de relaciones hace 40 años.

Aunque en el periodo 1982-1987 no hubo cambios de política interior en China tan estrepitosos o tan dramáticos como en el pasado, me tocó testimoniar la regularización de las reuniones claves del sistema chino, como los congresos del partido y de la Asamblea Popular Nacional, los que a partir respectivamente de 1982 y 1983, se efectúan puntualmente cada 5 años: primero es el congreso del partido y luego el de la Asamblea. Dichos congresos se abrieron a diplomáticos y a observadores extranjeros, en contraste con los habidos en los setenta, que eran casi secretos. En 1982 la Asamblea proclamó una nueva Constitución -la cuarta en 62 años de vida de la República Popular- vigente hasta la fecha, aunque con varias reformas, con las que se ha apuntalado en la letra lo que está ocurriendo en la práctica: la implantación de una economía de mercado mixta.

Los herederos visibles de Deng -quien ejerció un liderazgo más compartido que el de Mao y nunca ocupó la posición de jefe de Estado o de gobierno- eran Hu Yaobang en el partido y Zhao Ziyang en el gobierno. El primero tenía fama de flexible e incluso democrático, pero cuando brotaron movimientos espontáneos de protesta, su propio mentor político, Deng, lo obligó a renunciar en 1987 y en su lugar colocó a su otro cachorro, Zhao Ziyang, quien en 1989 habría también de caer por la dramática crisis de la Plaza de Tiananmen. Pero este último hecho ocurrió dos años después de haber terminado mi segunda estadía en China.

\section{Conclusión}

La conclusión que saco de mis experiencias en China, relatadas brevemente y únicamente con el fin de fundamentar mi visión sobre las relaciones sino-mexicanas, es que los gobiernos mexicanos del siglo pasado invirtieron mucho en el capital político de esa relación, mismo que no se ha aprovechado por varios factores, uno ya explicado en lo referente a los años ochenta y el otro, referente a los noventa, cuando el gobierno y los intereses económicos mexicanos estaban volcados a la apertura económica y a la consolidación de la relación con América del Norte, por lo que China no contaba en las perspectivas de la estrategia exportadora mexicana.

Cuando China ingresa a la OMC, el gobierno de Vicente Fox negocia bilateralmente condiciones especiales en cuanto al uso de impuestos compensatorios a una economía amiga, pero crecientemente competidora de la nuestra. A mediados de 2003, China desplaza a México como segundo principal proveedor al mercado de Estados Unidos, a pesar de no contar con el tratamiento preferencial del que México gozaba por el TLCAN, 
y entonces cundió el pánico en nuestro país por la amenaza china. Sin embargo, el gobierno mexicano hizo esfuerzos políticos por encontrarle ventajas al reto chino y a fines de ese año se estableció, durante la visita a México del primer ministro Wen Yaobao, que la relación entre ambos países se hiciera de carácter estratégico.

El gobierno actual mantuvo por un tiempo la tónica de que China es estratégica para México y actuó en consecuencia. Pero a partir de la fiebre porcina que estalló en Asia, surgieron varias fricciones entre los dos países, alguna tan innecesaria como que el presidente Calderón haya recibido al Dalai Lama cuando había dado la señal de que no lo haría, con lo cual la relación política entre China y México entró a su peor época. Nuestro país debe reconstituir su diplomacia hacia China, proseguir con la idea de mantener una buena relación política con ella, lo cual no significa sumisión ni mucho menos, y construir una verdadera estrategia de largo plazo para aprovechar, en beneficio de los intereses más amplios del país, las ventajas que ofrece la economía más dinámica del mudo y que en 2010 se volvió la dominante en materia comercial a nivel global; o de contrarrestar, sin llegar a la confrontación, las desventajas que esa potencia comercial nos pueda traer.

\section{Bibliografía}

- Engel, Jeffre A. (edited by) (2008). China Diary of George H. W. Bush. The making of a Global President. Princeton Univesrity Press. Princeton and Oxford.

- MacFraquhar, Rederick y Michael Schoenhals (2006). Mao's Last Revolution, The Belknap Press of Harvard University Press. Cambridge, Massachusetts, and London, England.

- Pardinas, Felipe (1982). Relaciones diplomáticas entre México y China, 1898-1948, dos tomo. Archivo Histórico Diplomático Mexicano, Secretaría de Relaciones Exteriores.

- Vogel, Ezra F. (2011). Deng Xiaoping and the Transformation of China. The Belknap Press of Harvard University Press. Cambridge, Massachusetts, and London, England.

\section{Documentos}

- Banco de México, informes anuales de: 1984 a 1989.

-Kessing's Contemporary Archives. Logman (anuarios): 1971-1972; 1982. 



\section{México ha dejado de soñar. No perdamos lo mejor que tiene un país: su juventud}

Cecilio Garza Limón

La vida me ha dado la enorme fortuna de vivir en China, de representar a México en China, de hacer diariamente negocios comerciales con China y de tener una hija que ha finalizado sus estudios en una universidad china. A partir del último trimestre de 2011, he iniciado una nueva etapa con esta cultura, participando en una empresa sinonorteamericana-mexicana de productos biogenéticos que serán comercializados inicialmente desde China y producidos después en México para su distribución local y para el consumo del mercado centroamericano.

Pero a pesar de que mis últimos 16 años han sido de una gran intensidad oriental, cuando me solicitan realizar un comentario o una opinión sobre las relaciones entre ambas naciones, el peso de mi preocupación es enorme pues sé que la evolución a la que está sujeta la República Popular en su vertiginoso ascenso al mundo desarrollado, me impide expresar algo que no se haya movido ya de su lugar y que haya sido sustituido por algo mejor o por una política más novedosa.

Procuro visitar a mis proveedores y a mis socios chinos al menos tres veces por año y estar en ferias y seminarios en esa misma proporción. Sin embargo, cada viaje a China es motivo de nuevo asombro, que de pronto se transforma en nota de decepción cuando comparo y pienso por qué en mi país querido no podemos evolucionar en esa forma. Carecemos del sentido de la urgencia, del ahorro, del sentido de la innovación y mejora, de la investigación, de la planeacion y a veces hasta del sentido de la propia dignidad.

Baste ir en México a lugares de masas como a una estación de autobuses, un palenque en provincia, a unos baños públicos, a un concierto o a un partido de futbol, a un mercado y compararlo con los mismos eventos en China y nos daremos cuenta a primera vista de que nosotros mismos no hemos encontrado este camino que se están dando los chinos socialmente, que es el de la dignidad personal. En 16 años, el comportamiento humano en estos sitios se ha revertido tristemente en contra nuestra.

¿Y por qué hablo de la dignidad personal? Porque es lo que más aprecio en mi observación de la evolución china (y coreana) y de la involución mexicana. A pesar de la ascensión de su "nuevaricracia", los valores tradicionales prevalecen en China como en Corea y en otros pueblos asiaticos y el método de preservación y desarrollo de éstos se encuentran referidos y sustentados en tres aspectos importantísimos del desarrollo: planeación, educación y atención a los jóvenes.

He querido mencionar lo anterior, porque mi comentario en este documento irá encaminado a insistir nuevamente en que el gobierno de México debe crear políticas de largo plazo hacia y con China. No sé si tiene que ser al través de la creación de una Secretaría de Planeación, para ordenar finalmente el paso del país y cuyos resultados mejorarían indudablemente el papel de la economía y del empresariado nacional. 
Pero si no se creara la Secretaría de la Planeación o Planificación, los demás órganos gubernamentales, privados y académicos deben orientar en definitiva el desarrollo socioeconómico de México definiendo los caminos que habremos de recorrer en sectores y segmentos de la sociedad, pero también respecto de nuestros socios extranjeros. Es ya una burla a la dignidad de los mexicanos la falta de reformas urgentísimas que el país necesita, al igual que la tolerancia a las corruptas directivas de muchos líderes sindicales.

Pero lo fundamental hoy, por su urgencia y porque no habrá otra oportunidad, es saber cómo vamos a inducir a los más de 30 millones de jóvenes mexicanos, que le otorgan hoy al país el mayor y mejor bono demográfico de su hisoria y la oportunidad de transformar realmente a México en 20 años, como lo han hecho justamente China, Corea, España y lo están haciendo hoy Sudáfrica y Brasil, entre muchos otros.

Los estadistas ya no tienen que recurrir a bolas de cristal o ser aprendices de mago para saber cómo será el país que gobiernan después de 20 años. La directriz es simple: invertir en la juventud. El desarrollo de las naciones será directamente proporcional al tamaño y forma de la inversión que a los jóvenes se les haya dado. ¿Queremos un México próspero, tecnológicamente avanzado, sano y fuerte? La solución es invertir tiempo y recursos en los jóvenes de hoy, como lo hace China y en 20 o 30 años tendremos el país que deseamos.

Pero simultaneamente también tenemos que definir por una vez qué tipo de país queremos y podemos tener. Cuáles pueden ser nuestras áreas de especialización. Decidir qué vamos a hacer con el campo y el agua y, en el ámbito que nos compete, estructurar el cómo van a ser las relaciones de México con la República Popular China para los próximos 30 años.

Es inconcebible que el gobierno no tenga la motivación ni la preocupación (ni la obligación) de producir y publicar documentos especializados en donde se oriente el camino por donde se quiere llegar a una interacción bilateral, ya no lo pidamos con todos los países, pero al menos con nuestros principales socios comerciales y políticos.

Hasta hoy es imposible conocer cómo van a ser y qué debemos esperar de las relaciones con Estados Unidos, República Popular China, España, Guatemala, Brasil, Rusia, Japón, Corea, Alemania, Francia, etcétera, para los próximos treinta años. Qué esperamos de estos socios y qué vamos a ofrecerles. Hoy apenas podemos conocer lo que nos depara el año siguiente o cuando mucho, si hubiese foros previstos, a dos o tres años.

El desplazamiento del poder político y económico del epicentro Atlántico al del Pacíficio inició hace ya varios años. El presidente Obama lo acaba de confirmar en la última reunión de APEC, a la que el presidente Calderón no asistió, cuando señaló que Estados Unidos es un país "del Pacífico" y anunció el incremento de su participación en el Acuerdo de Asociación Transpacífico (TPP).

Mientras Europa se tambalea y Estados Unidos pierde vigencia, el continente asiático se fortalece. Vale la pena visitar el análisis en su giro de estrategia de la secretaria de Estado Hillary Clinton en el último Foreign Policy (nov 2011) hacia esta región. La reconfiguración del mundo se está dando y aunque otra vez de forma reactiva, afortunadamente en este caso, México está actuando en consecuencia. Obama ha decidido que la prioridad de su país se llama Asia. ¿Cuál es la mexicana? 
Asia tiene la mitad de la población del mundo; las relaciones de seguridad se determinarán en el siglo XXI entre los ejércitos de EU, de China y en menor medida de Rusia; con la claudicación europea en temas de seguridad, China se convierte en la contraparte del ejército americano; también las decisiones en el cambio climático y las contingencias ambientales se tendrán que dar necesariamente entre América y Asia. La mayor parte del mundo está consciente de ello, pero en México muy pocos centros de análisis y estudio asumen esta situación.

Uno de ellos, el Centro de Estudios China-México (Cechimex) de la Universidad Nacional Autónoma de México y su invaluable director, Enrique Dussel Peters, hacen un esfuerzo loable para impulsar con seriedad esta necesidad. Sin embargo, el esfuerzo realizado en los documentos que publica el Cechimex, tiene logros desproporcionados en relación con los apoyos que se le otorgan. Y no obstante la calidad y cualidades de los integrantes de este grupo conductor, no se ha logrado llegar a influir suficientemente en esta tan necesaria planeación de la relación a futuro con China.

Necesitamos concebir, en el gobierno o en la iniciativa privada, a este grupo de expertos, mexicanos o extranjeros, que a la brevedad defina las acciones de planeación política entre las dos naciones. No podemos como hasta ahora, contar a veces con que los embajadores o empresarios que eventualmente han hecho incursiones temporales por Asia se deben considerar expertos. Se requiere de verdaderos especialistas investigadores que hablen el idioma y entiendan la idiosincracia, los que de no encontrarse en México deberán venir del extranjero, pero no podemos continuar dando palos de ciego en nuestras relaciones con el mundo e improvisando soluciones reactivas.

Poco ha importado que China se haya convertido desde 2003 en nuestro segundo socio comercial y nos haya desplazado como segundo actor en las relaciones comerciales con Estados Unidos para tomar conciencia de la importancia en planeación de esta relación y acelerar nuestra interacción hacia ellos.

Consideremos como los dos ejemplos fallidos mas evidentes: la industria zapatera y el Dalai Lama.

\section{La (falta de) planeación}

Es innegable que el desconocimiento y la falta de información sean algunas de las características actuales de las relaciones sino-mexicanas: hay muy pocos enterados en el lado mexicano y cada vez menos prioridades en lado chino para con nosotros.

Hemos desaprovechado momentos importantísimos en la relación, sobre todo cuando la República Popular más nos necesitaba a finales de los años 90. Muy probablemente 15 años después las seguimos desaprovechando pero ya desde un punto menos sólido para México.

El año 2011 fue importante para China. Se cumplieron 100 años de la Revolución de 1911 que enterró al imperio y a las dinastías. Un año después de que Francisco Indalecio Madero iniciara su lucha en contra de la dictadura de Díaz, Sun Yat Sen puso fin al sistema feudal de los Qing, lo que realmente provocó un sinnúmero de reformas periódicas que han llevado a China a ser uno de los actores más importantes y respetados del planeta. 
Incontables similitudes nos unen a ambas naciones. Desde la débil base ecosocial con la que iniciamos ambos hace 100 años, las intervenciones de potencias externas en nuestros territorios, la creación de una clase media emergente, hasta el deseo de apertura internacional para el que no teníamos en ambos casos otra opción.

Durante el último cuarto del siglo XX, mucho investigó y aprendió China de México. El propio Presidente Jiang Zemin me comentaba durante la presentación de mis cartas credeciales, que él mismo había vivido entre Tijuana y Ciudad Juárez por varios meses, aprendiendo del sistema de maquiladoras fronterizas, para más tarde como jefe de proyecto, mejorar el esquema y plasmarlo en lo que hoy es uno de los baluartes de la industria electrónica china: Shenzhen.

Recordaba el presidente que en ese entonces no existía en el mundo ninguna frontera similar en condiciones geoeconómicas tan dispares como las que se presentaban entre Estados Unidos y México y Gran Bretaña con Hong Kong y la República Popular China de entonces.

Jiang Zemin estudió muy bien a México, desarrolló un mejor sistema de maquila y fue premiado primero con la subsecuente planificación de Shanghai y posteriormente con la presidencia de la República.

Hoy en día, las condiciones en la frontera de China y Hong Kong se han armonizado, mientras que las de las ciudades fronterizas mexicanas se han deteriorado fuertemente.

El otro ejemplo fue la creación a finales de los años 90 y como consecuencia de la grave crisis mexicana de 1995, del programa "One Stop Shop" con el que el gobierno chino estuvo promoviendo ante los industriales maquiladores extranjeros asentados en México, las virtudes y apoyos que tendrían si se desplazaban hacia territorio chino. Este programa logró sacar del país a una cantidad considerable de empresas, sin que hubiese contraataque mexicano.

En el mismo tiempo en el que nosotros desmantelamos nuestros ferrocarriles, China invierte en el sector y ahora es capaz de producir decenas de trenes de alta velocidad y de detentar ya el record mundial de velocidad sobre rieles con $486.1 \mathrm{~km} / \mathrm{h}$.

Mientras que en los deltas del Yang-tze y del Perla se unen las ciudades más importantes de la región (incluyendo en esta última a Hong Kong) para hacer conjuntamente promoción industrial y de inversión extranjera, en México observamos frecuentes guerras fraticidas entre diferentes entidades federativas para captar un proyecto grande, sin importar ofrecer hasta la dignidad. El resultado de esta coordinación económica china es digna de imitar y adaptar.

En fin, no se trata en esta breve intervención de señalar lo que China está haciendo bien y México simplemente no está haciendo. Trato simplemente de destacar que así como China en su momento vino a México a adaptar las acciones atinadas que entonces realizábamos, hoy nosotros debemos actuar de la misma forma e investigar, estudiar y adaptar a nuestra realidad muchas de las excelentes políticas chinas que están dando resultado antes que nos despeguemos más.

Como señala Isabel Turrent, las recetas de Deng Xiaoping no sólo son totalmente vigentes, sino aplicables a una democracia funcional como la que deseamos y requerimos. 
Ya el actual Plan Quinquenal va a modificar el modelo económico chino reajustando la economía y la producción de bienes y servicios. China va por el desarrollo acelerado de las nuevas industrias como la informática de última generación, nuevos materiales, biofarmacuéutica y biogenética, entre muchas otras. En adelante, ya no escucharemos que tal o cual producto está "hecho" en China sino "creado" en China. Y nuevamente la pregunta es ¿por qué en tan poco tiempo China puede darse este lujo? Porque gracias a su acervo educativo China ha construido en los últimos 20 años las bases necesarias para ser un líder mundial en los profesionales de la investigación y el desarrollo y estar dentro de los cinco países que más registran anualmente patentes ante la OMPI en Ginebra. La respuesta una vez más nos lleva a educación y atención a los jóvenes.

Ante la actual crisis mundial y la probable baja en las economías de Estados Unidos y Europa, que frenará el consumo de sus productos, China ha decidido dedicar los próximos cinco años a fortalecer su consumo interno para mantener activa su economía sin tanta necesidad del exterior. La economía china va dar a su población más dinero para que consuman más y se conviertan en una sólida clase media.

Aprovechan esta situación de coyuntura para corregir la capacidad productiva del Estado, que se ha comido a la capacidad de consumo de la población, resultando una escasez de la demanda y una ampliación en la brecha entre ricos y pobres y urbanos y rurales.

Estados Unidos se ha percatado claramente que no sólo su discurso debe contener el cada vez mayor peso chino en los asuntos internacionales, sino contrarrestar también en la práctica el innegable liderazgo chino en materia de comercio internacional.

La próxima ampliación del Acuerdo de Asociación Transpacífico, constituirá un nuevo bloque de comercio internacional, que eliminará aranceles y mejorará las condiciones a la inversión, el empleo y el control del medio ambiente. Y para mayor solidez de este bloque Estados Unidos está promoviendo la inserción de nuevos participantes en el TPP, entre ellos México, Canadá, Japón y probablemente la República de Corea. ${ }^{1}$

Y la pregunta consecuente es: una vez que México se integre al TPP, ¿cómo lo aprovechará?

Una de las respuestas evidentes es que mientras que con el fortalecimiento del TPP, Estados Unidos crea un contrapeso a China, México estaría haciendo lo mismo hacia Brasil, consolidando la iniciativa de la Cumbre de Mérida, del 5 de diciembre de 2011, cuando con Colombia, Chile y Perú -y Panamá, en estado de observador-acordaron fundar otro bloque que se conocerá como Alianza del Pacífico, y que estaría formalizándose el 4 de junio del 2010 en Santiago.

En incontables ocasiones desde la década de los 80 se ha levantado la voz diciendo que es temerario tener una balanza comercial con un solo socio. Queda siempre la esperanza, como sucedió con el TLC con Europa, que estas plataformas facilitadoras le dieran a México una mejor distribución de su comercio e inversión hacia otros continentes o regiones, como lo hacen Chile, Brasil y Argentina.

1 TPP conformado por EU, Australia, Nueva Zelanda, Singapur, Vietnam, Chile y Perú. 
Pero de nuevo, sin una planeación rigurosa, sin saber qué somos y para qué servimos y sin un proceso educativo moderno, por más acuerdos y tratados que se firmen, se avanzará como hasta ahora, lentamente.

Estamos como estamos, porque somos como somos y porque no decidimos qué es lo que queremos ser.

\section{La (falta de) educación y la (falta de) atencion a los jóvenes}

México ha dejado de soñar y el carácter de las personas como el de los pueblos se forja al perseguir un ideal, una visión, un sueño.

Nuestro país, y principalmente nuestra juventud ha perdido optimismo y la porción de la sociedad madura y experimentada ha sido echada de lado, porque en México, ser mayor de 45 años, es casi sinónimo de inservible.

La visión actual de los mexicanos es pesimista y tiene fundamento. Estamos destacando en muy pocas cosas. La paciencia de la sociedad civil es cada vez menor y los problemas crecen día a día. La corrupción y la impunidad (criminal y sindical) nos laceran, la violencia y la falta de estrategia (por mala planeación) para combatirla nos abruman y nuestra imagen internacional es francamente mala.

De acuerdo con el Latinobarómetro de la revista The Economist (octubre 2011) el grado de satisfacción de los mexicanos con su sistema político ocupa el último lugar en la región.

México padece una grave crisis de seguridad en la que los principales actores son bandas delincuenciales bien organizadas constituidas primordialmente por jóvenes. La desesperanza y la falta de optimismo y oportunidades ha hecho que la mentalidad juvenil prefiera vivir bien cinco años y morir, que seguir arrastrando una existencia de miseria toda su vida. En los medios nacionales y en las familias se habla recurrentemente de violencia, resentimiento y falta de oportunidad de una sociedad que está resquebrajándose porque si ya no migra no encuentra su salida.

De pronto, hace apenas dos años, a la sociedad y al gobierno se les apareció el concepto "nini". El año pasado en México fueron sensados por el INEGI casi 8 millones de jóvenes menores de 30 años, que "ni estudian ni trabajan" y de los que el 75\% son mujeres, de acuerdo con la Encuesta Nacional de Juventud (SEP, 2010).

Frente a una China omnipresente, nueva, optimista y persistente, el rezago de los estudiantes de México en cantidad como en calidad educativa frente al mundo es preocupante y tanto en escolaridad pública como privada. De acuerdo con los parámetros de la OCDE, al paso que lleva la educación nacional, se requerirán 50 años para dar alcance al promedio en matemáticas de los países que integran esta organizaicón y de 170 años para equilibrar a su nivel nuestra comprensión en lectura.

México sigue siendo un país de educación básica, con altos grados de deserción y con muy mal balance entre la escuela y el trabajo. Nuevamente, la falta de planeación, ahora en la educación, hace estragos en nuestro desarrollo y desata problemas sociales de alta proporción.

Al contrario que en Estados Unidos y en China, los universitarios en México tienen una proporción mayor en el desempleo y la razón es simple: el perfil de los egresados 
no es consecuente con lo que los empleadores buscan. La falta de calidad educativa y de planeación de largo plazo, hacen que los universitarios mexicanos busquen carreras "fáciles" que les permiten ingresar a las universidades, pero cuya desembocadura al mercado de trabajo los hace enfrentar luego mucha competencia. Obviamente la enorme deficiencia en la enseñanza de las matemáticas en secundaria y preparatoria influye operativamente al seleccionar una carrera profesional de mayor dificultad que a la larga le daría mejores expectativas de empleo.

Hoy en día, ser "licenciado" ya no es suficiente mérito para el posicionamiento social y laboral, lo que vuelve a exacerbar la escala de pesimismo social imperante en la juventud mexicana.

Mientras tanto, China ha comprendido que la innovación y la creatividad son las herramientas más importantes para el hombre, para la empresa y para una nación.

A partir de 1978 se inició el florecimiento científico de China; en 1995 se sentaron las bases y la estrategia de fortalecimiento del país mediante la ciencia y la educación y finalmente en 2006 se fijó claramente el objetivo de hacer de China un país innovador.

En 30 años, China ha logrado avances importantes, tanto en materia militar y aeroespacial, como civil e industrial, sin dejar de lado la investigación y el desarrollo agropecuario. Al tiempo que logra concebir y operar la supercomputadora más importante y avanzada del mundo, mantiene como hace 2000 años sus proyectos de irrigación de las zonas norteñas con agua del sur.

En México no tenemos siquiera planes para abastecer a las zonas áridas de Oaxaca con los excedentes fluviales de su vecino Tabasco y nos conformamos con observar cómo unos se ahogan mientras los otros se mueren en la sequía. Se nos ha olvidado que el agua, antes que la educación es la base de toda civilización que pretenda ser progresiva y que la informática es la actual herramienta del saber.

Pero cómo vamos a innovar si no tenemos educación, cómo vamos a conocer si no sabemos planear y cómo vamos a planear si no estamos unidos como nación y carecemos de metas y resultados que nos inyecten optimismo.

México puede hacer grandes cosas, pero se necesita de una visión de conjunto como lo están haciendo China y también los demás integrantes de los BRIC más Sudáfrica.

Esos cinco países con los que usualmente nos comparamos, tienen también severas deficiencias en sus estructuras productivas y sociales. India arrastra una pobreza enorme, Rusia, la RSA y Brasil son altamente dependientes de sus recursos naturales, son también inseguros, con altos índices de corrupción y todavía no consolidan sus instituciones. En un comparativo de las estructuras productivas, México no quedaría tan mal parado si contase con las instituciones públicas, educativas, laborales y de infraestructura científica más funcionales y primordialmente en atención a la juventud.

Pero lo que realmente hace la diferencia entre los BRICS y México son dos factores fundamentales: el optimismo y el consenso social. En efecto, más que algunas políticas económicas específicas que expliquen el éxito de los BRICS, es el entusiasmo que sus ciudadanos sienten por su desarrollo, el elemento destacado para la competitividad y una actitud firme y segura hacia el futuro. Igualmente, el consenso social es utilizado por estos gobiernos para dirigir las acciones del país hacia la prosperidad. 
Podemos finalizar esta participación insistiendo en que a nuestro juicio la mejor y más segura salida que tiene México, además de la adecuada planeación, es la atención a la juventud.

Reitero la demostración de muchos ejemplos en países que han atendido a tiempo a su juventud y que en 20 años han visto excelentes resultados. ¿Por qué España es primer lugar en tantas disciplinas deportivas?, porque no sólo organizó las Olimpiadas de Barcelona en 1992 sino aplicó políticas públicas apropiadas que aprovecharon esta circunstancia. ¿Por qué Corea ha logrado un nivel de vida mayor al promedio europeo, cuando en 1960 era más pobre que Bangladesh y no contaba con recursos naturales y sigue estando en pie de guerra? Porque destinó su planificación hacia la educación y a sus jóvenes que hoy son destacados empresarios, músicos, investigadores, etcétera.

Los ejemplos contrarios en el mundo han sido Argentina, Uruguay y en menor medida Gran Bretaña y hoy Estados Unidos, en donde no se aplicaron las medidas apropiadas para la atención de la juventud cuando ésta fue mayoría. En el caso de los países latinoamericanos retrocedieron severamente en sus índices de desarrollo socio-económico, que entonces eran de los más elevados en América Latina. En el caso británico, lograron corregir pronto sus políticas hacia los jóvenes, pero ello no está sucediendo en Estados Unidos.

En agosto de 2010, México junto con la Organización de las Naciones Unidas fue el anfitrión de la Conferencia Mundial de la Juventud y con este evento la ONU decretó el inicio del año mundial de la juventud, que desde hacía 25 años no se celebraba. Se reunieron más de 35 mil jóvenes de 140 países, asistieron cerca de 70 ministros y viceministros responsables de la juventud y los altos responsables de las agencias de las Naciones Unidas y de las principales organizaciones globales como la Liga Arabe, el Banco Mundial, la OCDE y el BID. Sin embargo, el evento no fue razón suficiente, ni por estar enmarcado dentro del Bicentenario, para que el presidente de México lo visitara, o al menos la secretaria o algún subsecretario de Relaciones Exteriores, porque era un evento que le correspondía a la SEP. Fue un mensaje decepcionante que sintetiza el lugar que ocupan los jóvenes en el quehacer político actual.

Por ello, los fondos anuales que se le otorgan al Instituto Mexicano de la Juventud, que si uno lo visita podría decirse estar en el Instituto Nacional de la Decrepitud, no rebasan los 400 millones de pesos anuales.

Es una verdadera tristeza constatar lo poco importante que resulta el IMJUVE para la administración pública mexicana mientras países como China, Chile, Brasil, Sudáfrica y España, le otorgan la mayor de las prioridades a sus organismos juveniles y lo elevan a rango de ministerio o de un poderoso protectorado que depende directamente del partido comunista en el caso chino.

Hoy México posee la mejor de las oportunidades para restaurar la poca o nula atención que se la ha dado a la juventud recientemente. Nos quejamos de la violencia, pero no le damos oportunidad a los jóvenes para no delinquir. Es impostergable la creación de la Secretaría de la Juventud, que debe operar por cierto tiempo y dejar sentadas las bases de un nuevo país, el cual se conformará a lo largo de los próximos 25 años y que finalmente nos otorgará la satisfacción y los resultados que la generación 1976 dejó caer. 
Construir el porvenir radica primordialmente en poder pensar y actuar a través de la juventud.

\section{Conclusiones}

Primera. En los próximos cinco años al menos, China pondrá el acento en la reforma sobre la distribución de la renta y en el aumento de los ingresos de la población, pasando del $43 \%$ actual al $60 \%$.

El cambio de modelo chino para activar el consumo de la clase media es otra nueva oportunidad para los empresarios mexicanos que han buscado desde hace 30 años cómo venderle “...un lápiz a cada chino" (penoso concepto que sin embargo evoca una realidad todavía latente).

Segunda. México necesita dotarse urgentemente de un organismo de planeación que defina de una vez el camino a seguir en los próximos 30 años y de estudios específicos que determinen la estrategia y el posicionamiento del país frente a sus principales socios y rivales económicos y su participación dentro de los nuevos bloques como el TPP y la Alianza del Pacífico.

Tercera. México tiene que aprovechar el bono demográfico actual en el que la tercera parte de su población es joven y, por ello, temporalmente crear la Secretaría de la Juventud y otorgar a este importantísimo segmento de la población los apoyos necesarios para transformar el país en 25 años.

Es la oportunidad ideal de volver a crear optimismo y fortaleza y establecer metas de desarrollo creíbles.

Ya se perdieron dos momentos invaluables en esta última generación: cuando el sexenio salinista dejó inconclusas muchas de las reformas necesarias hoy en día y cuando Fox dilapidó miserablemente el capital político del país y dejó las cosas como estaban o peor. No perdamos lo mejor que tiene un país: su juventud.

Cuarta. Las reformas laboral, política, educativa y económica son indispensables para generar un cambio estructural que empiece a generar optimismo y consenso social. Con ello, México podría dar una gran sorpresa y erigirse en una economía de rápido crecimiento y ser más influyente en el mundo. 



\section{Algunas reflexiones sobre el futuro de la relación México-China}

Sergio Ley López

Conmemorar el 40 aniversario del establecimiento de relaciones diplomáticas entre México y la República Popular China es una ocasión propicia que invita a la reflexión sobre lo que han sido cuatro décadas de intensos intercambios en todos los ámbitos y sobre lo que el futuro depara a ambos países en un incierto panorama internacional.

El reconocimiento por parte de México de la República Popular China como la única representante de todo el pueblo chino se dio en los momentos en que su parte continental se encontraba en plena ebullición. Pese a que los efectos de la Revolución Cultural iniciada años antes por el "Gran Timonel" habían creado un clima de desconfianza e incertidumbre en el interior de China, su política exterior mostraba gran empuje, apertura y seguridad. México, por su privilegiada posición de puente entre el mundo desarrollado y el mundo en desarrollo, por su búsqueda de liderazgo en el Tercer Mundo y por su política exterior flexible e independiente, desprovista de las ataduras a cualquiera de los dos polos en conflicto durante la Guerra Fría, se convirtió en el aliado estratégico de China en Latinoamérica.

En la primera década de estos cuarenta últimos años se dieron intensos intercambios con efectos que perduran hasta nuestros días. Basten como ejemplos tres acciones de gran envergadura:

1. El programa de estudiantes chinos de El Colegio de México que permitió la capacitación de más de 200 cuadros del partido y del gobierno chinos en asuntos latinoamericanos.

2. El entrenamiento de médicos mexicanos en las técnicas y prácticas de la medicina tradicional china.

3. La entrega de la simiente madre del maíz híbrido desarrollado en México a las autoridades chinas, que permitió a la República Popular convertirse, en pocos años, en el primer productor de esta gramínea en el mundo y palió, en gran medida, los efectos de hambrunas producidas por la naturaleza y el hombre.

Quizás el sello distintivo de la segunda década, 1982-1990, fue un retraimiento de la cooperación internacional de México derivado de la profunda crisis económica que obligó a la nación azteca a cancelar muchos de los programas que mantenía con terceros países. Uno de ellos, de vital importancia, fue el de becarios que El Colegio de México mantenía con la República Popular, privándonos así de una importante manera de influir en el conocimiento que China deseaba adquirir sobre Latinoamérica. Otros acomodos y cambios geopolíticos contribuyeron al desplazamiento paulatino de México como socio de privilegio en la región. Las prioridades chinas se renfocaron, las contradicciones en 
el seno de su dirigencia política se resolvieron, y China se embarcó en su propio proceso de desarrollo que, en pocos años, logró convertir al país en la fábrica del mundo.

Los años subsiguientes fueron marcados por los desencuentros. México, al sentir al país oriental como una amenaza que desplazaría a la industria nacional de su mercado interno y de los mercados tradicionales en el exterior, impuso altas tarifas compensatorias a un número importante de productos chinos. Al mismo tiempo que México negociaba el Tratado de Libre Comercio de América del Norte (TLCAN) con Estados Unidos y Canadá y posponía sine die la firma del tratado comercial con China, condición sine qua non para el acceso de la República Popular a la Organización Mundial de Comercio, los productos chinos inundaban los mercados mexicanos causando mayores fricciones en la relación. En los círculos académicos y, tal vez también, en algunos sectores del gobierno y del partido chinos, se interpretaron estas acciones de México como un realineamiento de su política exterior y de sus prioridades geoestratégicas.

En la primera década del siglo XXI, la llegada de Vicente Fox y de un nuevo partido político, Partido Acción Nacional, a la Presidencia de la República fue percibida en China como una buena oportunidad para replantear una nueva estrategia en su relación con México. Además, las acciones concretas de la nación azteca para relanzar la relación bilateral entre los dos países incluyeron la firma del tratado comercial, instrumento indispensable para la adhesión de China a la OMC, rubricado la víspera de su admisión. Esta percepción de un nuevo ímpetu se vio reforzada con las dos visitas del presidente Fox a China. La primera tuvo el carácter de visita de Estado y la segunda se realizó en el marco de la Reunión Cumbre de Líderes de APEC en Shanghai. La República Popular China correspondió al gesto con la vista oficial del primer ministro Wen Jiabao en diciembre de 2003. En esta ocasión, el jefe de gobierno chino y el mandatario mexicano acordaron privilegiar a los dos países con una relación estratégica. Para instrumentar esta alianza, las partes determinaron crear la Comisión Binacional Permanente como un recurso de alto nivel para promover, reforzar y planear la relación bilateral a largo plazo y en todos los ámbitos. La primera reunión se realizó el 14 de agosto de 2004 y viajaron a Pekín seis secretarios de Estado, dos miembros del gabinete, senadores, diputados federales, empresarios y representantes de destacados medios de comunicación. A la fecha, se han celebrado cuatro reuniones. En la última, de julio del 2011, se aprobó el Programa de Acción Conjunta para el periodo 2011-2016 que incluye acciones específicas a llevarse a cabo en el quinquenio para planificar y orientar la más amplia cooperación entre ambas partes.

Además de lo acordado en las reuniones de la Comisión Binacional, una acción de gran trascendencia fue la apertura del Consulado General de México en Cantón, en enero de 2006, instrumento estratégico para dar apoyo a los crecientes intercambios que realizan empresarios mexicanos y chinos, así como enviar un mensaje político y económico al ampliar y consolidar la presencia mexicana en la importante zona del Delta del Río Perla.

Otro instrumento importante en le relación bilateral, creado en este decenio con el propósito de avanzar y consolidar una relación económica equilibrada, lo constituye el Grupo de Alto Nivel (GAN) integrado por la Secretaría de Economía mexicana y el Ministerio de Comercio chino. En su pasada reunión de marzo de 2011 se acordó facilitar 
el comercio y la cooperación en sectores como la minería, infraestructura, industria electrónica, automotriz, alimentos, entre otros.

En la actualidad, las relaciones de China con México se inscriben en el conjunto de relaciones de la República Popular China con América Latina, no así las relaciones de México con China, las cuales están definidas por el tamaño de la economía china, su peso específico en el contexto internacional, su creciente poderío militar, regional y global, y por su posicionamiento, en los últimos años, como su segundo socio comercial, a pesar de la ausencia de un tratado de libre comercio. Asimismo, el empresariado mexicano concibe a China como un formidable competidor que lo ha desplazado de sus mercados tradicionales, como el de Estados Unidos, y que mantiene cerrada su economía a las exportaciones mexicanas.

En 2010, el volumen total de comercio con la República Popular China fue de 52,428 millones de dólares, cifra que confirma su posición como el segundo socio comercial de México en el mundo y que puede ser refutada porque no aparece en ninguna de las estadísticas oficiales de los dos países. Sin embargo, refleja los intercambios económicos bilaterales reales, ya que incluye el comercio que se realiza a través de terceros países. China computa transacciones por un total de 24,700 millones de dólares, mientras que nuestra Secretaría de Economía calcula la suma de importaciones y exportaciones con ese país en 49,790 millones de dólares. Esta considerable diferencia refleja que una parte muy importante de nuestras transacciones comerciales con China se realizan por la intermediación de terceros países, principalmente Estados Unidos y en menor medida Hong Kong.

Aparte de la disparidad de las cifras, hay un hecho que es irrefutable: tenemos un gigantesco déficit comercial con China que, en el peor de los casos, asciende a 38,788 millones de dólares. De China importamos mercancías por valor de 45,608 millones de dólares; en cambio, México sólo exporta a China 6,820 millones de dólares. En términos de porcentaje, esto quiere decir que a China le vendemos apenas el $15 \%$ de lo que este país nos vende. En el largo plazo, una situación así es insostenible para una sana evolución de los intercambios económicos bilaterales. Por lo tanto, es importante un replanteamiento integral de las relaciones económicas sino-mexicanas.

Las alternativas para mejorar la balanza comercial entre México y China pueden ser varias y diferentes. Importantes, entre otras, serían incrementar sustantivamente nuestras exportaciones y alentar la inversión china en la planta productiva de nuestro país.

Si se analiza detenidamente la composición de las importaciones provenientes de China, salta a la vista que gran parte de éstas son componentes electrónicos que serán incorporados a productos que se arman en México. Es decir, son importaciones que realiza la industria maquiladora y es imposible detener este flujo so pena de aniquilar la maquila. Lo que sí es posible y deseable es exhortar por una mayor integración nacional de la industria maquiladora con políticas públicas de apoyos decididos a este sector para que incentive a sus empresas proveedoras extranjeras a venir a México a producir sus componentes. Tales políticas crearían un círculo virtuoso cuyos efectos producirían una mayor creación de empleos, la transformación de las maquiladoras en industrias nacionales, el anclaje de las empresas a suelo mexicano que impediría, o al menos dificultaría, su migración a otras latitudes, el incremento de la recaudación fiscal y, por último, una disminución sustantiva del déficit comercial con China. 
Más aún, para detonar una verdadera alianza trascendente con China, México podría ofrecerse como una plataforma sólida y estratégica que sirva a los ambiciosos planes de la industria automotriz china para conquistar los mercados internacionales, en especial el estadounidense. La localización geográfica de nuestro país, la infraestructura de los clusters automotrices existentes y la mano de obra calificada ofrecen oportunidades inigualables para este propósito.

Asimismo es urgente en México poner en práctica políticas de incentivos para alentar exportaciones a China. Para ello hay que reconocer que las Pymes necesitan apoyos decididos e información amplia, veraz y actualizada que sólo las instituciones mexicanas pueden proporcionar. También reconocer que es imperativo culminar las negociaciones de protocolos para el acceso de mayor número de productos agropecuarios. La experiencia nos dice que estas negociaciones generalmente son lentas, altamente burocratizadas, no exentas de un trasfondo de barrera no arancelaria al comercio, pero impostergables para este sector productivo. En el terreno de la minería, China, por su parte, podría venir en auxilio de los mineros descapitalizados que no pueden poner en operación sus concesiones y así diversificar la inversión extranjera en este campo.

En los años recientes, China se ha convertido en un destacado proveedor de planeación, fabricación e instalación de sistemas de trenes de alta velocidad. Un proyecto de gran envergadura e importancia para la infraestructura de México sería el desarrollo integrado de un sistema de trenes de alta velocidad entre la Ciudad de México y Guadalajara; Ciudad de México y Monterrey; Guadalajara y Monterrey. Este proyecto colocaría a nuestro país a la vanguardia en América Latina en transportación ferroviaria, rescataría del olvido un servicio de transporte de pasajeros altamente eficiente sin contaminar el medio ambiente $y$, finalmente, podría llevarse a cabo a un costo considerablemente más bajo que cualquier otra tecnología disponible. Además sería factible contar con financiamiento de instituciones chinas.

En la actualidad, China invierte grandes recursos económicos y humanos en investigación y desarrollo, y ha invitado a naciones e instituciones extranjeras a que contribuyan conjuntamente en este esfuerzo. México podría participar en proyectos específicos en los campos de nanotecnología, materiales de alta conducción, biotecnología y exploración espacial, con inversión y recursos humanos, que le permitirían no sólo disfrutar de los beneficios, también explotar los resultados de las investigaciones.

El turismo representa otra gran oportunidad de expandir la relación económica bilateral con China. En 2010, cerca de 45 millones de turistas chinos salieron al extranjero. La Organización Mundial del Turismo estima que para el año 2020 los viajeros chinos al exterior sumen más de 100 millones de personas. Las autoridades francesas de turismo calculan que de sus visitantes extranjeros los que más gastan son los chinos, con un promedio de 2,500 dólares diarios por persona durante su estancia en Francia. México, con todos sus atractivos turísticos, podría captar un buen porcentaje de esos viajeros. Nuestra historia milenaria, sus vestigios arqueológicos, su herencia colonial, su creatividad barroca, su particular cultura culinaria, su música, sus artes visuales, sus artesanías y folclore son elementos suficientemente poderosos para atraer al turista chino.

Sin embargo, es imprescindible crear la infraestructura turística necesaria para hacer sentir al viajero de este país oriental bienvenido a nuestro territorio. Un componente 
sustancial de esta infraestructura se refiere a hoteles y restaurantes. Los primeros deberán de proporcionar, por escrito, un mínimo de instrucciones de seguridad y procedimientos de evacuación en idioma chino y los segundos deberán de tener menús en chino con descripciones, aunque someras, de los ricos platillos de la cocina mexicana. Otros servicios que resultan indispensables son el entrenamiento y capacitación de guías de turismo mexicanos para dar, en idioma chino, una visión propia de México. Así, atendiendo a estas condicionantes, podremos labrar un nicho en esa significativa veta del turismo internacional y reducir en parte el colosal déficit comercial con esa nación en vías de convertirse en la otra superpotencia de la época contemporánea.

México dispone ya de los mecanismos para llevar a cabo estos objetivos. La Comisión Binacional Permanente México-China es el instrumento de más alto nivel para diseñar las políticas que comprometan a los dos Estados en el camino de crear una auténtica asociación estratégica. Este mecanismo posee amplias facultades propositivas como quedó de manifiesto el importante documento emanado de la cuarta sesión que tuvo lugar en la Ciudad de México.

No obstante los sólidos pilares sobre los que se sustenta la Comisión, es fundamental fortalecerla y dotarla de mayor amplitud para la participación en la toma de decisiones de otros actores importantes en la relación bilateral.

El Grupo de Alto Nivel (GAN) es un mecanismo de acercamiento institucional de consulta permanente para temas comerciales y de inversión bilaterales con capacidad de identificar oportunidades de negocios, nichos de mercado, promover el acceso de productos mexicanos al mercado chino y atraer inversión china a México. En la quinta reunión del GAN que tuvo lugar en la Ciudad de México, por primera vez fueron invitados académicos y empresarios para participar en las deliberaciones, una importante contribución al desarrollo de los trabajos, ya que éstos últimos son los directamente beneficiarios o perjudicados por las acciones que se tomen en el seno de este Grupo.

China constituye un socio trascendental para México, más aún cuando existen amplios espacios y oportunidades para intensificar y diversificar las relaciones comerciales y de inversión. Encontrar y desarrollar estos nichos y vacíos de manera eficiente y rápida, es el reto donde se juega, en buena medida, el futuro de la asociación estratégica entre los dos países.

El desconocimiento generalizado de lo que ocurre en China y de lo que supone su rápido crecimiento y ascenso como potencia mundial parece ser la norma en la sociedad mexicana, salvo honrosas excepciones. Los estudios académicos serios sobre China elaborados en nuestro país son escasos. Escasa es también la información que difunden los medios, con el agravante de que suele ser subjetiva y tendenciosa. Evidentemente, esta situación en nada contribuye a disipar las dudas que genera el rápido avance chino.

No faltan voces, a lo largo de México, que perciben la presencia de China en el país más como amenaza y como un formidable competidor en multitud de sectores globales, que como oportunidad para diversificar mercados y recibir otras fuentes de capital y tecnología. Si bien es cierto que el abultado déficit comercial no ayuda a mitigar esas voces, también es cierto que no se ha avanzado de manera coherente en la diversificación de los mercados de exportación. 
Finalmente, una consideración para tener en cuenta: el desarrollo económico, social y militar de China y su posicionamiento como superpotencia no se va a detener. México, entonces, debería buscar posicionarse como el verdadero socio estratégico del país asiático en América Latina.

Tenemos que recuperar la condición de asociado indispensable que éramos al inicio de las relaciones diplomáticas y que los reacomodos geoestratégicos de la región nos arrebató y obligó a cambiar de posición. El reto es formidable, pero los dividendos compensarán con creces el esfuerzo que se haga. Ahora, los costos son relativamente bajos; en el futuro, serán tan altos que no los podremos sufragar y nos lo reclamarán las generaciones venideras. 


\section{Intercambio cultural y asistencia técnica. Grupos de estudiantes chinos en otros países. La experiencia mexicana en los años 70}

Omar Martínez Legorreta

Recibí la distinción de ser designado embajador de México en China a fines de 1975 y lo fui hasta 1979. Tuve la fortuna de atestiguar los grandes cambios que en esos años sobrevinieron a la República Popular con motivo de la muerte del presidente Mao; el conflicto político interno que se sucedió, la última caída y resurrección política de Deng Xiaoping y la proclamación, casi inadvertida, de las Cuatro Modernizaciones que, a finales de 1978, iniciaron una nueva apertura de China al mundo exterior.

Meses antes de mi llegada a Pekín, en mayo de 1975, estuve por primera vez en esa capital y visité la Universidad de Pekín, cuando viajaba con el presidente de El Colegio de México, Víctor Urquidi, para invitar a académicos chinos a viajar a México para asistir al Congreso Internacional de Ciencias Humanas en Asia y África que se celebraría en la capital mexicana en septiembre del año siguiente, organizado por esa institución académica. Esa visita y la conversación con el rector de la Universidad, la recordaría posteriormente, cuando en marzo de 1976 visité la misma universidad, ya como embajador de México, y pude atestiguar los efectos de empujar a los estudiantes a movimientos políticos desquiciadores, que los alejan de sus propósitos. En esa ocasión el móvil era la campaña política desatada para contrarrestar al "Viento Derechista empeñado en contravenir las justas decisiones de la Revolución Cultural". Eran los días en que cayó en desgracia Deng Xiaoping y viajó a refugiarse al sur del país, en Guangdong. Todas esas experiencias me llevan, necesariamente, a rememorar los antecedentes que, en materia de intercambio estudiantil, tuvo China en el siglo XIX y el segundo decenio del siglo XX, que incluyen el Movimiento Estudiantil del Cuatro de Mayo con el que los estudiantes chinos protestaron por el fracaso de la Conferencia de Paz de Versalles en 1919 y las Veintiún Demandas que hizo Japón a China en enero de 1915, ante la continua debilidad de su gobierno.

\section{Un poco de historia}

El choque cultural que significó la expansión de Europa en Asia, principalmente a partir de la segunda mitad del siglo XVIII, tuvo sus episodios más difíciles a partir de 1840, cuando la primera Guerra del Opio enfrentó a Inglaterra, por ese entonces la principal potencia militar y naval occidental, con China. Ese encuentro bélico demostró al imperio chino su evidente atraso en cuanto a armamento bélico y técnicas de guerra, también puso en evidencia que su concepción del mundo era errónea y que el País del Centro no era el rector en un sistema internacional de naciones que no la reconocía en ese papel. La derrota en aquella experiencia armada impuso a China los primeros "tratado 
desiguales" y abrió al comercio exterior los puertos de Cantón y otros en la costa china, además de crear por la fuerza la primera colonia británica desmembrada del territorio chino, la isla y puerto de Hong Kong.

Aquellas primeras concesiones a los países europeos impulsaron a sus gobiernos para demandar mayores facilidades que el gobierno chino era incapaz de negar, al tiempo que pretendía no cumplir los tratados que había firmado. El resultado fue el nuevo enfrentamiento conocido como la segunda Guerra del Opio que de nuevo enfrentó a China con las potencias europeas en 1860. Las negociaciones que concluyeron con la firma de nuevos "tratados desiguales" demostraron también la incompetencia e ignorancia de los intérpretes y lingüistas chinos de Cantón, empleados en esa circunstancia, quienes fueron severamente criticados por un funcionario chino de alto rango, Feng Kueifen.

Aquel nuevo desastre bélico, debido a la inferioridad de las armas chinas frente al armamento y técnicas de guerra de los occidentales, hizo pensar a los funcionarios chinos que en el gobierno se debía saber más sobre "asuntos extranjeros", en especial sobre armas de fuego y buques occidentales. Un primer paso en ese sentido fue el establecimiento del Dungwen Kuan o Colegio de Lenguas Extranjeras, en Beijing en 1862, como una oficina subordinada al Tsungli Yamen (una Secretaría de Asuntos Extranjeros) y de una Escuela de Ciencias y Lenguas Extranjeras que se abrió en Shanghai en 1863, que posteriormente se anexó al Arsenal de Kiangnan en 1869. Por entonces se invitó también a trabajar en China a un grupo de instructores extranjeros de los que se sospechaba su lealtad, según varios funcionarios conservadores. Esas experiencias, tiempo después, llevarían al gobierno chino a llegar a una conclusión obvia: si China quería aprender los secretos de la tecnología extranjera y de las formas como se gobernaba en otros países, era necesario enviar a jóvenes para estudiar y ser entrenados en los países extranjeros.

El envío de estudiantes varones jóvenes a otros países se hizo por primera vez en 1875, cuando un grupo viajó a Estados Unidos como parte de los primeros contactos de China y ese país. Con anticipación a aquella experiencia, los funcionarios chinos revisaron cuidadosamente la que se obtuvo del proyecto del primer estudiante chino graduado de una universidad norteamericana, Yung Wing, egresado de la Universidad de Yale en 1854. Una vez que se tomó la decisión de enviar al grupo, el proyecto llevó a 120 estudiantes chinos a Estados Unidos durante los años de 1872 a 1881. Otro proyecto semejante envió 30 estudiantes chinos a Inglaterra y Francia en 1876, para recibir entrenamiento técnico. En aquellos años se dieron también proyectos similares organizados por misioneros protestantes y por grupos de "chinos de ultramar", ${ }^{1}$ un ejemplo de ellos fue el caso de Sun Yatsen. Esos grupos formaron parte del mayor movimiento en el campo de la aculturación consciente que se dio en la historia.

El funcionario chino de más alto rango y más distinguido en este periodo histórico de China, Tseng Kuofang, en una serie de reflexiones que se contuvieron en un Memorial que dirigió al Trono en 1871, en el que demostraba una visión de largo alcance, expuso con gran habilidad y claridad las razones que aconsejaban y fundamentaban la conveniencia de enviar estudiantes a prepararse a otros países (Teng, 91-96).

1 Esos grupos se denominaban así, por residir en países extranjeros vecinos a China, que tenían fuertes lazos económicos y comerciales con sus lugares de origen en China. 
Primero se debía hacer una selección de jóvenes brillantes para enviarlos a estudiar administración militar, administración naviera, tácticas de infantería, matemáticas, fabricación de armas y otros temas. Se calculaba que después de un periodo de 10 años fuera habrían completado su entrenamiento y regresarían a China, de tal manera que a donde fueran enviados pudieran aprender por completo las técnicas nuevas en que los occidentales eran particularmente fuertes, con lo cual se podría empezar a planear, gradualmente, el autofortalecimiento de China.

Como ya se habían dado los casos de algunos funcionarios de distintos rangos, que después de haber viajado por varios países, por orden imperial, y así pudieron apreciar los aspectos esenciales de las condiciones del mundo exterior, encontraron que mapas nuevos, matemáticas, astronomía y navegación, construcción naval, fabricación de armas y de otros aspectos, todos eran avances logrados en apoyo de los asuntos militares. Por lo tanto, todos lo que hubieran estudiado en países extranjeros y aprendido técnicas superiores, debían ser invitados por las academias para unirse de inmediato con el objeto de enseñar sobre diferentes temas y continuar su propia preparación.

Cuando en 1868 se concluyó el primer tratado entre China y Estados Unidos, el Artículo VII del mismo indicaba que los chinos que desearan inscribirse en las distintas escuelas del gobierno, superiores o inferiores, para aprender ciencias y literatura, gozarían de un trato igual al lado a los nacionales, según los términos de la cláusula de "nación más favorecida". Los países extranjeros permitirían a los chinos aprender sus técnicas superiores junto con sus propios ciudadanos. El razonamiento central era que si los chinos deseaban adoptar las técnicas superiores $y$, de pronto, trataran de adquirir todo tipo de maquinaria extranjera, no solamente su posibilidad económica era insuficiente para hacerlo en ese momento, sino que no tendrían manera de asimilar los principios fundamentales o los detalles de las ideas más profundas contenidas en las técnicas superiores, a menos que las hubiesen estudiado antes y practicado con ellas por largo tiempo.

Según razonaba Tseng, ese plan una vez adoptado, se iniciaría con abrir una oficina en Shanghai para seleccionar a jóvenes brillantes de todas las provincias del imperio. El número seleccionado sería de 30 jóvenes por año, durante 4 años, en total 120 estudiantes, los cuales, después de pasar 15 años fuera empezarían a regresar a China en la misma secuencia de su envío; para ese entonces los jóvenes tendrían 30 años de edad, en plena capacidad de dar sus servicios a su gobierno y al país. Ese proyecto funcionó cuando se dio la aprobación imperial necesaria y los estudiantes seleccionados viajaron y aprendieron en instituciones académicas de Estados Unidos durante el decenio de 1872-1881, pero el experimento tan prometedor terminó abruptamente sin que se volviera a proseguir. Las razones fueron varias pero las más importantes fueron las que esgrimieron algunos funcionarios chinos de alto rango, en especial el superintendente de los estudiantes, agregado a la embajada china en Washington, que informaron que los estudiantes estaban olvidando su identidad y civilización original y descuidaban sus actitudes hacia sus mayores y sus maestros. Si bien podían tener éxito en sus estudios, no servirían para gran cosa a China cuando regresaran. En 1881 se terminó esa primera experiencia.

Como sucedió con los estudiantes que viajaron a Estados Unidos, a los enviados a países europeos se les ordenó su regreso inmediato. Algunos tuvieron la oportunidad 
de participar en aspectos de la Restauración Tongzhi de 1861-1875, que hubiera resultado en la renovación de la dinastía Qing y terminó en el rotundo fracaso en 1907-1911, cuando la abdicación del último emperador dio paso a la Revolución Republicana de 1911.

La Revolución Bolchevique de 1917 llevó nuevas ideas y experiencias a los intelectuales, ideólogos y estudiantes chinos, cuando la experiencia desconocida de China de participar en una guerra mundial, la Gran Guerra (1914-1919), los Ilevó a considerar que necesitaban enviar de nuevo jóvenes estudiantes a países europeos, esta vez inspirados por las ideas de Marx y el triunfo de Lenin en Rusia. Nuevos estudiantes chinos en Francia fueron Chou Enlai y Deng Xiaoping y sus compañeros en París, que habrían de pertenecer al grupo que acompañó a Mao Tsetung en la aventura que concluyó con la proclamación de la República Popular China en 1949.

\section{Una segunda experiencia}

Entre 1948 y 1963 China envió a la URSS 8 mil estudiantes aproximadamente, destinados a estudiar en instituciones de educación superior e institutos de investigación; ese número representaba casi $80 \%$ del total de estudiantes extranjeros llegados a la Unión Soviética. En los años 50 los estudiantes chinos eran casi el $50 \%$ del total de estudiantes extranjeros; de ellos dos tercios estudiaban ciencias e ingenierías, pues eran relativamente pocos los que fueron aceptados para estudiar asuntos militares, política, artes y humanidades.

Aquel envío de estudiantes fue una iniciativa costosa y masiva que representó un esfuerzo bilateral serio de transferencia de tecnología, basado en el supuesto de que la Revolución China irremediablemente caería dentro del mundo socialista y, como de hecho fue, se alinearía con el desarrollo de posguerra de la Unión Soviética que se encaminaba hacia una tecnocracia socialista. Todo ese proyecto era uno de los aspectos más tangibles y manifiestos de la amistad sino-soviética, que era el complemento de la política más planeada del envío de expertos soviéticos a China (Bernstein, 361).

\section{Una novedosa experiencia: estudiantes chinos en México en 1974}

El decenio de los años 70 en América Latina fue especialmente difícil e importante. En aquellos años, tres gobiernos latinoamericanos de izquierda buscaban acentuar su independencia política, entre otros aspectos mediante el reconocimiento de la República Popular China y su gobierno y desconocer a la República de China. El antecedente y ejemplo fue el que dio el gobierno de Cuba, que en septiembre de 1960 reconoció a la RP China y su gobierno. Le siguió diez años más tarde el gobierno de Salvador Allende en Chile, que en diciembre de 1970 reconoció al gobierno de Beijing; a ese reconocimiento le sucedió el del gobierno del Perú con el presidente Velasco Alvarado en noviembre de 1971. En la escena internacional el inicio de la crisis del petróleo y la apertura del gobierno de Estados Unidos hacia China, con la visita secreta del secretario de Estado, Kissinger, a ese país, a la que siguió el viaje del presidente Richard Nixon, contribuyeron a crear una atmósfera de expectativa respecto a las intenciones reales 
de esas visitas y la recomposición de las relaciones internacionales en el contexto de la Guerra Fría.

El gobierno de México reconoció al de la República Popular China como el legítimo representante del pueblo chino el 14 de febrero de 1972, fecha en que se cortaron las relaciones oficiales que existían con la República de China asentada en Taiwán. Esa formalidad fue el paso lógico que siguió al discurso del presidente mexicano ante la Asamblea General de la Organización de las Naciones Unidas, en septiembre de 1971, en que abogó por el reconocimiento de la RP China por la organización. El reconocimiento de México y el inicio de las relaciones diplomáticas con China abrieron múltiples oportunidades para el intercambio y la cooperación entre los dos gobiernos. Entre las primeras acciones estuvo aquella que concluyó en un acuerdo para el recibir a un grupo de estudiantes chinos en México. Este proyecto formaba parte de uno mayor por el cual el gobierno mexicano, que presidía Luis Echeverría Álvarez, deseaba incrementar las relaciones de todo tipo, en especial las culturales, por medio de acuerdos de intercambio estudiantil que implicaron, en un primer momento, el ofrecimiento del gobierno mexicano de recibir hasta 25 estudiantes a los que ofrecía becas especiales para venir a México a seguir un programa de estudios destinado a ampliar su conocimiento sobre el país y América Latina. Este ofrecimiento y acuerdo consiguiente se le hizo también al gobierno de Japón.

El intercambio de estudiantes fue acordado por los gobiernos chino y mexicano en 1973. El propósito subyacente era que esa experiencia le sirviera a México y a la República Popular de China en un momento en que ambos países llevaban a cabo procesos de apertura a la nueva escena internacional. Aunque ideológicamente diferentes, ambos procesos tuvieron la misma meta: la de encontrar su propio lugar en la comunidad internacional, y proporcionar así un impulso al desarrollo social y económico. Ello fue también una manera de legitimizar sus regímenes después de las violentas manifestaciones estudiantiles que tuvieron lugar en ambos países. Por razones políticas, el acuerdo se negoció y convino discretamente, tanto en México como en China, de manera que no antagonizara las élites nacionales y extranjeras. Después de todo, el gobierno de la República Popular acababa de ser bienvenido en la Organización de las Naciones Unidas como el verdadero representante del pueblo chino y había ocupado su lugar en el Consejo de Seguridad, donde sus políticas estaban siendo minuciosamente analizadas y monitoreadas en la atmósfera de la Guerra Fría.

En 1974, dos años después de que México y China establecieran relaciones diplomáticas, se inició el intercambio estudiantil entre los dos países. El gobierno mexicano, en acuerdo con el gobierno de la República Popular, recibió a un grupo de 25 estudiantes en México, el primero en ir a un país no socialista durante la Revolución Cultural. El grupo siguió un programa especial de enseñanza con cursos en historia mexicana y latinoamericana, literatura latinoamericana, idioma español, aspecto del desarrollo social, económico y político de México y América Latina. Este proyecto especial se le encomendó a una institución especial: El Colegio de México, “porque era la única institución en México y en Latinoamérica que había organizado un programa de enseñanza relacionado con estudios sobre Asia, ofreciendo un programa de grado para estudios chinos". Este razonamiento fue típico a la hora de explicar por qué el programa había 
sido confiado a esta institución. En mi calidad de director del Centro de Estudios de Asia y África del Norte de El Colegio de México, me tocó organizar el programa y recibir a los primeros grupos de estudiantes chinos que llegaron.

El experimento fue un éxito de ocho años y terminó por mutuo acuerdo. Por el lado de los estudiantes chinos, el programa abrió ventanas a una parte del mundo sobre el cual sabían muy poco o nada. Eso les amplió sus horizontes y les permitió convertirse en recursos humanos bien entrenados, muchos de los cuales fueron designados para trabajar en las nuevas embajadas chinas en Latinoamérica. Algunos estudiantes se destinaron para trabajar en la enseñanza e investigación en instituciones chinas de investigación y educación superior, así como a dependencias del gobierno, en especial el Ministerio de Relaciones Exteriores. De aquella experiencia me parece importante destacar que maestros y profesores mexicanos, quienes enseñaron y dieron conferencias a los estudiantes chinos, encontraron esa experiencia muy gratificante. Algunos desecharon viejos clichés y otros, que posteriormente fueron invitados a viajar a China como profesores visitantes, escribieron artículos o dieron entrevistas a los medios de comunicación respecto a su experiencia cuando impartieron cursos o conferencias a otros estudiantes en sus universidades.

Desde que se inició este intercambio, se especificó en el acuerdo respectivo, que éste sería de dos vías, es decir, que estudiantes mexicanos irían a China, pero muy pocos estudiantes fueron a estudiar a las universidades chinas; ciertamente ningún programa especial había sido creado para recibir a estudiantes mexicanos, similar al organizado para estudiantes chinos en México, las condiciones fueron muy diferentes. Para los primeros grupos de estudiantes chinos que llegaron, el gobierno mexicano también proveyó condiciones especiales para su alojamiento y transporte en la Ciudad de México. Se habilitó una casa en el sur de la ciudad, que se puso al cuidado de una señora que atendió su alimentación y otras necesidades domésticas; en tanto que, para su traslado diario al edificio que ocupaba El Colegio de México en la calle de Guanajuato en la colonia Roma, se destinó un microbús; al concluir sus clases del día, los llevaba a su casa sin dejarlos ir a otros lugares. La interacción y socialización del grupo estuvo limitada a la que lograban con sus profesores y otros estudiantes dentro del edificio de El Colegio. La embajada china en México era puntualmente informada del avance del programa de cursos y estaba pendiente del comportamiento de sus nacionales en su residencia. Por parte del gobierno mexicano, era un funcionario de la Secretaría de Hacienda, designado personalmente por el presidente de México para vigilar e informar sobre la buena marcha del Acuerdo. Estas condiciones especiales se parecieron mucho a las que tuvieron otros grupos de estudiantes chinos en otros países, en aquellas primeras experiencias a las que me referí antes.

Durante mi estancia en Pekín, al regreso de los primeros estudiantes que estuvieron en México, tuve oportunidad de reunirlos para comentar con ellos sus experiencias en México. Los pocos estudiantes mexicanos que llegaron para estudiar en alguna universidad de la capital china también iban a comentarme sus avances y sus carencias. En adelante, los que fueron con becas del gobierno chino, regresaron a México con una visión diferente del mundo. Ninguno lamenta el tiempo que pasaron en China. Tanto para estudiantes chinos y mexicanos, la dicotomía Este-Oeste se convirtió en algo casi 
sin sentido. Se dieron cuenta de que en Latinoamérica, como en Asia o en China, hay seres humanos que experimentan los mismos problemas planteados por el desarrollo en la globalización: los intercambios estudiantiles indudablemente permiten comparar a las personas de los países y regiones, en la manera como están organizados para solucionar problemas similares mientras se desarrollan y avanzan, así como los regímenes políticos y los gobiernos que los rigen.

Tan sólo por esos resultados, es necesario continuar con esos intercambios que crean puentes entre el Este y el Oeste. Hay mucho que aprender unos de otros y una buena manera de hacerlo es por medio del intercambio académico. Esa es una de las facetas de la cooperación internacional que es necesario impulsar

Sin duda alguna, muchos de los estudiantes chinos que estuvieron en México en el proyecto inicial de intercambio contribuyeron a esa apertura y a facilitar las relaciones entre su país y México, así como con otros países de América Latina.

\section{Bibliografía}

-Bernstein, Thomas P. and Yu Li, Hua (Editors), China Learns from the Soviet Union, 1949-present, Lexington Books, 2010.

- Teng Ssu-yu and Fairbank, John King: China's response to the West, Harvard University Press, 1979. 



\title{
La relación bilateral China-México: una reflexión personal
}

\author{
Jorge Eduardo Navarrete
}

Participo, complacido y agradecido, en este importante seminario que conmemora cuatro decenios de relaciones bilaterales de México con la República Popular China. Aporto, como se ha pedido a los mexicanos que hemos tenido el privilegio de actuar como embajadores en algún periodo de esos cuarenta años, una breve reflexión personal sobre el camino recorrido, cuyo extenso trazo parece difuminarse y perderse en ciertos momentos, y, en especial, sobre cómo vislumbro el porvenir de esas relaciones, ahora que China se ha transformado en la segunda potencia global.

Uno. A comienzos del decenio de los 70 del siglo pasado, alrededor de la restitución a la República Popular de los derechos de representación de China en la Organización de las Naciones Unidas, incluyendo su posición como miembro permanente del Consejo de Seguridad, se produjo un gran número de lo que entonces se denominó "reconocimientos". Naciones que hasta entonces habían mantenido relaciones con la llamada República de China, en Taipei, o que no las habían establecido, decidieron aceptar el principio de "una sola China" y al gobierno de Pekín como su único representante legítimo.

Numerosos países, tanto del entonces llamado Tercer Mundo como naciones avanzadas, habían dado ese paso sin esperar al nihil obstat del organismo mundial, o el de Estados Unidos. En ese sentido, México se cuenta entre las naciones que sólo tardíamente abrieron los ojos a la realidad evidente de la República Popular como gobierno real del conjunto del pueblo chino.

Un grupo de mexicanos distinguidos, aglutinados alrededor de la Sociedad de Amistad con China, propugnó, sobre todo en los años 60, por desarrollar lazos de conocimiento y cooperación mutuos con China. Debe recordárseles como pioneros, que apuntaron el camino a seguir. Menciono ahora, con la selectividad arbitraria de la memoria, los nombres de Guillermo Nasser Quiñones, que previó el potencial de las relaciones comerciales y económicas bilaterales, y de la maestra María Elena Torres, interesada sobre todo en los contactos e intercambios culturales y educativos. Hay que mencionar al senador Manuel Moreno Sánchez, incansable promotor de la diversificación de las relaciones políticas internacionales de México.

Los primeros 15 a 20 años de la relación diplomática entre México y China fueron, me parece, fructíferos para ambas partes. Las dos naciones, alejadas a pesar de una larga historia común de encuentros y desencuentros, se descubrieron una a la otra en sus respectivas realidades contemporáneas. Una manifestación central de ese periodo tuvo como protagonistas a los jóvenes chinos que vinieron a instituciones educativas mexicanas a aprender el castellano y a estudiar la historia y cultura del país y de América Latina. Muchos de ellos regresaron a desempeñar funciones de relevancia en la diplomacia y el gobierno chinos. 
Sobre todo en los 70, China y México encontraron causas compartidas en las relaciones internacionales: la defensa de la autodeterminación y la lucha contra los vestigios del colonialismo fueron banderas destacadas. Con algunas diferencias de matices y prioridades, se empeñaron en la construcción de un nuevo orden económico internacional y respaldaron la nueva institucionalidad, recién construida, para la cooperación económica internacional, por ejemplo a la Conferencia de las Naciones Unidas sobre Comercio y Desarrollo. Hubo también áreas, como la desnuclearización y el desarme, en las que las respectivas posiciones difirieron.

En esos primeros lustros, China encontró en México a un país que marcaba derroteros para la región latinoamericana, viéndolo como instrumental para el objetivo de ampliar sus relaciones diplomáticas en las subregiones de América Central y las Antillas, en las que se prolongaba la presencia de Taipei.

También en esos años y más adelante, México fue apreciado como país que planteaba iniciativas de alcance global en las Naciones Unidas, entre ellas la Carta de Derechos y Deberes Económicos de los Estados, aprobada en 1976 por la Asamblea General, y el Plan Mundial de Energía, cuya discusión quedó inconclusa a principios de los 80.

Cuando se desea elegir un solo indicador para apreciar la importancia de alguna relación bilateral suele acudirse al comercio con el país de que se trate. Se supone que el intercambio comercial refleja, de algún modo, el alcance y solidez del conjunto de una relación bilateral. Un intercambio comercial balanceado y floreciente, supone buenas relaciones de inversión y financieras, entendimientos políticos razonables y proporciona impulso a otros aspectos de la relación, como los educativos y culturales.

Si se da por bueno este indicador, en el caso de México y China se parte de la insignificancia: en 1972, las importaciones mexicanas procedentes de China continental equivalían a menos de una décima de $1 \%$ de las compras al exterior totales y las ventas a China apenas al 1\% del total de exportaciones. Dos decenios después, en 1992, esas participaciones seguían siendo insignificantes, inferiores al $1 \%$ en ambas corrientes. Sin embargo, un aspecto cambió radicalmente: el resultado del comercio bilateral se movió de un amplio superávit para México en 1972 a un déficit desmedido 20 años después, de acuerdo con las cifras mexicanas.

Más allá del comercio, en esos 20 años hubo muchos aspectos enriquecedores, entre ellos los arriba señalados, en el contacto y la colaboración entre los dos países. Es claro, con todo, que China y México se vieron uno a otro como socios marginales, en el comercio y en todo lo demás.

Dos. Mi misión en China se inició en 1989, el año del "incidente de Tiananmen", para usar el circunloquio favorecido por el gobierno chino. La reacción internacional condenatoria, impulsada por Estados Unidos y Europa occidental, se expresó en la interrupción de iniciativas y visitas diplomáticas, moratorias en el comercio de bienes bélicos, intercambios culturales, científicos y técnicos, participación en ferias y otras promociones comerciales. Hasta 1991 o 1992 China vivió en un relativo aislamiento, pues la congelación dictada por las potencias occidentales fue seguida, en menor o mayor medida, por países en desarrollo, México entre ellos.

Por debajo de la superficie, varias naciones, en especial de Europa occidental y notoriamente Alemania, continuaron y ampliaron sus acciones y proyectos de cooperación 
económica, sus inversiones y la presencia de sus empresas. Otros, como la República de Corea y las naciones del Sudeste Asiático, no se sumaron en momento alguno a las acciones de aislamiento o a las expresiones de censura.

Me parece que puede afirmarse que los cimientos de las relaciones económicas bilaterales que diversos países han construido con China y que ahora son las más importantes, se establecieron precisamente a lo largo de los años 90, un decenio en el que México concentró su atención en otra parte. No es necesario aclarar que esa otra parte fue el NAFTA. Se impuso la noción -que por desgracia ha sobrevivido- de que para todo propósito práctico, el resto del mundo, por lo que respecta a México, se constreñía a Norteamérica. Si se acude de nuevo al comercio exterior como indicador de la importancia global de la relación, en los 90 la de los socios de NAFTA y en particular la de Estados Unidos aumentó notoriamente. En 1990, 65.3\% del comercio exterior de México se realizó con Estados Unidos $(62.5 \%$ de las importaciones y $68.8 \%$ de las exportaciones). Tras un decenio de concentración en Norteamérica estos porcentajes habían pasado, en 2000, a 80.7, 73.1 y 88.7, respectivamente. La importancia relativa de un resto del mundo que comprendía, entre muchos otros, a China, se comprimió entre 10 y 15 puntos porcentuales, por así decirlo. Es claro que el camino elegido condujo a una mayor concentración y a una dependencia que en otros textos he caracterizado como umbilical.

En suma, los años 90, que permitieron a numerosos países potenciar sus relaciones bilaterales o regionales con China, no fueron aprovechados de manera semejante por México.

En los 90 se pensó que la participación de México en el NAFTA tendría para China el atractivo de aprovechar la plataforma del mercado mexicano para potenciar su acceso a los otros dos mercados de Norteamérica, en especial el estadounidense. La realidad mostró que China no sólo penetró el mercado del norte sin necesidad de apoyarse en la plataforma ofrecida, sino que desplazó de ese mercado a diversas exportaciones manufactureras mexicanas.

Sin embargo, esa noción obviamente ingenua sigue siendo esgrimida en la actualidad. Al examinar el panorama bilateral en materia de inversiones, en la página web de la embajada de México en China (consultada durante la redacción de esta nota) se expresa la esperanza de que los inversionistas chinos "buscarán posicionarse fundamentalmente en los sectores de manufactura, donde las empresas chinas podrían aprovechar el acceso al mercado norteamericano".

Tres. En el presente siglo, para decirlo en una sola frase, no se registran avances reales en la construcción de una relación bilateral sólida, creciente y mutuamente benéfica. Otra es la imagen, desde luego, si se atiende a la retórica bilateral, en especial la proveniente de la parte mexicana. En 2003, por ejemplo, a instancias de México se decidió constituir una asociación estratégica entre ambos países.

Ya para ese momento la brecha entre los ritmos de crecimiento de las economías china y mexicana se había expandido de manera incesante. La influencia internacional de uno y otro resultaba también incomparable. Si uno se pregunta qué aportaba México al supuesto carácter estratégico de la relación bilateral se concluye que muy poco, más allá de un mercado ávido y en creciente expansión para las relativamente baratas mercancías de consumo producidas en China. 
No se ignoran, al afirmar lo anterior, avances puntuales en algunos aspectos de la relación bilateral: proyectos específicos de cooperación técnica o de intercambio cultural, aprovechamiento de algunas oportunidades de inversión, coincidencia en algunos temas de la agenda global, en especial los de carácter político, como el rechazo a la imposición unilateral de sanciones, al margen de la autoridad del Consejo de Seguridad, o el dilatado proceso de reforma de la Organización.

Lo que no termina de integrarse es una relación cuya dimensión, importancia y oportunidades de expansión la sitúen dentro del limitado número de relaciones prioritarias que cada país establece. Ni México se cuenta entre las prioridades internacionales de China, ni China recibe la atención suficiente para convertirla en uno de los países prioritarios para México en el universo de sus relaciones bilaterales. Un universo, por cierto, muy limitado: México mantiene relaciones diplomáticas con embajadas residentes en 73 países; China en 169.

Cuatro. Cualquier visión del futuro de la relación sino-mexicana debe partir de un enfoque realista de los roles que a uno y otro país corresponderá jugar en el escenario global. No se argumenta que una relación bilateral significativa sólo pueda construirse si los países que la mantienen desempeñan papeles de prominencia similar en el mundo de la globalidad. Lo que se requiere es que el papel y posición que correspondan a cada uno ofrezcan oportunidades atractivas de cooperación y complementación. Estas oportunidades no surgen de manera espontánea, hay que construirlas, asumiendo riesgos y tomando iniciativas.

Un gobierno mexicano interesado en recuperar y fortalecer un espacio para iniciativas nacionales o multilaterales en el escenario mundial podría encontrar en el gobierno chino un eventual participante en algunas de ellas.

La consulta bilateral de alto nivel debe desburocratizarse y realizarse de manera regular, sin suspensiones ni retrasos. Su objetivo central debe ser la identificación de opciones de cooperación en todos los ámbitos. Esta identificación puede exigir, en algunos casos, como algunos de los que en seguida se mencionan, la realización de estudios de factibilidad. Otro requisito es que los proyectos que se aprueben no estén sujetos a vaivenes dictados por los cambios de gobierno.

Deben buscarse intereses coincidentes en los organismos y mecanismos multilaterales en que los dos países participan. Se requiere, para hacer factibles algunas de estas opciones, que México adopte posiciones más de vanguardia, menos atadas a los dictados convencionales de Estados Unidos y otros países avanzados. Tal es el caso, por ejemplo, de las cuestiones vinculadas a la reforma del sistema monetario y financiero mundial, donde en los últimos años las posiciones mexicanas han estado entre las más tímidas y pacatas.

Las cuestiones energéticas y ambientales, vistas con enfoque amplio, podrían abrir frentes de cooperación en no pocos espacios:

- En el bilateral, México podría plantear un programa de desarrollo de sus recursos geotérmicos en colaboración con empresas chinas de equipo y servicios tecnológicos. 
- Otra área de posible cooperación bilateral, en la que pueden explorarse otras opciones tecnológicas, es la generación nucleoeléctrica, cuando en México supere la veda que se ha mantenido de hecho desde la conclusión de Laguna Verde.

- En el subregional, México podría atraer a su territorio a fabricantes de equipo y desarrolladores de tecnología para, por ejemplo, energía solar con paneles fotovoltaicos o parques eólicos costa afuera, en escalas y con características adecuadas para el área mesoamericana, en el istmo y en el archipiélago.

- En el regional, sería concebible un programa de repotenciación de las plantas hidroeléctricas de América Latina, dotándolas de turbinas de mayor rendimiento producidas en consorcios sino-latinoamericanos que sustituyan equipos en ocasiones técnicamente obsoletos.

- En el global, existen intereses comunes de largo plazo para minimizar los costos de la necesaria reducción de emisiones de GEl en los próximos decenios, que pueden alimentar propuestas de países en desarrollo que, como China y México, son grandes emisores, para mejorar las opciones técnicas de supresión o captura de $\mathrm{CO} 2$.

Hay que imaginar grandes proyectos que capturen la imaginación de los agentes económicos, científicos y técnicos de los dos países; como lo demostró Brasil desde los años 80 del siglo pasado, el aeroespacial puede ser uno de ellos. Si México va a establecer, en los próximos dos decenios, una red propia de satélites geoestacionarios para posicionamiento o a sustituir satélites de comunicaciones, el empleo de cohetes portadores chinos podría ofrecer ventajas interesantes.

La posición de clara avanzada que China ha alcanzado en la construcción de redes de transporte ferroviario de alta velocidad podría ser base de una asociación para construir, primero, líneas troncales y, más adelante, hacia mediados de siglo, conexiones interurbanas que racionalicen el dispendioso transporte carretero de bienes y personas.

Como muestra el espectacular desarrollo de las relaciones entre China y la República de Corea, pasado un cierto punto se produce un efecto de causación acumulativa o, si se prefiere, la relación queda inscrita en un círculo virtuoso. Crear la masa crítica para que esto ocurra en la relación con China es, en la actualidad, sobre todo responsabilidad de México. Nos corresponde imaginar y proponer las iniciativas que persuadan a China de que, más allá de la retórica y las cortesías mutuas de la diplomacia, vale la pena ver a México, no como la plataforma hacia el mercado estadounidense de que se sigue hablando en el discurso oficial, sino como una nación que puede convertirse en un socio confiable y potencialmente significativo. 

Sección 2:

Economía, comercio e inversión 



\section{Aspectos comerciales y de inversión entre China y México: ¿colisión o acuerdo?}

Enrique Dussel Peters

México presenta en 2011 una larga agenda pendiente en temas tan apremiantes como su masiva pobreza, el rezago agrícola, el abandono de los problemas étnicos y de los pueblos indígenas, así como la profundización de la polarización socioeconómica y territorial desde el proceso de apertura económica a finales de la década de los 80 , insuficiente generación de empleo, crisis del sector manufacturero y mínimos aumentos de los salarios reales, además de un mediocre crecimiento per cápita en las últimas tres décadas. Considerando los aspectos anteriores (Dussel Peters, 2000; Moreno Brid y Ros, 2010), este documento se concentra en la relación económica entre México y China -con énfasis en el comercio y la inversión- con base en un breve diagnóstico y una posterior segunda sección de propuestas para una futura agenda bilateral entre ambos países.

\section{Principales condiciones de la relación de México con China}

Desde una perspectiva del 2011, ¿qué esfuerzos se han venido haciendo en los últimos años para mejorar la relación con la República Popular China? Un par de aspectos institucionales son críticos en la historia más reciente, y favorecen comprender la problemática comercial y de IED entre México y China':

1. Más allá de añejas relaciones diplomáticas y políticas - de la Nao hasta el importante acercamiento en la década de los setenta con el presidente Echeverría (Anguiano Roch 2007)- es a partir de 2003-2004 que inicia cualitativamente una nueva etapa en la relación binacional, coincidente también con el crecimiento económico y comercial de la relación binacional. Durante la década de los 80 y los 90 México desperdició las excelentes relaciones políticas con China que había cultivado hasta los 70 del siglo XX, básicamente dado que las élites económicas y políticas concentraron su proyecto socioeconómico futuro en América del Norte y en la integración con Estados Unidos, debido a que las estrategias socioeconómicas y estratégicas se concentraron en América del Norte y Estados Unidos desde finales de los 80 y los 90, mientras que se dejó de lado la integración con ALC y otros países en Asia y por ejemplo con China.

2. En 2003-2004 concurren dos elementos importantes: China se convierte, desde 2003, en el segundo socio comercial de México -y uno de los primeros casos de América Latina y significativo para la relación con Estados Unidos- y se crea

1 Para un análisis detallado, véase: COMEXI (2008); Cornejo (2008); Dussel Peters y Trápaga Delfín 2010. 
la Comisión Binacional México-China en agosto, mientras que en septiembre se establece el Grupo de Alto Nivel (GAN) que se reúne por primera vez en enero de 2005. Mientras que la Binacional es bianual, el GAN debiera hacerlo con mayor frecuencia y es el grupo "técnico" para solucionar temas de la Comisión Binacional y la relación binacional.

3. Desde 2003, y con base en una asociación estratégica formal, se han realizado diversos esfuerzos en materia binacional para formalizar relaciones en términos de combate al comercio ilegal (2004), el reconocimiento de México como un "destino turístico autorizado" (2004), así como más de una docena de acuerdos en materia de transporte aéreo (2005), marítimo (2005), de cooperación minera (2005) y un Acuerdo para la Promoción y Protección Recíproca de Inversiones (APPRI) de julio de 2008 que permite la protección jurídica de flujos de capital destinados al sector productivo en forma recíproca (Dussel Peters, 2012).

Reconociendo los esfuerzos anteriores, un hecho refleja la inquietud social y política en México ante los retos planteados por China: en diciembre de 2007 empresarios y varias decenas de miles de trabajadores vinculados a la producción de cuero y calzado marcharon en la ciudad de León para protestar contra las masivas importaciones chinas, un hecho con pocos precedentes en la reciente historia de México. Esta protesta fue el corolario de una serie de peticiones y presiones que empresarios realizaron durante 2007 para impedir una medida: la eliminación de unas mil 300 fracciones arancelarias, algunas superiores a $1000 \%$, que México imponía a las importaciones de diversas manufacturas chinas, entre ellas: textiles, prendas de vestir, juguetes, maquinaria industrial, productos químicos, entre otros. $Y$ es que, con el ingreso de China a la Organización Mundial de Comercio (OMC) en 2001, los países miembros de este organismo internacional -entre ellos México- se comprometieron eliminar en un plazo de seis años los aranceles que imponían a la importación de los productos de la nación asiática (Dussel Peters, 2011/c).

En los hechos, sin embargo, los empresarios mexicanos se encuentran profundamente divididos en este tema. Para un grupo de ellos, China ha significado enormes oportunidades para realizar importaciones de productos que son más baratos a los ofrecidos por otros competidores extranjeros o respecto a los existentes en el mercado nacional. Muchos otros, en cambio, se muestran reacios a aceptar la eliminación de esas cuotas compensatorias como resultado del desplazamiento de sus productos y como resultado de la profunda crisis del sector productivo mexicano. La Cámara de Senadores tomó partido en el asunto y a finales de 2007 solicitó al gobierno rechazar la eliminación de los aranceles a los productos chinos. También pidió aclarar las aparentemente secretas negociaciones sobre las cuotas compensatorias durante 2007, así como definir los costos y beneficios de dichas cuotas compensatorias, sobre cuyos efectos no existen evaluaciones.

A mediados de 2008, y después de varios meses de tensas negociaciones considerando que el acuerdo anterior había vencido en diciembre de 2007, se logró el Acuerdo Comercial de Transición en materia de Cuotas Compensatorias mediante el cual se establece que la mayor parte de las fracciones a las que México le imponía una cuota compensatoria se elimina: de las 953 fracciones de importación de China a las cuales México 
le imponía una cuota compensatoria, para 78.6\% de las fracciones la cuota será eliminada y sólo se mantendrá hasta el 11 de diciembre de 2011 para 204 productos que México definió como "sensibles" (particularmente productos en las cadenas hilo-textil-confección y cuero-calzado) (Monitor de la Manufactura Mexicana 2009; Ruiz Chávez 2008). Este acuerdo establece al menos dos puntos importantes para la futura relación China-México: a) las instituciones encargadas de la relación económica y comercial entre ambos países deben hacer un máximo esfuerzo para que la relación no vuelva a tensarse de nuevo de tal forma (las cuotas compensatorias como un buen ejemplo de lo que no debiera volver a suceder) y b) ambos países deben trabajar conjuntamente para que en tres años del nuevo convenio (en 2011), y cuando se eliminen por completo las cuotas compensatorias, no vuelvan a presentarse quejas por parte de empresarios mexicanos.

Es importante destacar en el contexto anterior que la relación política entre ambos países ha alcanzado su peor condición en 2011 en los últimos cuarenta años y ante un grupo de factores. Por un lado, la visita del Dalai Lama en septiembre de 2011 y su encuentro con el presidente Calderón, el posterior comunicado del Ministerio de Relaciones Exteriores de la República Popular China del 10 de septiembre en el que indica que el encuentro pasó "por alto las repetidas representaciones y el resuelto rechazo de la parte china al respecto...", siendo que el Tíbet es un "asunto interno de China", por lo que China "demanda de la parte Mexicana que adopte medidas para eliminar los efectos negativos, salvaguardando con acciones reales el desarrollo sano" entre ambos países. Posteriormente, el 28 de septiembre de 2011 la Secretaría de Economía suscribió una carta enviada al Ministerio de Comercio Chino señalando su "preocupación" en torno a las "irregularidades" de productos chinos importados en México que afectan a la economía mexicana y que contravienen a la Organización Mundial del Comercio (OMC). Durante noviembre y diciembre de 2011 buena parte del sector productivo y manufacturero -particularmente en sectores como hilo-textil-confección, cuero y calzado y el acero, pero también organismos como la Concamin y la Canacintra- así como diversos organismos sindicales como la CROC, el SNTE, Pemex, la CNC, entre otros, suscribieron un "Pronunciamiento contra la voracidad de los países asiáticos" ${ }^{2}$ y explícitamente dirigido a las importaciones de productos chinos.

En este contexto, ¿cuáles son los principales aspectos de la relación comercial y de inversiones entre México y China? Con respecto a los tópicos comerciales, y más allá de importantes diferencias estadísticas particularmente en el caso China-México, sobresalen varios aspectos, incluyendo:

1. Más allá de que China fuera el segundo socio comercial de México desde 2003, siendo que su participación comercial se incrementó de $0.3 \%$ en 1995 a $8.30 \%$ en 2010, la misma presenta un problema estructural insoslayable para México: la relación importaciones-exportaciones con China fue de 11:1, generó desde 2010 un déficit comercial superior a los 40,000 millones de dólares y representa un problema comercial que requiere de solución bilateral.

2 Véase: inserción pagada por las respectivas instituciones en varios periódicos de circulación nacional, lunes 26 de diciembre, 2011. 
2. Además de las dificultades para encontrar productos de exportación a China, durante 2000-2010 las exportaciones mexicanas se han ido "latinoamericanizando" crecientemente: si en 2000, 86.53\% de las exportaciones a China estaban vinculadas con la electrónica y el sector automotriz, éstas representaron menos de $30 \%$ en 2010 y en este último año los minerales, particularmente petróleo y el cobre en diversas formas, y otras materias primas generaban más de $53 \%$ de las exportaciones a China.

3. No menos preocupante resulta el importante desplazamiento de productos mexicanos en su principal mercado de exportación, Estados Unidos: en términos agregados México llegó a ser el segundo exportador a Estados Unidos en 2001-2002 con una participación de $11.61 \%$ en 2002 y cayó a $11.33 \%$ en 2009 , mientras que durante el mismo periodo la china aumentó de $10.81 \%$ a $19.03 \%$ (véase el gráfico 1). Si bien este retroceso ha sido generalizado, se ha notado particularmente en cadenas de valor como la electrónica e hilo-textil-confección, mientras que la cadena autopartes-automotriz ha logrado consolidarse en el mercado estadounidense todavía.

Gráfica 1

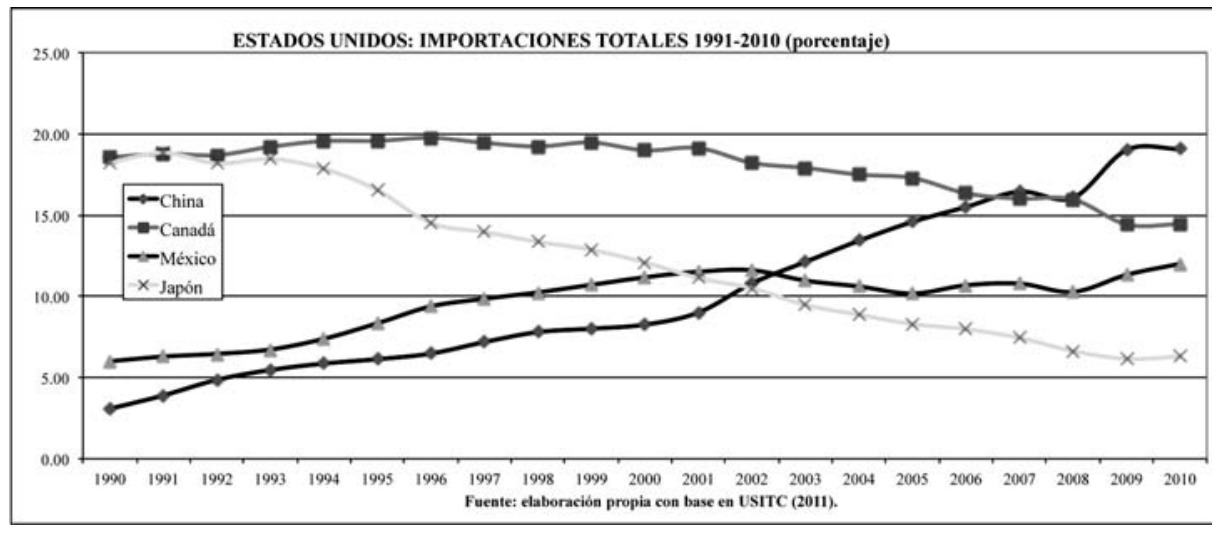

4. Por último, y un aspecto poco estudiado todavía en México y en China (Dussel Peters, 2011/b/c) y contrario a lo esperado, las importaciones mexicanas provenientes de China se especializan en bienes de capital e intermedios, conjuntamente participaron con el $91 \%$ de las importaciones de China, es decir, la participación de las importaciones de bienes de consumo (y que compiten directamente en el mercado doméstico con otras exportaciones y/o con la producción nacional) es inferior que del resto de las importaciones. El tema es crítico para comprender la importancia de China en México y su aparato productivo.

¿Qué aspectos pueden destacarse en torno a las inversiones chinas en México? En primer lugar, las mínimas inversiones chinas en México hasta 2010. Según las estadísticas chinas la OFDI (overseas foreign direct investment) china a México acumuló 76.9 


\section{Cuadro 1}

México: IED proveniente de China por sectores (1999-2010)

\begin{tabular}{|c|c|c|c|c|c|c|c|c|c|c|c|c|c|c|}
\hline & & 1999 & 2000 & 2001 & 2002 & 2005 & 2004 & 2005 & 2006 & 2007 & 2008 & 2009 & 2010 & $\begin{array}{l}1999 \\
2010\end{array}$ \\
\hline \multicolumn{15}{|c|}{ millones de dólares } \\
\hline & $\begin{array}{l}\text { Agricultura, ganadería, caza, silvicultura y } \\
\text { pesca }\end{array}$ & 0 & 0 & 0 & 0 & 0 & 0 & 0 & 0 & 0 & 0 & 0 & 0 & 0 \\
\hline & Minería y extracción de petroleo & 0 & 0 & 0 & 0 & 0 & 0 & 0 & 0 & 0 & 0 & 27 & 1 & 3.7 \\
\hline & $\begin{array}{l}\text { Industrias manufactureras, incluye los esta- } \\
\text { blecimientos maquiladores }\end{array}$ & 4.1 & 9.1 & .5 & -4.3 & 4.7 & 7 & 12 & 1.6 & 4.1 & 1 & 3.1 & 0.2 & 43.1 \\
\hline & Construcción & 0 & 0 & 0 & 0 & 0.2 & 0 & 0 & 0 & 0 & 0.4 & 0 & 0 & 0.6 \\
\hline & Comercio & 0.7 & 1.6 & 1.8 & 1.3 & 2.2 & 1.5 & 2.7 & 16.9 & 4 & -1.5 & 22.8 & 0.8 & 54.8 \\
\hline & Transportes y comunicaciones & 0 & 0 & 0 & 0 & 0 & 0 & 0 & 0 & 0.2 & 0.4 & 0 & 0 & 0.6 \\
\hline & $\begin{array}{l}\text { Servicios financieros de administración y al- } \\
\text { quiler de bienes muebles e inmuebles }\end{array}$ & 0 & 0 & 0 & 0.8 & 8.4 & 3.1 & -1 & 1.3 & 0.3 & 0 & 0 & 0 & 12.7 \\
\hline & $\begin{array}{l}\text { Servicios comunales y sociales; hoteles y res- } \\
\text { taurantes; profesionales, técnicos y personales }\end{array}$ & 0.2 & 0 & 0.1 & 0.5 & 10.1 & 0.3 & 0.2 & 0.3 & 0.2 & -0.6 & 0 & 0 & 11.3 \\
\hline TOTAL & & 5 & 10.7 & 2.4 & -1.7 & 25.6 & 11.9 & 13.9 & 20.1 & 8.6 & -0.3 & 28.6 & 2 & 126.8 \\
\hline \multicolumn{15}{|c|}{ participación } \\
\hline & $\begin{array}{l}\text { Agricultura, ganadería, caza, silvicultura y } \\
\text { pesca }\end{array}$ & 0.00 & 0.00 & 0.00 & 0.00 & 0.00 & 0.00 & 0.00 & 0.00 & 0.00 & 0.00 & 0.00 & 0.00 & 0.00 \\
\hline & Minería y extracción de petroleo & 0.00 & 0.00 & 0.00 & 0.00 & 0.00 & 0.00 & 0.00 & 0.00 & 0.00 & 0.00 & 9.44 & 50.0 & 2.92 \\
\hline & $\begin{array}{l}\text { Industrias manufactureras, incluye los esta- } \\
\text { blecimientos maquiladores }\end{array}$ & 82.00 & 85.05 & 20.83 & 252.94 & 18.36 & 58.82 & 86.33 & 7.96 & 47.67 & -333.33 & 10.84 & 10.00 & 33.99 \\
\hline & Construcción & 0.00 & 0.00 & 0.00 & 0.00 & 0.78 & 0.00 & 0.00 & 0.00 & 0.00 & -133.33 & 0.00 & 0.00 & 0.47 \\
\hline & Comercio & 14.00 & 14.95 & 75.00 & -76.47 & 8.59 & 12.61 & 19.42 & 84.08 & 46.51 & 500.00 & 79.72 & 40.00 & 43.22 \\
\hline & Transportes y comunicaciones & 0.00 & 0.00 & 0.00 & 0.00 & 0.00 & 0.00 & 0.00 & 0.00 & 2.33 & -133.33 & 0.00 & 0.00 & 0.47 \\
\hline & $\begin{array}{l}\text { Servicios financieros de administración y al- } \\
\text { quiler de bienes muebles e inmuebles }\end{array}$ & 0.00 & 0.00 & 0.00 & -47.6 & 32.81 & 26.05 & -7.19 & 6.47 & 1.16 & 0.00 & 0.00 & 0.00 & 10.02 \\
\hline & $\begin{array}{l}\text { Servicios comunales y sociales; hoteles y res- } \\
\text { taurantes; profesionales, técnicos y personales }\end{array}$ & 4.00 & 0.00 & 4.17 & 29.41 & 39.45 & 2.52 & 1.44 & 1.49 & 2.33 & 200.00 & 0.00 & 0.00 & 11.3 \\
\hline TOTAL & & 100.00 & 100.00 & 100.00 & 100.00 & 100.00 & 100.00 & 100.00 & 100.00 & 100.00 & 100.00 & 100.00 & 100.00 & 100.00 \\
\hline
\end{tabular}

millones de dólares durante 2003-2009, o 0.03\% del total de la OFDI china durante el

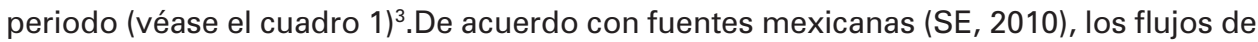
IED china durante 2003-2009 fue de 108.4 millones de dólares o menos de $0.03 \%$ de la IED total que ingresó a México durante este periodo. Estos valores y presencia mutua contrastan con el dinamismo comercial.

3 Las diversas fuentes divergen significativamente. Hasta 2008, por ejemplo, otras fuentes chinas oficiales (CCPIT, 2010; Chen, 2009) señalan que las inversiones chinas en México de 375 empresas fue superior a los 500 millones de dólares, mientras que las mexicanas en China de 116 empresas alcanzaron 319 millones de dólares. EI CCPIT (2010), sin embargo, indica que hasta 2009 las inversiones chinas en México fueron de apenas 173.9 millones de dólares. 
En segundo lugar, la Secretaría de Economía (2011) lleva a cabo un minucioso reporte trimestral sobre los flujos de IED en México. Destaca para la IED de China que para el periodo 1999-2010 se realizaron 597 transacciones chinas y que la gran mayoría se concentra en el comercio (con $43.22 \%$ de la IED china) y manufactura (33.99\%) (véase el cuadro 1). Sorprende, y a diferencia de otros países latinoamericanos, los reducidos montos de la IED china en el sector agrícola y de la minería.

La información a nivel de empresa es limitada y contrasta con la información pública de ambos países. El cuadro 2 refleja que con base en una compilación estadística detaIlada se registraron al menos 11 proyectos de OFDI china por más de 670 millones de dólares durante 2000-2009. Incluso esta estructura refleja que por el momento la OFDI china a México es muy reducida y se encuentra muy por debajo de los niveles y características en ALC y a nivel global. También, y a diferencia de otros países latinoamericanos, la OFDI china se concentra mucho más en proyectos que van más allá de la minería y le energía. Destacan varios proyectos vinculados a la manufactura de productos de exportación, sobre todo a Estados Unidos, y la importante inversión de Hutchison Ports Holdings en el Puerto Lázaro Cárdenas que pudiera convertirse en uno de los principales puertos de ALC con Asia y China. El fracaso de la coinversión entre Grupo Salinas y FAW para ensamblar autos -un típico caso de búsqueda de mercado con la opción de exportar- ha contaminado el ambiente binacional y particularmente en una cadena de valor tan prometedora como la de autopartes-automotriz.

\section{Cuadro 2}

F \& A de China en México principales transacciones (según su monto)

\begin{tabular}{|c|c|c|c|c|c|}
\hline & Fecha & Emprasa o proyacto objotiva & Sactor & Empresa china & Monto \\
\hline 1 & 2009 & Hutchison Ports Holdings & Infraestructura-puertos & Hutchison Ports Holdings & 220 \\
\hline 2 & 2008 & Tyler Resources & Minería & Jinchuan Group & 214 \\
\hline 3 & 2008 & Sinatex S.A. de C.V. & Textil & China Hengtian Group Corp & 56.98 \\
\hline 4 & 2009 & Golden Dragon & Manufactura de tubos de cobre & Golden Dragon Precise Copper Tube Group & 50 \\
\hline 5 & 2007 & Lenovo Group & Electrónica & Lenovo Group & 40 \\
\hline 6 & 2004 & International Sources & Confección-textil & Li \& Fung Limited & 27 \\
\hline 7 & 2006 & Huaxi Group & Minería & Huaxi Group & 25 \\
\hline 8 & 2000 & Huawei Technologies & Electrónica & Huawei Technologies & 20 \\
\hline TETAL & & & & & 67298 \\
\hline
\end{tabular}

Fuente: elaboración propia con base en Mergemarket (2010); Thomson-Reuters (2010) e información propia

Históricamente y hasta la década de los 70 México logró mantener excelentes relaciones diplomáticas con la República Popular China. Desde entonces, sin embargo, y particularmente ante la creciente orientación de las estrategias mexicanas hacia Estados 
Unidos y la dinámica descrita en Asia y en China, esta relación fue desaprovechada, es decir, México no ha sabido insertarse a nivel mundial ante la demanda de China. Si bien diplomáticamente México ha suscrito importantes acuerdos (véase la Comisión Binacional, el Grupo de Alto Nivel y varios otros, destacando el APPRI en 2008), en términos reales la relación ha sufrido un importante deterioro en los últimos años, y particularmente en términos de la IED china a nivel global. Mientras que países latinoamericanos como Brasil, Chile, Argentina y Perú han recibido masivas inversiones chinas, en el caso de México éstas han sido limitadas y han permeado un ambiente negativo como en el caso de FAW y Golden Dragon. Diversas empresas chinas (por ejemplo LiFan, Geely y otras en la cadena autopartes-automotriz) han indicado su interés en invertir en México en los últimos años, aunque sin transacciones concretas. Adicionalmente, el embate del narcotráfico y la inseguridad también han afectado negativamente el potencial de la OFDI china en México. No obstante lo anterior, las expectativas desde 2010-2011 son positivas: a decir de fuentes oficiales chinas y mexicanas directamente consultadas para este proyecto a finales de 2010, se esperaba que en 2011 se concluyeran varias inversiones chinas en hidrocarburos y en proyectos de proveeduría para la empresa Pemex en estados como Tamaulipas, Campeche y Tabasco, entre otros. También en estos casos el tema de la inseguridad pudiera ser un criterio definitivo para la OFDI china. Destaca, por último, que México refleja un extremo opuesto a buena parte de las experiencias de ALC con China: México fue en los últimos 15 años un "caso de éxito" por su orientación exportadora en manufacturas a los mercados industrializados -particularmente hacia los Estados Unidos- y ha sido justamente esta especialización productiva y comercial la que ha generado una mayor tensión económica y comercial con China, a diferencia de otros países en América del Sur. Esta tensión-específica en sectores como hilo-textil-confección, electrónica y, crecientemente, autopartes-automotriz- no ha sido sobrellevada al momento y se refleja en un muy alto déficit comercial de México con China.

\section{Hacia una agenda estratégica de corto, mediano y largo plazo entre México y China ${ }^{4}$}

Es importante entonces reconocer, como se hizo en el primer apartado del documento, que los gobiernos federales y las entidades federativas, destacando el Distrito Federal y Michoacán, han realizado esfuerzos importantes en los últimos años con respecto a China. Sin embargo, éstos han sido insuficientes institucionalmente y para hacer justicia ante el segundo socio comercial de México y una potencia regional que en el futuro incrementará su presencia en todos los ámbitos. En México, diversas instituciones y autores (ver apartado anterior) han presentado propuestas sobre temas diversos como las estadísticas bilaterales, turismo, infraestructura, temas migratorios, comercio, inversión, servicios, vuelos aéreos, la agenda política binacional y multilateral, entre muchos otros.

4 Para un análisis detallado, véase: Dussel Peters y Trápaga Delfín, 2010; y Dussel Peters, 2011/a. 
No obstante, y considerando la importancia de la relación China-México en el futuro, consideramos relevante recuperar el esfuerzo realizado por el Grupo de Trabajo México-China (GTMC) que se reunió durante 2008-2010. El grupo contó con miembros de alto nivel de los sectores público, privado y académico y con una relativa heterogeneidad política. En aras de lograr una primera agenda estratégica para un diálogo entre ambos países se destacaron tres ejes temáticos prioritarios para México y 29 propuestas vinculadas a los tres temas:

1. Las instituciones binacionales

2. Migración y turismo

3. Economía, comercio, inversión e infraestructura

Sobre el primer tema es importante ampliar y profundizar los Programas de Acción Conjunta -el último para 2011-2015- entre los sectores interesados y afectados e involucrar a otros; por el momento su definición y seguimiento ha sido muy limitado y no ha logrado involucrar a los sectores afectados e interesados en ambos países. Las instituciones binacionales, particularmente la Comisión Binacional México-China y el Grupo de Alto Nivel, requieren de apoyo financiero, institucional y político del más alto nivel para cumplir con sus compromisos y la agenda que se ha planteado desde sus primeras reuniones. Sin las condiciones anteriores el trabajo de estas instituciones bilaterales bien pudiera continuar generando listados de temas a resolver y sin mayor impacto en una efectiva profundización y solución de los temas relevantes. El trabajo de corte “horizontal" en el sector público -a todos sus niveles- y con organismos empresariales y la academia, es otro aspecto fundamental para hacer frente a múltiples aspectos; ambos países deben realizar un esfuerzo mayor bajo este rubro.

El segundo tema (migración y turismo) refleja la urgencia y relativa simpleza de enfrentar temas binacionales en el corto plazo y con un enorme potencial. Si se busca atraer turismo chino a México -y con un enorme potencial económico y en otros ámbitos- es indispensable solucionar problemas migratorios y facilitar el ingreso de ciudadanos chinos a México, ofrecer servicios adecuados, una infraestructura con características culturales y en chino, así como transporte aéreo con precios y en condiciones idóneas son otros aspectos que deben abordarse inmediatamente en caso de querer efectivamente atraer turismo chino. La temática es un excelente ejemplo para efectivamente medir el desempeño en el corto, mediano y largo plazos de la relación binacional. Estos rubros reflejan que existen temas en el corto, mediano y largo plazos que pudieran abordarse en forma importante y exitosa entre ambos países, en caso de existir voluntad política y "descomercializar" -es decir, no darle al comercio la prioritaria o hasta única relevancia estratégica binacional- la agenda entre México y China.

El tercer ámbito (economía, comercio, inversión, servicios e infraestructura) es seguramente el tópico al que mayor atención le han dedicado las instituciones públicas federales; por ello también la crítica a la excesiva "comercialización" de la agenda bilateral, con sus respectivos efectos negativos y contaminación en el resto de los ámbitos. Considerando que China es mucho más importante para México que México para China -y con base en lo elaborado en el primer apartado de este documento-, es crítico que 
México dinamice y profundice las problemáticas puntuales que ya han sido destacadas en estos ámbitos. En términos de una agenda bilateral -y no multilateral- con China México deberá responder a la solicitud de China de ser considerada una "economía de mercado" y, en forma estructurada, entablar un diálogo puntual con respecto a inversiones en materias primas (particularmente minería y petróleo), siendo que en algunos rubros seguramente estas inversiones pudieran no realizarse ante las condiciones constitucionales existentes. Por parte de México se requiere todavía de un diagnóstico más puntual -por ejemplo en torno al destino final de las masivas importaciones chinas (para su consumo en México, como exportaciones, etc.)- y una agenda que se concentre en: a) la "insustentabilidad" de la relación comercial y del masivo déficit fiscal, b) un diálogo puntual en cadenas de valor como infraestructura, electrónica y autopartes-automotriz (entre otras) para lograr inversiones chinas, tal y como lo está haciendo en otros países latinoamericanos, c) México deberá proveer de infraestructura portuaria en el Pacífico a uno o varios puertos que hagan frente al crecimiento del comercio con Asia y particularmente China en el corto, mediano y largo plazos.

Todo lo anterior bien podría gestarse con actores interesados y comprometidos con el tema en el corto, mediano y largo plazos. Por otro lado, esta agenda no solucionará problemas estructurales entre México y China. Es decir, China en la actualidad es un "espejo" para México y refleja sus limitaciones productivas, sociales y políticas y la falta de una estrategia de desarrollo nacional y en el largo plazo, independientemente de China.

\section{Bibliografía}

-Anguiano Roch, Eugenio. 2007. “Relaciones México-China en su perspectiva histórica". En, Dussel Peters, Enrique y Yolanda Trápaga Delfín. “China y México: implicaciones de una nueva relación". La Jornada, Fundación Friedrich Ebert, ITESM y UNAM-Cechimex, México, pp. 25-50.

-BM (Banco Mundial). 2011. Multipolarity: The New Global Economy. Banco Mundial, Washington, D.C.

- CCPIT. 2010/d. La inversión directa de China en América Latina. CCPIT, México.

-Chen, Yuming. 2009. "¿Cómo hacen negocios en China?". Ciclo de Conferencias China-México del Centro de Estudios China-México de la Facultad de Economía de la Universidad Nacional Autónoma de México. UNAM, México, febrero 25.

- COMEXI (Consejo Mexicano de Asuntos Internacionales). 2008. La China del Siglo XXI. Reto y oportunidad para México. COMEXI, México.

- Cornejo, Romer (coord.). 2008. China. Radiografía de una potencia en ascenso. EI Colegio de México, México.

- Dussel Peters, Enrique. 2000. Polarizing Mexico. The Imapct of Liberalization Strategy. Lynne \& Rienner, Boulder, Colorado.

- Dussel Peters, Enrique. 2005/a. Economic Opportunities and Challenges Posed by China for Mexico and Central America. Deutsches Institut für Entwicklung/German Development Institut, Bonn. 
-Dussel Peters, Enrique. 2011/a. “México: hacia una agenda estratégica en el corto, mediano y largo plazo con China. Propuestas resultantes de las labores del Grupo de Trabajo México-China (2009-2010)". Cuadernos de Trabajo del Cechimex 1, pp. 1-8.

-Dussel Peters, Enrique. 2011/b. “¿Qué estamos importando de China?”, Reforma, octubre 28, pp. 8A.

-Dussel Peters, Enrique. 2011/c. "11.12.2011, ¿último round?", Reforma, noviembre 29, pp. 4A.

-Dussel Peters, Enrique. 2012. “Hacia una agenda bilateral de largo plazo entre México y China". En, José Luis Calva (edit.). Nueva política de industrialización. Vol. 7 de Análisis Estratégico para el Desarrollo. Juan Pablos Editor/Consejo Nacional Universitario, México.

-Dussel Peters, Enrique, Luis Miguel Galindo Paliza, Eduardo Loría y Michael Mortimore. 2008. La inversión extranjera directa en México. Una perspectiva macro, meso, micro y territorial. Siglo XXI, Secretaría de Economía y Cechimex/UNAM.

- Dussel Peters, Enrique y Yolanda Trápaga Delfín. 2010. Hacia un diálogo entre México y China. Dos y tres décadas de cambios socioeconómicos. Cámara de Senadores, Fundación Friedrich Ebert, CICIR y UNAM/CECHIMEX, México.

- Moreno-Brid, Juan Carlos y Jaime Ros. 2010. Development and Growth in the Mexican Economy. A Historical Perspective. Oxford University Press, USA.

- Monitor de la Manufactura Mexicana. 2009. Monitor de la Manufactura Mexicana 5(7), pp. 1-50. UNAM, Canacintra y Cechimex, México.

- Oropeza García, Arturo. 2008. China-Latinoamérica. Una visión sobre el nuevo papel de China en la región. UNAM, México.

- Ruiz Chávez, Rocío. 2008. Consideraciones sobre el impacto de la medida de transición negociada con China. Ponencia en el "Ciclo de Conferencias China-México del Centro de Estudios China-México de la Facultad de Economía de la UNAM, México, D.F., agosto 13. 


\section{La Cámara (general) de Empresarios Chinos en México}

Jimmy Li

Bajo el lema Puente de Intercambio, Lazos de Amistad, el 14 de febrero del 2001, preciso día del 29 aniversario del establecimiento de relaciones diplomáticas entre China y México, fue fundada la Cámara (general) de Empresarios Chinos en México, con presencia de Luis Echeverría, expresidente de México, como testigo de honor, junto con Shen Yun'ao, embajador de la República Popular China en México.

En los últimos 11 años, nuestra Cámara ha venido prestando suma atención a los quehaceres económicos, comerciales y culturales, entre ambos países, aparte de brindar servicios integrales a los miembros afiliados, editando boletines informativos electrónicos, organizando foros y congresos temáticos (administrativos, aduanales, contables y fiscales), vinculando a sectores empresariales e industriales, protegiendo los intereses y derechos de nuestros agremiados, tipificando casos de éxitos y fracasos, para ayudar a los nuevos socios a instalarse en México de manera eficaz y sostenible.

Al constituirse, cuatro años después, la Confederación de Asociaciones Chinas en México (Cachimex) nuestra Cámara se convierte en la primera agrupación que integra a esta máxima cúpula de las principales organizaciones chinas adscritas en México, para así sumar esfuerzos en fortalecer la presencia china en los múltiples aspectos bilaterales y desarrollar conjuntamente distintas actividades que fomentan la amistad, conocimiento e intercambio binacionales, con permanente presencia y valiosa contribución en los más destacados eventos bilaterales, en forma individual o colectiva, sola o con otras organizaciones chinas.

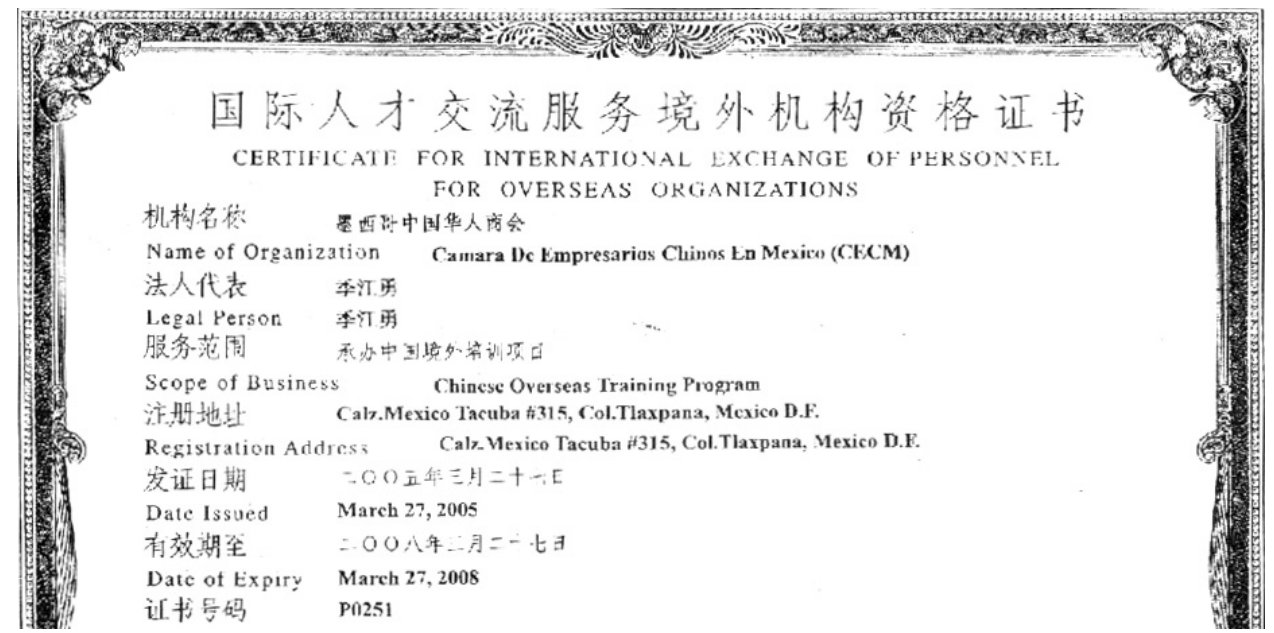


En marzo de 2005, la Administración Estatal de Asuntos de Expertos Extranjeros (SAFEA por sus siglas en inglés) de China, previa certificación junto con la Embajada China en México, nos otorgó la acreditación oficial como organización para realizar intercambio y capacitación de funcionarios públicos de los diferentes niveles de gobiernos de toda China.

Con la renovación distintiva anual, somos la única entidad en México autorizada por el gobierno federal de China para la recepción de delegaciones oficiales federales, provinciales y municipales, en su estudio, investigación y capacitación de diferentes campos: político, social, económico, comercial, académico y científico, entre otros, ya que contamos con personal altamente calificado para la consecución de amplios propósitos y, a la vez, excelentes relaciones políticas y sociales con las contrapartes mexicanas, especialmente con gobiernos locales de la República Mexicana como es el Inafed-Segob (Instituto Nacional para el Federalismo y Desarrollo Municipal) y otros.

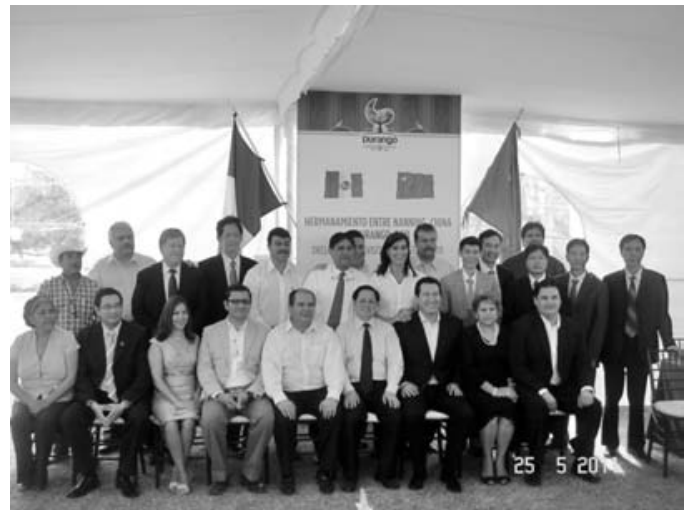

Para promover el intercambio económico-comercial entre gobiernos y empresarios locales, concertamosvarios hermanamientos sino-mexicanos. La gráfica muestra el sister-cities entre Nanning con Durango.

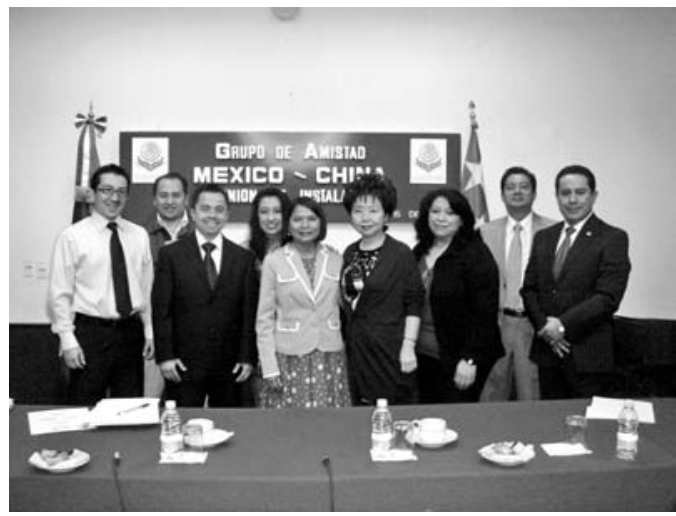

Desde la altura legislativa federal, la presencia de Cámara, en vinculación amistosa bilateral. Lupita Chu, vicepresidenta y Dip. Fed. Sofía Castro, presidenta del Grupo de Amistad Mexico-China. 
Cada año, gestionamos intercambios y capacitaciones federales y locales para unas 100 comitivas chinas y otras docenas mexicanas en visitas recíprocas, principalmente en rubros económicos, comerciales y culturales.

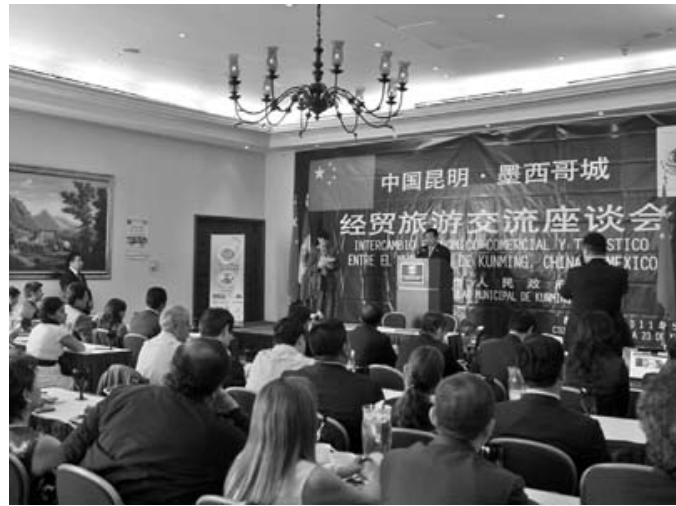

La agenda bilateral económico-comercial y turística no refleja las necesidades de los pueblos de China y México, tampoco ha aprovechado las abundancias sectoriales de ambas naciones. Nuestra Cámara identifica la complementariedad respectiva para fomentar la interacción ganar-ganar. La gráfica muestra el encuentro local entre el Municipio de Kunming con Naucalpan, Tlaxcoapan y otras ciudades mexicanas.

De las actividades sobresalientes, destaca la Expo China-México y Expo Asia-Pacífico, de las cuales esta Cámara forma parte del equipo ejecutor y se encarga de la promoción y acercamiento de este importante evento anual que se celebra cada noviembre en el WTC de la Ciudad de México, en la cual se reúnen anualmente más de 300 empresarios de ambos países, en su mayoría pymes, no sólo para promover "Made in China" de alta tecnología, sino también las exportaciones mexicanas.

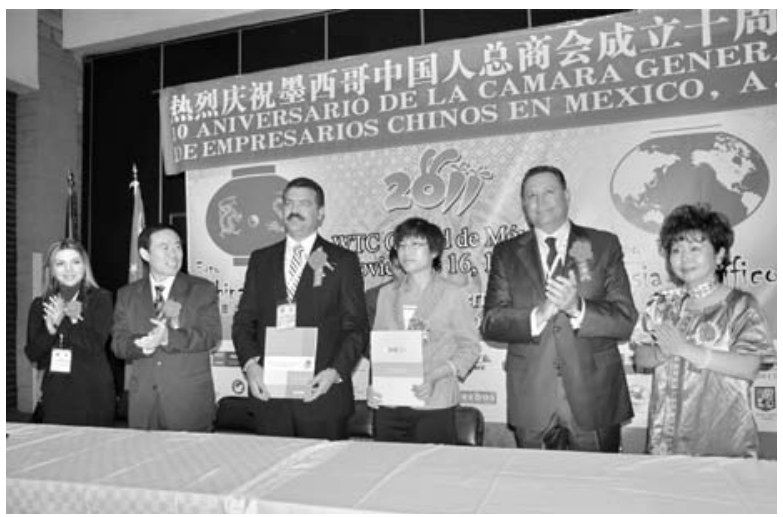

En el marco de la Expo China-México 2011, se celebró el 10 Aniversario de nuestra Cámara, en el acto, Dongying City firmó Memorandum de Cooperación Económico-Comercial y Cultural con el Municipio de Empalme, Sonora. 
Los resultados han sido alentadores con números duros: en cada edición se concerta exportación directa de más de 100 millones de dólares de productos mexicanosa China y a las comunidades chinas en todo el mundo (EU, Canadá y Vietnam), en diversificadas mercancías. De Tecomán, Colima, sólo en 2010, a través de las Expos, exportaron los primeros 12 contenedores de fibra de cocos a Guangdong; de Empalme, Sonora, casi 100 contenedores de aguamala y calamar a Dalian; de Tapachula, Chiapas y Martínez de la Torre, Veracruz, más de 1,000 toneladas de rambután y litchi, respectivamente, a EU y Canadá, entre otros casos de éxito histórico.

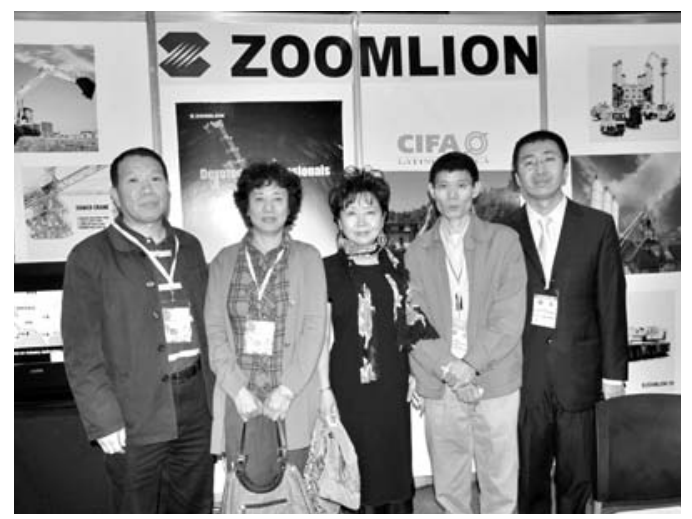

Ayudar a empresas chinas de primer nivel a aterrizar en México, también es tarea de nuestra Cámara. Zoomlion es otra firma que se beneficia en nuestra Cámara, en esta noble causa de vinculación y asesoría económicoComercial.

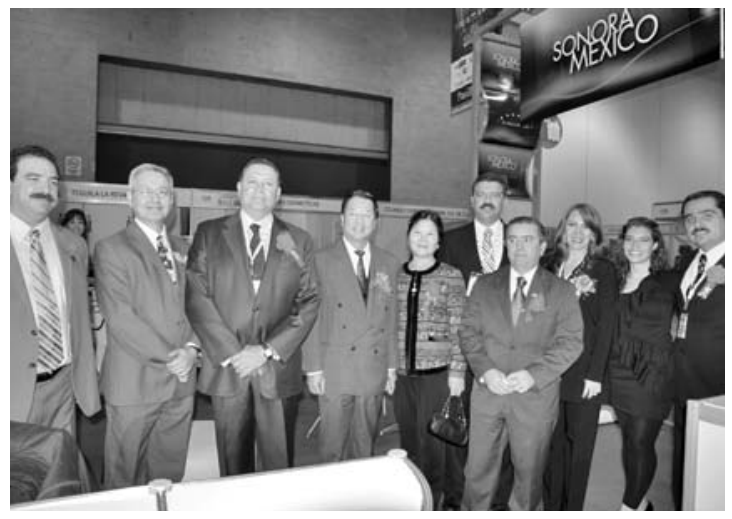

Sonora, uno de los estados más beneficiados en los proyectos realizados por nuestra Cámara, y sus municipios como Benito Juárez es pionero en exportar mariscos a Dalian, China, con nuestro apoyo administrativo y logístico.

Diversificar el comercio complementario y equilibrar el balance comercial bilateral es tarea de todos, y primordial de nuestra Cámara. Ver a China como competencia no resuelve los conflictos existentes, hacerle socio en un escenario mundial cada día más 
globalizado, es la salida inteligente. La Cámara (general) de Empresarios Chinos en México, ha puesto su granito de arena, y estamos dispuestos a sumar más esfuerzos para construir mejores relaciones estratégicas entre dos pueblos milenarios y visionarios, los de China y de México.

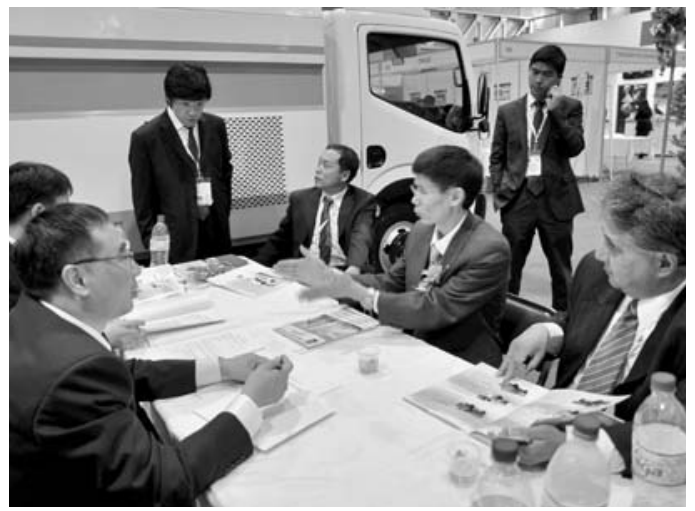

Muchos municipios mexicanos firmaron MOUs con BESECO (Beijing Ambiental) para comprar equipos ecológicos para tratar basura. Otro caso de éxito en Expo China-México y Expo Asia Pacífico para la protección del medio ambiente

Detrás de los éxitos tangibles y reconocidos que hemos logrado en los últimos años, debemos aprender de las lecciones inevitables, no sólo para los miembros de esta Cámara, sino también de toda la comunidad empresarial china instalada en México. Empresas tan grandes como la petrolera Sinopec, cuya sucursal en México tuvo una multa multimillonaria por no haber cumplido con los requisitos de ITR (importación temporal) de sus equipos de exploración del crudo y empresas tan pequeñas como la gastronómica R.F. Restaurante, fue clausurada por casi 6 meses por haber incurrido en faltas de protección civil.

Se ha discutido y analizado por destacados académicos y sobresalientes estudiosos, inclusive por los propios empresarios chinos o chino-mexicanos sobre la esquiva situación de la inversión y presencia empresarial y comercial de China, sin que nadie pudiera explicar la difícil situación en la que nos encontramos hoy en día. Me parece, sin embargo, que las opiniones expresadas en general han sido superficiales; como vicepresidente de esta Cámara, con más de 20 años ejerciendo activamente el comercio complementario binacional, me parece que el impedimento sustancial radica en una sola palabra: la falta de integración.

Nuestro mayor problema es la falta de integración de la comunidad china a la sociedad mexicana, en sus amplios sentidos: político, social, cultural, educativo, empresarial, inclusive religioso, entre otros. Al no contar a la fecha con nuestros propios medios de comunicación, o sea sin TV, sin periódico, sin revistas, sin radio... estamos medio ciegos y, peor aún, muy pocos sintonizamos TV ni radio mexicanas, tampoco leemos sistemáticamente los periódicos mexicanos (casi nadie suscribe al Diario Oficial de la Federación) para conocer las legislaciones, políticas públicas ni las reglas del juego. 
Surge entonces la pregunta ¿cómo podemos actualizar la situación política y económica del país?, ¿cómo nos adaptamos a la mexicanidad y mejoramos las prácticas comerciales? Las consecuencias son desastrosas: cada año, productos chinos con valor de millones y millones de dólares son confiscados en las aduanas de México por no cumplir con la normatividad. Los conflictos laborales en las empresas chinas en México son frecuentes y pocos socios mantienen al corriente su situación contable y fiscal ante el SAT. En fin, si uno va a Roma y no hace lo que los romanos hacen, difícilmente se consigue lo que uno planea obtener. Pero, así estamos.

La internacionalización de empresas chinas se ha rezagado mucho más que las de Japón, Corea o inclusive de la provincia de Taiwán, pues para un chino le es más difícil adecuarse al trato de las personas en México.

Lo anterior se refleja en las actividades, implica grandes dificultades en el manejo de las empresas y sus empleados, así como en el cumplimiento de la normatividad local. Sin embargo, la regulación gubernamental no distingue: el que no sabe, paga sus consecuencias. Radicados en México, debemos adaptarnos a la mexicanidad, por lo menos intentar hacerlo, para poco a poco, integrarnos a la sociedad local, frente a la acelerada globalización mundial, para cumplir con nuestros propios objetivos comerciales, contribuyendo al comercial bilateral.

Diversificar el comercio complementario y equilibrar el balance comercial bilateral es tarea de todos, y primordial de nuestra Cámara.

Con tres ediciones consecutivas, la Expo China-México se ha convertido en el evento más popular y representativo en las relaciones económico-comerciales y culturales en los últimos 40 años en que ambos países mantienen sus relaciones diplomáticas, pues China el segundo socio comercial de México en el mundo, aunque falta mucho que mejorar.

En la gráfica, distinguidas personalidades políticas, empresariales, comerciales y académicas, en el presidium del acto inaugural de la Expo China-México y Expo AsiaPacífico 2011. Primera fila desde la izquierda: José Luis Beato, vicepresidente de Coparmex-DF; Zeng Gang, embajador chino; Ma. del Rosario Castro, titular del Inafed-Segob; Sofía Castro, diputada y presidenta del Grupo de Amistad México-China, Cámara de Diputados; Haiyan Chu, presidenta de Cachimex; Enrique Dussel Peters, coordinador Cechimex-UNAM; Zeng Yafei, vicepresidente de CCPIT Subconsejo Comercial y Jimmy Li, vicepresidente de la Cámara (general) de Empresarios Chinos en México. Segunda fila, desde la izquierda: Luis Martínez, socio de PWC-México; Azucena Olivares, alcaldesa de Naucalpan y presidenta de AMMAC; Zhao Fu'en, vicealcalde de Dongying City; Juan de Dios Barba, presidente del Consejo Económico y Social del DF; Luis Erasmo Terán, representante del gobierno de Sonora; Francisco Javier Caraveo, alcalde de Empalme; Saúl Magaña Madrigal, alcalde de Tecomán; Sergio Montiel, alcalde de Tetla; Manuel de Jesús Bustamante, alcalde de Benito Juárez, Sonora, y Chen Siliang, profesora del Instituto de Confucio de la UNAM. 


\section{2, año de oportunidad para renovar votos con China}

Rafael Valdez Mingramm

Hablar de economía, política e inversión entre México y China obliga a un análisis cuantitativo y cualitativo de los diferentes periodos en la historia y de las relaciones políticas, económicas y comerciales entre dos naciones que se respetan, se complementan y que continuamente buscan resolver diferencias. La celebración de 40 años de relaciones diplomáticas con China -en vísperas de un cambio de gobierno en ambos países durante el 2012- genera una ventana de oportunidad muy especial para promover e impulsar un diálogo estratégico de alto nivel, realinear objetivos y propuestas, y junto con ello renovar votos de confianza que le permitan a México recuperar su lugar como socio estratégico de China en América Latina.

En esta breve intervención no busco criticar distintas formas de pensar con respecto a la posición que México tiene o debería tener en relación con China, sino simplemente hago referencia a algunas de ellas, buscando promover una reflexión individual, enriquecer el diálogo y generar propuestas colectivas. No busco tampoco generar controversia sobre ciertos acontecimientos que pudieran haber afectado la relación con China o sobre las ventajas comparativas que tiene nuestro país respecto a otros de América Latina, en específico Brasil, Chile, Perú y Costa Rica. Por el contrario, refiero algunos indicadores comerciales y de inversión de estos países con el único propósito de resaltar la oportunidad que tendría México de mejorar su balanza comercial y atraer inversión en montos mayores si realineara sus estrategias y renovara votos con China.

Sin entrar en detalle, haré referencia a cinco periodos históricos, incluyendo el que pudiera iniciarse en el 2012, que han definido la compleja y hoy un tanto distante, pero muy prometedora, relación estratégica entre México y China:

\section{1) 1564 - 1810. La Nueva España y China, socios comerciales}

Periodo enmarcado por un intenso intercambio comercial a través de la famosa Nao de Filipinas o Nao de China que durante 250 años conectó los puertos de Acapulco y Manila, ${ }^{1}$ permitiendo que productos de la Nueva España como el maíz, la papa, el tomate, el cacahuate y el tabaco encontraran destino final en el interior de China a través de pequeñas embarcaciones, al igual que una variedad de productos asiáticos encontraran destino final en España, dando con ello vida a la tan deseada Ruta de la Seda marítima.

En el continente asiático, elementos como la moneda de plata conocida como "Columnaria" o "Real de a Ocho", acuñada por la entonces Real Casa de Mo-

1 El Puerto de Manila era el centro de acopio de productos asiáticos (i.e. sedas, maderas, telas, especias y metales preciosos) que se embarcaban en la Nao de China hacia el puerto de Acapulco. Estos productos, a su vez, se transportaban por tierra hasta Veracruz, se embarcaban hacia La Habana y finalmente a Cádiz en España. 
nedade México, son un claro testimonio de este importante intercambio. ${ }^{2}$ En nuestro hemisferio, el legado de la presencia oriental es también imborrable: las peleas de gallos, la cerámica de Talavera, los rebozos de seda y la famosa "China Poblana".

La integración económica -por no decir monetaria-, comercial y cultural de este periodo fue, sin lugar a dudas, mucho mayor en términos relativos a la de cualquier otro período en la relación de ambas naciones, incluyendo el actual.

\section{2) 1810-1972. México y China, amigos distantes}

El siglo XIX se caracterizó por un contacto mínimo como resultado de un aislamiento gradual de China hacia el mundo occidental, por el deterioro de su economía y sus relaciones comerciales con el exterior, ${ }^{3}$ y por acontecimientos de carácter insurgente en lo que hoy se conoce como América Latina. Este distanciamiento comenzó a finales del siglo XVIII al abrirse rutas comerciales independientes entre España y Filipinas, acentuándose con la promulgación de la independencia de México en 1810.

En China, por su parte, la dinastía Qing perdía gradualmente poder y enfrentaba rebeliones que concluirían con el fin de la era imperial en 1912. En ese proceso se sucedieron disputas comerciales con Occidente que debilitaron aún más al país en términos comerciales y derivaron en la pérdida de la soberanía sobre Hong Kong, además de derechos comerciales y control sobre algunas rutas de navegación. El conflicto y la derrota frente a Japón derivó a su vez en la independencia de Corea y en el establecimiento de la República de China, nombre oficial de Taiwán; Estado soberano reconocido diplomáticamente por la mayoría de los países latinoamericanos.

En este siglo, más que un intercambio comercial se dio un flujo de personas de China a América Latina al empezar la trata de culiés chinos por parte de Inglaterra y Portugal. ${ }^{4}$ Desde 1840 y hasta 1870 , entre 300 y 400 mil trabajadores chinos fueron contratados en Cuba, Perú, Chile, Panamá y México para trabajar en plantaciones de caña de azúcar, minas e importantes obras de infraestructura, incluido al Canal de Panamá.

No fue sino hasta la fundación de la República Popular China (RPC) en 1949, que el gobierno chino reformuló su orientación internacional y empezó a restablecer vínculos amistosos y a promover intercambios culturales y económicos con miras a establecer asociaciones de amistad con otros países. ${ }^{5}$ Se estima que de 1949 a 1959, alrededor de 1,200 personalidades de la cultura y arte, al igual

2 Moneda utilizada no sólo para regular transacciones comerciales sino como medio de pago en China Continental.

3 De acuerdo con un estudio de Angus Maddison de la Universidad de Groningen, la participación de China de la economía global, medida en términos del producto interno bruto del país a precios constantes de 1990 (USD) ajustados por el poder adquisitivo disminuyó del $32 \%$ en 1820 a menos del $28 \%$ en 1870 , a $11 \%$ en 1900 y $5 \%$ en 1970. http://visualecon.wpengine.netdna-cdn.com/wp-content/uploads/2008/01/percentworld-gdp-15001.jpg

4 Culí, apelativo utilizado para designar a los emigrantes de India, China y otros países asiáticos que eran contratados en las colonias británicas, francesas y holandesas. http://es.wikipedia.org/wiki/Cul\%C3\%AD

5 En 1953 se establece la Asociación de Amistad México-China y en 1963 se lleva a cabo la Exposición Económica y Comercial de China en México con la participación del presidente Adolfo López Mateos. 
que activistas sociales latinoamericanos visitaron China, incluyendo al muralista mexicano Diego Rivera y al activista social Lázaro Cárdenas.

\section{3) 1972-2000, México y la República Popular China, el rencuentro}

No fue sino hasta 1970 cuando el todavía presidente de la RPC, Mao Ze Dong, y el presidente de Estados Unidos, Richard Nixon, restablecen relaciones diplomáticas, facilitando que otros países como México, primer país de América Latina en hacerlo, estrecharan lazos diplomáticos nuevamente. Esto se logró bajo el gobierno del presidente Luis Echeverría mediante un comunicado conjunto emitido en las Naciones Unidas por los representantes permanentes de ambos países el 14 de febrero de 1972. Dicho acto estableció los nuevos términos de intercambio comercial, científico y cultural, e hizo patente la hermandad entre ambas naciones.

En 1973 se llevaron a cabo entrevistas oficiales en Beijing con Mao Ze Dong, con el entonces ministro del Consejo de Estado de China, Zhou Enlai, y el viceprimer ministro chino, Deng Xiaoping. Años más tarde el presidente López Portillo se reunió en México con Ye Jianying, presidente del Comité Permanente de la Asamblea Popular Nacional de China, dando pie a un intercambio técnico y científico que se intensificaría después.

En la década de los 80 se llevaron a cabo múltiples reuniones no sólo a nivel presidencial, incluyendo la reunión del presidente Miguel de la Madrid con su homólogo en Beijing, sino a otros niveles de gobierno, incluyendo integrantes del poder legislativo y de las fuerzas armadas. Intercambios técnicos en el sector agrícola continúan a la par de eventos y exposiciones de productos y artesanías chinas en distintas ciudades en México. A nivel educativo, la UNAM celebra el Festival de la Cultura de China, seguido de exposiciones de fotografías y de otros intercambios académicos. ${ }^{6}$

En 1990, el presidente Carlos Salinas de Gortari le da la bienvenida a México a Yang Shangkun, presidente de Estado de China, y establece el marco de colaboración que daría vida en 1993 a la Comisión Mixta China-México de Economía, Comercio, Ciencia y Tecnología. Ese mismo año el presidente de México se reúne en Beijing con el presidente Jiang Zemin, con el propósito de suscribir distintos acuerdos de cooperación económica, cultural, diplomática, científica y tecnológica.

En 1996, el presidente Zedillo viaja a China para reunirse con su contraparte chino y para participar en un encuentro empresarial. Meses después, recibe en México a Hu Jintao, entonces miembro del Comité Permanente del Buró Político del Comité Central del Partido Comunista de China (PCCh). Al año siguiente el presidente chino, Jiang Zemin visita México.

Durante los siguientes años, en vísperas de la llegada del nuevo milenio, se habrían aumentado las reuniones, intercambios comerciales, culturales, tec-

6 Se destaca la labor del Centro de Estudios de Asia y África del Colegio de México y del Instituto de Investigaciones Económicas (IIE) y del Centro de Estudios de Lenguas Extranjeras (CELE) de la UNAM. 
nológicos, científicos y comerciales, haciendo valer los vínculos históricos y estratégicos entre México y China.

\section{4) 2000 - 2011, un distanciamiento silencioso}

El año 2000 es acompañado de un cambio mayor en el sistema político mexicano con la llegada de Vicente Fox, candidato del Partido Acción Nacional, a la presidencia de la república, quien redefine la política exterior mexicana y da un giro a la relación con China construida en las décadas anteriores, aunado a un desbalance incremental en la balanza comercial entre México y China que conlleva cierto distanciamiento gradual.

Si bien reuniones a nivel presidencial y ministerial seguían siendo parte de la agenda de ambos países, con una visita del presidente Fox a Beijing en el 2001, la visita del Primer Ministro chino Wen Jiabao a nuestro país, el establecimiento de la Asociación Estratégica entre México y China en 2003 y la Comisión Permanente Binacional en 2004, varios encuentros y reuniones de dirigentes de APEC y una visita oficial del presidente Hu Jintao a México en 2005, la relación estratégica que prevalecía al final de los 90 gradualmente empezaba a deteriorarse, principalmente a nivel comercial. ${ }^{7}$

En el sexenio de Felipe Calderón tuvieron lugar algunos encuentros adicionales, incluyendo su visita oficial a China en julio del 2008, en la cual acordó con su homólogo chino la celebración de un diálogo estratégico entre ambos países y la visita del vicepresidente chino, Xi Jinping, en febrero del 2009. Asimismo, se produjeron varias visitas a nivel ministerial y empresarial impulsadas tanto por organismos públicos como privados. ${ }^{8}$

A pesar de que la relación entre la RPC y México se había incrementado en forma significativa a nivel político, cultural y académico hacia finales del 2011, la relación económica había sufrido desencuentros importantes. A pesar de que China se mantiene desde el 2003 como segundo socio comercial de México y de que ocupa el tercer lugar en exportaciones para productos mexicanos desde el 2010, la brecha entre exportaciones e importaciones se hacia cada vez mas grande, alcanzando un coeficiente de 11:1 en $2011 .^{9}$

7 De acuerdo con cifras oficiales, las exportaciones de México a China en 1990 fueron de 9 mdd y las importaciones 15.8 mdd. Para 2004, las exportaciones habrían aumentado a 466.7 mdd mientras que las importaciones a 14,457,7 mdd respectivamente, alcanzando un coeficiente de 30:1. En materia de crecimiento económico, de 1980 a 1990 China creció a un ritmo de $9.2 \%$ promedio anual y México en 2.5\%; en la década 1991-2000 el primero lo hizo en $10.1 \%$ y el segundo en $3.5 \%$; y en el periodo $2001-2005$ las tasas de crecimiento alcanzaron niveles de $8.6 \%$ y $1.9 \%$, respectivamente.

8 Es oportuno resaltar la creación y múltiples publicaciones y eventos organizados por el Centro de Estudios China-México (Cechimex) de la UNAM, los esfuerzos del Consejo Mexicano de Comercio Exterior, Ciencia y Tecnología COMCE), al igual que la creación de la Cámara de Comercio de México en China (Mexcham) y la Cámara de Comercio y Tecnología México-China (Chinacham) en 2008.

9 De acuerdo con cifras oficiales, las exportaciones de México a China en el 2011 sumaron 4,198 mdd, mientras que las importaciones 45,725 mdd en dicho periodo. 
Superávit / Déficit comercial de algunos países latinoamericanos con China (miles de dólares)

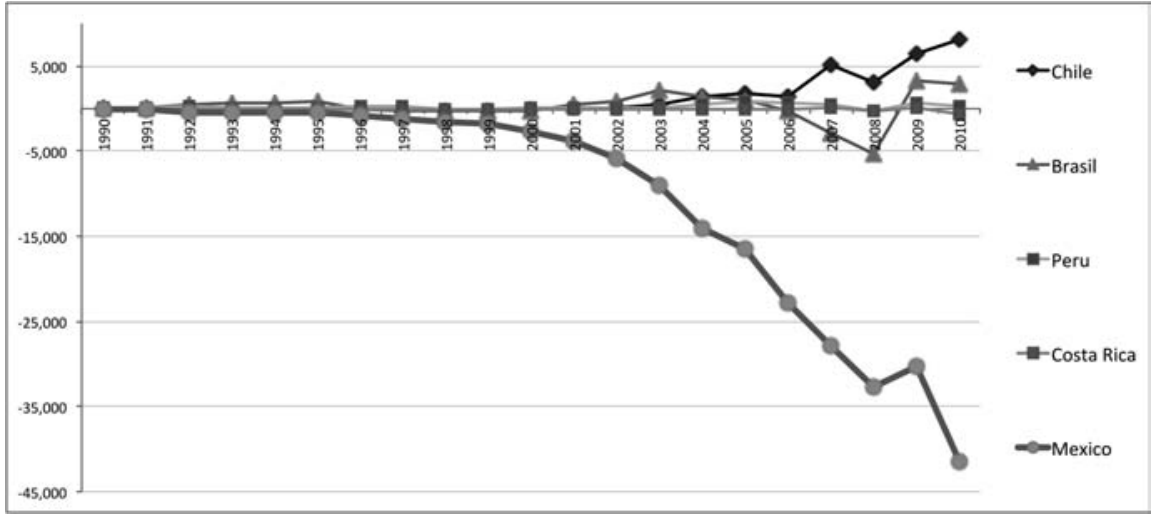

Fuente: Base de Datos Estadísticos de Comercio Exterior, CEPAL. División de Estadística y Proyecciones Económicas.

Como se observa en esta gráfica, la estructura comercial entre México y China refleja un grave problema de cooperación y dirección ante la importación de productos manufacturados y de creciente valor tecnológico y la baja exportación de materias primas en comparación a otros países como Perú, Chile y Brasil, ${ }^{10}$ y de productos de alto valor agregado. Esto, sin tomar en cuenta la pérdida en competitividad y participación del mercado norteamericano.

Esta situación denota una falta de visión y estrategia tanto del gobierno mexicano como del sector empresarial que aún mantiene una dependencia, para muchos preocupante, del mercado estadounidense, sobre todo al existir múltiples sinergias y ventajas comparativas no debidamente aprovechadas en su relación con China, incluyendo la ubicación geográfica, la integración comercial de México con Estados Unidos y Canadá, un importante y creciente mercado doméstico, al igual que recursos técnicos y humanos calificados.

En materia de inversión, los resultados son también alarmantes. De acuerdo con la Comisión Económica para América Latina y el Caribe (ECLAC), ${ }^{11}$ México registra una inversión extranjera directa acumulada y anunciada proveniente de China de 1990 a 2011 de tan sólo 132 mdd, en comparación a 9,223 mdd en Argentina, 19,688 en Brasil o 718 mdd en Costa Rica. Si bien esta cifra no coincide con la registrada por la Secretaría de Economía de México, equivalente a 400 mdd, es sin duda limitada, ${ }^{12}$ al equivaler al $0.6 \%$ de la inversión acumulada en los principales países de la

10 Debate recurrente en múltiples foros al no considerarse México un exportador predominante de materias primas; argumento infundado al tener nuestro país importantes reservas (no explotadas) de minerales demandados en China.

11 Véase publicación del jueves 29 de diciembre de 2011, página 22 del periódico El Economista.

12 La principal diferencia pudiera ubicarse en el país de registro de la inversión debido a que varias transacciones han tenido lugar en jurisdicciones que se consideran paraísos fiscales o en países como Canadá. 
región registrada en los últimos 20 años. Aun no tomando en cuenta las inversiones anunciadas en el 2011 y las confirmadas en el 2010, en su mayoría en el sector petrolero, ${ }^{13}$ la inversión que registró México de 1990 a 2009 representaría tan sólo el $1.73 \%$ de total.

Inversión Extranjera Directa (IED) de China en algunos países de América Latina y el Caribe (mdd)

\begin{tabular}{|c|c|c|c|c|}
\hline & $\begin{array}{l}\text { Inversión } \\
\text { 1990-2009 }\end{array}$ & $\begin{array}{l}\text { Confimada } \\
2,010\end{array}$ & $\begin{array}{l}\text { Inversión Anunciada } \\
2011 \text { en adelante }\end{array}$ & Total \\
\hline Argentina & 143 & 5,550 & 3,530 & 9,223 \\
\hline Brasil & 255 & 9,563 & 9,870 & 19,688 \\
\hline Colombia & 1,677 & 3 & & 1,680 \\
\hline Costarica & 13 & 5 & 700 & 718 \\
\hline Ecuador & 1,619 & 41 & & 1,660 \\
\hline Guayana & 1,000 & & & 1,000 \\
\hline México & 127 & 5 & & 132 \\
\hline Perú & 2,262 & 84 & 8,640 & 10,986 \\
\hline Venezuela & 240 & & & \\
\hline TOTAL & 7,336 & 15,251 & 22,740 & 45,087 \\
\hline
\end{tabular}

Fuente: Comisión Económica para América Latina y el Caribe (ECLAC) con base en información de Thomson Reuters, fDi Markets (online), fuentes oficiales y entrevistas a empresas. ${ }^{14}$

Lo anterior constata claramente una situación desfavorable para nuestro país en cuanto a la captación de inversión extranjera directa, sobre todo al irse convirtiendo China en los últimos años en uno de los principales inversionistas a nivel mundial, y colocando a América Latina y el Caribe dentro de sus áreas prioritarias-estratégicas en materia de cooperación económica e inversión. ${ }^{15}$

Aun dejando de lado las inversiones en el sector de energía, primordialmente de petróleo y gas, que abarcan más de $70 \%$ del monto total en países como Argentina, Colombia y Brasil, los resultados son desfavorables para México. Esto obedece, en parte, a un manejo de la política exterior cuestionable en administra-

13 Incluyendo las inversiones de CNOOC en Bridas, con operaciones en Argentina, y Sinochem en Statoil Brasil.

14 Información publicada en el Capítulo III del Reporte de Inversión China en América Latina y el Caribe de ECLAC, http://www.eclac.cl/publicaciones/xml/0/43290/Chapter_III._Direct investment_by_China_in_Latin America_and the Caribbean.pdf

15 En noviembre de 2008, el gobierno chino publicó el primer libro blanco sobre su política hacia América Latina y el Caribe en un esfuerzo por intensificar el diálogo y la comunicación con la región y ampliar el consenso estratégico y las relaciones comerciales y de inversión. 
ciones recientes y a esfuerzos en materia comercial y de atracción de inversiones a grandes luces insuficientes. México necesita replantear su agenda estratégica con China en el corto, mediano y largo plazos.

La responsabilidad no es exclusiva del Estado. El sector privado mexicano necesita modificar de igual manera su agenda con China, ver más allá de intereses particulares o de grupo, aprovechando la amplia oferta exportable de nuestro país y explotando, entre otras, las ventajas comparativas brevemente señaladas en este documento, así como buscando áreas de oportunidad y complementariedad. Sólo de esta manera podremos reducir el déficit comercial tan alarmante que se tiene con China y evitar conflictos de otra naturaleza.

\section{5) 2012 en adelante, la gran oportunidad}

La celebración del 40 aniversario de las relaciones diplomáticas entre México y China en un año en que habrá cambio de gobierno en ambas naciones, ofrece una oportunidad muy especial para reflexionar profundamente sobre los vínculos y resultados de los periodos anteriores, y también para replantear estrategias y objetivos conjuntos de corto, mediano y largo plazos. México y China necesitan encontrar puntos de encuentro, impulsar proyectos de manera conjunta en sectores manufactureros y de servicios y evitar a toda costa un escalamiento mayor de sus diferencias. China debe ser percibida no como una amenaza sino como una gran oportunidad para México y América Latina.

En este contexto, habrá que atender y solventar favorablemente una serie de diferencias o situaciones inherentes, muchas de ellas legítimas y bien fundamentadas, como son las importaciones irregulares, ante instancias internacionales, en específico la Organización Mundial de Comercio (OMC).

Relacionado con lo anterior, representantes de ambos países han manifestado en ocasiones su interés y disposición para regularizar el desbalance comercial y promover inversión de empresas chinas en México. Un ejemplo de ello es una carta enviada por el ministro chino de Comercio, Chen Deming, al secretario de Economía de México, Bruno Ferrari, el pasado 24 de noviembre, ${ }^{16}$ proponiendo una reunión en el marco del Grupo de Trabajo de Alto Nivel entre ambos países hacia finales del primer trimestre de 2012, con la condición de que México documente las presuntas prácticas anticompetitivas señaladas por el secretario Ferrari en una reunión de la APEC, con la finalidad de regularizar la situación con base en fundamentos legales. ${ }^{17}$

Esta reunión que se propone será de mayor relevancia, en la medida en que ambos países adopten posiciones propositivas y busquen de manera responsable establecer una nueva agenda con objetivos y propuestas conjuntas que pudieran entrar en vigor este mismo año, sobre todo al haberse agotado la vigencia de cuotas compensatorias sobre productos chinos en varias fracciones arancelarias

16 http://eleconomista.com.mx/industrias/2011/12/28/china-dispuesta-ordenar-comercio-mexico

17 México ha acumulado 17 medidas antidumping contra productos chinos, ubicándose en la décima posición entre los integrantes de la OMC que recurren a esa herramienta contra China. 
(incluyendo productos de calzado, vestido y juguetes). De no hacerlo en esta coyuntura o en reuniones subsecuentes este año, la situación pudiera agravarse. ¿Qué han hecho países como Chile, Perú, Brasil y Costa Rica? En términos muy generales, estos países han mantenido una visión y una política de Estado con miras a fortalecer la relación económica y comercial con China, buscando en parte reducir la dependencia relativa con socios comerciales tradicionales. Desde 1930 y hasta febrero de 2009, Brasil tenía a Estados Unidos como principal socio comercial; a partir de marzo de ese año, esa posición la ha ocupado China. Una situación similar se avecina en Perú, Chile y otros países exportadores de materias primas, pero también en economías que no dependen de industrias extractivas como Costa Rica, país que ubica a China como su segundo socio comercial y con el cual mantiene una balanza comercial equilibrada. ${ }^{18}$

Chile fue el segundo país de la región en establecer lazos diplomáticos con China y el primero en suscribir un tratado de libre comercio con este gigante asiático (2005), Perú el segundo al firmarlo en 2009, entrando en vigencia al año siguiente, y Costa Rica el caso más reciente al restablecer relaciones diplomáticas en 2007 y suscribir un TLC el año pasado con un tipo de acuerdo en bloque, como el peruano. Brasil ha firmado una serie de acuerdos de cooperación y protección recíproca de inversiones pero no ha requerido de un tratado de libre comercio con China para aumentar sus relaciones comerciales con el país asiático.

Estos acuerdos se han ido instrumentando de manera gradual. En el caso de Chile, éste inició con el capítulo de bienes, permitiendo que el comercio entre 2006 y 2010 aumentara cuatro veces. Posteriormente ingresaría el capítulo de servicios y por último el de inversiones. En palabras de funcionarios chilenos, "Chile quiere ser más que cobre, vinos y uvas", ${ }^{19}$ al buscar introducir una variedad de frutas como el durazno, la ciruela o la cereza, y junto con ello desarrollar canales de distribución que permitan ofrecer precios más competitivos para ganar mercado. Asimismo, el país explora la posibilidad de exportar carne de cerdo a China, como lo hace a Japón y Corea.

En otros ámbitos, Chile ha puesto sobre la mesa distintos temas a desarrollar en conjunto con China, en los sectores de ciencia y tecnología, educación y energías renovables, y enfocado sus estrategias para posicionar sus productos al interior de China y no depender únicamente de ciudades de la costa este ya saturadas de productos extranjeros.

Por su parte, Costa Rica, país que mantenía ya una fuerte relación comercial con China antes de restablecer relaciones diplomáticas y una balanza comercial equilibrada, ${ }^{20}$ busca posicionarse como el centro de operaciones de los inversionistas chinos en Centroamérica y servir como plataforma a las empresas chinas que quieran ingresar al mercado estadounidense. Busca también aumentar sus

18 El $85 \%$ de las exportaciones de Costa Rica son componentes electrónicos y dispositivos médicos. Sus principales 20 productos exportados representan $99.3 \%$ del total vendido en 2009 .

19 http://blogs.elcomercio.pe/planetachina/2011/01/companeros-del-viaje-tlciano.html20

20 China y Costa Rica buscan incrementar las exportaciones agropecuarias de alta calidad por su amplio margen de ganancia y nicho de mercado. 
exportaciones agropecuarias de alta calidad, desarrollar el mercado de productos "premium" para el consumidor chino y potenciar su turismo ecológico.

En el caso de Perú, las expectativas son similares. En el marco de la inauguración de la V Cumbre Empresarial China-América Latina que tuvo lugar en noviembre de 2011 y en la cual estuve presente, el presidente Humala resaltó la necesidad no sólo de pensar en exportar minerales, sino en productos con valor agregado. “El futuro no es solamente quedarnos en exportar minerales. El futuro es dar un paso más y ese paso más es el proceso de industrialización, y en eso cuenten con el Estado, con el Gobierno que debe ir de la mano con sus empresarios...", señaló el presidente en su discurso inaugural.

De la misma manera, la presidenta de Brasil, Dilma Rousseff, en su primera visita oficial a China en abril de 2011, recalcó que se debía establecer un equilibrio en el comercio y suscribió acuerdos de intercambio para que la empresa brasileña Embraer construya y venda aviones comerciales al gigante asiático a cambio de que se instale, en el país sudamericano, una fábrica de trenes eléctricos para generar empleos. ${ }^{21}$

La pregunta es ahora ¿qué esta haciendo México? ¿Cómo lograr solventar las diferencias y recuperar la posición estratégica que mantenía nuestro país con China hasta finales de los 90 ? Esperemos que el 40 aniversario de las relaciones diplomáticas entre México y China, junto con el intercambio de ideas en publicaciones y eventos como éste, y la llegada de nuevos gobiernos e interlocutores en 2012 nos den la respuesta.

\section{Una última reflexión}

Si bien en los últimos años América Latina se ha convertido en el primer proveedor de materia prima para el gigante asiático, el costo de proveerla pudiera provocar condiciones desfavorables para asegurar un desarrollo integral. Esto obliga al intercambio tanto de materia prima como de productos manufacturados. México es potencia en ambos, cuenta con importantes recursos minerales, energéticos y agropecuarios que son demandados en China, así como con recursos humanos y técnicos calificados para suministrar productos de valor agregado.

Lo único que hace falta es dejar de enfocarnos exclusivamente en el mercado norteamericano y retomar la relación estratégica que llevamos construyendo con China los últimos 500 años. Porfirio Díaz, quien acuñara la muy citada frase "pobre México, tan lejos de Dios pero tan cerca de Estados Unidos" hoy bien pudiera decir "pobre México, tan lejos de Dios, y hoy también lejos de China".

21 http://www.porlalibre.mx/viveros/11051 


\section{Bibliografía}

- Cámara de Diputados, Centro de Estudios de las Finanzas Públicas. 2005. MéxicoChina: Relaciones desiguales, retos y oportunidades para México. http://www. cefp.gob.mx/intr/edocumentos/pdf/cefp/cefp0572005.pdf

- Clara Martín Ramos. Las Huellas de La Nao de la China en México (La herencia del Galeón de Manila). http://es.scribd.com/doc/13984088/Las-Huellas-de-la-Nao-dela-China

- ECLAC. 2010. Capítulo III. ‘Direct investment by China in Latin America and the Caribbean'. http://www.eclac.cl/publicaciones/xml/0/43290/Chapter III._Direct_investment_by_China_in_Latin_America_and the_Caribbean.pdf

- Hernández Contreras y Jiao Zhenheng. 2007. Las Relaciones Comerciales de México y China en la Historia. Observatorio de la Economía y la Sociedad de China No 05. http://www.eumed.net/rev/china/

- Centro de Estudios de Estudios China-México. 2007. Informe de Labores. http:// www.economia.unam.mx/cechimex/informes/informe labores_07.pdf

- Joseph Fan, Randall Morck, Bernard Yeung. 2011. NBER Working Paper Series, Capitalizing China. Working Paper 17687. National Bureau of Economic Research. http://www.nber.org/papers/w17687

- La Cámara de Comercio de México en China (MEXCHAM). 2010. Informe de Actividades para el Periodo 2009 - 2010. Contribución del Dr. Enrique Dussel, Cechimex.

- Mauricio Mesquita Moreira, Coordinador del Departamento de Investigación, Banco Inter-Americano de Desarrollo (IDB, Integration and Trade Sector). 2010. Ten Years After the Take-off, Taking Stock of China-Latin America and the Caribbean Economic Relations.

- Oficina de Información del Consejo de Estado de la República Popular China. 2007. China - México, libro publicado con motivo del 35 aniversario de las relaciones entre México y China. China International Press.

- PROCOMER. Reporte de la primera Cumbre Empresarial China-Costa Rica. http:// www.procomer.com/contenido/news/2011/03/24/inicia-primera-cumbre-empresarial-china-costa-rica.html

-Wolfgang Keller, Ben Li, Carol H. Shiue. 2010. NBER Working Paper Series, China's Foreign Trade: Perspectives from the Past 150 years. Working Paper 16550. National Bureau of Economic Research. http://www.nber.org/papers/w16550.pdf

-Xu Shicheng. Las Culturas de China y de América Latina: Características, Nexos Históricos e Influencias Mutuas. Biblioteca Virtual del Instituto de Investigaciones Jurídicas de la UNAM. http://www.bibliojuridica.org/libros/6/2702/5.pdf 


\section{Cooperación económica y comercial entre China y México: elevando el nivel desde una óptica estratégica}

Yang Zhimin

I. Panorama del desarrollo de las relaciones económicas y comerciales entre China y México

\section{Comercio}

El comercio entre China y México creció rápidamente durante la década pasada, con el año 2009 como una excepción, cuando fue afectado por la crisis financiera global y se registró una caída comparada con el mismo periodo del año anterior. Según los datos chinos, el volumen del comercio entre ambas partes creció 13 veces y pasó de 1,830 millones de dólares de 2000 a 24,690 millones de dólares de 2010. En 2010, México llegó a ser el tercer socio comercial (detrás de Brasil y Chile), el segundo mercado de exportación (Brasil como el primero) y la tercera fuente de importación (detrás de Brasil y Chile) de China en esta región (cuadro 1). ${ }^{1}$

Cuadro 1. Comercio entre China y México, 2000-2010 (100 millones de dólares)

\begin{tabular}{|c|c|c|c|c|c|c|}
\hline \multirow[t]{2}{*}{ aи̃o } & \multicolumn{2}{|c|}{ Exportación e importación } & \multicolumn{2}{|c|}{ Exportación de China } & \multicolumn{2}{|c|}{ Importación de China } \\
\hline & volumen & variación anual\% & volumen & variación anual\% & 4.9 & 206.3 \\
\hline 2000 & 18.3 & 92.6 & 13.4 & 69.6 & 4.9 & 206.3 \\
\hline 2001 & 25.5 & 39.9 & 17.9 & 34.1 & 7.6 & 55.9 \\
\hline 2002 & 39.8 & 56.0 & 28.6 & 60.0 & 11.1 & 46.5 \\
\hline 2003 & 49.4 & 24.2 & 32.7 & 14.1 & 16.8 & 50.4 \\
\hline 2004 & 71.1 & 43.9 & 49.7 & 52.2 & 21.4 & 27.6 \\
\hline 2005 & 77.6 & 9.2 & 55.4 & 11.4 & 22.3 & 4.0 \\
\hline 2006 & 114.31 & 47.2 & 88.24 & 59.3 & 26.07 & 17.1 \\
\hline 2007 & 149.7 & 31.0 & 117.1 & 32.8 & 32.6 & 24.9 \\
\hline 2008 & 175.6 & 17.3 & 138.5 & 18.3 & 37.1 & 13.6 \\
\hline 2009 & 161.8 & -7.8 & 123.0 & -11.3 & 38.8 & 5.2 \\
\hline 2010 & 246.9 & 52.6 & 178.7 & 45.4 & 68.2 & 66.0 \\
\hline
\end{tabular}

1 中国商务部：《对外投资和国国别（地区指南）墨西哥2011年版》。 
Fuente: Aduana china, sobre la base de los datos del Ministerio de Comercio de China.

Según los datos mexicanos, el volumen total del comercio entre ambas partes ya alcanzó a 49,810 millones de dólares en 2010 y México tuvo un déficit equivalente a 41,410 millones de dólares, que aumentó en 36,6\%. Para este país, China es el tercer mercado de exportación y la segunda fuente de importación. Los productos minerales, los del metal básico y los equipos de transporte constituyen los tres primeros artículos exportados por México hacia China, significando $74.1 \%$ del volumen total. Los volúmenes de exportación alcanzaron, respectivamente, 1,760 millones, 730 millones y 640 millones de dólares, registrando un aumento de $215.8 \%, 22.5 \%$ y $206.1 \%{ }^{2}$

Cuadro 2. Los principales artículos exportados de México a China, 2010 (capítulo) (millones de dólares)

\begin{tabular}{|c|c|c|c|c|c|}
\hline $\begin{array}{l}\text { código } \\
\text { HS }\end{array}$ & artículos & $\begin{array}{c}\text { ene-dic } \\
2010\end{array}$ & $\begin{array}{l}\text { ene-dic } \\
2009\end{array}$ & $\begin{array}{l}\text { variación } \\
\text { anual(\%) }\end{array}$ & porcentaje del total(\%) \\
\hline sección & volumen total & 4,198 & 2,216 & 89.5 & 100.0 \\
\hline 26 & asperón mineral y escoria & 1,028 & 553 & 85.9 & 24.5 \\
\hline 27 & $\begin{array}{l}\text { combustible mineral y los deriva- } \\
\text { dos, betún }\end{array}$ & 724 & 0 & 0.0 & 17.3 \\
\hline 87 & $\begin{array}{l}\text { vehículos y las piezas (menos los } \\
\text { ferrovialrios) }\end{array}$ & 641 & 209 & 206.2 & 15.3 \\
\hline 74 & cobre y los productos & 619 & 408 & 51.7 & 14.8 \\
\hline 85 & $\begin{array}{l}\text { maquinaria eléctrica, equipo au- } \\
\text { diovisual y las piezas }\end{array}$ & 301 & 269 & 11.9 & 7.2 \\
\hline 84 & $\begin{array}{l}\text { reactor nuclear, caldera, aparato } \\
\text { mecánico y las piezas }\end{array}$ & 198 & 124 & 60.0 & 4.7 \\
\hline 29 & producto de química orgánica & 180 & 94 & 92.8 & 4.3 \\
\hline 39 & plástico y los productos & 103 & 122 & -15.6 & 2.5 \\
\hline 76 & aluminio y los productos & 68 & 43 & 56.5 & 1.6 \\
\hline 52 & algodón & 50 & 23 & 118.9 & 1.2 \\
\hline 40 & caucho y sus productos & 33 & 20 & 66.0 & 0.8 \\
\hline 90 & equipo óptico y médico & 32 & 24 & 34.4 & 0.8 \\
\hline 32 & $\begin{array}{l}\text { material para el curtido, pigmento, } \\
\text { pintura, tinta,etc. }\end{array}$ & 30 & 22 & 32.9 & 0.7 \\
\hline 32 & $\begin{array}{l}\text { material para el curtido, pigmento, } \\
\text { pintura, tinta,etc. }\end{array}$ & 30 & 22 & 32.9 & 0.7 \\
\hline 41 & piel y cuero & 23 & 45 & -49.2 & 0.5 \\
\hline
\end{tabular}

2 中国商务部：《国别贸易报告：2010年墨西哥货物贸易及中墨双边贸易概况, 2011 年第 1 期, http://countryreport.mofcom.gov.cn/record/qikan110209.asp?id=3240。 


\begin{tabular}{|c|c|c|c|c|c|}
\hline 47 & pasta de madera, papel usado & 19 & 4 & 436.2 & 0.5 \\
\hline 03 & pez y los otros productos acuáticos & 18 & 22 & -16.7 & 0.4 \\
\hline 72 & acero e hierro & 15 & 109 & -86.3 & 0.4 \\
\hline 78 & plomo y sus productos & 13 & 3 & 267.1 & 0.3 \\
\hline 55 & fibra química & 11 & 14 & -18.6 & 0.3 \\
\hline 22 & bebida, alcohol y vinagre & 8 & 10 & -18.7 & 0.2 \\
\hline 70 & cristal y los productos & 8 & 2 & 308.9 & 0.2 \\
\hline 73 & producto de acero e hierro & 7 & 5 & 40.5 & 0.2 \\
\hline 23 & $\begin{array}{l}\text { residuos de la industria de } \\
\text { alimentos, forraje }\end{array}$ & 6 & 3 & 98.6 & 0.2 \\
\hline 38 & productos químicos & 6 & 5 & 35.2 & 0.2 \\
\hline 25 & $\begin{array}{l}\text { sal, azufre, tierra y piedra;cal y } \\
\text { cemento,etc. }\end{array}$ & 6 & 4 & 48.7 & 0.1 \\
\hline 37 & $\begin{array}{l}\text { productos fotográficos y cinema- } \\
\text { tográficos }\end{array}$ & 5 & 11 & -52.2 & 0.1 \\
\hline 28 & $\begin{array}{l}\text { productos de química inorgánica; } \\
\text { compuesto de los metales preciosos }\end{array}$ & 5 & 3 & 54.9 & 0.1 \\
\hline 81 & $\begin{array}{l}\text { otros metales básicos, cerámica } \\
\text { metálica y los productos }\end{array}$ & 3 & 3 & 3.1 & 0.1 \\
\hline 42 & $\begin{array}{l}\text { productos de piel y cuero, maleta } \\
\text { de viaje }\end{array}$ & 3 & 3 & -13.8 & 0.1 \\
\hline \multirow[t]{2}{*}{13} & $\begin{array}{l}\text { cola de insecto, goma, resina y los } \\
\text { otros líquidos de planta }\end{array}$ & 3 & 3 & -5.7 & 0.1 \\
\hline & Total & 4,167 & 2,160 & & \\
\hline
\end{tabular}

Fuente: Ministerio de Comercio de China: Informe del comercio de los países: el comercio de bienes de México y el comercio entre China y México, 2010, Vol. 1, 2011.http://countryreport.mofcom.gov.cn/

Los productos importados por México de China están concentrados en los del sector eléctrico, cuyo volumen llegó a 32,410 millones de dólares en 2010 (71.1\% del total), con un aumento de $43.7 \%$. En este aspecto China se enfrenta con varios rivales tales como Estados Unidos, Corea del Sur, Japón y Alemania. En los mercados mexicanos de muebles y juguetes, China también posee bastante competitividad y es la primera (superior a EU) fuente de importación de México en estos dos sectores, ocupando el $41.8 \%$ de estos mercados. En cuanto a los mercados de metal básico y los productos, equipos ópticos y médicos, plástico y caucho, China constituye la segunda fuente de importación de México, detrás de EU.

Como se ha desarrollado rápidamente la industria automovilística de México estos años, en 2004 empezó a exportar a China en gran volumen automóviles y las piezas del motor. A medida que China muestra una demanda cada vez mayor de los recursos minerales debido al dinámico crecimiento económico, las exportaciones de México a China de productos de cobre como el asperón mineral han aumentado en gran medida. ${ }^{3}$

3 中国商务部：《国别贸易报告：2010年墨西哥货物贸易及中墨双边贸易概况，2011年第1期， http://countryreport.mofcom.gov.cn/record/qikan110209.asp?id=3240。 


\section{Cuadro 3: Los principales artículos importados por México de China, 2010 (capítulos) (millones de dólares)}

\begin{tabular}{|c|c|c|c|c|c|}
\hline $\begin{array}{l}\text { código } \\
\text { HS }\end{array}$ & artículos & $\begin{array}{l}\text { ene-dic } \\
2010\end{array}$ & $\begin{array}{l}\text { ene-dic } \\
2009\end{array}$ & $\begin{array}{l}\text { variación } \\
\text { anual(\%) }\end{array}$ & porcentaje del total( $\%)$ \\
\hline sección & volumen total & 45,608 & 32,529 & 40.2 & 100.0 \\
\hline 85 & $\begin{array}{l}\text { maquinaria eléctrica, equipo au- } \\
\text { diovisual y las piezas }\end{array}$ & 21,755 & 15,361 & 41.6 & 47.7 \\
\hline 84 & $\begin{array}{l}\text { reactor nuclear, caldera, aparato } \\
\text { mecánico y las piezas }\end{array}$ & 10,658 & 7,199 & 48.1 & 23.4 \\
\hline 90 & $\begin{array}{l}\text { equipo óptico y médico y las pie- } \\
\text { zas }\end{array}$ & 2,066 & 1,279 & 61.5 & 4.5 \\
\hline 95 & $\begin{array}{l}\text { juguetes, productos de juego y } \\
\text { deporte y las piezas }\end{array}$ & 1,353 & 1,610 & -160 & 3.0 \\
\hline 39 & plástico y los productos & 1,023 & 776 & 31.9 & 2.2 \\
\hline 87 & $\begin{array}{l}\text { vehículo y las piezas(menos los } \\
\text { ferroviarios) }\end{array}$ & 824 & 537 & 53.3 & 1.8 \\
\hline 73 & producto de acero e hierro & 707 & 659 & 7.2 & 1.6 \\
\hline 29 & producto de química orgánica & 591 & 479 & 23.5 & 1.3 \\
\hline 94 & $\begin{array}{l}\text { mueble, ropa de cama, lámpara, } \\
\text { casa móvil }\end{array}$ & 549 & 410 & 33.9 & 1.2 \\
\hline 40 & caucho y los productos & 526 & 323 & 63.0 & 1.2 \\
\hline 83 & producto de metal básico & 360 & 269 & 33.8 & 0.8 \\
\hline 42 & $\begin{array}{l}\text { productos de piel y cuero, maleta } \\
\text { de viaje }\end{array}$ & 290 & 229 & 26.5 & 0.6 \\
\hline 76 & aluminio y los productos & 233 & 137 & 69.6 & 0.5 \\
\hline 96 & producto general & 202 & 141 & 43.0 & 0.4 \\
\hline 69 & producto de cerámica & 201 & 137 & 46.3 & 0.4 \\
\hline 82 & $\begin{array}{l}\text { instrumentos de metal básico, afi- } \\
\text { lador, cubierto y las piezas }\end{array}$ & 179 & 111 & 60.9 & 0.4 \\
\hline 60 & producto textil & 164 & 123 & 33.5 & 0.4 \\
\hline 32 & $\begin{array}{l}\text { material para el curtido, pigmento, } \\
\text { pintura, tinta, etc. }\end{array}$ & 139 & 104 & 33.7 & 0.3 \\
\hline 27 & $\begin{array}{l}\text { combustible mineral y los deriva- } \\
\text { dos, betún }\end{array}$ & 134 & 103 & 30.4 & 0.3 \\
\hline 28 & $\begin{array}{l}\text { productos de química inorgánica; } \\
\text { compuesto de los metales pre- } \\
\text { ciosos }\end{array}$ & 129 & 91 & 42.0 & 0.3 \\
\hline 63 & otros productos textiles viejos & 126 & 97 & 30.4 & 0.3 \\
\hline 72 & acero e hierro & 125 & 116 & 8.4 & 0.3 \\
\hline 31 & abono & 125 & 52 & 140.7 & 0.3 \\
\hline 70 & cristal y los productos & 124 & 83 & 50.0 & 0.3 \\
\hline
\end{tabular}




\begin{tabular}{|c|l|c|c|c|c|}
\hline 03 & pez y los otros productos acuáticos & 119 & 72 & 65.8 & 0.3 \\
\hline 38 & producto químico general & 112 & 70 & 60.6 & 0.3 \\
\hline 44 & madera y los productos, carbón & 108 & 80 & 36.2 & 0.2 \\
\hline 64 & $\begin{array}{l}\text { zapatos, botas, espinillera y las } \\
\text { piezas }\end{array}$ & 106 & 73 & 45.4 & 0.2 \\
\hline 48 & pasta de madera, papel usado & 98 & 84 & 16.2 & 0.2 \\
\hline & Total & 43,239 & 30,873 & 40.1 & 94.8 \\
\hline
\end{tabular}

Fuente: Ministerio de Comercio de China: Informe del comercio de los países: el comercio de bienes de México y el comercio entre China y México, 2010, Vol. 1, 2011 (http://countryreport.mofcom.gov.cn/)

Sin embargo, el volumen del comercio entre los dos países implica una proporción aún limitada respecto a sus actividades comerciales al exterior. Según los datos mexicanos, a pesar de que ha crecido el comercio entre México y la Unión Europea y los países asiáticos, EU sigue siendo su socio comercial más grande y más importante. Durante los cinco años pasados, las exportaciones mexicanas al vecino del norte sólo registraron una leve caída de 5\% del volumen total; a su vez, las importaciones de ese país disminuyeron en $11.9 \%$ en cuanto al porcentaje del volumen total. En 2010, las participaciones estadounidenses alcanzaron $80 \%$ de las exportaciones y $48.1 \%$ de las importaciones mexicanas. Comparadamente, las de China fueron, respectivamente, $1.4 \%$ y $15.1 \%$. Véase en el cuadro 4 y 5.

Cuadro 4: Volumen de exportaciones mexicanas a los principales socios comerciales, 2010 (millones de dólares)

\begin{tabular}{|l|c|c|c|}
\hline \multicolumn{1}{|c|}{ país y regíon } & volumen & variaación anual & en porcentaje del total \% \\
\hline total & 298,230 & 29.9 & 100.0 \\
\hline Canadá & 238,522 & 29.0 & 30.0 \\
\hline China & 10,616 & 89.5 & 1.4 \\
\hline Brasil & 4,198 & 54.7 & 1.3 \\
\hline Colombia & 3,786 & 50.4 & 1.3 \\
\hline España & 3,762 & 53.7 & 1.2 \\
\hline Alemania & 3,678 & 11.1 & 1.2 \\
\hline Japón & 3,574 & 19.4 & 0.7 \\
\hline Chile & 1,927 & 77.2 & 0.6 \\
\hline Holanda & 1,866 & 20.2 & 0.6 \\
\hline Argentina & 1,847 & 62.8 & 0.6 \\
\hline Reino Unido & 1,770 & 38.4 & 0.6 \\
\hline
\end{tabular}




\begin{tabular}{|l|c|c|c|}
\hline Venezuela & 1,565 & 10.1 & 0.5 \\
\hline Guatemala & 1,467 & 22.8 & 0.5 \\
\hline la India & 1,009 & -7.0 & 0.3 \\
\hline
\end{tabular}

Fuente: Ministerio de Comercio de China: Informe del comercio de los países: el comercio de bienes de México y el comercio entre China y México, 2010, Vol. 1, 2011.

Cuadro 5: Volumen de importaciones mexicanas de los principales socios comerciales, 2010 (millones de dólares)

\begin{tabular}{|l|c|c|c|}
\hline \multicolumn{1}{|c|}{ país y regíon } & volumen & variación anual & en porcentaje del total \\
\hline \multicolumn{1}{|c|}{ total } & 301,482 & 28.6 & 100.0 \\
\hline EU & 145,007 & 29.0 & 15.1 \\
\hline China & 45,608 & 40.2 & 5.0 \\
\hline Japón & 15,015 & 31.7 & 4.2 \\
\hline Corea del Sur & 12,731 & 16.3 & 3.7 \\
\hline Alemania & 11,077 & 13.9 & 2.9 \\
\hline Canadá & 8,607 & 17.9 & 1.9 \\
\hline Provincia Taiwán de China & 5,621 & 22.4 & 1.8 \\
\hline Malasia & 5,276 & 30.7 & 1.4 \\
\hline Brasil & 4,327 & 23.8 & 1.3 \\
\hline Italia & 3,997 & 27.0 & 1.1 \\
\hline España & 3,232 & 7.6 & 1.0 \\
\hline Francia & 3,024 & 20.9 & 0.9 \\
\hline Holanda & 2,811 & 29.5 & 0.9 \\
\hline Tailandia & 2,698 & 36.0 & 0.7 \\
\hline Reino Unido & 2,005 & & \\
\hline
\end{tabular}

Fuente: Ministerio de Comercio de China: Informe del comercio de los países: el comercio de bienes de México y el comercio entre China y México, 2010, Vol. 1, 2011.

\section{Inversiones directas y cooperación económica entre ambas partes}

Según los datos del Ministerio de Comercio de China, la inversión directa de China a México alcanzó a 45,411.000 dólares en 2010. Los 46 contratos recién firmados entre las empresas chinas y la parte mexicana implicaron un monto de 329 millones de dólares, entre los cuales el volumen de los contratos de obras equivale a 329 millones de dólares y el de los de cooperación laboral, 480,000 dólares. Hasta el fin del mismo año, se cumplió un volumen de negocios de 392 millones de dólares, 
incluidos 390 millones en cuanto a los contratos de obras y 1,170,000 dólares de los de cooperación laboral. ${ }^{4}$

Hasta el final de 2010, la inversión china a México se acumuló a 500 millones de dólares. El volumen registrado de los contratos de obras, cooperación laboral, diseño y consejo llegó a 2,050 millones de dólares y se cumplió un volumen de negocios de 2,910 millones de dólares. Hasta hoy día se encuentran más de 20 empresas chinas que tienen inversiones en México y que se concentran en los sectores de servicio petrolero, textil, desarrollo agrícola, producción de televisores, tubo de cobre para refrigeración y productos de impresión, etc. Los contratos de obras se relacionan, entre otras, con las industrias de petróleo, la exploración y topografía del gas natural, la perforación de pozos y la reparación y las telecomunicaciones. ${ }^{5}$

\section{Problemas observados en las relaciones económicas y comerciales entre China y México}

A pesar de que ha crecido rápidamente estos años el comercio entre ambas partes, se observan varios problemas notables en el proceso:

\section{Grandes diferencias entre los datos comerciales de los dos países}

Ya se mencionó este aspecto; sólo cuando se empleen métodos estadísticos acordados por ambas partes, se reflejarán más objetivamente las situaciones comerciales; la preocupación por un déficit cada día mayor de México frente a China, según la estadística mexicana, obstaculizará el desarrollo del comercio entre las dos naciones. Como se ve en el cuadro 6, de acuerdo con los datos chinos, el déficit mexicano frente a China de 2010 fue de 11,050 millones de dólares, pero según los datos mexicanos, la cifra subió a 41,400 millones de dólares, 30,000 millones más alto que la anterior.

México manifiesta que sus déficit comerciales provienen principalmente del comercio con China, Japón y Corea del Sur, que registraron en los tres países en 2010, respectivamente, 41,410 millones, 13,090 millones y 11,800 millones de dólares. A su vez, su superávit comercial se obtuvo de los EU, equivalente a 93,520 millones de dólares. ${ }^{6}$

\footnotetext{
中国商务部：《对外投资和国国别（地区指南）墨西哥2011年版》。

中国商务部, http://mds.mofcom.gov.cn/

中国商务部《国别贸易报告：2010年墨西哥货物贸易及中墨双边贸易概况，2011年第1期, http://countryreport. mofcom.gov.cn/record/qikan110209.asp?id=3240
} 


\section{Cuadro 6: Balanza comercial de México y los principales socios (millones de dólares)}

\begin{tabular}{|c|c|c|c|}
\hline país y regíon & ene-dic 2010 & ene-dic 2009 & variación anual(\%) \\
\hline total & $-3,251$ & $-4,764$ & -31.8 \\
\hline \multicolumn{4}{|l|}{ fuentes del déficit } \\
\hline China & $-41,409$ & $-30,313$ & 36.6 \\
\hline Japón & $-13,088$ & $-9,783$ & 33.8 \\
\hline Corea del Sur & $-11,801$ & $-10,446$ & 13.0 \\
\hline Alemania & $-7,503$ & $-6,510$ & 15.3 \\
\hline Provincia Taiwán de China & $-5,300$ & $-4,415$ & 20.0 \\
\hline Malasia & $-5,166$ & $-3,898$ & 32.5 \\
\hline Italia & $-3,345$ & $-2,628$ & 27.3 \\
\hline Tailandia & $-2,549$ & $-1,882$ & 35.4 \\
\hline Francia & $-2,438$ & $-2,002$ & 21.8 \\
\hline Filipinas & $-1,464$ & $-1,018$ & 43.8 \\
\hline \multicolumn{4}{|l|}{ fuentes del superávit } \\
\hline EU & 93,515 & 72,445 & 29.1 \\
\hline Colombia & 2,966 & 1,882 & 57.6 \\
\hline Canadá & 2,009 & 1,071 & 87.5 \\
\hline Guatemala & 979 & 695 & 40.8 \\
\hline Venezuela & 925 & 986 & -6.2 \\
\hline
\end{tabular}

Fuente: Ministerio de Comercio de China: Guía de inversión al extranjero: México, 2011.

\section{Fricciones comerciales}

En el proceso del rápido crecimiento, China ha tenido que enfrentarse con cada día más fricciones comerciales tanto con los países desarrollados como con los en vía de desarrollo, entre las cuales destacan las fricciones con las naciones latinoamericanas. Como uno de los países más activos del mundo que aplican las políticas de protección del comercio, México ha efectuado contra China medidas drásticas de antidumping, a pesar de que no constituye el objetivo más importante en este aspecto.

Según los datos de la OMC, el número de los casos antidumping formulados por México contra China pasó de 16 durante el periodo 1990-1994 a 18 durante 1995-2003, y estos 34 casos significan $10 \%$ (ocupando el segundo puesto) de todos los casos similares propuestos por los países en desarrollo contra China. México figura en los primeros 10 puestos de los países que aplican esta política contra China. De acuerdo con la estadística china, México sigue recaudando derechos antidumping sobre más de 1,300 partidas arancelarias de las exportaciones chinas, tales como las de productos textiles, 
vestidos, zapatos, bicicletas, juguetes, maquinarias eléctricas y sus piezas, productos de química orgánica, equipos y piezas electrónicos.

Sobresale que últimamente México está proyectando tomar medidas positivas para promover el desarrollo del comercio entre los dos países. Con la expiración de algunos acuerdos pasados, desde el 11 de diciembre de 2011 México empezó a recaudar derechos aduaneros comunes de 0\%-30\% sobre los 204 artículos de China y anuló los impuestos adicionales anteriores de 45\%-250\%. Según algunas fuentes informativas, ambas partes manifestaron que los acuerdos pasados no se prolongarían y el gobierno mexicano está convencido de que las importaciones de China crecerán moderadamente, aunque la cancelación de las medidas de transición contra los artículos chinos podría imponer alguna presión sobre las empresas mexicanas.

Con la anulación de las medidas de transición, China sólo pagará unos derechos aduaneros de 15\%, igual que los otros 151 países miembros de la OMC, cuando exporte algunos artículos como lápices, bicicletas, juguetes, cerraduras, aparatos manuales, encendedores y triciclos para niños; en cuanto a los zapatos de China, 10\%-30\%; los vestidos, 30\% como máximo; instrumentos y maquinarias eléctricas, $20 \%$ como máximo; productos textiles e hilos, $5 \%-10 \%$; y velas, $25 \% .^{7}$

\section{Competencia en el tercer mercado (principalmente en el de EU)}

Algunos investigadores han analizado con modelos cuantitativos los efectos del NAFTA sobre las exportaciones chinas, indicando que ese acuerdo no ha causado efectos de transferencia sobre las exportaciones chinas a los EU. A pesar de que las ventas de algunos sectores chinos habían disminuido, China aventajó a México y volvió a ser el primer exportador a EU. Objetivamente, NAFTA ha promovido el ajuste de la estructura china de exportación y gracias a esto, el comercio entre China y EU ha mantenido un buen crecimiento, por lo cual México no dejaría la percepción de que China constituye el mayor competidor en el mercado norteamericano.

\section{Rechazo mexicano al estatus completo de economía de mercado de China}

México todavía no ha reconocido el estatus de economía de mercado de China. Según los reglamentos mexicanos sobre la discriminación de precios (dumping), basados en los principios antidumping, si las empresas exportadoras venden a México a precios más bajos del normal del país original, se trata de una discriminación de precios. La Administración General de Comercio de México elegiría como referencia los datos de algún país de economía de mercado, tales como los precios en su mercado interno, precios de exportación al tercer país y precios estructurales, haciendo una comparación con los precios de artículos exportados a México de un país de economía no de mercado, para confirmar la discriminación y su grado.

Redunda en perjuicio de China el hecho de que México no la considera como un país de economía de mercado, aplica investigaciones de antidumping y compara los precios

7 中国驻墨西哥大使馆经商处：《取消过渡性措施并不是一个威胁》, http://mx.mofcom.gov.cn/aarticle/ jmxw/201112/20111207867646.html 
de China con los de otros países. Mientras tanto, se estima que México aprovechará el periodo de protección de más de diez años después de que China ingresó en la OMC.

\section{Las estrategias de elevar el nivel de la cooperación económica y comercial entre China y México}

\section{Desarrollo de relaciones económicas y comerciales sostenibles}

Según el informe de 2011 elaborado por el Banco Interamericano de Desarrollo (BID), durante estos diez años, el desarrollo de la economía latinoamericana no sólo se ha beneficiado directamente de la gran demanda china de importación, sino también, indirectamente, del crecimiento de China, ya que éste ha contribuido mucho a la recuperación de la economía mundial. En cuanto al primer canal, China ha hecho una aportación apreciable a la mejora de los términos de intercambio de la región. Concretamente, éstos se han mejorado en $20 \%$ gracias al hecho de que los precios de los productos primarios hayan aumentado debido a la gran demanda china y los precios del sector manufacturero, en sentido adverso. ${ }^{8}$

Destacar que esta complementariedad -la gran demanda china de recursos naturales y la gran capacidad de la región de suministrarlos- constituye una característica ventajosa de la cooperación entre las dos partes. Sin embargo, esta complementariedad ha ocultado limitaciones y fragilidad: algunos investigadores creen que la gran dependencia que han mostrado muchos países de la región de las exportaciones de ciertos productos primarios causada por este tipo de estructura comercial va en detrimento del empleo y del desarrollo sostenible de la economía. Al hablar de las estrategias chinas orientadas a exportaciones ya efectuadas por 30 años, no debemos ignorar, al reconocer los éxitos, las desventajas manifestadas sobre todo durante la crisis financiera global de 2009, tales como la insostenibilidad, la dependencia china de la demanda exterior, imponiendo una competición a las empresas del mercado de exportaciones.

Durante mucho tiempo, con un costo bajo de la mano de obra como una ventaja comparativa, China se ha concentrado en desarrollar una industria procesadora orientada a exportaciones intensivas en fuerza de trabajo y recursos, la cual tiene una característica de alto gasto de energía, alta contaminación y la gran dependencia de la materia prima, por lo cual resulta que en China cuanto más rápido crece el comercio exterior, más se demandan los recursos naturales; cuanto más se exporta, más deterioro se causa al medio ambiente y, al mismo tiempo, menos dinámica hay para ajustar la estructura sectorial. Además, el comercio chino caracterizado por el bajo costo tiene más posibilidad de enfrentarse en los mercados extranjeros con las fricciones comerciales. Sumado a esto, este tipo de modelo ha recibido muchas críticas por su gran gasto de recursos naturales. En este contexto, China ha formulado la estrategia económica de "ajustar la estructura y transformar el modelo" para lograr un desarrollo sostenible y unas relaciones saludables con las economías del mundo.

8 IDB, Ten years after the take-off, taking stock of China-Latin America and the Caribbean economic relations, 2010. 


\section{Construcción de relaciones económicas y comerciales armoniosas}

Para resolver los problemas existentes en las relaciones económicas y comerciales entre China y México tales como la asimetría comercial, diferencias en los métodos estadísticos y las competiciones, hay que aplicar las estrategias siguientes:

2.1. China debe aumentar las importaciones de México, ajustar las estrategias de exportación y resolver el desequilibrio mejorando la estructura comercial

Al estallar la crisis financiera global, China no tardó en ajustar las políticas macroeconómicas, siguiendo el principio de ampliar las demandas internas y aumentando las importaciones al mantener el volumen de exportaciones para contribuir al equilibrio del comercio exterior. Como resultado de las políticas, el superávit comercial de China registró una obvia caída, pasando de un valor máximo de 300,000 millones de dólares (6.5\% del PIB) de 2008 a 107,100 millones (2.2\% del PIB) de los primeros tres trimestres de 2011, lo cual se encuentra en una franja razonable a la vista internacional. ${ }^{9}$

En cuanto a las exportaciones chinas, los mercados de América Latina se clasifican en tres tipos: primero, los países que tienen competencia intensa con China; segundo, los que se complementan mucho con China a pesar de tener alguna competencia con ella; tercero, los que tienen gran complementariedad con China. Como México se figura en los primeros mencionados, China debe dar mucha importancia a las exportaciones de los productos de alta tecnología y de más valor adicional. Además, hay que establecer fábricas en México para realizar un ajuste del modelo de comercio, convirtiendo las exportaciones de bienes en otras de capital, equipo, administración y servicios. La práctica manifiesta que la elevación del nivel sectorial y el mejoramiento de la estructura de exportación pueden contribuir a aliviar la competencia en los mercados del tercer tipo. Siguiendo las políticas de "ajustar la estructura y transformar el modelo", en China se elevarán el nivel de estructura sectorial y, como un resultado directo, el de estructura de exportación. Con la mejora de la estructura sectorial mexicana, el comercio intrasectorial entre los dos países aumentará y el intersectorial disminuirá, lo cual favorecería la atenuación de la competencia.

2.2. En cuanto a las diferencias en los métodos estadísticos, hay que "buscar puntos de acuerdo y reservar las divergencias" primero en los círculos académicos

Como los métodos estadísticos usados por México se diferencian de los de China, el déficit comercial mexicano se ha ampliado y no se ha reflejado la realidad del comercio bilateral. Además, los datos elaborados según estos métodos constituyen los fundamentos de las políticas de protección comercial. A pesar de que no han logrado un acuerdo los dos gobiernos, los académicos pueden realizar juntos una investigación para aclarar las diferencias y explicar las razones de su existencia. En este aspecto, serían un buen ejemplo los estudios sobre tales divergencias efectuados por China y

9 陈德铭：《坚持扩大内需战略 促进外贸平衡发展》http://news.ifeng.com/mainland/deta 
EU. En 1994, preparado por las comisiones de comercio de los dos países, se formó el grupo de estadística del comercio bilateral para hacer una serie de estudios sobre las diferencias en ese campo entre ambas partes. Como frutos del trabajo, se publicaron varios informes del grupo y el último salió a la luz en 2010. En opinión de los informes, en la estadística de EU sobre las importaciones se ignoraron los tránsitos y sus valores adicionales y por eso se sobreestimó el volumen de las importaciones de China. A su vez, en su estadística sobre las exportaciones no se incluyeron los tránsitos y se subestimaron la cantidad de las exportaciones hacia China. En 2006, por ejemplo, ese grupo hizo una serie de ajustes cuantitativos sobre las divergencias estadísticas y el déficit estadounidense frente a China se redujo en 26\%, de 232,600 millones de dólares a 173,400 millones. De hecho, tales estudios sobre esas diferencias sí son una prueba valiosa para la reforma estadística del comercio internacional.

En realidad, el problema de la norma estadística está atrayendo cada día más atenciones. Varias instituciones, tales como la OMC, el Banco Mundial, la Conferencia de las Naciones Unidas sobre Comercio y Desarrollo, la OCDE, se han puesto, juntas o separadamente, a efectuar los estudios sobre este tema y algunos centros académicos europeos se han concentrado en las investigaciones sobre los casos especiales de los diversos países. Como es sabido, en el contexto de la globalización, la producción nacional se ha convertido en una producción mundial y, como consecuencia, el comercio de bienes tradicional se ha transformado en un comercio de cadena. Sin embargo, los métodos estadísticos de comercio que corresponden al modelo tradicional del comercio de bienes no pueden reflejar objetivamente las cadenas productivas que ubican todos los eslabones distribuidos en diversos países, ni calificar correctamente las contribuciones ofrecidas por el comercio al empleo y al ingreso. Usando estos métodos, los gobiernos no pueden lograr informaciones exactas al delinear políticas al respecto. ${ }^{10}$

\subsection{Hay que buscar un camino hacia la institucionalización de las relaciones económicas entre} China y México

Durante muchos años América Latina no ha dejado de ser una de las regiones en desarrollo que toman más medidas de defensa comercial contra China. En 2010 China se hizo víctima de las políticas de protección comercial al enfrentarse con 64 casos de fricción comercial, implicando un volumen de 7,000 millones de dólares. Entre los países en desarrollo, Brasil y Argentina tuvieron más roces comerciales con China. De enero a octubre de 2011 se produjeron más de 40 eventos de defensa comercial contra China en unos países en vía de desarrollo, tales como Argentina, México, Brasil, Turquía, India, entre los cuales se encontraron 14 casos nuevos, 12 de antidumping, uno de antisubsidios y uno de protección. La segunda indagación de antidumping contra China hecha por Brasil se relacionó con un caso de un volumen máximo de 300 millones de dólares. A su vez, la indagación "doble" (tanto de antidumping como de antisubsidios) efectuada por México sobre los productos de amoxicilina trihidrato fabricados en China fue iniciadora en la historia de la región en esta área. ${ }^{11}$

\footnotetext{
10 《现行统计方法造成我国贸易顺差严重夸大》（社科调研），《人民日报》，2011年10月21日。

11 出口贸易摩擦激增 多国围堵中国》, http://www.baoyuntong.com/datum/show-22820.html。
} 
Destaca que los tratados de libre comercio favorecen al comercio bilateral en sus diversas etapas: contribuye a que se liquiden las divergencias ex ante durante las negociaciones, ofrece los reglamentos institucionales que son indispensables en el proceso del comercio y suministra ciertos mecanismos para que se resuelvan las disputas ex post. Hasta hoy día China ha firmado tratados de libre comercio con Chile, Costa Rica y Perú, los cuales han tenido unos efectos ejemplares y, al crear un nuevo modelo, proveerán dinámicas al libre comercio, la apertura del mercado y el desarrollo de inversiones de la región.

\section{Creación de relaciones económicas y comerciales innovadoras}

Afectados por la crisis financiera, muchos países padecen un apuro ya que les falta dinero, pero parece que China no tiene tal preocupación: en marzo de 2011, las reservas internacionales de China acumularon 3,200,000 millones de dólares. Con esta ventaja, China ha desarrollado creativamente relaciones económicas con los países de América Latina: en 2009 se convirtió en el 48 miembro formal del BID; firmó con Argentina el acuerdo bilateral de cambio monetario; firmó con Brasil, la República Bolivariana de Venezuela y Ecuador el acuerdo de "préstamo en cambio de petróleo"; reinvirtió con Venezuela al fondo conjunto de inversión. El banco central de Chile está dispuesto a alinear la moneda china (RMB) en su conjunto de reservas internacionales. Cabe reflexionar si hay posibilidades entre China y México de elevar el nivel de cooperación económica mediante los mencionados modelos innovadores.

¿Cómo aprovechará China un volumen tan grande de reservas? Primero debe utilizarse en las importaciones de productos de energía y otros recursos naturales que hacen falta para el desarrollo interno y segundo, más importante, debe gastarse en las actividades de inversiones en el extranjero. Durante el periodo del duodécimo plan quinquenal, China entrará en una etapa de aceleración de inversiones en el exterior. Según la política de "dirigirse al mercado externo", los puntos clave de inversiones en el extranjero consisten en los aspectos siguientes: construir los canales comerciales y crear marcas famosas; desarrollar las instituciones financieras transnacionales; mejorar la vida del pueblo de los países de meta de inversión.

El gobierno de Brasil da la bienvenida a las inversiones extranjeras y les ofrece un trato nacional. Según la Constitución brasileña, tanto las empresas de propiedad exclusivamente extranjera como las de capital mixto se consideran como "empresas nacionales brasileñas". A mi parecer, para corresponder a la hospitalidad, los inversores chinos deben prestar más atención a la vida del pueblo de los países y asumir las responsabilidades sociales. ${ }^{12}$

12 IDB, Ten years after the take-off, taking stock of China-Latin America and the Caribbean economic relations, 2010. 


\section{Bibliografía}

- 陈德铭：《坚持扩大内需战略 促进外贸平衡发展 http://news.ifeng.com/mainland/deta。

-胡锦涛: 《转变发展方式 实现经济增长》，

http://news.xinhuanet.com/world/2011-11/13。

- 《出口贸易摩擦激增 多国围堵中国》, http://www.baoyuntong.com/datum/show-22820.html。

-《现行统计方法造成我国贸易顺差严重夸大》，《人民日报》，2011年10月21日。

- 中国商务部：《国别贸易报告：2010年墨西哥货物贸易及中墨双边贸易概况》，2011 年第1期， http://countryreport.mofcom.gov.cn/。

- 中国商务部《对外投资和国国别（地区指南）墨西哥2011年版》。

-中国商务部, http://mds.mofcom.gov.cn/。

-中国驻墨西哥大使馆经商处: 《取消过渡性措施并不是一个威胁》, http://mx.mofcom.gov.cn/。

- CEPAL, La República Popular China y América Latina y el Caribe. Hacia una nueva fase en el vínculo económico y commercial, July 2011.

- CEPAL, Forum for East Asia-Latin America Cooperation (FEALAC). New biregional trade and investment relations in a changing world economic environment, $A u$ gust 2011.

- IDB, Ten years after the take-off, taking stock of China-Latin America and the Caribbean economic relations, 2010.

- World Economic Forum," Latin America @ risk", http://www.weforum.org/pdf/grn/LatinAmericaRisk.pdf.

- World Bank: 'Mexico: exports dynamics and productivity', Repot No.19864-ME. 
Sección 3:

Aspectos culturales 



\section{La fábrica 798 de Pekín, un ejemplo elocuente de arte público y una nueva plataforma para la cooperación cultural independiente entre México y China}

Edgardo Bermejo Mora

\section{La fábrica 798 y el nuevo paisaje cultural chino}

En términos urbanos y arquitectónicos, Pekín ha resentido como casi ninguna otra capital del mundo el peso terrible de las ideologías y las fiebres revolucionarias, y el violento convulsionar que acaso resume al siglo $X X$; invadida y golpeada por siete ejércitos occidentales, más Japón al inicio del siglo XX, para castigar la llamada Rebelión de los Boxer; ocupada por el militarismo japonés por casi una década durante la Segunda Guerra Mundial; más tarde resintió el cisma fundacional del maoísmo que mandó derrumbar sus antiguas murallas, sobre las que se trazó la línea del metro y el primer periférico que tuvo la ciudad. Al estropicio comunista le siguió una nueva racha destructiva durante la Revolución Cultural (1966-1976), que demolió al por mayor monumentos y templos del pasado "feudal" o "burgués" de la ciudad imperial; mientras que antes y después de aquella década de locura colectiva la ciudad se pobló de construcciones de factura soviética y otros bloques de concreto y ladrillo de evocación estalinista.

La apertura económica de finales de la década de los 70, y el periodo de reformas económicas que llega hasta nuestros días tras un cuarto de siglo de transformaciones, ha desfigurado el rostro de la ciudad a través de una compleja y obsesiva operación arquitectónica que rinde culto al rascacielos, los bloques masivos de vidrio y acero, y en general el rasgo "modernizante" de un urbanismo desbocado, consumista, intrusivo y fetichista en su idea del "progreso", que ha sido menos elogiado que criticado por sociólogos, urbanistas y medioambientalistas de todas las tendencias, dentro y fuera de China.

Hay por supuesto diversas excepciones a esta tendencia, que se nos presentan como oasis estimulantes en medio del ruidoso festín del urbanismo triunfalista chino, que en general afea y uniforma a sus grandes y medianas ciudades. Casos emblemáticos y ya icónicos para la arquitectura mundial como el del Estadio Olímpico de Pekín, conocido como "el nido", y en general las instalaciones Olímpicas de 2008; el Centro Nacional de Artes Escénicas, conocido como "el huevo"; el nuevo edificio de la Televisión Central de China, y el renovado Museo Nacional de la Plaza de Tienamen, entre muchos otros, y para los cuales, por otra parte, se ha acudido a grandes estrellas de la arquitectura mundial, Norman Foster y Jean Nouveau, por ejemplo, o bien a artistas al mismo tiempo ultracélebres e inquietantes para el gobierno como Ai Wei Wei, quien participó en el diseño del estadio olímpico y meses después sería el incómodo artista disidente sobre el que recayó el peso de la ley. 
En un escenario tan adverso y trepidante es que se presenta a partir de 2003 la aparición silenciosa de un sitio, la Fábrica 798 del distrito de Dashanzi, que a casi una década de estar abierto al público se ha convertido en el emblema de la acción cultural independiente de la gran capital china: un espacio esencialmente libre, abierto, con rasgos autonómicos -por demás inusuales en el paisaje artístico de China al momento de su surgimiento- que recicla e interviene, sin destruirla, la arquitectura del pasado inmediato y le da una nueva dimensión simbólica, que convoca a las nuevas generaciones de creadores y les ofrece un espacio en donde se respira pluralidad, que abre las puertas a la pequeña y mediana inversión en el ámbito de las industrias culturales y confirma el surgimiento y la consolidación de una nueva clase media urbana, ilustrada y cosmopolita, con aprecio por su independencia, y capaz de invertir y de vivir de la cultura, que atrae el interés de instituciones culturales, coleccionistas y galerías importantes de todo el mundo, y que, pese a todos estos rasgos sin duda renovadores y estimulantes, mantiene un grado de dependencia mayor a las autoridades locales, que a través del arrendamiento de los espacios a los artistas y promotores independientes (chinos y extranjeros) controla, hasta donde puede, el devenir de este gran experimento urbano, artístico y social.

De manera que La Fábrica 798 es un espacio al mismo tiempo institucional e independiente, en el que late una permanente pulsión crítica dentro de los márgenes que tolera el gobierno, más anchos y permisivos de lo que suele admitirse, y no obstante siempre en el límite de ellos. De alguna manera la Fábrica 798 resume, en su multiplicidad de formas y acciones, el temperamento de una nueva generación de artistas e intelectuales chinos capaces de establecer un dialogo crítico, severo, incluso áspero pero no precisamente antisistémico con el modelo en el que finalmente se insertan sus obras y sus acciones, que es la China de la apertura capitalista y el mantenimiento de los rasgos autoritarios, centralizados y conservadores de su modelo político.

Al respecto hay que advertir que muchos de los artistas, promotores culturales y empresarios del arte que le dieron vida a la Fábrica 798 pertenecen a la generación de estudiantes que les tocó sufrir y digerir -o no- los efectos devastadores de la violencia con la que se acallaron las revueltas estudiantiles y sociales de 1989. Hablamos de toda una generación de creadores que vivieron el aislamiento internacional de su país, y al mismo tiempo la exacerbación del control y la censura sobre la comunidad artística e intelectual en el largo proceso de cicatrización de las heridas del 89. A la vuelta de una década esto determinó en mucho los registros, estilos, temas obsesiones y propuestas del arte chino contemporáneo. Por ejemplo, la escasez de espacios de exhibición para la pintura y la escultura en los años 90, provocó que de manera espontánea florecieran otros formatos para el arte, particularmente el performance, que es parte central de su producción en el último cuarto de siglo y se podía hacer en cualquier sitio, de manera subrepticia o incluso clandestina. Es posible decir entonces que el performance fue la respuesta callada y creativa de los artistas visuales chinos a los años del aislamiento posTienanmen, de la misma manera que la eclosión internacional del arte chino en los grandes mercados de museos y colecciones del mundo en la primera década del siglo XXI, fue resultado del reingreso estelar de China a las primeras ligas de la era global. 
Pero sobre todas las cosas la Fábrica 798 es un modelo extremadamente complejo y estimulante de los alcances y posibilidades del arte público. En esto sigo al antropólogo brasileño Antonio Texeira cuando señala que "el arte verdaderamente público no es solamente para ser visto, es para ser vivido", que un principio del arte público es que "congrega, no aparta; aproxima y no distancia", que a fin de cuenta en el arte público "el receptor de la obra es también un autor de la pieza", y que debe ser por sistema un sitio que respeta "los derechos culturales" de los ciudadanos.

Todo estos atributos convergen, como he señalado, en el lugar llamado simplemente la Fábrica 798. Se trata de un complejo de galerías -locales e internacionales-, estudios de pintores, restaurantes, bares, librerías, centros culturales, residencias artísticas de corta estancia, espacios abiertos para esculturas e instalación, despachos de firmas de diseño gráfico, de moda e industrial; todo ello asentado sobre los galerones oficinas, bodegas y diversas construcciones de una vieja fábrica de equipo electrónico para fines militares construida entre 1952 y 1957, en el momento cumbre de la cooperación de China con el llamado bloque soviético. Actualmente coexisten estos espacios con los remanentes de la producción industrial y la actividad fabril de una empresa perteneciente al Estado.

La fábrica formaba parte de un ambicioso plan de crear cerca de 200 fábricas con la abierta cooperación y asesoría de técnicos y capitales del antiguo bloque socialista. En este caso en particular, se obtuvo la ayuda de ingenieros y arquitectos de Alemania Oriental, que produjeron un espacio fuertemente influenciado por el Bauhaus. Estas fábricas administradas directamente por el Ejército de Liberación del Pueblo (EPL) recibían un número y en el caso de la que nos ocupa fue asignado el 798 , del que deriva su actual nombre.

En este espacio, concebido como la proyección física del paraíso obrero en el apogeo de la ideología comunista, no sólo se asentaba la zona fabril, sino también las viviendas de los trabajadores, la escuela para sus hijos, el mercado, el hospital y las zonas recreativas y deportivas se concentraban dentro del mismo perímetro, de modo que en total ocupaba 640 mil metros cuadrados de superficie y en su mejor momento dio empleo a 20 mil trabajadores.

Aquella fábrica, considerada un modelo de organización y producción, no resistió sin embargo, los embates de la apertura económica Despojada del subsidio estatal, retrasada en su infraestructura industrial y obsoleta en más de un sentido, terminó por despedir a más de 75 por ciento de su planta laboral, y por reducir su producción al mínimo. A finales de los 90 se encontraba prácticamente en ruinas y casi abandonada, no obstante mantenía su misión original de producir equipo electrónico para el sector militar, ahora bajo la modalidad de una empresa pública perteneciente a la municipalidad de Pekín.

Para evitar su definitiva extinción el comité de administración que aún subsistía decidió rentar los espacios. Se pensó originalmente en pequeñas y medianas empresas privadas, e incluso se planeó construir viviendas modernas o un gran centro comercial, como los muchos que ahora infestan las metrópolis chinas y que son un síntoma claro del surgimiento de la sociedad de consumo más importante sobre la tierra. Pero ocurrió entonces que con la renta de uno de esos viejos galerones a un reconocido escultor de 
Beijing a finales del año 2000, se desató el fenómeno de ocupación legal de los espacios por personas vinculadas a la comunidad de artistas e intelectuales de la ciudad, que en un principio rentaron galerones y bodegas a un precio irrisorio.

En menos de tres años pasaron de uno a 67 los sitios alternativos, hasta que en 2003 se conformó como espacio múltiple con identidad propia, que habría de convertirse en un fenómeno sin precedentes en la escena cultural china y que ha llamado la atención internacional, para lo cual ya se han publicado varios libros que explican y analizan su aparición. Entre ellos, Beijing 798, Reflextion on Art, Architecture and Society in China, editado por Huan Rui en 2004. Se trata de una edición bilingüe (inglés-chino) editada con el apoyo del gobierno alemán y es una estimulante reflexión colectiva sobre el fenómeno del arte público en el contexto de un proceso de transformación vertiginosa del paisaje físico y espiritual, estético y material, de la comunidad artística china.

En la actualidad conforman la Fábrica 798 más de 200 espacios independientes, se realizan festivales internacionales de arte en diversas disciplinas, se han establecido galerías e instituciones culturales privadas de Japón, Alemania, Italia, Francia, Bélgica, Corea, Singapur, España, Australia y Reino Unido, se ha incorporado a todas las guías turísticas y se ha replicado este experimento en otros suburbios de la ciudad donde florecen nuevas galerías, residencias artísticas y completos culturales al estilo de la Fábrica 798.

De manera que los artistas, intelectuales y empresarios culturales que protagonizan la escena en la Fábrica 798 conforman un grupo heterogéneo y novedoso en el panorama social y cultural de la china posmaoísta, que ya había logrado crear espacios alternativos en dos ocasiones a lo largo de diez años, aunque resultaron fallidos ambos intentos por la voracidad del crecimiento de la ciudad que les obligó a desplazarse. Esta vez, en otro contexto político para el país, lograron finalmente asentarse con mayor éxito, no obstante que durante los primeros años existía el riesgo latente de su cancelación, ante las presiones de las voces más conservadoras dentro del gobierno de la ciudad y del gobierno central que se inquietaban por su existencia, dada su visible independencia, al mismo tiempo que reclamaban el espacio para fines de mayor rentabilidad comercial, como la pretendida construcción de un gran centro comercial que sustituyera a los espacios culturales, y en contra del cual se aglutinó un gran número de artistas locales.

En los primeros años de su lucha por sobrevivir se realizaron también actividades con las secciones culturales de algunas embajadas acreditadas en China, que apoyaron desde un principio el proyecto hasta otorgarle un aval político y diplomático que de algún modo contribuyó a impedir los intentos por echarlo atrás. Más tarde la Fábrica 798 no sólo incorporó a firmas de arte extranjeras de gran prestigio, sino que adquirió cierta legitimidad oficial luego de que fue arropado por el propio gobierno chino, que lo incorporó al canon de los recorridos turísticos de la ciudad, del mismo modo que florecieron los anuncios comerciales para la televisión, los videoclips musicales, las películas y toda clase de eventos comerciales y sociales de alta sofisticación realizados en los múltiples espacios de este magnífico escenario, ruinoso y luminoso al mismo tiempo. Valga decir al respecto que, junto las embajadas de Francia y Alemania, la de México fue una de las primeras embajadas que programó 
actividades culturales en este espacio en los primeros meses de su creación, y que sería el primer país iberoamericano en organizar todo un festival independiente en este espacio, del que se hablará en la segunda parte de esta presentación.

Uno de los aspectos más llamativos de la Fábrica 798 es que se trata de un fenómeno hasta cierto punto espontáneo e involuntario, que responde en todo caso a un estado de ánimo colectivo pero para el que no hubo una planeación precisa y deliberada. Ocurre también que en su novedad y éxito insospechado tomó por sorpresa a las autoridades culturales del país, que del desinterés y hasta la crítica han terminado por asumir la existencia de esta vigorosa bocanada de oxígeno al espacio cultural pekinés. Subsiste además, sin ninguna clase de apoyo o patrocinio estatal, lo que representa una novedad y un desafió en el horizonte de la promoción cultural y del arte en China, fuertemente centralizado por el Estado y sus instituciones. Además, al elegir la vieja fábrica de la era soviética, al redescubrir su estética y proyectarla sobre un nuevo plano de legitimidad, se ha establecido un diálogo edificante y creativo con el pasado inmediato; no ya la simple negación del pasado revolucionario, sino una nueva narrativa de lo que China representa como un espacio cultural habitado por un tiempo entrecruzado y que admite aproximaciones múltiples. Se trata ciertamente de una batalla contra la uniformidad. Si en la era maoísta se uniformó el atuendo de la gente y su adoctrinamiento ideológico, en la era de la reforma capitalista se han pretendido nuevas formas de uniformar, como el paisaje urbano de rascacielos y centros comerciales que pintan de un solo color y de una sola geometría el horizonte urbano.

Viajar y conocer Pekín, o vivirlo desde dentro, es acercarse a una forma radical de la experiencia del cambio, Pekín es un enorme monumento al desarrollo urbano, pero es también una grieta, una anomalía del tiempo, una fractura de la razón civilizatoria. La velocidad que se le imprime a su transformación resulta perturbadora, pues se percibe en ella un intento por abolir el pasado.

Si acaso sobrevive la historia entre algunos de sus muros y callejones, si Pekín conserva alguna veta de identidad milenaria en su nueva traza, no lo es tanto por tratarse de una resistencia cultural desde adentro, sino tal vez porque en la maqueta futurista que se edifica a diario sobre lo que fuera la capital imperial -y por mucho menos tiempo el centro rojo del poder maoísta-, al pasado se le ha reservado un íntimo lugar en el imaginario urbano: el mismo lugar que se ha dispuesto para los museos, los monumentos históricos, los pocos templos que sobreviven a las décadas de estropicio revolucionario y ocupaciones extranjeras, los mercados de antigüedades, las estampas postales y las escenografías decorativas para el turismo. Fuera de estos últimos rincones donde se conserva, se venera -o se vende- lo ancestral, el resto del espacio urbano, por encima y por debajo del suelo, es una gran maquinaria puesta al servicio del crecimiento y sus fetiches: el consumo, el automóvil, la expansión de la mancha urbana, el rascacielos, la aglomeración desbocada, el tren subterráneo que orada la tierra como un gusano y se multiplica, el arribo jubiloso a una modernidad que sustituye el verde o el gris y el rojo de los callejones y los viejos muros imperiales por los destellos metálicos, el vidrio de sus altas torres y las luces de neón. La Fábrica 798 es una gran excepción a esta tendencia, y de ahí su singular riqueza y su potencial. 
Con la Fábrica 798 y los espacios similares que han florecido en el espacio de una década, asistimos a la conformación de algo que pudiéramos llamar la nueva identidad urbana de Pekín, que es compleja, múltiple y plural. No una sino diversas tradiciones históricas y culturales le conforman. El campo visual que abarca esa construcción alcanza fronteras insospechadas y por lo mismo sorprendentes. Una suerte de carnaval que entremezcla elementos antiguos y rabiosamente contemporáneos. Como un gran disfraz cosmopolita debajo del cual se percibe la piel longeva de una sociedad urbana china, cocinada a fuego lento en el decurso de los milenios.

La Fábrica 798 es en muchos sentidos una lectura crítica y profundamente disidente de esta realidad. El surgimiento casi espontáneo y de ninguna manera planificado de este distrito artístico en lo que fuera uno de los emblemas de la era comunista, ofrece una crítica implícita y aguda a esta obsesión de la modernidad y sus revoluciones de fundar con base en la destrucción y la negación de lo anterior.

Con la reinvención de este espacio, los artistas y promotores culturales recuperaron un emblema del "pasado" y lo reinventaron en el "presente". El resultado es impresionante: una exposición de instalaciones de vanguardia china en un gran galerón de una arquitectura muy estimulante, europea, profundamente histórica, y en cuyas paredes aún subsisten las consignas revolucionarias del tiempo de la Revolución Cultural con frases como "larga vida al camarada Mao" o "10 mil años de Revolución".

Si como dice Teixeira el "arte público es la piedra de toque por excelencia de la política cultural como instrumento de cultura política", y si consideramos a la Fábrica 798 como un ejemplo notable de arte público, que ha reivindicado los derechos culturales de las nuevas generaciones de artistas en China, y del público mismo que asiste los fines de semana al lugar, lo mismo para comer, comprar un libro, dar un paseo o asistir a un performance, entonces es justo señalar que asistimos en esta experiencia a un buen ejemplo de política cultural encaminada a la creación de una nueva cultura política, que hacía inevitable acercarse a ella desde las herramientas de la diplomacia cultural.

\section{México en la 798}

Como parte de las actividades de difusión cultural de la Embajada de México en la República Popular China, en octubre de 2005 se organizó en la Fábrica 798 de Pekín un festival artístico multidisciplinario dedicado a mostrar la intensa vida cultural de la colonia Condesa de la Ciudad de México. La actividad fue concebida como un diálogo cultural multidisciplinario que se proponía acercar a las comunidades artísticas de dos espacios urbanos que se caracterizan por concentrar una intensa actividad creativa. En el caso de la Fábrica 798 se trata, como ya hemos visto, de un complejo de espacios culturales independientes, asentados sobre lo que fuera una antigua fábrica de la era maoísta, que se había convertido muy pronto en el emblema cultural independiente de la ciudad, y en el sitio que mejor resumía el espíritu contemporáneo, innovador y vanguardista de la cultura china en su etapa modernizadora.

Para el festival se presentaron simultáneamente una exposición de artistas plásticos mexicanos avecindados en la colonia Condesa, una exposición fotográfica dedicada 
a este barrio de la Ciudad de México, una colección de ropa mexicana de diseño contemporáneo, un festival gastronómico de alta cocina mexicana, un concierto de música electrónica y una exposición de libros de arte de una librería de la misma colonia.

La curaduría y los contenidos del festival fueron decisión de los artistas participantes en coordinación con los anfitriones de los diversos espacios en los que se llevó a cabo; se obtuvo asimismo patrocinio público y privado tanto mexicano como chino para su realización, lo que constituía un acercamiento al nuevo modelo de cooperación que se buscaba.

Ofrecer durante el espacio de dos semanas una muestra diversa y multidisciplinaria de la producción artística y cultural contemporánea de la Ciudad de México, en el espacio de mayor prestigio y creciente influencia en la escena cultural y artística de Pekín, era parte de una estrategia de largo plazo encaminada a relaborar y fortalecer la imagen de México en China, país al que la política exterior de México reconoce como un socio estratégico en el ámbito económico, comercial, educativo y cultural.

Al inicio de la primera década del siglo XXI la cooperación cultural entre México y China se desarrollaba básicamente en el marco del Convenio de Intercambio Cultural suscrito en Pekín en 1978. Muy diversos frutos habían arrojado este convenio, que era y ha sido sin duda la piedra angular de la relación en este ámbito. No obstante, el carácter institucional de la cooperación gubernamental, a través de las canales diplomáticos formales, ya no respondía por entero al surgimiento de una comunidad artística independiente en China, que demandaba un nuevo acercamiento y nuevos proyectos de cooperación con sus contrapartes mexicanas, desde un ámbito de mayor autonomía.

En los primeros años del nuevo siglo era cada vez más frecuente el surgimiento de iniciativas y actividades que se inscribían fuera del marco institucional formal, lo que constituía un momento distinto en la maduración de los contactos bilaterales en materia educativa y cultural. La misión de este proyecto se orientó por lo tanto a construir un nuevo modelo para la difusión y la gestión cultural entre México y China, así como ofrecer nuevos contenidos para la misma, lo que representaba una diferencia notable con el esquema tradicional de intercambio de actividades artísticas y culturales con auspicio gubernamental, y que había marcado las relaciones culturales entre ambos países. Se buscó de esta manera construir nuevos puentes de comunicación directa entra las comunidades de creadores de ambos países.

En general debe hacerse hincapié en el hecho de que el proceso de cambio acelerado de China experimenta desde que inició su etapa de apertura ha modificado sensiblemente las condiciones en las que se pensó y diseñó el modelo bilateral de cooperación educativa y cultural en el marco del Convenio de 1978, y que de igual manera la gestión de actividades culturales en México se ha diversificado notablemente en los últimos años, al tiempo que el horizonte de la creación y de las artes se ha diversificado, multiplicado y alcanzado nuevas escalas en ambos países, bajo un contexto de creciente autonomía de sus comunidades creativas, con respecto de la gestión gubernamental directa.

La creciente autonomía del intercambio cultural en México en China era, en efecto, la mayor oportunidad que se presentaba de cara a este proyecto, y de esta manera permitía cumplir con el papel primigenio de la gestión cultural, como una actividad que 
impulsa y estimula el intercambio y la creación sin pretender desplazar a los actores creativos como los auténticos productores de cultura.

Para ello debía tomarse en cuenta el alto nivel de desarrollo y apertura que presenta el mercado chino para la difusión de arte y cultura extranjera en la actualidad, lo que hace indispensable pensar en nuevas estrategias de promoción de las manifestaciones mexicanas, especialmente de aquellas de carácter contemporáneo, urbano, universal y transfronterizo. En este contexto era igualmente indispensable buscar espacios alternativos de difusión en los nuevos foros y escenarios.

Por otra parte debe señalarse que, hasta muy recientemente, en el aspecto del contenido el acento principal había estado puesto en la difusión de manifestaciones diversas del folclor y las artes populares de ambos países, que tendían gradualmente a enriquecerse con otros campos de las manifestaciones contemporáneas del arte y la cultura.

Se hizo necesario por lo tanto reforzar la presencia en China de las manifestaciones contemporáneas de la cultura mexicana, cuya escasa presencia en tres décadas de relaciones políticas no se correspondía con el nivel de inquietud que en ambos países existe sobre su respectiva actualidad.

En este sentido cobró su verdadera dimensión el proyecto de organizar un festival multidisciplinario en el que participaron artistas y promotores culturales de la colonia Condesa de la Ciudad de México y del Distrito Artístico de Dashanzi, como dos ejemplos en creciente expansión de comunidades urbanas que elaboran cada día su propio ethos cultural.

Es por que ello que se ha vuelto necesario ajustar los ritmos, contenidos y formas de la actividad cultural bilateral, por una parte fortaleciendo la cooperación institucional, que sin duda ha sido el factor clave y protagónico en tres décadas de acciones, pero abriendo a su vez nuevos espacios y oportunidades a formas diversificadas de la cooperación, particularmente a través de involucrar a la iniciativa privada de ambos países, así como de estimular y promover el diálogo directo entre las comunidades emergentes de creadores intelectuales y artistas.

El nivel de desarrollo y apertura creciente que presenta el mercado chino para la presentación de arte y cultura extranjera, hace indispensable pensar en nuevas estrategias de promoción de las manifestaciones mexicanas, especialmente en los diversos festivales artísticos internacionales que organiza China, cuya notoriedad e impacto regional ha incrementado en los últimos años.

Asimismo se ha hecho indispensable buscar espacios alternativos de difusión en los nuevos foros y escenarios donde se verifican a diario los registros contemporáneos del ser cultural de la nueva China, bajo un manto renovado de cosmopolitismo, sofisticación y búsqueda de elementos identitarios acordes con el periodo de apertura y transición por el que atraviesa el país.

Deme tomarse en cuenta por otra parte el marcado interés por conocer diversos aspectos sobre México por parte de un nuevo público urbano chino de clase media, interesado en nuestro país como destino turístico. Esto último representa uno de los aspectos estratégicos de la gestión cultural en China toda vez que se espera que incremente significativamente el flujo turístico de ciudadanos chinos a México en los próxi- 
mos años, luego de que el gobierno de China le otorgó a México el grado de destino turístico abierto para sus ciudadanos en 2004.

China y México tienen la oportunidad de sostener un diálogo creativo, novedoso y plural sobre uno de los temas cruciales de la agenda cultural contemporánea, y que hace referencia al debate sobre globalización y particularismo, en un contexto de creciente integración regional.

China y México viven procesos simultáneos de emergencia y amenaza de sus industrias culturales, a las cuales se les busca una salida en el contexto global que permita su supervivencia. En este sentido resulta estratégico para ambos países vincularse en formas de cooperación encaminadas a la protección de sus industria culturales, particularmente la cinematografía, la televisión de entretenimiento y educativa, las artes escénicas, el turismo cultural y la industria editorial. Cualquier proyecto de cooperación bilateral vinculado con estos temas resultará fundamental en los próximos años.

Es previsible que en los próximos años se observe un mayor florecimiento de iniciativas de vinculación cultural y educativa en el plano social y de los actores culturales, con independencia de la gestiones gubernamentales de ambos países que se acuerdan en el ámbito institucional.

\section{Conclusiones}

En los últimos años ambos países hemos asistido al florecimiento de la presencia de artistas, estudiantes, productores y productos culturales de México y China circulando con relativa facilidad en los mercados locales de cada país. La irrupción en la escena cultural de Pekín de una nueva comunidad creativa, que hace una lectura crítica y propositiva del acelerado proceso de modernización y apertura de China, le otorga una legitimidad intelectual altamente valorada en el exterior, y de una enorme potencialidad para establecer una nueva alternativa de diálogo cultural para el siglo XXI entre China y México.

El público que se congrega en la Fábrica 798 de Pekín tiene el potencial de convertirse en el referente central de la producción artística e intelectual de China en los próximos años. Establecer con ellos un diálogo creativo encaminado a repensar los espacios urbanos destinados a las comunidades culturales, es una manera de incidir en la agenda y el imaginario cultural chino contemporáneo.

Al establecerse un nuevo tipo de cooperación para la gestionan cultural en China, con independencia de las iniciativas realizadas en el marco tradicional del convenio de cooperación gubernamental, se abre la posibilidad de potenciar este nuevo puente de comunicación directa entra las comunidades de creadores de ambos países. La creciente autonomía del intercambio cultural entre México en China, es la mayor oportunidad que se nos plantea en los años venideros.

Una adecuada planeación de las políticas culturales de México en China deberá reflejarse, por citar algunos ejemplos, en la presencia de arquitectos, restauradores, diseñadores y decoradores mexicanos en la construcción de obras pública y privada de China; en la circulación en el ámbito comercial y cultural de productos audiovisuales; 
en una mayor presencia de la industria editorial mexicana y especialmente un mayor número de autores mexicanos traducidos al idioma chino; en el florecimiento de los acuerdos bilaterales entre instituciones educativas mexicanas y chinas, y consecuentemente el aumento significativo de la presencia de estudiantes de estudiantes chinos en México y viceversa; en la participación más activa de México en los festivales culturales y artísticos de China, así como en la creación de festivales alternativos diseñados específicamente para fomentar el encuentro de sus comunidades culturales, a la manera del que se ha presentado en estas líneas.

Es necesario establecer nuevos esquemas de cooperación para el caso de los proyectos culturales que vinculan a México y China, que involucre a un gran número de instituciones públicas y privadas de ambos países y a sus comunidades creativas para ajustarse a las prácticas actuales de la promoción cultural, que ponen énfasis en el papel del Estado como gestor e intermediario, antes que como productor o regulador cultural.

\section{Bibliografía}

-Barmé, Geremie R., 1999, In The Red. On Contemporary Chinese Culture. Nueva York: Columbia University Press.

- Jiang, Yaron y Ashley, David (2000) Mao's Children in the New China. Voices from the Red Guard Generation. Londres: Routledge

-Feng, Lingyu y Shi, Weimin, 2001, Perfiles de la Cultura China. Beijing: China Intercontinental Press.

- Gang, Lin y Xiaobo, Hu, 2003, China After Jiang. Washington: Woodrow Wilson Center Press y Stanford University Press.

- Garza Limón, Cecilio (comp.), 2001, México y China. Testimonios de Amistad. México: Secretaría de Relaciones Exteriores.

- He, Zhaowu; Tang, Yuyuan y Sun, Kaitai, 1991, An Intellectual History of China. Beijing: Foreign Language Press.

-Huang, Rui, 2004, Reflections on Art, Architecture and Society in China. Beijing 798. Beijing: Timezone 8 Ltd + y Thinking Hands.

-Lu, Peng, 2000, 90s Art China 1990-1999. Hunan: Hunan Fine Arts Publishing House

-Puel, Caroline, 2004, Sens Interdits? Forbidden Senses? La sensualité dans l'art contemporain chinois. Sensuality in contemporary Chinese art. Beijing: Editions Xin Dong Cheng.

-Sosa, Ernesto (coord.), 2003, La cultura en un mundo global. Una perspectiva desde México. Ciudad de México: Instituto Matías Romero.

\section{Fuentes Hemerográficas}

-Aguilar, Héctor, Ehrenberg, Felipe y Ochoa Sandy, Gerardo (2002) Agregados culturales de México: tres experiencias. En Revista mexicana de política exterior. No. 66. 
-Bermejo Mora, Edgardo (2002) Big Mac, Small World. En La Crónica de Hoy. Disponible en: http://www.cronica.com.mx

-_-(2000) El mundo es una marca. Status mata rollo. En Etcétera. Política y cultura en línea. Disponible en: http://www.etcetera.com.mx

- - Edgardo (2000) Exabruptos de la identidad. Fanatismo en Singapur. En Etcétera. Política y cultura en línea. Disponible en: http://www.etcetera.com.mx

-__- (2002) Norteados. En La Crónica de Hoy. Disponible http://www.cronica. com.mx

- Changyan, Xiao. Pioneer film. En Beijing Weekend. Junio 10-12, 2005

- Chong, Hao (2005) Beyond Shock Value. En City Weekend. Vol. 6, No. 10.

- García Canclini, Néstor (2004) ¿Cómo se ocupan los medios de la información cultural? La información cultural en los periódicos mexicanos. En Etcétera. Una ventana al mundo de los medios. Disponible en: http://www.etcetera.com.mx

-_- (2003-4) México en el nuevo escenario cultural internacional. En Revista mexicana de política exterior. No. 70.

- Hale, David y Hale Lyric Hughes (2004) China levanta el vuelo. En Foreign Affairs en español. Vol. 4, No. 1.

-Han, Junwei y Otto, Nick. Sultans of Style. Beijing's desgins on greatness. En That's Beijing. No. Mayo, 2005.

- Holden, Kevin (2005) Around the World. Chinese DJ's start spinning on the globe's music stage. En City Weekend. Vol. 6, No. 7.

- Holden, Kevin. E-music strikes a cross-border chord. En China Daily. Junio 2, 2005.

- Hutchihnson, Laura (2004) The Mutation Project. En City Weekend. Vol. 5, No.8.

- Jiao, Priscilla. Something Old, something New. En That's China. No. Abril, 2005.

- Lin, Shujuan. An unlikely rocker. Wu Hongfei exercises her demons through song. En Beijing Weekend. Mayo 20-22, 2005.

- Medeiros, Evan y Fravel, M. Taylor (2004). La nueva diplomacia china. En Foreign Affairs en español. Vol. 4, No. 1.

- Mei, Zhaorong (2002) La política exterior de China. En Revista mexicana de política exterior. No. 65.

- Navarro, Adriana (2009) Arte para disfrutar a pie. En La Gaceta de la UdeG . No. 558

- Roy, Shannon (2004) Fully Furnished Life. En Beijing this month. No. 126.

-Sen, Amartya (2004) ¿Cómo importa la cultura en el desarrollo?. En Letras Libres. Año IV, No. 71

-Zhou, Hellen (2005) 'Meet in Beijing' Arts Festival. Feast of Talen for all Tastes. En Beijing this month. No. 138. 



\section{Continuidad y fractura en la cultura china}

Flora Botton Beja

En un mundo de por sí cambiante, China es tal vez el país que mayores cambios ha experimentado en un siglo. Es tal el ritmo de la transformación sobre todo en los últimos veinticinco años que estudiar a la China actual implica un constante esfuerzo de actualización por parte de quienes, como académicos, sentimos que los cambios van más rápido que nuestro mismo poder de asimilación. A fin de describir la situación actual, una actualidad que también está en constante proceso de transformación en economía, política, sociedad y cultura, tenemos necesariamente como punto de referencia la China que resultó de la revolución que encabezó Mao Zedong y que culminó en 1949 con la fundación de la República Popular.

Sin embargo, ¿podemos decir que a partir de 1949, China dejó atrás toda su tradición y su historia? Los estudiosos de China se plantean el problema de la continuidad o no continuidad de la tradición china, tanto ideológica como cultural, y al enfrentarse a una situación peculiar que no tiene correlación con el mundo occidental, al tratar de comprender el "camino chino hacia el socialismo" o la "revolución cultural", o el mismo cambio que resultó en la nueva China, tratan de ver si acaso el pasado puede ofrecer una explicación para el presente. Aquí quisiera hacer algunas reflexiones que me han preocupado como historiadora sobre la relevancia del pasado para entender a la China de Mao y que sería un primer paso para encontrar los antecedentes de la nueva situación.

China es vista a través del prisma de su economía, de las oportunidades que ofrece como socio comercial y a veces, pero menos, se estudia su sistema político. El estudio del presente y de la historia contemporánea es imprescindible en cualquier caso; sin embargo, ¿cómo emprender seriamente el estudio de una sociedad contemporánea desconociendo su bagaje histórico y cultural? ¿Podríamos estudiar la Europa contemporánea sin conocer la cultura grecorromana, las religiones monoteístas, la ilustración...? De la misma manera, el pasado de China, al que frecuentemente podemos reconocer en el presente, no puede ni debe ser una nota que encabeza los seminarios sobre China, en los cuales se pide una síntesis breve para explicar todo el pasado y toda la cultura china, ni tampoco debe ser meramente un capítulo introductorio en los múltiples libros que se publican sobre la China actual.

Muchos son los temas de la historia de China que debemos conocer para entender la dimensión total de su presente. Voy a referirme sólo a algunos. En primer lugar debemos explicar cuáles son las raíces de la continuidad de las instituciones chinas, de su sistema político, de su pensamiento, de sus creencias y de su arte. ¿Cuáles son los orígenes de la identidad china? ¿En qué momento reconocieron una afinidad los habitantes de un territorio cuya gran extensión aun en épocas antiguas, no permite explicarla meramente por la contigüidad? La tradición escrita nos revela peculiaridades 
de la autopercepción de ese pueblo en cuya mitología los héroes son más sabios que guerreros y cuya máxima contribución son los elementos civilizadores y las obras para el beneficio del pueblo. Esos reyes sabios no estaban a la merced de dioses injustos o vengadores, sino de una fuerza superior, el cielo, que simplemente castiga a los villanos y recompensa a los virtuosos haciendo énfasis más sobre la responsabilidad que sobre el destino. El deber más importante de los soberanos y por lo que eran juzgados, era el de servir a los demás hombres del presente y del pasado, es decir a sus súbditos y a sus ancestros. No faltan en el pensamiento antiguo nociones abstractas como el yin y el yang, fuerzas complementarias pero no necesariamente antagónicas, que no representan la pugna entre el bien y el mal, sino el proceso natural de la generación y decadencia de todas las cosas y su eventual regeneración.

En el siglo XIX, la mayoría de los chinos se hubieran sorprendido al escuchar la expresión "cultura china" . La cultura china es "china" específicamente en tanto se le aplican criterios de evaluación occidental, pero para los chinos fue durante muchos siglos la cultura, la única posible, la que era válida universalmente. Sin ser la civilización más antigua, China es, sin duda, la de mayor continuidad. Su organización social sus instituciones y la permanencia de la ideología confuciana que las apuntalaba, sus logros materiales y artísticos, amen de la escritura que fue siempre un elemento unificador, duraron más de dos mil años.

La continuidad de la cultura china es tal vez un fenómeno único en el mundo y entenderlo es un desafío. El aislamiento geográfico de China posiblemente favoreció, en épocas muy tempranas, el desarrollo de una cultura sin fracturas ni desafíos y que, ya consolidada, resistió cualquier interferencia y conservó sus características esenciales. La ecología, que privilegia la actividad agrícola, podría también explicar el desarrollo de una sociedad patriarcal cuya característica es la obediencia a la autoridad.

Las corrientes de pensamiento no fueron meramente juegos intelectuales, sino que se volvieron patrones de vida y guías para gobernar. Qué mejor ejemplo que el confucianismo, que recoge todos los elementos antes mencionados, construye una doctrina en la que preceptos morales y políticos se confunden y aboga por un gobierno de hombres de mérito, de soberanos preocupados por el bienestar del pueblo y de un pueblo que obedece a la autoridad y venera a sus ancestros. En la relación que todos los chinos tienen con sus ancestros podríamos encontrar la explicación del respeto tradicional por los mayores y el énfasis sobre el amor filial que contrasta con la rebelión hacia la figura paterna, tan frecuente en la tradición grecorromana. El confucianismo, que no es propiamente una religión, le dio una cohesión ideológica duradera a la organización social, la familia, el Estado y una continuidad insólita en una forma de gobierno, el Estado centralizado burocrático cuyo modelo, resistiendo invasiones y rebeliones, perduró a través de los siglos.

Si el confucianismo parte de uno de los aspectos de la tradición antigua, que enfatiza la centralidad del hombre y de su posición en la sociedad, no debemos olvidarnos de que otras corrientes de pensamiento favorecieron el desarrollo de la literatura y de las expresiones artísticas. El daoísmo filosófico, en contraste con el confucianismo, permite al ser humano espacios de libertad y creatividad, de escepticismo ante los valores morales impuestos por el quehacer social y de duda sobre la eficacia de un gobierno 
controlador. Sin embargo, ambas corrientes de pensamiento presentes en la más antigua tradición, convivieron jugando cada una su papel.

En China se llevó a cabo una transformación y se creó una sociedad nueva con valores diferentes, una sociedad en la cual se negaron valores y virtudes milenarios. La armonía y conciliación tan ponderadas en el pensamiento filosófico tradicional dejan lugar a la lucha de clases y se rechaza hasta el postulado tan arraigado en el confucianismo de una naturaleza humana capaz de amor hacia la humanidad, pues según Mao esto no corresponde a una realidad de lucha de clases en la cual conceptos de "rectitud", "bondad", "lealtad", pertenecen a la clase social que los formula y no tienen un contenido abstracto general. En una sociedad en donde la familia jugó un papel muy importante, en donde la edad era de por sí un favor que merecía respeto, los jóvenes se enfrentaron a padres, maestros y venerables ancianos.

Los ejemplos de rechazo al pasado son numerosos y hacen afirmar a Franz Schurmann: "La cultura china no ha desaparecido pero el sistema social tradicional de China, sí". Sin embargo, a la actitud de Schurmann se oponen las de otros autores como Ho Ping-ti, quien afirma que "muchos aspectos de la herencia de China (...) nos pueden ayudar a agudizar nuestra percepción del presente", o como Benjamín Schwartz, que ve, a pesar de la actitud negativa consciente de Mao hacia el pasado, posibles actitudes inconscientes o semiconscientes derivadas del pasado.

En el siglo XIX sucedieron algunos de los acontecimientos que más marcaron a China y la empujaron hacia el enorme cambio que sufrió. El régimen imperial no fue derrocado sino hasta 1911, pero durante todo el siglo anterior hubo señales de tensiones y mucho de lo sucedido en este siglo nos puede ayudar a entender (al igual que la herencia de un pasado más remoto) algunos aspectos de la China de Mao. En primer lugar, fue en el siglo XIX que China experimentó una serie de humillaciones impuestas por las potencias extranjeras. El impacto de Occidente le enseñó mucho a China, pero también dejó un enorme rezago de amargura provocada por varios años de intervención, explotación, concesiones y abusos. Si China desconfía de Occidente es porque ha tenido experiencias que la han hecho desconfiar, desde la Guerra del Opio hasta nuestros días.

A pesar de su rechazo a los valores tradicionales, la herencia cultural es algo que preocupó enormemente a Mao. La ideología del pasado puede ser rechazada fácilmente, pero miles de años de cultura manifestada en formas literarias y artísticas no pueden ser negados con la misma ligereza. Como dice Mao en El Papel del Partido Comunista Chino en la guerra nacional, en el capítulo llamado Estudio:

Otra tarea de nuestro estudio consiste en estudiar nuestro legado histórico y resumirlo críticamente desde el punto de vista marxista. Nuestra nación tiene una historia que data de varios miles de años, una historia que posee sus propias características y está llena de tesoros. Pero en ese sentido somos simples escolares. La China actual ha surgido de la China de la Historia. Como nosotros creemos en el enfoque histórico del marxismo no debemos separarnos de todo nuestro pasado histórico. Debemos hacer una recapitulación desde Confucio hasta Sun Yat Sen y heredar este precioso legado. 
Una gran parte de esta cultura ha sido generada en condiciones sociales inaceptables, refleja valores rechazados y es obra de individuos que pertenecían a clases sociales repudiadas. ¿Cuánto se puede guardar y cuánto hay que rechazar? Dice Mao: “Debemos tratar el arte y la literatura del pasado según su actitud hacia el pueblo y juzgar si son progresistas a la luz de la historia". Sabemos que los juicios sobre la cultura tradicional cambiaron en varias circunstancias, y llegaron hasta la casi destrucción del pasado durante la revolución cultural; sin embargo, aun durante ese periodo se conservaron algunas formas cuyas raíces populares no podían ser puestas en duda.

A primera vista, el pensamiento de Mao y su puesta en práctica pueden ser vistos como una destrucción sistemática de los valores que él considera "feudales" y de los usos y costumbres de una sociedad confuciana que se oponía al cambio, al progreso y al desarrollo. Mao no es el primero en señalar los defectos de una sociedad estancada y retrógrada. Los intelectuales de principios de siglo, los participantes del movimiento del 4 de mayo (1919) estaban de acuerdo en que un cambio debería operarse. Como dice Hu Shih, el máximo exponente del movimiento de reforma, los dirigentes de este movimiento:

Quieren inculcar en la gente una nueva actitud hacia la vida que los liberará de las cadenas de la tradición y los hará sentirse cómodos en el mundo nuevo y su nueva civilización. Quieren un aprendizaje nuevo que nos capacitará para entender inteligentemente la herencia cultural del pasado y también nos preparará para una participación activa en el trabajo de investigación en la ciencia moderna.

Se han hecho muchas generalizaciones superficiales sobre el despotismo, el sinocentrismo, la raíces humanistas del pensamiento tradicional chino para explicar aspectos del régimen político chino y sus bases autoritarias. Sin caer en paralelismos fáciles no podemos ignorar que en la tradición confuciana el soberano si bien tiene un poder absoluto, debe gobernar tomando en cuenta el bienestar del pueblo, pero decide cuáles son las pautas de este bienestar. El lema tan común en la terminología del socialismo en China "servir al pueblo" si bien tiene connotaciones diferentes al sentido que se le daba en la China tradicional, no era un concepto del todo extraño, como tampoco el que fueran los dirigentes quienes decidieran lo que implicaba.

Una característica del pensamiento de Mao que ha llamado siempre la atención de los occidentales, es su insistencia en que el cambio material es necesario, pero más importante aún es el cambio de mentalidad, el cambio que viene de adentro. Es la transformación del hombre, la clave de la transformación de la sociedad y del progreso económico. Mao está seguro de poder moldear la mentalidad china y así lo afirma en su artículo que publicó en la revista Hongqi en 1958:

La conciencia política de las masas aumenta rápidamente... En vista de eso, nuestro país tal vez no necesita tanto tiempo como antes se pensaba para ponerse al día con los grandes países capitalistas en cuanto a producción industrial y agrícola. El factor decisivo, aparte del liderazgo del Partido, son los 600 millones de gente. 
Y sigue diciendo más adelante:

Además de otras características, los 600 millones de gente en China tienen dos peculiaridades notables: son, en primer lugar, pobres, y en segundo, están en blanco. Los pobres quieren cambios, quieren hacer cosas, quieren revolución. Un pedazo de papel en blanco no tiene manchas y es así como las palabras más nuevas y más bellas pueden ser escritas sobre él, las imágenes más nuevas y más bellas pueden ser pintadas sobre él.

En otra ocasión, hablando de los componentes de su primer ejército, dice que lo primero que tuvo que hacer con estos elementos humanos tan dispares fue inculcarles una conciencia de lo que se esperaba de ellos. El concepto del autocultivo presente en todos los filósofos confucianos es retomado por Liu Shaoqi en su obra "Cómo ser un buen comunista" En esta obra el "autocultivo" es fundamental para forjar y transformar al individuo. Marx afirmó que el ser humano tiene la capacidad de cambiar, también lo dicen los filósofos confucianos. Un buen comunista subordina su interés personal al del partido, si sustituimos "partido" por "soberano", tenemos un claro ejemplo de "lealtad" confuciana. El cambio por la transformación interna es un tema que aparece en todos los escritos confucianos y está mejor ilustrado en el libro de la Gran Sabiduría:

(...) cuando la voluntad es sincera, la mente es rectificada; cuando la mente es rectificada, la vida personal es cultivada, la familia será ordenada; cuando la familia está ordenada, el Estado estará en orden y cuando el Estado está en orden habrá paz en todo el mundo. Desde el hijo del Cielo hasta la gente común, todos deben ver el cultivo de la vida personal como la raíz o el fundamento.

La educación es un instrumento esencial para que se opere este cambio desde adentro. Es por eso que la educación fue una preocupación fundamental para los pensadores de la China tradicional. En primer lugar, Confucio mismo había hecho hincapié en la necesidad de una educación universal: “En la educación no debería haber distinciones de clases", es una frase de Confucio que todo chino siempre ha citado con orgullo. China, además, tuvo una enorme ventaja para lograr una unidad cultural, a través de una lengua escrita igual en todas partes y una tradición oral transmitida de norte a sur. Mientras las clases más privilegiadas estudiaban a los clásicos confucianos y se empapaban de las ideas contenidas en ellos, el pueblo escuchaba en las plazas cuentos ilustrando las virtudes confucianas. En China, la difusión del pensamiento de Mao se hizo tanto en las escuelas como en los lugares de trabajo, en las plazas de las aldeas, usando canciones, cuentos y teatro callejero.

La educación, desde Confucio en adelante, tiene un carácter doble de educación tanto intelectual como moral. Aprender no es únicamente aprender una técnica, un oficio, es volverse "bueno", como dice el filósofo del siglo IV Xunzi,: "Si oprimimos la madera contra otra para enderezarla, podemos enderezarla; si acercamos el metal a la piedra de afilar podemos afilarlo; si el hombre superior estudia mucho y se autoexamina cada día su sabiduría será aparente y su conducta intachable." Tanto en la China de Confucio como en la China de Mao existe la creencia de que se puede transformar educando 
y que la educación constituye un instrumento de cambio social y político. Como dice Mao: “Nuestra política educativa debe permitirle a cualquiera que recibe una educación, desarrollarse moral, intelectual y físicamente y volverse un trabajador con consciencia socialista y con cultura".

La educación tradicional en China, la que recibían los que serían los funcionarios del gobierno era una educación basada en los clásicos confucianos y más que dar conocimientos prácticos se pretendía formar individuos ideológicamente moldeados según la moral confuciana. Durante los años de gobierno socialista, se planteó en China más de una vez el problema de ser rojo y experto. Para los observadores occidentales era interesante ver cuánto énfasis se ponía al rojo y cuánto al experto en diferentes épocas para determinar fluctuaciones ideológicas. En el plano ideal, sin embargo, no han sido jamás separados los dos conceptos y no es cuestión de proporción de cuánto de uno o de otro tendrá un buen comunista; volverse experto es educarse, y educarse implica tanto adquirir un oficio como conciencia socialista. Son innumerables los intentos para lograr estas dos funciones de la educación, y si examinamos los textos escolares de la época a partir del nivel de primaria, en cada experiencia educativa hay un elemento que trata de incorporar la ideología.

En muchas épocas de crisis en la historia de China y durante la época comunista se ha propuesto remediar una crisis política y social a través de un cambio educativo. Durante la dinastía Song (s.10-13) se habló de un cambio en el sistema de educación y de exámenes para conseguir un cambio político y social. En la China nacionalista, gente como Hu Shih gritaba: "salven al país por la educación", y Dewey se volvió el filósofo predilecto de esa época, pues decía: “La democracia es una cuestión de creencias, de actitud hacia la vida, de hábitos mentales y no solamente una cuestión de formas de gobierno". En cuanto a Mao, desde 1964, como medida contra el revisionismo, implantó algunas reformas educativas, como la de crear escuelas de mitad-trabajo, mitad-escuela, enviar estudiantes al campo, etc., y cuando empezó la revolución cultural fueron cerradas las escuelas a fin de organizar una reforma más a fondo que llevaría a una verdadera sociedad sin clases. El ataque feroz a los intelectuales en esa época, se justificaba por la percepción de Mao de que a pesar de todos los años que habían pasado desde el triunfo de la revolución, no se había logrado borrar la diferencia de los que según el filósofo confuciano Mencio trabajan con la mente y los que trabajan con sus manos. En una sociedad que se quería igualitaria, esto era inadmisible. Al mismo tiempo, los ideólogos del partido encontraron en la escuela rival del confucianismo, el legalismo, una doctrina que justificaba el poder total del soberano pero basado en leyes y reglas a las que debían someterse todos, sin diferencias de clase.

Otro paralelismo en la idea de la educación, tanto en la China tradicional como en la China de Mao, es la creencia de que se puede aprender a través de la imitación de modelos. Desde la antigüedad siempre se habló del papel del hombre superior como paradigma para los demás. Los paradigmas eran los reyes sabios de la antigüedad cuya conducta intachable había creado una época de oro, y su ejemplo era un modelo tanto para el emperador como para los funcionarios y cualquier individuo que siguiera este tipo de conducta podía volverse sabio. Para Mao, los miembros del partido deben servir de modelos a fin de "consolidar la nación y desembarazarse del atraso". Se crearon 
personajes ejemplares como el joven virtuoso Lei Fang, cuya historia es contada aún ahora, se habló de obreros y de campesinos modelo. En las escuelas, la educación política estaba a cargo de cuadros del partido cuyas experiencias servían de guías para la conducta y que enseñaban por el ejemplo de lo que eran y de lo que lograron.

¿Qué queda de la tradición china en la actualidad? A veces parecería que la misma China de Mao pertenece a un pasado lejano que poco tiene en común con la China actual cuya economía pujante, estabilidad política y enorme población le han dado estatus de potencia mundial. ¿Es suficiente conocer únicamente esta China para entenderla en su cabalidad? Uno de los peligros a los que nos enfrentamos al ver a China de manera superficial es caer en estereotipos como "la China milenaria" y el "sabio mandarín" tan frecuentemente usados en el pasado (que en algunas épocas tuvieron connotaciones positivas pero hieráticas y en otras significaron estancamiento, inmovilidad y atraso) y en el presente tienen sus equivalentes en el "milagro chino" o "el gigante asiático". Si los sinólogos de antaño tuvieron que combatir la intolerancia que generaban nociones racistas como la de "peligro amarillo", ahora oímos hablar del "peligro comercial" .

¿Cuál es la percepción de los chinos de sí mismos en la actualidad globalizada? Es cierto que la superioridad de la cultura china no es un tema que se discute abiertamente aun en China. Sin embargo, en la China moderna e inclusive en la actual, la desconfianza de los valores occidentales y la ponderación de los "valores asiáticos" y la convicción de que lo que es mejor para China es lo chino, han sido la base del nacionalismo chino. Chiang Kai-shek lo manifestó desenterrando "valores morales" confucianos, Mao señalando el "camino chino" hacia el socialismo que enriqueció al marxismo-leninismo con el "pensamiento Mao Zedong". Ello está presente ahora cuando China rechaza cualquier injerencia externa que cuestione la conducción de su economía o su actuación en derechos humanos. 



\section{Testimonios y pinceladas acerca de la realidad en 40 años de relaciones diplomáticas entre China y México}

Raúl Lomelí Rodríguez

\section{Inicio}

Cuando el cinco de octubre de 1971 me dispuse a ver la transmisión por televisión, en vivo, del discurso pronunciado por el entonces presidente de México, Luis Echeverría Álvarez, quien, en la ciudad de Nueva York ante la Asamblea General de las Naciones Unidas en su XXVI Periodo Ordinario de Sesiones, fijaba la postura de nuestro país respecto de la necesaria universalidad que debería tener esa organización, jamás me imaginé la trascendencia con la que repercutiría en mi vida. En aquella ocasión dijo:

Si desde 1945 hemos sido partidarios de que la Organización tuviera un carácter universal, es fácil entender la satisfacción con que hemos visto un constante aumento de sus miembros que de 51 han pasado a 130 con el ingreso de Bután, Qatar y Bahrein. Un avance trascendental para realizar el principio de universalidad será dar la bienvenida durante el actual periodo de sesiones a los representantes de la nación que alberga en su territorio la cuarta parte de la población del mundo: la República Popular de China y su consecuente ingreso al sitio que le corresponde en el Consejo de Seguridad.

Además añadió: “Al mismo tiempo será necesario reconocer que la soberanía y la integridad territorial de la nación de China son jurídicamente indivisibles".

Así quedó oficialmente marcada la ruta para la pronta apertura de relaciones diplomáticas entre nuestros dos países, formalmente establecidas el 14 de febrero de 1972. Dichas palabras me motivaron a reflexionar porque, en mis tiempos de estudiante universitario, constantemente había escuchado napoleónicas palabras de que China era un león dormido y que el mundo cambiaría cuando el dragón despertara.

Ese tema, por un lado, me hizo recordar algunos intermitentes contactos con personas que habían viajado a ese milenario país, geográficamente lejano pero cercano en similitudes: por su enorme riqueza cultural, trascendentes inventos reconocidos globalmente y larga relación comercial conocida en México desde hacía siglos, cuando la Nao China llegaba al puerto de Acapulco. Y, por el otro, cuando les escuché sus interesantísimas experiencias a dos personajes como fueron Felipe Pardinas, quien me daba la cátedra de Filosofía de la Ciencia, y al connotado periodista Agustín Barrios Gómez, quienes estuvieron por allá a principios de los años 60, cuando a China se le consideraba un enigma porque entonces se encontraba cerrada a Occidente.

Pronto se incrementaron los intercambios de todo tipo con China: políticos, diplomáticos, comerciales, culturales etcétera. 
Cuando en 1971 me integré como subdirector en la recién fundada Dirección de Noticieros de Telesistema Mexicano (compañía que posteriormente se convertiría en Televisa, en 1973 y su fundador titular era el licenciado Miguel Alemán Velasco, quien fungía como director general), debido a mi actividad informativa, constantemente debía atender invitaciones a asistir a diversas actividades con China, lo que me obligaba a ordenar cubrir para nuestros espacios de noticias esos acontecimientos derivados de la recién establecida relación bilateral.

Entre los primeros contactos con funcionarios, delegados y visitantes procedentes de China debo destacar la primera delegación comercial con que tuve contacto; fue en una reunión con el presidente de la Confederación de Cámaras Comercio (Concanaco), el empresario Miguel Blázquez, la que derivó en la oportunidad de conocer a quien en ese momento era el corresponsal de la agencia noticias china XINHUA (Nueva China), Pang Bingan, y a su asistente, Ma. Ellos estaban cubriendo la información del evento para su agencia. Desde entonces, Pang me distingue con su amistad.

Meses después concluimos las negociaciones que condujeron a la firma del primer contrato de suministro informativo de la Agencia XINHUA con una televisora mexicana, Televisa, y del primero con un periódico mexicano, el diario Novedades.

Debido a su talento y al dominio del idioma español, Pang Bingan ocupó diversos cargos en su caminar dentro de la agencia y abrió la brecha para el posicionamiento y desarrollo de XINHUA en nuestro continente. Entre ellas, dos destacan especialmente: estableció en la Ciudad de México la sede de la Oficina Regional para América Latina, la cual no sólo permanece en la misma ubicación hasta la fecha, sino que mantiene un constante e importante crecimiento en el continente. También llegó a ocupar la subdirección general para América Latina desde donde continuó ampliando las actividades informativas en nuestra región, lo que sin duda ha contribuido a fomentar un mejor conocimiento acerca de China en nuestros países y una presencia estratégica de XINHUA en nuestra región.

Por otro lado, una vez formalizadas las relaciones diplomáticas entre México y China, gracias a mi permanente atención y contacto con el desarrollo de la relación bilateral, primero como ejecutivo en la televisión (1972.02-1989.02), luego como empresario (1989.03-2010.12) y actualmente como consultor, desde 2011, he tenido la oportunidad de conocer y atender en México a los trece embajadores que han representado a la República Popular China en nuestro país, así como a numerosos funcionarios, diplomáticos, delegaciones culturales y comerciales, etc. También a múltiples funcionarios, empresarios, artistas, periodistas etc., en China.

El primer embajador de China en México, Xiong Xianghui (1972.08-1973.05) fue quien me brindó todo su apoyo para facilitar la compleja instrumentación de la cobertura para Televisa de la visita de Estado que el entonces presidente Luis Echeverría realizó a la República Popular China, en abril de 1973, cuando además de cumplir con la agenda protocolaria que esas circunstancias requieren, convivió con el pueblo chino en Pekín, Dazhai, provincia de Shanxi (población donde se desarrolló el modelo agrícola que en ese momento era ejemplo en toda China) y Shanghai.

Nunca olvidaré la extraña y única sensación que me invadió cuando por primera vez me comuniqué telefónicamente al Hotel de las Minorías, en Pekín, donde se alojaron 
nuestros colaboradores que llegaron de avanzada para preparar las transmisiones radiofónicas y televisivas, previo a la visita de Estado programada. No podía creer que mi voz estaba dentro de la República Popular China.

En Pekín, el 19 de abril de 1973 durante la recepción que ofreció en el Palacio del Pueblo el gobierno chino, el presidente Echeverría destacó: “Las relaciones entre nuestros Estados se han iniciado con franqueza ejemplar (...) Conozcámonos mejor y organicemos, desde luego, mecanismos permanentes de intercambio (...) La amistad es un bien escaso que enriquece, más que cualquier otro, a quien lo recibe. Netzahualcóyotl, el rey poeta de los antiguos mexicanos, comparaba los jades con los príncipes amigos. Hago otro tanto".

De ahí surgieron programas de intercambio de estudiantes, en los que inicialmente algunos mexicanos fueron a China a especializarse en medicina tradicional, la acupuntura, tan popular actualmente en nuestro país. También estudiantes chinos se matricularon en el Colegio de México de donde, entre otros egresados, han salido destacados embajadores chinos en América Latina, de los cuales dos se han acreditado en México: el actual embajador Zeng Gang y su antecesor, Yin Hengmin (2007.02-2011.01), quien actualmente desempeña sus funciones diplomáticas en la República Argentina.

Fue durante el periodo del segundo embajador, Yao Guang (1973.09-1977.05), cuando se dieron las condiciones y se realizaron los trámites para mi primera visita a la República Popular China mediante una invitación de Radio Pekín, con motivo de las fiestas de la conmemoración del $26^{\circ}$ aniversario de su fundación en 1975.

Fue un viaje muy oportuno en las postrimerías de la revolución cultural. Como anfitrión nos acompañó durante toda la visita Liu Xilian, quien años después se convertiría en el viceministro encargado del radio, la televisión y cine a nivel nacional. En él también encontré un amigo generoso.

La invitación consistió en un recorrido de varias semanas que inició en Pekín y concluyó es la ciudad de Shenzhen: en Pekín asistimos a la cena oficial del mencionado aniversario nacional, que en el Palacio del Pueblo presidió Deng Xiao Ping. Cuándo me iba a imaginar compartir la mesa con quien se convertiría en el artífice de la modernización de China.

En los parques de la ciudad disfrutamos de los juegos y espectáculos que se ofrecían al pueblo los días 1 y 2 de octubre con motivo del mencionado festejo nacional. Durante el recorrido pudimos convivir con el pueblo, constatar la disciplina y tenacidad de los trabajadores, admiramos sus históricos y majestuosos palacios y zonas arqueológicas, así como comunas agrícolas o agropecuarias aledañas, como en la que se engordaban a los patos para la preparación del famoso platillo: el pato laqueado.

Pekín era una ciudad muy plana, casi no había edificios y los que existían tenían aproximadamente 20 pisos, como máximo. No tenía anuncios publicitarios y los únicos espacios espectaculares anunciaban consignas del presidente Mao.

La vida en la ciudad era tempranera, a las seis de la mañana estaba en completa ebullición y, por la tarde, alrededor de las siete, prácticamente todos se retiraban a sus habitaciones. Recuerdo que a las ocho o nueve de la noche la ciudad estaba completamente desierta, como si fueran las tres de la madrugada en nuestras ciudades. Nada que ver con las construcciones y vida nocturna de la actualidad. 
En aquellos momentos casi no había extranjeros visitando China. Fue muy impactante observar que sorpresivamente, debido a nuestra forma de vestir y a los rasgos físicos con características occidentales, cuando al pasear caminando por sus calles, de pronto nos veíamos seguidos por muchísimos peatones o citadinos con sus bicicletas (al menos un ciento), todos vestidos (hombres y mujeres) con el característico traje Mao. Por la extraordinariamente ancha avenida principal Chang An, solamente circulaban bicicletas, transporte público y algunos automóviles de uso oficial. Hoy miles de automóviles la mantienen completamente llena, casi intransitable en las horas pico.

Cuando salimos de la capital continuamos nuestro programa por Ta Chai, la población del modelo agrícola para la nación que manejaba el viceprimer ministro encargado del campo, Chen Yonggui. Ese modelo implicaba esfuerzos titánicos para modificar montañas con el propósito de crear terrazas que contribuyeran a aprovechar mejor los ciclos agrícolas y en especial el agua en los cultivos que se sembraban.

Después, Shanghai con su importantísimo puerto, nos brindó la oportunidad de convivir con alegres niños que nos ofrecieron un espectáculo musical dedicado al presidente Mao, donde parte de su arquitectura con indiscutible influencia británica, como es el caso del Hotel Peace, en nada se asemeja con su aspecto actual y mucho menos con el desarrollo de Pudong.

Seguimos por la provincia de Hunan, la tierra del presidente Mao Zedong: Shaoshan, donde nació y Changsha donde, estudió. Guangshou, donde por primera ocasión visitamos su famosa feria y en una comuna en las afueras de la ciudad, junto con algunos estudiantes, cortamos de sus plantas un poco de té verde.

De ahí, por tren viajamos a la ciudad de Shenzhen, la cual era una población agrícola muy pequeña. Quién iba a decir que en tan sólo unos cuantos años se convertiría en una ciudad donde habría cantidad de fábricas y mucha inversión extranjera porque el artífice de la modernización, Deng Xiaoping, la escogió para detonar la primera zona abierta a la inversión extranjera.

Finalmente, nuestros anfitriones nos acompañaron hasta el puente que conectaba con el área de Hong Kong, que todavía estaba en manos de los británicos, lo recorrimos solos hasta llegar a los territorios donde nos esperaban algunos unos guías. El choque cultural fue impresionante.

Los siguientes 14 años, con esmero continué cultivando esa relación, lo que me permitió, en varias ocasiones, viajar a China para establecer y desarrollar una fructífera relación con el Ministerio de Cine, Radio y Televisión. Diseñamos lo que, en su momento, fue un audaz plan de cooperación con intercambio de programas radiofónicos y televisivos y una cordial relación que cimentó un sólido futuro comunicativo entre los dos países.

\section{Golpe de timón}

En 1989, al convertirme en empresario, después de mi caminar por la televisión, me dirigí a la República Popular China para investigar algunas posibles opciones de negocios que ofrecieran una valor agregado a los consumidores mexicanos porque sabía que 
años atrás Deng Xiao Ping había iniciado reformas para la modernización de China y era posible encontrar algunas opciones de negocio.

En aquel momento, el nuevo gobierno de la Ciudad de México que había iniciado su mandato a finales de 1988, tenía una enorme preocupación por la contaminación del aire que producían los vehículos automotores, principalmente por monóxido de carbono, hidrocarburos y óxidos de nitrógeno.

En Estados Unidos, diversos países de Europa y Japón, para combatir ese tipo de contaminación, se producían varios tipos de convertidores catalíticos fabricados con metales llamados preciosos, los cuales sólo funcionaban con gasolina sin plomo porque éste contaminaba esos metales y los volvía inservibles. Por ello, para México, preocupación adicional era el plomo porque en nuestro país todavía se consumía un tipo de gasolina con plomo.

Como medida preventiva, el gobierno de la ciudad estableció el programa "Hoy No Circula" y la obligatoria verificación de los vehículos con el propósito de frenar la contaminación, mientras se realizaban los estudios que permitieran establecer la políticas públicas conducentes. Por cierto, posteriormente estas medidas también fueron aplicadas por el gobierno chino.

Por su parte, China tenía en Beijing una fábrica de convertidores catalíticos llamada "La Gran Muralla" que producía diversos modelos, tanto para camiones como para automóviles, que tenían la particularidad de que se podían usar en vehículos que utilizaran gasolina con plomo porque estaban fabricados con una cerámica enriquecida con metales preciosos, la que les permitía hacer su labor a pesar del plomo, sin que éste los inutilizara por su contaminación. Ésta era la opción.

Firmamos un convenio con "La Gran Muralla" para poner una sucursal de la fábrica en México. China pondría 3000 convertidores para hacer una prueba de mercado, su tecnología, la línea de producción, personal técnico y, a través del Bank of China, ofrecería un crédito de diez millones de dólares al uno por ciento anual. Los empresarios mexicanos se encargarían de la importación e instalación de los 3000 convertidores para la prueba, aportarían la nave industrial para la fábrica, tramitarían los permisos gubernamentales para la operación, obtendrían las ventajas fiscales que facilitaran el despegue del negocio, así como los trabajadores, el personal administrativo y de ventas.

El gobierno de la ciudad decidió establecer un programa para retirar la gasolina con plomo y estableció como norma el uso de convertidores catalíticos fabricados en Occidente. Por esas razones ya no se llevó a cabo este proyecto que hubiera contribuido a acelerar el mejoramiento de la calidad del aire en la ciudad capital.

En 1990, al asociarme al Consejo Empresarial Mexicano (CEMAl) fui propuesto para integrarme como vicepresidente del Comité México-China que presidía el ingeniero Mario Abedrop Dávila. Esa posición me acercó al Consejo Chino para el Fomento del Comercio Internacional (CCPIT), organismo empresarial contraparte del CEMAI.

Las reuniones bilaterales anuales de ambos consejos, que se alternaban entre China y México, me permitieron conocer la oficina central del CCPIT en Beijing y algunas de sus representaciones dentro de China, otras que tiene en el extranjero y, por supuesto, la que funciona en nuestro país, con el consecuente beneficio de ampliar la visión panorámica en la búsqueda de nuevos horizontes, lo que facilita el contacto con nuevas relaciones chinas y mexicanas para el logro de nuevas oportunidades empresariales. 
Varios viajes realizados con misiones empresariales organizadas por el CEMAI y, en especial, realizadas durante las visitas de Estado de los presidentes Carlos Salinas de Gortari (diciembre de 1993) y Ernesto Zedillo Ponce de León (octubre de 1996) inyectaron aire fresco al desarrollo de nuevos proyectos.

Independientemente de actos de comercio realizados durante años, directamente o por medio de terceros, en 1996 formulamos dos megaproyectos que hubieran sido muy benéficos para nuestro país y para la relación bilateral: uno de China a México, la introducción masiva de tractores pequeños y medianos en el campo mexicano y, el otro de México a China, la instrumentación de una franquiciadora de taquerías en Asia, tomando como punto de partida Hong Kong y Singapur para luego expandirse al interior de la República Popular China y finalmente proyectarse en otros países de esa región.

\section{Proyecto de tractores}

Para llevar a cabo el primero de ellos se diseñó el Proyecto para la introducción comercial e industrial de maquinaria agrícola de la República Popular China en los Estados Unidos Mexicanos, bajo las siguientes premisas:

Para satisfacer la demanda de los agricultores poseedores de predios pequeños y medianos, que requieren de instrumentos de trabajo al alcance de sus posibilidades, se propone un plan para la introducción de equipos agrícolas, de fabricación china, en el mercado mexicano a través de coinversiones que contemplan dos etapas:

\section{Comercialización:}

Con la finalidad seleccionar los equipos más adecuados para su introducción en el mercado mexicano, a fin de procurar su venta y utilización en la siembras del año de 1998, dichos equipos serán tractores de bajo caballaje (entre 18 y 50 h.p.), los cuales estarán complementados con equipos de bombeo (impulsados por diesel o celdas solares), generadores de energía eléctrica de diesel y rociadores (sprinkles) para riego.

Tomando como base un plan de distribución y ventas progresivo en su cobertura, que vaya aumentando su radio de acción de acuerdo con el prestigio que esos equipos logren en las aéreas donde se introduzcan con éxito.

Dicho prestigio deberá sustentarse en la productividad, garantía de calidad, servicio y partes de repuesto, porque es la forma de proveer a los campesinos de los elementos mecánicos básicos para realizar, de manera más provechosa, sus tareas en la producción agrícola, lo que facilitará el acceso a los subsidios que ofrece "la alianza para el campo".

\section{Ensamble y Fabricación.}

Una vez obtenidos los resultados deseados en los trabajos de comercialización, se pasará a la segunda etapa, la que garantizará la permanencia de los tractores en el mercado mexicano. Esta segunda etapa abarca dos fases: 


\subsection{Instalación y operación de una planta de ensamble de tractores.}

Con ella se abatirán tiempos y costos, lo que permitirá iniciar una etapa de venta masiva de los tractores seleccionados para el mercado mexicano, lo que contribuirá al mejoramiento del servicio y al suministro de las partes.

\subsection{Integración de partes mexicanas en el ensamble de los tractores.}

Para hacerlos más competitivos y acordes con la realidad de nuestro campo y las costumbres de los campesinos mexicanos, se integrarán partes compatibles, de fabricación mexicana o accesorios mexicanos. Esto ahorrará tiempo y dinero en el envío de partes y accesorios desde China y los hará más versátiles. Debido a esa importante integración de partes nacionales, el tractor tendrá una marca mexicana.

Después de cubrir el mercado interno, se podrá explorar la posibilidad de exportar de los tractores a algunos países del sur del continente americano. En el caso de los países con quienes tenemos tratados de libre comercio, cuando se cumplan las reglas de origen vigentes, justamente por la integración de partes mexicanas, se facilitará la exportación de dichos equipos a esos mercados en condiciones muy favorables.

Con esos objetivos, en octubre de 1996, firmamos un convenio con Orient Group para su desarrollo. Aparentemente prácticas monopólicas de quienes controlan el mercado de tractores en nuestro país impidieron que este esfuerzo llegara a buen fin.

Este proyecto sigue estando vigente porque los migrantes mexicanos han dejado abandonadas enormes extensiones de tierra.

Proyecto de las taquerías. En 1992 asesoramos a unos inversionistas suizos y norteamericanos para instalar un restaurante mexicano llamado "La Placita" en el edificio Times Square que, en 1993, se estrenó en el área financiera de Hong Kong con mobiliario y enseres $100 \%$ llevados desde México. Al frente de la comida estaba un chef oriundo de Nogales, Sonora, México, quien garantizó un menú muy completo tradicional mexicano mediante el respeto de las recetas originales. Se contrató el suministro de gran variedad de bebidas típicas como son: tequilas, mezcales y cervezas (prácticamente se contaba con todas las marcas principales).

Como "La Placita" tuvo sorprendente éxito, en 1996 me asocié con su director general para hacer una prueba de mercado a través de una taquería con el mismo nombre que se encontraba en Cameron Road y Hua Fook Street en Kowloon, con el propósito de hacer los estudios pertinentes para establecer, con éxito, una franquiciadora en Asia asociados con empresarios de Singapur, expertos en franquicias en Asia, una franquiciadora de taquerías mexicana y algunas empresas que nos facilitarían suministros comestibles y bebidas para el control de la calidad de la carta.

El menú ofrecía tacos: al pastor, de carne asada, pollo, frijoles, pescado, camarones, mariscos, vegetariano y quesadillas que se podían acompañar con guacamole y rajas de chile jalapeño.

También se vendían por separado para llevar: tortillas de maíz y de harina de trigo en paquetitos, totopos y salsas verde o roja, entre otras cosas. 
Cuando estuvo terminado un sólido plan de negocios con su programa que consideraba la posibilidad de tener 1000 taquerías instaladas en toda Asia, en un plazo no mayor de diez a doce años, se vio frustrado el proyecto al retirarse la franquiciadora mexicana sin mayores explicaciones.

\section{Reflexiones acerca de las relaciones entre México y China}

Se puede observar que la relación entre los dos países al inicio de estos 40 años y, durante un lapso aproximado de 15 años, estuvo fundamentalmente orientada a la política porque los intercambios económicos apenas llegaban aproximadamente a los 100 millones de dólares anuales.

Después con los cambios que sucedieron a partir de las reformas que propició Deng Xiao Ping, la relación se transformó fundamentalmente en económica hasta alcanzar los niveles de comercio actuales (de casi 50,000 millones de dólares en 2010), lo que convierte a China en el segundo socio comercial de México.

La relación bilateral entre estos dos países milenarios que históricamente tienen Ilamativas similitudes y convergencias que pueden detectarse en su rico pasado cultural, en el que sus ancestros dejaron testimonio en su pintura, escultura, o en sus conocimientos en el uso de ricas herbolarias que sustentan sus medicinas tradicionales, etc., puntos de concordancia que naturalmente los acercan.

Cuarenta años de actividades informativas, comerciales, turísticas y amistosas con la República Popular China nos muestran elementos y situaciones que inciden en el limitado progreso en la actividad comercial y cultural entre ambos países. El análisis profundo de esa experiencia contribuirá al sano fomento e incremento de estas relaciones comerciales y culturales.

Posiblemente la lejanía y un insuficiente conocimiento actualizado de ambos países, ha obligado a llevar una relación con cautela que no ha permitido detonar el potencial que se encuentra latente. Por lo anterior, con el fin de buscar la manera idónea de hacerlo, me parece impostergable desarrollar un proyecto comunicacional e informativo profesional, cuyo enfoque y finalidad sea la de promover esa relación cultural y comercial vigorosa que corresponda a su verdadero potencial. El turismo sería un excelente instrumento también.

Sabemos que el desarrollo económico de China tiene un progreso constante e irreversible, que su pueblo y gobierno han demostrado su determinación de avanzar en la consecución de sus metas de crecimiento. También conocemos su voluntad de incrementar su conocimiento, amistad y relaciones con nuestro país.

Sin embargo, estamos conscientes de que en México existen opiniones negativas sobre los productos chinos. En ocasiones, debido a su competencia con similares productos mexicanos y, en otras, por desinformación o cuestionamiento de su calidad. Por ello, con imaginación hay que buscar los caminos que nos acerquen y faciliten la derrota de los factores que nos pudieran alejar.

Estas circunstancias no deben dejarse a la deriva, a su solución accidental, requieren de un plan de trabajo profesional que nos lleve por un camino trazado con objetivos concretos, productivos y medibles. 
Ya el Centro de Estudios China-México de la Facultad de Economía en la Universidad Autónoma de México muy atinadamente ha dado un gran paso académico en esta tarea.

La creación del "Sistema logístico para el monitoreo de las relaciones bilaterales comerciales entre la República Popular China y los Estados Unidos Mexicanos" aportará los elementos que permitan mejorar la idea que muchos tienen de esta relación bilateral para transformar, con nueva perspectiva, la solidez de las futuras actividades culturales y comerciales.

Así, a 40 años de relaciones diplomáticas podemos observar con beneplácito los logros alcanzados, que aunque insuficientes, pueden transformarse e incrementarse porque nos han brindado la experiencia para trazar un provechoso camino a recorrer. Como dirían en China: larga vida a las relaciones entre México y China 



\section{Culturas, encuentro, sí; confrontación, no}

Wu Yongheng

Hoy día es un hecho irreversible que la humanidad vive en un mundo cada vez más globalizado y el planeta donde vivimos tiende a ser una aldea de la Tierra.

En el año 1993, el ahora difunto profesor haveriano Samuel Huntington dio a luz su libro de The Clash of Civilizations (La Confrontación entre Civilizaciones). A pesar de algunas afirmaciones en el sentido de que el incidente del 11 de septiembre, ocurrido en el año 2001 haya corroborado la aseveración del profesor, la tesis sigue siendo polémica y controvertida.

En China, la mayoría de los eruditos y académicos difieren con el criterio de "clash" y abogan por el intercambio, el encuentro, la armonía y la integridad entre diversas civilizaciones, pues desde tiempos antiguos la filosofía china preconiza la integridad del ser humano con la naturaleza y propugna siempre por la armonía y paz.

La civilización es la manifestación de las riquezas espirituales de las naciones o grupos étnicos. La historia de la civilización china en sí es un largo proceso de mezcla, fusión, integración y desarrollo conjunto de diferentes civilizaciones que comparten el mismo hábitat. La civilización mexicana se forjó de la misma manera tal como testimonia la plaza de las Tres Culturas de Tlatelolco, sin hablar de más ejemplos y sin necesidad de entrar en detalles.

La cultura es una de las interpretaciones más importantes de la civilización y un puente más accesible para enlazar diferentes civilizaciones, en particular para China y México, ambas igualmente orgullosas de su historia, etnicidad, idiosincrasia, tradición y estilo de vida.

De acuerdo con Arturo Oropeza, China y México han tenido tres encuentros históricos. Primero en el siglo XVI, con el arribo del Galeón San Pablo a las costas de Acapulco. La famosa Nao China simboliza el primer encuentro de las dos culturas. El Tratado de Amistad, Comercial y Navegación suscrito entre ambos gobiernos en 1899 constituye algo emblemático del segundo encuentro entre las dos naciones, ya de carácter oficial. El 14 de febrero de 1972, fecha en que China y México establecieron relaciones diplomáticas marcó un hito significativo en los anales de la historia de los dos países.

A raíz del establecimiento de las relaciones diplomáticas, los lazos entre los dos países se vienen estrechando en los más amplios campos. Si bien es cierto que ambos países difieren en la ideología, sistema social, modelo de desarrollo y política, han tenido problemas en el área de comercio. No es menos cierto que la cultura siempre ha sido el sector de mayor identidad y coincidencia.

En América Latina, México lleva la delantera en el intercambio cultural con China. Sólo en el último lustro, se llevaron a cabo importantes eventos culturales y artísticos en ambos países. En 2006, México fue el país invitado en el Festival Artístico de Beijing y en 2007 China fue el país invitado del Festival Cervantino en Guadalajara, México. En 
el mismo año de 2007, entre julio y agosto, se realizaron actividades culturales "Experimentando China en México" en diversas ciudades mexicanas.

La cultura constituye un reflejo del nivel de civilización de un país y de una nación. Para China la cultura significa una palanca preponderante para empujar la economía.

En el año 2010, el valor de producción cultural alcanzó al nivel de un billón cien mil millones de yuanes, aproximadamente unos 1750 mil millones de dólares y equivalente a $2.75 \%$ del valor total del producto interno bruto del año.

Los medios informativos son los mejores vehículos y transmisores de cultura. La presencia de los medios informativos más influyentes de China en México constituye un testimonio de la importancia e interés que tienen tanto el gobierno como el pueblo chinos. Entre los medios chinos acreditados en México figuran la Agencia de Noticias Xinhua, el Diario del Pueblo, la Revista China Hoy, la Radio Internacional, la Central de Televisión de China, el Diario Wenhui y la Televisión Fénix.

Los medios informativos cumplen su función profesional en beneficio de la promoción de la comprensión y entendimiento de los dos pueblos. Citando el ejemplo de la Revista China Hoy, que desde el año 2004 se edita y distribuye en México, se puede decir que es una ventana por la cual los lectores pueden conocer China sin visitarla en el sentido de que la publicación presenta un panorama global del país oriental sobre su desarrollo económico, su progreso social, sus vínculos con otros países, en particular con las naciones hispanoamericanas, además de su cultura, historia y tradiciones. Hoy día la palomita, figura del logo de la revista, vuela a lo largo y a lo ancho del país azteca llevando el mensaje de amistad del pueblo chino a miles y miles de familias mexicanas.

En este aspecto, cabe meditar sobre el papel que debe y puede jugar el periodismo. “Libertad es el derecho que todo hombre tiene a ser honrado a pensar y hablar sin hipocresía. Si un hombre oculta lo que piensa o no se atreve a decir lo que piensa no es un hombre honrado." Eso que dijo el apóstol cubano José Martí debería ser una de las bases de la ética profesional de quienes ejercen el periodismo.

El periodismo desde que surgió debería estar al servicio de la sociedad, particularmente al servicio de la mayoría de personas que integran la comunidad social. Debería ser un medio masivo de comunicación social multilateral, y en este sentido no un sencillo vehículo de divulgación unilateral de pregones oficiales y mucho menos una imposición de hacer escuchar lo que los grupos poderosos quieran que sepan.

El derecho de expresión no debe ser una exclusividad de los que gobiernan ni tampoco un privilegio de quienes mucho tienen, o sea de los grupos de poder y grupos de interés. Los que menos tienen, que en muchos casos forman las mayoría de las masas humanas en los países de este mundo, también tienen su derecho a la palabra, su derecho a ser escuchados.

Por eso es menester que quienes practican la profesión periodística siempre tengan presente su deber social de que el clamor de los que menos tienen en esta sociedad desigual sea escuchado.

La objetividad es la línea vital del periodismo. Ésta siempre es la primera frase que digo en el aula al asistir a mi primera clase. Lamentablemente "del dicho al hecho hay un mucho trecho". Se puede afirmar que en cierto sentido tanto para China como para México, las relaciones bilaterales de nuestros dos países han sido y siguen siendo víctimas del mal uso de la lengua. 
El desarrollo de unas buenas relaciones, no sólo entre China y México, sino entre los países en general, no es de exclusiva responsabilidad de los gobiernos, tampoco debe limitarse a las actividades en los campos económico y comerciales. Para que esas relaciones se desenvuelvan sobre una base sólida y sustentable, no puede faltar la aportación de los medios informativos. Sin un ambiente mediático sano y saludable, las relaciones bilaterales difícilmente se puede mantener mucho menos lograr un desarrollo sostenible y durable. Si no, todos los esfuerzos, por más sinceros que sean, serán erosionados, que harán a muchos exclamar como el Libertador de las Américas, Simón Bolívar: "arar en el mar".

No existe la menor idea de poner en duda las intenciones de aquellos periodistas mexicanos de distorsionar la verdad y como consecuencia hacer confundir a los receptores.

Se recuerda que en la primavera del año recién pasado, cuando empezó a aflorar la ola de convulsiones sociales en Medio Oriente y Norte de África, ciertos sectores de Occidente comenzaron a agitar el ambiente y en su vana ilusión esperaban que China fuera azotada por una supuesta "Revolución Jazmín". Una noche, conversando sobre el tema, el entrevistado, un especialista le decía a la presentadora que en todas las páginas cibernéticas de China ya se eliminó la palabra "Jazmín". Y la presentadora ingenuamente exclamó "censura". No se sabe si el especialista conoce caracteres chinos y si de veras buscó en alguna página la palabra "Jazmín". El efecto fue sensacional. No obstante, para quien en el mismo instante buscó la palabra "jazmín" y la encontró, obtuvo un resultado ridículo y pueril.

Otro ejemplo fue una aseveración de un periódico mexicano que citando a su corresponsal acreditado en Beijing acusaba a China de "la dictadura más sofisticada y mejor engranada del planeta".

Hubo tiempos en que los medios locales se inundaron de informaciones negativas sobre China. Es cierto que de estas informaciones que tergiversan y distorsionan la verdad muy pocas son originales de la prensa mexicana, sino importadas con o sin respetar el copy right. De los autores de estas informaciones desagradables, no se debe pensar que lo hacían con la intención de ridiculizar, ultrajar y humillar a otro pueblo o nación.

Un refrán chino decía que el primer perro que ladra es por haber sido alertado por una sombra vana, los otros cien perros ladran por haber oído el ladrido del primero. Este fenómeno es difícil de evitar en las circunstancias en que los medios informativos están controlados y manipulados por los grandes grupos de interés del Occidente y la independencia informativa de los países en vías de desarrollo todavía es una meta por alcanzar.

El hecho es que existe una batuta invisible que tiene el poder mágico de hacer unificar las voces cuando sea necesario hacer un coro contra algún objetivo. Entonces no es nada extraño que en un país supuestamente amistoso la prensa suele prestase a juntar esfuerzos por satanizar a otro país hermano como China.

Obviamente, sin investigar o averiguar la veracidad del hecho, al hacer ampliar el eco de lo que vocifera otro, está cometiendo involuntariamente una falta a la ética profesional. Y la divulgación irresponsable de informaciones falsas constituyen en sí una falta de respeto a los receptores. 
La aplicación cada vez más generalizada del celular, de internet, así como de blogs y twitter, por una parte concede acceso más fácil y expedito a las informaciones, y por la otra, corre el riesgo de hacerlas más vulnerables al manejo irresponsable. Dentro del proceso acelerado de globalización, la universalización del uso de estos medios sofisticados ofrece mayor oportunidad y facilidad de intercambio entre la gente y al mismo tiempo ha de acarrear choques de ideas y culturas.

En este sentido, los medios informativos de ambos países tienen toda la razón para ser mensajeros y embajadores culturales y unir esfuerzos para dar a otros países y pueblos un ejemplo de cómo dos culturas milenarias se encuentran, en tiempos modernos, de entendimiento, armonía y amistad. 
Sección 4:

Aprendizaje del Chino 



\title{
Enseñanza del idioma chino. La experiencia de la Universidad Nacional Autónoma de México
}

\author{
Jenny Acosta Trujillo
}

\section{Antecedentes}

En el CELE de la UNAM se ha impartido el idioma chino en las cuatro habilidades desde el año 1979 a la fecha. Desde entonces se ha contado con la colaboración de profesores invitados del gobierno chino, la mayoría de la Universidad de Beijing de Lengua y Cultura.

Al mismo tiempo, el CELE ha sido sede de la organización de la aplicación del Examen HSK y de la preselección del Puente Chino.

A la fecha podemos nombrar una gran cantidad de instituciones que también imparten chino como el Colegio de México, la FES Acatlán, la UAM, los institutos Confucio en Chihuahua, Nuevo León, Yucatán y en la Ciudad de México.

\section{Examen HSK}

El año 2003 se firmó el convenio entre la Oficina Nacional de Enseñanza del Idioma Chino como Lenguas Extranjeras (HANBAN) y la UNAM, y se ha aplicado el examen HSK, examen oficial de certificación del idioma chino a partir de 2004. El CELE fue el único centro certificador en América Latina hasta 2008, cuenta con participaciones de alumnos de Mexico, Brasil y Perú. A la fecha se hace el examen dos veces por año.

\section{Instituto Confucio}

El Instituto Confucio es un organismo público no lucrativo que tiene como objetivo fundamental la divulgación de la lengua y cultura chinas en diversos países del mundo.

El Instituto Confucio de la Universidad Nacional Autónoma de México pertenece al Centro de Enseñanza de Lenguas Extranjeras, institución reconocida a nivel internacional en la enseñanza de lenguas y en la formación de profesores de idiomas. También está respaldado por la Universidad de Lengua y Cultura de Beijing, una de las mejores universidades en la enseñanza del idioma chino a extranjeros.

El objetivo principal del Instituto Confucio, como ya se comentó, es difundir el idioma y la cultura de China, así como intensificar la cooperación en materia educativa y fortalecer la comprensión mutua y la amistad entre los dos pueblos.

Dado el respaldo de estas instituciones, el Instituto Confucio de la UNAM, cuida el nivel y la calidad de la enseñanza del idioma y la difusión de la cultura china. Otro de los objetivos es preparar a profesores locales de chino para satisfacer la demanda que 
tiene México de profesores y especialistas en traducción, ya que prácticamente no hay traductores y los profesores son muy pocos.

\section{Historia}

El Instituto Confucio es una idea de Hanban, institución no gubernamental con plena personalidad jurídica bajo el auspicio directo del Ministerio de Educación de China. Se dedica a ofrecer materiales y servicios de enseñanza del idioma y la cultura china para contribuir al desarrollo de una cultura multilateral y un mundo armónico.

El Instituto Confucio en la UNAM quedó establecido en la Antigua Escuela de Economía, una de las sedes externas del CELE.

La directora general de Hanban, Xu Lin, visitó las instalaciones de la Antigua Escuela de Economía de la UNAM para conocer el lugar donde se instalaría el Instituto Confucio de la UNAM. El 22 de noviembre de 2006 se firmó el convenio de colaboración entre Hanban y la UNAM.

Dado que se tienen relaciones de más de 20 años con la Universidad de Lengua y Cultura de Beijing (BLCU), ya que en el CELE se han recibido profesores de esta universidad en los últimos años, se propuso a esta misma universidad para establecer el convenio de colaboración académica.

María Eugenia Herrera Lima, en ese entonces directora del CELE, realizó una visita a dicha universidad en agosto de 2007, en la que se realizaron reuniones de trabajo que resultaron favorables para la colaboración de ambas universidades. En octubre se recibió una propuesta del convenio de colaboración con la BLCU, la cual fue revisada de acuerdo a la normatividad de la UNAM, y en diciembre se les hizo llegar la contrapropuesta, que a la fecha cuenta con la autorización de la $\mathrm{OCl}$ para dicho convenio.

El tres de marzo de 2008 se iniciaron los cursos del primer nivel del idioma chino con dos grupos; se atendió a un total de 30 alumnos. Para finales de 2008 se programó la visita a la UNAM de los representantes de la Universidad de Lengua y Cultura de Beijing. El 12 de noviembre de ese año se inauguró el Instituto Confucio en la UNAM y para enero de 2009 se comenzó a trabajar con las dos directoras del Instituto Confucio, Jenny Acosta Trujillo, como directora por la parte de México y Meng Aiqun, como directora por la parte de China.

Durante el primer aniversario del Instituto Confucio en la UNAM, en noviembre de 2009, se llevó a cabo la primera reunión del Consejo Directivo del Instituto Confucio en la UNAM, en la que se designó a los miembros que formarían parte de este consejo, en el que quedaron tres miembros por la parte de China y 4 miembros por la parte de México.

\section{Enseñanza}

Se imparten tres cursos trimestrales por año, cada trimestre es un nivel y en cada nivel se imparten 70 horas de clase. Se cursa un total de 10 niveles en el Instituto; cuando 
los estudiantes los concluyen se les entrega una constancia que avala el conocimiento adquirido en éstos, a partir de ello pueden presentar una certificación de nivel HSK 3 o B1+. Además se ofreden cursos de fonética y caligrafía china, con clases de lunes a domingo en horarios disponibles de lunes a viernes de 7:00 a 20:00 horas; fines de semana: sábados de 8:00 a 13:30 horas y de 14:00 a 19:30 horas, domingos 8:00 a 13:30 horas. En el CELE se imparten clases semestrales de ocho horas a la semana, sólo de lunes a viernes.

\section{Crecimiento}

\section{Crecimiento de la población de estudiantes de chino}

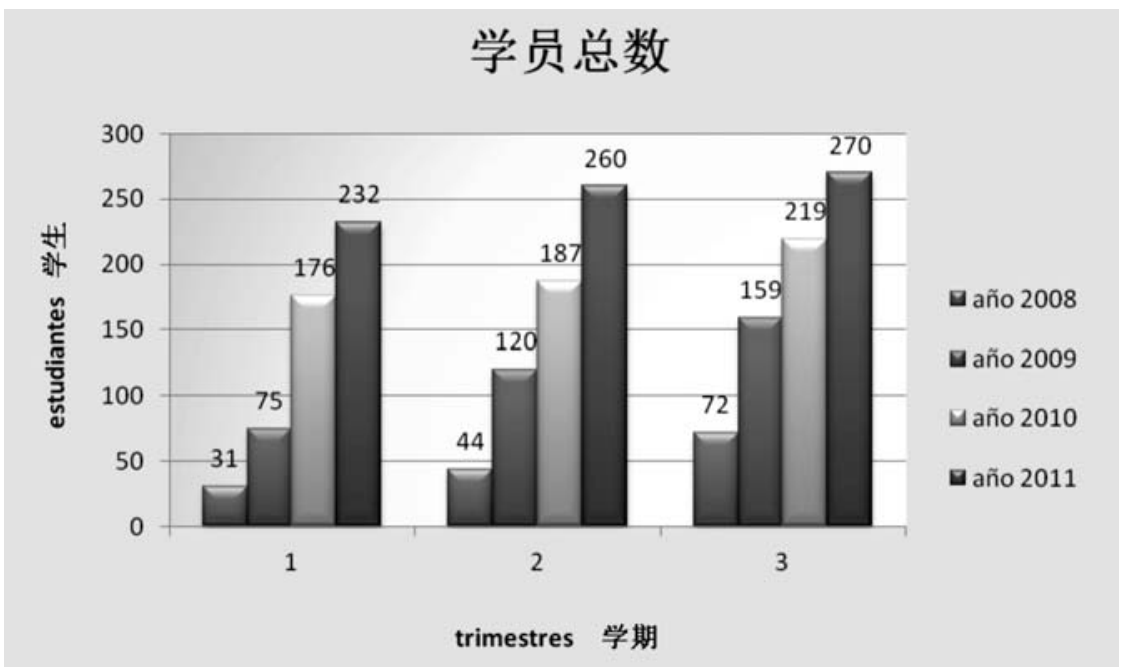

Total de alumnos en $2008=147$

Total de alumnos en $2009=354$

Total de alumnos $2010=582$

Total de alumnos en $2011=762$

En el CELE de la UNAM se tiene un promedio de 260 alumnos de chino por semestre, lo que hace un total de 520 alumnos de chino al año. En este último trimestre el Instituto Confucio de la UNAM abrió un curso de primer nivel en la Secretaría de Relaciones Exteriores y apoyó dos grupos de primer nivel en las sedes externas de Tlalpan y Coapa. 


\section{Actividades}

Las actividades culturales son muy importantes para la difusión de la cultura; en 2009 se realizaron las siguientes:

1. Primer Encuentro Cultural Chino Cele-Instituto Confucio de la UNAM, en este primer encuentro contamos con la participación de varios estudiantes del idioma, quienes demostraron sus conocimientos de la cultura y el idioma chino mandarín.

2. Exposición Fotográfica del Tíbet, representada con más de 30 imágenes.

3. Segundo Encuentro Nacional de los Institutos Confucio de México. El 17 de julio de 2009 tuvimos la presencia de los representantes de los Institutos Confucio de: Nuevo León, Yucatán, Chihuahua y el de la UNAM.

4. Primer Curso de Formación de Profesores de Chino en México. Comenzó el 20 de julio de 2009, fue impartido por profesores enviados de la Universidad de Lengua y Cultura de Beijing, además se contó con aproximadamente 40 profesores que tomaron dicho curso.

5. Selección de becarios para estudiar en China ( 1 becario de un año de idioma, el primer becario del Instituto Confucio en la UNAM enviado a China por parte de la Universidad de Lengua y Cultura de Beijing).

6. Ciclo de Videoconferencias divididas de la siguiente manera:

- Relaciones China-México

- Educación y becas en China

- Economía y comercio de China con México

- Medicina tradicional China

En esta ocasión tuvimos enlace vía internet con los Institutos Confucio de Chihuahua, Nuevo León y Yucatán y contamos con la presencia física de más de 150 alumnos en estas videoconferencias.

7. Proyección del Desfile del 60 Aniversario de la Fundación de la República Popular China; se tuvo la oportunidad de contar con más de 100 alumnos que presenciaron esta proyección.

8. Participación en el Festejo de la Nao en Acapulco, con conferencias sobre el idioma chino; las profesoras Meng Aiqun y Jenny Acosta hablaron de la cultura y el idioma chinos.

9. Exposición Fotográfica sobre el desarrollo de China en los últimos 60 años; esta es una de las actividades que atrae el interés de los alumnos al idioma chino mandarín, por lo que se procura que sea abierto al público para promover un conocimiento amplio de la cultura.

10. Participación en la Celebración por el Día Nacional y el Día de la Luna; nuestros profesores participaron con un baile tibetano, propio de una de las etnias chinas.

11. Celebración del primer aniversario del Instituto Confucio de la UNAM, mediante una amplia invitación a alumnos, profesores y público en general que estuviese interesado en conocer un poco más de la cultura china. 
12. Exposición de libros (más de 300 títulos).

13. Participación en el $4^{\circ}$ Congreso Mundial de Institutos Confucio en Beijing, China, presidida por Magdalena Martínez Martínez, coordinadora de Centros y Programas Externos del CELE de la UNAM; Jenny Acosta Trujillo, directora mexicana del Instituto Confucio de la UNAM, y Meng Aiqun, directora china del Instituto Confucio de la UNAM.

\section{En 2010}

1. El desfile del Año Nuevo Chino el 13 de febrero. Se participó con el baile de la cultura china, ejecutado por alumnos y profesores, y un desfile de trajes típicos de algunas de las diferentes etnias.

2. Presentación artística de cantos y bailes de China el 7 de marzo; ésta fue la primera gira artística china por parte del Instituto Confucio.

3. Concurso "Puente Chino" el 12 de mayo. Contamos con la participación de varios alumnos que demostraron el conocimiento adquirido sobre la cultura y el idioma chino.

4. Segundo curso de formación de profesores de chino en México, del 20 al 29 de julio; se contó con 40 profesores.

5. Participación en el $2^{\circ}$ Congreso Iberoamericano de Institutos Confucio en Chile; asistieron Magdalena Martínez Martínez, coordinadora de Centros y Programas Externos del CELE de la UNAM, y Jenny Acosta Trujillo, directora china.

6. Conferencia: "Malentendidos entre la cultura china y mexicana" el 11 de agosto.

7. Conferencia dictada por expertos en estudios tibetanos.

8. Conferencia de "Pintura China" el 28 de septiembre; se contó con la presencia de la delegación china.

9. Breve exposición de fotos de algunas etnias de China, el 25 de octubre.

10. Selección de becarios del Instituto Confucio en la UNAM para estudiar en China (tres becarios de un año de idioma); becas otorgadas por la Universidad de Lengua y Cultura de Beijing.

11. Conferencia "Caracteres, el arte de la escritura china" el 28 de octubre. La finalidad de esta conferencia fue dar a conocer de una manera detallada la escritura de los caracteres chinos.

12. Segundo Aniversario del Instituto Confucio en la UNAM, en esta ocasión pudimos contar con más de 200 personas que asistieron al evento, el cual fue desarrollado coordinadamente por las directoras del Instituto Confucio en la UNAM, profesores, alumnos y personal administrativo.

13. Participación en el $5^{\circ}$ Congreso Mundial de Institutos Confucio en Beijing, China, en donde se presentó la ponencia por parte de Jenny Acosta Trujillo, directora mexicana del Instituto Confucio en la UNAM, en compañía de Magdalena Martínez Martínez, coordinadora de Centros y Programas Externos del CELE de la UNAM, así como de Meng Aiqun, directora china del Instituto Confucio en la UNAM. 


\section{En 2011}

1. Organización de la segunda gira artística de China en México. 26, 27, 28 de febrero CUC, Centro Cultural Ollin Yoliztli, Facultad de Arquitectura y 2 de marzo IPN.

2. Participación en la reunión anual de Institutos Confucio de México, el 14 de marzo en Huaxia.

3. Participación en el comité de la selección de candidatos para becas a China de la Secretaría de Relaciones Exteriores, el 18 de marzo de 2011.

4. Organización del $10^{\circ}$ Concurso Universitario de Puente Chino, eliminatoria regional, México. 12 de mayo de 2011 en el CELE.

5. Apoyo al CELE en examen de certificación de idioma chino HSK el 20 de mayo de 2011.

6. Selección de becarios del Instituto Confucio en la UNAM para estudiar en China ( 6 becarios de un año de idioma y 2 de maestría en Enseñanza Internacional del Idioma Chino) por parte de la Universidad de Lengua y Cultura de Beijing.

7. Inauguración de la Biblioteca del Instituto Confucio, 3 de junio de 2011. Contó con la presencia de Zeng Gang, embajador chino en México; Ding Wenlin, primer secretario de Educación de la Embajada de China en México; Estela Morales Campos, coordinadora de Humanidades de la Universidad Nacional Autónoma de México, y Alina Signoret Dorcasberro, directora del Centro de Enseñanza de Lenguas Extranjeras de la UNAM. La directora del Instituto Confucio en la UNAM, Jenny Acosta Trujillo, presidió la ceremonia de inauguración en la que el embajador chino destacó que la biblioteca "será vital en la enseñanza del idioma chino para los mexicanos, ya que permitirá que conozcan más a fondo la cultura china".

8. El Instituto Confucio de la UNAM apoyó con profesores como jurado en el concurso juvenil de Puente Chino, el 4 de junio, en la escuela Huaxia.

9. Participación en el Tercer Congreso Iberoamericano de Institutos Confucio. Del 20 al 23 de junio, en Argentina.

10. Conferencia sobre la "Experiencia de estudiar en China", en la UAM Cuajimalpa, octubre 4.

11. 3er. Aniversario del Instituto Confucio de la UNAM, en esta ocasión se tuvo la participación de aproximadamente $80 \%$ de los alumnos del Instituto Confucio con cantos, bailes y la presencia de 250 espectadores.

12. Participación en la organización del Foro Educativo UNAM-China.

13. Presentación del DVD “Uso del Diccionario en Chino" en el CELE de la UNAM, con apoyo del área de producción del CELE de la UNAM y de algunos alumnos.

El Instituto Confucio de la UNAM participa activamente con el CELE de la UNAM en las actividades relacionadas con la enseñanza del idioma chino. Asimismo asesora a escuelas que piensan abrir cursos de idioma chino y apoya a la Embajada de China en México en diversas actividades culturales. 


\section{Actualización de profesores}

Los profesores del Instituto Confucio participan en talleres y cursos impartidos en el CELE de la UNAM para su continua actualización profesional. Este año profesores del Instituto participaron en los siguientes:

- Taller: Estrategias de enseñanza en el aula. Organizada por el Departamento de Lenguas Asiáticas, en el CELE, 2 horas, 8 de abril de 2011.

- Curso: Diseño Curricular y Evaluación, Organizador Centros y Programas, en el CELE, del 16 al 19 de mayo de 2011. 16 horas.

Además de estos cursos en 2009 y en 2010 se organizaron cursos de verano de formación de profesores de chino, con el apoyo de la Universidad de Lengua y Cultura de Beijing, a los que asistieron 90 profesores, de los cuales 39 lograron obtener su diploma y acreditación avalada por HANBAN como profesor de chino. Cabe destacar que todos los profesores mexicanos que trabajan en el Instituto Confucio en la UNAM han acreditado el examen de este curso.

\section{Congresos}

Como ya se mencionó en las actividades, el Instituto Confucio en la UNAM ha participado todos los años en los congresos mundiales organizados por HANBAN, compartiendo en conferencias la experiencia en formación de profesores; asimismo ha participado en los últimos congresos de lberoamérica de institutos Confucio, en donde se han intercambiado ideas y experiencias con otros institutos Confucio.

\section{Convenios}

Este año se estableció un convenio de colaboración con el Instituto Matías Romero para impartir clases de chino. Las clases iniciaron el 7 de julio y terminan el 10 de noviembre de 2011. Dicho curso continuará en el siguiente año.

\section{Programas y materiales}

Actualmente el instituto se encuentra en el proceso de la elaboración y pilotaje de planes y programas.

De acuerdo al plan de desarrollo institucional 2009-2013 del Centro de Lenguas Extranjeras (CELE) de la Universidad Nacional Autónoma de México (UNAM), es indispensable la creación de planes y programas de estudio de chino mandarín, los cuales pretenden brindar al profesorado una guía en la cual se encontrarán las herramientas 
necesarias para la adecuada enseñanza del idioma chino de acuerdo con las necesidades de la comunidad estudiantil universitaria y el público en general.

Para tal efecto, el proyecto se llevará a cabo en diferentes etapas: diseño y aplicación de encuestas, recolección e interpretación de resultados, creación de planes y programas, comprobación y reporte final.

Como primera etapa del proyecto se realizaron encuestas a los estudiantes de idioma chino en el Instituto Confucio de la UNAM, así como en las sedes externas del CELE. De esta manera se pudieron conocer las necesidades específicas del alumnado en torno a las clases actualmente impartidas.

De acuerdo con los resultados obtenidos de dichas encuestas se procedió a la realización de los programas que abarcarán 10 niveles, cada uno de los cuales tendrá una duración de 3 meses y 70 horas de clase. De esta manera se planea que al término de cada 3 niveles los estudiantes podrán presentar la certificación HSK avalada por la Oficina para la Enseñanza del Idioma Chino en el Extranjero (HANBAN), de acuerdo cob los siguientes niveles:

\begin{tabular}{|l|l|l|l|l|l|l|l|l|l|l|}
\hline Idioma & 3Módulos (70 horas) \\
\hline Chino & 1 & 2 & 3 & 4 & 5 & 6 & 7 & 8 & 9 & 10 \\
\hline MCRE & & & A1 & & & A2 & & & B1 & B1+ \\
\hline Certificación & & & HSK 1 & & & HSK 2 & & & HSK 3 & \\
\hline
\end{tabular}

Cada módulo es un nivel y en cada nivel se ven diferentes unidades. En los niveles 1 y 2 se estudian 8 unidades en cada uno, en los niveles 3 y 4 se estudian 7 unidades y en el resto de los niveles se estudian 6 unidades por nivel.

El eje principal son las competencias pragmáticas, lingüísticas y socioculturales, el eje de apoyo son las habilidades y el eje transversal es actitudinal.

Hasta el momento se tienen terminados los tres primeros niveles y se encuentran en la fase de pilotaje con gran éxito, ya que todos los alumnos de $6^{\circ}$ nivel que presentaron el examen de certificación HSK 2 obtuvieron su certificación.

Con respecto a los programas se tomó como referencia "International Curriculum for Chinese Language Education" editado por HANBAN (Oficina Nacional de Promoción Internacional de la Lengua China). Además, para este programa se usaron herramientas como cuestionarios para alumnos y profesores, aplicados en los trimestres 2010-III y 2011-I, con preguntas abiertas y cerradas referentes a: Datos personales, expectativas y estrategias de enseñanza-aprendizaje.

La colaboración de los profesores enviados por la Universidad de Lengua y Cultura de Beijing y los profesores mexicanos de chino fue de gran importancia para este proyecto.

El material didáctico consta de dos DVD para el uso del diccionario en chino y contará con manual de ejercicios. Este año se ha terminado el primer DVD. 


\section{Resultados}

Es importante resaltar que las metas que se plantearon para el año 2012 ya se han cumplido, ya que el Instituto Confucio de la UNAM es reconocido como el mejor instituto de México y en el año 2010 recibió el premio “The 2010 Confucius Institute Individual Performance Excellence Award".

Además del crecimiento que ha tenido en cuanto al número de inscritos, con más de 600 alumnos por año, se ha destacado por ser el primer instituto que ha ofrecido cursos para profesores locales de chino, formando a cerca de 40 profesores que lograron obtener su certificación avalada por HANBAN (Oficina Nacional de Promoción Internacional de Chino).

Actualmente hay 2 profesores en la Universidad de Lengua y Cultura de Beijing que cursan la maestría de "Enseñanza del Idioma Chino".

\section{Plan de desarrollo}

Como institución comprometida con la sociedad, la UNAM tiene como propósito central el fortalecimiento de las capacidades que permitan mantener el liderazgo de la institución en la educación superior del país, mediante la formación de profesionales, científicos, tecnólogos, humanistas y artistas del más alto nivel, y la generación, transmisión, difusión, uso y transferencia del conocimiento vinculado con las necesidades y los problemas fundamentales de la sociedad mexicana.

La realización de las acciones que se proponen requiere de la participación de escuelas, facultades, centros, institutos, dependencias académico-administrativas, de los cuerpos colegiados, así como de los alumnos, académicos y trabajadores administrativos de la UNAM.

Dentro de la UNAM, el Centro de Enseñanza de Lenguas Extranjeras tiene como misión desarrollar e impulsar la enseñanza y el aprendizaje de lenguas extranjeras en diferentes modalidades; la certificación, la formación y actualización de recursos humanos; la investigación en lingüística aplicada y la extensión y difusión de estos servicios de calidad a la sociedad mexicana en general y a la comunidad de la UNAM en particular, para lograr su desempeño académico, laboral y profesional.

El Instituto Confucio en la UNAM se rige por estos mismos principios y su labor es la enseñanza y difusión de la cultura y todos aquellos aspectos relacionados con el idioma. Por esto el plan de desarrollo consiste en:

\section{Formación y actualización de profesores}

Para formar profesores locales es necesario tener un curso bien estructurado con base en las necesidades específicas para poder satisfacer la demanda de nuestros estudiantes mexicanos. 
Este curso estará formado por especialistas tanto chinos como mexicanos y tendrán materias de tronco común, además de las clases optativas y especializadas. Este curso tendrá una duración de un año, con 20 horas de clase por semana.

También se tendrán de forma simultánea el curso de actualización para profesores en México, en donde se invitará a especialistas de China para impartir los cursos enfocados a problemas específicos en la enseñanza, además de clases sobre cultura como danza china, manualidades chinas (papel picado, nudos chinos) pintura y caligrafía.

Todos estos cursos se realizarán con el apoyo de la Universidad de Lengua y Cultura de Beijing, que es nuestra universidad hermana y que tiene la mayor experiencia en la enseñanza de chino para extranjeros.

Además de estos cursos se enviarán profesores a BLCU para que tomen cursos de actualización en el verano y cursos para profesores que deseen hacer estudios de posgrado en la misma universidad.

Elevar el nivel de nuestros profesores es esencial para el desarrollo del Instituto Confucio en la UNAM, ya que todos sabemos que "buenos profesores hacen buenos alumnos".

\section{Docencia}

Se prevé el diseño completo de los planes y programas del Instituto Confucio en la UNAM de acuerdo con el International Curriculum for Chinese Language Education y enfocado a las necesidades de la población mexicana que se atiende.

Igualmente se considera el desarrollo de cursos de chino para negocios, conversación, fonética, caracteres y de las cuatro habilidades para facultades de la UNAM, como Economía, Filosofía y Letras y cursos para diplomáticos.

Se consolidará el uso de tecnologías, laboratorio y cursos de apoyo en línea, como herramientas en el aprendizaje del idioma.

Se obtendrá la evaluación y certificación HSK.

\section{Investigación}

Líneas de investigación enfocadas a la docencia y otras áreas del chino.

\section{Difusión}

El propósito es llegar a más personas interesadas en el idioma y la cultura, con eventos de interés para el público en general, como las giras artísticas, exposiciones fotográficas, conferencias y festivales que despierten el interés de la población mexicana y que afiance a los estudiantes del idioma.

Con este plan esperamos colocarnos como una de las mejores instituciones para formar profesores calificados y especialistas en chino.

Hay mucho trabajo por hacer, por lo que considero que es indispensable unir esfuerzos para continuar con esta gran labor. 


\section{La enseñanza del chino en México: qué, cómo y para qué}

Liljana Arsovska

\section{Antecedentes y situación actual}

China y México cumplen 40 años de haber establecido relaciones diplomáticas. Durante todos estos años, dos instituciones de excelencia en México se han destacado por sus esfuerzos de acercar a México y China: El Colegio de México con su Centro de Estudios de Asia y África y la Universidad Nacional Autónoma de México con su Centro de Enseñanza de Lenguas Extranjeras donde por más de 30 años se ha impartido la enseñanza del chino.

A China y México los separan una gran distancia geográfica y sobre todo importantes diferencias históricas y culturales. La Nao de China que por más de 250 años (desde la mitad del siglo XVI hasta los finales del siglo XVII) llegaba puntualmente desde Manila a Acapulco además de traer muchos productos de China y de Asia en general, trajo las primeras comunidades de chinos a México, tendiendo así un primer puente de acercamiento e intercambio. La plata mexicana, llevada por la Nao, durante muchos años fue moneda circulante en China.

Desde entonces han pasado más de 200 años que han traído grandes cambios en los panoramas de China y de México. Durante las décadas de los 70 y 80 del siglo XX los esfuerzos de El Colegio de México y de la UNAM de enseñar el idioma chino y preparar a estudiantes mexicanos y latinoamericanos en historia, filosofía y cuestiones de la actualidad china de alguna manera satisfacían las necesidades de las relaciones México-China; sin embargo, con la apertura y las reformas económicas de China a partir de los años 80, cuando China comenzó a jugar un rol cada vez más importante en todos los escenarios internacionales, en México se observó una importante carencia de recursos humanos y talentos con capacidad de procesar y transmitir los vertiginosos cambios de China.

China, por su lado, enfrentó a México y a Hispanoamérica bastante bien preparada, pues en los finales de los 70 y en los inicios de la década de los 80, muchos chinos que en la actualidad son embajadores, consejeros, académicos y empresarios, fueron formados en El Colegio de México. Su dominio del español y sus conocimientos sobre la historia, la cultura y el presente de Hispanoamérica representaron una importante ventaja en sus relaciones con nosotros. Mucho antes de abrir sus puertas al mundo, visionariamente, más de veinte instituciones académicas importantes de China tenían licenciaturas en español y literatura hispana, donde expertos españoles y latinoamericanos enseñaban lengua, historia, literatura, etcétera.

Dada la creciente importancia de China, en la última década del siglo $X X$ y sobre todo en la primera del siglo XXI, muchas instituciones públicas y privadas en México emprendieron cursos de chino, diplomados, especialidades, maestrías, doctorados y 
otras actividades académicas, encaminadas hacia la formación de recursos humanos especializados.

La enseñanza del chino, en México hoy en día es una moda y una necesidad. Para enseñar el chino se necesitan maestros y México no cuenta con el número de profesores necesarios para satisfacer la creciente demanda. Al igual que en el pasado, el Ministerio de Educación de China sigue satisfaciendo en la medida de sus posibilidades la demanda de profesores de chino en México.

En el siglo XXI en China nació el Instituto Confucio bajo el patrocinio de la Oficina de Enseñanza del Chino de la República Popular China. Esta nueva y vigorosa institución se ha esparcido por todo el mundo, abriendo un sinnúmero de institutos Confucio en muchos países. En los cinco institutos Confucio de México (dos en el Distrito Federal y uno en Chihuahua, Yucatán y Nuevo León respectivamente), maestros chinos y mexicanos trabajan conjuntamente en la enseñanza del chino. Sin embargo y a pesar de todos los esfuerzos, la demanda de aprender chino crece mucho más rápido que la oferta de enseñanza, lo cual nos obliga a redoblar los esfuerzos para mejorar la cantidad y sobre todo la calidad de la enseñanza.

\section{La calidad de la enseñanza del chino, retos y posibles soluciones}

Aunque la oferta de cursos de chino está creciendo no ocurre lo mismo con la calidad de la enseñanza, pues a pesar del tamaño de su población, China no cuenta con suficientes profesores especializados en la enseñanza del chino para extranjeros para satisfacer la demanda de todos los institutos Confucio del mundo y otras instituciones que incorporan la enseñanza del chino en sus aulas.

Por lo general, las diversas instituciones mexicanas que enseñan chino, utilizan libros de texto producidos en la República Popular China por expertos en la enseñanza del chino para extranjeros. Esos libros de texto, por lo general en inglés, son en su mayoría pensados para el estudiante extranjero que estudia chino en China. Después de las clases esos estudiantes tienen a más de mil millones de "language partners" con los cuales pueden practicar todas las tardes el vocabulario coloquial, aprendido en las mañanas. Nuestros estudiantes en México no tienen esa ventaja.

Regresando a los libros de texto, es fácil de entender que los especialistas chinos no pueden elaborar libros de texto para cada país del planeta. Es responsabilidad de nosotros, los que enseñamos chino en México, adecuar los libros de texto y los diversos materiales de enseñanza a las necesidades y a las dificultades particulares de nuestro estudiante mexicano.

El sistema fonético pin-yin, indispensable a la hora de aprender, fue hecho a partir del abecedario del inglés. Es también comprensible que los especialistas chinos no pueden elaborar un sistema fonético adaptado a cada lengua del planeta. Otra vez, es responsabilidad de nosotros acercar al pin-yin a la fonética del español para facilitar el aprendizaje de muchos sonidos y fonemas inexistentes en el castellano.

La gramática, como parte de la lingüística occidental, nació como instrumento de análisis y aprendizaje de las lenguas indoeuropeas. Aunque el chino no pertenece a esa 
familia lingüística, hoy en China y en todo el mundo se usa el esquema aristotélico de substancia-accidente (sujeto-predicado) para analizar y enseñar el chino. A pesar de varias importantes especificidades del chino (enunciados sin sujeto, la eminente polisemia de la palabra-caracter, la pronunciada homofonía, etc.), el esquema sujeto-predicado se ha aplicado con eficiencia considerable, pues muchos extranjeros hemos aprendido el chino por medio de este esquema. Sin embargo, las diferencias estructurales del chino, nos obligan a buscar constantemente nuevos métodos y técnicas que nos permitan mejorar la eficacia del proceso enseñanza-aprendizaje.

\section{Algunas características del chino}

Alrededor de la lengua china se han tejido muchos mitos, "el chino es imposible de aprender", cualquier cosa difícil "está en chino", etcétera.

Considero que la dificultad del chino reside en sus grandes diferencias con las lenguas indoeuropeas.

Walter Benjamin (Benjamin, 1994), reconocido filósofo, lingüista y crítico literario, al plantear la existencia de la "lengua pura" como el código de comunicación de Dios, demuestra claramente su visión eurocentrista para la cual el mundo empieza y termina allí donde hay un Dios único que genera el mundo y luego se separa de él. Las dicotomías Dios vs. mundo, religión vs. ciencia, materia vs. idea, sujeto vs. predicado, rigen el quehacer y el saber humano del hemisferio occidental desde sus orígenes hasta la fecha. Estas dicotomías son el tema central tanto de la religión judeocristiana como de la cultura grecorromana en su conjunto, y son ambas productos y representaciones del hemisferio occidental.

El mundo, sin embargo, tiene otro hemisferio, el oriental, cuyo representante en este trabajo es China. China no tiene a un Dios, a un creador único, que después de generar al hombre y al mundo, se separa de ellos. China en cambio desarrolló el concepto del 道 dao, un ente que genera y es generado por todas las cosas; contiene las diez mil cosas 万物 wanwu, y es contenido en ellas. Entre el 道 dao y el 天地 tiandi, universo, no hay diferencias temporales ni espaciales. El hombre 人 ren en la trilogía cielo, hombre, tierra天人地 tianrendi, es el eslabón menos perfecto. El universo 天地, en cambio, es perfecto, por ello todas las doctrinas filosóficas chinas, a lo largo de la historia, se esfuerzan en el perfeccionamiento del hombre a imagen y semejanza del universo 天 地 tiandi.

La característica principal del 道 dao es la armonía de sus componentes 阴 yin e yang, es la unión y no la lucha. A partir de 道 dao, China desarrolló sus propias doctrinas filosóficas como el daoísmo, el confucionismo, el legalismo y otras, que rigen su cosmovisión. También desarrolló sus propias religiones como la religión daoísta y la doctrina Chan Budista para explicar y llenar los vacíos que la filosofía dejó descubiertos.

En cuanto a la lengua china como instrumento de comunicación, generación y transmisión del conocimiento, según la tipología lingüística, el chino es una lengua aislante en la que predominan las palabras monosilábicas. La palabra-caracter china es unidad acabada que posee forma, sonido y significado. El significado, sin embargo, es amplio, 
impreciso y ambiguo. Sólo el lugar que ocupa la palabra en una frase o enunciado, puede determinar su significado con precisión. La palabra por ello es como dao que posee en sí muchas posibilidades.

De la naturaleza aislante del chino se derivan muchas características:

- La imprecisión de la palabra aislada

- La polisemia de la palabra

- El multifuncionalismo de la palabra

- La capacidad de generar nuevos conceptos a partir de una palabra-caracter

- El orden relativamente fijo de las palabras en el enunciado

- La importancia prominente del contexto

- La necesidad de incorporar partículas gramaticales, sin significado, que modulan y matizan el significado concreto dentro del enunciado

\section{La ambigüedad y la polisemia de la palabra-carácter}

La mayoría de los caracteres-palabra chinos poseen más de un significado en los diccionarios. Por ejemplo, la palabra 学 xué puede significar estudiar, aprender, estudio, imitar, logos, conocimiento, sabiduría, ciencia, escuela, etc., de acuerdo al lugar que ocupa en la sintaxis del enunciado chino. ${ }^{1}$

\section{El multifuncionalismo de la palabra}

El carácter-palabra, intrínsecamente multifuncional, logra su categoría gramatical y su significado concreto a partir de la posición que ocupa dentro del enunciado.

Tomemos el caso del carácter 热rè, caliente:

今天很热!

Jintiān hĕn rè.

iHoy es muy caliente!

我喜欢热!

Wö xìhuān rè.

¡A mí me gusta el calor!

你把饭热一下!

Ni bă fàn rè yĩ xià

iCalienta un poco la comida!

En el primer caso热 rè ocupa el lugar del predicado en un enunciado adjetivo por lo que 热 rè es adjetivo calificativo que significa caliente. En el segundo ejemplo ocupa el

1 http://www.chino-china.com/diccionario 
sitio del objeto directo, es sustantivo y significa calor; en el tercer ejemplo, ocupa el sitio del verbo, es verbo y significa calentar.

En otras palabras, la palabra china es ambivalente y polisémica. Para aterrizar su significado, necesita de un contexto donde ocupa un lugar fijo. Las palabras de la lengua china, debido a su monosilabismo y su peculiar representación gráfica, no dan cabida a informaciones gramaticales como categoría gramatical o función sintáctica. Según Shen Xiaolong ${ }^{2}$ (2008, p. 156), la flexibilidad del chino se basa en el aislamiento de monosilabismo; de este modo, el valor de la unidad logra consolidarse sólo dentro del contorno.

\section{Capacidad de generar nuevos significados}

El radical en el caracter compuesto es el elemento que insinúa tanto su posible significado como su campo de influencia (Arsovska). El campo de influencia puede definirse como la distancia entre la denotación y todas las posibles connotaciones de la palabra, alcanzadas a través del proceso de creación de palabras bi y polisílabas.

Ejemplos:

La palabra 学 xué a través de su campo de influencia participa en la generación de muchas nuevas palabras y conceptos. El significado de las palabras polisílabas donde aparece 学 $x u$ é, se puede deducir con relativa facilidad conociendo el significado de las monosílabas. Así tenemos:

\begin{tabular}{|l|l|l|l|}
\hline & & & \\
\hline 学习 & xuéxí & estudiar & (estudiar, practicar) \\
\hline 学生 & xuésheng & estudiante & (el estudio, nacer) \\
\hline 学校 & xuéxiòo & escuela & (escuela, escuela) \\
\hline 学会 & xuéhui & asociación & (estudio, reunión) \\
\hline 学徒 & xuétú & aprendiz & (aprender, seguidor) \\
\hline 学制 & xuézhi & sistema académico & (estudio, sistema) \\
\hline 学费 & xuéfei & colegiatura & (escuela, costo) \\
\hline 学者 & xuézhě & erudito & (el que estudia, la persona que estudia) \\
\hline 医学 & yixxué & medicina & (medicina, estudio) \\
\hline 文学 & wénxué & literatura & (estudio del lenguaje literario) \\
\hline 民族学 & mínzúxué & etnología & (etnia, estudio) \\
\hline 大学 & dàxué & universidad & (grande escuela) \\
\hline
\end{tabular}

2 http://www.confuciusinstitute.ac.uk/about/shen-xiaolong.html 


\begin{tabular}{|c|c|c|c|}
\hline 经济学 & jīngjìxué & economía & (economía, estudio) \\
\hline 生长 & shēngzhăng & crecer & (nacer, crecer) \\
\hline 生活 & shēnghuó & vida & (nacer, vivir) \\
\hline 生产 & shēngchăn & producir & (dar vida, manufacturar) \\
\hline 生病 & shēngbìng & enfermarse & (nacer, enfermedad) \\
\hline 生词 & shēngcí & vocabulario & (nuevo, desconocido, palabra) \\
\hline 生人 & shēngrén & extraño & (persona desconocida) \\
\hline 生物学 & shēngwùxué & biología & (organismo vivo, cosa viva, estudio) \\
\hline 生意 & shēngyì & comercio & (dar vida al deseo, a la idea) \\
\hline 先生 & xiānsheng & señor & (nacer primero) \\
\hline 陌生 & mòshēng & desconocido & (raro, extraño) \\
\hline 发生 & fāshēng & ocurrir & (explayar, nacer) \\
\hline 卫生 & wèishēng & salud, higiene & (preservar, proteger la vida) \\
\hline 看 & kàn & & $\begin{array}{l}\text { (significa ver, mirar) y forma un gran número de pa- } \\
\text { labras }\end{array}$ \\
\hline 好看 & hăokàn & bonito & (bueno de ver) \\
\hline 看法 & kànfă & punto de vista & (mirar, manera) \\
\hline 看病 & kànbìng & consultar (a un médico) & (mirar, enfermedad) \\
\hline 看待 & kàndài & tratar & (mirar, tratar) \\
\hline 看轻 & kànqīng & despreciar & (mirar, ligero) \\
\hline 看重 & kànzhòng & valorar & (mirar, pesado) \\
\hline 难看 & nánkàn & feo & (difícil de mirar) \\
\hline 察看 & chákàn & investigar & (examinar, mirar) \\
\hline
\end{tabular}

Éstos son sólo unos pocos ejemplos para mostrar la elasticidad del carácter-palabra. Su capacidad de generar muchos significados en el dominio de su potencialidad es enorme. Justo la ambigüedad y la polisemia del caracter-palabra permiten la generación de nuevas palabras y conceptos al enfrentarse a palabras de origen extranjero.

\begin{tabular}{|l|l|l|l|}
\hline & & & \\
\hline 网络 & red, red fina & Internet & (estudiar, practicar) \\
\hline 电视机 & electricidad, ver, aparato & televisión & (el estudio, nacer) \\
\hline 录像机 & grabar, imagen, aparato & videograbadora & (escuela, escuela) \\
\hline 酒精 & vino-licor, esencia & alcohol & (estudio, reunión) \\
\hline
\end{tabular}




\section{Sintaxis, la gramática china}

El célebre lingüista y precursor de la gramática china, Zhao Yuanren ${ }^{3}$ (1968: iv y v) dijo: "toda la gramática china es sintaxis, la sintaxis china es el orden de las palabras, por lo tanto, toda la gramática china es el orden de las palabras".

En sintaxis, el esquema básico del enunciado chino es sujeto+predicado. El esquema de sujeto y predicado nace vinculado a los idiomas indoeuropeos, a los cuales el chino no pertenece. Lingüistas chinos y no chinos desde hace muchos años están desarrollando otro esquema de análisis sintáctico basado en: tema (foco, tópico) y comentario.
A) Sujeto + Predicado
B) Tema + Comentario

En el primer esquema entre el sujeto y el predicado por lo general existe una relación directa y subordinada. El predicado por lo general es una acción (verbo) que recae en el objeto directo.

El segundo esquema sólo divide al enunciado en dos elementos que se complementan (explican, aclaran) mutuamente.
$\mathrm{S}+\mathrm{P}$ O.d.
$\mathrm{T}+$ Com.
老师教汉语。
$\checkmark$ O.d.
El maestro enseña chino.
桌子上有书。
Sujeto: el maestro
Encima (sobre) la mesa hay libro (s).
Verbo: enseña
Sujeto: (enunciado sin sujeto)
Objeto directo: chino.
Verbo: hay
Objeto directo: libro (s)

Conforme los dos esquemas de análisis sintáctico, tal vez podemos decir concluir que los únicos enunciados del chino que pueden emplear el esquema sujeto+predicado son los verbales, donde el verbo principal implica acción, 走 zou (caminar), 跑 pao (correr), 教jiao (enseñar), 学习xuexi (estudiar), 听 ting (escuchar),etc.

Los enunciados adjetivos, los sustantivos, los de localización 在 zaiy aquellos de predicado nominal como los 是 shi y los 有 you, encajan mejor dentro del esquema Tema + Comentario.

Sin embargo, debido a la familiaridad con el esquema sujeto+predicado en la mayoría de las instituciones de enseñanza del chino en el mundo se emplea dicho esquema.

Adoptando cualquiera de los dos esquemas, S+P o T+Com, tanto el sujeto (tema) como el predicado (comentario) pueden estar compuestos de una o varias palabras. El orden de las palabras no sólo determina el significado del conjunto sino también de cada uno de los elementos que lo componen.

3 http://en.wikipedia.org/wiki/Chao_Yuen_Ren 
He aquí unos ejemplos de la formación de enunciados. Con sólo tres o cuatro caracteres formaremos varias sintaxis $y$, por ende, varios significados diferentes:

\begin{tabular}{|l|l|}
\hline & \\
\hline 他 & ta, él \\
\hline 好 & hao, bueno, bien, amable, gustar, sano, para que, etc. \\
\hline 看 & $\begin{array}{l}\text { kan, ver, mirar, leer, pensar, creer, considerar, juzgar, tratar (a un paciente), cuidar, visitar, } \\
\text { depender }\end{array}$ \\
\hline 了, & partícula gramatical \\
\hline 他好看 & Él es guapo \\
\hline 看好他! & Véalo bien (cuídalo) \\
\hline 他看好了 & Él eligió \\
\hline
\end{tabular}

Estos enunciados claramente ejemplifican la multifuncionalidad, la ambigüedad, la polisemia y la importancia del sitio que la palabra ocupa dentro del contexto, los diferentes significados no se derivan de la palabra en sí, sino del sitio que la palabra ocupa en el enunciado y su relación con los demás elementos.

\section{La importancia de las palabras vacías}

Todas las palabras del chino se dividen en llenas y vacías. Las llenas son aquellas que poseen un significado y las vacías son aquellas que cumplen una función gramatical. Las partículas gramaticales (estructurales) 了, 着, 过, 的, 地, 得y (modales) 吗, 呢, 吧, etc., son caracteres vacíos, también llamados funcionales, que no poseen o sacrifican su significado propio. Estos elementos funcionales son imprescindibles para realizar la sintaxis del enunciado y para determinar el significado concreto de las palabras y del enunciado en su conjunto.

\section{El Dao 道 y la lingüística}

Cada lengua es producto del contexto sociocultural en el cual nace. El chino no es la excepción. A lo largo de la historia varias escuelas y doctrinas filosóficas chinas se han referido al lenguaje, su naturaleza y función.

Las premisas de la escuela daoísta, como el 道 dao, 阴 yin e 阳 yang o 有 you y 无 wu respectivamente, pueden aplicarse tanto en el análisis del carácter como del enunciado chino.

En el carácter pictofonográfico, el radical es 阴 yin y la parte fonética es阳 yang. Ambos tienen sus propios significados; juntos, generan un nuevo dao de múltiples posibilidades. 
衣 +申=神， 口+土=吐，丝+只=织，

木+交=校，言+身+寸=谢

Transferidos al enunciado, el sujeto podría ser 阴 yin y el predicado 阳 yang.

Las características básicas del yin e yang son: contrarios, complementarios, relativos y dialécticos.

Yin sólo se define en relación con yang y viceversa. ¿Acaso eso no es la característica principal de la lengua china? Es decir, cada elemento del enunciado chino adquiere significado y función sólo en relación con el resto de los elementos del enunciado.

Mientras que en español, el sustantivo acotado por el género y el número, el verbo, acotado por el número y el tiempo gramatical y el adjetivo calificativo, acotado por el género y el número son universos independientes que se explican por sí solos, en el chino, cada elemento sólo se explica en función de su relación con el resto del conjunto.

Las palabras, entes relativamente independientes del español, puestos en cualquier lugar del enunciado no cambian ni su significado propio ni el significado del enunciado en su conjunto. En chino, en cambio, una leve modificación del orden sintáctico modifica el sentido del enunciado.

El maestro ayer enseñó caligrafía.

Ayer caligrafía enseñó el maestro.

Caligrafía enseñó el maestro ayer.

Caligrafía ayer el maestro enseñó.

老师昨天教书法。El maestro ayer enseñó caligrafía.

昨天书法教老师。Ayer, caligrafía enseñó a maestro.

En la esfera de las palabras llenas (sustantivos, verbos, adjetivos y números) y las palabras vacías (partículas gramaticales, 了, 着, 过, 得,的,地, adverbios 就, 才, 常, 向), las palabras Ilenas son estructurales, es decir son 阴 yin o 有 you, mientras que las vacías son funcionales, 阳 yang o 无 $w u$. Las palabras llenas 阴 logran su propósito, el significado, sólo con la ayuda de las palabras vacías 阳。

Así como el espacio无 wu o 阳 yang entre los rayos de la rueda 有 you o 阴 yin conforman la rueda (realizando su función) (Lao Zi, cap. 13), de la misma manera el 的 convierte a los sustantivos en adjetivos, el 地 convierte a los adjetivos en modificadores circunstanciales de modo, el 得 forma complementos, el 吗 convierte los enunciados afirmativos o negativos en interrogativos. etc.

Antes de concluir quiero mencionar la ausencia de conceptos absolutos como todo, nada, todos, nadie, siempre, nunca, doquier, ningún lado, etc., en la lengua china.

En chino estas ideas se forman con la ayuda de pronombres interrogativos y adverbios.

\begin{tabular}{|l|l|l|l|l|l|l|l|}
\hline & & & & & & \\
\hline 什么都, & 什么都不, & 谁都, & 谁都不, & 哪儿都, & 哪儿都不, & 什么时候都, & 什么时候都不, \\
\hline Todo, & nada, & todos, & nadie, & doquier, & ningún lado & siempre, & nunca \\
\hline
\end{tabular}


Pero ¿acaso en los planteamientos yin yang y dao caben los absolutos?

En resumen, aprender chino es sumergirse en la milenaria cultura que dio origen a esta lengua, es penetrar en el pensamiento y la filosofía que moldea y es moldeada por el lenguaje donde nace, crece y se desarrolla.

\section{Bibliografía}

-Arsovska, Liljana, Gramática práctica del chino, El Colegio de México, México, 2011.

-Benjamin, Walter, "La tarea del traductor", Revista de Filosofía, Universidad de la Laguna, España, 1994. 


\section{El idioma chino en el Centro de Enseñanza de Lenguas Extranjeras (CELE-UNAM)}

Edmundo Borja Navarro

El idioma chino (汉语 Hànyǔ) es uno de los idiomas con mayor número de hablantes en todo el mundo debido a su amplia población. En general, el idioma chino pertenece a la familia de lenguas sino-tibetanas, con las principales características de ser una lengua aislante y tono-distintiva, es decir, formada por sílabas cuyo tono marca la diferencia de significado. El mandarín estándar o pǔtōnghuà 普通话 (literalmente lenguaje común), está basado en el dialecto de la ahora capital Beijing y es el idioma oficial de la República Popular de China, así como una de las seis lenguas oficiales de la ONU.

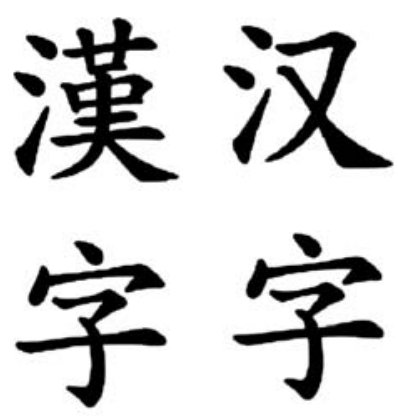

La fonología del chino está formada por sílabas, a la vez constituidas por 3 partes: una inicial (normalmente una consonante), una final (una vocal) y un tono.

La forma de escritura del idioma chino es mediante caracteres, los cuales puedes dividirse en: pictogramas, ideogramas, fonogramas e ideopictogramas. Personalmente creo que éste es un primer impacto cultural al momento de estudiar el idioma. Como cultura occidental, estamos acostumbrados a leer a través de las uniones de letras, formando sílabas, para tener un significado dentro de ese pequeño o gran conjunto de letras. Ahora bien, ¿cómo vamos a leer los caracteres chinos si no están formados por letras? Aquí entra una de las dificultades para los estudiantes del idioma: la memorización y repetición.

El método de enseñanza del idioma chino es tradicionalista, basado en la repetición de sonidos, memorización de estructuras y enfocado en la traducción. Desde el inicio de la enseñanza del chino en el CELE, es este mismo método el que se ha empleado para la enseñanza y aprendizaje de los alumnos. Debido a las particularidades fonéticas y de escritura del idioma chino, el único método existente y comprobado para el aprendizaje es la memorización y repetición, teniendo dos enfoques: en la fonética, y en la escritura de los caracteres. Desde el primer nivel se enseña a los alumnos a conocer los trazos básicos de los caracteres así como el orden que tienen para escribirse, haciendo estos ejercicios de repetición incluso hasta niveles intermedios. 
Igualmente, al ser un idioma tonal, los niveles básicos tienen un énfasis mayor en fonética, y únicamente estudiando estructuras gramaticales sencillas siguiendo el mismo patrón de S-V-O. En niveles intermedios y avanzados el método de enseñanza cambia de énfasis, orientándose en estructuras gramaticales y vocabulario, aunque sin dejar de lado la fonética del idioma.

Entonces, ¿cómo es la enseñanza de la fonética del idioma chino en el CELE? Básicamente muy sencillo. En 1979, la Organización Internacional de Normalización (ISO) adoptó un sistema de transcripción fonética del idioma chino basado en el alfabeto latino, y lograr una estandarización de la pronunciación. Este sistema se transcripción fonética se llama pīnyīn (拼音, literalmente: deletreo fonético).

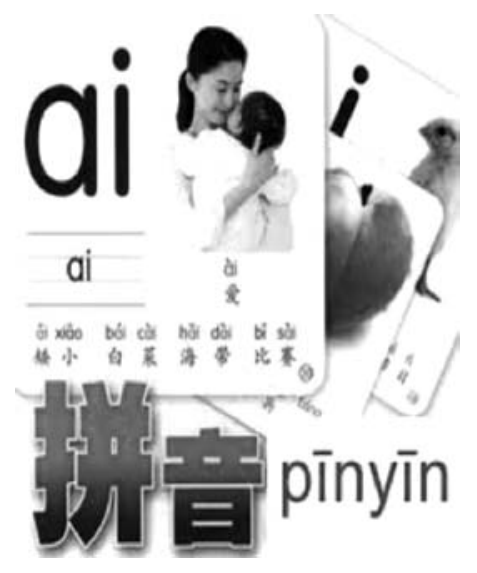

Pero el método de enseñanza del pinyin no es el mismo para un nativo hablante, que para un extranjero, y muchos menos para los latinos. Por lo que en el CELE, al momento de enseñar la fonética del chino, no se puede dar de manera separada con la del español. Es decir, se hace una comparación de la fonética de ambos idiomas para lograr un mejor entendimiento. Sin embargo surgen otros problemas con la forma escrita del pinyin y la forma en que los mexicanos están acostumbrados a pronunciar las letras, así como los sonidos no existentes en el español. Los principales problemas de los estudiantes son las distinciones de sonidos nasales, consonantes explosivas y no explosivas, fricativas y retroflexivas.

Un segundo impacto al estudiar el idioma es la fonética. En español, podemos cambiar la tonalidad de una oración sin cambiar drásticamente su significado. Incluso en ocasiones no es sencillo distinguir algún cambio tonal. Pero en chino ésta es la base del habla, de la comunicación. Un mismo conjunto de sílabas pueden expresar un significado totalmente diferente con un tono distinto. $Y$ es justamente este punto con el que los estudiantes del CELE se enfrentan durante los niveles básicos de enseñanza.

A mi parecer, es sumamente importante hacer énfasis en la diferencia tonal, no sólo durante una semana de clases, o en primer semestre, sino en todo momento. $Y$ una manera sencilla es a través de ejemplificaciones que muestren la importancia de la variación tonal. Por ejemplo: 


\begin{tabular}{|l|l|l|l|}
\hline \multicolumn{2}{|l|}{ Sílaba "wen" } \\
\hline 闻 Wén & (segundo tono) & $=$ & oler \\
\hline 吻 Wěn & (tercer tono) & $=$ & besar \\
\hline 问 Wèn & (cuarto tono) & $=$ & preguntar \\
\hline
\end{tabular}

Se usa esta misma sílaba dentro de una oración:

\begin{tabular}{|l|l|l|l|}
\hline 我闻你 & Wǒ wén nǐ & $=$ & Yo te huelo \\
\hline 我吻你 & Wǒ wěn nǐ & $=$ & Yo te beso \\
\hline 我问你 & Wǒ wèn nǐ & $=$ & Yo te pregunto \\
\hline
\end{tabular}

\section{Otros ejemplos:}

\begin{tabular}{|l|l|l|l|}
\hline \multicolumn{2}{|l|}{ Sílaba "ai" } \\
\hline 爱 & ài & $=$ & Amor, amar \\
\hline 挨 & ái & $=$ & Sufrir, aguantar, soportar \\
\hline
\end{tabular}

\begin{tabular}{|l|l|l|l|}
\hline \multicolumn{2}{|l|}{ Sílabas "shangai" } \\
\hline 上海 & Shànghăi & $=$ & Shanghai (ciudad) \\
\hline 伤害 & shānghài & $=$ & lastimar, herir \\
\hline
\end{tabular}

\begin{tabular}{|l|l|l|l|}
\hline \multicolumn{2}{|l|}{ Sílabas "shujiai" } \\
\hline 书架 & shūjià & $=$ & estantería \\
\hline 暑假 & shǔjià & $=$ & vacaciones de verano \\
\hline
\end{tabular}

Sin embargo, este aspecto no termina aquí. El idioma chino está formado únicamente por alrededor de 400 sílabas, pero el rango fonético es aún mayor si se toman en cuenta los diferentes 4 tonos para cada sílaba. Lo que nos lleva a un idioma compuesto por un gran número de homófonos. ¿Cómo se pueden distinguir los significados de homófonos en chino? A través de la estructura gramatical, es decir, el orden de los elementos de una oración china es sumamente importante, ya que la posición que ocupa en la oración nos indica el uso gramatical de la palabra, así como significados diferentes dentro de un contexto determinado.

\begin{tabular}{|l|l|l|}
\hline \multicolumn{3}{|l|}{ Las siguientes sílabas tienen la misma pronunciación: shì } \\
\hline 是 & shì & verbo “ser" \\
\hline 事 & shì & asunto \\
\hline 试 & shì & intentar, probar, examinar \\
\hline 市 & shì & ciudad \\
\hline
\end{tabular}




\begin{tabular}{|l|l|l|}
\hline 室 & shì & salón, sala, laboratorio \\
\hline 世 & shì & mundo \\
\hline 誓 & shì & promesa \\
\hline
\end{tabular}

En estos casos, la única manera de poder entender la palabra de la que se está hablando es teniendo una oración dentro de un contexto. $Y$ es de esta manera como en el CELE se explica la importancia tonal y de significado dentro de un contexto ya estructurado.

\section{Acuerdos y Convenios}

Uno de los principales acuerdos con los que cuenta el CELE es con la Embajada de la República Popular China a través de la sección de Educación, así como con el Primer Secretario de Educación. Es mediante esta dependencia y la Oficina Nacional de Enseñanza de Chino como Lengua Extranjera (HanBan) que cada dos años el gobierno chino envía a maestras especializadas en la enseñanza del idioma chino como lengua extranjera, para poder cubrir la demanda del idioma dentro del centro.

Posteriormente, uno de los primeros convenios que el CELE estableció con instituciones chinas fue el Convenio Específico de Colaboración entre la Universidad Nacional Autónoma de México y el Comité Nacional del Examen de Nivel de Idioma Chino de la República Popular China (Examen HSK), con el cual el CELE pudo comenzar a aplicar el Examen HSK del idioma chino (niveles básico, elemental-intermedio y avanzado), así como certificar los conocimientos correspondientes. Este convenio fue firmado el 15 de octubre de 2003.

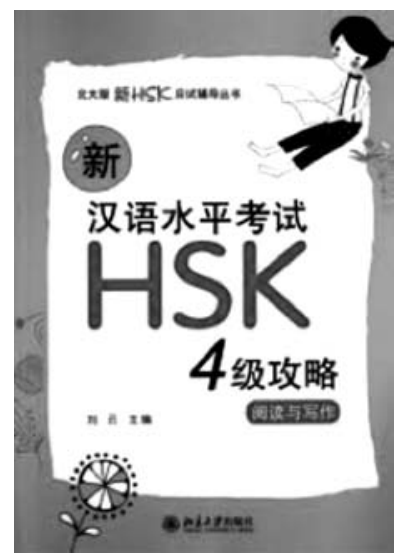

Entre las principales responsabilidades de ambas partes están:

- Difundir el examen HSK

- Realizar la inscripción al examen

- Elaborar el cuestionario del examen HSK 
- Definir el lugar del examen y preparar la logística para su aplicación

- Elaborar pruebas y papeletas del examen

- Grabar el material auditivo

- Revisar y calificar las pruebas

- Imprimir la lista de calificaciones y relación de las personas que tengan derecho a certificados

- Imprimir y emitir certificados

Un mes después, el 19 de noviembre de 2003, se firmó la Carta de Intención entre la Universidad Nacional Autónoma de México y la Universidad de Estudios Internacionales de Shanghai. Dentro de las modalidades de cooperación encontramos las siguientes áreas de mutuo interés:

- Intercambio académico de profesores de chino como lengua extranjera.

- Actualización de los profesores del Departamento de Chino del Centro de Enseñanza de Lenguas Extranjeras en la Universidad de Estudios Internacionales de Shanghai.

- Elaboración de materiales didácticos para la enseñanza del idioma chino a estudiantes hispanohablantes.

- Realización de investigaciones de chino del Centro de Enseñanza de Lenguas Extranjeras con la Universidad de Estudios Internacionales de Shanghai

No obstante, uno de los recientes y principales convenios es el Convenio de Colaboración entre la Oficina Nacional de la Enseñanza del Chino como Lengua Extranjera de China (Hanban) y la Universidad Nacional Autónoma de México (UNAM) para el establecimiento del Instituto Confucio de la UNAM. Este convenio fue firmado el 22 de noviembre de 2006 y se realizó con el fin de intensificar la colaboración entre China y México en educación, apoyar y fomentar el desarrollo de la enseñanza del chino, fortalecer la comprensión mutua y la amistad entre los dos pueblos a través del establecimiento del Instituto Confucio, el cual será un organismo educativo sin ánimo de lucrativo que tendrá como objetivo difundir la cultura y el idioma chinos y en consecuencia el conocimiento de China en México.

Las principales actividades que el Instituto Confucio realiza, de acuerdo con el convenio, son:

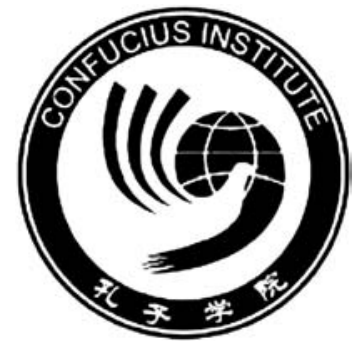

- Enseñanza de la lengua china

- Formación de profesores de la lengua china para universidades 
- Celebración de los exámenes de chino y de capacitación de la enseñanza de este idioma como lengua extranjera

- Enseñanza de cursos de diversos temas y aspectos para personas de distintas áreas

- Organización de actividades académicas y concursos relacionados con la lengua y cultura chinas

- Proyección de películas y programas chinos

- Asesoramiento a personas con interés de estudiar en China

Y finalmente, durante este año, el 16 de julio de 2011, se renovó el Convenio para la realización del Examen de Dominio del Idioma Chino HSK, con la modalidad de llevarse a cabo dos veces al año, en mayo y octubre, de acuerdo con el calendario nacional de exámenes de HSK en China.

\section{Demanda del chino en el CELE}

La enseñanza del chino mandarín, al ser una lengua extranjera que tradicionalmente no se consideraba de alta demanda en el mundo occidental, ha quedado rezagada en su integración y en los centros de estudio de lenguas extranjeras de países occidentales y particularmente en nuestro país este ha sido el caso. EI CELE es una importante referencia en este campo de la enseñanza de lenguas extranjeras y una referencia obligada ante cualquier institución educativa que en el futuro tenga interés en el aprendizaje y enseñanza de la lengua china.

Debido al mercado y crecimiento de la economía del país asiático, la demanda por aprender y encontrar instituciones calificadas para la enseñanza de la lengua china está en aumento. Desafortunadamente, la oferta actual para este mercado interesado no llega a cubrir la gran demanda del mismo. No obstante, el CELE año tras año busca la mejora tanto en la enseñanza como en la difusión de la cultura y del idioma chinos.

A continuación se presenta una pequeña gráfica que muestra la relación de alumnos inscritos a los cursos regulares de idioma chino del CELE, desde el semestre 2009-1 hasta el semestre 2012-1:

\section{Alumnos inscritos a los cursos regulares de idioma chino en el CELE}

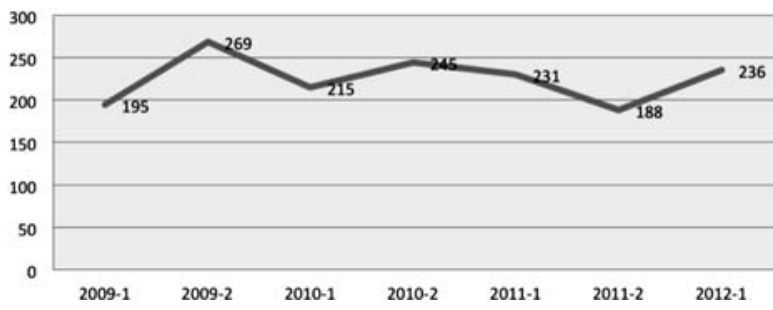

Nota1: Información obtenida a través de Sección Escolar del CELE.

Nota2: La información no contiene el total de número de alumnos inscritos en talleres de perfeccionamiento (niveles 7 y 8 ). 
Esta gráfica muestra cómo ha sido la inscripción de alumnos de chino durante los últimos tres años. Es importante señalar que de todos los alumnos registrados para las inscripciones de primer nivel, desafortunadamente sólo se acepta un promedio del $10 \%$, debido a la falta de espacios del centro.

Sin embargo, igualmente podemos advertir que la tendencia se sigue manteniendo por arriba de los 150 alumnos. Actualmente, el idioma chino dentro del Departamento de Ruso, Lenguas Asiáticas y Griego Moderno se encuentra en el segundo lugar por alumnos inscritos, únicamente por debajo del idioma japonés. En el último semestre (2012-1), el total de alumnos en japonés fue de 321, y el total de alumnos en chino de 268.

Continuando con esta tendencia, el CELE se encuentra desarrollando programas de estudios basados en las necesidades de los estudiantes mexicanos, para lograr un buen desarrollo académico y tener un excelente desarrollo profesional, dadas las demandas actuales del uso de lenguas extranjeras, principalmente del idioma chino.

Favorablemente, en colaboración con el CELE, la Embajada de la República Popular China, El Colegio de México, el Instituto Confucio en la UNAM y el Departamento de Formación de Profesores del CELE, a partir del próximo año 2012, se abrirá un primer grupo de Curso de Formación de Profesores en Chino.

\section{Resumen}

Gramaticalmente, el chino tiene poca morfología; resulta en ese aspecto más sencillo que el español. Entre los elementos más destacados se pueden mencionar:

- Las palabras (formadas por una o más sílabas) son flexibles, por lo que el orden gramatical es rígido. Es decir, debido a que una misma palabra puede tener la función de verbo, adjetivo, sustantivo o adverbio, el orden que tenga en la oración es relevante para conocer su función y significado.

- No tiene flexiones ni de género ni de número (excepto por algunas formas de plural en los pronombres personales).

- Los verbos no varían según la persona, el número o el tiempo gramatical, es decir, en el idioma chino no existen las conjugaciones verbales.

- En cuanto al orden gramatical, predomina el orden S-V-O

- Cuenta con los Ilamados "clasificadores", los cuales son obligatorios entre un numeral y el sustantivo al que rige, y están relacionados generalmente con la forma del objeto al que se refiere el sustantivo o el campo semántico del mismo.

- La escritura igualmente es bastante particular, ya que la forma del mismo caracter chino (ideograma) representa toda una idea que a través de los años se ha conservado hasta nuestros días y ha llegado a desarrollar nuevos caracteres formados por dos partes: una semántica y otra fonética.

El material de apoyo de enseñanza está elaborado por una de las universidades con mayor reconocimiento y difusión del idioma chino como lengua extranjera. Dicho material es bastante adecuado para los alumnos del CELE, debido a que es un método amigable y sencillo durante su proceso de aprendizaje, va guiando a los estudiantes a través de 
situaciones cotidianas que pueden encontrarse al vivir en China como estudiante extranjero.

Hoy en día, este mismo método sigue vigente como eje de enseñanza del chino: explicar a los alumnos que el adecuado aprendizaje del idioma requiere un nuevo proceso de memoria y repetición, proceso que deberá ser constante durante todo su estudio, debido a la variedad fonética, variedad tonal y número de caracteres utilizados en la vida diaria.

Actualmente en el CELE el programa de chino está elaborado para 8 niveles, al final de los cuales los alumnos podrán obtener una certificación de HSK4, equivalente a un nivel B2. 


\title{
El aprendizaje de chino en México Breve reflexión sobre cómo optimizar su aprendizaje
}

\author{
María de Lourdes Cuéllar Valcárcel
}

Antes de centrar el tema daré un breve encuadre de la problemática general sobre el aprendizaje del idioma chino en México. Para el ordenamiento de esta reflexión me apoyaré en el método estructural dinámico (MED) propuesto por el Centro Mundial de Estudios Humanistas (Pompei et al), particularmente en lo que se refiere al análisis en estática, ya que el espacio de este escrito no permite un desarrollo más extenso.

Para fijar el objeto de estudio partí de una primera premisa que surge de la experiencia cotidiana en mi trabajo como docente y como asesora: qué está pasando con el aprendizaje del idioma chino en México. Como este tema resulta demasiado amplio, busqué algo más específico y surgieron muchas preguntas más: ¿en qué contexto social se da el aprendizaje de chino?, ¿cómo elevar y acelerar la formación de profesores?, ¿cómo impulsar el uso de otras modalidades fuera del salón de clases, como el aprendizaje autodirigido o a distancia?, ¿son posibles estas modalidades en el caso del chino?, ¿qué factores generan la deserción?, ¿cuál será la o las metodologías más adecuadas para aprender esta lengua-cultura en particular?, ¿qué dificultades específicas presentan los estudiantes mexicanos?, ¿qué características debería tener un material didáctico para mexicanos que estudian en México?, ¿será posible lograr proyectos de investigación binacionales sobre la enseñanza del chino en nuestro país?, ¿por qué y para qué optimizar su estudio?, ¿qué podría facilitar el aprendizaje del chino en México?

Estas interrogantes corresponden a distintos aspectos de una misma problemática y su análisis podría generar muchas líneas de investigación. Seguramente entre los profesores de chino que trabajamos en este país ya se cuenta con experiencia acumulada que compartir, intercambiar y trabajar. Ojalá en conjunto podamos optimizar el estudio de este idioma y dar respuestas más amplias a las necesidades que hoy se nos presentan, que van más allá de la lengua misma.

El objetivo de este escrito, sin embargo, es mucho más sencillo. Es una reflexión que no pretende agotar todas las interrogantes planteadas ni hacerlo en profundidad. Tomaré una sola pregunta: ¿Qué podría facilitar el aprendizaje del idioma chino en México? Mi objeto de estudio queda definido entonces como el aprendizaje del chino en México desde un punto de vista académico y con el interés de optimizar su estudio y disminuir las dificultades, en muchos casos aparentes. Para el análisis en estática describiré lo que el MED Ilama ámbito mayor, ámbito medio y ámbito menor.

\section{Ámbito mayor}

El interés por el aprendizaje del chino ha crecido considerablemente en los últimos años. Desde el punto de vista de las instituciones, nos encontramos con que la oferta, 
aun cuando ha crecido, no logra atender la creciente demanda, sea por falta de espacios, profesores o presupuestos institucionales. Este interés por China ha ido aumentando no sólo por su auge económico, sino también por el avance de los medios de comunicación que nos han acercado culturas tan lejanas como ésta. El interés por el estudio del idioma en particular ha crecido de manera exponencial y dar respuesta a esta situación es urgente. No se trata solamente de aumentar instituciones o capacitar docentes, sino también de generar proyectos de investigación conjuntos sino-mexicanos que puedan incidir en el mejoramiento del proceso de enseñanza-aprendizaje en todos sus aspectos.

\section{Ámbito medio}

En este ámbito incluyo a los docentes, los materiales didácticos, los planes y programas de estudio y los aprendientes.

El perfil de los profesores en México es diverso y su experiencia en el campo docente no es homogénea. Hay profesores chinos de carrera, voluntarios y aquellos formados en la práctica de manera circunstancial. También hay profesores mexicanos con muy distintos niveles, tanto de dominio del idioma como de formación académica y todos se enfrentan a la misma problemática de cómo optimizar el aprendizaje del idioma.

La mayoría de los materiales de enseñanza se elaboran en China y se dirigen a estudiantes extranjeros en China. A mi parecer no hay libro de texto ideal, pues cada profesor y cada aprendiente tienen sus propios estilos y estrategias de enseñanza-aprendizaje; sin embargo, sería interesante y deseable lograr, entre los involucrados en la docencia, ciertos consensos sobre los aspectos sine qua non para aprender chino fuera de China. Motivar la discusión y el intercambio sobre estos temas podría ayudar a elevar y acelerar el aprendizaje y podría dar bases sólidas para la elaboración de libros y materiales didácticos más adecuados a nuestros contextos. Aquí quiero mencionar como aportes importantes el libro editado por el CELE en 1998 Chino para hispanoparlantes, de Li Weiji, y la recientemente publicada Gramática práctica de chino, de Liljana Arsovska, publicada por el COLMEX en 2011. Esta última es un muy buen ejemplo de lo que significa enfocar la enseñanza a estudiantes con una mentalidad occidental y que estudian en un ambiente no chino.

Respecto a los planes y programas de estudio encontramos que no siempre se trabaja con un plan de estudios. Muchas veces se trabaja con base en un libro de texto (o materiales diversos), sin que exista un programa institucional que dé lineamientos generales. En los casos en que se cuenta con planes y programas, la gama es variada y los resultados disímiles. La diversidad es un elemento muy positivo; sin embargo, sería necesario estudiar la posibilidad de contar con marcos de referencia comunes que garanticen un buen nivel en de enseñanza.

Desde el punto de vista de los aprendientes también encontramos diversidad. En el caso del CELE, la mayoría de los estudiantes son universitarios y en el COLMEX se trata en principio de investigadores académicos relacionados con la temática china, pero en los institutos Confucio y otras instituciones encontramos otro tipo de compositiva que incluye, además de universitarios, empleados, amas de casa y estudiantes de educación 
media. Es evidente que uno de los factores que ha despertado el interés por la lengua es el acelerado crecimiento económico de China, lo que se demuestra en el número cada vez mayor de estudiantes de economía o relaciones internacionales que se acercan al idioma. Pero no por que aumenten los estudiantes de estas áreas disminuyen los que vienen por curiosidad, por reto personal o movidos por una particular atracción hacia la cultura o filosofía chinas. Las motivaciones son diversas, pero no siempre resultan suficientemente profundas como para sostener el estudio hasta llegar por lo menos a un nivel básico de dominio. Esto genera otro problema grave: la deserción, sobre todo en los primeros niveles de aprendizaje. Definitivamente todos los que llegan a un salón de clases de cualquier institución quieren aprender chino, pero los intereses que los llevan a este punto son muy diversos, pues van desde querer hablar lo suficiente para negociar o viajar, hasta los que tienen un interés académico y quieren leer a los clásicos. Todo esto genera dificultades en el armado de planes y programas de estudio y nos obliga a pensar en modalidades fuera del salón de clases, como ya se está haciendo en el CELE, donde desde hace 18 años se ofrece la modalidad de aprendizaje autodirigido en varios idiomas y hoy se está trabajando en la inclusión del chino.

Recapitulando sobre el ámbito medio: la situación actual de la enseñanza de chino en México es reflejo de los caminos que se han tomado para responder a la necesidad de atender a la creciente y acelerada demanda producida por el desarrollo económico de los últimos años y la presencia de China en todos los ámbitos internacionales. Dentro de este contexto, el aprendizaje del idioma chino en México, que se venía dando a un ritmo sostenido por algunas instituciones como el CELE o el COLMEX, se ha diversificado aceleradamente en los últimos años. El crecimiento ha sido un tanto caótico y desigual tanto en propuestas educativas como en calidades, producto de la necesidad de dar respuestas al desarrollo avasallante de China. Este contexto no facilita la aplicación de estrategias y tácticas para facilitar el aprendizaje.

\section{Ámbito menor}

Este ámbito corresponde a los elementos que hacen al aprendizaje mismo del idioma, entre ellos las características propias del chino y los factores que hacen al aprendizaje, particularmente al aprendizaje de lenguas y más particularmente al aprendizaje de chino.

En el caso de las características propias de la lengua, podemos enumerar tres aspectos fundamentales:

- La fonética, particularmente los tonos, que no existen en español y que representan una dificultad considerable para los alumnos mexicanos, ya que en muchos casos no tienen desarrollada la habilidad auditiva necesaria para distinguirlos y producirlos.

- La escritura, a base de ideogramas o caracteres, y que corresponde a una forma distinta de estructurar el lenguaje escrito con base en ideas, más que de sonidos, como sería en el caso de las letras del español. 
- La gramática, particularmente la morfosintaxis, que no es otra cosa sino el reflejo de la estructura misma del pensamiento, de la interpretación del mundo que se hace desde cierta mirada, desde cierto enfoque socio-cultural.

Estos tres aspectos corresponden a una forma distinta de organizar el pensamiento y las ideas, que es propia de una cultura y una filosofía basadas en principios distintos a los occidentales.

Como hay muchos especialistas que ya trabajan en el tema de los aspectos lingüísticos, quiero centrarme en tres aspectos un tanto intangibles, pero que considero funda $\neg$ men $\neg$ tales para facilitar $u$ optimizar el aprendizaje de este idioma: la motivación, las represen $\neg$ taciones mentales y la "flexibilidad mental".

Comienzo por desarrollar la motivación o el gusto por la lengua. ¿Qué motiva a los estudiantes a aprender chino y qué podría ayudarlos a mantener su motivación hasta terminar el proceso? Para Ricardo Solana “la motivación es lo que hace que un individuo actúe y se comporte de una determinada manera. Es una combinación de procesos intelectuales, fisiológicos y psicológicos que decide, en una situación dada, con qué vigor se actúa y en qué dirección se encauza la energía". En términos generales ningún estudiante en México tiene la obligación apremiante de estudiar chino: no lo requiere para su titulación y, si bien puede ayudarle a mejorar sus condiciones de empleo, no parece ser causal de despido laboral. La mayoría viene por decisión propia y -podría pensarse- con cierto gusto o disposición inicial. Sin embargo, tener un interés manifiesto por aprender la lengua no necesariamente implica que se tenga un gusto genuino por esta lengua-cultura. Algunos aprendientes muestran una gran atracción por "lo chino", por lo que se muestran empáticos y flexibles ante las diferencias culturales y las dificultades propias de la lengua; pero para otros, las diferencias culturales no sólo resultan incomprensibles, sino incluso desagradables y el solo hecho de pensar en el esfuerzo que implica el estudio de una lengua tan distinta puede ser frustrante. Esta falta de gusto por la cultura o la poca disposición a aceptar una cultura diferente no se da en el momento inicial pero es frecuente en el proceso de aprendizaje y puede disminuir la motivación y obstaculizar el rendimiento académico. Es tan importante la motivación durante el proceso que vale la pena preguntarse cómo incentivarla o cómo mantenerla.

La motivación es el corazón del aprendizaje, pero éste puede presentar arritmias, dificultades en el bombeo de la sangre, problemas de colesterol, etc. A quien padece dificultades con el corazón, no se le pueden pedir sobreesfuerzos y eso es lo que pasa con quien está desmotivado. ¿Qué tanto tiene que ver la deserción con los “problemas cardiacos"? ¿Cómo fortalecer el corazón y mantenerlo en buena forma?

Silo dice que "en todo proceso de adaptación la estructura psicofísica se orien $\neg$ ta por los indicadores de placer y displacer. El displacer se conforma como se $\neg$ ñal de lo que es peligroso para la vida, de lo que es tóxico, represivo o, en general, perjudicial para la estructura psicofísica. El placer, a la par que estimula y mo $\neg$ tiva al psiquismo, traza las direcciones óptimas a seguir" (Silo, 2006, p. 49). Esto resulta fácilmente comprobable en la experiencia cotidiana: nos atrae lo que nos gusta y rechazamos lo que nos disgusta. De acuerdo con estas apreciaciones, una pauta para lograr la motivación del estudiante de chino estaría ligada a lograr, dentro del salón de clases o dentro del ámbito de experiencia de aprendizaje, cierto placer en el proceso de aprender, y esto 
no sólo implica el ambiente físico externo donde el estudiante se ubica, sino el ámbito de la experiencia misma: el acto de aprender. ¿Quién no ha sentido una gran emoción cuando entiende algo, cuando encuentra una respuesta o cuando descubre un nuevo conocimiento? ¿Quién no disfruta el hecho de comprender un texto extranjero o comunicarse en una lengua que no es la propia? Sabemos que lo que produce placer atrae y sabemos también que el aprendizaje puede producir sensaciones placenteras, pero aun así no tenemos la llave maestra para lograr una total y permanente motivación. Si bien en este campo no todo corresponde a los docentes, considero fundamental la reflexión sobre la parte que nos toca como profesores o asesores y que tiene que ver con enamorar a nuestros alumnos de la lengua-cultura que enseñamos, producir gusto o mínimamente generar ambientes agradables. En el proceso de aprendizaje, “los datos que se proporcionan al aprendiente se relacionan inevitablemente con su contexto, que es un contexto situacional emotivo" (Silo, 2006, p. 49) y que debería ser parte del plan de clase.

Pasaré ahora a las representaciones mentales, definidas por Martha Cecilia Arbeláez como "ideas preconcebidas que el individuo genera a partir de sus experiencias académicas y su contexto, para comprender e interpretar el mundo que lo rodea". Estamos hablando de las creencias que se tienen alrededor de la enseñanza de chino. ¿Cuál es la más generalizada de estas creencias?, que "está en chino". Se cree que es extremadamente difícil y esto influye enormemente en la actitud y la disposición de los estudiantes. Y por si fuera poco, esta idea muchas veces es fomentada y fortalecida por las instituciones y los profesores. ¿En qué se basa esa creencia? ¿Qué experiencia concreta podrían tener los alumnos para sostener tal aseveración? Puede ser la precepción inmediata de otro tipo de escritura o el sonido tonal tan característico y "extraño", pero también puede ser la experiencia en el salón de clases que se propaga entre compañeros. Desde mi punto de vista para aprender chino se requiere más gusto y menos miedo, pero veamos la dificultad con mayor detalle. De los tres aspectos característicos de la lengua china que mencionamos al inicio, la fonética es cuestión de práctica que luego se mecaniza; la gramática se reduce al orden de las palabras en la oración, sin conjugaciones verbales, ni declinaciones, ni artículos; y la escritura, aun cuando requiere de un mayor esfuerzo, también tiene sus trucos para facilitar su aprendizaje. Si consideramos el caso de que la experiencia en el salón de clases fortaleció la creencia, entonces tendremos que revisar qué sucede en ese ámbito y qué tácticas podrían servir para disminuir ese registro. Desde mi experiencia lo más difícil es aceptar las diferencias y "flexibilizar la cabeza".

El chino, como cualquier otra lengua, representa una forma particular de organizar el pensamiento y las ideas sobre el mundo que nos rodea. La lengua fue tomando su estructura particular de acuerdo a la interpretación del mundo que desde la antigüedad hicieron los chinos; y esa forma interpretativa resultó muy distinta de la que se hizo en Occidente, corresponde a otro paisaje, entendiendo este concepto de la siguiente manera: "Paisaje externo es lo que percibimos de las cosas, paisaje interno es lo que tamizamos de ellas con el cedazo de nuestro mundo interno. Estos paisajes son uno y constituyen nuestra indisoluble visión de la realidad" (Silo, 2002, p. 86). 
Enseñar chino o mostrar caminos para aprenderlo nos da la posibilidad de ayudar a los aprendientes a comprender que el mundo admite muchas interpretaciones, que aunque distintas, son igualmente válidas, que nuestras representaciones mentales tienen que ver más con nuestra cultura y la manera en que desde ella se interactúa con el paisaje externo que con nuestras decisiones. Es imprescindible entonces acercarnos, mimetizarnos y comprender esa cultura y ese pensamiento como algo indudablemente distinto y es a esta actitud a la que llamo "flexibilidad mental". Nuestros alumnos llegan a clase o se acercan al estudio del chino con mayor o menor gusto, con intereses precisos o difusos, con necesidades concretas o sin ellas, pero siempre vienen cargando un paisaje cultural y una mirada, entendida ésta como un acto, complejo y activo, organizador de paisajes y no un simple acto pasivo de recepción de datos externos (Silo, 2002, p. 122). Esa mirada lleva implícita un sistema de creencias ya establecido basado en la cultura, la época y la manera habitual de pensar, además de las valoraciones y emociones de la propia experiencia. ¿Qué sucede cuando esta mirada no alcanza a comprender que existen otras miradas posibles?, ¿o cuando no se es sensible o abierto a esa posibilidad?

La filosofía china antigua por ejemplo, y particularmente el taoísmo, ha dejado una huella que aún hoy es claramente visible en su cultura, su escritura y su gramática, pero esta huella está en la "copresencia", constituyen el campo central de la atención, campo de la presencia, que en nuestro caso estaría dado por el aprendizaje de la lengua. Es importante considerar que "el conocimiento se entiende en el campo de copresencia, por lo que al ampliarlo, se amplía también la capacidad de relacionar" (Silo, 2006, p. 30). La capacidad de relacionar datos es lo que permite ampliar o fortalecer el conocimiento sobre cierto objeto de estudio, que bien puede ser el dominio del idioma. "Presencia y copresencia configuran la imagen del mundo que tiene un individuo. Aparte de conceptos e ideas, la conciencia cuenta con elementos no pensados, copresentes, que son las opiniones, creencias, supuestos, a los que rara vez se atiende. Cuando este sustrato con el que se cuenta varía o cae, es la imagen del mundo la que cambia o se transforma" (Silo, 2006, pp. 30-31). Cuando se amplían los datos de presencia y copresencia en la experiencia del aprendizaje del chino, se está modificando la imagen del mundo de nuestros aprendientes y se está posibilitando no sólo una mayor comprensión de la lengua-cultura meta, sino una modificación de la percepción que se tiene del mundo en general.

Citaré sólo un ejemplo de lo que sucede con esta copresencia en el caso de la cultura china: el concepto de Dao. La primera dificultad es tratar de comprender o explicar este concepto chino buscando "equivalentes" o forzando similitudes. Tratemos de aceptar las diferencias. En la cultura china no ha existido nunca el concepto de Dios, como ser único creador del mundo. En esta cultura la preocupación se centró en comprender ese mundo en el que estaban puestos y no en indagar sus orígenes. Para los chinos resultaba claro que había cosas que podían ver y otras que no, que había un mundo tangible y otro intangible, y que estas dos facetas de un misma realidad eran mutuamente complementarias. De ahí surge esta idea del Dao, que pretende describir una suerte de totalidad en la que todo cabe, sea perceptible o no para el ser humano.

1 Sobre el término copresencia, se puede consultar: Silo, Apuntes 
Cuando el ser humano percibe algo nuevo, busca en su memoria algo parecido que le ayude a comprender, algún elemento que le sirva de parámetro para relacionar y asociar. Éste es un mecanismo normal en el funcionamiento de la psique humana, pero quedarse allí nos puede llevar a simplificar demasiado y a sacar conclusiones precipitadas, como por ejemplo que el Dao es Dios.

Esta idea oriental de dos elementos complementarios que componen la realidad, que está en la copresencia, permea toda la estructura de la lengua-cultura, y es justamente en esta forma de interpretar la realidad percibida donde radica la mayor diferencia con nuestra cultura y tal vez la mayor dificultad para su aprendizaje. Intentar comprender conceptos que no existen en nuestro sistema de ideación o que incluso rompen nuestros paradigmas occidentales no es tarea fácil. Frente a este fenómeno de "incomprensión" se tiende a negar, rechazar o degradar ese conocimiento o esa forma que no se corresponde con la nuestra. No hay antecedentes en nuestro contexto ni referentes; hay que construirlos, generarlos y aceptarlos para que pasen a formar parte de nuestro "universo mental". ¿Cómo se enfrenta esta dificultad en el salón de clases? ¿Es posible, necesario o deseable incluir esta temática en una clase de chino? ¿Reflexionar sobre estos temas resulta motivador o frustrante? ¿Sirve a efectos de facilitar el aprendizaje del idioma?

De acuerdo con todo lo expuesto hasta aquí y a mi experiencia en la docencia, así como al cotejo de ésta con otros colegas, creo indudablemente que tomar en cuenta las motivaciones, las representaciones mentales y la flexibilidad mental repercuten muy positivamente en el aprendizaje del idioma.

Hasta aquí he definido los ámbitos mayor, medio y menor del aprendizaje de chino desde la perspectiva académica y con el interés de optimizar su estudio. La situación actual que se deduce de este breve análisis es que la demanda por el aprendizaje de chino en México ha aumentado aceleradamente y la oferta de cursos y modalidades de aprendizaje no alcanza a cubrirla. El perfil de instituciones y docentes es muy diverso, así como los intereses de los aprendientes. Las características propias del idioma, así como los intangibles en el proceso enseñanza-aprendizaje no siempre son tomados en cuenta en los planes, programas y estrategias utilizados, lo que genera dificultades en el aprendizaje del idioma.

Es evidente la necesidad de ampliar y profundizar en el estudio de los factores que facilitan el aprendizaje de chino, pues al lograr mayor eficacia, se optimizarán los recursos institucionales y docentes. De este primer acercamiento a una problemática tan compleja se desprende la propuesta de generar espacios de trabajo e intercambio entre los docentes de chino, así como líneas de investigación y rescate de experiencia de lo que para muchos de nosotros significa no sólo nuestro campo laboral, sino nuestra pasión: la lengua-cultura china. 


\section{Bibliografía}

- Pompei, Jorge et. al., Teoría y práctica del método estructural dinámico: seminario, taller, Centro Mundial de Estudios Humanistas, Buenos Aires, 2008. También se encuentra en línea en la página web del Centro de Estudios Humanistas de Buenos Aires: http://www.cehba.org/metodo-estructural-dinamico/

- Silo, Obras completas, tomo I, Humanizar la tierra, Plaza y Valdés, México, 2002.

- Silo, Apuntes de psicología, Ediciones Ulrica, Rosario, 2006. 


\section{El idioma chino, la lengua del futuro. Instituto Confucio, el camino para llegar a él}

Lingyan Zhou Li

Desde siempre y en especial ahora la comunicación en las sociedades humanas ha sido de vital importancia para su desarrollo. En nuestros días esta comunicación ha tomado mayor importancia por la globalización del desarrollo de las actividades del hombre. De aquí la importancia de las herramientas que permiten esta comunicación en el éxito de las empresas y de las personas que las emprenden. El manejo de los idiomas es una de estas herramientas que permiten a los profesionistas de todos los campos alcanzar altos niveles en su desempeño.

En México tenemos la fortuna de comunicarnos en uno de los idiomas hablado por más personas en el mundo. Por los derroteros que ha tomado la educación, el idioma inglés se aprende en forma casi obligatoria y natural en prácticamente todas las escuelas superiores del país. Con esto los profesionistas mexicanos cuentan con una gran herramienta para su desarrollo personal y profesional. Una tercera o cuarta lengua ha sido una opción para una pequeña porción de los graduados de México; si los profesionistas mexicanos aprendemos chino, estaremos hablando en los tres idiomas más hablados en el mundo y podremos comunicarnos en cualquier parte de él.

Cuando se restablecieron las relaciones entre México y China, aún no se podían ver los alcances que ha alcanzado la revolución china de 1949 dentro del propio país y en el resto del mundo, mucho menos prever la importancia que con esto alcanzaría el idioma chino.

Hoy, la República Popular China ha mantenido un crecimiento económico del $10 \%$ durante dos décadas y tiene un papel preponderante en el desarrollo global del mundo, influye en todas las actividades industriales y comerciales de todos los países. De aquí el hecho de que la lengua china se haya convertido en la primera opción como segunda o tercera lengua en la preparación de los profesionistas del futuro de todo el mundo, tendencia observada también en nuestro país.

Hace poco tiempo las instituciones en México que ofrecían el idioma chino como opción eran contadas con los dedos de las manos, en la actualidad un gran número de organizaciones están ofertando la enseñanza del idioma chino para atender la creciente demanda.

El gobierno de la República Popular China, poco después de su fundación y por las diferentes variantes del idioma chino que existen dentro de China, llevó a cabo una simplificación y estandarización del idioma que llevó a unificar a una sola lengua oficial, el mandarín. Con esto se alcanzó una mejor comunicación entre las diferentes regiones de este inmenso país. Una vez alcanzada la meta se inició la etapa internacional del proyecto con la creación de Hanban, la Oficina Internacional del Consejo para la Difusión y Enseñanza del Idioma Chino, en 1984, una institución no gubernamental y no lucrativa afiliada al Ministerio de Educación Chino. 
Hace pocos años, en 2004, inició el proyecto conocido como Instituto Confucio, con el objetivo de difundir, promover, regular y certificar la enseñanza y aprendizaje del idioma chino en el mundo. En poco más de 6 años, para fines de 2010 se han creado alrededor de 322 institutos Confucio y 369 aulas Confucio en 94 países del mundo. El Ministerio de Educación Chino estima que hay alrededor de 100 millones de estudiantes de mandarín fuera de China y proyecta contar con 1000 institutos y aulas Confucio para 2020, meta que seguramente será superada por mucho, ya que hay más de 300 solicitudes para la creación de nuevos institutos o aulas Confucio en otros 50 países. Para 2006 se tenían como meta 100 institutos y se alcanzaron más de 160. En México hay cinco institutos Confucio:

- Instituto Confucio de la Ciudad de México

- Instituto Confucio de la Universidad Nacional Autónoma de México

- Instituto Confucio de la Universidad Autónoma de Yucatán

- Instituto Confucio de la Universidad Autónoma de Chihuahua

- Instituto Confucio de la Universidad Autónoma de Nuevo León

El Instituto Confucio de la Ciudad de México, albergado en el Instituto Cultural Chino Huaxia, es único en su tipo en todo el mundo, ya que además de no estar radicado en una institución universitaria, desde sus inicios se ha dedicado a atender la enseñanza del idioma chino principalmente en niños. El gran trabajo desarrollado por Huaxia en la difusión del idioma chino en niños mexicanos fue uno de los factores para que Hanban otorgara en 2006 el nombramiento de Instituto Confucio de la Ciudad de México y se estableciera como el primer Instituto Confucio en Latinoamérica.

El Instituto Cultural Chino Huaxia es una asociación civil de carácter cultural no lucrativo que nace con el objetivo inicial de enseñar cultura e idioma chino a 16 hijos de inmigrantes; con el paso de los años vio la necesidad de abrir sus horizontes para atender la demanda de familias mexicanas que tuvieron la visión de que sus hijos aprendieran chino para su preparación futura, y poco a poco fue creciendo al grado que el día de hoy estamos atendiendo más de 2600 alumnos, incluyendo adultos, preescolares, alumnos de primaria, secundaria y preparatoria.

En un principio sólo llevábamos nuestras acciones dentro de las instalaciones del instituto por el hecho de contar con limitados recursos, materiales y humanos; sin embargo, concretamos la idea de salir hacia escuelas externas donde se sembró la idea de incluir al idioma chino como materia, generando mayor demanda a la oferta de nuestros servicios de difusión del mandarín. De esta manera estamos impartiendo el idioma chino en 15 escuelas del Distrito Federal, Estado de México y Morelos. Aún existe demanda no atendida por falta de un mayor número de profesores.

La certificación del conocimiento del idioma chino se realiza a través del instrumento conocido como HSK, examen desarrollado por Hanban que certifica el nivel de conocimiento de la lengua china, desde 1990, y que cuenta con el aval del gobierno de China. Este instrumento ha certificado el conocimiento de casi un millón de personas que han estudiado el mandarín como lengua extranjera alrededor del mundo. En México hay tres instituciones sedes para la aplicación de este examen que son: el Instituto Confucio 
de la UNAM, el Instituto Confucio de la UADY y el Instituto Confucio de la Ciudad de México. En este último, además, somos sede para la aplicación del YCT, instrumento que certifica el aprendizaje en niños y jóvenes, y estos dos exámenes se aplican dos veces al año.

El gobierno chino también ha instrumentado el concurso Puente Chino, como herramienta para estimular a los estudiantes del idioma chino a continuar adelante, ya que los estudiantes ganadores en las etapas de cada país asisten a la final mundial que se lleva a cabo en China, con todos los gastos pagados y tienen el acceso a becas para continuar sus estudios en China. En México, el Puente Chino universitario tiene como sede al Instituto Confucio de la UNAM y es organizado por el Instituto Confucio de la Ciudad de México. En los últimos dos años la selección mexicana para el Puente Chino de educación media ha alcanzado el tercer lugar por equipos, además de otros premios individuales, en la final mundial realizada en Chongqing, China, lo que demuestra el avance que se ha tenido en el aprendizaje del idioma en esta categoría.

El Instituto Confucio de la Ciudad México realiza diversos eventos para la difusión de la cultura china con la finalidad de hacer más integral la enseñanza de la lengua de la Han y de ser un foro donde conocer más de esa milenaria cultura.

Se dice que la locomotora china está en marcha y que hay que subirse a ella para no quedarse atrás, una forma de abordarla es aprender chino y para aprender chino el camino es los institutos Confucio. 

Sección 5:

Minería, agricultura y medio ambiente 



\section{La minería: el puente de plata estratégico entre México y China}

Simón Levy-Dabbah

El parecido de la situación y las circunstancias de la actualidad de la minería como eslabón entre México y China provoca el rescate necesario de la historia de esta importantísima actividad económica mundial, en aras de entender lo estratégico que ha resultado la relación bilateral de los dos países desde los primeros contactos comerciales marítimos entre chinos y novohispanos.

Ya con Alfonso de Albuquerque y Álvaro Saavedra y Zerón en 1511 y 1522, respectivamente, y luego a partir de 1564 desde que la Nao San Pedro zarpara de Barra de Navidad en Jalisco con Fray Andrés de Urdaneta y Miguel López de Legazpi, el establecimiento de la ruta comercial para anclar las relaciones comerciales entre México, China y Asia fue en gran medida inspirado y propiciado por la plata y los minerales procedentes de México, que el entonces Virreinato de la Nueva España, posicionó como una de las mercancías más demandadas por parte de los súbditos del imperio celeste y mercaderes asiáticos.

Fue tal la importancia de la minería mexicana que rebasa toda la narrativa histórica que hasta el día de hoy se haya realizado enfocando todo al establecimiento del sistema comercial del Galeón de Manila o la Nao de China. No, la minería mexicana sirvió para una elocuente y trascendente misión de los españoles.

Además de ser la base de negociación y fundamento en gran parte de los motivos intrínsecos de la conquista de las islas de las especierías -las llamadas "Philipinas"- por Ruy López de Villalobos en alusión a Felipe II, realmente impulsó el establecimiento de la primera embajada española en China encomendada a Miguel de Loarca, así como para la evangelización de la fe católica en el país asiático con Fray Martin de Rada pasando finalmente a los ilusos planes de conquista de España sobre ese país de Francisco de Sandes.

La fundación de Filipinas por Miguel López de Legazpi permitió, como ya lo he mencionado, que Felipe II a través de Miguel de Loarca, Fray Martin de Rada, Francisco Sandes y Guido de Lavezaris comenzaran a tener contacto con los Ilamados Sangleys (comerciantes chinos basados en aquel entonces en Filipinas), quienes establecieron el interés fundamental por la minería mexicana a cambio de especias orientales y los refinados productos chinos como la porcelana y la seda.

No era de extrañar que gran parte de la plata producida en las minas de Nueva España, particularmente las de Guanajuato, San Luis Potosí y Zacatecas, tuviera como destino final Asia, y sobre todo el imperio chino.

En ese entonces, como ahora, la minería mexicana -como se subraya- ha jugado un papel geoestratégico de primerísimo orden. El logro del establecimiento de la primera embajada española en China fue obtenido gracias al intercambio de minerales y plata que el emperador de la dinastía Qing, Wan Li, requirió de Miguel de Loarca aunado al 
intento frustrado de captura del pirata chino Lín Feng o mejor conocido como Limahong en 1574.

Establecido el acuerdo inicial de relaciones comerciales, hasta esos lugares llegó una gran cantidad de comerciantes procedentes de las actuales provincias chinas de Zhejiang, Fujian y Guangdong, la mayoría en búsqueda de plata.

Al continuar con la llamada política fiscal de cobrar impuestos en plata, la dinastía Qing (1644-1911) siguió dependiendo en parte del metal blanco obtenido de las minas de la Nueva España.

Tras la conquista de Filipinas en 1565, el imperio chino se alzaba en el horizonte de los conquistadores españoles como un desafío desconocido y hostil, aunque cargado de promesas de riqueza. No faltó quien soñó con emular a Hernán Cortés, creyendo que con un puñado de hombres se podría conquistar el gran imperio celeste.

Manila acabó convertida en una floreciente y mercantil ciudad poblada mayoritariamente por chinos, con una pequeña elite dominante española. El sueño de una armada invencible en los mares de China se convirtió en la realidad del Galeón de Manila que unía Acapulco con Manila, donde llegaban cada año los juncos chinos cargados de seda, especias y porcelanas para volver al continente asiático con prácticamente un único producto a cambio: la plata y los minerales mexicanos.

Y ello es tan representativo puesto que México, desde 2010, ha ocupado nuevamente el primer lugar en producción de plata mundial según cifras del Instituto de la Plata que aduce que nuestro país generó 128 millones de onzas troy de plata en 2010, lo que representa más de la sexta parte de las 735.9 millones de onzas troy producidas en el año.

\section{Situación estratégica de México y su acervo minero frente a China}

Ahora parece que el ciclo histórico reclama aquellos momentos y crea nuevas coyunturas para inspirar una nueva relación y rumbo con China como aquellos años dorados para así establecer por medio de entre muchos otros factores y vicisitudes, la Nueva Nao, la "Neonao" del Siglo XXI.

En aras de construirla, es menester comprender la importancia que el sector minerometalúrgico representa para México, ya que cuenta con una amplia riqueza de minerales en todo el territorio nacional, tanto minerales metálicos como en no metálicos. En nuestro país se encuentran yacimientos de clase mundial, como son las salinas de Guerrero Negro, las más grandes del planeta; el yeso de la Isla San Marcos y de la costa oriental de la península de Baja California, con reservas de 70 años; Las Cuevas, la mina más grande de fluorita en el mundo; Fresnillo, el yacimiento de plata más rico y más grande que haya descubierto la humanidad; Molango, el depósito más importante de manganeso en Norteamérica; las minas de carbón de la Cuenca de Río Escondido, entre otras.

Según datos del Instituto Nacional de Estadística Geografía e Informática (INEGI) las 32 entidades federativas de la República Mexicana cuentan con yacimientos mineros. 
A nivel nacional destaca la producción de 10 minerales (oro, plata, plomo, cobre, zinc, fierro, coque, azufre, barita y fluorita), seleccionados por su importancia económica y su contribución a la producción nacional.

Producción minerometalúrgica durante enero-octubre de 2011

(Variación porcentual real aspect al mismo lapso de 2010)

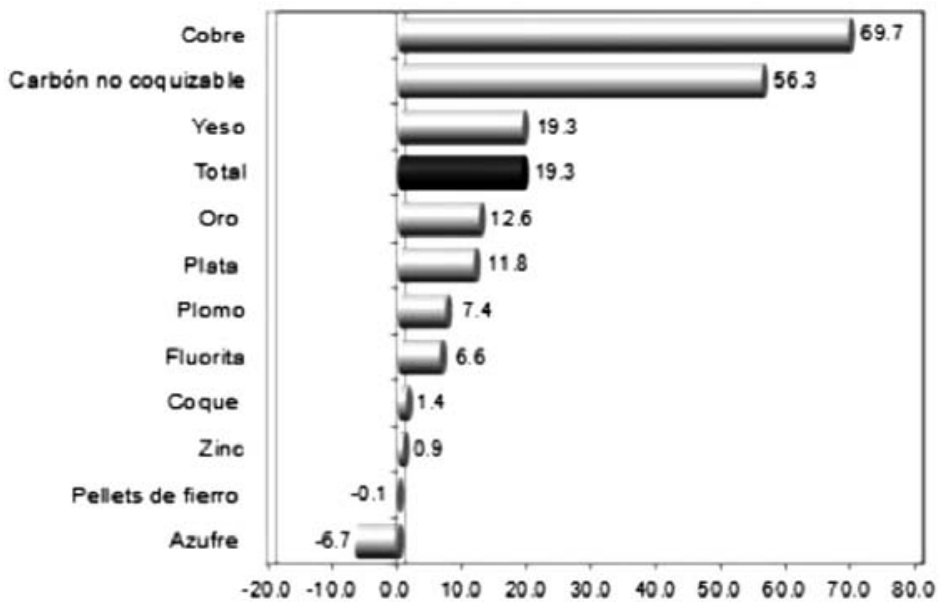

Fuente:INEGI

\section{Cifras desestacionalizadas y tendencia-ciclo de la producción minerometalúrgica a octubre de 2011 \\ (Índice de volumen físico, 1993=100)}

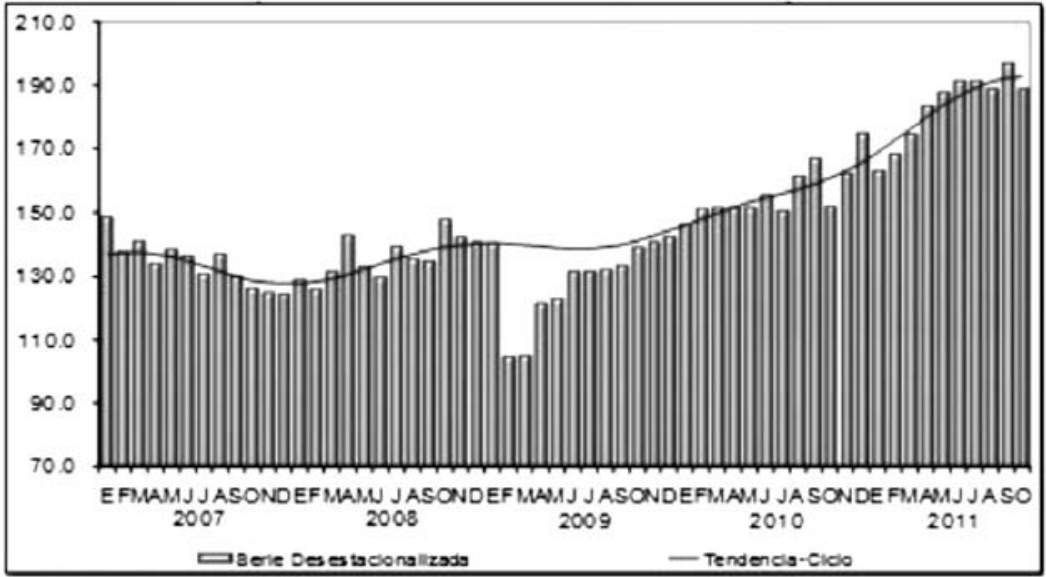

Fuente:INEGI

De acuerdo con el análisis desarrollado por el Instituto Tecnológico Autónomo de México (ITAM) por su Centro de Estudios de Competitividad, el sector minero en México 
aporta entre el $1.17 \%$ y $1.5 \%$ al producto interno bruto nacional, mantiene un saldo positivo en la balanza de pagos y contribuye con el $1.5 \%$ al empleo nacional. De manera estimada la producción minera nacional representa el $2.4 \%$ de la producción minera mundial.

México ocupa el $9^{\circ}$ lugar en la producción minera mundial y el $4^{\circ}$ lugar en la producción minera de Latinoamérica. Los países a los cuales se exporta la producción minera nacional son Estados Unidos, China, Japón, Perú, Suiza, República Dominicana y Canadá, entre otros (Abdel, p. 5).

El estudio en comento indica que "la inversión minera mundial está al alza en América Latina, con lo que se vislumbran importantes perspectivas para nuestro país y de acuerdo con las acciones estratégicas, el análisis competitivo realizado al sector minero basándonos en el Diamante de Porter concluye que las ventajas competitivas del sector están centradas en:

- La gran minería cuenta con tecnologías avanzadas en exploración, explotación y beneficio de minerales.

- La gran minería contribuye en gran medida al desarrollo social de diversas regiones del país.

- El sector minero cuenta con las ventajas que ofrecen los acuerdos de libre comercio suscritos entre México y diversas economías del mundo.

- Las empresas mineras que generan mayor valor agregado a los minerales son competitivas y están en posibilidad de mantenerse a la vanguardia.

- México cuenta con instituciones de apoyo a la minería cuyo esfuerzo ha logrado consolidar una legislación minera a la vanguardia, no obstante requieren de un nuevo enfoque dirigido a crear y propiciar el desarrollo de empresas mineras competitivas.

- El sector minero nacional cuenta con dos negocios tipo "estrella", la fluorita y la plata, es decir, líder en un mercado de gran crecimiento y presentan las mejores oportunidades en términos de crecimiento de las utilidades y de inversión que poseen las empresas" (Abdel, p. 5.).

\section{China y su relación con América Latina en la minería}

Todos estos datos han sido ampliamente estudiados y considerados por el gobierno chino, que ha impulsado a sus empresas paraestatales a través de la política "go west" que promueve las inversiones en el exterior, con el objetivo responder a la necesidad de autosuficiencia y su independencia (económica y a nivel energético).

Para ello, China ha desplegado importantes estrategias políticas y económicas, así como la instrumentación de políticas y mecanismos públicos para realizar un incremento considerable sobre el desarrollo y acceso a materias primas de todo el orbe, tomando como base fundamental el de los metales.

Parte de esas estrategias es el despliegue de importantes cantidades de inversión en infraestructura pública y en menor medida de transferencia de tecnología que ha venido 
realizando en países proveedores -situación que en México no se ha podido lograr-, de tal suerte que desarrolla carreteras, oleoductos, vías de ferrocarriles para facilitar el transporte de los recursos. Casos como empresas chinas estatales que comercian con el acero brasileño, el hierro argentino, el cobre de Chile, por el níquel de Cuba y por los recursos mineros de Canadá, Perú y de Australia.

En este sentido, el primer gran reto de México es dejar de ser un importante exportador-proveedor para convertirnos un estratégico receptor de inversión, infraestructura y sobre todo de recursos financieros que permita el desarrollo estratégico de la impactante cantidad de pequeñas y medianas empresas mexicanas.

Junto con los fenómenos económicos, migratorios, de crecimiento de consumo interno, el creciente poderío no sólo de la acumulación de minerales en territorio chino sino toda su política orientada al manejo de la cadena de materias primas hasta la producción final, como la acumulación de 95 millones de toneladas como reservas de hierro en los puertos Chinos (Xinhua, 2011), me ha llevado a manifestar en diversos foros y en obras de mi autoría ("China, la nueva fábrica del mundo" ) 2004 y "Rumbo a China", 2005) la necesidad de abandonar la visión acuartelada que se tiene sobre China en el sector comercial para contar con una visión integral que eleve el tema de nuestra relación con el país asiático al darle el grado de estrategia nacional, idea basada en la necesidad de analizar y crear un conjunto de estrategias que responda al cambio del equilibrio de diferentes componentes no comerciales (migratorios, medio ambiente, financiero) y desde luego del comercio de las materias primas, por la alarmante capacidad de acumulación que lleva a una dependencia para con los compradores y aproveche la importante acumulación de recursos financieros chinos, como su creciente despliegue tecnológico para potenciar la actividad no sólo minera sino toda la actividad económica de México, argumento que cobra vigencia como nunca antes, sobre todo con la reciente terminación de las Medidas de Remedio Comercial entre México y China (2008-11, diciembre de 2011) para la urgente necesidad de un nuevo instrumento que reúna las condiciones para tener una relación madura, inteligente y de progreso, tal como un acuerdo de complementación económica ya apoyado por otros destacados economistas como lgnacio Martínez Cortés, así como una nueva visión ampliamente descrita por Arturo Oropeza, Enrique Dussel Peters y el propio embajador Eugenio Anguiano.

Para evidenciar la reciente acumulación y control de China sobre los recursos minerales del mundo, puede verse el caso de la joint-venture por parte de China del grupo chileno Codelco, que representa $12 \%$ de la producción mundial de cobre con la compañía china Minemetals, la cual recibirá 55,000 toneladas de cobre por año, y que entre otras cosas ello distendió el paso a la celebración de Chile del Tratado de Libre Comercio con el país asiático.

Otros casos pueden verse con Cuba, donde China ha desarrollado la extracción y la producción de níquel o lo hecho en Zambia y sus yacimientos de cobre.

Merece la pena destacar que China consume una tercera parte del cobre del mundo y $40 \%$ de los metales básicos, y produce la mitad del acero mundial. Ocupa además el primer lugar en las producciones de oro, zinc y plomo. 
Empresas con sede en China o en Hong Kong participaron en compras e inversiones mineras en el extranjero valoradas en 13,000 millones de dólares el año pasado, 100 veces más que en 2005, según la firma de investigación de mercado Dealogic.

\section{La minería frente a la política monetaria china}

Con la creciente acumulación del déficit comercial que Estados Unidos tiene respecto de China, y que el país asiático cada día acumula una mayor reserva de dólares, le exige desplegar estrategias y una inteligente diversificación comercial para la instrumentación eficaz del yuan. Por ello, el comercio con minerales resulta ser la base de esa estrategia junto con otras materias primas como el uso de su flujo en dólares para comprar reservas de oro y plata, petróleo, gas, uranio, carbón, así como metales industriales.

\section{Situación actual de México frente a China}

Es dable considerar que México se ubica en los primeros diez lugares de producción mundial de 18 minerales, incluyendo, como ya se ha mencionado, el primer sitio en plata. El $70 \%$ del territorio nacional es susceptible de ser explotado.

Sin embargo, actualmente la producción minera contribuye con $1.6 \%$ del Producto Interno Bruto del país, únicamente por debajo la industria del petróleo y los ingresos por remesas.

Es una fuente tan importante de divisas para nuestro país que la producción minerometalúrgica ascendió a 13 mil 900 millones de dólares en 2010, superando a la industria turística.

La ubicación de los minerales industrialmente más comerciales se ubican en la costa del Pacífico, que sitúan a México en una condición de privilegio para la exportación a los grandes consumidores de la Cuenca del Pacífico, sobre todo China, Estados Unidos, Japón y Corea del Sur.

\begin{tabular}{|c|}
\hline Volumen de exportación de México en China en miles de pesos (INEGI) 2010 \\
\hline Cobre, $4,367,000$ \\
\hline Fierro $1,273,000$ \\
\hline Manganeso 74,000 \\
\hline Plata 103,000 \\
\hline Plomo $1,433,000$ \\
\hline Zinc 822,000 \\
\hline
\end{tabular}




\section{Sectores de la minería nacional frente a China}

Para hablar de la forma en que nuestro país se relaciona en materia minera con China puede decirse que actualmente la explotación puede considerarse en dos vertientes que comercian con China: por una parte la gran minería (grupos de fuerza industrial, básicamente 4 grupos productores) y por la otra la mediana y pequeña minería, vertiente entorpecida por la carencia de capital, el excesivo intermediarismo de brokers internacionales y por la delincuencia organizada a diversos niveles, afectando ya también en menor escala a la gran minería y a empresas inversionistas canadienses.

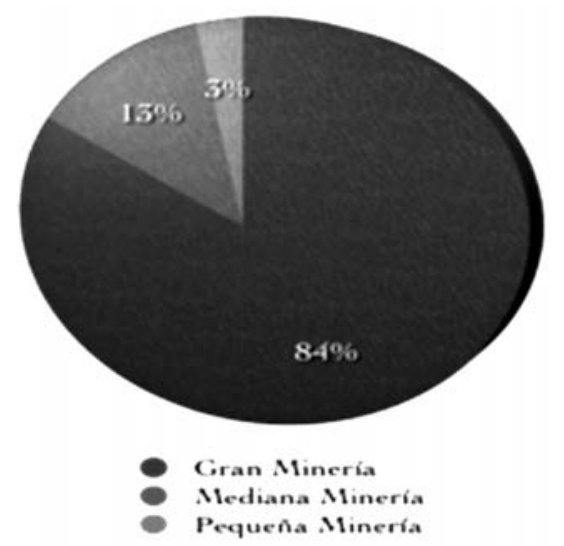

Fuente: Elaboración por parte de LAtinasia Group

\section{Los sectores mineros en México frente a China}

El sector minero mexicano está altamente concentrado en la gran minería, mismo que se compone de pocas empresas que cuentan con capital, tecnologías avanzadas en exploración, explotación y beneficio de minerales, son competitivas y generan valor agregado a los minerales para su exportación y consumo nacional.

En contraste, el sector minoritario de la pequeña y mediana minería trabaja en condiciones muy adversas de escasez de capital de trabajo y financiamiento, lo que redunda en un casi nulo acceso a tecnologías de explotación, ya que la gran mayoría de estos lotes mineros se encuentran en terrenos ejidales, cuyos propietarios son diferentes a los denunciantes poseedores de los títulos de concesión y también distintos a quienes podrían financiar la explotación y en su caso la exportación.

\section{Causas externas de la problemática actual frente a China}

A causa del gran crecimiento de las economías asiáticas, sobre todo China como la "fábrica del mundo", se ha generado una enorme demanda de algunos minerales útiles para la in- 
dustria y el comercio globales, tales como fierro, cobre, manganeso, zinc, plomo y aluminio, lo que ha servido de incentivo para que las empresas de ese y otros países hayan dedicado recursos de todo tipo a la búsqueda de esa materia prima en todo el planeta, generando un boom de demanda sobre todo en los últimos tres años, provocando un aumento en precios sin precedentes, pero ello no ha propiciado la atracción de inversión extranjera directa, empleos, ni transferencia de tecnología, pero sí que el crimen organizado sea el verdadero beneficiado de los bienes de la nación al cobrar cuotas de peaje y movimiento.

En México, el efecto ha sido la incursión multitudinaria de compradores, muchos de ellos intermediarios de intermediarios -o directamente defraudadores que les pagan con falsas cartas de crédito o documentos incobrables- que han contribuido a encarecer el mercado sobre todo en los casos de mineral de hierro, cobre y manganeso.

\section{Causas internas de la problemática actual frente a China}

La presión externa causada por la enorme demanda mundial de minerales para ser utilizados sobre todo como materia prima por China originó incentivos para que empresas formales e informales, intermediarios de diversa índole y hasta comercializadores sin experiencia en el ramo viniesen desde mediados de la década pasada a intentar comprar minerales, sobre todo hierro, cobre y manganeso.

Debido a que estos compradores e intermediarios tienen acceso nulo o muy limitado con las grandes empresas mexicanas, se han concentrado en la pequeña y mediana minería, con la informalidad que ello implica. Este exceso de demanda ha provocado presión para elevar los precios a pie de mina, donde los mineros o dueños de la tierra o denunciantes carecen de los recursos económicos para explotar y de los conocimientos para solicitar apoyos financieros gubernamentales o privados.

\section{Problemática del sector pequeña y mediana minería frente a China}

Los dueños de fundos tienen la problemática de que la gran mayoría se encuentra en terrenos ejidales impidiendo la posibilidad de desplegar operaciones comerciales con la debida certeza jurídica y agilidad comercial.

Los denunciantes o poseedores de los títulos de concesión suelen ser diferentes a los dueños de las tierras, lo cual crea un ambiente pleno de inestabilidad, falta de certeza jurídica, pero sobre todo entre inversionistas dispuestos a desarrollar inversiones.

La mayoría de los denuncios no tienen el sustento de reservas probadas, sino únicamente cuentan con estudios superficiales con estimaciones o reservas probables, en el mejor de los casos.

Unos y otros carecen de una estructura de organización que les permita acceder a créditos para explorar, realizar estudios geológicos, transportar mineral y comercializar. Estas múltiples carencias los hacen totalmente vulnerables a los especuladores, cadenas de intermediarios y sobre todo al crimen organizado que viene operando sobre todo en Michoacán, Guerrero, Colima, Jalisco, Sinaloa y Sonora. 
Estas organizaciones delictivas los obligan a pagar "peajes", "derechos de piso", cuotas por tonelada extraída, o bien los fuerzan a transferirles los denuncios o toman control de sus minas.

\section{Algunos proyectos mineros relevantes}

Según datos de la Secretaría de Economía de México (2010), las empresas chinas Zhong Ning México y Mining Investment Co han invertido 15 millones de dólares en proyectos de exploración minera en Guerrero y Michoacán. Originarias de Nimbo, China, los minerales de interés para ambas compañías son oro, plata, plomo, zinc, cobre y manganeso. ${ }^{1}$

Otra empresa, Desarrollo Minero Unificado de México, con base en Tianjin, China, inició la exploración de hierro en Colima, con un presupuesto aún desconocido. En Chihuahua, la empresa Jinchuan Group Ltd. gastó 25 millones de dólares en la exploración del proyecto minero Bahuerachi para producir zinc, cobre, molibdeno y plata, y planea invertir otros 590 millones para construir la mina en el 2010 y el 2011. Otra empresa china, Shaanxi Dong Ling Group, desembolsó 3.4 millones de dólares para el proyecto minero Los Vasitos, en Sinaloa, en donde produce hierro. Erogó además 500,000 dólares en la exploración de dos nuevos proyectos en el mismo estado: Las Andreas, para producir oro, cobre, plata y zinc, y Reyna del Cobre, para extraer hierro y cobre.

\section{Propuestas de valor}

La solución de profundidad para el sector de la Pequeña y Mediana Minería en México e incluso para los problemas recientes de la gran minería que han ahuyentado a los inversionistas extranjeros, es obviamente el reforzamiento de la seguridad brindada por los gobiernos de todos los niveles en las zonas sobre todo de la costa pacífica, tarea de largo plazo.

Aunado al aporte de este trabajo, planteamos estas cuatro propuestas concretas para el sector:

1. Creación de un fondo bilateral minero-metalúrgico entre México y China.

2. La creación de zonas económicas minero-metalúrgicas para que empresas chinas no sólo exploten y compren materia prima, sino que desplieguen actividad de producción en México.

3. Crear una ventanilla única de atención al pequeño y mediano minero -física y a través de internet-, a través de la cual se le brinde apoyo personal y guías abreviadas para que estructure su explotación y comercialización, así como obtención de créditos gubernamentales para hacerse de maquinaria, financiar

1 María Jimena Valverde, entonces coordinadora general de Minería de la Secretaría de Economía. Actualmente, Ney Dávila. 
transporte y obtener asesoría comercial que le permitan vender a clientes finales o compradores seguros en puerto, a través de uniones de productores mineros.

4. Reorientar parte de los fondos mineros de apoyo financiero (como el Fideicomiso de Fomento Minero (FIFOMI]) para crear plantas beneficiadoras regionales que permitan disminuir costos y agregar valor al mineral, no solamente para exportación como materia prima, sino como producto terminado o materia prima preparada de mayor valor comercial.

\section{Bibliografía}

-Abdel Musik, Guillermo, 2004, “El sector minero en México; diagnóstico, prospectiva y estrategia", Centro de Estudios de Competitividad del Instituto Tecnológico Autónomo de México.

-Agencia Xinhua. Ye, Xu. "La minería en México".

- Secretaria de Economía (SE) 2011. Dirección General de Minería. Resumen de indicadores básicos de Minería, 2010 y 2011.

- Instituto Nacional de Estadística Geografía e Informática (INEGI), boletín de prensa núm. 382/11 15 de diciembre de 2010 y 2011. 


\section{Lo urbano-ambiental en la relación entre México y China}

Sergio E. Martínez Rivera

Han pasado 40 años desde que México y la República Popular China (China en adelante) establecieron relaciones diplomáticas, en un continuo diálogo se han incluido paulatinamente temas que en la teoría propiciarían el beneficio mutuo. Entre esos grandes rubros se cuentan: cultura y educación, ciencia y tecnología, economía y comercio, inversión e infraestructura, regulaciones legales y sanitarias, medio ambiente, entre otros. Claramente, la temática económico-comercial ha tenido un lugar preferencial, lo que ha propiciado incluso que gran parte de las áreas de trabajo y acciones se orienten en buena medida con tal cometido. Ello se constata al revisar el contenido de la política exterior promovida con China en la década reciente en materia de tratados, acuerdos, convenios, memorándums de entendimiento y protocolos. ${ }^{1}$

En este contexto, un punto que merece ser elevado al mismo rango de importancia que el económico, es el del medio ambiente, el cual siempre es mencionado en sus diversas expresiones; sin embargo, es necesario que sea integral y congruente con la realidad ambiental que se vive en el planeta y no que se reduzca sólo al aspecto de garantizar el abastecimiento de recursos naturales (petróleo y sus derivados, madera, alimentos, metales y minerales, etc.); que se pretenda que las reglamentaciones y leyes ambientales o laborales sean más laxas o bien modificar el carácter jurídico de la tenencia de la tierra como pretenden algunos sectores empresariales y políticos sinomexicanos. Todo bajo el supuesto de que con ello el flujo de inversión extranjera directa aumentaría hacia México.

Existe todo un cúmulo de asuntos por atender en materia ambiental, sobre todo en China al estar posicionado entre los países que ejercen una mayor presión al ambiente dentro y fuera de sus límites territoriales y aun cuando México no experimenta la misma situación, bien puede proponerse una agenda de temas prioritarios que pudieran ser de interés mutuo.

En este documento se propone que el binomio ciudad-medio ambiente o bien urbano-ambiental sea considerado para integrarse en las mesas de trabajo binacionales. La justificación de tal incorporación es que actualmente China y México, junto con el resto de los países en vías de desarrollo enfrentan el reto histórico de administrar el alto dinamismo urbano presentado en su territorio, mismo que tiene múltiples expresiones ambientales, sociales y económicas y que condicionan la reproducción no sólo de las propias urbes sino a cada nación.

“La población urbana en México representa 71.4\% de la población total (78 millones de habitantes) y actualmente cuenta con 56 áreas metropolitanas donde se aglomera cerca de $53 \%$ de la población total del país $(57,878,905$ de habitantes). Por su parte, China presenta una población urbana de $47 \%$ de la población total (635.839 millones de

1 Para mayor detalle al respecto, consultar la presentación en extenso del Ministro Armando Álvarez Reina: http:// www.economia.unam.mx/cechimex/AAC2009iyii/Ministro\%20Alvarez\%20Reyna\%20Armando081008.pdf 
habitantes) mientras que cuenta con 53 áreas metropolitanas, donde se concentra $30 \%$ de la población nacional (380 millones de habitantes)".

China acusa condiciones y problemáticas urbano-ambientales complejas, derivadas principalmente del crecimiento económico sostenido en los últimos 30 años, para lo que se han consumido masivamente servicios ambientales, ergo la generación intensiva de residuos contaminantes (sólidos, líquidos y gaseosos). El resultado de tal comportamiento se ha reflejado en la transformación completa de todo su territorio y en la degradación de los ecosistemas locales. Este crecimiento no puede explicarse ceteris paribus sin la conformación y consolidación de un espacio urbano-industrial para el desarrollo incesante de todas las actividades de extracción y transformación, comerciales y financieras. Sin embargo, la ausencia de regulaciones ambientales eficientes y su mala administración urbana han propiciado que algunos de estos espacios literalmente hayan rebasado su resiliencia. El Banco Mundial señala que 16 de las 20 ciudades más contaminadas en el mundo son chinas. Por su parte, el Blacksmith Institute reporta que las ciudades chinas Tianjing y Linfen pertenecen al club de las 10 urbes más contaminadas en el mundo (BI, 2007). ${ }^{2}$

“Tianjin es reconocida como la principal productora de plomo (50\% de la producción nacional) en China. Debido a que se emplea tecnología atrasada y las regulaciones ambientales son prácticamente inexistentes. Los habitantes de Tianjin acusan una alta incidencia de enfermedades respiratorias, de la piel y cáncer de pulmón, además de que consumen alimentos como trigo, con un contenido de plomo hasta 24 veces más elevados de los aceptables (idem)".

A pesar de que las ciudades y zonas metropolitanas mexicanas acusan problemáticas cualitativa y cuantitativamente asimétricas con las chinas, es posible intercambiar experiencias, conocimientos y acciones concretas para varios aspectos entre los que destacarían (Martínez, 2012):

-Planificación y control del uso de suelo para evitar el crecimiento desordenado de la ciudad.

- Calidad del aire: modernización de la industria y transporte.

- Servicio de transporte público: movilidad y diversificación.

- Racionalidad, reutilización y aprovechamiento del agua.

- Construcción de inmuebles bajo normas sustentables como diseño y aprovechamiento de energía.

- Innovaciones urbanas para disminuir el impacto negativo de la ciudad al ambiente.

- Apoyo al sector rural y producción de alimentos locales.

- Manejo y tratamiento de residuos: sólidos, líquidos, gaseosos.

- Economía verde.

- Prevención y manejo de desastres naturales.

- Energía y cambio climático.

Una ventaja que se tiene para diseñar y promover una agenda a partir de esta larga lista de áreas de oportunidad, es la experiencia de los gobiernos locales, que han logrado es-

2 El resto de las ciudades más contaminadas en el mundo son: Sumgayit (Azerbaiyán), Sukinda y Vapi (India), La Oroya (Perú), Dzerzhinsk y Norilsk (Rusia), Chernobyl (Ucrania) y Kabwe (Zambia). 
tablecer vínculos con contrapartes chinas para establecer relaciones de diversa índole. Tal es el caso de la Ciudad de México, que el 19 de octubre de 2009 suscribió con Pekín un acuerdo de hermanamiento. Este acuerdo se rige sobre los principios de igualdad y beneficio recíproco, por medio del diálogo, igualdad, comunicación de información, visitas recíprocas, estudios e investigaciones conjuntas y cooperación de proyectos, refuerzan el desarrollo de intercambio y cooperación de múltiples modalidades en los terrenos económico, científico-tecnológico, cultural, turístico, educativo, deportivo y sanitario y de la construcción urbana, a fin de promover la prosperidad y el desarrollo compartido.

Considerando que este hermanamiento es de reciente creación, el apartado referente a la Construcción y administración urbana es aceptable en primera instancia; sin embargo, debe reformularse e incorporar paulatinamente los elementos antes mencionados y, en general, apegarse al planteamiento de ciudad sustentable propuesto por el Programa de Asentamientos Humanos y el Programa de Medio Ambiente de la ONU.

Una ciudad sustentable es aquella donde los logros en el desarrollo social, económico y físico están hechos para durar. Tiene una oferta perdurable de los recursos ambientales de los cuales depende su desarrollo solamente si su uso es sustentable. Una ciudad sustentable mantiene una seguridad permanente frente a los riesgos ambientales que tienen el potencial de amenazar los logros de su desarrollo, permitiendo sólo niveles de riesgo aceptables (CNUAH-ONU: 2000).

Por otra parte, exceptuando a la Ciudad de México, al mes de julio de 2011 la Secretaría de Relaciones Exteriores registró 7 hermanamientos, 2 a nivel estatal y 5 municipales; 16 convenios u otro tipo de acuerdos que no son hermanamientos, de los que 13 son estatales y 3 municipales. No obstante, al igual que a nivel federal en el contenido de estos convenios la parte urbano- ambiental no es sobresaliente y en algunos casos no está considerada dado que el tema económico-comercial es prioritario (ver cuadro 1).

Un par de instrumentos que pueden servir de referencia para futuros acuerdos ya sea a nivel de provincias o ciudades por su contenido son: el Plan Verde de la Ciudad de México $^{3}$ y el Plan Maestro de Tianjin ${ }^{4}$ de ciudad ecológica. Dado que ambos planes son de reciente creación sería importante que los resultados obtenidos paulatinamente pudieran intercambiarse para desarrollar una base de acciones y estrategias concretas, considerando, claro está, el tipo, la escala y magnitud de los fenómenos. Debe tenerse en cuenta que para aspirar a que las ciudades alcancen una mayor sustentabilidad debe incorporarse el aspecto económico y social. Esto significa que los procesos productivos y de consumo sean ecológicos, que se logre una mayor equidad entre los individuos, mejorar el aspecto de los derechos humanos, etc. No es sólo concentrarse en la lógica de crear ciudades verdes per se, sino que también sus habitantes puedan alcanzar una mayor calidad de vida.

3 http://www.planverde.df.gob.mx/planverde/

4 http://www.siww.com.sg/pdf/08_Developing_a_city_of the_future_Sino_singapore_Tianjin_Eco_city.pdf http://www.tianjineco-city.com/en/eco_city/Eco_City Master_Plan/988.aspx 
China está invirtiendo significativamente en investigación y desarrollo para atender la gama de retos de carácter urbano-ambiental que está experimentando y que prevé se complejizará, ya que por ejemplo se espera que para el año 2025 su población urbana será de 926 millones de habitantes. En términos entrópicos esto supondrá una mayor huella ecológica y por ello el gobierno chino está tratando de prepararse en distintos frentes.

Un ejemplo de esto es la activa realización de eventos ad hoc, como el "2011 World Cities Scientific Development Forum" realizado en agosto de 2011 en Chengdu, donde se discutieron temas como planeación urbana y diseño para ciudades resistentes a desastres, manejo de emergencias y desastres en ciudades; transición económica y desarrollo sustentable en urbes, cooperación bilateral y multilateral para el desarrollo de ciudades sustentables.

A esto hay que agregar el intenso impulso de ramas productivas asociadas a la creación de energías renovables, tratamiento y aprovechamiento de residuos solidos, transporte, etc., también conocido como Green business. Una crítica a este tipo de mecanismos y negocios es que el objetivo real de la conservación ambiental puede desvirtuarse, al presentarse un escenario donde ciertos rubros del ambiente no puedan mercantilizarse, o bien si no se puede tener acceso a infraestructura y tecnología sustentable.

Cuadro 1. Tipo de acuerdos entre entidades mexicanas y chinas al 2011.

\begin{tabular}{|l|l|l|l|}
\hline \multicolumn{1}{|c|}{ Entidad mexicana } & \multicolumn{1}{|c|}{ Entidad china } & Techa de suscripción & \\
\hline Estado de México & Guandong & 3 de junio de 2002 & $\begin{array}{l}\text { Convenio del establecimiento de la relación de } \\
\text { amistad entre ambos. }\end{array}$ \\
\hline Estado de México & Chongqing & 11 de mayo de 2004 & Memorando de entendimiento \\
\hline Hidalgo & Henan & 26 de septiembre de 2006 & Acuerdo de hermanamiento \\
\hline Jalisco & Shanghai & 18 de noviembre de 1998 & $\begin{array}{l}\text { Convenio del establecimiento de la relación de } \\
\text { amistad entre ambos. }\end{array}$ \\
\hline Hidalgo & Henan & 26 de septiembre de 2006 & Acuerdo de Colaboración \\
\hline Jalisco & Shangai & 15 de julio de 1999 & Memorando de entendimiento \\
\hline Jalisco & Henan & 1 de septiembre de 1999. & Memorando de Cooperación \\
\hline Jalisco & Shanghai & 11 de abril de 2005. & Fortalecer la comunicación \\
\hline Jalisco & Xiamen & 23 de mayo de 2002. & Memorando de Entendimiento \\
\hline Querétaro, Querétaro & Hebei & 28 de octubre de 1996 & Acta Protocolo de Hermanamiento \\
\hline $\begin{array}{l}\text { Toluca, } \\
\text { Estado de México }\end{array}$ & $\begin{array}{l}\text { Nanchang, } \\
\text { Jiangxi }\end{array}$ & 16 de agosto de 1998. & Acta de Hermandad \\
\hline
\end{tabular}




\begin{tabular}{|c|c|c|c|}
\hline Entidad mexicana & Entidad china & Fecha de suscripción & Tipo de acuerdo \\
\hline Coatzacoalcos, Veracruz & Rizhao, Shangdong & 23 de octubre de 2008 & Acuerdo de Hermanamiento \\
\hline Hidalgo & Henan & 20 de noviembre de 2007 . & $\begin{array}{l}\text { Memorando de Comprensión del Fortalecimiento } \\
\text { de Cooperaciones }\end{array}$ \\
\hline Jalisco & Shanghai & 26 de noviembre de 2008 & Acuerdo de Cooperación \\
\hline Jalisco & Shanghai & 8 de diciembre de 2008 & Acuerdo de Cooperación \\
\hline $\begin{array}{l}\text { Tlalnepantla, } \\
\text { Estado de México }\end{array}$ & $\begin{array}{l}\text { Maanshan, } \\
\text { Anhui }\end{array}$ & 15 de septiembre de 2008 . & Hermanamiento \\
\hline Chihuahua & Shandong, & 31 de marzo de 2006. & $\begin{array}{l}\text { Acuerdo de Entendimiento para Fortalecer la Co- } \\
\text { municación Amistosa y la Cooperación Económica }\end{array}$ \\
\hline Chihuahua & Henan & 5 de abril de 2006 . & $\begin{array}{l}\text { Acuerdo de Entendimiento para Fortalecer la Co- } \\
\text { municación Amistosa y la Cooperación Económica }\end{array}$ \\
\hline Quintana Roo & Provincia de Hainan & 30 de septiembre del 2008. & Acuerdo de Establecimiento de Hermanamiento \\
\hline $\begin{array}{l}\text { Culiacán, } \\
\text { Sinaloa }\end{array}$ & $\begin{array}{l}\text { Ciudad de } \\
\text { Zhongshan, }\end{array}$ & 01 de junio de 2007 & $\begin{array}{l}\text { Memorando de Entendimiento sobre las Coopera- } \\
\text { ciones Amistosas }\end{array}$ \\
\hline $\begin{array}{l}\text { Zapopan, } \\
\text { Jalisco }\end{array}$ & $\begin{array}{l}\text { Ciudad de Chengdu, } \\
\text { Sichuan, }\end{array}$ & 10 de septiembre de 2010 . & Memorando de Cooperación Amistosa \\
\hline $\begin{array}{l}\text { Zapopan, } \\
\text { Jalisco }\end{array}$ & $\begin{array}{l}\text { Distrito de } \\
\text { Putuo, Shanghai, }\end{array}$ & 22 de octubre de 2010 . & Acuerdo de Cooperación \\
\hline Guadalajara, Jalisco & Ciudad de Xiamen & 22 de junio de 2011. & Acuerdo de Ratificación de Hermanamiento \\
\hline
\end{tabular}

Fuente: Elaboración propia con base en la SER (2011). ${ }^{5}$

En suma, es importante que México aproveche al máximo la sinergia de lo que está desarrollando China en materia urbano-ambiental, al mismo tiempo que tenga la capacidad de ofrecer convenios y acuerdos que sean de interés en este sentido. No es una tarea sencilla, pues el rubro ambiental es uno de los más críticos a cualquier nivel, ya que obliga a asumir costos y compromisos que repercuten en lo político y lo económico a nivel nacional e internacional.

Debe propiciarse que en las mesas de trabajo y negociación se tenga como eje de las discusiones ambientales los planteamientos y postulados del Desarrollo Sustentable e incluso superarlos. Es urgente que las relaciones sino-mexicanas mejoren y atiendan aspectos más allá del esquema primario exportador de recursos naturales, ya que este modelo ambientalmente no conviene a México, pues la degradación que se genera no es asumida por China con por cualquier otro país como ha sucedido en diferentes latitudes del planeta (selva amazónica brasileña, pampas argentinas, minas chilenas y peruanas, etc.).

Finalmente, México a diferencia de sus principales vecinos latinoamericanos (Argentina, Brasil y Chile), no ha obtenido los mismos beneficios de su relación con China. Existen múltiples argumentos explicativos de esta situación, los cuales a veces son meramente especulativos y otras reflejan la realidad del fenómeno como tal. Entre estos argumentos se cuenta, por ejemplo, que el gobierno federal mexicano no accede a

5 Para mayor referencia de revisar: www.sre.gob.mx/gobiernoslocales/ 
diseñar una agenda nacional de largo alcance con China por una supuesta presión de Estados Unidos para evitar que México se convierta plenamente en la puerta de entrada para mercancías y migrantes chinos a su territorio; la inexistencia de un órgano institucional especializado encargado de estudiar la dinámica de China, ergo formular las políticas y acciones que pudieran beneficiar a México y al mismo tiempo ser atractivas para China; la insuficiencia de cuadros de asesores y políticos especializados en los distintos ordenes de gobierno (federal, estatal y municipal) y en lo privado, entre otras.

En este escenario, tal parece que el futuro más inmediato para poder promover algún tipo de acuerdo de carácter urbano-ambiental seguirá siendo a nivel municipal o estatal. Por ello sería importante convocar a diversos actores en la academia, el sector privado y público para proponer estrategias solventes. Una posible limitante podría ser la álgida relación que en veces suele presentarse entre ambos gobiernos como el más reciente evento, cuando en septiembre de 2011 el presidente Felipe Calderón dio la bienvenida al Dalai Lama, lo que provocó molestia e inconformidad por parte del gobierno chino. Sin embargo, esperemos que este 2012 represente el fin de una era y el comienzo de otra en la relación entre México y China.

\section{Bibliografía}

-Blacksmith Institute (BI), (September 2007), The World's Worst Polluted Places: The Top Ten of The Dirty Thirty. New York-USA.

- CNUAH-ONU, 2000, Conferencia de las Naciones sobre Asentamientos Humanos (Habitat II) Naciones Unidas, Declaración Final. Asamblea Mundial de Ciudades y Autoridades Locales, Estambul.

-Martínez, Rivera Sergio E., 2012, “Ciudades sustentables: conceptualización y crítica". En Sergio E Martínez, Rivera y Yolanda Trápaga, Delfín (editores), Construyendo ciudades sustentables: intercambio de experiencias de Pekín y la Ciudad de México. Centro de Estudios China-México, FE-UNAM, México.

\section{Referencias electrónicas}

- www.economia.unam.mx/cechimex/AAC2009iyii/Ministro $\% 20$ Alvarez $\% 20$ Reyna\%20Armando081008.pdf

- www.planverde.df.gob.mx/planverde/

- www.sre.gob.mx/gobiernoslocales

- www.siww.com.sg/pdf/08_Developing_a_city_of the future Sino_singapore_Tianin_Eco_city.pdf

- www.tianjineco-city.com/en/eco_city/Eco_City_Master_Plan/988.aspx 


\title{
China. Políticas agrícolas antes y después de la crisis alimentaria de 2008
}

\author{
María Teresa Rodríguez y Rodríguez
}

\section{Introducción}

Durante la crisis financiera global de 2007-2008, la República Popular China estuvo entre las pocas naciones cuya economía continuó creciendo, y parece haber salido muy rápidamente de la relativa deflación que sufrió en $2009 .{ }^{1}$ En realidad, China ha experimentado crecimiento económico continuado desde principios de los $80,{ }^{2}$ con transformación de su estructura productiva y mejoramiento sustancial del ingreso y de los niveles de vida de su población.

Es decir, junto al crecimiento económico ha habido desarrollo en el sentido amplio del término, y reducción del número de pobres, los que según la Organización Internacional del Trabajo (OIT) representaban 33\% de la población rural (o 250 millones de personas) en 1978; $11 \%$ en 1984; $8 \%$ en 1994 y $3.7 \%$ en 2000 (o 30 millones de personas). ${ }^{3}$ En cuanto a indicadores de desarrollo humano, el Programa de las Naciones Unidas para el Desarrollo (PNUD) sitúa a China en el sitio 101 de un total de 187 países, lo que la coloca entre los de desarrollo humano medio (PNUD 2011: 144).

Pero junto al desarrollo socioeconómico ha habido distorsiones, una de las cuales es el deterioro progresivo de la distribución del ingreso, ${ }^{4}$ que entre otras cosas se presenta como diferenciación creciente de niveles de vida entre ciudad y campo, en perjuicio de los habitantes de zonas rurales. ${ }^{5}$ También por las exigencias del crecimiento económico, en cuanto a adición de insumos materiales como forma de lograr las metas fijadas por

1 En mayo de 2009 el índice de precios al consumidor disminuyó 1.5 puntos porcentuales en las ciudades (98.5 respecto a 100 en mayo 2008) y 1.0 punto en el campo (99.0 respecto a 100 en mayo 2008), pero productos como la carne y el pollo redujeron sus precios en más de 15 puntos porcentuales (84.5 promedio), (en http://www.stats.gov.cn/english/statisticaldata/monthlydata/t20090626_402568089.htm ).

2 El PIB a precios constantes de 1978 creció $9.91 \%$ entre 1978 y 2010, ó $10.46 \%$ entre 1990 y 2010 , y el PIB per cápita creció 8.77 y $9.55 \%$, respectivamente para los años citados, ello a pesar de que durante el 1 er trimestre de 2009, respecto al mismo periodo del año anterior, el crecimiento del PIB fuera de apenas $6.1 \%$, y durante el $2^{\circ}$ trimestre del mismo año de 7.9\% (información de la Oficina Estatal de Estadísticas de China, China Statistical Yearbook 2011, p. 48; información emitida el 20 de abril y otra del 16 de julio de 2009, respectivamente para el primero y segundo trimestres de ese año, se tomó de The Wall Street Journal Online, del 17 julio 2009).

3 Por su parte, el Banco Mundial señala que en China en 1990, los pobres todavía representaban 31\% de la población rural y en $199811 \%$ de la misma.

4 El coeficiente Gini de ingresos, que en 1978 era de 28, en 2001 era de 39 (Ravallion, 2007: 51-52), y para 2002011 (el dato se refiere al año más reciente disponible dentro de este periodo) había subido a 41.5 (UNDP, 2011: 154). Cabe señalar que en el coeficiente de Gini la igualdad total se representa como cero (0), y la desigualdad absoluta sería cien (100), lo que querría decir que un individuo del grupo acapara la totalidad de la riqueza disponible.

5 En 1985, pocos años después de haberse introducido reformas a la economía, la disparidad entre ingresos urbanos y rurales era de 1.9 a 1, y en 2010 dicha disparidad ya era de 3.2 a 1. NBS, CSY2011: 330). 
los líderes, se ha producido deterioro del medio ambiente, que se contrapone con la sustentabilidad del desarrollo que se pretende alcanzar en el largo plazo.

En este contexto de crecimiento rápido pero desbalanceado, ${ }^{6}$ en el umbral del cambio de siglo el liderazgo chino comenzó a tomar conciencia del impacto que el modelo de desarrollo estaba teniendo sobre la estructura económica y, más importante, sobre la distribución de los beneficios del desarrollo. Los resultados prácticos de este cambio de percepción son todavía incipientes, pero por lo pronto puede hablarse de nuevas políticas económicas, más enfocadas al desarrollo socioeconómico integral, las que se espera rindan frutos en el mediano plazo.

Esta ponencia tiene como propósito presentar las políticas agrícolas en operación en China, que son parte integral de su proyecto de desarrollo y se han visto influidas por el mencionado cambio de percepción de su liderazgo: un conjunto de medidas que desde luego se enfocan al desarrollo de la agricultura, pero cuyo verdadero campo de acción es el medio rural. En esta ocasión quiero examinarlas en conexión con la crisis alimentaria o de seguridad alimentaria global más reciente, la ocurrida en 2008.

Con esta idea en mente, haré un recuento breve de la crisis de alimentos, mencionando las que se considera son sus causas principales y las políticas económicas con las que se ha tratado de superarla, adoptadas por una gran diversidad de países en desarrollo, los más afectados por dicha crisis. Pero el tema central de este trabajo sigue siendo China, de forma tal que una parte importante del mismo se dedicará a las políticas agrícolas (en sentido amplio) en operación en China, las existentes antes de la mencionada crisis alimentaria y las que se aplicaron durante la misma, fueran nuevas o como reforzamiento de las anteriormente establecidas. Finalmente, de lo tratado a lo largo del texto se derivarán conclusiones, básicamente para lo relativo a China.

\section{La crisis de seguridad alimentaria de 2008 , causas de la misma y políticas introducidas en países en desarrollo para contrarrestarla.}

Después de más de dos décadas durante las cuales prevalecieron precios bajos de los alimentos, si acaso con alzas estacionales de los mismos, en 2006 los precios de cereales y oleaginosas, principalmente, comenzaron a subir, primero lentamente pero en forma cada vez más rápida, una tendencia al alza que continuó en 2007 y se aceleró en 2008, cuando los precios de los cereales alcanzaron un máximo. ${ }^{7}$ Incluso en términos reales, en el cuadro 1 al final del texto se observa que varios cereales, así como el frijol de soya y el azúcar, experimentaron aumentos de precios de entre 20 y $45 \%$ en 2008 respecto a 2007 (Brahmbhatt, 2008: 6). Muy pronto pudo verse que la crisis alimentaria de 2008, eleva los precios promedio por encima de los alcanzados durante la crisis de principio de los años setenta.

6 Por el que se ha dado prioridad a la inversión sobre el consumo (con términos de intercambio desfavorables para la agricultura) y a las exportaciones más que a fortalecer el mercado interno.

7 Lo que más subió fue el arroz en los mercados internacionales de alimentos. En 1990 una tonelada de arroz costaba alrededor de 300 dólares de Estados Unidos por tonelada (\$EU/Ton.); en 2004 su precio bajó a 200 \$EU/Ton.; en enero de 2008 llegó a 400 \$EU y en mayo de ese mismo año alcanzó 1,100 \$EU, casi el triple que cuatro meses antes (Brahmbhatt, 2008: 3-6). 


\subsection{Causas de la crisis alimentaria de 2008}

A diferencia de la crisis de 1973-74, cuando los precios de los alimentos subieron debido principalmente a incrementos en los precios del petróleo, trasladados a los precios de los fertilizantes y los transportes, en esta ocasión, aunque ése ha sido uno de los factores de distorsión de precios no ha sido el único, sino ha ido acompañado de cambios en la ecuación oferta-demanda de alimentos, por causas reales pero también por intervención discrecional, privada y pública, en el mercado internacional y en los diferentes mercados nacionales de alimentos.

Por el lado de la oferta parece haber habido descuido de países productores y consumidores, los primeros poco estimulados a producir más y los segundos convencidos de la conveniencia de importar en vez de producir en condiciones menos competitivas que las de sus proveedores regulares, lo cual en la mayoría de los casos estuvo acompañado de reducción de la inversión en infraestructura agrícola. A incrementos en la producción per cápita entre 1961 y 1981-1985, le siguieron reducciones de la misma como resultado de un ritmo de crecimiento menor al de la población (ver cuadro 2 en apéndice estadístico).

En lo referente a medidas discrecionales tomadas por los gobiernos, que también han resultado en reducción de la oferta en el mercado internacional de alimentos, está la formación de reservas de granos muy por encima de las consideradas normales, en combinación con la prohibición de exportarlos de parte de algunos países productores, y las compras de pánico de los deficitarios, como protección ante la escalada de precios. A todo ello se añade la especulación, agudizada en 2008 por la incertidumbre en cuanto a seguridad alimentaria se refiere.

Por el lado de la demanda se mencionan India y China como los principales causantes de su rápido crecimiento, tanto por el tamaño de sus poblaciones como por el mejoramiento de sus respectivos niveles de vida, que ha llevado a mayor consumo total y a cambios en los hábitos de consumo de alimentos de sus poblaciones (hacia el mayor consumo de carne, huevo y, en el caso de India, lácteos, con la consecuente desviación de cereales para la alimentación de aves y ganado); no hay que olvidar que en los países desarrollados el consumo de carne, huevo y lácteos es mayor que el promedio mundial y desde luego mucho mayor al de la mayoría de los países en desarrollo (ver ejemplos en cuadro 3). Pero además de los incrementos en el consumo humano y animal, está produciéndose desviación de cereales y de oleaginosas para la producción de combustible, y aquí el culpable principal aunque no el único sería Estados Unidos. Este último tipo de demanda influye particularmente sobre los precios del maíz y de algunas oleaginosas.

\subsection{Políticas económicas frente a la crisis de alimentos}

Las políticas económicas introducidas o reforzadas en conexión con la crisis de alimentos de 2008 se clasifican en:

Políticas comerciales, entre las que destacan la reducción de las tarifas de importación y la prohibición para exportar o la imposición de cuotas a la exportación de cerea- 
les, ello con el propósito de garantizar un volumen dado de alimentos al interior del país de que se trate y de proteger al mercado interno de la volatilidad de los precios internacionales de los alimentos. Al interior de los países, la mayor intervención del gobierno como distribuidor de los alimentos disponibles ([producción interna + importaciones + reducción de inventarios] - [incremento de inventarios + exportaciones]) generalmente resulta en reducción de la incertidumbre y en baja de precios.

Políticas de apoyo a los consumidores, consistentes en apoyos directos a los grupos más vulnerables, sea en especie o en dinero, ${ }^{8}$ en apoyos al incremento del ingreso disponible (básicamente reducción de impuestos) y en medidas para la preservación del ingreso real (control de precios de los alimentos).

Políticas de apoyo a los productores a fin de que incrementen la producción, entre las que predominan los subsidios a los insumos y todo tipo de apoyos a la producción. Para el mediano plazo es de esperarse que el cambio de perspectiva lleve a creación de infraestructura, a ampliación de recursos para la investigación y el desarrollo y a nuevas formas de extensión agrícola, sobre todo porque este tipo de esfuerzos no se contrapone con lo establecido por la Organización Mundial de Comercio (OMC) para los países miembros en cuanto a límites a los apoyos a la producción agropecuaria.

Pero no hay que olvidar que la aplicación de políticas económicas como respuesta a los altos precios de los alimentos, lleva a utilización de recursos públicos: sea para la comercialización de los alimentos básicos, para la provisión de subsidios a los productores, para el otorgamiento de créditos en condiciones preferenciales o, en lo referente a los apoyos a los consumidores, para transferencias a las familias vulnerables, razón por la cual en cada caso se hace necesario llevar a cabo análisis de costo-beneficio. Al mismo tiempo, la eficacia de las políticas comerciales de algunos gobiernos para aislar a sus economías de los cambios en los precios internacionales no siempre es positiva para el mercado internacional de alimentos, pues resulta en reducción de la oferta comercializable total, y en ese sentido contribuye a la volatilidad de los precios internacionales de los alimentos, y a un mayor grado de vulnerabilidad en las economías más desprotegidas.

\section{Políticas agrícolas en aplicación en China, anteriores y durante la crisis de seguridad alimentaria de 2008}

La República Popular China tiene una larga experiencia de diseño y aplicación de políticas agrícolas y de apoyo al sector rural, las que en varias ocasiones se han visto influenciadas por el clima político prevaleciente. Con posterioridad al ingreso de China a la OMC y más todavía en conexión con el cambio reciente de perspectiva de su liderazgo en cuanto a los objetivos que debe alcanzar el crecimiento económico, expresados en

8 Desayunos escolares como forma de mantener a los niños en la escuela; apoyos en dinero a los niños y adolescentes, con la condición de que asistan a la escuela y se hagan revisar la salud con regularidad, los que pueden ser individuales o para la familia a la que pertenecen (el caso del Programa Progresa/Oportunidades en México). 
el Undécimo Plan Quinquenal 2006-2010, y reiterados en el siguiente (12 P. Q. 20112015), ${ }^{9}$ se ha buscado la modernización de la agricultura a partir de la restructuración de los cultivos y la especialización por regiones, además de que los apoyos a productores y consumidores han cobrado mayor importancia; en lo relativo a las políticas comerciales, China ha hecho ajustes graduales tendientes a la apertura del sector agropecuario, consecuentes con los compromisos que adquirió al momento de su entrada a la OMC. Puede decirse que desde antes de la mencionada crisis de alimentos de 2008, China ya contaba con una estrategia sólida para el mejoramiento del campo, apoyada en políticas económicas para el sector que se encuentran en constante evolución.

La idea detrás de las modificaciones a las políticas agrícolas respecto a las aplicadas durante las primeras dos décadas de reforma económica es que, en el contexto de creciente apertura al exterior y de búsqueda de un desarrollo armónico, ${ }^{10}$ hay que incrementar la eficiencia productiva, pero ya en función del aprovechamiento de las ventajas comparativas, las del país en su conjunto y las de cada región del mismo.

Al mismo tiempo, la cada día más amplia diversificación de la producción agropecuaria, y su mayor calidad, deben basarse en mejoras de productividad más que en aumento indiscriminado de insumos materiales, lo que definitivamente es esencial para la preservación del medio ambiente. Para que eso se logre tiene que haber amplia participación del gobierno, lo que no quiere decir centralización de las actividades productivas ni control administrativo sobre los actores económicos participantes en ellas. Más importantes son los incrementos de recursos financieros destinados a créditos a la agricultura, a la I\&D y a la difusión de los avances técnicos y tecnológicos para el sector, y los apoyos gubernamentales a la comercialización agrícola y a la integración del sector al resto de la economía, todo ello a fin de facilitar su participación amplia en el comercio con el exterior en condiciones competitivas. Por el lado de los actores económicos involucrados se requiere la acción coordinada de los productores, ello a partir de la constitución de organizaciones cooperativas, cuyos miembros más importantes sean los agricultores de tiempo completo, los más necesitados de estímulos materiales y organizativos.

\subsection{Objetivos y políticas más relevantes de la estrategia imperante para la agricultura}

- Construcción de infraestructura agrícola, de transporte y comunicaciones

-Apoyos a la comercialización de la producción agropecuaria

9 Los lineamientos del $11^{\circ}$ plan quinquenal (2006-2010), de los que se desprende una serie de orientaciones de política, objetivos, tareas por cumplir y prioridades estratégicas, son: 1) mantener un desarrollo económico continuado y rápido, 2) acelerar la transformación del patrón de crecimiento económico, 3) mejorar la capacidad para la innovación independiente, 4) promover el desarrollo coordinado entre áreas urbanas y rurales, 5) construir una sociedad armoniosa centrada en la gente, 6) profundizar en la reforma y la apertura al exterior (World Bank, diciembre 2008: 7).

10 Específicamente con relación a la búsqueda de la armonía en la sociedad, ésta no podrá alcanzarse si no se corrige la tendencia a la disparidad de ingresos y niveles de vida entre campo y ciudad, la que comenzó a crecer más rápidamente a partir de principios de los años 90, o desde antes, por el desgaste durante la segunda mitad de los 80 , de las medidas de política aplicadas en el campo durante la primera mitad de esa década. Y el desarrollo armónico se sustenta en el llamado desarrollo científico, un concepto recientemente acuñado que para el caso de la agricultura se refiere a modificar, desarrollar y elevar sus niveles; en suma, buscar su modernización integral. 
-Absorción, por medio de mejoras de la productividad, de los incrementos de precios de los insumos materiales y, eventualmente, de los incrementos salariales de la mano de obra rural

- Apoyo a la creación de organizaciones campesinas, lo que redundará en mejor aprovechamiento de los servicios de extensión agrícola. Esto no puede lograrse sin la aceptación, por parte del gobierno chino, de las organizaciones no gubernamentales (tradicionalmente estigmatizadas por las autoridades)

- Constitución de empresas productoras a las que se les autoricen superficies de tierra agrícola por encima del promedio nacional (que es de entre 0.40 y 0.50 de hectárea por trabajador agrícola), medida que se espera beneficie a los agricultores de tiempo completo

Nuevas políticas agrícolas introducidas en China en conexión con los objetivos anteriores

A. Aquellas que representan un "ajuste estratégico de la agricultura", que redunde en mejoramiento de la calidad de los productos agropecuarios y de la productividad, a saber:

- Establecimiento de proyectos de mejoramiento de semillas para optimizar las variedades de cultivo

- Desarrollo de actividades de procesamiento industrial

-Ajuste de los patrones regionales de cultivo en función de las ventajas comparativas regionales

-Apoyos a la transferencia intersectorial de mano de obra

B. Las específicas para el aprovechamiento de las ventajas comparativas regionales, que lleven a una modificación gradual del patrón regional de cultivos:

- Identificación de las ventajas comparativas por aprovechar

- Extensión gradual del cultivo del arroz al norte y al noreste del país; eso sin abandonar el cultivo ya existente en el sur de China

- Concentración de la producción de otros cereales en la región central

- Concentración de la producción de frutas y verduras en la región costera

- Aceptación de la conveniencia de importar trigo y frijol de soya, con la posibilidad de exportar cantidades crecientes de arroz

Cabe destacar que la construcción de infraestructura agrícola, de transporte y comunicaciones no es algo nuevo, pues formaba parte integral del proyecto maoísta de capitalización de la agricultura, y se alcanzaba a partir de la utilización masiva de la mano de obra rural más un mínimo de insumos materiales. No implicaba una desviación de recursos financieros ni se hacía a costa del cumplimiento del objetivo central del modelo de planificación centralizada, de acumulación para la industrialización. En la actualidad, las autoridades chinas reconocen que la creación de infraestructura de cualquier tipo requiere de montos muy grandes de recursos financieros, y que la 
infraestructura agrícola no es excepción a esa regla; es decir, al incluir este objetivo dentro de la nueva estrategia para la agricultura, el liderazgo actual está comprometiéndose a transferir recursos del resto de la economía a la agricultura, para su modernización.

\subsection{Nueva estrategia para el desarrollo del sector rural}

Uno de los objetivos del $11^{\circ}$ plan quinquenal (2006-2010) fue el de adoptar un enfoque integral para el desarrollo del sector rural, y aunque se presente como una tarea, la de construir un campo de carácter socialista, también se le interpreta como el desarrollo armonioso de los tres 'nong': nongye (农业), o agricultura; nongmin (农民), campesino o campesinado y nongcun (农村), o campo. A final de cuentas representa una reiteración del frecuentemente mencionado interés por el desarrollo del campo, en esta ocasión como parte de un enfoque de desarrollo que engloba a toda la economía y a la sociedad.

Entre los objetivos de la nueva estrategia para el desarrollo rural destacan:

- Estímulo renovado a la industrialización en zonas rurales, sin consideración del tipo de propiedad de las empresas

- Urbanización de pequeñas poblaciones anteriormente rurales, a las que debe dotarse de servicios urbanos básicos; más aceptación y apoyo a la migración de los pobladores rurales a las ciudades medianas y grandes

- Unificación de las cargas tributarias al campesinado (las que no deben superar el $5 \%$ de su ingreso)

- Abolición del impuesto agrícola (que se basaba en el número de miembros por familia y en el área cultivada por ella)

- Medidas para la transferencia expedita de los derechos al uso de la tierra agrícola

- Replanteamiento de los apoyos gubernamentales al campo, con base en las reglas de la Organización Mundial de Comercio

- Consolidación de las reformas ya existentes en el sistema de financiamiento rural (para que se tome en cuenta la diversidad de condiciones de los prestatarios).

\subsection{Medidas coyunturales adoptadas por China como respuesta al alza de precios de los alimentos} en 2008

Como se deduce de los objetivos y las políticas enumerados en párrafos anteriores, en China existe la convicción de que la agricultura es importante para el desarrollo del conjunto de la economía, y en años recientes eso ha llevado al diseño y a la aplicación de políticas agrícolas y de desarrollo rural más acordes con el cambio económico habido en el resto de su economía. Eso no significa que se hayan modificado radicalmente las prioridades establecidas al inicio de las reformas, de rápido crecimiento del $\mathrm{PIB}$, sino solamente que se ha llegado a un punto en el que se hace necesario rectificar a fin de que continué operando el modelo de desarrollo, simplemente con la introducción del cambio de perspectiva ya mencionado. 
En todo caso, al igual que en muchos otros países en desarrollo, la crisis de alimentos obligó a las autoridades chinas a tomar medidas específicas de protección de la economía interna, en particular en lo relativo a garantizar la oferta interna de alimentos (ver cuadro 4), y su distribución a precios accesibles para los consumidores rurales y urbanos. $Y$ aunque las medidas que se adoptaron en 2008 pueden ser clasificadas como de protección y apoyo a los productores para que continúen produciendo; de apoyo a los consumidores en condiciones de alza de los precios de los alimentos básicos o de protección comercial, la realidad es que su característica principal fue que estuvieron enfocadas a resolver un problema de corto plazo. Eso no forzosamente implicó su abandono inmediato después de pasados los efectos más fuertes de la crisis, pero en el caso de China, como en el de muchos otros países en desarrollo, está el compromiso de gradualmente abrir el sector agropecuario a la competencia internacional.

En 2008, el presupuesto del gobierno central para la agricultura, los campesinos y las áreas rurales (los Ilamados tres 'nong') se incrementó en 30\% en comparación con 2007. ${ }^{11}$ A principios de 2008, China aumentó los precios mínimos de acopio de trigo y arroz, y mejoró los instrumentos de apoyo financiero a los agricultores. Se incrementaron los subsidios a las semillas y a otros insumos agrícolas, así como los recursos públicos disponibles para infraestructura agrícola. Al mismo tiempo, dado que los fertilizantes más que duplicaron su precio durante los meses de la crisis, China impuso altos impuestos a la exportación de los mismos (Demeke, 2008: 3 y 19). ${ }^{12}$

Las redes de protección social jugaron un papel clave en la limitación del impacto de la crisis alimentaria de 2008 al interior de China, que fue uno de los pocos países en Asia del Este que introdujo transferencias en efectivo para los grupos más vulnerables; como apoyos en especie, se estableció la práctica de dar alimento a los niños en las escuelas, no en forma generalizada sino en comunidades muy pobres. Está además el mejoramiento del sistema de pensiones, que siendo un mecanismo recientemente introducido parece tener objetivos de gran alcance (FAO 2011: 32). ${ }^{13}$ Menciono aquí que el monto de las pensiones es muy reducido en comparación con las existentes incluso en otros países en desarrollo, pero es importante en China, país que después de haber introducido las reformas económicas a principios de los 80 , desmanteló prácticamente todos los programas de protección social de la era maoísta, mismos que ahora está tratando de recuperar.

Uno de los propósitos primordiales del gobierno chino durante la crisis de alimentos fue aislar a la economía interna de las alzas internacionales en sus precios, para lo cual se aprovechó que China cuenta con reservas de granos muy por arriba de las de otros países en desarrollo, de forma tal que se designó a compañías comercializado-

11 Referencia en nota de pie de (Demeke, 2008: 18).

12 La política de subsidios a la producción de fertilizantes ya estaba en operación en China antes de la crisis, pero tomó fuerza a mediados de la primera década del siglo XXI, y en noviembre de 2008, se vio complementada con la introducción de impuestos de exportación estacionales, tan bajos como 10\% fuera de temporada, y tan altos como $110 \%$ en temporada (Demeke, 2008: 3)

13 Cualquier residente rural mayor de 16 años es elegible para unirse a un programa por el que recibirá en el futuro una pensión mensual básica de entre 60 y 300 Yuanes (Renminbi), equivalentes a entre 9 y 44 \$EU, dependiendo de la región y del tamaño de la cuenta individual. No sólo eso, sino que su cambio de residencia no implica su salida del programa. Se espera que este programa cubra a 800 millones de personas. 
ras estatales para que distribuyeran alimentos básicos a precios subsidiados; simultáneamente se restringieron de diversas formas las exportaciones de alimentos y se redujeron los aranceles a las importaciones de los mismos, así como los impuestos a la producción de cereales. ${ }^{14}$

Y como forma de evadir los altibajos del comercio internacional de alimentos, China tiene una política proactiva de adquisición de tierra cultivable en territorio de otros países en desarrollo (por compra, renta y a concesión), ello a fin de garantizar el abastecimiento oportuno de los alimentos que ahí se produzcan. ${ }^{15}$

\section{Conclusiones}

Las crisis de alimentos son un fenómeno recurrente sobre el que hay que cobrar conciencia, básicamente a fin de preservar las fuentes de recursos indispensables para la producción de los alimentos necesarios para la subsistencia de las poblaciones; y esta toma de conciencia debe traducirse en mayor cuidado de la agricultura, de la población a cargo de esta actividad y del medio ambiente. Pero también es cierto que tanto la más reciente crisis alimentaria como la ocurrida a principios de los años 70 no se han producido por falta de tierra cultivable o de otros recursos necesarios para la producción de alimentos, ni han sido crisis en el sentido maltusiano del término; ${ }^{16}$ y sin embargo, en cada ocasión la atención del mundo entero se centra en naciones como China e India, por su enorme población y más recientemente por el cambio económico experimentado por ellas, que ha llevado a mejoramiento de los niveles de vida de sus poblaciones.

En el caso de China está claro que casi desde sus inicios como nación, más concretamente desde principios de los años 70, sus dirigentes han optado por una estrategia consistente de seguridad alimentaria, que en momentos de mayor incertidumbre ha rayado incluso en autosuficiencia alimentaria al nivel de aldea rural. Los años transcurridos desde el inicio del siglo XXI no han sido una excepción a la regla de que la seguridad alimentaria sea el factor clave que hay que tener en cuenta cuando se diseñan las políticas para la agricultura y el sector rural. Y si se examina esta situación desde un punto de vista global, queda claro que China debería ser vista como un factor de estabilidad en lo que al mercado internacional de alimentos se refiere.

14 Los precios del arroz en China durante la crisis aumentaron únicamente 26\%, en comparación con el aumento promedio mundial, de entre 95 y $135 \%$, o incluso en comparación con los aumentos habidos en otras economías de Asia del Este: Sri Lanka (75\%) y Bangladesh (52\%) (Demeke, 2008: 22).

15 Se mencionan tratos con la República Democrática del Congo; con Mozambique; con Tanzania (ya firmado); con Zambia; con Filipinas (descontinuado), y con Camerún (en aplicación). Y en Latinoamérica están México, Cuba y Brasil, donde China renta tierra cultivable (Braun, 2009: varias páginas).

16 Thomas Robert Malthus (1766-1834) señaló que la población mundial se duplicaba cada 25 años, pues crecía en proporción exponencial, en tanto la producción de alimentos aumentaba a una tasa aritmética, de forma tal que la primera siempre crecía más rápidamente que la segunda. Ésta es una explicación muy antigua sobre las causas de la pobreza y del deterioro ambiental. En http://en.wikipedia.org/wiki/Thomas_Robert_ Malthus 


\section{Bibliografía}

-Actionaid, No more Food Crisis: The Indispensable Role of Food Reserves, June 2011. Banco Mundial (2008), Mid-term Evaluation of China's 11th Five Year Plan. Poverty Reduction and Economic Management Unit, East Asia and Pacific Region, 18 de diciembre de 2008.

-Brahmbhatt, Milan y Luc Christiaensen, Rising Food Prices in East Asia: Challenges and Policy Options, mayo 2008

-Braun, Joachim von y Ruth Meinzen-Dick, "Land Grabbing" by Foreign Investors in Developing Countries: Risks and Opportunities. International Food Policy Research Institute (IFPRI) Policy Brief 13 April 2009.

- Chand, Armes, The Global Food Crisis: Causes, Sweverity and Outlook, en Economic and Political WEEKLY, Review of Agriculture, June 28, 2008.

- Food and Agriculture Organization of the United Nations (FAO), Food and Agricultural Policy Trends after the 2008 Food Security Crisis: Renewed Attention to Agricultural Development, 2011.

-FAO, IFAD, WFP. The State of Food Insecurity in the World 2011.

- Demeke, Mulat, Guendalina Pangrazio y Materne Maetz, Country responses to the food security crisis: Nature and preliminary implications of the policies pursued. Publicación de FAO de diciembre 2008.

- Ministry of Agriculture of the People's Republic of China, 2007, 2005 y 2003 China Agricultural Development Report, China Agriculture Press, Beijing, PRC.

- National Bureau of Statistics of China (NBS) (2011), China Statistical Bookyear 2011, Beijing, China Statistics Press, septiembre.

- Programa de las Naciones Unidas para el Desarrollo, Informe sobre Desarrollo Humano 2011. Sostenibilidad y Equidad: Un mejor futuro para todos. 195 páginas.

- Ravallion, Martin, "Inequality is Bad for the Poor", pp. 37-61 en Jenkins, Stephen P. and John Micklewright, Inequality and Poverty Re-examined, Oxford University Press, 2007.

-The) World Bank, Mid-term Evaluation of China's 11th Five Year Plan, diciembre de 2008.

-(The) World Bank, World Development Report 2008, Agriculture for Development, Washington D. C. 2008. 


\section{Apéndice estadístico}

Cuadro 1. Índices de precios reales internacionales de alimentos 2007-2010, y su proyección al año $2015 *$

\begin{tabular}{|l|c|c|c|c|c|}
\hline & 2007 & 2008 & 2009 & 2010 & 20015 \\
\hline Maíz & 100 & 122 & 129 & 124 & 110 \\
\hline Trigo & 100 & 134 & 132 & 129 & 100 \\
\hline Arroz & 100 & 145 & 153 & 160 & 145 \\
\hline Frijol de soya & 100 & 124 & 122 & 118 & 105 \\
\hline Azúcar & 100 & 120 & 130 & 130 & 136 \\
\hline
\end{tabular}

Fuente: World Bank Development Prospects Group, abril 2008.

* A precios reales: Son los precios de las materias primas estratégicas (commodities) en dólares de Estados Unidos (\$EE.UU.), deflacionados por un índice en \$EE.UU., de los valores unitarios de las exportaciones de manufacturas

Cuadro 2. Tendencia de la producción mundial per cápita de cereales, 1961-2007 (Kg.)

\begin{tabular}{|c|c|c|c|c|}
\hline Periodo & Trigo & Arroz & Maíz & Total cereales \\
\hline $1961-1965$ & 67 & 50 & 77 & 271 \\
\hline $1966-1970$ & 74 & 54 & 87 & 295 \\
\hline $1971-1975$ & 90 & 56 & 91 & 308 \\
\hline $1976-1980$ & 98 & 58 & 93 & 334 \\
\hline $1981-1985$ & 104 & 63 & 90 & 327 \\
\hline $1986-1990$ & 104 & 64 & 94 & 317 \\
\hline $1991-1995$ & 100 & 64 & 101 & 310 \\
\hline $1996-2000$ & 100 & 66 & 104 & 314 \\
\hline $2001-2005$ & 95 & 63 & 108 & 319 \\
\hline $2003-2007$ & 94 & 65 & & \\
\hline
\end{tabular}

Fuente: FAOSTAT and FAO Food Outlook, varios números, tomado de Chand, Ramesh, p. 115 
Cuadro 3. Consumo per cápita de algunos alimentos en India, China, Estados Unidos y el promedio mundial, 2004 a 2006 inclusive (Kg.)

\begin{tabular}{|l|c|c|c|c|}
\hline & India & China & Estados Unidos & Mando \\
\hline Cereales & 175.1 & 287.9 & 953.0 & 316.0 \\
\hline Carne & 5.3 & 56.8 & 126.6 & 40.2 \\
\hline Leche & 84.5 & 22.7 & n.d. & 97.8 \\
\hline Huevo & 1.8 & 21.6 & 15.2 & 9.7 \\
\hline
\end{tabular}

Fuente: FAOSTAT link to OECD http://stats.oecd.org/wbos/viewhtml.aspx, tomado de Chand, Ramesh, p. 118 
Cuadro 4. China. Balance alimentario 2007

\begin{tabular}{|c|c|c|c|c|c|c|c|}
\hline Concepto & Producción & $\begin{array}{l}\text { Importacio- } \\
\text { nes }\end{array}$ & $\begin{array}{l}\text { Variación } \\
\text { inventarios }\end{array}$ & $\begin{array}{l}\text { Exportacio- } \\
\text { nes }\end{array}$ & $\begin{array}{c}\text { Oferta } \\
\text { interna }\end{array}$ & $\begin{array}{c}\text { Para } \\
\text { alimentos }\end{array}$ & $\begin{array}{l}\text { Alimentos } \\
\text { per cápita }\end{array}$ \\
\hline Cereales & 395,286 & 8,958 & $-6,154$ & 11,701 & 386,690 & 203,774 & 152.50 \\
\hline Trigo & 109,298 & 2,061 & $-1,486$ & 3,759 & 106,114 & 90,141 & 67.40 \\
\hline Arroz & 124,994 & 1,000 & 172 & 1,312 & 124,854 & 102,640 & 76.80 \\
\hline Maíz & 152,419 & 4,656 & $-4,989$ & 5,591 & 146,496 & 89,994 & 6.70 \\
\hline Tubérculos & 146,658 & 18,849 & 491 & 1,265 & 164,733 & 82,720 & 61.90 \\
\hline Papa & 64,837 & 645 & 460 & 792 & 65,150 & 43,481 & 32.50 \\
\hline Camote & 75,800 & 5 & -- & 23 & 75,783 & 35,806 & 26.80 \\
\hline Oleaginosas & 52,805 & 35,042 & 452 & 1,375 & 86,923 & 8,487 & 6.30 \\
\hline Frijol de soya & 12,721 & 33,198 & -91 & 533 & 45,299 & 5,298 & 4.00 \\
\hline Aceites vegs. & 16,436 & 10,199 & 40 & 333 & 26,342 & 12,618 & 9.40 \\
\hline De soya & 6,552 & 2,931 & 39 & 87 & 9,435 & 4,820 & 3.60 \\
\hline De palma & 221 & 5,628 & 0 & 52 & 5,797 & 2,286 & 1.70 \\
\hline Vegetales & 447,701 & 1,380 & 23 & 11,083 & 438,022 & 374,089 & 279.90 \\
\hline Frutas & 102,430 & 3,437 & 3 & 6,443 & 99,426 & 86,094 & 64.40 \\
\hline Manzana & 27,866 & 292 & 0 & 2,542 & 25,616 & 18,015 & 13.50 \\
\hline Carne & 70,428 & 2,537 & 65 & 1,541 & 71,490 & 71,436 & 53.40 \\
\hline Cerdo & 43,933 & 620 & 0 & 505 & 44,048 & 44,017 & 32.90 \\
\hline Aves de corral & 15,039 & 1,560 & 65 & 818 & 15,846 & 15,829 & 11.80 \\
\hline Huevo & 25,654 & 100 & 0 & 135 & 25,620 & 23,264 & 17.40 \\
\hline Leche & 39,824 & 2,266 & 2 & 1,009 & 41,033 & 38,354 & 28.70 \\
\hline Pescado & 46,841 & 9,407 & -1 & 8,173 & 48,075 & 35,364 & 26.50 \\
\hline
\end{tabular}

Fuente: FAOSTAT, FAO, en http://faostat.fao.org/site/368/DesktopDefault.aspx?PagelD=368

Nota: Población $=1,336,550$ personas. Cifras asentadas en columnas 2 a 7 inclusive en miles de toneladas. Alimentos per cápita en Kg. 



\section{Cuarenta años de las relaciones sino-mexicanas: evaluación, perspectiva y reflexión}

Yang Shouguo

\section{Relaciones políticas estables}

China y México, dos países herederos de civilizaciones muy antiguas, han mantenido una relación de amistad a lo largo del tiempo. Se han comunicado y han cooperado entre sí durante más de 400 años, desde que se estableció la Ruta Marina de la Seda en el Siglo XVI.

Después de la fundación de la Nueva China en 1949, ningún país en América Latina tenía relaciones diplomáticas con China. En la era de la Guerra Fría, los países occidentales aplicaban una política de aislamiento contra China. En 1960, Cuba fue el único país en América Latina y el Caribe que estableció relaciones diplomáticas con China. Desde la década de los 70, el contexto internacional ha cambiado mucho. Muchos países comenzaron pensando en establecer relaciones formales con China. Durante el gobierno de Luis Echeverría (1970-1976), la diplomacia mexicana realizó cambios fundamentales basados en una política exterior activa, autónoma y no subordinada, los principios de coexistencia pacífica. En la 26 Asamblea de la ONU, Echeverría asistió personalmente con una propuesta inspirada en la justicia y el respeto a la dignidad y la soberanía. Aquel 5 de octubre de 1971, el presidente mexicano afirmó en histórica sesión: “la soberanía e integridad territorial de China son indivisibles en lo jurídico". Después de que la Asamblea General de la ONU aprobara la histórica resolución sobre la devolución de su puesto legal a China en la organización internacional, la Secretaría de Relaciones Exteriores de México emitió un comunicado en el cual reconoció que el gobierno chino es el único representante legítimo de China en la ONU. EI 25 de octubre la República Popular China ocupó su asiento y el 16 de noviembre del mismo año México declaró por iniciativa propia la ruptura de relaciones con Taiwán y reconoció a la República Popular China. El 14 de febrero de 1972, el entonces embajador de China en la ONU, Huang Hua, firmó en Nueva York con el representante mexicano Alfonso García Robles, el comunicado sobre el establecimiento de relaciones diplomáticas entre China y México. El contenido del comunicado es el siguiente:

De acuerdo a los principios de igualdad, el respeto mutuo de la soberanía y la integridad territorial, la no agresión y la no intervención mutua en los asuntos internos y externos, la República Popular China y los Estados Unidos Mexicanos acuerdan desde hoy establecer las relaciones diplomáticas y enviar lo antes posible a sus embajadores respectivos.

En mayo del mismo año, México estableció su embajador en Beijing y en junio China hizo lo propio en la Ciudad de México. Las relaciones bilaterales abrieron un nuevo capítulo. Después, el presidente Luis Echeverría realizó una visita de Estado a China y fue objeto de una calurosa bienvenida y gran recepción por parte del gobierno y el 
pueblo de China. El presidente Mao lo recibió afectuosamente y, es importante subrayar, durante toda su estancia el mandatario mexicano estuvo acompañado por Deng Xiaoping, quien fue sin duda el gran arquitecto de la Reforma y Apertura de China y su entrada triunfante al mundo global.

En los años transcurridos desde entonces hasta la fecha, las relaciones entre China y México han registrado un rápido desarrollo. Los altos dirigentes de ambos países han hecho visitas mutuas y han mantenido frecuentes contactos. En las visitas bilaterales a alto nivel se destacan: por la parte china: presidente Yang Shangkun, en mayo de 1990; viceprimer ministro Zhu Rongji, en mayo de 1993; primer ministro Li Peng, en octubre de 1995; miembro del Comité Permanente del Buró Político del Comité Central del Partido Comunista de China Hu Jintao, en enero de 1997; presidente Jiang Zemin, en noviembre de 1997; primer ministro Wen Jiabao, en diciembre de 2003; vicepresidente Zeng Qinghong, en enero de 2005; presidente de la Conferencia Consultiva Política del Pueblo Chino Jia Qinglin, en mayo de 2005; presidente Hu Jintao, en septiembre de 2005; miembro del Comité Permanente del Buró Político del Comité Central del Partido Comunista de China Li Changchun, en marzo de 2007; vicepresidente Xi Jinping, en febrero de 2009. Por la parte mexicana: presidente Luis Echeverría Álvarez, en abril de 1973; presidente José López Portillo y Pacheco, en octubre de 1978; presidente Miguel de la Madrid Hurtado, en diciembre de 1986; presidente Carlos Salinas de Gortari, en noviembre de 1993; presidente Ernesto Zedillo Ponce de León, en noviembre de 1996; presidente Vicente Fox Quesada, en junio de 2001; presidente Felipe Calderón Hinojosa, en julio de 2008.

Se estableció el Mecanismo de Consulta Política entre las cancillerías de los dos países en 1993, del cual se han realizado ocho reuniones desde la primera en 1996 hasta la fecha. El primer ministro chino Wen Jiabao y el presidente mexicano Vicente Fox Quesada anunciaron el establecimiento de la Asociación Estratégica entre ambos países durante la visita de Estado a México del premier Wen en diciembre de 2003. Se estableció la Comisión Permanente Binacional en agosto de 2004. El presidente mexicano Felipe Calderón Hinojosa visitó China en julio de 2008 y acordó con su homólogo chino Hu Jintao la celebración de Diálogo Estratégico entre ambos países. En agosto de 2009, el vicecanciller chino Li Jinzhang visitó México y realizó exitosamente con su contraparte mexicana Lourdes Aranda, subsecretaria de Relaciones Exteriores, la primera reunión del Diálogo Estratégico.

La confianza política mutua sigue siendo profunda en 2010. Del 28 al 30 de julio, el canciller Yang Jiechi realizó una visita oficial a México, durante la cual se reunió con el presidente mexicano Felipe Calderón, y copresidió junto con la secretaria de Relaciones Exteriores, Patricia Espinosa, la cuarta reunión de la Comisión Permanente Binacional entre China y México. Las dos partes firmaron el Programa de Acción Conjunta 20112015, el Acuerdo sobre Reconocimiento Mutuo de Certificados de Estudios, Títulos y Diplomas, y el Acta de la Cuarta Reunión de las relaciones China-México Permanente Binacional de la Comisión, así como un canje de notas sobre la prórroga del periodo de vigencia del Convenio sobre Aviación Civil Transporte. Del 7 al 11 de octubre, la secretaria de Relaciones Exteriores, Patricia Espinosa, asistió a la Conferencia de la ONU sobre Cambio Climático celebrada en Tianjin, e hizo una visita de trabajo a China durante la 
cual se reunió con el viceprimer ministro Li Keqiang y el ministro de Relaciones Exteriores Yang Jiechi.

Como países en vías de desarrollo, China y México comparten intereses en común y puntos de vistas similares en muchos ámbitos, tales como la defensa de la soberanía, la autodeterminación y la solución de asuntos internacionales. A partir de que se establecieron las relaciones diplomáticas, China manifiesta su aprecio a la posición de México. Como potencias emergentes en el escenario global, los dos países se coordinan, cooperan y se apoyan mutuamente en los foros multilaterales como la ONU, G5, G20, APEC, a fin de contribuir a la construcción de un renovado orden político y económico mundial y a la búsqueda de solución de los problemas de importancia global. Los sucesivos gobiernos mexicanos siempre han acatado decididamente el principio de "una sola China" y reconocido el hecho de que Tíbet forma parte inalienable del territorio chino. México votó a favor del ingreso de China como observador en la Organización de Estados Americanos (OEA) y la Confederación de Parlamentos Americanos (COPA) y apoyó la adhesión de China en el Banco Interamericano de Desarrollo (BID).

La asociación estratégica entre China y México tiene una sólida base histórica y una necesidad práctica. Desde una perspectiva histórica, no hay conflictos históricos entre ambos países. Las relaciones bilaterales ya han cumplido cuatro décadas de desarrollo. Desde la realidad objetiva, las relaciones sino-mexicanas están desarrollándose con frecuentes visitas de alto nivel, el aumento mutuo de confianza política, la expansión de los intercambios en los campos diversificados. Desde las necesidades estratégicas, China y México tienen intereses comunes para construir un mundo justo.

\section{Intercambios culturales frecuentes}

La cultura mexicana tiene una historia larga, rica y ampliamente reconocida. El pueblo de México, con su extraordinaria inteligencia y creatividad ha hecho importantes contribuciones al progreso de la civilización humana.

México es uno de los países latinoamericanos que han mantenido intercambios culturales más frecuentes con China. La gran exposición de patrimonio cultural, titulada “China en la Época de la Dinastía de Xi'an", se exhibió en decenas de estados y municipios de México desde septiembre de 2000. En 2007, China participó en el Festival Cervantino celebrado en Guanajuato y realizó una serie de actividades culturales bajo el Programa "Experimentar China en México". Se exhibió “La Exposición Artística de Estatuas de Buda Guanyin en la Antigüedad de China" en Monterrey, DF y Tijuana desde septiembre de 2007 hasta julio de 2008. Por otra parte, México es el país latinoamericano que más intercambio cultural realiza con China. En 2001 se llevó a cabo la Exposición “La Cultura Maya” en Xi'an, Guangzhou, Beijing, y Shanghai. En mayo de 2006, México participó como país invitado de honor en el Festival Encuentro en Beijing. En febrero de 2006, China y México firmaron el Memorándum de Entendimiento sobre la Instalación de Instituto Confucio en la Universidad Nacional Autónoma de México, la Universidad Autónoma de Nuevo León, la Universidad de Guadalajara y la Universidad Autónoma de Yucatán. El Instituto Confucio de la Ciudad de México, el primero en toda América 
Latina, empezó a funcionar en septiembre de 2007. Se han establecido cinco institutos de Confucio en México hasta hoy. En 2008, cerca de 50 colegios y universidades mexicanas ofrecen asignaturas del estudio del idioma chino. De 2005 a 2010, China viene ofreciendo anualmente 32 becas a los jóvenes mexicanos, mientras México, a su vez, proporciona anualmente 30 becas a los jóvenes chinos. En mayo de 2008, Aeroméxico abrió una línea directa Ciudad de México-Tijuana-Shanghai. Y en 2010, México participa en Expo Universal 2010 Shanghai con el tema "Vivir Mejor".

Las cooperaciones científicas y tecnológicas sino-mexicanas implican sectores de física, química, matemática, prevención de desastres y de sismos, industria y agricultura, transporte y comunicación, energía y construcción, etc. Se han celebrado cinco reuniones en el marco del Comité Mixto de Cooperación Científica y Tecnológica, en las cuales se han definido más de cien proyectos de aplicación.

A pesar de que China tenga intercambios culturales más frecuentes con México que con otros países latinoamericanos, el conocimiento de uno hacia otro es aún muy limitado. Según las encuestas de "América Latina a los ojos de los chinos" realizadas por la Academia de Ciencias Sociales, la mayoría de los chinos tiene poco conocimiento de esta región. Sobre México, sólo $75 \%$ sabe que forma parte de América Latina y $51 \%$ sabe que abundan los nopales. Hay poco conocimiento de la civilización maya, el tequila, la industria petrolera. Lo curioso es que cuando se les preguntó con qué países latinoamericanos firmó China un TLC, 21\% eligieron México, cifra más alta que Chile, Brasil, Perú y Costa Rica. El conocimiento de los mexicanos sobre China tampoco ha sido suficiente.

\section{Relaciones económicas complicadas}

Desde que China y México establecieron relaciones diplomáticas en 1972, las cooperaciones comerciales y económicas entre los dos países entraron en una nueva etapa de desarrollo. Han firmado muchos acuerdos de cooperación económica. Ambos países llegaron al acuerdo binacional sobre el ingreso de China a la Organización Mundial de Comercio (OMC) en septiembre de 2001, en el cual la parte mexicana se comprometió a levantar las medidas antidumping que violaron las reglas vinculantes de la OMC dentro de seis años. Ambos países firmaron el Acuerdo sobre las Medidas de Compensación Comercial en junio de 2008, en el cual México se comprometió a levantar incondicionalmente las medidas compensatorias contra productos chinos en 2012. En 2008, China y México firmaron el Acuerdo de la Promoción y Protección de Inversión Mutua.

Desde el año 2000, el comercio bilateral ha mostrado un crecimiento rápido y sostenido. Según las estadísticas de la aduana china, de 2001 a 2005, la tasa media anual de crecimiento del comercio bilateral fue de $34.6 \%$, las exportaciones e importaciones Chinas aumentaron 34.4\% y 36.9\% respectivamente. De 2006 a 2009, el incremento medio anual de las exportaciones e importaciones Chinas aumentaron $24.8 \%$ y $15.2 \%$ respectivamente. En 2009, el volumen del comercio bilateral alcanzó 16,181 millones de dólares, de los que 12,299 millones correspondieron a exportaciones chinas y 3,882 millones a importaciones. En 2010, el comercio bilateral alcanzó 24,690 millones de 
dólares, un aumento de $52.6 \%$, esto es cinco veces mayor que el volumen comercial de 2003, cuando ambos países establecieron la Asociación Estratégica. En enero a noviembre de 2011, el comercio bilateral llegó a 30,450 millones de dólares, un aumento de $37.2 \%$, de los cuales China exportó 21,915 millones de dólares e importó 8,535 millones, aumentos de $34.6 \%$ y $44.3 \%$ respectivamente. China es el segundo mayor socio comercial de México, después de EU. México es el tercer mayor socio comercial de China en América Latina, después de Brasil y Chile.

Sobre la estructura comercial de China y México, en 2010 China exporta 12,800 millones de dólares de productos electromecánicos, 1,790 millones de dólares de productos de industria ligera, 1,320 millones de dólares de prendas de vestir, que representan respectivamente $71.6 \%, 10 \%, 7.4 \%$ de las exportaciones totales a México. Esto representa la alta concentración del comercio.

En el ámbito de la inversión, hasta noviembre de 2011, la inversión acumulada de China en México llegó a 614 millones de dólares. 41 empresas chinas como Huayuan, Jinlong y Lenovo han invertido en los sectores de Petróleo, contratación de obra portuaria, telecomunicaciones, minería, textiles y prendas de vestir, agricultura, ensamble de televisiones y otros. Por la parte de México, los productos electrónicos y de telecomunicación, el tequila, la cerveza Corona y las tortillas Maseca han entrado en el mercado chino.

Pero las estadísticas de México y China tienen gran diferencias. Las de México han incluido los productos chinos que reexporta EU a México. En 2010, según la estadística del Ministerio de Economía de México, el comercio de México con China ascendió a 49,810 millones de dólares, un aumento de 43.3\%, casi el doble de la estadística china. De ellos, las exportaciones a China fueron de 420 millones de dólares, las importaciones de China llegaron a 45,610 millones de dólares. El déficit de México llegó a 41,410 miIlones de dólares, un aumento de $36.6 \%$. Para México, China es el tercer mayor destino de exportaciones y la segunda fuente más grande de importaciones.

A pesar del rápido desarrollo, la cooperación económica entre China y México todavía no está a la altura de la relación política bilateral y tampoco coincide con el tamaño de las dos economías. Además se observa un gran desequilibrio comercial entre ambos países.

Como lo hemos observado, han surgido algunos problemas y retos en lo comercial. Aunque China y México han establecido relaciones de socios estratégicos, la base de la confianza estratégica mutua no es tan sólida. Ambos parten de sus propios intereses y a veces no quieren hacer concesiones. La sociedad de México otorga mucha atención a los productos chinos que según los mexicanos han impactado la propia industria mexicana. La opinión sobre la "amenaza china" va creciendo. China desea que los principales países de América Latina puedan reconocer su posición en la economía de mercado, pero la actitud mexicana no es tan activa como la de Brasil, Argentina, Chile y Perú. Al mismo tiempo, China no ha dado mucha atención a la asimetría entre México y China. Los chinos creen que los negocios entre China y América Latina están por lo general equilibrados y el déficit para México no es tan grave. Todo esto ha demostrado que China y México deben fortalecer el intercambio y la comunicación para promover la confianza estratégica. 
La competencia económica entre China y México no se podrá mejorar en el corto plazo. En primer lugar, ambos países están en el comienzo de transformación de su estructura económica, la competencia de las industrias textil, de calzado y de juguetes no va a disminuir rápidamente. Desde 1993, México inició numerosas investigaciones antidumping contra más de mil productos chinos. En segundo lugar, la competencia en el mercado internacional, sobre todo en EU, sigue a pesar de la contracción del mercado estadounidense después de la crisis financiera. Después del inicio del Tratado de Libre Comercio de América Norte en 1994, las exportaciones de México a EU han crecido rápidamente. México fue el segundo socio comercial de EU. Sin embargo, con el ingreso a la OMC, China sigue aumentando sus exportaciones a EU y en 2005 sobrepasó a México como segundo socio comercial de EU. En tercer lugar, la competencia por la inversión extranjera, coloca a China y a México como dos de los principales destinos de inversión internacional.

A decir verdad, las relaciones económicas entre China y México en estas cuatro décadas no han sido tan exitosas, debido a varias causas. En los 70, China estaba muy lejos de abrirse al mundo, por tanto las relaciones económicas no pudieron lograr un gran avance. En los 80, China despegaba en su inserción al mundo y México sufría la crisis de deuda; ambos países no tenían convergencia económica. En los 90, ambos países aceleraron la expansión de sus exportaciones, pero la política mexicana se concretaba tanto en la vinculación con el TLCAN e ingreso al "club de los ricos" (la OCDE), de modo que los mexicanos no tenían interés en China. En la década del nuevo siglo, ambos países empezaban a conocer la importancia de sus vínculos, así que establecieron la Asociación Estratégica que hasta ahora está lejos de ser un éxito.

\section{Nuevas tendencias}

Por causa de la distancia geográfica, diferencia cultural y sobre todo la semejanza de estructura económica, existen desafíos en las relaciones bilaterales. Afortunadamente, ambos países pueden tratar los problemas y retos de un modo positivo. Generalmente podrían llegar a un consenso: las relaciones comerciales implican más oportunidades que obstáculos. Desde esta perspectiva, ambos países lograrán un beneficio mutuo mediante diálogos e intercambios y con la explotación de sus potencialidades en materia de cooperación.

A partir de la crisis financiera en 2008, tanto China como México han aplicado una nueva estrategia interna y externa para enfrentar a los nuevos desafíos. En tal contexto, se ofrecen muchas oportunidades para las relaciones entre China y México.

El proyecto del XII Plan Quinquenal para el Desarrollo Económico y Social (20112015) de China busca un desarrollo más sostenible e inclusivo. La nueva estrategia de la economía china se orienta hacia un desarrollo más apoyado en el consumo interno, más sustentable y con mayor cohesión social. El Plan busca reorientar el modelo de desarrollo económico chino desde el actual énfasis en la inversión y las exportaciones baratas hacia un mayor privilegio del consumo interno y de la innovación y el desarrollo científico para elevar la calidad de sus productos. El rebalanceo hacia un mayor 
consumo interno es necesario no sólo para compensar la debilidad que se prevé en la demanda de los países industrializados, sino también para mejorar los indicadores distributivos que muestran un deterioro de los ingresos y un incremento de la concentración del ingreso. De este modo, los aumentos del salario mínimo y otras medidas orientadas a estimular el consumo interno de los hogares de las clases medias y bajas, especialmente en las áreas interiores del país, irán acompañados de un mayor gasto público en viviendas sociales y seguro social, buscando reducir las diferencias de ingreso y de calidad de vida entre la población urbana y la rural.

Otro énfasis del Plan es privilegiar el carácter sustentable del crecimiento, impulsando para ello una importante restructuración productiva, un mayor énfasis en la innovación tecnológica y la calidad de los productos, una mejor protección al medio ambiente y una menor intensidad energética y emisión de carbono por unidad de producto. En materia de innovación y restructuración productiva, se privilegiará el desarrollo de las energías renovables, los nuevos materiales, la biomedicina y las ciencias biológicas, las exploraciones geológicas, el espacio marino y las redes de información. En cada uno de estos ámbitos, el potencial de colaboración entre China y México es considerable y debiera ser incorporado en una agenda actualizada de las relaciones económicas.

Al mismo tiempo, México está buscando nuevos mecanismos que le permitan romper la dependencia que tiene del mercado estadounidense. Primero, en los últimos años, el gobierno mexicano ha acelerado la negociación de libre comercio con otros países para aumentar las exportaciones y mejorar la competitividad de su economía. Desde 1994, México ha firmado 11 acuerdos de libre comercio con 43 países, incluyendo Estados Unidos, Canadá, Mercosur, la Comunidad del Caribe, la Unión Europea y otras organizaciones económicas regionales. México se ha convertido en el país con mayor grado de liberalización del comercio en América Latina. México está negociando un acuerdo de integración económica con Brasil, un tratado de libre comercio con Perú. Esta tendencia ayudará a China a expandir sus exportaciones a otros países latinoamericanos. Segundo, la crisis financiera mundial, sobre todo la recesión de la economía de EU, ha tenido un impacto directo a la economía mexicana. México se ha dado cuenta del riesgo de esta dependencia y ha dado mucha importancia a diversificar los mercados. La región del Asia y Pacífico, la más dinámica de la economía mundial, naturalmente se ha convertido en la prioridad de la estrategia de México. China representa más del $20 \%$ de la población mundial y su clase media está en continuo aumento. Se trata de un mercado potencial crucial que México debería examinar con atención. Tercero, el gobierno de México formuló una serie de planes industriales importantes. “El plan de reforma 2009-2021" subrayó el desarrollo de las industrias de alta tecnología que incluyen nuevas energías, telecomunicaciones, minería, infraestructura. Esta política amplía la complementariedad y oportunidad de la colaboración económica entre China y México.

El 11 de diciembre de 2011 fue el día de la finalización de las Medidas de Transición pactadas ante la Organización Mundial de Comercio (OMC) entre ambos países. México tendría entonces con China 6,960 fracciones arancelarias en cero y una tasa arancelaria promedio de 6.4 por ciento. Sería una oportunidad para las empresas chinas.

China cree que México juega un papel importante en América Latina. México posee ventajas geográficas únicas: la ubicación en el mercado más importante a nivel mundial 
en América del Norte, el vínculo entre América Central y América del Sur, el enlace que conecta el área Asia Pacífico y América del Norte/Sur. México puede representar un puente para China en América Latina y, por otro lado, China puede ayudarle a México a abrir camino hacia mercados asiáticos.

Recientemente, China ha expresado su deseo de dialogar con México para potenciar su relación comercial. A fines de 2011, el ministro de Comercio chino, Chen Demin, ha hecho público su interés de negociar con el gobierno de México sobre la regularización del comercio entre sus países y potenciar la inversión de las empresas de China en proyectos mexicanos. Dijo:

La parte china comprende la inquietud de la parte mexicana sobre el déficit en el comercio bilateral. Nunca ha sido la intención china procurar tener un superávit comercial, China está dispuesto a promover a las empresas chinas a realizar importaciones desde México y estimular más empresas con capacidades para explorar posibilidades de inversión en México.

Portavoces del gobierno de China han anunciado su disposición para enviar una delegación de empresarios a tierras mexicanas durante los seis primeros meses de 2012 para promocionar el comercio y la inversión.

Sobre la posibilidad de libre comercio entre China y México, la actitud de China se ha vuelto positiva. Un consejero económico de la embajada china en México ha expresado abiertamente:

China tiene mucho interés en suscribir un tratado de libre comercio con México, como los que ya tenemos con Chile, Perú y Costa Rica. Pero para poder negociar un acuerdo tenemos que tener un tratamiento igual y la condición previa es que exista un reconocimiento de economía de mercado, y México no quiere reconocer ese estatus a China, y como no hay esa condición previa no podemos negociar.

China tiene en la actualidad siete tratados de libre comercio: con la ASEAN (Asociación de Naciones del Sudeste Asiático: Indonesia, Malasia, Filipinas, Singapur, Tailandia, Brunei, Myanmar, Camboya, Laos y Vietnam) y con Paquistán, Singapur, Perú, Nueva Zelanda, Chile y Costa Rica. Actualmente, se encuentra negociando con el GCC (Consejo de Cooperación del Golfo: Kuwait, Bahrein, Arabia Saudita, Qatar, Emiratos Árabes Unidos y Omán), así como con Australia, Islandia, Noruega y la Unión Aduanera del Sur de África o SACU (Sudáfrica, Botsuana, Lesoto y Suazilandia).

Parece que en México no existe actualmente ni la intención ni la voluntad para lograr cualquier tipo de acuerdo comercial con China, es claro que al menos en el corto plazo no podrá entablarse esta relación. Sin embargo, esto se puede ver como una oportunidad para México en aspectos de inversión, ya que los sectores productivos con mayor valor agregado en China como los de electrónicos, electrodomésticos y automotriz, entre otros, podrían fabricar en México y llegar a países de Norte y Centroamérica con costos competitivos y políticas de servicio con tiempos de respuesta más cortos.

China también desea ampliar la cooperación con México en temas tales como la no proliferación de armas nucleares y desarrollo del recurso nuclear para fines pacíficos, 
el desarrollo ecológicamente sustentable, etc., los cuales son promisorios para las relaciones bilaterales sino-mexicanas.

\section{Conclusiones}

La emergencia de China ha sido el cambio más importante del orden internacional desde el final de la Guerra Fría. China no es una amenaza para el comercio mundial, sino todo lo contrario, es una oportunidad. China continuó impulsando el crecimiento de América Latina aun después de la crisis. Durante la próxima década de relaciones bilaterales, México no puede perder esta oportunidad. Por eso, el gran reto para México será voltear la mirada al gigante asiático para formar parte de sus principales aliados comerciales.

Una estrategia más integral y equilibrada debe ser explorada por China y México para mantener un desarrollo sostenible de relaciones bilaterales. Ambas partes deben hacer esfuerzos conjuntos para explorar un nuevo modelo de comercio e inversión más diversificada.

Para China, reducir las exportaciones de los productos de la industria tradicional como el textil, ropa, zapato, juguete, seguir mejorando la calidad y estructura de inversión, incrementar la cantidad y variedad de importaciones de México, crear más mecanismos de cooperación económica, tratar con cuidado las fricciones comerciales, será necesario para desarrollar las relaciones económicas.

Para México, el objetivo más importante sería llegar un consenso interno sobre la estrategia hacia China y aprovechar al máximo el crecimiento de China.

\section{Bibliografía}

- CEPAL, 2011, La República Popular China y América Latina y el Caribe, Hacia una nueva fase en el Vínculo Económico y Social, Naciones Unidas, Santiago de Chile, Junio.

-Eugenio Anguiano Roch, 2010, “Perspectivas a largo plazo de la relación sino-mexicana". Hacia un diálogo entre México y China, UNAM, México.

- La Embajada de China en México, en: http://mx.china-embassy.org/chn/.

-Wu Hongying, 2010, "Treinta años de relaciones de China y México como socios estratégicos, desarrollo económico y social". Hacia un Diálogo entre México y China, UNAM, México.

-Xu Shichen, 2007, "Some Thoughts on Development of Sino-Mexican Relations". Journal of Latin American Studies, Beijing, No.4, April. 



\title{
Transformación de la propiedad colectiva a la privada en la tenencia de tierra
}

\author{
Una primera aproximación de las experiencias \\ mexicanas y sus implicaciones para China
}

Liu Sun Xuedong

Las reformas sobre el artículo 27 constitucional efectuadas en 1992 prácticamente determinaron el fin de las políticas de reparto de las tierras entre los campesinos y la restitución de las mismas a las comunidades iniciadas desde 1995, a consecuencia de la Revolución Mexicana. ${ }^{1}$ Hasta la fecha, estas nuevas medidas instrumentadas por las autoridades han resultado poco efectivas, ya que, por un lado, se han recibido pocas inversiones privadas tanto nacionales como extranjeras en las actividades agrícolas en contraste con las perspectivas derivadas de la reforma; por otro lado, los campesinos también han demostrado poco interés de adoptar el régimen del dominio pleno de la tierra y ceder el derecho de la misma asociándose con los inversionistas.

Sobre este tema relacionado con la privatización de la tierra a partir del régimen de tenencia colectiva se han generado debates importantes en China desde mediados de la década pasada, lo mismo ha sucedido en México en su momento cuando se aplicaba la reforma agraria. Por un lado, los protagonistas a favor de la privatización argumentaban que el cambio del patrón en la tenencia de tierra podría propiciar el mejoramiento en el nivel de vida de los campesinos, mediante la modificación en el uso de suelo, la llegada de inversiones millonarias, aceleración en el proceso de urbanización, la concentración masiva de tierra y la modernización del campo, etc. (Zhou Qiren, Chen Zhiwu, entre otros). Por su parte, la corriente conservadora comenta que la privatización no es la solución mágica del campo ya que la posible inversión masiva llegaría a campo con propósito de obtener utilidades en lugar de beneficiar a los millones campesinos de gratis (Wen Tiejun, He Xuefeng, Li Changping, etc.). Además, la vigencia milenaria en la que había prevalecido la tierra como propiedad privada ya comprobó la inefectividad para salir de las condiciones precarias antes del establecimiento de la Nueva China en $1949 .{ }^{2}$

Este trabajo tiene el propósito de realizar la primera aproximación en la evaluación de los impactos derivados de las modificaciones al artículo 27 constitucional en 1992 en la economía campesina y, como se podrá recordar, esta reforma agraria formaba un

1 El anuncio de la reforma al artículo 27 constitucional lo hizo el presidente Venustiano Carranza en Veracruz después de realizar las adiciones al Plan de Guadalupe y dictar la ley agraria al principio de 1915, destinada a la devolución de tierras a las comunidades y el derecho de todos los campesinos a poseer un pedazo de tierra. Miguel A. Samano Rentería, "La política salinista hacia el campo, un balance crítico (1994)”, David, Chacón Hernández, etc., "Efectos de las reformas al agro y los derechos de los pueblos indios en México", Universidad Autónoma Metropolitana, 1era edición 1995, México. Hector Aguilar Camín y Lorenzo Meyer, “A la sombra de la Revolución Mexicana", 2005, Cal y Arena, México.

2 En este trabajo no se analizarán con detalles los debates sobre los sistemas en la tenencia de tierra, ya que el presente trabajo forma parte del proyecto de investigación “El patrón en la tenencia de tierra y el desarrollo regional, un estudio comparativo entre China y México, 1980-2010". Sin embargo, a raíz de las grandes similitudes que se habían visto hace 20 años en México sobre el mismo tema, solamente se presenta este resumen. 
elemento importante durante la administración del presidente Salinas para la modernización del sector agropecuario y de la economía mexicana. La primera parte del estudio presentará una breve revisión de las políticas en el reparto de tierras a los campesinos durante un proceso de casi 80 años, cuya afectación abarca casi la mitad del territorio nacional. En la tercera parte se analizarán el contenido principal de la reforma agraria en 1992 y sus implicaciones para la economía de los ejidatarios y de los comuneros. Finalmente se realizarán las evaluaciones de las nuevas medidas derivadas de la reforma para fomentar la producción agrícola de los campesinos y se hará una breve presentación de las conclusiones e implicaciones para el campo chino.

\section{Antecedentes de la reforma agraria en 1992}

Como uno de los frutos derivados de la Revolución Mexicana y la consecuencia de un proceso largo de lucha por la equidad social, ${ }^{3}$ la aplicación de las medidas de reparto de tierras a los campesinos se prolongaba casi 80 años hasta el anuncio de la reforma agraria en 1992. Los procedimientos legales del reparto consistían en tres aspectos básicos, que incluían la restitución de tierras, bosques y aguas, para los pueblos que habían sido despojados de ellos; la dotación, de acuerdo la cual, los grupos de campesinos (núcleo de población) que carecieran de tierras o no las tuvieran en cantidad suficiente para satisfacer sus necesidades, tenían derecho a ser dotados con propiedades "afectables; y la creación de nuevos centros de población, para el reparto de tierras ubicadas en lugares poco poblados (Téllez).

Durante un lapso de casi 80 años (desde su anuncio formal en 1915 hasta 1992 cuando se reformó el artículo 27 constitucional) en la aplicación de las políticas encaminadas al reparto de tierras a los campesinos, se lograron resultados significativos: se constituyeron más de 30,000 ejidos y comunidades agrarias y se benefició a más de 3 millones de solicitantes en más de la mitad del territorio nacional, de 103 millones de hectáreas. ${ }^{4}$ De tal manera se puede inferir que en promedio cada ejido o comunidad se forma por aproximadamente 100 miembros y con una extensión de alrededor de 3,400 hectáreas; cada ejidatario cuenta con una parcela de 30 hectáreas aproximadas.

Si se analizan las cifras registradas por la administración presidencial se observan disparidades enormes. A pesar de que el primer mandatario anunció el inicio de la refor-

3 En el México central, la propiedad de la tierra fue causa de conflicto y litigio judicial, que a veces devenían en enfrentamientos y motines. En los estudios históricos se ha privilegiado el conflicto entre las comunidades indias y los particulares españoles a costa del conocimiento de otra de sus expresiones en la que se enfrentaban dos o más comunidades indígenas (Warman).

4 Cabe mencionar que las cifras estadísticas registran discrepancias. Por un lado si se suman las cifras reportadas por cada administración presidencial, la extensión de tierras repartidas llegó a un total de 107 millones de hectáreas, mientras que los datos censales fueron de 103 millones de hectáreas. Por su parte, el número de beneficiados derivados de la aplicación de las mismas políticas fue de un total de un poco más de 3 millones de campesinos al sumar las cifras reportadas durante todos los sexenios implicados en el lapso, en contraste con 3.5 millones de acuerdo con datos censales. La explicación de la primera es que podrían existir resoluciones presidenciales publicadas en el Diario Oficial de la Federación que aún se encuentran pendientes por ejecución; en referente al número de los beneficiarios, el número es mayor en el censo pues se han sumado ejidatarios en virtud de cesiones o incorporación de nuevos miembros por aceptación de la asamblea. 
ma agraria, entre 1915 y 1920 sólo se repartieron 173 mil hectáreas en beneficio a 44 mil campesinos, cifras inclusive inferiores a las arrojadas en el sexenio de Salinas, de 803 mil has. y 43 mil agricultores. De esta manera, las promesas agrarias del gobierno de Carranza sólo quedaron en el papel. En contraste, Gustavo Díaz Ordaz fue el presidente que más tierras repartió con $\mathbf{2 4 . 7 4}$ millones de hectáreas, seguido por Lázaro Cárdenas que durante su administración llegó a un total de 18.79 millones de hectáreas dotadas a 729 mil beneficiados; durante el gobierno de Echeverría, las cifras fueron de 12.77 millones y 278 mil, respectivamente.

A pesar de los avances importantes en la distribución de tierras entre los campesinos y la equidad social, el promedio de extensión por ejidatario registraba una tendencia a la baja, además de calidad cada vez inferior en cuanto a las tierras repartidas. Es decir, seguir repartiendo tierras se encuentra cada vez más difícil que antes debido al agotamiento del territorio nacional, lo cual a su vez generaría cierta incertidumbre e inseguridad en la tenencia de tierra para los ya beneficiados debido a la afectabilidad. Además de lo anterior, el crecimiento de la población rural en términos absolutos, por un lado, y que los otros sectores de la economía han perdido dinamismo en la generación de empleo desde el inicio de los años de 80, por otro lado, la población rural ha encontrado cada vez más dificultades que antes para migrar a las zonas urbanas ante la falta de oportunidades de trabajo y se ha tenido que arraigar en el campo. Es decir, ante una tendencia decreciente registrada en la tenencia de tierra por campesino, la presión de los productores agrícolas sobre la tierra se ha deteriorado aún más.

En resumen, el reparto de la tierra sin cuidar aspectos de seguridad jurídica en su tenencia en lugar de dar solución al campo mexicano, se ha convertido en un factor, a pesar de no ser el único ni exclusivo, que ha afectado el desarrollo eficiente de la economía campesina y el mejoramiento en el nivel de vida de los habitantes rurales.

\section{Contenido principal de la reforma agraria en 1992 y sus implicaciones para los campesinos}

Las modificaciones al artículo 27 constitucional y la aplicación de la nueva Ley Agraria del 6 de enero de 1992 forman parte del proceso de la reforma agraria. Al respecto existe una gran expectativa y reacciones encontradas. Para unos las nuevas medidas agrarias significarían la solución definitiva que podría reactivar las actividades agrícolas por otorgar la seguridad jurídica en la tenencia de tierra y atraer inversiones masivas; para otros, las mismas acciones implicarían un retroceso en las conquistas sociales del régimen de tenencia de la tierra colectiva y la inminente privatización de la tierra ejidal y comunal, así como la concentración de la tierra en unas cuantas manos.

La reforma al marco jurídico agrario termina formalmente el sistema de redistribución de la tierra, garantiza la libertad de decisión y gestión de los ejidos y de sus integrantes, concede definitividad a los derechos individuales de los ejidatarios y permite la propiedad de sociedad. Para lograr estos objetivos, la nueva legislación establece un régimen flexible de tenencia de la tierra ejidal a través de dividir las tierras del ejido en tres tipos: asentamiento humano, uso común y parceladas y de ellos cada uno está sujeto a distintas modalidades. 
Las tierras de asentamiento humano son las áreas ocupadas por la zona de urbanización, la reserva de crecimiento de poblados y las parcelas destinadas por la asamblea del ejido a servicio de la comunidad. Estas áreas son inalienables, imprescriptibles e inembargables, con excepción de los lotes en que habitan los miembros de los miembros del ejido. Por su parte, las tierras de uso común están sujetas a las decisiones de la asamblea del ejido, que pueden ser una aportación en propiedad a una sociedad en la que participen los ejidatarios y otros inversionistas para el desarrollo de un proyecto productivo; también pueden ser objeto de contratos de renta o cualesquiera otros que impliquen el uso de estas tierras por 30 años y su usufructo se puede otorgar en garantía de las obligaciones contraídas por el ejido. Igualmente a las del asentamiento humano, estas tierras de uso común tampoco pueden enajenarse.

En cuanto a las tierras parceladas, forman parte de la propiedad del ejido, pero los miembros de la comunidad, en lo individual, gozan del derecho permanente de uso y disfrute sobre su respectiva parcela. Mientras la parcela está sujeta al régimen ejidal, el ejidatario, con absoluta libertad, puede contratar su uso o dar en garantía su usufructo hasta por 30 años renovables. También puede vender o enajenar a otros ejidatarios o miembros del núcleo de población. Bajo el nuevo esquema legal, la asamblea del ejido está facultada y capacitada para autorizar la desincorporación de las tierras parceladas del régimen ejidal y, con base de esta autorización, los ejidatarios en lo individual pueden ejercer el derecho de cambiar el régimen de tenencia de su parcela al de pequeña propiedad. Convertida la parcela ejidal en pequeña propiedad, el ejidatario puede venderla o enajenarla a personas distintas a los miembros del núcleo de población, hipotecarla o realizar cualquier acto de dominio sobre la misma.

Las modificaciones jurídico-institucionales de 1992 tenían el propósito de dar respuestas a las condiciones precarias prevalecientes en el campo mexicano al permitir nuevas modalidades de aprovechamiento y asociación. De tal manera, se logran: 1. alentar la capitalización del campo, 2. introducir relaciones del libre mercado en el agro, 3. expulsar la burocracia de la vida ejidal y 4 . lograr mayor eficiencia en la producción.

Lo anterior indica que los ejidatarios cuentan con la facultad jurídica a elegir entre diversas opciones desde seguir lo que había prevalecido antes de la aplicación de las nuevas medidas derivadas de la reforma, hasta asociarse con terceros en sociedades mercantiles. Por su parte, los que negocien con ellos sabrán que existen alternativas, por lo que buscarán que su planteamiento sea el más atractivo y conveniente para los campesinos. Los ejidatarios podrían determinar el uso de su parcela que más les beneficiara y el núcleo de población establecería la forma de distribuir y explotar los bienes en común. Con esto, el ejidatario tendría disposición sobre sus derechos individuales, lo que le daría capacidad y poder de negociación para obtener beneficios de su propiedad.

\section{Evaluación sobre la reforma agraria en 1992}

Hasta la fecha, la reforma agraria ya cumplió casi 20 años, los resultados preliminares indican que los únicos derechos transferidos significativamente corresponden a los de usufructo. En cambio, la transferencia de propiedad sólo resulta atractiva cuando la 
superficie agraria se encuentra cercana o inmersa en las ciudades y puede ser urbanizada (Zepeda). De esa forma, el campo mexicano ha permanecido casi sin cambio alguno: los campesinos siguen viviendo en condiciones precarias y las actividades agrícolas han demostrado un nivel de rentabilidad bajo con poca perspectiva a modernizarse. Es decir, los pronósticos realizados por diversas corrientes no se han cumplido, las tierras de los ejidatarios no se han privatizado y mucho menos se han concentrado para formar latifundios; la seguridad jurídica en la tenencia de tierra tampoco ha contribuido en gran magnitud a la reactivación de las actividades agrícolas ni al mejoramiento en el nivel de vida de los campesinos.

Las expectativas generadas en su momento derivadas de la reforma agraria en 1992 se han efectuado de manera insignificante, sobre todo en los aspectos en que los ejidatarios y comuneros podrían optar por el régimen de dominio pleno sobre las tierras parceladas $y$, consecuentemente proceder a la venta de las mismas o asociarse con las sociedades mercantiles con la tierra como acciones. De acuerdo con las cifras arrojadas por los censos agropecuarios, para enero de 1997 se registraron un total de 193 solicitudes de adopción de dominio pleno con trámite agotado, entre ellos 141 ejidos consideraban que todos sus miembros habían asumido esta nueva modalidad en la tenencia de la tierra tras la autorización de la asamblea mientras, que en los 52 ejidos restantes no todos los miembros del núcleo habían adoptado el dominio pleno (parcial). Entre estos ejidos con dominio pleno parcial se encuentran 10 ejidos en los que tres o menos ejidatarios han asumido el dominio pleno sobre sus parcelas, por lo que la transformación del régimen se da sobre una superficie mínima. Según Arturo Warman, “... el cambio de dominio de parcelas ejidales..., se decidió para incorporarse con legalidad y ventajas al desarrollo urbano. También las sociedades mercantiles, menos de una docena, se constituyeron con el mismo propósito, y se conformaron inmobiliarias ejidales con cientos de socios, todos ejidatarios, para urbanizar la tierra y recibir el precio justo. No se ha dado el cambio de dominio pleno en ejidos rurales. La privatización no está sucediendo".

Por su parte, de 1998-2007 el número de ejidos que adoptaron el nuevo esquema en la tenencia de tierra a consecuencia de la reforma agraria en 1992 es 5,914, entre ellos 4,194 correspondían al dominio pleno para todos sus miembros respectivos y 1,720 con parcialidad. En cuanto a la extensión implicada en este cambio de tenencia de tierra, se relaciona con 4.66 millones de hectáreas. Si se agrega la cifra registrada hasta 1997, de 55 mil hectáreas, la suma alcanzó a 4.71 millones de hectáreas, esto es, 4.4 por ciento de las tierras ejidales.

La gran mayoría de los ejidos en los que se ha agotado el trámite del dominio pleno, comparte una característica: se trata de ejidos inmersos o cercanos a zonas urbanas. Por ejemplo, 124 de los 193 ejidos que habían adoptado la nueva modalidad en la tenencia de tierra hasta 1997 se encuentran localizados en municipios comprendidos en algunas de las 58 zonas metropolitanas más grandes de México. El resto de los núcleos ejidales que obtuvieron la autorización del dominio pleno son considerados inmersos y cercanos a asentamientos humanos urbanos, algunos de ellos en ciudades que, aunque no se encuentran en el listado de las grandes urbes del país, no dejan de tener gran relevancia, como los Cabos de Baja California Sur, Puerto Vallarta, Lagos de Moreno y 
Chapala en Jalisco, San Juan del Río y Aguaprieta en Sonora, Huamantla en Tlaxcala, Jerez en Zacatecas, por citar algunas.

Además de que la transferencia de dominio se ha dado en la mayoría de los casos en áreas urbanas y no en zonas de producción agrícola, por un lado, y que por otro lado, el cambio de régimen en la tenencia de tierra ha representado un mínimo entre un total de más de 300 mil ejidatarios y comunidades relacionadas con más de la mitad del territorio mexicano, la compra-venta de las tierras tampoco se ha efectuado en gran magnitud. Entre una extensión total de 4.71 millones de hectáreas adoptadas al régimen de dominio pleno, la superficie vendida en el lapso de 1998-2007 fue de 3.10 millones de hectáreas de acuerdo con los datos revelados por el Censo Agropecuario 2007, IX Censo Ejidal, Ags. 2009. Los comparadores de las mismas tierras implicadas en el cambio del régimen en la tenencia, en su mayoría correspondían a los mismos ejidatarios y a los avecinados o posesionarios, los cuales representaban una suma de 14,999 personas, o 71.45 por ciento entre un total de 20,989. Es decir, a pesar de que en el lapso mencionado, más de 66.60 por ciento de los ejidos y comunidades registraban compraventa de tierras, la extensión involucrada fue mínima; además, lo significativo de esto es que las operaciones se efectuaron mayoritariamente entre los mismos miembros del núcleo poblacional.

Lo anterior se debe fundamentalmente a que la actividad agropecuaria no permite amplios márgenes de ganancia y a que en las pequeñas comunidades rurales los ejidatarios suelen agregar una valoración subjetiva a su parcela. El resultado de estos factores es una pronunciada diferencia en la valoración de la tierra entre los posibles compradores y los propietarios. Por un lado, la tierra es considerada por los ejidatarios y comuneros como el origen de toda la riqueza, un bien no sustituible y una conquista derivada de las luchas centenarias y multigeneracionales. Ceder o vender la parcela implicaría convertirse en jornaleros, en empleados de otros que antes eran sus iguales; de tal manera, en mayoría de los casos quien vende su tierra lo hace para cambiar su residencia o como la última instancia.

Por su parte, los posibles compradores de tierra, de acuerdo con los pronósticos, serían los grandes productores y los agroempresarios, quienes se encuentran eficientemente integrados en los eslabones desde la siembra, cosecha, procesamiento de los productos agrícolas hasta su comercialización en los mercados tanto nacionales como internacionales. No obstante, estos agentes económicos han optado por una clara de tendencia de obtener el excedente de producción agrícola en instancias financieras y de comercialización, en lugar de acceder a convertirse en propietarios de tierra y explotarla de manera directa. Es decir, los empresarios, grandes consorcios tanto nacionales como internacionales, en lugar de invertir comprando las tierras, han registrado una tendencia inminente a celebrar convenios con los productores agrícolas para asegurar los abastecimientos de los productos agropecuarios y al mismo tiempo evitar los riesgos implicados en la explotación directa de la tierra. Cabe destacar que el régimen de propiedad privada ha existido en México inclusive antes de la reforma agraria en 1992, ya que el esquema ejidal y comunero solamente involucra un poco más de la mitad del territorio nacional, y los pequeños propietarios han vivido al mismo tiempo sin presentar tendencia evidente de concentración de las tierras implicadas. 


\section{Algunas conclusiones e implicaciones para el campo chino}

Desde la aplicación de las nuevas medidas relacionadas con las modificaciones al artículo 27 constitucional en 1992, México ha experimentado cambios importantes en aspectos socioeconómicos. Para la economía campesina la reforma agraria ha arrojado resultados insignificantes en el mejoramiento en el nivel de vida de los agricultores ejidatarios y comuneros, así como en las perspectivas encaminadas a la modernización en el campo a pesar de los buenos propósitos deseados al momento de aplicar las reformas.

- Se ha observado poco interés de los ejidatarios y de los comuneros en la adopción del nuevo esquema en la tenencia de tierra, esto es, el dominio pleno de las parcelas.

- Las operaciones de compraventa de tierra se han efectuado mayoritariamente dentro de los mismos ejidatarios y la participación de personas ajenas al ejido ha sido mínima.

- La privatización de la tierra se ha presentado como un fenómeno aislado para las zonas productoras agrícolas; en consecuencia la concentración de la tierra no ha sucedido.

- Las inversiones masivas aún no han llegado al campo mexicano a pesar de la eliminación de los impedimentos relacionados con la compra-venta de la tierra.

- De lo anterior se puede observar que el cambio de régimen en la tenencia de tierra no ha resuelto el problema del campo y mucho menos de las condiciones precarias que viven los campesinos en países como México y China, las cuales, por cierto, no se deben a la baja eficiencia registrada en la producción de la tierra sino a la escasez de la tierra en relación con el número de campesinos. De esta forma, la modernización del campo es un proceso largo y complicado, sobre todo ante una población rural de esa magnitud registrada en ambas naciones y los demás sectores cuyas capacidades en la generación de nuevos puestos de empleo todavía se encuentra lejos de las necesidades del mercado.

\section{Bibliografía}

-Arturo Warman, 2003, Los indios mexicanos en el umbral del milenio, Fondo de Cultura Económica, México.

- Chen Zhiwu, 2005, “Degradación ambiental en 50 años superó a la de 5,000 años”, Riqueza Nueva, revista escrita en chino, núm. 1.

- Guillermo Zepeda, 2000, Transformación agraria, los derechos de propiedad en el cambio mexicano bajo el nuevo marco constitucional, Centro de Investigación para el Desarrollo (CIDAC) y Miguel Ángel Porrúa, mayo de México.

- Héctor Aguilar Camín y Lorenzo Meyer, 2005, A la sombra de la Revolución Mexicana, Cal y Arena, México. 
- He Xuefeng, “La lógica de propiedad de tierra, el sistema de la propiedad de tierra en China", artículo en http://wenku.baidu.com/view/f730eed728ea81c758f578b3. html.

- Luis Téllez Kuenzler, 1994, La modernización del sector agropecuario y forestal, un visión de la modernización de México, Fondo de Cultura Económica, México.

- Miguel A. Samano Rentería, “La política salinista hacia el campo, un balance crítico (1994)", en David, Chacón Hernández, etc., Efectos de las reformas al agro y los derechos de los pueblos indios en México, Universidad Autónoma Metropolitana, 1era edición 1995, México.

-Wen Tiejun, “La privatización de la tierra no es el futuro del campo chino”, “Empresarios globales", revista escrita en chino, núm. 13, 2008, China.

-Zhou Qiren, "Régimen de propiedad de tierra y uso del suelo, decisión crítica ante la urbanización", Economía trimestral, revista escrita en chino, núm. 4, 2004. 


\title{
La producción alimentaria en China y México. Dos historias contrapuestas del subdesarrollo
}

\author{
Yolanda Trápaga Delfín
}

En 1973 el gobierno de Luis Echeverría Álvarez establece relaciones diplomáticas con la República Popular China, y es el tercer país en reconocer al gobierno socialista del presidente Mao Tsedong, después de Cuba y Chile, con Fidel Castro y Salvador Allende a la cabeza, respectivamente. México era una economía en pleno crecimiento pero que, sin embargo, había empezado a dejar de ser eficiente en la producción agropecuaria para autoabastecerse en el terreno alimentario. China, por su parte era una economía de las más pobres del planeta, con serios problemas para incrementar de manera sostenida la producción de alimentos y con menores posibilidades todavía para lograr una diversificación importante en la canasta alimentaria para sus entonces $881,940,000$ habitantes, 15 veces más que la población de México en ese año.

A diferencia de China, México había iniciado ya la adopción del patrón occidental de consumo alimentario basado en la producción de proteínas de origen animal, que hace muy ineficiente el uso de los recursos naturales, independientemente de que se utilice la mejor tecnología disponible y se aumente la productividad de manera sostenida. En las cuatro décadas transcurridas desde entonces, los procesos de desarrollo de cada nación se desplegaron en distintas direcciones que dieron también resultados no sólo diferentes, sino también en alguna medida inesperados. En estas líneas analizaremos la evolución en la concepción de cada país en lo relativo a la producción y abasto de alimentos, pero sobre todo el modelo vigente en la actualidad en China por tratarse de una situación inédita entre las economías subdesarrolladas.

\section{La producción de alimentos en el desarrollo}

A pesar de la participación regresiva del sector primario en el producto nacional y de que a mayor contracción de su contribución puede suponerse un mayor nivel de desarrollo macroeconómico, es indiscutible que la estructura de la producción y el comercio agropecuarios, así como la política sectorial, son los verdaderos indicadores de la capacidad de una economía para satisfacer la demanda doméstica de alimentos, partiendo de determinada combinación entre la producción interna y las importaciones. La historia moderna ha demostrado que todos los países industrializados han optado por generar ellos mismos el máximo de autosuficiencia en una canasta de productos agrícolas y pecuarios resultante de considerar distintos factores, tales como: a) la dotación de suelos, agua y clima, b) el patrón histórico-cultural de consumo y c) reforzar aspectos relevantes, tales como el desarrollo regional, el fomento de ciertas prácticas agrícolas, la adopción de tecnologías, la regulación de la expulsión campo-ciudad, la protección de determinados grupos de productores, la conservación de los recursos naturales, etc. 
Siendo China una economía que ha estado cerrada durante 60 años para el libre flujo de su población al extranjero, el objetivo del máximo grado de autosuficiencia en básicos -granos y tubérculos fundamentalmente- producidos domésticamente ha sido el eje de su política alimentaria. Lo que le ha redituado buenos resultados en términos de estabilidad macroeconómica, control de su balanza comercial agroalimentaria y poca vulnerabilidad de los mercados mundiales de alimentos (Trápaga, 2005).

Por su parte, México ha transitado en el mismo lapso, de una economía autosuficiente y hasta excedentaria en granos y otros bienes agropecuarios, a un modelo deficitario con una importante polarización de la estructura productiva del campo, donde los productores más capitalizados se han especializado mayoritariamente en frutas y hortalizas para la exportación, dejando el abasto de básicos en manos de los agricultores más pobres y menos productivos, así como dependiendo de manera creciente de las importaciones, a partir de un gradual desmantelamiento de las producciones más importantes tales como maíz, frijol, trigo, arroz, oleaginosas, leche y cárnicos. Desde mediados de los años 80, con la adhesión del país al Acuerdo General sobre Aranceles y Comercio, la agricultura mexicana sufre una profunda reestructuración que se inscribe en un conjunto de reformas tendientes a acelerar la inserción competitiva de las explotaciones en los mercados agrícolas, sobre todo en el marco de la entrada en vigor en 1994 del Tratado de Libre Comercio con América del Norte; en el tema de la tenencia de la tierra en 1991 se reforma el artículo 27 de la Constitución mexicana señalando el fin del reparto agrario y la conformación de un mercado de tierras que tendría que absorber las parcelas asignadas por la reforma agraria bajo el régimen de propiedad social y no privada, con el fin de que se relocalizaran en los sectores de mayor eficiencia productiva, propiciando la concentración de grandes superficies, aun en contradicción con el Código Agrario que prohíbe la gran propiedad en México.

China ha aplicado una política de autosuficiencia a toda costa, completando el proceso con la creación primero y el fomento más tarde de empresas rurales que contribuyeron en su mejor momento a completar los ingresos agrícolas y logrando por esa vía la retención de los campesinos en el campo, pues la sola existencia del sistema de registro hukou no hubiera sido suficiente como instrumento de arraigo, de haber persistido condiciones deficientes para la reproducción de los habitantes rurales.

Este sistema se agotó y la línea de política más reciente es la de trasladar a los pobladores del campo hacia las urbanizaciones ya existentes y construir nuevas para albergarlos en un proceso de urbanización acelerada inédito en la historia.

México, por su parte, abrió tempranamente sus puertas a la instalación del patrón de consumo alimentario occidental con base en la autosuficiencia generada domésticamente, para renunciar a la producción interna de básicos en la década de los 80 a favor del esquema de las ventajas comparativas, la expulsión sin control de los agricultores pobres hacia las ciudades y masivamente hacia el extranjero, con la ventaja de la cuantiosa generación de remesas que completaron los ingresos de las familias fragmentadas que no tuvieron a su disposición una política de ocupación alternativa ni complementaria.

Con $22 \%$ de la población del mundo y sólo $7 \%$ de las tierras agrícolas, China tiene un altísimo nivel de autosuficiencia en granos, oscilando alrededor de 100\% para trigo, 
arroz, maíz y algunos tubérculos; asimismo exporta de manera creciente hortalizas, frutas, flores, intensivos en mano de obra, pero su enorme población, los ingresos crecientes, el cambio acelerado hacia el patrón de consumo alimentario estadounidense, así como la contracción constante de su superficie agrícola por causa de la industrialización, la urbanización, la construcción de infraestructura y la desertificación, al mismo tiempo que la contaminación y la sobrexplotación de sus existencias de agua hacen escaso el recurso, todo lo cual cuestiona seriamente la capacidad de autoabastecerse en la misma proporción cada día (Bolpress, 2008).

Ambas naciones tienen poca tierra y son excedentarios en mano de obra. Desde el punto de vista social, el problema rural más importante en ambas economías es el subempleo o desempleo oculto que es la raíz de 100 millones de población migrante dentro de China y de la masiva emigración a Estados Unidos (EU en adelante) de mexicanos. México ha transitado por un proceso de cuatro décadas de creciente empobrecimiento de su población y no tiene la capacidad de cubrir sus necesidades alimentarias con oferta doméstica, habiendo visto crecer su dependencia de los mercados estadounidenses principalmente en un contexto en que los precios de los alimentos en el mercado mundial no han dejado de aumentar en los últimos cuatro años.

Nunca estará suficientemente subrayado que tanto China como México ${ }^{1}$ pertenecen a los 12 países de mayor diversidad biológica del mundo, lo que los hace zonas muy importantes desde el punto de vista de la conservación. Sin embargo, en la historia moderna estas naciones han aplicado políticas que no toman en cuenta esta riqueza y que, por el contrario, se vuelve un factor que eleva los costos de la inversión. Toda esta biodiversidad es contraria al enfoque de un modelo uniforme de producción agrícola y forestal que prevalece en el mundo desde los años 40 y cuya aplicación ha significado deteriorar los sistemas biológicos prevalecientes en aras de homogeneizar los recursos y adaptarlos a la lógica industrial de alta especialización, monocultivo, agroquímicos e irrigación masiva. En términos generales, tanto uno como otro son países predominantemente áridos y con poca agua y mal distribuida, con una geografía de una enorme diversidad, que en términos económicos equivale a enfrentar una heterogeneidad de regiones que van desde la extrema pobreza hasta la relativa prosperidad, así como condiciones físicas para la inversión, que no son fácilmente remontables y que marcan un punto de partida adverso para las políticas de equidad regional.

Mientras que el $80 \%$ de la población de México vive en ciudades, China se mantuvo como un país predominantemente rural hasta recientemente. Hoy la República Popular se encuentra inmersa en un proceso de urbanización nunca antes visto, a la par del mayor movimiento migratorio registrado por la humanidad y dirigido expresamente por el gobierno comunista para reubicar en las ciudades a la mayoría de los 750 millones de pobladores del campo. El exceso de población rural en relación a la poca tierra agrícola y la escasez de agua han sido interpretados desde hace décadas por el gobierno mexicano, y más recientemente por el gobierno chino, con un enfoque productivista que

1 México cuenta con alrededor de 200 mil especies diferentes, es hogar de 10 a 12 por ciento de la biodiversidad mundial y tiene el primer lugar en biodiversidad de reptiles con 733 especies conocidas, segundo en mamíferos con 448 especies, cuarto en anfibios con 290 especies, y cuarto en flora, con 26,000 diferentes especies. México es también considerado el segundo país en el mundo en ecosistemas y el cuarto en total de especies. 
pretende instalar un modelo de grandes superficies, permitiendo hacer economías de escala, sustituir por tecnología la fuerza de trabajo humana y animal, al mismo tiempo que mueve a las ciudades a la mayor parte de la población rural, pues literalmente resulta excedentaria. Diversas fuentes estiman que China tendrá 221 ciudades con más de un millón de habitantes en 2025; mientras que México tiene 11 y Europa tiene sólo 25 tras haber concluido ya su proceso de urbanización (The economist, 2011).

El cambio es de tal magnitud que implica consecuencias ambientales muy importantes, tanto por la alta concentración de personas en las ciudades como por la generalización del patrón de vida urbano que es por naturaleza insustentable, altamente demandante de recursos naturales, sobre todo teniendo en cuenta la necesidad de construir infraestructura, vivienda, dotar de servicios, de agua, de electricidad y hacer una adecuada disposición final de los desechos que cada día son y serán más voluminosos. Independientemente de la forma en que el gobierno chino administre el proceso, se traducirá en impactos mundiales muy importantes en el bienestar de su población y en la conservación del planeta. Esto implica un horizonte difícil desde el punto de visa de la demanda de materiales para la construcción que vendrán en gran parte y de manera creciente de fuera de China, ${ }^{2}$ pero que parece claro que el gobierno no moderará en la medida en que la construcción se ha confirmado como una de las palancas privilegiadas del crecimiento económico de ese país.

En contra de lo que sucede en México, frente a un aumento en los ingresos de las familias urbanas chinas de más de $300 \%$ en la década pasada, se estimuló considerablemente la demanda de alimentos, sobre todo de carnes rojas, aves y, lácteos. ${ }^{3}$ Pero ya en 2010 China se convirtió en importador neto de maíz por primera vez en más de 10 años $^{4}$ (Bloomberg News, 21/10/2011), entendiendo que en la actualidad, cualquier cosa que los chinos consuman más implicará incrementar la oferta desde fuera, lo que significa producir, procesar y asociarse con proveedores de otros países. ${ }^{5}$

\section{Dos procesos en direcciones opuestas}

La gran hambruna de 1958-1961 en China mató cuando menos a 36 millones de personas. $Y$ es a partir de entonces que producir suficientes alimentos se vuelve una altísima prioridad para el gobierno comunista que lo lleva a estimular por todos los medios la producción de granos que se incrementa de manera sostenida hasta el año 2000, a partir de dos factores:

2 China es el primer consumidor mundial de cemento, cobre, cinc, hierro, acero, madera, etc.

3 De un esquema alimentario basado predominantemente en granos, tubérculos y algunas hortalizas y frutas, la incorporación de los productos de origen animal implica un creciente uso de granos para alimentar al ganado, perdiendo cada día más eficiencia en el uso de los recursos para la agricultura en un contexto de agotamiento absoluto de su frontera agrícola, de producción estancada, rendimientos decrecientes, pérdida constante de suelos y agua que están transformando a China en un próximo importador neto de alimentos.

4 Las importaciones de arroz pueden alcanzar 8 millones de toneladas anuales en 2015, pero es más crítico el maíz que puede alcanzar hasta 20 millones de toneladas en función de la creciente demanda como alimento de la ganadería y más aún como insumo para la producción de almidón, de papel y para usos farmacéuticos.

5 Frank Ning, presidente de COFCO Ltd, la empresa comercializadora de granos más grande de China, propiedad del estado, declaró estar buscando invertir en EU, América del Sur, Australia y Rusia para asegurar la oferta de materias primas, incluyendo soya, trigo y azúcar. 
a) La adopción del enfoque de la revolución verde: adquiriendo créditos para semillas híbridas de occidente, importando la tecnología primero y desarrollando después la producción a gran escala de nitrógeno como fertilizante, desarrollando sus propias tecnologías hasta producir sus propias semillas híbridas, sus semillas de alto rendimiento de arroz y su propia biotecnología agrícola. Todo, sin embargo, con un impacto negativo muy importante en los suelos y el agua. En la actualidad China tiene rendimientos decrecientes y una producción estancada en granos, efecto principalmente de la degradación de los suelos por el uso excesivo de nitrógeno como fertilizante.

b) Desplegando, a fines de la década de los 70, reformas radicales en la estructura del esquema productivo, en el sentido de descentralizar y descolectivizar la organización agrícola, volviendo el centro de la organización a las familias de productores, al mismo tiempo que orientando más hacia el mercado la producción después del cumplimiento de cuotas, lo que incidiría en un incremento de los ingresos agrícolas, con el simultáneo y pleno desarrollo de las empresas rurales que producirían tanto para el mercado interno como para la exportación, completando los ingresos totales de los campesinos y permitiendo la existencia de campesinos sin tierra y trabajadores industriales fuera de las ciudades. En contraparte, la adopción del enfoque productivista de la revolución verde generó una enorme desigualdad entre los agricultores, así como impactos ambientales muy importantes como la desaparición de los campos de muchas de las variedades chinas -y mexicanas en su caso- de semillas, resultado de la utilización de las semillas de alto rendimiento, de semillas híbridas y ahora por la introducción de organismos genéticamente modificados. ${ }^{6}$

En la actualidad son tres los ejes que hay que considerar para poder prever la dirección que tomará la agricultura en China: a) el cambio en la demanda, tanto en cantidad como en calidad, debido al aumento del ingreso, b) cambios en la orientación de la especialización debidos a la participación de la agricultura china en el mercado mundial y c) la política de autosuficiencia alimentaria.

A pesar de las enormes ganancias en productividad durante los años 80 y 90 , desde 1998 los rendimientos en la producción de granos en China han venido disminuyendo. Sólo en 2003, y en una tendencia sostenida, la reducción en trigo, maíz y arroz -los tres cereales principales-, alcanzó 70 millones de toneladas menos que en 1998. Entre las medidas más importantes para resolver este problema, el gobierno chino tomó las siguientes medidas de política agrícola: a) reducir o hasta eliminar el impuesto sobre el ingreso de los agricultores, b) otorgar subsidios directos a los productores de granos, c) generar inventarios de granos y d) fomentar la producción de granos en el extranjero mediante el alquiler o la compra de tierras (Xinhua, 2004).

6 Todas esas semillas están diseñadas para no poder seleccionadas, guardadas y replantadas, lo que obliga a los agricultores a comprar cada nuevo ciclo la dotación de simientes necesaria para la producción. Obviamente, los pobres no pueden enfrentar este aspecto, los ecosistemas se degradan cuando se usan y las compañías productoras de semillas se benefician. Tanto chinos como mexicanos dependen de proveedores de semillas que en el caso de México se trata de compañías extranjeras y en China de firmas estatales y privadas. 
México, por su parte, no ha cambiado la dirección de su política alimentaria, largamente dependiente del exterior y con un importante abandono del campo y sus habitantes, tras el desmantelamiento de una estructura de investigación, producción gubernamental de semillas y fertilizantes, extensionismo agrícola, infraestructura de acopio y comercialización.

De acuerdo con diversas estimaciones, incluyendo la del gobierno chino, la República Popular se convertirá en un periodo de entre cinco a diez años en el primer importador mundial de productos agrícolas. Pero si tomamos en cuenta que el país consume 160 millones de toneladas de arroz al año, entendemos que ningún país puede ofrecer suficiente grano si empezara a crecer el déficit interno de manera sostenida. ${ }^{7}$ Frente a lo cual existe la intención del gobierno de mantener en lo esencial la autosuficiencia durante los cinco años próximos, ${ }^{8}$ en el entendido de que la siguiente década será un periodo de fuerte crecimiento del consumo chino de productos alimentarios, sobre todo de aves, carnes rojas, huevos y lácteos.

Hoy, la República Popular forma parte de la tendencia reciente promovida por un grupo de países, en su mayoría importadores netos de alimentos, de buscar recursos naturales para la agricultura fuera de sus fronteras, con el objetivo de garantizar el control no sólo en el abasto, sino en la misma producción, por la vía del control directo de los recursos productivos en distintas latitudes del planeta donde eso sea posible.

La seguridad alimentaria es un tema central en la agenda del gobierno chino y también lo son la energía y los minerales, por lo que se vuelven claves en la geopolítica de inversión de ese país. Nada de esto tiene la misma importancia en la agenda del gobierno mexicano.

\section{El acaparamiento de tierras: nueva expresión de la cooperación}

El gobierno chino no está dispuesto a abandonar el control total de sus aprovisionamientos alimentarios, pues se trata de un renglón estratégico en el funcionamiento de cualquier economía. $Y$ en la perspectiva de depender de fuentes externas, China se ha orientado a encontrar fuentes de producción y aprovisionamiento seguras por su accesibilidad y por el control que se pueda tener de ellas en relación a qué se produce, cómo se produce, quién lo produce y por cuánto tiempo. Se trata de suelo agrícola que se ubica predominantemente en ciertas zonas de su periferia asiática, de África, América Latina, Oceanía y algunos puntos de EU.

En el contexto de la crisis de precios de los alimentos del 2007, un grupo de países como los Estados del Golfo, Corea del Sur, China y Japón, ${ }^{9}$ se ha involucrado en

$7 \quad$ Tailandia es el principal país exportador y vende sólo 8 millones de toneladas.

8 Paralelamente, y para enfrentar una demanda creciente de productos agrícolas, COFCO dedicará más de 10 mil millones de dólares a lograr fusiones y adquisiciones en el extranjero, concretamente en EU, en Australia y en el sudeste asiático, en el plazo de los cinco próximos años. COFCO compró en julio una participación de 99\% en la sociedad azucarera australiana Tully Sugar. En 2008 había adquirido una participación de 4.95\% en Smithfield Foods, primer productor estadounidense de carne de puerco (Niu et al, 2011).

9 Entre los acaparadores de tierra más relevantes están: China, India, Japón, Malasia y Corea del Sur en Asia; Egipto y Libia en África; y Bahréin, Jordania, Kuwait, Qatar, Arabia Saudita y los Emiratos Árabes Unidos en el Medio Oriente. 
un proceso de alcance mundial, buscando tierras para la agricultura de alimentos o de combustibles bajo distintos esquemas de adquisición (compra, renta o concesión) de largo plazo (30 a 99 años), incorporando enormes superficies que pueden alcanzar medio millón de hectáreas en una sola transacción, sobre la base de acuerdos de "cooperación" que incluyen transferencia de tecnología agrícola, importación de maquinaria, de insumos y hasta de agricultores del país inversionista y la mayor parte de las veces los gobiernos receptores apoyan y facilitan los acuerdos. Lo más relevante es que no se trata del esquema tradicional de la agricultura por contrato, de la integración vertical generalizada en el mundo desde mediados del siglo XX, sino de lo que podríamos calificar como la expansión de la frontera agrícola alimentaria y energética fuera de los países inversionistas. No se trata de inversiones para participar en el mercado mundial ni en los mercados de los países huéspedes. Se trata de la producción destinada al mismo país dueño del capital, que cancela ese recurso para los ciudadanos del país que recibe el capital. Los productos son enviados a la nación que adquirió la tierra como la mejor solución frente a un mercado que es considerado no confiable.

Son dos las líneas presentes en este proceso: seguridad alimentaria y energética de largo plazo y ganancias especulativas. Por un lado, se trata de países importadores netos de alimentos o que prevén la necesidad de garantizar la seguridad alimentaria y que ven en este proceso una estrategia de largo plazo para asegurar el abasto de básicos a precios bajos y con mayor certeza que lo que puede percibirse de las tendencias de los mercados internacionales de alimentos; por el otro, de corporaciones alimentarias e inversionistas privados que buscan tierra arable por las altas ganancias que el sector financiero no está generando, lo que resulta en un acelerado proceso de acaparamiento de recursos naturales, fuentes energéticas, yacimientos mineros y tierras, que si bien no es nuevo en la historia, sí lo es por cuanto que ya no hay más tierras disponibles en el planeta. Los impactos son de distinto tipo, pero muy importantes, en África, Asia y América Latina, donde muchos gobiernos reciben con plácemes esta situación por considerar que se trata de inversión extranjera directa para el desarrollo y que será registrado como exportaciones disminuyendo el déficit en la balanza comercial. En ese contexto, los países inversionistas reciben todo tipo de beneficios. ${ }^{10}$ Los principales actores no son países ni gobiernos, sino corporaciones en su mayoría privadas. Sin embargo, es claro que algunos gobiernos tienen una participación directa muy importante, como serían los casos de Arabia Saudita, Corea del Sur y China.

10 En 2009 los principales compradores de tierras en el mundo eran: Corea del Sur con 2,306,000 hectáreas principalmente adquiridas en Indonesia, Mongolia, Sudán, Madagascar y Argentina; China, con 2,090,796 hectáreas de Filipinas, Laos, Australia, Tanzania, Uganda, Camerún, Cuba, México (1,050ha), Rusia y Kazakstán; Arabia Saudita, con 1,610,117 ha de Indonesia y Sudán; Emiratos Árabes, con 1,282,117; y Japón, con 324,262 (Grain, 2009a). 
Es claro que este fenómeno deja atrás cualquier consideración ligada al desarrollo y extrae de los países con disponibilidad de recursos primarios no sólo los productos, sino la posibilidad de que los agricultores domésticos accedan a la tierra (Grain, 2011).

Desde marzo de 2008, oficiales de alto nivel de esas naciones han desplegado misiones diplomáticas buscando tierra fértil en países como Uganda, Brasil, Camboya, Sudán y Pakistán, sin importar que en algunos de ellos parte de la población padezca hambre como en Camboya o Sudán.

Hoy, más que nunca, controlar el suelo y el agua para la producción agrícola es una poderosa arma económica y política, es una forma moderna de colonialismo, y China es un actor principal adquiriendo tierra en todo el mundo y participando de manera muy relevante en la crisis alimentaria global con el argumento de la cooperación.

La producción de alimentos de China fuera de sus fronteras antecede en varios años a las crisis mencionadas y se inserta en una tendencia que otros países con pocos recursos para la agricultura, como Japón, han desplegado desde hace muchas décadas. ${ }^{11}$ Con la estrategia de "ir al extranjero" e invertir, China ha firmado alrededor de 30 acuerdos de cooperación con "países amigables" sólo en Asia y África, para que empresas chinas estatales accedan a tierras agrícolas, a cambio de tecnologías, capacitación y financiamiento de infraestructura $^{12}$. Cualquier decisión que China tome, como principal consumidor de granos del mundo para invertir en la agricultura africana tendrá grandes implicaciones.

Para lograr la máxima eficiencia productiva, fuera de sus fronteras China aplica el modelo contrario al que ha usado dentro, ${ }^{13}$ favoreciendo el enfoque de la agricultura industrial, instalando operaciones agroindustriales a gran escala a partir de grandes extensiones, esquema maquinizado, monocultivos a gran escala, químicos, combustibles fósiles, ${ }^{14}$ exclusión de los agricultores locales importando trabajadores chinos, produciendo para "exportar", beneficiándose de precios baratos del suelo y el agua, cuando no los consigue gratis, con exenciones fiscales y hasta subsidios. Estas producciones técnicamente califican como exportaciones para el país donde se producen, pero los ingresos no se quedan ahí sino que son para las empresas o para el gobierno chino (Grain, 2010a) cuya mayor producción en el extranjero es arroz, soya y maíz, así como caña de azúcar, mandioca, sorgo y también maíz como agrocarburantes. ${ }^{15}$

11 La inversión pública para asegurar los productos básicos no es un fenómeno nuevo. Japón, por ejemplo, invierte en terrenos agrícolas en el extranjero desde hace un siglo, y la superficie extranjera que ha consolidado es tres veces el tamaño de su superficie arable doméstica.

12 El gobierno chino anunció que se comprometería para que esas empresas invirtieran 5 mil millones de dólares durante los próximos 50 años en la agricultura africana a través del Fondo de Desarrollo China-África para producir alimentos (Johnny, 2008).

13 El modelo utilizado desde las reformas se basa en lo fundamental en la producción familiar, el arraigo de los agricultores, parcela de autoconsumo, complemento de ingresos a través de industrias rurales.

14 La revolución verde de nueva generación que se ofrece como la solución al rezago productivo de África tiene dos aspectos principales a considerar: a)ignora la situación energética mundial, dado que el petróleo es el insumo más importante del esquema de agroquímicos del paquete tecnológico y b) la dependencia tecnológica de los agricultores que tienen que comprar el insumo más importante, las semillas, pues son híbridas y sólo las producen empresas, no pueden generarlas y seleccionarlas ellos mismos; con un efecto de marginación de los campesinos pobres, reproduciendo el modelo de todo el tercer mundo en el sentido de no resolver ni el problema del hambre, ni el de la productividad, ni el de mejorar la condición económica de la mayoría de los agricultores, sólo de los que tienen capital.

15 Recientemente, Sinopec y The Chinese National Overseas Oil Corporation, dos gigantes propiedad del estado, invirtieron 5 mil millones de dólares y 5 mil quinientos millones, respectivamente, en Indonesia, para cultivar y procesar maíz en energético para exportar a China. 
Dadas las características del proceso, con estos acuerdos se exporta la inseguridad alimentaria de los países inversionistas a los países receptores (Al Jazzera, 27/10/2011).

\section{Acuerdos firmados o propuestos por China}

\begin{tabular}{|c|c|c|c|}
\hline País receptor & inversionista & acuerdo & status \\
\hline Rep. Dem. de Congo & ZTE International & $2,800,000$ ha (aceite de palma y agrocarburantes) & desconocido \\
\hline Mozambique & gobierno & $\begin{array}{l}\$ 800 \text { millones para aumentar producción de arroz, } \\
\text { de } 100 \text { mil a } 500 \text { mil toneladas. Oposición política }\end{array}$ & descontinuado \\
\hline Filipinas & $\begin{array}{l}\text { privadas } \\
\text { Beidahuang } \\
\text { Beidahuang }\end{array}$ & $\begin{array}{l}\text { 1,240,000 ha (arroz, maíz, azúcar y pescado) } \\
\text { Oposición pública } \\
200,000 \text { ha (arroz y maíz) } \\
320,000 \text { ha (granos) }\end{array}$ & $\begin{array}{l}\text { bloqueado pero no } \\
\text { cancelado } \\
\text { firmado desconocido }\end{array}$ \\
\hline Laos & Municipio de Chongqing & $\begin{array}{l}5,000 \text { ha (arroz y otros granos) } \\
10,000 \text { chinos empleados }\end{array}$ & firmado \\
\hline Zimbabue & gobierno & 101,171 has & firmado \\
\hline Kazakstán & gobierno & $\begin{array}{l}7,000 \text { ha (soya y trigo) } \\
3,000 \text { chinos empleados }\end{array}$ & firmado \\
\hline Australia & $\begin{array}{l}\text { ABS } \\
\text { Beidahuang }\end{array}$ & $\begin{array}{l}45,000,000 \text { ha } \\
80,000 \text { ha }\end{array}$ & $\begin{array}{l}\text { firmado } \\
\text { propuesto }\end{array}$ \\
\hline Papúa N. Guinea & China, Malasia y Singapur & $5,200,000$ ha (aceite de palma) & firmado \\
\hline Benin & SYNPA & $\begin{array}{l}236,100 \text { ha } \\
\text { (maíz, arroz, mandioca, frutas y jatropha) }\end{array}$ & firmado \\
\hline Zambia & $\begin{array}{l}\text { GLP } \\
\text { gobierno }\end{array}$ & $\begin{array}{l}634,850 \text { ha } \\
2,000,000 \text { ha (biocarburantes) }\end{array}$ & $\begin{array}{l}\text { firmado } \\
\text { firmado }\end{array}$ \\
\hline Brasil & $\begin{array}{l}\text { Chongqing Grain Group } \\
\text { Empresas estatales }\end{array}$ & $\begin{array}{l}100,000 \text { ha (soya) } \\
\text { producir } 6,000,000 \text { ton soya anua }\end{array}$ & $\begin{array}{l}\text { firmado } \\
\text { firmado }\end{array}$ \\
\hline Argentina & Beidahuang & 330,000 ha (soya, maíz por 20 años) & firmado \\
\hline Colombia & gobierno & $\begin{array}{l}400,000 \text { ha (granos) importar de China } \\
\text { trabajadores, insumos y maquinaria }\end{array}$ & no concretado \\
\hline
\end{tabular}

Elaboración propia con base en: Grain y PEAC 2010 y Von Braun 2011

Una demanda espectacular por agrocombustibles, así como acceso a nuevas fuentes de materias primas para la manufactura, también son factores que inciden en este proceso. Por ejemplo, varias compañías chinas aseguraron acuerdos en el sudeste de Asia para cultivar árboles de hule, procesarlos y exportar el látex que China demanda en forma creciente, pues se espera que la República Popular consuma 30 por ciento del hule del mundo en 2020. Por su parte, en Camboya se han despejado campos arroceros para sustituirlos por árboles de hule para abastecer con casi todo el producto a China. $\mathrm{Y}$ en Burma, que de acuerdo a FAO tiene una severa inseguridad alimentaria, se han hecho concesiones de tierra a compañías chinas para establecer también plantaciones de hule (Grain, 2009b). 
De la misma manera, la inversión de China en América Latina comenzó rentando tierra para producción alimentaria en Cuba y México desde hace 10 años, aunque con participaciones muy modestas por las restricciones en la tenencia de la tierra existentes en ambos países. Pero estas inversiones en otras economías de la región alcanzaron 15.6 mil millones de dólares entre mayo de 2010 y mayo de 2011, casi tres veces más que en 2009-2010, destinando 40\% para Argentina y casi el 60\% Brasil. También en América Latina operan los grupos Beidahuang ${ }^{16}$ y Suntime; ésta es una de las nacientes corporaciones agrícolas chinas, con operaciones en Cuba, Kazakstán y México; y desarrolla proyectos utilizando suelos y agua en América del sur, Australia y Rusia. (Callick, 2008).

Porcentaje de la tierra arable controlada por extranjeros para la producción de alimentos en A.L. (2011)

\begin{tabular}{|l|l|l|l|}
\hline Argentina & $10 \%$ & Colombia & $1 \%$ \\
\hline Bolivia & $4 \%$ & Paraguay & $25 \%$ \\
\hline Brasil & $2 \%$ & Uruguay & $26 \%$ \\
\hline
\end{tabular}

Fuente: Grain, 2011

Es necesario señalar que en México existe inversión extranjera para la producción de alimentos, pero incluyen distintas modalidades que han surgido justamente de la barrera que impone la tenencia de la tierra para la compra directa de suelo agrícola, lo que no ha impedido las inversiones para la producción de hortalizas en el norte del país, sobreexplotando los acuíferos subterráneos, además de a la fuerza de trabajo agrícola que es la de peores condiciones salariales y de todo tipo en México. Y de la misma manera, el fenómeno se ha manifestado con las alianzas empresariales establecidas por el grupo chino Suntime International Techno-Economic ${ }^{17}$ para operar unas mil hectáreas para producir granos, particularmente arroz (La Jornada, 29-11-2009).

Cada año, más de 40 millones de hectáreas de tierras agrícolas en el mundo son objeto de demandas de adquisición por inversionistas, más de un tercio de las adquisiciones de tierra a gran escala, según el Banco Mundial (De Schutter, 2010). Y China es

16 El Grupo Beidahuang es un conglomerado de agroempresas estatales asentado en Harbin, provincia de Heilongjiang. Es uno de los mayores molineros de arroz de China y uno de los cinco mayores procesadores de soya a través de su subsidiaria Jiusan Oil and Grain Group. De acuerdo al sitio de internet de la empresa, posee casi 5.5 millones de hectáreas (12\% del total del área de la provincia de Heilongjiang), 418,094 cabezas de bovinos para carne, 267,266 vacas lecheras, 1,315,000 puercas para cría, 2,062,000 cabras y 6,352,000 aves. También es dueña de 54 aeropuertos y 30 aeronaves agrícolas, 198 centros procesadores de grano, 59 instalaciones procesadoras de oleaginosas y 24,151 tractores. Beidahuang es una de las pocas compañías domésticas procesadoras de soya en China que sobrevivió al ingreso del país a la Organización Mundial de Comercio en 2001, cuando el gobierno relajó el control de precios sobre las importaciones de soya. China se volvió el primer importador de soya e industria doméstica procesadora de soya fue controlada por las corporaciones que controlan el comercio mundial de esa oleaginosa: Wilmar, Cargill, ADM, Bunge, y Louis Dreyfus. Las empresas extranjeras participan en 64 de las 97 mayores procesadoras y controlan $80 \%$ del total de la capacidad procesadora del país.

17 Suntime International Techno-Economic Cooperation (Group) Co., Ltd., es una empresa china fundada en 1990, con sede en Urumchi y que opera en el ámbito de los bienes raíces, futuros, y comercio en China, EU, México, Cuba, Australia, Tanzania, y Rusia. Sus actividades incluyen la “cooperación económica y tecnológica", futuros, vino, desarrollo de bienes raíces, turismo, importaciones y exportaciones, desarrollo agrícola y producción de muebles (Bloomberg, 2012). 
cada vez más dinámica en ese proceso, mientras que el gobierno mexicano se lamenta por no poder recibir estas inversiones en montos crecientes.

\section{Conclusiones}

Después de cuatro décadas de haber establecido relaciones diplomáticas, México y China se encuentran hoy en situaciones opuestas por haber tomado decisiones radicalmente diferentes en la concepción de su política alimentaria. Uno es deficitario y demanda inversión extranjera para salir del atolladero, renuente a establecer una política de soberanía que fortalezca al conjunto de la economía, mientras que China es hoy una economía que ordena los mercados por su capacidad productiva y de demanda, al mismo tiempo que ha tomado la ruta de las grandes potencias de la historia: dominar sobre los recursos de otros países para beneficio propio. Ninguna de los dos caminos nos parece digno de un verdadero desarrollo.

\section{Bibliografía}

-Al Jazzera, China's farming history misapplied in Africa, 27 October 2011, http://farmlandgrab.org/post/view/19573

-Bloomberg, 2012, Suntime International Techno-Economic Cooperation (Group) Co., Ltd, REAL ESTATE MANAGEMENT AND DEVELOPMENT, Bloomberg.com, January 07, 2012 4:29, http://investing.businessweek.com/research/stocks/private/ snapshot.asp?privcapld $=23008010$

-Bloomberg News, 2011, Cofco seeks acquisitions to 'balance' China's food demand, http://farmlandgrab.org/post/view/19494

-Bolpress, 2008, La crisis capitalista y el hambre avivan febril apropiación y concentración de tierras, http://www.bolpress.com/art.php?Cod=2008113001

- Callick, Rowan, 2008, Chinese firms eye Aussie farmland, The Australian, May 12, 2008, http://farmlandgrab.org/post/view/2350

- De Schutter, Olivier, 2010, La pression sur les terres dans le monde augmente à un rythme sans précédent, Nations Unies - 23 novembre 2010, http://www.reporterre.net/spip.php?article1410 http://angel-invest.us/apps/newsFr/...

- GRAIN, 2009a, Adquisició de terres per a l'agricultura a tot el món, Map compiled by Panorama (Catalan) using data provided by GRAIN, 2009 http://www.grain.org/system/old/landgrab/mapa-landgrab.jpg

- GRAIN, 2010a, The new farm owners: Corporate investors lead the rush for control over overseas farmland. A background article on landgrabbing by GRAIN, published as a chapter in the Monthly Review Press book 'Agriculture and food in crisis'. November 2010, grain-4389-the-new-farm-owners-corporate-investorslead-the-rush-for-control-over-overseas-farmland-pdf

- ___ and PEAC 2010, From green to gene revolution: How farmers lost control of the seeds from agricultural modernisation, GRAIN and PEAC, 09 October 2010, 
http://www.grain.org/article/entries/4151-from-green-to-gene-revolution-how-farmers-lost-control-of-the-seeds-from-agricultural-modernisation

- 2009b, What's on Irri's table, In Land Grab, Food Is Not the Only Consideration, New from GRAIN, The New Security Beat | 3 March 2009 http://www.grain. org/pe/?id=232

- Grist, Land grabbing and the global food crisis, Grist, 11/2011, http://www.grain.org/system/old/o files/landgrabbing-presentation-11-2009.pdf

- Johnny, T. Michael, "China earmarks us \$5 billion for food production on continent", The News, Monrovia, 23 April, 2008.

http://allafrica.com/stories/200804230844.html

- La Jornada, 2009, “Alimentación: hacia un nuevo colonialismo”, La Jornada, 29 de noviembre 2009, http://farmlandgrab.org/post/view/9369

- Niu, Shuping, Ken Wills y Wilfrid Exbrayat, La Chine deviendra le premier importateur mondial, Reuters (Niu, Shuping, Ken Wills y Wilfrid Exbrayat por el servicio francés, editado por Benoit Van Overstraeten), 07 Nov 2011, http://farmlandgrab.org/post/view/19566

- Trápaga Delfín, Yolanda 2005, Agricultura, medio ambiente y reformas económicas en China y en México, en Dussel, Enrique y Yolanda Trápaga (editores), Hacia un diálogo entre México y China: dos y tres décadas de cambios socioeconómicos, Cechimex-UNAM, CICIR, Friedrich Ebert Stiftung, Senado de la República, 2010.

-The economist, 2011, Asian Green City Index, Assessing the environmental performance of Asia's major cities. A research project conducted by the Economist Intelligence Unit, sponsored by Siemens, Munich, The economist, Germany, 2011, http://www.businessresearch.eiu.com/asian-green-city-index.html

- Von Braun, Joachim y Ruth Meinzen-Dick, "Land Grabbing" by Foreign Investors in Developing Countries: Risks and Opportunities, International Food Policy Research Institute, IFPRI Policy Brief 13 • April 2009, http://www.ifpri.org/pubs/bp/bp013.asp -Xinhua, 2008, China to lease overseas farmland to solve food problem, Xinhua, 24 May 2008, http://farmlandgrab.org/emailthis/index/2364 
Sección 6:

La relación política binacional 



\section{De la coincidencia diplomática a la competencia económica}

Romer Cornejo

Una revisión histórica a las relaciones entre México y la República Popular China revela tres elementos importantes: el cambio en México de una política exterior que consideraba el nacionalismo revolucionario entre sus principios, lo cual coincidía con los planteamientos de Beijing cuando se iniciaron las relaciones diplomáticas, hacia una indefinición nacional propia del neoliberalismo, la constante por parte de China de tener claros principios en su política exterior y la situación del momento actual cuando la indefinición del proyecto nacional en México está confrontada y sin respuestas ante la racionalidad de la diplomacia y los retos del crecimiento económico de China. ${ }^{1}$

\section{El inicio de las relaciones}

Para fines de la década de 1960, China pasaba por una gran crisis política, las movilizaciones de masas de la revolución cultural (1966-1969) y la enconada lucha por el poder habían dejado al partido debilitado, el enorme crecimiento de la población no estaba aparejado con un consecuente crecimiento económico, el rezago tecnológico preocupaba a muchos líderes y la confrontación con la Unión Soviética y la creciente presencia de Estados Unidos en Vietnam colocaba al país en una situación vulnerable. En su percepción de esta situación, que en ese momento ya apuntaba a lo que sería la llamada teoría de los tres mundos, la contradicción era con las dos grandes potencias, que ocupaban el primer mundo, entre las cuales China percibía a la Unión Soviética como contradicción principal, por su enorme frontera y por su capacidad de penetración ideológica dentro del partido comunista. De allí que, apenas terminadas las movilizaciones de masas de la revolución cultural en 1969 y con los líderes radicales en el poder enviando un enconado discurso de confrontación desde los medios de comunicación, el gobierno de Mao Zedong y Zhou Enlai inició el acercamiento con Estados Unidos y las negociaciones para el reingreso a la ONU.

El acercamiento entre China y Estados Unidos y la readmisión del primero en la ONU y en su Consejo de Seguridad, en octubre de 1971, fueron el preludio y la anuencia para que México cambiara su reconocimiento oficial de Taipei a Beijing el 14 de febrero de 1972. Esta circunstancia coincidió con un cambio importante en la política exterior de México bajo el gobierno de Luis Echeverría (1970-1976). Este sexenio fue un momento complicado para México, el crecimiento económico estaba afectado, entre otros por la

1 Una parte sustancial de este trabajo está basado en el capítulo “México y China. Ironías y perspectivas de su relación" en Blanca Torres y Gustavo Vega (Coordinadores) Relaciones Internacionales, México, El Colegio de México, 2010 (Los Grandes Problemas de México Vol. 12). 
carencia de capitales para la inversión, ${ }^{2}$ había una gran presión por empleo y servicios dado el enorme crecimiento de la población, se suscitaron algunas fricciones con Estados Unidos por tarifas aduaneras a productos mexicanos y, como resultado del descontento social y la ausencia de canales legales de expresión política, algunos grupos de izquierda recurrieron a la guerrilla. El nuevo presidente optó por la búsqueda de apoyos políticos internos entre intelectuales y liberales inconformes por la represión estudiantil en 1968, cuando él mismo era secretario de Gobernación. Todos esos factores y la propia personalidad del presidente le imprimieron al discurso político y a la política exterior un fuerte acento en el nacionalismo y en la alianza con sectores desprotegidos y en el exterior con países lesionados en su soberanía, algunos de independencia reciente, presentados como víctimas de potencias hegemónicas.

Los textos oficiales sobre la política exterior estaban salpicados de conceptos, hoy extintos del lenguaje político y académico, como soberanía nacional, hegemonía de las potencias, autodeterminación, Tercer Mundo, cambios estructurales. Mientras reprimía a la activa guerrilla desatada en varios partes de la república, el presidente cooptó con cargos a muchos intelectuales nacionales que se ubicaban en la izquierda, y se nutrió de las elites académicas que buscaron exilio de la represión de las dictaduras sudamericanas. Con su ayuda, se elaboró un discurso que buscaba construir una identidad para el país, o personalidad en lenguaje del presidente, se rastreaba en el pasado las raíces de esa identidad que acentuaba el pasado de intervención extranjera, el impulso por la independencia nacional, la lucha por la libertad y la justicia, etc. Ése era el contenido fundamental del llamado nacionalismo revolucionario que impregnaba el discurso en la política exterior.

Uno de los cambios más importantes fue la decidida búsqueda de la diversificación en las relaciones con el exterior. Parecía que el país quería establecer límites en sus relaciones con Estados Unidos, sobre ellas el presidente Echeverría expresaba en 1971:

No nos ocultamos las dificultades que derivan de los muy diferentes estadios de nuestros respectivos países; pero, como en el pasado, aspiramos a preservar nuestra soberanía política y acrecentar nuestra personalidad cultural, por encima de cualquier logro o progreso material. ${ }^{3}$

El presidente trataba de construir un discurso basado en un modelo propio de desarrollo dentro de un orden internacional más justo:

La superación del país, como la del ser humano, no tiene únicamente signos económicos, se basa también, y fundamentalmente, en la necesidad de optar por un modelo propio de desarroIlo. La imitación irracional envilece y despersonaliza a los pueblos. No queremos competir con las grandes potencias en la insensata carrera de una economía de desperdicio que sólo acarrea el deterioro irreversible del medio ambiente. Rechazamos muchos de los objetivos que son

2 Las complejidades de la situación económica para 1970 son explicadas por muchos autores, entre otros véase Leopoldo Solís, La realidad económica mexicana: reprovisión y perspectivas, México, Siglo XXI Editores, decimoprimera edición revisada, 1981 y Enrique Cárdenas, La política económica en México, 1950-1994, México, El Colegio de México y Fondo de Cultura Económica, 1996.

3 Luis Echeverría Álvarez, Informes Presidenciales, México: Cámara de Diputados, LX Legislatura, 2006 en www.diputados.gob.mx/cedia/sia/re/RE-ISS-09-06-14.pdf 
signos de crisis o decadencia de las sociedades opulentas (...) Lo que pretendemos en nuestra política exterior no es obtener ventajas del modelo económico dominante sino transformarlo. Cuarto Informe de Gobierno, 1 de septiembre de 1974.

México busca en el ejercicio de su política exterior la realización de las siguientes metas: la consolidación de la independencia nacional, la búsqueda de elementos externos para apoyar su progreso exterior y la estructuración de un orden mundial justo que conduzca a la paz. Quinto Informe de Gobierno, 1 de septiembre de 1975.

En la práctica, México se abocó a un acercamiento con los países socialistas y con América Latina, estableció relaciones con casi todos los países del mundo. Asimismo recibió exiliados de las dictaduras latinoamericanas y fue muy activo en el ámbito internacional buscando un papel protagónico en foros multilaterales sobre la paz, el desarme y el establecimiento de un nuevo orden económico internacional. Entre muchas de sus actividades internacionales, México asumió en 1974 la presidencia del grupo de los 77, que intentaba presionar por un orden económico más justo, apoyó la proposición en la ONU de la Carta de los Derechos y Deberes económicos de los Estados y fue miembro fundador del Sistema Económico Latinoamericano (SELA) en 1975.

En ese momento de inicio de las relaciones ambos países se ubicaban del mismo lado en su percepción del mundo, en el Ilamado Tercer Mundo, teoría que ya había sido sistematizada y expuesta por Deng Xiaoping en un discurso en la ONU en 1974. Los acercaba el discurso antihegemónico y coincidían en diferentes proyectos de diplomacia multilateral en la Organización de las Naciones Unidas y otros mecanismos que se crearon en esa época. Probablemente uno de los eventos más importantes de este primer momento de la relación bilateral con la República Popular China fue que, después de múltiples y complicadas negociaciones, México logró la cooperación de China para la firma del Tratado para la Prohibición de las Armas Nucleares en América Latina (Tratado de Tlatelolco), con el que se creó la primera región del mundo libre de armas nucleares. Durante el viaje del presidente Echeverría a Beijing en abril de 1973 el gobierno chino le comunicó su decisión de firmar el Protocolo Adicional Il del Tratado.

A partir de la apertura de las relaciones diplomáticas comenzó la construcción de un esquema institucional de las relaciones entre ambas partes. Fue un comienzo lento, pues más allá de las coincidencias sobre asuntos internacionales, las relaciones no fueron muy estrechas. Sin llegar a ser significativo, el flujo comercial aumentó considerablemente, con una balanza comercial notablemente favorable para México cuyos totales de exportación tuvieron grandes cambios. En esta relación, uno de los logros destacados de México en el plano diplomático fue el Programa Especial para la Enseñanza del Español a Estudiantes de la República Popular China auspiciado por la Secretaría de Educación Pública y desarrollado por El Colegio de México, que entre 1974 y 1987 preparó a un total de 151 alumnos. Este Programa dio frutos a la relación en el largo plazo, pues la mayoría de sus egresados fue la fuente de abastecimiento de diplomáticos chinos en los países hispano parlantes, lo que era una plataforma 
favorable para las buenas relaciones bilaterales. Hoy la mayoría de los egresados de este programa ya están en retiro o en proceso de hacerlo. La impronta dejada en la memoria de la diplomacia china por este excelente inicio no ha sido recuperada hasta el momento.

En la primera parte de la década de 1970, China atravesaba por un momento políticamente difícil y paralizante que comenzó a despejarse después de la muerte de Mao en 1976. El movimiento posterior fue la purga subsiguiente contra los líderes maoístas radicales y la consolidación en el poder de un grupo que se había dado cuenta que los grandes problemas del país no podían ser resueltos sin una profunda reforma en la economía. Estas reformas se anunciaron a fines de 1978 y durante los catorce años siguientes el país llevó a cabo transformaciones muy profundas en su economía, todavía con un grupo de líderes en el poder que mostraba reticencia hacia ellas y con la presión de algunos sectores sociales que buscaban cambios políticos. Las reformas se hicieron de manera gradual e implicaban, en términos generales, la aceptación de inversiones extranjeras, la apertura del mercado, el desmantelamiento de las comunas y las unidades cooperativas en el campo y el adelgazamiento de la participación y la dirección estatal en la economía. En este contexto de liberalización económica se produjeron varios movimientos de protesta social que pugnaban por la liberalización política, el más conocido de los cuales fue el de 1989 por la violencia con la que fue reprimido. A partir de este acontecimiento, el gobierno chino estuvo tres años diplomáticamente boicoteado por los países de Europa Occidental y Estados Unidos, por lo que Beijing volcó sus esfuerzos diplomáticos a fortalecer sus relaciones con otras regiones, de esa manera se dio el primer viaje de un presidente chino a América Latina. En ese contexto, el presidente para ese momento, Yang Shangkun, parte del ala dura del gobierno, fue recibido en México en mayo de 1990 por el presidente Carlos Salinas.

Ya en México se había producido un cambio importante en la elite gobernante. Para principios de la década de 1980, la situación económica no era particularmente senciIla, la reincorporación de los ingresos petroleros a la economía y la crisis de la deuda externa habían introducido nuevos elementos. El gobierno decidió hacer cambios sustanciales y apostar por la búsqueda de nuevas maneras de relacionarse con el exterior económicamente, particularmente pensaba en la exportación de manufactura, y en agosto de 1986 México suscribió el Acuerdo General sobre Aranceles y Comercio (GATT). Esta tendencia cristalizó bajo el gobierno de Carlos Salinas (1988-1994) quien sistematizó la nueva política y transformó una parte de le estructura económica del país para abrirla al exterior, sus principios liberales en política económica se mantienen hasta hoy. Al igual que China se buscaba la inserción de la economía del país en el contexto internacional como productor de manufacturas, a través de una serie de medidas tendentes a bajar a un máximo la participación estatal en la economía y la construcción de un marco institucional a través de tratados de libre comercio con diferentes países. Con esa plataforma México comenzó a considerar en el discurso a Asia como parte del contexto internacional. No obstante, en la práctica, se concentró en su integración al mercado norteamericano sin considerar las transformaciones que ocurrían en China, a pesar de las diversas alertas desde el ámbito académico. 
Para la década de 1990, superada la guerra fría, ambos países estaban decididamente embarcados en reformas económicas que en esencia eran muy parecidas, en el plano internacional ambos buscaban insertarse en el mercado mundial como exportadores de manufacturas, como centros de atracción del inversión extranjera y asumiendo las reglas dictadas por la organización auspiciada por la mayoría de las potencias económicas, el GATT primero y la Organización Mundial de Comercio (OMC) a partir de 1995. Ambos países habían abandonado la búsqueda de su propia concepción de un Nuevo Orden Económico Internacional y habían adoptado el orden económico de las economías más poderosas.

Para ese momento, las ventajas de México sobre China eran obvias: cercanía y afinidades con Estados Unidos y Europa, existencia de un empresariado consolidado, mejores índices de educación, mayores ingresos per cápita, mayor difusión del inglés, mayor experiencia en contactos con el exterior, mayor desarrollo institucional, particularmente en finanzas, membresía en el GATT, etc. Además, en México la apertura del mercado, las privatizaciones y las reformas en el sistema financiero fueron muy rápidas, mientras en China ese mismo proceso ha sido gradual. A partir de 1992 China decidió dar un enorme impulso a las reformas económicas y emprender una nueva ola de reformas institucionales que permitieran la recuperación de la credibilidad del capital internacional, perdida por la represión en Tiananmen. Durante su viaje al sur Deng Xiaoping emitió un inequívoco mensaje al exterior sobre la certeza y profundidad de las reformas, el cual fue inmediatamente respondido con la llegada de nuevos capitales y empresas extranjeras. El producto interno bruto de ese país comenzó a crecer a tasas superiores al 10 por ciento. Ambos países comenzaron a integrarse en los diversos foros internacionales que propiciaban sus proyectos, China ingresó en el Foro Cooperación Asia Pacífico (APEC) en 1991 y México lo hizo en 1993, México firmó el Tratado de Libre Comercio de América del Norte en 1992, que entró en operación en 1994, año en el que también ingresó a la OCDE. Después de arduas negociaciones China finalmente ingresó a la OMC en 2001. Para ese momento, la elite política mexicana, que no había considerado previamente el motor económico en el que se estaba convirtiendo China, fue reacia a firmar el acuerdo correspondiente con ese país, de hecho fue el último país que lo firmó.

En el plano diplomático, las reformas en ambos países condujeron a una especie de economicismo en la formulación y acción de su política exterior. En México, el discurso presidencial cambió de manera importante, la palabra modernización comenzó a figurar cada vez más y se inició una interesante transición en la redefinición del nacionalismo. El presidente Salinas en su cuarto informe de gobierno el 1 de noviembre de 1992, redefinió al nacionalismo y sus ideas sus ideas siguen vigentes en el siglo XXI:

El nacionalismo mexicano en nuestros tiempos, y de cara al siglo $\mathrm{XXI}$, reafirma su herencia histórica y no olvida las heridas causadas a la nación por pretensiones intervencionistas, añoranzas de fueros o abusos de grupos de poder. Pero si nacionalista es lo que fortalece a la nación, las fórmulas de otros tiempos, en un mundo que tanto ha cambiado, ya no robustecen al país y podrían debilitarlo. 
Nuestro nacionalismo se expresa hoy a favor de la interrelación económica de naciones soberanas, en el respeto a la libertad de creencias, en la necesidad de dar más participación a la sociedad civil, en la reafirmación del compromiso de revertir la pobreza en las colonias populares y la injusticia en el campo. Es una nueva expresión del nacionalismo para asegurar que el país crece con justicia; que las libertades florecen, que avanza la democracia y nuestra presencia en el mundo. ${ }^{4}$

En el plano de los hechos, durante la década de 1990 ambos países coincidieron en considerar a Estados Unidos su prioridad fundamental como fuente de capitales, tecnología y mercado para sus productos. Sin embargo, a diferencia de México que concentró prácticamente toda su atención en su vecino del norte, China puso paralelamente una gran atención en regiones como el Sureste de Asia, Asia Central, América Latina y África. En sus países vecinos China vio un mercado natural para sus productos y allende sus fronteras, además, pensó en el largo plazo y en su creciente necesidad de materias primas. En 1992 China se convirtió en un importador neto de petróleo y progresivamente en el mayor consumidor de cobre del mundo y un gran consumidor de hierro y otras materias primas. Con los países de Asia Central y Rusia logró un amplio acuerdo de cooperación económica y política. Con el Sureste de Asia comenzó una política de acercamiento para cambiar la percepción de desconfianza, lo que logró con su actuación durante la crisis de 1998, y posteriormente se abocó al establecimiento de un acuerdo comercial que comenzó a entrar en operación en 2010. Asimismo se dedicó a estrechar sus relaciones con África y a establecer pactos con las elites de los países productores de petróleo.

El interés de China por América Latina se expresó desde principios de la década de 1990. En 1991 ese país se convirtió en observador del Banco Interamericano de Desarrollo y desde 1993 reiteró continuamente su petición de convertirse en accionista del banco, lo cual fue finalmente aprobado en octubre de 2008, en medio de la crisis financiera, y en la reunión de Medellín, Colombia, de marzo de 2009, hizo su debut como miembro donante de 350 millones de dólares. ${ }^{5}$ La mayoría de los proyectos de inversión del banco son en materias primas como petróleo y minerales. En 1990, China también estableció el diálogo político con el Grupo de Río. Dado su interés en la región, en junio de 1994 se convirtió en el primer país asiático en ser observador de la Asociación Latinoamericana de Integración (ALADI) y en mayo de 1997 fue admitido en el Banco de Desarrollo del Caribe. En 1994 el Banco de China estableció su primera sucursal en Panamá, país con el que hasta la fecha no tiene relaciones diplomáticas. Además, China ha establecido mecanismos de diálogo con Mercosur, con la comunidad andina y con el mercado común del Caribe, y a partir de 2004 se convirtió en observador permanente

4 En http://www.biblioteca.tv/artman2/publish/1992_58/Mensaje_del_Cuarto_informe_de_gobierno_de_ Carlos_S 76. shtml

525 millones se destinarán al Fondo de Operaciones Especiales del BID, el cual provee préstamos blandos a Bolivia, Guyana, Haití, Honduras y Nicaragua; 75 millones de dólares irán a diversos fideicomisos del BID para fortalecer la capacidad institucional de los gobiernos y municipios, así como a instituciones del sector privado; 75 millones de dólares formarán parte de un fondo de inversión que será administrado por la Corporación Interamericana de Inversiones (CII), que apoya a la pequeña y mediana empresa; además, otros 75 millones de dólares serán administrados por el Fondo Multilateral de Inversiones (Fomin), que se especializa en microempresas. 
en la Organización de los Estados Americanos y en el Parlamento Latinoamericano. En contraste México dejó de lado su política exterior y su presencia económica en Asia.

En 1996 el Ministerio de Comercio y Cooperación Económica con el Exterior de China, renombrado en 2003 Ministerio de Comercio, anunció que buscaba lanzar una campaña hacia América Latina, argumentando entonces que necesitaba de los recursos minerales, forestales, agropecuarios y pesqueros de la región. Wang Zhiquan, en ese momento director para América Latina del citado ministerio, declaró en mayo de 1996: "Si invertimos nuestros fondos y tecnologías en proyectos de explotación de recursos en ese continente, podrá incrementarse nuestra importación de recursos y la exportación de productos. ${ }^{\prime 6}$ Con muy escasas relaciones económicas para entonces, las prioridades sobre su política en la región ya estaban plenamente establecidas y este interés permanece en el presente.

Los inicios de la administración del presidente Zedillo se mostraban prometedores con respecto a las relaciones con China, pues la importancia de este país fue reconocida en el Plan Nacional de Desarrollo 1995-2000, sobre el resto de la región. En la enumeración de "los nuevos vínculos de la política interior y exterior", después de los apartados de América del Norte, Centroamérica y el Caribe y América del Sur, se consideran otros importantes, el penúltimo de los cuales corresponde a la región del Pacífico asiático; llama la atención que el párrafo dedicado a ésta finalice diciendo: "Asimismo, buscaremos establecer vínculos más estrechos con la República Popular China, con el fin de multiplicar las oportunidades de intercambio comercial con esa nación." 7 China fue el único país del área que mereció una mención especial en el citado plan. La visita de Estado del presidente mexicano a China se realizó del 21 al 24 de noviembre de 1996; fue un gesto interesante el momento de esta visita, en el primer año de su gobierno, ya que los presidentes anteriores lo habían hecho en el último año de su mandato. El gobierno chino mostró su agradecimiento al mexicano por su apoyo en diversos foros internacionales a la política de una sola China, y por su posición en relación con el Tíbet, la no interferencia en asuntos internos con el pretexto de la protección de los derechos humanos y por el apoyo al ingreso de China a la Organización Mundial de Comercio, que aún estaba en discusión. Paralelamente a este lenguaje diplomático de respeto mutuo, los funcionarios de las secretarías encargadas de las relaciones económicas del gobierno de Zedillo estaban conscientes de que China era un competidor importante de la economía nacional en dos áreas fundamentales: la inversión extranjera y los principales mercados del mundo. ${ }^{8}$

Casi paralelamente a la visita del presidente mexicano, una delegación china estuvo oficialmente en México exponiendo la posición de su gobierno en relación con el Tíbet. La visita del presidente Zedillo fue aprovechada por China para conseguir su apoyo a fin de participar como observador en la Asociación de Estados del Caribe y en el Parlamento Latinoamericano (Parlatino). En el clima de cordialidad que privó en la visita, Zedillo

6 Zhou Xi, “Nueva orientación comercial para con América Latina” Beijing Informa, No. 20, 14 de mayo de 1996, p. 10.

7 Plan Nacional de Desarrollo 1995-2000, México, Secretaría de Hacienda y Crédito Público, 1995, p. 14.

8 Discurso de Luis Fernando de la Calle Pardo, subsecretario de Negociaciones Comerciales Internacionales, SECOFI, en el seminario "México y China en el nuevo milenio", 13 de enero de 2000. 
destacó que el porcentaje de coincidencias en la votación de México y China en la ONU era superior a noventa.

En respuesta a la invitación de Zedillo, el presidente Jiang Zemin realizó una visita de Estado a México del 29 de noviembre al 3 de diciembre de 1997. Un elemento interesante en esta visita es que ambos mandatarios hicieron explícito que una de las razones por las cuales se buscaba profundizar la relación bilateral era lo que cada país podía hacer por el otro en términos de vínculos regionales. Aquí se reveló una gran diferencia en la aproximación de ambos países a la economía de mercado, mientras China se percibía interesada en el mercado global y, por lo tanto, en el de América Latina, México se concentró sólo en América del Norte sin mucho interés en sus vecinos de América Latina ni en los mercados asiáticos en general, donde China le podía servir de puente. En este sentido el interés de China en Centroamérica, región donde un buen número de países sostiene relaciones con Taiwán, era un factor importante en su relación con México, así como lo sigue siendo su interés manifiesto en los grandes productores de materias primas de la región y en su mercado. En esta ocasión, el gobierno de México expresó su voluntad de coadyuvar al fortalecimiento y ampliación de la presencia de China en Centroamérica y América del Sur.

En relación con el legislativo, por iniciativa del Senado mexicano se constituyó el grupo parlamentario de amistad México-China, el 30 de junio de 1995. Esta iniciativa tiene como objetivos el mantenimiento de una comunicación permanente mediante visitas parlamentarias, la organización de seminarios y el intercambio de publicaciones en materia legislativa y otros campos de interés mutuo.

En resumen, en el lapso que va desde la apertura de relaciones diplomáticas con la República Popular China y hasta el año 2000 resaltan dos rasgos fundamentales: un paulatino acercamiento entre ambos países, con ausencia de conflictos diplomáticos, y un interés más marcado de China en la relación con México. Esto último se puede explicar, en un principio, por las coincidencias importantes en intereses globales y por estar en Centroamérica el mayor número de países que regionalmente no reconocen aún a Beijing. Posteriormente, y sobre todo a partir de la década de 1990, el interés de China se explica por los grandes recursos naturales en la región, por la firma del Tratado de Libre Comercio de América del Norte, que aumentó las ventajas de México en el mayor mercado del mundo, y por el aumento del flujo comercial bilateral, que a mediados de los noventa comenzó a tener un gran aumento y una creciente balanza favorable para China. Los intercambios de visitas al más alto nivel han sido frecuentes. Todos los presidentes de México viajaron a China y se entrevistaron con el presidente de ese país en reuniones de varios foros multilaterales. Visitaron México los presidentes Yang Shankun y Jiang Zemin. Se intercambiaron delegaciones a los más altos niveles. De igual manera que se crearon mecanismos de consulta y un respetable y amplio esquema institucional para enmarcar las relaciones.

A partir de sus reformas económicas, sobre la base de situarse como exportadores de manufacturas y receptores de capitales extranjeros, ambos países se colocaron como abiertos competidores en la arena internacional. Los elementos de conflicto entre las dos economías surgieron pronto: en 1994 México fue el primer país en América Latina en imponer a China medidas antidumping. 


\section{China y México en el siglo XXI}

Especificar las relaciones entre México y China en el siglo XXI no está motivado por el cambio de siglo, sino que obedece a que coincide con dos elementos fundamentales en la relación: el ingreso de China a la OMC y el cambio en el partido de gobierno en México, después del largo período de monopolio unipartidista.

Precisamente, el primer evento importante de las relaciones entre ambos países durante la administración del presidente Vicente Fox (2000-2006) fue la conclusión de las arduas negociaciones bilaterales sobre el acceso de China a la OMC. México fue el último país de esa organización en lograr el acuerdo bilateral correspondiente con China, firmado en septiembre de 2001. México buscaba importantes reducciones de aranceles en productos del mar, frutas y legumbres, azúcar, jugo de naranja, café, cerveza, tequila y otros licores, cemento, tabaco, productos químicos y farmacéuticos, caucho, vidrio, hierro y acero, productos electrónicos y eléctricos, automóviles, camiones y autopartes, entre otros, con el objeto de tener una presencia mayor en el mercado chino. Estas negociaciones se enmarcaron en un protocolo especial de adhesión de la República Popular China a la OMC que se acordó en Ginebra y en el cual se definieron, entre otros, asuntos concernientes a la metodología de cálculo de antidumping para los productos chinos, el control de precios para algunos productos objeto del comercio internacional y el comercio de productos chinos comercializados por el Estado. Para China era importante lograr el levantamiento de las cuotas compensatorias impuestas por México a muchos de sus productos en 1994 como resultado de una investigación sobre dumping. Sin embargo, según el acuerdo logrado entre China y México en 2001, estas cuotas debían mantenerse hasta 2008.

Consecuente con los cambios políticos internos y con la búsqueda de diferenciación, por lo menos en el plano discursivo, con el partido de gobierno anterior, México definió los nuevos objetivos estratégicos de su política exterior en el Plan Nacional de Desarrollo 2001-2006:

(...) la labor del gobierno en materia de relaciones exteriores para el período 2001-2006 se articulará en torno a cinco objetivos estratégico: primero, promover y fortalecer la democracia y los derechos humanos como bases fundamentales del nuevo sistema internacional; segundo, fortalecer nuestra capacidad para proteger y defender los derechos de todos los mexicanos en el extranjero; tercero, intensificar la participación e influencia de México en los foros multilaterales, desempeñando un papel activo en el diseño de la nueva arquitectura internacional; cuarto, utilizar los esquemas de concertación regional para equilibrar la agenda de la política exterior mexicana, creando nuevos ejes de acción política, y quinto, apuntalar y encabezar los esfuerzos de promoción económica, comercial, cultural y de la imagen de México en aras de un desarrollo nacional sustentable y de largo aliento. ${ }^{9}$

Por parte de China, la principal meta de su política exterior era, y aún es, propiciar un ambiente internacional pacífico, favorable para el intercambio y el desarrollo

9 Plan Nacional de Desarrollo 2001-2006, publicado en el Diario Oficial de la Federación, 30 de mayo de 2001, última vez consultado el 2 de mayo de 2007 en http://www.economia.gob.mx/pics/p/p1376/PLAN1.pdf 
económico, es decir mercado para sus productos y fuentes de materias primas. Así mismo, su necesidad de ocupar un espacio acorde con su auto representación de gran país, con larga historia y merecedor de estar en el primer lugar entre los países desarrollados, le conduce a pugnar por lo que llama un orden internacional justo, es decir por la multipolaridad y la ruptura del hegemonismo unilateral que ha caracterizado al mundo posguerra fría.

El tamaño que ha logrado su economía, su comercio exterior y sus reservas, así como su acción diplomática han conducido a que China sea percibida por la comunidad internacional como una potencia en ascenso a la que los países más poderosos del mundo le dan una gran prioridad en sus relaciones con el exterior y donde muchos países en desarrollo proyectan la solución de sus problemas internos.

La relación entre la formulación de la política exterior y las acciones en ese sentido en México no es muy clara. En su política exterior hacia China se pueden constatar un fuerte acento en la relación económica, una confusión en torno a la definición del interés nacional en cuanto a esta relación y a las prioridades del país en su política exterior, una ausencia de respuesta coherente entre los poderes y sectores de la sociedad y una falta de reconocimiento en la práctica de la nueva situación de China.

Siguiendo la inercia de los dos últimos gobiernos anteriores, se percibe en la práctica de la elite política la búsqueda de inversiones del exterior, pero no parece considerar al exterior en toda su extensión, sino que se quedó determinada en su percepción por el peso de la relación económica con Estados Unidos, sin examinar la necesidad de otros socios ni la inevitabilidad de que surjan otros competidores en ese mercado. Ello fue patente en la reacción de sorpresa que tuvo la opinión pública cuando en 2003 China desplazó a México como el segundo abastecedor de las importaciones de Estados Unidos y además se convirtió en el segundo socio comercial del México. Debido a esta falta de previsión, se agravó la crisis del sector manufacturero nacional ante la competencia de China, sin que las reacciones el la elite política y económica hayan pasado de los ataques verbales que culpabilizan a China de la situación.

La ausencia de coherencia en cuanto a principios ha sido evidente. En aras de las buenas relaciones, pero actuando en contra del primer eje que articuló su política exterior, el gobierno del presidente Fox, en abril de 2004, no votó en la ONU contra los intereses del gobierno chino en lo referente a derechos humanos, lo cual sí hizo en el caso de Cuba, esgrimiendo la importancia de los derechos humanos como uno de los pilares de la política exterior.

Durante 2001, el presidente Fox visitó China en dos ocasiones, la primera fue una visita de estado en junio y la segunda, en octubre, fue para asistir a la reunión de APEC en Shanghai. Las desavenencias entre altos funcionarios en el gobierno fueron frecuentes y ello impidió el logro de consensos aun dentro del gabinete del presidente en asuntos importantes de la política exterior. Los presidentes de ambos países se encontraron de nuevo en las reuniones de APEC en los años subsiguientes.

Como producto de iniciativas previas, el 16 de agosto de 2004, durante la visita del secretario de Relaciones Exteriores, Luis Ernesto Derbez, a Beijing, se firmó un memorando de entendimiento mediante el cual se estableció la Comisión Bilateral Permanente 
México China. ${ }^{10}$ Este mecanismo se estructura con base en comisiones mixtas en materia económico-comercial, educativo-cultural y técnico-científica, así como un mecanismo de consultas políticas. En esa misma oportunidad se firmó el acuerdo de aviación civil, según el cual cada país puede designar dos aerolíneas para realizar vuelos directos sin límites de número de vuelos y dos cartas de intenciones. En septiembre de 2004, como parte de la Comisión Bilateral, se estableció el Grupo Bilateral de Alto Nivel en materia de comercio e inversión que tuvo su primera reunión en enero de 2005.

En la visita realizada por el vicepresidente de China, Zeng Qinghong, entre el 23 y 24 de enero de 2005, se firmaron siete documentos para apoyar el marco institucional de la relación y un memorando de entendimiento para la facilitación de viajes de turistas chinos en grupo a México. En septiembre de 2005 el presidente Hu Jintao realizó una visita de Estado a México donde con gran propaganda se firmaron algunos otros documentos.

El 22 de febrero de 2006, la subsecretaria de Relaciones Exteriores de México, Lourdes Aranda, inauguró el Consulado de Carrera de México en Guangzhou, capital de la provincia de Guangdong, que tiene además jurisdicción sobre la provincia de Hainan y la región autónoma de Guangxi. El establecimiento de este consulado en una de las regiones comerciales más importantes de China, además del ya existente en Shanghai, fue definitivamente un paso importante de apoyo institucional a la relación comercial entre ambos países.

El 18 y 19 de mayo de 2006 se llevó a cabo en la Ciudad de México la segunda reunión de la Comisión Binacional Permanente México-China. Los resultados de esta reunión se plasmaron en el Programa de Acción Conjunta 2006-2010 firmado por los cancilleres Derbez y Li Zhaoxing en la sesión de clausura. En el marco de la reunión se suscribieron cuatro documentos. ${ }^{11}$

La relación económica ha sido cada vez más estrecha con un significativo crecimiento de las exportaciones chinas a México. La medición del intercambio real es muy difícil debido a la disparidad en los criterios de medición, al comercio a través de Hong Kong y otros intermediarios y al comercio ilegal. Las cifras que tomamos como referencia son sólo un indicativo de su estado. Según datos de las autoridades mexicanas, las importaciones chinas en 2010 ascendieron a 45,607,6 millones de dólares, mientras que las exportaciones mexicanas solo fueron de 4,197,8 millones.

\section{Los efectos de la estructura de la relación en las percepciones}

El papel de la ideología en las relaciones internacionales, excelentemente analizado en un trabajo ya clásico de Michael Hunt, ${ }^{12}$ resulta muy relevante para comprender

10 La delegación mexicana estuvo compuesta por 80 funcionarios y empresarios, incluidos seis secretarios de Estado (los secretarios de Relaciones Exteriores; Agricultura, Ganadería, Desarrollo Rural, Pesca y Alimentación; Comunicaciones y Transportes; Desarrollo Social; Economía y Turismo y la presidenta de Conaculta y el director general de Conacyt) y más de 30 de empresarios, http://www.ipsnoticias.net/ interna. asp?idnews $=31057$

11 Secretaría de Relaciones Exteriores, comunicado de prensa No. 105, 19 de mayo de 2006.

12 Ideology and U.S. Foreign Policy, New Haven: Yale University Press, 1987 
algunos de los elementos en la relación entre México y China, en esta oportunidad lo analizaremos desde la perspectiva de la autopercepción y la percepción del otro. En el caso de China, el gobierno muestra interés por México en consideración de sus recursos del subsuelo en el largo plazo, su cercanía con Estados Unidos y su mercado de bienes de consumo. Por lo tanto lo que se trasluce de su percepción es una intención de acercar las relaciones y un reclamo por las cuotas compensatorias impuestas en 1994. Dado que el país tiene un bajo perfil en las relaciones diplomáticas y económicas para China, a que la prensa está controlada por el Estado y a la sobriedad de los funcionarios chinos, no hay fuentes escritas de donde pueda extraerse una percepción que vaya más allá de la buena voluntad diplomática y del reclamo por la suspensión de las medidas antidumping que gravan gran cantidad de bienes chinos. Algunos estudios de opinión llevados a cabo en ese país a lo sumo corroboran el desconocimiento de México

El caso de México es diferente. Por una parte existe una prensa formalmente independiente del Estado y por otra parte los sectores productivos han sido seriamente afectados por la competencia de productos chinos tanto en sus exportaciones a Estados Unidos como en el mercado nacional. Todo ello en el marco de un gobierno que desde que abrió el mercado en la década de 1990 no ha deseado responder con políticas eficaces y de largo plazo a la competencia comercial externa. Como puede constatarse en la prensa mexicana de los últimos años, ${ }^{13}$ el extraordinario desarrollo económico de China y las consecuencias en términos de posicionamiento en el mercado de Estados Unidos y de aumento significativo de sus exportaciones a México, ha sido percibido por sectores de gobierno, empresariales y de opinión mexicanos como amenaza. La ausencia de estrategia para enfrentar la competencia es justificada a través de la construcción de un imaginario negativo sobre China que en ocasiones ha hecho resurgir el racismo antichino que tuvo graves consecuencias en las tres primeras décadas del siglo pasado. Funcionarios mexicanos del más alto nivel han culpabilizado a China directamente de los problemas de la economía mexicana y hasta de la crisis económica mundial, han criticado abiertamente el sistema político de ese país, contraponiéndolo con la democracia en México, todo lo cual ha deteriorado las relaciones diplomáticas.

\section{Consideraciones finales}

El lapso que hemos revisado someramente de la relación entre México y la República Popular China puede analizarse desde diversas perspectivas. Para concluir voy a sintetizar las relaciones en dos momentos. El primer momento es el del reencuentro diplomático de 1972, ambos países se percibían como víctimas de las potencias hegemónicas del mundo, ambos se reconocían de un tercer mundo marginado, buscaban la ayuda mutua y la cooperación entre ellos. México, con más recursos, brindó la cooperación que podía: la enseñanza del español y de la cultura hispana. Fue un

13 Puede verse El Universal y Reforma, como diarios representativos. Para este texto utilicé también Milenio Diario, El Financiero, El Economista y La Jornada. 
momento de grandes coincidencias, entre otras en la búsqueda fallida de un Nuevo Orden Económico Internacional.

El segundo momento es la primera década del siglo XXI, cuando después de la búsqueda fallida de un nuevo orden, ambos países ya habían decidido jugar con las reglas del viejo orden, el de las potencias hegemónicas, el libre comercio. La elite china lo hizo de manera nacionalista, adoptó las reglas a sus propias concepciones, y la elite mexicana lo hizo de una manera ortodoxa, intentando "comportarse" bien con las reglas del orden económico internacional. El resultado, conocido por todos, ha sido diametralmente diferente en cada país y es lo que condiciona hoy su relación.

Una parte importante de la explicación de los 40 años de las relaciones la podemos encontrar en la forma cómo las elites de México y de China han elaborado la percepción del otro y al papel de sí mismas en la elaboración de sus proyectos de país. La elite política y económica de México no respondió a los retos que enfrentó desde que decidió poner en práctica las reformas de libre mercado, sabe que el momento de hacerlo pasó. Por ello cultiva la percepción de culpabilizar a China de sus fracasos económicos, lo cual le resulta fácil porque está en línea con una percepción negativa de las potencias hacia ese país que no han aceptado completamente su legitimidad debido a que está gobernado por un partido que se sigue autodenominando comunista.

El crecimiento de China no ha sido asimilado por la elite política y económica actual de México. Ante ese crecimiento, ante la autorrepresentación de grandeza y el consecuente comportamiento de China, las elites mexicanas muestran respeto y lejanía, consideran los logros de China difícilmente alcanzables. No desean ahondar en su análisis, pues las confronta. En este marco, muestran una posición de reconocimiento de la superioridad del otro y ceden, la mayoría de las veces sin necesidad real, ante sus presiones, y no se atreven a colocarse en una posición de competencia Por su parte, las elites chinas mantienen dentro de la representación de su país la grandeza imperial del pasado, de las épocas cuando tenía mayor avance científico y tecnológico que el resto del mundo. Desde la fundación de la República Popular su propósito explícito ha sido recuperar esa posición. Hoy las elites chinas saben que su país tiene las mayores reservas monetarias del mundo, que es una potencia comercial y que ha establecido una relación de interdependencia con la mayor potencia del mundo, y comienzan a comportarse en consecuencia. En su percepción del mundo exterior prevalece la obsesión por alcanzar y sobrepasar a Estados Unidos, Alemania y Japón en sus logros científicos, económicos y sociales, el resto de los países es percibido sólo como instrumento para estos fines. En ese resto, México es visto por su posibilidad de ser fuente de materias primas, por su mercado y por la posibilidad de ser un puente para exportar más a Estados Unidos. A 40 años se vislumbran pocos cambios en la estructura actual de la relación. 



\title{
China: una relación prioritaria para México en el futuro inmediato
}

\author{
Rafael Fernández de Castro y Diego Cándano Laris
}

Durante las reuniones extraordinarias de la Unión Europea para hacer frente a la abultada deuda italiana, Silvio Berlusconi insistía en que China vendría al rescate de su atribulada economía. De la noche a la mañana Estados Unidos había dejado de ser la esperanza o el prestamista de último recurso. Hoy en día China tiene también ese potencial. Los números hablan: Estados Unidos tiene una deuda de 13.98 billones de dólares, mientras que China mantiene las más abundantes reservas internacionales del planeta con 2.9 billones de dólares. ${ }^{1}$

En 2009 la economía china rebasó a la economía japonesa colocándose cómo la segunda del mundo, sólo atrás de la estadounidense. Los pronósticos son que para la próxima década China sea el primer mercado del mundo. El Fondo Monetario Internacional (FMI) pronostica que en 2016 superará el PIB de Estados Unidos en términos de paridad de poder de compra. Asimismo, China ha aprovechado con sagacidad la crisis occidental para ganar terreno político y económico a costa de Estados Unidos y la Unión Europea. ${ }^{2}$

Para muchos analistas, el hecho de que China continuara creciendo durante la crisis económica que ha azotado a Occidente desde 2008, ha sido un factor decisivo para aminorar la crisis global. Más aún, las importaciones y las inversiones chinas en países latinoamericanos como Brasil, Argentina y Perú, explica que nuestros colegas latinoamericanos hayan podido campear la crisis. Incluso durante la recesión de 2009, el desempeño de Brasil fue superior a la media mundial, el PIB decreció únicamente $0.2 \%$, ${ }^{3}$ mientras que nuestra economía cayó 6.3\%. En 2009 las exportaciones de Brasil a China crecieron $27.12 \%$ mientras que las exportaciones de México a Estados Unidos se encogieron más de $20 \% .{ }^{4}$ China ha desplazado a México como el segundo exportador a Estados Unidos, sólo superado por Canadá.

China ha sido considerada una oportunidad para varias economías sudamericanas, como Brasil, Argentina y Perú, pero hay quien ha calificado de maldición su carácter de competencia para México. Por ejemplo, el mercado principal de los productos brasileños es China: en 2011 las exportaciones de Brasil a China representaron 44,315 millones

1 Banco Mundial, correspondiente al año 2011.

2 Jaume Giné-Daví, "Asia-Pacífico: el nuevo motor del crecimiento económico mundial", en Foreign Affairs Latinoamerica, vol. 11, núm. 4, 2011, pp. 50-51.

3 Ricardo Sennes y Angela Tepasse, "Brasil y China: una nueva relación comercial”, en Foreign Affairs, vol. 11, núm. 1, 2011, p. 23. En cambio, el crecimiento real del PIB de Brasil en 2010 fue de $7.5 \%$.

4 De acuerdo con el Banco de México, las exportaciones de México a Estados Unidos en 2009 fueron de 185,181 millones de dólares. 
de dólares. ${ }^{5}$ En cambio, México tiene su mayor déficit con China 33,601 millones de dólares. ${ }^{6}$

El tercer país inversionista en América Latina es China, por debajo de Estados Unidos y los Países Bajos. En 2010, Brasil captó 9,563 millones de dólares en inversiones provenientes de China, mientras que Argentina recibió 5,550 millones de dólares. En contraste, México prácticamente no recibe inversión de parte de China, pues ésta se ha mantenido a niveles muy bajos: en 2010 México recibió apenas 6.31 millones de dólares en inversiones chinas ${ }^{7}$.

China es el país emergente que ejerce mayor influencia en los foros internacionales. Es claramente el campeón del G77 y en dos de las negociaciones que más le interesan a México, cambio climático y coordinación financiera internacional a través del proceso G20, China es un actor de enorme relevancia. Como los mayores emisores de carbono y las mayores economías, China y Estados Unidos son los actores predominantes en los esfuerzos globales en ambos temas.

¿Está condenado México a que China sea una pesadilla económica y comercial? ¿Está condenado México a ser visto como el aliado de Estados Unidos y no poder hacer alianzas con China en temas bilaterales o multilaterales donde nuestra condición de economía emergente nos coloca muchas veces más cerca de las posiciones chinas?

Lo único que México no puede hacer es quedarse postrado ante la emergencia de China y su rápido acomodo como la potencia global que rivaliza con Estados Unidos. De cara al futuro, y dado que en la relación con China no se pueden aislar los temas económicos de los político-estratégicos, existen tres alternativas de acción:

1. Aceptar la condición de competidores de China. Esto nos llevaría a fortalecer nuestra posición como país norteamericano, tanto en lo económico como en lo político-estratégico. Una consecuencia natural sería acercarnos a otros actores en Asia, quizá a través del Trans-Pacific Partnership (TPP), que en noviembre de 2011 reunió a los líderes de Australia, Brunei, Chile, Malasia, Nueva Zelandia, Perú, Singapur, Vietnam y Estados Unidos.

2. Buscar un realineamiento hacia China. En este escenario tendríamos que acoplarnos a ciertas posiciones de China e incluso de otros países emergentes como India y Brasil. Por ejemplo, China, India y Brasil insisten en que la responsabilidad global sobre el cambio climático debe ser asumida principalmente por países desarrollados, mientras que México tiene una posición más madura en la cual también los países emergentes deben poner su granito de arena. En este escenario tendríamos que buscar un acuerdo comercial con China que favoreciera no sólo nuestras exportaciones, sino también la inversión en México.

5 Fuente: Ministerio de Desarrollo, Industria y Comercio Exterior de Brasil. China representa cerca del $17 \%$ de las exportaciones brasileñas totales.

6 Datos correspondientes al 2011.

7 Fuente: Secretaria de Economía. En 2010, México captó un total de 19,792 millones de dólares en Inversión Extranjera Directa; por lo tanto, las inversiones chinas en México equivalen a $0.03 \%$ en ese año. En 2011, en cambio, se registró una caída en las inversiones chinas en el país, con un saldo negativo de -5.1 millones de dólares. 
3. Acercamiento con China en temas estratégicos como la parte central de una estrategia integral de participación en el dinamismo de la región Asia-Pacífico. En este escenario, México debe identificar áreas económicas y políticas en las que exista convergencia de intereses entre ambos países y construir una relación de mayor confianza. Nuestra relación con América Latina, en especial la cuenca latinoamericana del Pacífico, tendría un papel estelar. Esta opción implicaría ejercer una diversificación en ayudaría a campear nuestra sobreconcentración en Estados Unidos. En ese escenario podríamos lograr una mayor autonomía de nuestro vecino del norte.

Consideramos que la opción más deseable es buscar un acercamiento estratégico y constructivo que no implique un alineamiento y que aproveche el dinamismo económico reciente de Asia del Este y de América Latina. Esta última opción implica un planteamiento audaz de vinculación con Asia-Pacífico, teniendo a China como eje principal.

La primera opción, además de no aprovechar las oportunidades generadas por China, tiene el inconveniente de que la actual crisis fiscal en Estados Unidos y la polarización política abren pocos espacios para un mayor acercamiento económico y menos una asociación estratégica. Además, implicaría erosionar nuestra capacidad para actuar como una potencia global emergente en los asuntos globales más apremiantes como el cambio climático y la coordinación financiera. Finalmente, la segunda opción, realineamiento hacia China, implicaría riesgos innecesarios en nuestra relación con Estados Unidos.

\section{Los caminos para lograr el acercamiento con China}

México requiere definir una relación estratégica e integral con China que le permita aprovechar su dinamismo económico y fortalecer el diálogo con uno de los actores predominantes en la conformación de un nuevo orden global. México tiene una imperiosa necesidad de aprovechar las oportunidades y enfrentar los retos derivados del impacto que China ejerce en nuestros intereses económicos.

La diplomacia mexicana ha demostrado, como en el caso de la COP 16, que cuando se define una prioridad -lograr en Cancún un avance de la negociación global de cambio climático-y se ejerce una voluntad política proporcional a la misión, es posible alcanzar objetivos complejos y ambiciosos. El acercamiento con China sólo se dará si se convierte en prioridad de la política exterior de México. El ejecutivo necesitará convocar a los principales sectores que participan en la relación con China: los empresarios, los gobiernos de las entidades federativas, el legislativo y las cúpulas académicas y científicas.

¿Qué debe hacer México?

1. Para lograr un diálogo político cercano con China, el liderazgo mexicano deberá entender de primera mano la visión que el liderazgo chino tiene del mundo, así como sus preocupaciones internas y geopolíticas. El próximo gobierno de México deberá 
identificar a los líderes claves a partir de 2012 y procurar un contacto directo; en especial, se debe cultivar la relación y confianza entre los ejecutivos y fortalecer los mecanismos de consulta.

2. Para sustentar este diálogo, México deberá asegurarse una adecuada representación diplomática y comercial, con especial atención en la embajada en Beijing y los consulados, principalmente en Shanghai. Si China pasa a ser la prioridad de la política exterior de México, consecuentemente la representación política y comercial más importante de México estará en China.

3. Hasta el momento, China ha presentado mayores retos que oportunidades para el desarrollo económico de nuestro país. Una agenda estratégica deberá trascender este enfoque para aprovechar las diversas áreas en las que nuestra relación bilateral presenta oportunidades. En primer lugar, México debe identificar áreas de posible inversión China para equilibrar la relación económica, específicamente en minería e infraestructura. Segundo, México debe buscar una mayor densidad en la relación, atrayendo de forma ambiciosa al turismo chino, cuyo crecimiento será exponencial en los próximos años. Para ello, México deberá atender temas migratorios pendientes. Finalmente, se deben desconcentrar las relaciones bilaterales en el rubro comercial; hay otros temas de cooperación, como son las energías renovables o en el ámbito académico (intercambios estudiantiles, presencia de universidades chinas y mexicanas, reuniones estratégicas entre profesores y rectores, proyectos académicos binacionales, entre otros).

4. Una auténtica relación México-China no podrá estar sustentada exclusivamente en el quehacer gubernamental. México, como país, requiere un acercamiento y una comprensión integral de China para poder aprovechar estratégicamente la emergencia de dicha nación en la esfera global. Los empresarios mexicanos, los legisladores, los gobernadores, los académicos y los operadores turísticos tendrán que identificar oportunidades para dar densidad a la relación y construir una agenda dinámica e integral, idealmente apoyada en misiones diplomáticas activas y receptivas.

5. México deberá aprovechar que América Latina y el Caribe en su conjunto son una región prioritaria para China. La intensa y efectiva labor diplomática y comercial realizada por México en la región, especialmente con los países de la cuenca del Pacífico (Foro Arco del Pacífico y Alianza del Pacífico), deben ser utilizadas para aprovechar regionalmente el dinamismo asiático, particularmente a través de la integración de cadenas de producción.

México no puede ser un observador de la ascendencia de China como el primer mercado del mundo y rival de Estados Unidos en los temas estratégicos. Australia, país que despliega una política exterior de gran activismo, ofrece un ejemplo importante. Es uno de los países del mundo que más provecho económico comercial han obtenido de la expansión del mercado chino, y esto lo ha logrado sin menoscabo de su estrecha alianza estratégico-militar con Washington. Las relaciones internacionales no son de suma negativa. 


\title{
La participación de China en la política internacional a través de su poder nacional
}

\author{
José Ignacio Martínez Cortés
}

\section{La construcción del poder nacional}

Durante la segunda mitad del siglo XX las relaciones de poder en la política internacional se transformaron en torno a varias vertientes: capital, tecnología y mercados donde la empresa transnacional se constituyó en un actor principal. De 1945 a 1989 el factótum de poder fue la combinación de tecnología e industria bélica en el enfrentamiento entre Estados Unidos y la Unión Soviética. Al colapso de la URSS la correlación de fuerzas cambió drásticamente: a través de la globalización, la lucha se trasladó a otros frentes.

El campo de acción está ahora en la competencia férrea del sector externo donde los países, principalmente los subdesarrollados, buscan atraer inversión extranjera a través de la apertura de sus mercados; el impacto se manifiesta en su inmediato (y artificial) crecimiento económico, pero ante la caída de los mercados internacionales provocado por crisis económicas, financieras, energéticas, políticas o sociales, ese dinamismo desvanece.

Con la nueva reconfiguración del escenario internacional, a partir de la década de los 90 hay una proliferación de nuevos actores políticos y económicos y cada vez más los Estados-nación van quedando atrás, como una manifestación de la globalización donde prevalecen más los intereses de las empresas transnacionales para que los países realicen cambios estructurales a sus economías acorde con el Consenso de Washington.

En este nuevo contexto global, sin duda un factor de peso para participar en la solución de los grandes problemas internacionales es el poder económico. Al respecto, es importante subrayar que ante las turbulencias exógenas, aquel país que no tenga un crecimiento endógeno suficiente y se manifieste en un constante y permanente crecimiento de su producto interno bruto, estará al margen de convertirse en un actor que incida en la política internacional, y quedará como un simple observador; en ello radica la nueva cara del poder, ya que la política es una lucha permanente para la obtención del poder, en donde el poder constituye la esencia misma de ésta, Morgenthau dixit.

El Estado que tiene poder (político y económico) tanto en la esfera nacional como en la escena internacional influye y decide a través de los mecanismos legales, institucionales, organismos internacionales, foros intergubernamentales (soft power) o mediante acciones coercitivas o empleando la amenaza del uso de la fuerza (hard power).

Antes la industria bélica otorgaba fuerza al Estado, ahora no sólo basta ello, ya que ante los vaivenes de la economía internacional, el poder económico brinda en este momento un nuevo sistema de seguridad y otorga una nueva forma de decisión en los foros internacionales ya que se tiene la capacidad de presentar, proponer, respaldar e incluso boicotear normas que regulen un nuevo orden jurídico. 
Sin duda la manifestación plena del poder nacional de un país se refleja en su política exterior, ya que ahora ese Estado, con el respaldo de un robusto crecimiento económico, del cual carecen otros países, es activo participante en las grandes decisiones de la política internacional. Para ello, el perfil de los tomadores de decisiones es fundamental, pues la variable idiosincrásica (es decir, los valores, nacionalismo, talento y experiencia), los convierten en líderes de sus pueblos, marcan una pauta en la política exterior de su país y hacen valer su presencia en las reuniones internacionales defendiendo su interés nacional jugando un rol y posición a la hora de adoptar propuestas y redefiniendo el sistema internacional.

Ahora bien, el poder nacional también se manifiesta en torno a un proyecto de nación de largo plazo en que los programas de gobierno se convierten en políticas de Estado y tienen como punto de partida el interés nacional al adecuar los factores de crecimiento exógenos a su desarrollo endógeno, por lo que su política exterior es consecuencia de los objetivos nacionales y de los medios para alcanzarlos, es decir, es una síntesis de los intereses nacionales. Karl Deutsch expresa que la política exterior de una nación descansa en dos vertientes, la primera en la preservación de su independencia y seguridad, y la segunda sobre el seguimiento y protección de sus intereses económicos.

El poder nacional, cuya cara en la política internacional es la política exterior, está determinada por diferentes factores, entre los cuales se señalan la geografía, el carácter nacional, la tradición, los valores culturales, una fuerte identidad nacional, fuerzas políticas internas cohesionadas entre sí y en torno a un aparato gubernamental dominante, diseño de políticas públicas desarrollistas, a través de inversión pública en infraestructura básica (puertos, carreteras, aeropuertos, ferrocarriles, telecomunicaciones), infraestructura tecnológica (investigación, desarrollo, innovación), infraestructura social (educación, salud, vivienda, cultura); ello aunado a una inversión privada para fortalecer la competitividad empresarial impulsada por la productividad de la economía y la seguridad social, pero el factor de mayor peso es sin duda el crecimiento económico impulsado principalmente por factores endógenos evitando así la dependencia externa.

La característica principal de este poder nacional radica en un Estado-nación fuerte que desarrolla un mercado interno altamente competitivo, que es el soporte para participar en la globalización, por lo tanto es el Estado el que determina el desarrollo y bienestar de su sociedad, no es la empresa la que, mediante reformas estructurales como condición para invertir, la que provoca el crecimiento del mercado. El poder nacional se construye desde adentro y su fuerza radica en el crecimiento económico que fortalecerá su política exterior para tener una presencia sólida en la política internacional.

\section{La internacionalización del poder nacional de China}

El despegue exitoso que tiene China se deriva del diseño de un proyecto de nación a largo plazo donde el mercado interno se ha convertido en el puntal de su crecimiento, con lo que se vincula al nuevo encadenamiento mercantil global. 
Sin duda, el artífice del poder nacional de China radica en el papel que juega el Estado, que desde el establecimiento de las reformas a fines de los años 70, que privilegió la inversión pública a la relocalización de la producción hacia las Zonas Económicas Especiales, lo que se complementó con la inversión extranjera. Esta estrategia mostró su resultado exitoso en la década de los 90, ya que en 1979 las exportaciones chinas sólo constituían el 10\% de su PIB, pero para 1999 significaron 38\%. Este crecimiento tiene como pivote al sector manufacturero que se ha convertido en el soporte de las exportaciones. En sectores específicos como el del calzado, China aumentó la participación de sus exportaciones en el mercado mundial de $2.4 \%$ en 1985 a $41 \%$ en 1998.

Las condiciones de la economía china en el entorno mundial provocaron una especialización de sus exportaciones. A partir de 1992,40\% de las exportaciones totales estaban integrados por artículos de confección, calzado, juguetes, bienes de escaso valor agregado. Sin embargo a partir de 1995 las exportaciones de productos de alta tecnología crecieron $50 \%$, en especial el sector de electrónicos, maquinaria y equipo.

Las reformas internas en China permitieron un mayor crecimiento en el comercio internacional, además de que recordaron que es una economía centralmente planificada, cuya variante es que en los últimos años instrumentó una política comercial de mercado bajo la conducción del Estado. El desarrollo de Empresas de Poblados y Villas asociadas a procesos de exportación con flujos masivos de inversión extranjera directa permitieron el aumento de empresas manufactureras y en especial maquiladoras, con lo que China se convirtió en el segundo receptor de IED sólo detrás de Estados Unidos.

En China, hasta antes de 1980, las exportaciones no sólo alcanzaban niveles bajos, sino que estaban basadas en productos petroleros. Desde inicios de los años 80 ese país instrumentó cambios en la política comercial, con efectos en el comercio internacional y en el flujo de inversión extranjera. China empezó a relajar las restricciones a la IED a fines de 1978 por lo que el régimen de IED se liberalizó gradualmente y se establecieron una serie de políticas y leyes para la atracción de estos capitales. Una característica de este proceso en China es que el Estado determinó fomentar proyectos productivos intensivos en tecnología a través del establecimiento de Zonas para el Desarrollo Económico y Tecnológico por medio de capitales extranjeros.

Si bien la incorporación de China a la economía mundial se debe, en gran medida, a las reformas aplicadas a la IED, el soporte de ese crecimiento es un Estado que invierte en la productividad de su economía y que paulatinamente se manifiesta en el bienestar de su población.

Se estima que la clase media en China asciende a 157 millones de habitantes y ya es más grande que la de los Estados Unidos. Para 2020 se proyecta que las clases medias chinas sumarían 500 millones, y constituirán el principal mercado global. China ya superó a Estados Unidos como el más importante mercado del mundo para celulares y automóviles. A diferencia del resto del mundo donde se busca que aumente el ahorro, China se esfuerza en hacer que su población consuma más. El aumento del ingreso per cápita previsto para las próximas décadas contribuiría a reforzar aún más la amplitud y el poder adquisitivo de la clase media china. Según proyecciones del FMI, el PIB de China, medido de acuerdo con el criterio de paridad de poder adquisitivo, superaría al de los Estados Unidos en el año 2016. Para ese año el FMI proyecta que el PIB chino 
superará al de los Estados Unidos por un $8 \%$ y el PIB por habitante ya equivaldrá a un cuarto del de Estados Unidos, aunque China se ha transformado en una fuerza económica y política para el mundo, requiere otros 20 años de crecimiento permanente para alcanzar a Estados Unidos en producción nacional.

\section{China: factótum de poder en el G-20}

En 1950 China no tenía la fuerza económica suficiente para establecer condiciones en la naciente Guerra Fría. Ahora con la reconfiguración económico-financiera a raíz de la reciente crisis y con un poder nacional dinámico, la política exterior de Beijing se manifiesta en torno a la ayuda que brinda a África, la influencia que tiene sobre Corea del Norte e Irán, la estrecha relación que ha construido con Brasil y Venezuela y la cooperación creciente que mantiene con Cuba, además del dialogo directo que conserva con Rusia. De hecho, China presionó para que Estados Unidos aceptara la propuesta de Francia para escalar el nivel del G-20 de ministros de finanzas a jefes de gobierno o de Estado y reunirse por primera vez en Washington en noviembre de 2008. También jugó un rol fundamental para resolver la crisis propia del euro.

Ante la crisis reciente de la economía internacional, sin duda el país que ha sido factor de decisión para el nuevo rumbo económico-financiero mundial es China, ya que su poder nacional manifestado en su crecimiento económico a una tasa anual de $10 \%$ durante casi diez años, la acumulación de reservas internacionales, la tenencia de bonos del tesoro de Estados Unidos, el segundo país exportador mundial, su aportación de 40 mil millones de dólares al FMI, convierten al gigante asiático en líder mundial y es una de las naciones claves en la aprobación de los planes de rescate económico.

China se ha convertido en el pivote de crecimiento para las exportaciones de otras economías que ven en el mercado chino una salida ante la caída del mercado estadounidense o europeo, ya que su demanda doméstica va al alza. Esto provoca que otros países se beneficien al exportar más a China puesto que la mejora del nivel de vida de una parte considerable de la población china y del aumento de la demanda interna del mercado chino ha provocado que otros países se beneficien de las compras foráneas que realiza el país asiático.

Sin duda, ahora China se ha convertido en polo de decisión en la nueva política internacional; sin embargo, en la siguiente década, China está propensa a transformaciones domésticas que pueden alterar su poder nacional, por lo que el gobierno de Beijing deberá ser cuidadoso en temas de política y economía, de lo que destaca:

a) Manejo del déficit público

b) Posible desaceleración de la economía nacional

c) Creciente dependencia de las exportaciones que pueden perder dinamismo

d) Caída de la IED

e) Desplome del consumo interno

f) Reducción de la inversión pública

g) Cambio en la correlación de las fuerzas del partido comunista chino 
h) Crecimiento de la clase media puede provocar una transformación social

i) Demanda de los derechos sociales es un detonante

j) Reducción del gasto social afectando la salud pública, educación, jubilación

k) Explosión demográfica en las zonas urbanas

Hasta ahora la economía china sigue manteniendo un ritmo alentador y las políticas macroeconómicas sanas pueden ser perturbadas por las oscuras perspectivas económicas mundiales. Por ejemplo, la pérdida de la confianza de los consumidores de Estados Unidos y de Europa puede afectar la producción industrial china. Otro factor exógeno que puede afectar la inflación en el mercado doméstico es la relajación de la política monetaria estadounidense que dispararía los precios de las materias primas que adquiere el consumidor chino.

Otro factor que otorga plusvalía al poder nacional chino es la fortaleza del yuan que frecuentemente provoca fricción con Estados Unidos, no obstante el FMI afirma que un yuan más fuerte ayudaría a estabilizar la economía global, además de que es un ancla para controlar la inflación y equilibrar la economía para hacerla más dependiente del consumo interno y menos de las exportaciones. China está utilizando sus cuantiosas reservas internacionales, aproximadamente 3.2 billones de dólares, de las cuales dos tercios son en moneda estadounidense y 1.2 billones están invertidos en deuda del Tesoro de Estados Unidos. El banco central del país asiático compra dólares para limitar la subida de su divisa. Esta práctica ha convertido a China en el mayor poseedor de bonos del Tesoro estadounidense. Asimismo, el banco central chino está aumentando sus reservas de oro y otros metales preciosos contemplando, por otro lado, globalizar el yuan.

Beijing teme que sus inversiones pierdan valor como consecuencia de una recesión global que afectaría gravemente sus exportaciones. Por ello, China está sumamente interesado en que los países afectados por la crisis adopten políticas fiscales y monetarias concretas y responsables para recortar sus déficit y gestionar de forma adecuada sus problemas de deuda. Asimismo, critica a Estados Unidos por su adicción a endeudarse. Todo ello con el fin de que su poder nacional no se debilite.

Si bien la política nacional es continuidad de la política exterior y ésta se manifiesta en la participación de la política internacional, el poder nacional de China puede tener un sesgo si no hay un meticuloso cuidado en el control de los cambios domésticos resultado de una transformación del mercado interno que puede alterar el orden social hasta ahora vigente y que es fuertemente regido por un Estado promotor que privilegia el desarrollo sobre el crecimiento, en el cual el éxito endógeno puede sucumbir ante la caída de los mercados internacionales. 



\title{
Cuarenta años de relaciones diplomáticas México-China. El nuevo diálogo de naciones amigas
}

\author{
Jorge Nuño Jiménez
}

Uno de los actos de mi vida que más me enorgullece es haber sido designado como ayudante militar y posteriormente colaborador cercano por más de cuatro décadas del presidente Luis Echeverría en sus múltiples actividades diplomáticas como expresidente, como fue el caso de la representación diplomática ante UNESCO en París, y posteriormente en la embajada de Australia. Pero sobre todo acompañarle en múltiples visitas a la República Popular China, lo cual me permitió tener el privilegio de conocer de manera directa la cultura y las tradiciones de ese país que en Occidente lo veíamos con cierto misterio. Hoy nos ha sorprendido en el siglo XXI con su transformación económica y social asombrosa. Esta experiencia singular de mi vida me obligó a estudiar a fondo su historia, economía, tradiciones populares y, sobre todo, comprender cabalmente aquellos viejos prejuicios occidentales que afirmaban que: “Cuando China despierte el mundo temblará" (Napoleón); nos damos cuenta de que hoy China ha despertado y que el mundo no está temblando y que de ninguna manera es el "peligro amarillo".

Como oficial de su Estado Mayor y ayudante personal del presidente Echeverría tuve el especial honor y privilegio de estar presente el día que le llamo -vía telefónica-, desde la Casa Blanca a su oficina de los Pinos, el presidente Richard Nixon en 1971, llamada con la cortesía diplomática debida y la expresión de respeto a la soberanía de México: le solicitó el presidente de Estados Unidos, muy atentamente, que estudiara el voto de México ante la XXVI Asamblea de la ONU, porque estaba programado en la agenda de la Organización de las Naciones Unidas el ingreso de la República Popular de China, pidiéndole que su voto fuera negativo porque traería como consecuencia una alteración grave a la estabilidad y la paz en la región asiática. El presidente Echeverría le manifestó que estudiaría con mucha atención su voto.

\section{Orígenes de la relación bilateral con China}

Durante el mandato del presidente Echeverría, México estableció una vigorosa política exterior, estableciendo relaciones diplomáticas con 49 Estados. Pero ninguna de la transcendencia histórica, política y económica como la que se estableció con la República Popular China a partir del 14 de febrero de 1972.

Como es conocido, la Asamblea General de la ONU se reúne en sesión ordinaria anualmente entre los meses de septiembre y diciembre, a esta sesión concurren normalmente los ministros y mandatarios de todos los países miembros, para abordar los temas de la agenda aprobada previamente cada año, así como tratar los diferentes temas internacionales que resulten especialmente interesantes o atractivos para que fije su posición al respecto determinado país. 
El 25 de septiembre de 1971 fue presentado a la Asamblea General un proyecto de resolución (A/L 630 y Add. 1 y 2) patrocinado por 23 Estados, entre ellos Albania e incluidos los 17 Estados que pidieron la inclusión de la cuestión en el programa. De acuerdo con el proyecto, la Asamblea General decidiría restituir a la República Popular China todos sus derechos y reconocer a los representantes de ese gobierno como únicos representantes legítimos de China en las Naciones Unidas, así como expulsar inmediatamente a los representantes de Chiang Kai-shek del puesto que ocupaban ilegalmente en las Naciones Unidas y en todos los organismos relacionados con ellas.

En este ambiente tenso, el presidente Echeverría se presentó a la XXVI Asamblea de la Organización de las Naciones Unidas con la convicción de que para realizar un avance trascendental del principio de universalidad sería un acto de justicia dar la bienvenida durante el actual periodo de sesiones a los representantes de la nación que alberga en su territorio la cuarta parte de la población del mundo (China contaba en aquel entonces con más de 700 millones de habitantes y Formosa 18 millones): la República Popular China y su consecuente ingreso al sitio que le correspondía en el Consejo de Seguridad. Al mismo tiempo sería necesario reconocer que la soberanía y la integridad territorial de la nación china, son jurídicamente indivisibles.

China y México formalizaron sus lazos de amistad y cooperación el 14 de febrero de 1972, Estados Unidos lo formalizó a partir de enero de 1979 gracias a las gestiones, primero secretas del consejero de Seguridad Nacional, Henry Kissinger, contando con la anuencia del presidente Nixon, de establecer un canal de comunicación confidencial, el cual se concretó en Varsovia el 20 de enero de 1970, la primera reunión con el embajador de Estados Unidos, Walter Stossel, y Lei Yang, encargado de negocios de la Republica Popular de China, en un ambiente terso bajo el manto de la Guerra Fría, durante la cual EU consideraba al régimen de Pekín como un reino amenazador, caótico, fanático y hostil, difícil de comprender e imposible de dominar, con la convicción de que la guerra de Vietnam se debía al expansionismo chino.

El comunicado conjunto sobre el establecimiento de relaciones diplomáticas entre los Estados Unidos Mexicanos y la República Popular China del 14.2.1972 sellaba históricamente la voluntad férrea e indeclinable de México de establecer relaciones diplomáticas con la Republica Popular de China y nos obliga hoy en día a reflexionar con sensatez y altura de miras sobre las relaciones amistosas y diplomáticas entre dos naciones amigas, por lo que es indispensable hacer un balance de los saldos de esta relación de ocho lustros que se iniciaran, como consta en los anales de la cancillería mexicana, el 14 de febrero de 1972 a iniciativa del presidente Echeverría, con fundamento en sus facultades constitucionales del Articulo 89, fracción X; tuvo como sustento además de las facultades inherentes al ejecutivo a su cargo un conocimiento muy profundo de la historia y tradiciones de ese país aislado por el orden internacional de la época, y seguramente el presidente conocía y había estudiado la vieja influencia de China en el poblamiento de América Latina.

Este pronunciamiento del presidente Echeverría, escuchado como una voz importante en las deliberaciones que culminaron con el reconocimiento de China como miembro de la ONU, se producía en momentos en que, en plena guerra fría, las grandes potencias que se disputaban la preponderancia en los polos del poder mundial 
se vieron obligadas por la fuerza de la razón a admitir la emergencia de los países en desarrollo que buscaban, en la independencia económica y política, el establecimiento de un orden mundial más justo.

La postura mexicana en esa histórica Asamblea de la ONU representaba no sólo una actitud de congruencia con los postulados de respeto a la soberanía y la autodeterminación de las naciones que México abrazó desde sus orígenes como nación independiente y los sentimientos de amistad que animaron la cambiante relación con el pueblo chino a través de la historia, sino que contribuía a afirmar en el concierto internacional la vocación de paz y de solución pacífica de los conflictos compartida por ambas naciones. Hacía patente en el máximo foro internacional de uno de los principios fundamentales de la política exterior de México, que esta relación debía ser respetuosa y tener como base los principios normativos de nuestro orden constitucional, para convivencia armónica de los pueblos del mundo: la autodeterminación de los pueblos, la no intervención la solución pacifica de las controversias, la proscripción de la amenaza o el uso de las fuerza en la relaciones internacionales, la igualdad jurídica de las controversias, la cooperación internacional para el desarrollo y la lucha por la paz nacional e internacionales, abstenerse de opinar sobre diferencias ideológicas o políticas, así como sus formas de gobierno.

La voz del presidente Echeverría fue escuchada con mucho respeto durante las deliberaciones que culminarían posteriormente en la votación respectiva a fines de ese mes de octubre con el reconocimiento de China como miembro legítimo en la ONU, y su asiento como miembro del Consejo de Seguridad. Debemos hacer notar que esta decisión valiente y con una gran visión de futuro se producía en momentos de la Guerra Fría en que las grandes potencias se disputaban los polos del poder mundial utilizando siempre la amenaza o la fuerza. Sin embargo la emergencia de una plataforma como fue la coalición de países del tercer mundo, integrada por países de Asia, África y América Latina buscaban el desarrollo con justicia social, la independencia económica y política y sobre todo un orden internacional basado en la justicia internacional y la equidad.

La posición de México en esa histórica asamblea de la ONU se basó sin duda alguna en los viejos postulados de México en sus luchas por la soberanía, la autodeterminación y la Independencia, así como el sentimiento de amistad muy añejo de la relación con el pueblo de China a través de la historia, que contribuía a reafirmar en el concierto internacional la vocación de paz y de solución pacífica de los conflictos compartida por ambas naciones.

Surgía en esos años el concepto del tercer mundo, el de los países en proceso de desarrollo que frente a las grandes potencias han propugnado la conformación de una comunidad internacional en la que prevalezcan la justicia distributiva y la independencia económica mediante la aprobación de un Nuevo Orden Internacional en el que se eliminen la especulación y la explotación de los recursos naturales para provecho de los menos, un orden en el que los países de menos crecimiento lo alcancen mediante precios justos a sus materias primas y se eviten las prácticas comerciales que privilegian al más fuerte. La ONU fue un fuerte baluarte de reivindicaciones de los pueblos subordinados a un orden injusto después de la Segunda Guerra Mundial, a través de un dinámico proceso de liberación que propicio el nacimiento de jóvenes Estados. 
La determinación de México no estuvo exenta de presiones por parte de los grandes centros de poder para convencer a su gobierno de votar en contra del ingreso de China a la ONU. Se aducían para ello argumentos que iban desde la conveniencia de mantener el equilibrio en la Guerra Fría hasta razones de estrategia militar para salvaguardar la seguridad y la precaria paz en el mundo.

La historia ha mostrado la justeza de las posturas de quienes, aun en la situación política mundial de aquellos años, sostuvieron el principio de reconocimiento a una nación que hoy ocupa un lugar preponderante como segunda potencia económica mundial y se ha erigido en uno de los pilares fundamentales en la superación de las crisis financieras que han afectado al mundo entero, como un contribuyente poderoso al comercio mundial y para México, el segundo socio en intercambio comercial.

\section{Comunicado conjunto: México-China}

Los representantes permanentes de los Estados Unidos Mexicanos y de la República Popular de China ante las Naciones Unidas, como resultado de negociaciones llevadas a cabo y con la debida autorización de sus respectivos gobiernos, convinieron en lo siguiente:

1. De acuerdo con los principios de igualdad jurídica de los Estados, el respeto mutuo de su soberanía, independencia e integridad territorial, la no agresión y la no intervención en sus asuntos internos o externos, los gobiernos de los Estados Unidos Mexicanos y de la República Popular China han decidido establecer relaciones diplomáticas, con efecto a partir de esta fecha, e intercambiar embajadores tan pronto como sea posible.

2. El gobierno mexicano y el gobierno chino han convenido en proporcionarse toda la cooperación necesaria para el establecimiento de misiones diplomáticas en sus capitales respectivas y para el desempeño de las funciones de dichas misiones, sobre bases de igualdad y reciprocidad y de acuerdo con el derecho y la práctica internacionales.

3. El gobierno chino apoya la justa posición de México y otros Estados latinoamericanos sobre el establecimiento de una zona libre de armas nucleares en América Latina y sostienen que todos los Estados poseedores de armas nucleares deben asumir la obligación de no emplear tales armas contra dicha zona o contra dichos estados. El gobierno mexicano toma nota con aprecio de esa posición del gobierno chino.

\begin{tabular}{|l|l|}
\hline \multicolumn{1}{|c|}{ Alfonso García Robles } & \multicolumn{1}{c|}{ Huang Hua } \\
\hline $\begin{array}{l}\text { Representante Permanente de los Estados Unidos Mexicanos } \\
\text { ante las Naciones Unidas }\end{array}$ & $\begin{array}{l}\text { Representante Permanente de la República Popular China ante las } \\
\text { Naciones Unidas }\end{array}$ \\
\hline
\end{tabular}

(Nueva York, N.Y., 14 de febrero de 1972) 


\section{Las relaciones entre México y China trascienden los aspectos económicos}

Los presidentes Mao Tse Tung y Echeverría manifestaron que las relaciones entre México y China trascendían los aspectos económicos durante el encuentro que años después de la histórica Asamblea de la ONU sostuvieron en Beijing en abril de 1973. Ambos evocaron la universidad de la Organización de las Naciones Unidas al escoger, por decisión de la mayoría de sus integrantes, a la nación que alberga a la cuarta parte de la población del mundo.

El presidente mexicano, conforme a la mejor tradición de la diplomacia mexicana, manifestó en Pekín que nuestro país no contempla a China sólo como un enorme mercado, sino "como una fuente de experiencias liberadoras". En la histórica sesión de la ONU, afirmó, sostuvimos que la presencia de China "significaba un avance trascendental para reafirmar ese principio de universalidad".

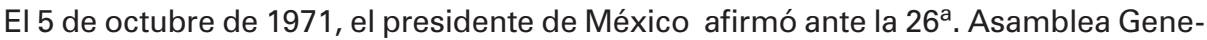
ral de la Organización de Naciones Unidas que: “la soberanía y la integridad territorial de China son indivisibles en lo jurídico", hacía patente en el máximo foro internacional uno de los principios fundamentales de la política exterior de su país: la relación respetuosa y fructífera que debe existir entre las naciones, abstracción hecha de sus diferencias ideológicas o políticas y de sus formas de gobierno surgidas de su libre determinación.

La entrevista sostenida por los presidentes Mao Tse Tung y Luis Echeverría figura de manera preponderante en los logros sobresalientes de la política exterior de México en la época que siguió a la Revolución Mexicana. Aparecen aquí capítulos importantes de las acciones de las relaciones exteriores de México durante la administración del presidente Echeverría, basadas en el diálogo con los líderes de las más diversas regiones del mundo tanto por su ubicación geográfica como por la naturaleza de los regímenes que representaban. Son una serie de testimonios de la posibilidad de alcanzar la paz en un mundo mejor mediante el entendimiento entre las naciones, la cooperación y la voluntad de superación de problemas, por arduos que sean. Son los mismos principios, profundamente humanos, que la República China ha sostenido a través de su historia.

Después del establecimiento de relaciones diplomáticas en 1972, la cooperación económica, científica y tecnológica de China y México es todo un reto y un desafío todavía por alcanzar, porque la relación de China como potencia económica de este siglo tiene mucho que aportar en temas de inversión y desarrollo tecnológico en nuestro país, en el marco de los acuerdos ya firmados sobre comercio, colaboración científica, transporte marítimo, créditos bancarios, cooperación social, económica, energética y agropecuaria.

Hoy en día China y México son sin duda alguna dos de los principales socios comerciales y receptores de inversión china en América Latina, y China es el segundo socio comercial.

Los intercambios culturales entre nuestros dos países con importantes antecedentes milenarios cuentan con simpatías de la población, con la convicción de que México es un país mundialmente reconocido por su enorme historia y cultura con fuertes raíces tradicionales populares, y una extraordinaria sabiduría que ha realizado grandes contribuciones al progreso de la civilización. China, por su parte, también con una enorme 
historia milenaria ha hecho muchas aportaciones culturales a Occidente. México fue el primer país latinoamericano que sostuvo contacto cultural e intercambio económico con China, tras la fundación de la nueva República en 1949.

China y México son el ejemplo más acabado de relaciones armoniosas en el mundo

En el siglo XXI las relaciones de cooperación entre China y México se han elevado a niveles de beneficio mutuo, sentando las bases para el establecimiento de asociaciones de cooperación en todos los ámbitos, con la convicción de que estos dos países pueden constituir una asociación estratégica con un potencial enorme para el intercambio político, económico, científico, tecnológico, cultural y educativo. Ambos países han apostado a la cooperación amistosa con fuertes intereses por ampliar las perspectivas del beneficio mutuo, pero en el marco de la cooperación Sur-Sur y la defensa de la paz y la promoción del desarrollo.

La postura mexicana en esa histórica Asamblea de la ONU representaba no sólo una actitud de congruencia con los postulados de respeto a la soberanía y la autodeterminación de las naciones que México abrazó desde sus orígenes como nación independiente y los sentimientos de amistad que animaron la cambiante relación con el pueblo chino a través de la historia, sino que contribuía a afirmar en el concierto internacional la vocación de paz y de solución pacífica de los conflictos compartida por ambas naciones.

En mayo de 1972 el Presidente Luis Echeverría presentó, ante la Conferencia de las Naciones Unidas sobre Comercio y Desarrollo, la propuesta de la Carta de Derechos y Deberes Económicos de los Estados. El 12 de diciembre de 1974 la Carta fue adoptada por la Organización de las Naciones Unidas por una amplia mayoría de votos. El documento, cuya vigencia se mantiene como una declaración de los estados miembros de la ONU, constituye un compromiso de los países desarrollados para conceder un trato preferencial a las naciones en desarrollo, sin reciprocidad y sin discriminación, en las esferas de la cooperación internacional en las que sea posible. El logro de la aceptación de la Carta se inscribe en la postura de los países del tercer mundo y de los no alineados en busca de la equidad en las relaciones internacionales y del diálogo constructivo entre las naciones, y debemos subrayar que China fue un aliado estratégico de este documento histórico.

Como resultado del debate en el seno de la Organización, las naciones ahí representadas aprobaron la reanudación del asiento legal de China en la ONU. México, cuyo voto afirmativo a la resolución era esperado, emitió de inmediato un comunicado a través de su Secretaría de Relaciones Exteriores en el que se expresaba lo determinante de su postura: "el Gobierno de Beijing -dice el documento- es el único representante legal de China".

Al término de la sesión celebrada en la ciudad de Nueva York, el Presidente Echeverría instruyó a su representante ante la Organización de las Naciones Unidas para entablar las negociaciones con el de la República Popular China tendientes al establecimiento de relaciones diplomáticas entre las dos naciones. El 16 de noviembre de ese mismo año el Gobierno de México anunciaba la ruptura de relaciones con el de Taiwán, y a principios de 
1972 México y China formalizaban sus relaciones diplomáticas, las primeras en América Latina en la nueva situación de reconocimiento internacional al Gobierno de Beijing.

La entrevista sostenida por los Presidentes Mao Tse Tung y Luis Echeverría figura de manera preponderante en el presente volumen, en el que se recogen los aspectos sobresalientes de la política exterior de México en la época que siguió a la Revolución Mexicana. Aparecen aquí capítulos importantes de las acciones de las relaciones exteriores de México durante la administración de Luis Echeverría basadas en el diálogo con los líderes de las más diversas regiones del mundo, tanto por su ubicación geográfica como por la naturaleza de los regímenes que representaban. Son una serie de testimonios de la posibilidad de alcanzar la paz en un mundo mejor mediante el entendimiento entre las naciones, la cooperación y la voluntad de superación de problemas, por arduos que sean. Son los mismos principios, profundamente humanos, que la República Popular China ha sostenido a través de su historia.

\section{Conclusión y propuestas para un futuro intercambio armonioso y de beneficio mutuo}

México y China de cara al futuro deberían tener un objetivo común: construir un futuro de prosperidad mediante relaciones comerciales equilibradas, compartidas como lo hicieran algunos países de América Latina como Perú. Se suscribió un tratado de libre comercio con China, lo cual le permitió equilibrar y fortalecer no solamente su balanza comercial sino la atracción de inversiones e intercambio tecnológico. Como algunos analistas han sugerido, debemos analizar el estado de las relaciones económicas con EU, relaciones realmente fallidas, ya que los objetivos de cooperación bajo el tratado del libre comercio, "la enchilada" completa, ha sido un fiasco en términos tecnológicos, cooperación científica, salud y, sobre todo, la severa crisis financiera que estalló en ese poderoso socio comercial y que ha obligado a su gobierno adoptar medidas de emergencia para rescatarlo del desastre y peligros de una recesión, fenómeno que afectó a México, dependiente de ese mercado.

China constituye uno de los mercados más importantes del mundo para todo tipo de productos, si tomáramos una muestra de 10 habitantes del planeta, al menos 2 serían de procedencia china, tal y como lo ha comentado nuestro amigo el embajador Eugenio Anguiano:

Este gigante asiático ha continuado con un crecimiento acelerado, constituyéndose en el motor más importante de la economía mundial, con una producción sostenida durante más de 30 años de empleo, ahorro, inversión, exportaciones, formación de recursos humanos y, sobre todo, un desarrollo tecnológico que ha logrado transformarse de un país muy atrasado en todos los órdenes en la década de los 70, a una poderosa industria global, la cual demanda de países que son una alacena de materias primas, como lo son Asia, África y nuestro continente, una mayor demanda de materias primas, por necesidades de su industria textil, ropa, calzado y juguetes, pero también debemos subrayar que en los años venideros, sin duda alguna, China será líder en las ramas de la economía del conocimiento, la conservación de energía, tecnología informática avanzada, biotecnología, transportes avanzados, aviones, trenes de alta velocidad, nuevas energías, vehículos ahorradores de energía. 
En caso de que China logre ser líder en estos temas y aunado a una política salarial de mayor equidad y sustentabilidad, no tengo la más mínima duda, de que logrará en el 2020 ser la primera economía del planeta, dependiendo de los contrastes de Estados Unidos, así como de la catástrofe Europea.

Hoy, los productores mexicanos quieren aprovechar ese potencial y tienen un gran interés en convertirse en proveedores destacados de bienes y servicios a China, pero no tenemos un plan definido estratégico que potencialice el talento y la inteligencia de los empresarios mexicanos, que algunos son ejemplares y que han sido dañados por la crisis del mercado de Estados Unidos. Así es que este es el momento de repensar como aprovechar nuestra relación con ese mercado con nuevos aliados como sería China e India. Pero pensando también en caminar juntos con América Latina en ramas como la industria automotriz, las autopartes que han crecido mucho al lado de sectores electrónicos, con empresas medianas y pequeñas al lado de grandes empresas como Pemex, Carso, Semex, Bimbo, Maseca, Femsa, empresas que todos sabemos que recientemente han preferido invertir en el exterior buscando, para aumentar su competitividad, salarios bajos; estas empresas, como todos sabemos, se han implantado y ya tienen presencia en Brasil y Argentina.

¿Entonces qué esperamos? ¿Queremos o no queremos cooperar con el gigante asiático?

Para avanzar en la dirección correcta y dejar de ser el traspatio de materias primas de Estados Unidos, tenemos que diversificar nuestra economía, rompiendo el modelo subordinado y la dependencia que nos imponen los compromisos contraídos con ese país tan poderoso pero cuya economía está en apuros.

De continuar en este camino, México no tiene futuro. Lo que necesitamos urgentemente es un nuevo proyecto nacional estratégico de desarrollo y de largo plazo que nos posicione ventajosamente en la nueva realidad internacional, con una visión estratégica de inserción ventajosa de cara a los cambios de las realidades internacionales, dejar el pasado y repensar en el futuro que nos permita aprovechar toda nuestra capacidad y talento en esta nueva era de la economía del conocimiento, porque lamentablemente la mayor capacidad de nuestro comercio está concentrada con el mercado de Estados Unidos, que nos ha obligado a una política monetaria supeditada y subordinada, con el descuido de nuestras grandes fortalezas; sin duda alguna, en América Latina y el Caribe, ignorando oportunidades que tenemos en África y el Medio Oriente.

Tan sólo en la última década, el intercambio comercial entre México y China creció más de 1,000\%, pasando de 4,300 mdd en 2001 a 49,800 mdd el año pasado.

Estos hechos hacen que hoy China sea el segundo socio comercial de México a escala mundial, tan sólo después de Estados Unidos. Sin embargo, hoy debemos impulsar también la inversión productiva que constituye la clave para lograr una mayor integración económica entre nuestros países está en la inversión.

De aquí en adelante debemos buscar fortalecer el vínculo de inversión entre México, China y la India, que es el camino que nos puede llevar a un destino común de bienestar y progreso concertadamente con América Latina

México y América Latina podrían ofrecer a los inversionistas de China una serie de ventajas competitivas sumamente atractivas para los negocios establecidos en el país por la posición estratégica. 
La cartera actual de proyectos susceptibles a confirmarse provenientes de China asciende a 44 proyectos de inversión en sectores como infraestructura, energías renovables, minería, entre otros, proyectos que representan un total de 2,575 millones de dólares, cifra que puede crecer de manera significativa si trabajamos de la mano.

Debemos llevar más presencia de México a China y más presencia de China a México. Necesitamos fortalecer la presencia de nuestros mercados y oportunidades entre nuestras naciones, tanto en su cultura y tradiciones, como en sus productos y oportunidades de negocios. 



\title{
La serpiente emplumada y el dragón chino: cuarenta años de un reencuentro ancestral
}

\author{
Arturo Oropeza García
}

|

La década de los 70 del siglo XX fue una de las etapas más emblemáticas de la segunda mitad de siglo. Muchos fueron los sucesos que empezaron a gestarse durante esos diez años, los cuales contribuyen en gran medida a explicar la realidad política y económica que vivimos en esta primera mitad del siglo XXI.

El 15 de agosto de 1971, por ejemplo, el presidente Richard Nixon tomó la importante decisión de desvincular al dólar del oro, finiquitando uno de los acuerdos financieros más importantes surgidos de la Ronda de Bretton Woods, hecho que se presentó junto con el inicio de la disminución de la tasa de crecimiento de la mayoría de los países capitalistas avanzados. De igual modo, en 1971 Estados Unidos perdió por primera vez su superávit comercial, el cual no ha recuperado hasta el día de hoy, salvo contadas excepciones. En el mismo año, el país americano se encontraba enfrascado en una guerra absurda e injustificada con Vietnam, la cual, junto con sus fallos económicos, empezaron a dibujar la crisis económico-política que sigue viviendo la nación norteamericana hasta el día de hoy.

En la década de los 70, después de 30 años de una relativa "pax" derivada de los acuerdos de terminación de la Segunda Guerra Mundial y de una bonanza económica para los países vencedores, en especial para Estados Unidos; la sensación de abundancia y predecibilidad empezó a cambiar radicalmente en todos los planos. Una nación norteamericana que en lo económico empezaba a perder sus ventajas, se combinaba con una posición política comprometida entre los desgastes de su Guerra Fría con el bloque socialista, como con los vientos de su anunciada derrota en el conflicto de indochina.

En la década de los 70, China tampoco transitaba por su mejor momento. En el terreno económico, sus programas de desarrollo del Gran Salto Adelante (1958-1960) y el de la Revolución Cultural (1965-1976) no habían producido los efectos deseados, y además de padecer una hambruna en que murieron millones de personas, China presentaba la insuficiencia para dar un desarrollo sustentable a más de 900 millones de personas. En lo interno, el fracaso de la Revolución Cultural llevó a un desajuste político que culminó con un atentado al presidente Mao Zedong en 1971 (Chen Jian, 2005) y en la insubordinación y muerte del sucesor de Mao, Lin Biao, en un accidente aéreo, en septiembre del mismo año. En lo geopolítico, la relación de China en la zona venía de una guerra con India en 1962 y una separación progresiva con la Unión Soviética desde principios de los 70, con la cual, en vez de resolver sus diferencias, éstas se fueron profundizando. Incluso con Vietnam, China, después de un gran apoyo en la década de los 70 en el marco de la confrontación del país asiático con Estados Unidos, fue disminuyendo su relación por diversas razones hasta la conflagración que registraron ambos países en 1979.

De manera especial, en esta década de profunda transformación que fueron los 70, también se produjo el hecho trascendental de la apertura China. El año de 1976, por 
ejemplo, marcó el fin de una etapa histórica del pueblo chino, en virtud de todos los sucesos que se registraron en el periodo. En enero murió Zhou Enlai, el gran líder de la línea moderada; en julio, Zhu De, que había sido el nominal jefe de Estado como presidente del Comité Permanente del Congreso Nacional del Pueblo y el 9 de septiembre fallecía el propio Mao Zedong. Aunque muchos de los antiguos líderes permanecieron en sus puestos, la ausencia de Mao motivó que los veteranos de la Revolución y formadores del estado comunista empezaran a ser desplazados por una nueva generación de políticos "pragmáticos"; sin embargo, en virtud de que no se tenían previsiones para una sucesión automática (ya que Lin Biao, el sucesor designado por Mao, como ya se dijo, murió en 1971), el campo se mostró propicio para una lucha abierta por el poder, con ventajas iniciales para la fracción radical, al impedir que Deng Xiaoping fuera elegido primer ministro y al lograr que fuera expulsado de sus cargos en el gobierno y en el partido, padeciendo por segunda ocasión la suerte de su exclusión. Como una solución temporal, basada en una opinión favorable de Mao antes de morir, Hua Guofeng, un administrador sin lazos cercanos con ninguna de las facciones enfrentadas se convirtió en primer ministro. Para consolidar su posición hizo arrestar y acusó de varios crímenes a la Banda de los Cuatro (nombre dado por los moderados a la viuda de Mao, Jiang Qing y otros tres dirigentes radicales). Hua se centró en el desarrollo de una política de estabilización, así como en la aplicación de un plan de ayuda a la población damnificada por los efectos de los terremotos que en el mismo año de 1976 devastaron la provincia de Tangshan y otras regiones del norte del país.

Como un triunfo inicial de las corrientes moderadas, en 1977 se reinstaló a Deng como vicepresidente del partido y también en los otros cargos de los que había sido expulsado. El X Congreso del Partido Comunista Chino, celebrado en julio de 1977, estuvo dominado por el presidente Hua, el vicepresidente Deng y Ye Jianying, e integró a los militares y oficiales veteranos del partido a los cargos directivos. El énfasis puesto en la moderación política y en la modernización económica del gobierno se reflejó desde el $\mathrm{V}$ Congreso Nacional Popular que se reunió en febrero y marzo de 1978, donde el primer ministro Hua fue reelegido, con Deng como sustituto.

En su entorno internacional, las presiones que en ese momento vivía China, eran tan intensas como las que se vivían al interior del partido. Cuando Vietnam invadió a Camboya y en enero de 1979 derrocó al gobierno de ese país, como ya se señaló, China tomó represalias y un mes después envió tropas a Vietnam. Ante el avance de estos conflictos limítrofes, que la amenazaban con quedar rodeada por los soviéticos y los vietnamitas, China aumentó sus contactos con el exterior, por lo que en enero de 1979 restableció relaciones diplomáticas con Estados Unidos, del mismo modo que estrechó los lazos con Japón y Europa Occidental.

A la muerte de Mao Zedong y Zhou Enlai en 1976, el sistema político se encontraba desarticulado y con un gran vacío de poder. El sucesor inmediato de Mao, Hua Guofeng, fue una figura de transición que no tenía la capacidad para delinear una política de largo plazo, lo cual generó la oportunidad para que en 1978, el político que había estado encabezando a los pragmáticos, Deng Xiaoping, asumiera finalmente el poder y se constituyera en el principal arquitecto y figura emblemática de la reforma económica que China inicio con todo éxito hace más de treinta años. 
En este breve cuadro de reacomodo político y económico sucedido en la importante década de los 70, es que en octubre de 1971, la República Popular China ingresa a la Organización de Naciones Unidas (ONU), recuperando un espacio que debió detentar y que le fue negado por más de dos décadas. Este hecho, de la mayor relevancia para el nuevo mundo global, fue acompañado por la visita histórica que hizo el presidente Richard Nixon a China en febrero de 1972, la cual motivó que estos dos países formalizaran sus relaciones diplomáticas en 1979, inaugurando una nueva era cuyas consecuencias todavía siguen siendo de la mayor relevancia para el concierto de las naciones.

II

En el marco de estos trascendentales acontecimientos, sucedidos en la década de los 70, el 14 de febrero de 1972, apenas a cuatro meses de su aceptación en la ONU, México ratificó su reconocimiento a una China, que no le era ajena y respecto a la cual mostraba una simpatía hacia su Revolución y sus postulados sociales; en remedo a la ancestral historia mexicana y a los eventos revolucionarios que su propia agenda había registrado en 1910, apenas un año antes del fin del imperio chino.

A principios de la década de los 70, México, a diferencia de China, vivía una etapa de desarrollo y estabilidad económica como resultado de registrar por más de 30 años (1941-1971) una tasa de crecimiento del 6\% anual promedio de su Producto Interno Bruto, acompañada con importantes logros en los sectores agrícola e industrial, así como en el empleo y el poder adquisitivo de los trabajadores. A la distancia, dentro del proceso que se llegó a llamar el "Milagro Mexicano", México seguía la etapa posrevolucionaria del pueblo chino con gran interés, y los dirigentes mexicanos de la época en múltiples ocasiones dieron claras muestras de simpatía hacia el pueblo chino, como la visita que hizo en 1959 el expresidente de México, el general Lázaro Cárdenas del Río, apenas diez años después del triunfo de la Revolución Popular China, durante la cual se celebró una importante entrevista con el presidente Mao Zedong.

De igual modo, apenas un año después de la formalización de las relaciones, el presidente mexicano, Luis Echeverría asistía a una visita oficial en abril de 1973 con el primer ministro del Consejo de Estado de China, Zhou Enlai, y con el presidente del Comité Central del Partido Comunista Chino, Mao Zedong. Este reconocimiento de México sobre su relación con China se ha continuado desde esa fecha, no sólo con el presidente Echeverría; el presidente López Portillo, por ejemplo, también visitó al país asiático en un viaje oficial en octubre de 1978. Haría lo propio en diciembre de 1986 en Beijing, el presidente Miguel de la Madrid, quien se entrevistó con el presidente de la Comisión Central de Asesoramiento del Partido Comunista, Deng Xiaoping. De igual modo, el presidente Carlos Salinas de Gortari, en diciembre de 1993 asistió al gran Palacio del Pueblo de Beijing y se entrevistó en con el presidente chino Jiang Zeming. En noviembre de 1996 el presidente Ernesto Zedillo también acudió a la cita de la amistad entre los dos países, en un viaje de Estado que fue atendido por el presidente Jiang Zeming. No obstante el cambio democrático surgido en México a partir del año 2000, el interés y la amistad de los dos países siguió estando en el primer plano y en junio de 2001 el presidente Vicente Fox realizó una visita oficial a China, la cual fue atendida de 
igual modo por el presidente del Estado chino en ese entonces, Jiang Zeming. Finalmente, el 11 de julio de 2008, el presidente Felipe Calderón también realizó un viaje de Estado a la República Popular China, dando fe con ello de la simpatía y el interés que ha mantenido la relación de los dos países desde hace cuarenta años, simpatía y amistad que van mucho más allá de estas cuatro décadas.

En el marco de la efeméride de esta celebración, resulta conveniente recordar que la relación de México y China rebasa los anales del registro que se desprende de la inserción de China como país integrante de la ONU. Basta caminar por las calles de Beijing o por las avenidas del centro de la Ciudad de México, para reconocer que la relación de los dos países rebasa los cuarenta años y la firma de un documento formal de febrero de 1972, o más aún, de diciembre de 1899, cuando se produjo el primer encuentro de carácter oficial entre México y China y ambos países celebraron un Tratado de Amistad, Comercio y Navegación. O más lejos todavía cuando en 1565 el Galeón San Pablo trajo a las costas mexicanas de Acapulco las primeras mercancías de un país asiático que se caracterizaba ya por el valor y la diferenciación de sus productos. Las semejanzas faciales que nos parecen conocidos tanto en las calles de Beijing o Shanghai a los mexicanos en la Ciudad de México o Puebla, es una identificación de la que poco se habla, pero que en el acercamiento de la geografía que ha permitido el avance tecnológico, es una realidad que tanto a chinos como a mexicanos nos resulta cada vez más familiar y más difícil de desconocer. En esta breve pero importante referencia tendríamos que reconocer tanto chinos como mexicanos, que los cuarenta años de hoy contrastan con los veinte o treinta mil años de ayer, cuando nuestros antecesores asiáticos entraron por la región de Alaska (Estrecho de Bering) y se convirtieron en los primeros habitantes de un continente en el que en México construyeron su más grande asentamiento de América y generaron el desarrollo de una cultura que en el detalle de la antropología y la costumbre transita por un camino de múltiples coincidencias que, no obstante la neblina del tiempo, permanecen en la idiosincrasia de los dos pueblos.

En este espejo de la historia aparece una serpiente emplumada, azteca o maya, que se mezcla y se emparenta con las miles de expresiones de un dragón chino, los cuales en la figura y en la forma se mimetizan y confunden en un parentesco histórico imposible de no reconocer. El tratamiento artístico del calendario azteca, por ejemplo, es parecido al arte del tambor y al espejo de bronce de China. De igual modo aparece que en el sistema de cinco elementos y ocho trigramas de los calendarios prehispánicos y chinos, los dos países encaran ideas de marcos universales que se caracterizan por un tipo de modelado y de holografía que alude en forma notable al tiempo, espacio y color de su época, reiterando la estrecha relación de ambas culturas, lo que nos habla, de muchos modos, de ese laberinto de coincidencias en donde se confunde la piel obscura y los ojos rasgados.

Por ello, al recordar las cuatro décadas de la formalización de las relaciones de China y México, su festejo no puede ser más que un buen pretexto para seguir profundizando en los términos de una relación cultural-histórica, que si bien ha estado privilegiada por la simpatía de las dos naciones, no se ha sabido reconocer en el espejo de las similitudes y de las coincidencias de un tiempo muy lejano, las cuales las dotan de un lazo de familiaridad que debe fortalecerse y que debe saber aprovecharse en la construcción de un vínculo estratégico que riegue los demás campos de la relación bilateral. 
En el campo diplomático, por ejemplo, México y China también encuentran una cantera de coincidencias muy valiosa que los identifica y los une. Desde de 1949 China viene aplicando una política exterior independiente de paz, siguiendo el camino del desarrollo de los Cinco Principios de Coexistencia Pacífica. De igual modo, China brinda suma importancia al desarrollo de la amistad y al desarrollo bilateral con los demás países. Recientemente, China desempeña un papel cada vez más importante en el escenario diplomático global y su participación en la solución de los conflictos y la cooperación multilateral es cada día más relevante. Al propio tiempo, China se ha caracterizado por ser un país de gran memoria, que sabe reconocer el valor estratégico e histórico de sus relaciones y que en su camino de apertura, en múltiples ocasiones ha subrayado la conveniencia del beneficio recíproco (ganar-ganar) de los participantes, a fin de lograr la construcción de un mundo armonioso de paz duradera y prosperidad conjunta. De manera sensible, China persiste "en tomar al hombre como lo principal"; y bajo el principio de la buena vecindad, China promueve la cooperación pragmática con las demás naciones, desarrollando la cooperación y creando un ambiente pacífico estable de igualdad y confianza mutua. De manera relevante, desde 2005, en la cumbre de Asia-África en Yakarta, China propuso la idea de edificar conjuntamente un "mundo armonioso", idea que ratificó en la ONU al señalar la importancia de "construir un mundo armonioso de paz duradera y prosperidad conjunta" entre todos los países.

México, por otra parte, siempre se ha caracterizado por una vocación solidaria y respetuosa con las demás naciones, vocación que ha estado fincada en los principios normativos de la autodeterminación de los pueblos, la no intervención, la solución pacífica de las controversias internacionales, la proscripción de la amenaza o del uso de la fuerza en las relaciones internacionales, la igualdad jurídica de los Estados, la cooperación internacional para el desarrollo y la lucha por la paz y la seguridad internacional (Art. 85 de la Constitución Mexicana). De igual modo, y acorde con los retos de una exigente modernidad, o de lo que se ha dado en llamar "una neutralidad ecológicamente sensible" (Guiddens, 2000), la política exterior de México se ha venido renovando en torno a los nuevos retos globales. Con base en estos principios, México ha declarado en los foros internacionales en los que ha participado que nada justifica la vulneración del derecho internacional, señalando también que la soberanía de los Estados es un término de gran vigencia, por lo que debe respetarse la decisión y voluntad de cada país para organizarse en la medida de sus posibilidades, ya que no existe un modelo único para el desarrollo económico y organización política de las estructuras sociales, por lo que el acatamiento por todas las naciones de las normas del derecho internacional es la única garantía en el orden mundial que puede brindar seguridad, justicia y paz a todos los individuos.

Lo anterior nos habla de las grandes semejanzas en la visión diplomática de México y China; las dos naciones han coincidido bajo su propia perspectiva en la aplicación de un esfuerzo de "contribuir a la armonía mundial", es decir, a la construcción de un mundo armonioso; los principios mexicanos, en su esencia, no son distintos a los principios torales de la diplomacia china adoptados en 1954, que se refieren al respeto mutuo, a la soberanía y la integridad territorial, a la no agresión, a la no intervención en los asuntos internos del otro y a la igualdad y beneficio recíproco y coexistencia pacífica. 
III

Bajo estas líneas generales podríamos señalar que los caminos de México y China son más coincidentes de lo que se les ha reconocido y su relación es más profunda de lo que se ha aceptado.

Desde su origen milenario, los dos pueblos parten de la coincidencia de un tránsito entre regiones facilitado por la naturaleza, cuyas expresiones físicas hoy son imposibles de negar, más allá de las vicisitudes y transformación de cada pueblo. La serpiente emplumada transformada en dragón y el dragón convertido en serpiente, nos refieren a un abrazo histórico que ha sido moldeado por los cauces del tiempo y que sigue en espera de un mayor reconocimiento por parte de ambas naciones. En el siglo XVI la casualidad vuelve a reunir a los dos países en un encuentro de aromas y sabores que se materializó en el primer intercambio de mercancías y productos autóctonos. La percepción del otro, entonces, se da por medio de una producción cultural que ya adivinaba las cercanías que se han ratificado con el paso del tiempo. El infortunio histórico tampoco les has sido ajeno: en 1860, mientras la ciudad China de Beijing era ocupada por tropas francesas, en 1862 la Ciudad de México vivía lo propio por parte de Francia e Inglaterra. Las dos revoluciones sociales de México y China, aunque separadas en su consumación por más de 30 años (1917-1949), son el reflejo de dos pueblos que han compartido ideales de justicia e igualdad social. Por ello, el festejo de estas cuatro décadas de la relación formal entre México y China, representa la oportunidad para que estos dos pueblos recuperen la memoria histórica y potencien la fuerza de un vínculo, que para cada una de las dos naciones guarda un significado que trasciende con mucho la efeméride de 1972.

El siglo XXI no será fácil para nadie, grandes y profundas transformaciones se sucederán en el plano geopolítico y económico de las próximas décadas. Nos encontramos en la conformación de una nueva geografía de la convivencia y el desarrollo global, donde los viejos paradigmas empiezan a caerse. Asistimos al pacto de una nueva época que tiene como principal característica la refundación de lo conocido, de la revisión de la mayoría de los temas económicos, políticos y sociales que nos rodean. En este sentido, tanto México como China tendrán la necesidad de contribuir a la mejora de una política internacional respecto a un proceso global que ya comenzó y es irremediable.

China, en su nuevo papel de hegemonía intermedia, por primera vez en su historia tendrá la oportunidad de contribuir a la mejora de un mundo global. Los últimos cien años, desde 1911, China ha enarbolado un discurso contra los imperialismos y se ha proclamado por una sociedad de beneficio recíproco que sea justa para todos. En los albores de una nueva era, la influencia de la economía China, pero de manera más, importante, de la filosofía internacional de China de ayudar a la construcción de un mundo "armonioso de paz duradera y prosperidad conjunta", tendrá la oportunidad de hacerla realidad ante una Unión Europea emproblemada y un Estados Unidos declinante. China vivió amurallada lejos del entorno global por más de dos mil años. Esa posibilidad se ha 
cancelado, y ahora una sociedad global retada en el siglo XXI a su sobrevivencia, estará demandando que un nuevo hegemón como lo es China, ayude de manera central a la solución de la sustentabilidad de un mundo que por sus retos colectivos y escasez de recursos naturales no acepta soluciones particulares.

México, por otra parte, solventada su sustentabilidad interna, deberá recuperar la voz y la influencia que por más de dos siglos han estado contribuyendo a la madurez de una región que aún tiene mucho que dar y mucho que ofrecer en la transformación de esta nueva época. En su calidad de segunda economía y demografía de la región, y de primera en el rubro comercial. Por sobre todo, en los principios siempre respetados de su política internacional, México es un país que resulta estratégico para una nueva hegemonía como China, cuya influencia en la zona se ha incrementado de manera relevante en los últimos diez años.

Tanto México como China, en el marco de su ancestral e importante relación, tienen ahora la oportunidad de ir más allá de los temas coyunturales de una agenda que de manera equívoca se ha ubicado preponderantemente por los dos gobiernos en sus temas de comercio, los cuales, sin demeritar su importancia sectorial, han ocasionado que se posponga la construcción de una agenda trascendente, de largo plazo, que resuelva no sólo la problemática comercial que enfrentan las dos naciones, sino que incluya los puntos integrales de una colaboración conjunta que aproveche el potencial de las dos naciones en los planos económico, educativo, tecnológico, cultural, etc.; de igual modo que considere su colaboración y participación conjunta en temas regionales y mundiales, donde la voz de dos países milenarios tiene mucho que proponer para la convivencia de la nueva sociedad global del siglo XXI.

La economía y el comercio global tendrán que pasar todavía por dolorosas etapas de adaptación antes de que puedan ofrecerse como una oferta sustentable para todos los países. El reacomodo geopolítico será la divisa de la próxima mitad del siglo XXI. Las demandas sociales cruzarán fronteras y una población global interconectada de siete mil millones de habitantes reclamarán los mismos derechos a través de inimaginables expresiones.

En el marco de todo este profundo cambio del siglo XXI, los valores y las raíces de una relación ancestral y profunda como la de dos naciones como México y China, deberán demostrarse a sí mismas y al mundo global, que hoy como ayer, son congruentes con la difícil tarea en la construcción de "un mundo armonioso".

En esta celebración de cuatro décadas de relación moderna, resulta deseable que la serpiente emplumada y el dragón chino, reconocidos en el espejo de su origen, sepan fortalecer la amplia línea de sus coincidencias, a fin de que estas les ayuden a entender y resolver las diferencias que se les estarán presentando en la inauguración de una relación bilateral más estrecha y comprometida. Las voces de sus principios y de su origen serán muy provechosas para conmemorar no sólo cuarenta años, sino muchas décadas más. 



\section{Mirada retrospectiva y reflexiones sobre la relación política entre China-México durante cuatro décadas}

Sun Yanfeng

\section{Relaciones políticas bilaterales antes y después del establecimiento de relaciones diplomáticas}

Desde que se "descubrió" el continente americano, China y México, a través del Pacífico Sur (Filipinas y otros países de Asia del Sudeste), establecieron un comercio frecuente. Hasta mediados del siglo XIX, con el desarrollo económico a gran escala en México, particularmente ante la alta demanda con la construcción del ferrocarril, en 1847 el primer barco cargado con los trabajadores chinos ("barco coolie") llegó a México y se estableció un gran número de trabajadores chinos en la región del este, norte y centro, de forma que llegaron a principios del siglo $X X$ unas 30,000 personas. Con el fin de regular y proteger los intereses de los trabajadores y comerciantes chinos, en 1894 el gobierno de la Dinastía Qing de China envió a visitar México al diplomático Yang Ru, que entonces trabajaba en Estados Unidos. El 14 de diciembre de 1899, el ministro de la embajada del gobierno Qing de China en EU, Wu Ting-fang, y el ministro mexicano en EU firmaron juntos el "Tratado de Amistad y Navegación entre China y México", con lo cual el gobierno chino empezó a enviar diplomáticos acreditados en México para abrir relaciones diplomáticas. Pero en la década 1910, con la onda de "exclusión de chinos" ocurrida en México, un gran número de chinos que vivían acá, tuvieron que trasladarse a otros países de América Latina, y las relaciones entre China y México fueron frías en los 20 años siguientes.

Después de la fundación de la "Nueva China" en 1949, debido a la relación especial con Estados Unidos, México mantuvo relaciones "diplomáticas" con las autoridades de Taiwán. Sin embargo, la China popular y México continuaron con intercambios no gubernamentales. El régimen socialista chino, la guerra de Corea y la victoria de la construcción del socialismo fueron acompañados por el mundo, y especialmente por la izquierda y la sociedad civil de América Latina, incluyendo México, quienes tenían el gran deseo de comprender la verdadera "China Roja". A finales de 1949, los dirigentes obreros mexicanos, como el secretario general del Partido Popular, Vicente Lombardo Toledano, visitaron China. En 1953 fue fundada la Asociación de Amistad en China y México, a través de la cual un gran número de personajes de la izquierda y políticos nacionalistas mexicanos visitaron China.

En 1970 asumió el cargo el presidente Echeverría, quien luchaba por una política independiente y reconoció el concepto del "Tercer Mundo" de China. Él anunció públicamente que México y los países del Tercer Mundo tenían intereses básicos comunes, y promovería activamente las cooperaciones amistosas con los países en desarrollo. Durante su mandato visitó decenas de países en Asia, firmando 160 acuerdos interna- 
cionales y estableciendo relaciones diplomáticas con más de 60 países, la mayoría de ellos países en desarrollo. Todo lo anterior evidenciaba que el polo de política exterior mexicana en ese periodo poco a poco se orientó hacia el Sur. Al mismo tiempo, la estrategia exterior de EU estaba en contracción y había establecido una relación triangular entre China, EU y la Unión Soviética, en la cual, China, como un país grande en desarrollo y una fuerza mundial importante, ganó la atención y apoyo desde México y otros del países del Tercer Mundo. El 26 de octubre de 1971, el presidente mexicano, Luis Echeverría, en el escenario de la 26a Asamblea General de la ONU, emitió un discurso a favor de la restauración del asiento de China en la Organización; claramente destacó que "la soberanía y la integridad territorial de China es indivisible" y en la votación que siguió apoyó a China. El gobierno chino apreciaba mucho la acción amistosa y la señal presentada del gobierno mexicano para mejorar las relaciones con China, y de inmediato instruyó a la misión de China en la ONU a contactar con la misión mexicana a fin de comenzar las negociaciones sobre el establecimiento de contactos diplomáticos.

Finalmente, el 14 de febrero de 1972, el embajador de China ante la ONU, Huang Hua, y el homólogo de México, García Robles firmaron en Nueva York la nota pública de establecimiento de relaciones diplomáticas bilaterales; por lo tanto, México se convirtió en el cuarto país de América Latina que tiene relaciones diplomáticas con China. El gobierno chino atribuye gran importancia a las relaciones con el gobierno mexicano, considerando a México como el país más cercano a EU y también uno de los mayores países en desarrollo que tenía relaciones diplomáticas con China, por lo cual envió al famoso diplomático Xiong Xianghui, quien ganó la confianza del más alto nivel, como el primer embajador en México. Como China y México tienen importantes posiciones geoestratégicas en el ámbito internacional y regional, el establecimiento de relaciones diplomáticas entre China y México en la década de 1970, fue una importante victoria diplomática de China como fruto brillante de la diplomacia del Tercer Mundo.

\section{Periodo de consolidación de las relaciones políticas (1970-1980)}

Después de que China y México establecieron relaciones diplomáticas, los dos gobiernos concedieron gran importancia a sus respectivos estatutos de política y las relaciones políticas entre sí, tratando a la otra parte como "camarada" y socio importante en el ámbito internacional. Los dos gobiernos impulsan la cooperación política bilateral en las áreas de antihegemonía y promoción de un mundo multipolar. En abril de 1973, el presidente Echeverría visitó China y recibió una bienvenida cálida, como primer jefe de Estado mexicano que pisó en el gigante asiático, el segundo de América Latina sólo después de Cuba. El primer ministro, Zhou Enlai, se entrevistó con él en cinco sesiones y lo acompañó personalmente a la visita fuera de Beijing. Y para demostrar la amistad con el pueblo mexicano regaló un par de pandas gigantes a México.

Durante este periodo, China y México han mostrado una fuerte convergencia política en relación con los temas de defensa de la soberanía de la economía y los recursos, que se manifestó en la firma del "Tratado de No-Proliferación Nuclear" y el fortalecimiento de la cooperación en el marco de la ONU. A finales de 1970, con la tendencia de cambio 
y reacomodo de potencias en el sistema internacional, México deseaba promover activamente la sustitución de importaciones y las industrias nacionales, especialmente a mediados de 1970 con el descubrimiento de grandes campos petroleros, se sumó a los países exportadores de petróleo. En este periodo, el gobierno mexicano de José López Portillo puso el foco diplomático en defensa de la soberanía económica nacional y la independencia nacional.

De acuerdo con este pensamiento, México estaba fortaleciendo las cooperaciones con China y otros países en desarrollo, que tenían aspiraciones políticas y económicas comunes y se complementaban y apoyaban mutuamente particularmente en la desnuclearización de América Latina, la defensa de la zona económica de 200 millas de mar y la nacionalización de los recursos nacionales. A finales de 1970, China abrió el camino de la reforma y apertura exterior, promoviendo el desarrollo económico, enfatizando la diplomacia pacífica e impulsando la relación de igualdad y cooperación de mutuo beneficio, lo cual se convirtió en los principios básicos del desarrollo de relaciones entre China y los países latinoamericanos, incluyendo México. En esta etapa, la cooperación política de los dos lados se mostraba principalmente a través de visitas de dirigentes de alto nivel y la firma de acuerdos de cooperación bilaterales.

En octubre de 1978 se realizó la visita del presidente López Portillo a China, con lo que se convirtió en el segundo jefe de Estado de México en visitar China; Portillo y los dirigentes chinos Hua Guofeng, Li Xiannian y otros líderes se reunieron para determinar el fortalecimiento de las relaciones políticas y la cooperación económica y comercial entre China y México. Desde entonces, las visitas oficiales a nivel ministerial y de altos funcionarios tuvieron mayor frecuencia. En octubre de 1981, el premier chino Zhao Ziyang, cuando asistió a la reunión de jefes de gobierno entre Norte-Sur sobre el tema de cooperación y desarrollo, en Cancún, realizó la primera visita oficial de un jefe de gobierno chino a México y América Latina.

Durante la administración del presidente Miguel de la Madrid (1982-1988), la política exterior independiente de paz de China ha sido ampliamente reconocida en México. Por lo tanto, aunque en este periodo México, por causa de la crisis de la deuda, estaba en recesión económica significativa, focalizaba la preocupación diplomática para América Latina y los países vecinos, pero China y México mantenían una buena cooperación política. China ofreció apoyos a México, como miembro del Grupo de Contadora, para resolver los conflictos centroamericanos. El presidente De la Madrid visitó a China en 1986, y se entrevistó amistosamente con los líderes chinos Deng Xiaoping y Li Xiannian y otros. Durante este periodo, ambos cancilleres intercambiaron visitas con frecuencia consultándose en relación con los principales temas de actualidad internacional y regional, tales como las negociaciones NorteSur, la cooperación Sur-Sur, el fin de la guerra civil centroamericana y otros temas.

\section{Periodo de asentamiento de una relación de socio estratégico (años 90)}

Ésta es la década de grandes y profundos cambios en el escenario internacional, fin de la Guerra Fría, desintegración de la estructura bipolar, la estructura política y económica a nivel mundial, y el "superhegemonismo" de EU, desfavorable a los países en desarrollo. 
Encarando este escenario, México comenzó a reconocer las preocupaciones de la región de Asia-Pacífico, y al mismo tiempo China también consideraba a América Latina como un socio clave de equilibrio contra la hegemonía de EU. Esta importancia recíprocamente estratégica impulsó cooperaciones políticas mutuas e intercambios económicos y comerciales bilaterales sentando una base sólida entre ambas partes para el establecimiento de relaciones estratégicas en los años siguientes.

En este periodo, la competencia económica se hace más intensa, y los intereses económicos se convierten en un factor dominante en las relaciones internacionales. En la administración de Carlos Salinas (1988-1994), para superar la crisis de la deuda de la década 1980, se unió cada vez más a Estados Unidos, firmando el Tratado de Libre Comercio de América de Norte (1992), con el cual la economía mexicana se vinculó más al vecino del norte. Al mismo tiempo, con el fin de adaptarse al aumento gradual de la globalización económica, el gobierno mexicano comenzó a fortalecer las relaciones con los países de Asia y el Pacífico, México se convirtió en el primero en unirse a la APEC en los países de América Latina, sino también para intensificar la presencia diplomática en China, con apertura del consulado en Shanghai por primera vez. Al mismo tiempo, en la parte china, para romper el bloqueo diplomático del Occidente para China en el inicio de la década de 1990, comenzó a dar mucha importancia a la relación estratégica con los países de América Latina. En mayo de 1990, el presidente Yang Shangkun visitó cinco países de América Latina, tales como México, Brasil, Argentina y otros, siendo la primera vez de visita de jefe de Estado en la región; México fue la primera escala, lo que muestra que la importancia del país en la diplomacia china. La visita exitosa del presidente Yang en México y otros países latinoamericanos verifica que la diplomacia china de fortalecer las cooperaciones estratégicas en los países en desarrollo, con el fin de romper el bloqueo diplomático de los países occidentales, tuvo éxito. Tres años después, 1993 fue un año histórico, porque se adquirieron mayor peso las relaciones entre China y México. En marzo y mayo, el ministro de Relaciones Exteriores chino, Qian Qichen, y el viceprimer ministro, Zhu Rongji, visitaron sucesivamente a México, y en diciembre de ese año, el presidente Salinas visitó de nuevo China. Este tipo y frecuencia de visitas de alto nivel fortalecen bastante la confianza mutua estratégica entre los dos países, y siguieron estableciendo el mecanismo de consulta política de relaciones exteriores entre dos países.

El presidente Zedillo asumió la presidencia en 1994, y debido a la profundización de la relación económica de México con Estados Unidos, la política exterior de México tuvo un importante ajuste, colocando poco a poco las relaciones con los EU como prioridad diplomática del país, y el crecimiento económico como prioridad interna, con lo que bajó la voz de antihegemonía y antiimperialismo. Durante el mismo periodo, China ha establecido el modo de desarrollo de la economía de mercado socialista con características chinas, debido a lo cual; China y México manifestaron una fuerte voluntad de compartir desarrollos económicos y sociales y la promoción de su comercio exterior. Por lo tanto, las dos partes en esta etapa focalizan las cooperaciones políticas en establecer principalmente los mecanismos de garantía para promover y asegurar cooperaciones económicas y comerciales y reducir fricciones mutuas. En octubre de 1995, el primer ministro Li Peng visitó México, y en noviembre del año siguiente, el presidente mexicano Zedillo visitó China. Al mismo tiempo, las consultas políticas entre el Ministerio de Relaciones 
Exteriores continúan permanentemente y el intercambio de visitas mutuas entre funcionarios a nivel ministerial también son más intensivos. Los dos países también firmaron muchos acuerdos cooperativos en las áreas de asuntos sociales, étnicos, telecomunicaciones, académicos, lucha contra las drogas, cooperaciones agrícolas, etc. En enero y noviembre de 1997, Hu Jintao, quien era miembro del Comité Permanente del Buró Político del Partido Comunista de China, y el presidente de entonces, Jiang Zemin, visitaron sucesivamente México. Durante las visitas de más alto nivel, China y México empezaron la planificación plena de relaciones de socios de cooperación integral bilateral. Durante el proceso, China tenía en cuenta que México es socio cooperativo de China en relación con la promoción de cooperación Sur-Sur, ajustamiento de relaciones NorteSur y el establecimiento de un nuevo orden internacional. México consideraba que el desarrollo de relaciones más estrechas con China pudiera tener importancia estratégica para atraer inversiones y oportunidades comerciales.

\section{Periodo de establecimiento y profundización de relaciones estratégicas (siglo XXI)}

En la elección presidencial de México en 2000, el partido político con poder más largo del mundo (71 años), el Partido Revolucionario Institucional, perdió, y ganó el candidato del opositor Partido Acción Nacional, Vicente Fox, quien tenía conocimientos de negocios y buena relación con Estados Unidos. Durante su administración, México continuaba ajustando la política exterior, determinando dos pilares de ésta: fortalecer las relaciones con EU e impulsar la diversificación diplomática. A China, hacia el nuevo siglo, le gustaría aprovechar la entrada en la OMC como una oportunidad para promover el desarrollos económico y social interno y la evolución multipolar del escenario internacional, para mejorar la adaptación e integración a la globalización. China y México tienen puntos en común en cuanto fortalecer el diálogo y la cooperación mutua, así como el establecimiento de un nuevo modelo de relaciones entre los países en desarrollo. En junio de 2001, se realizó la visita del Presidente Fox a China y en octubre él aprovechó la participación en la cumbre de la APEC en Shanghai para reunirse de nuevo con los líderes chinos. Durante este periodo, entre los dos países y con una fuerte presencia de la comunidad empresarial se efectuaba una serie de negociaciones intensas en relación con la entrada de China a la OMC. Gracias a la confianza política sólida, el problema finalmente se resolvió después de la visita del presidente Fox a China.

Después del incidente "9.11" de 2011, el enfoque estratégico de EU viró al Oriente Medio, por lo tanto la atención y el control de América Latina, incluyendo México, estaba en descenso. En este momento, gracias al crecimiento económico, México tenía deseos de convertirse en un líder regional, para lo cual necesitaría establecer con China un mecanismo de cooperación de mayor nivel. En febrero de 2002, el presidente Jiang Zemin y el presidente Fox intercambiaron cartas y telegramas para conmemorar el 30 aniversario de relaciones diplomáticas entre China y México. En mismo año, los dos Ministerios de Relaciones Exteriores celebraron la quinta consulta política, comunicándose profundamente en relación con la lucha contra el terrorismo, el Medio Oriente, la Península Coreana y otros aspectos de preocupación. México ha expresado en repe- 
tidas ocasiones que la relación con China no es de competencia, sino de asociación estratégica. En junio y octubre de 2003, el presidente Hu Jintao y el presidente Fox ha se reunieron dos veces, respectivamente en la Reunión Informal de Líderes del Norte y el Sur en Evian, Francia, y en la Cumbre de Líderes de APEC en Bangkok, Tailandia. En diciembre de 2003, el primer ministro Wen Jiabao visitó México, en su primera visita a América Latina. Durante la visita, los dos países anunciaron el establecimiento de relaciones de socio estratégico. Desde entonces, se profundizaría aún más la confianza política mutua y habría una cooperación más activa en los asuntos internacionales. México se ha convertido en uno de los socios políticos económicos y comerciales más importantes de China en América Latina. En agosto de 2004, China y México establecieron el Comité Permanente entre los dos gobiernos y firmaron un plan de acción conjunto para el periodo 2006-2010. En enero y septiembre de 2005, el presidente Hu Jintao y el vicepresidente Zeng Qinghong visitaron sucesivamente a México, marcando que las relaciones bilaterales han entrado en la mejor época en la historia.

En 2006, el Partido de Acción Nacional de México ganó de nuevo la elección presidencial, Calderón llegó al poder. En marzo de 2007, Li Changchun, uno de los líderes más importantes de China, visitó México y se reunió con el gobierno mexicano y el Congreso. En junio, el presidente Hu Jintao asistió a la Cumbre del G8+5, se reunió con Calderón y ambas partes reconocieron que tienen intereses comunes y amplios, bases políticas sólidas para la cooperación y perspectivas de desarrollo expansivas, además están dispuestos a seguir añadiendo nuevas áreas de cooperación, como el cambio climático, reforma del Consejo de Seguridad de la ONU y otros temas. En julio de 2008, el presidente Calderón realizó una visita de Estado a China y aprovechó para ver los Juegos Olímpicos en Beijing. Durante la visita anunciaron el establecimiento del diálogo estratégico entre China y México. En agosto de 2009 se realizó el primer diálogo estratégico entre China y México en la Ciudad de México y en julio de 2010 se celebró la cuarta reunión del Comité Permanente entre China y México en la Ciudad de México, durante la cual se firmó el "Plan de Acción Conjunta entre 2011 y 2015", con el fin de impulsar los intercambios relevantes y profundizar la cooperación y el desarrollo rápido en el área política. En enero de 2005 los dos países firmaron el “Tratado de Asistencia Penal Legal Mutua" y en julio de 2008 los dos Ministerios de Relaciones Exteriores también firmaron el "Tratado de Extradición entre China y México", con los cuales México se convirtió en el primer país latinoamericano que ha firmado acuerdos de extradición con China.

\section{Reflexiones sobre las relaciones políticas entre México y China durante cuatro décadas}

La relación política entre China y México por cuarenta años después de que establecieron relaciones diplomáticas ha reflejado los profundos cambios en la situación internacional y en sus respectivos modelos de desarrollo económicos y sociales internos, dentro de los cuales se destacan las cuatro características de la relación política entre China y México durante cuatro décadas. 
En primer lugar, la cooperación política entre China y México tiene un significado global. En la década de 1970, en que China y México establecieron relaciones diplomáticas, estaba en disputa la hegemonía de EU y la Unión Soviética, mientras se registraba el surgimiento del Tercer Mundo. Por lo tanto, la relación política entre China y México, ha reflejado plenamente la "cooperación Sur-Sur" entre los países en desarrollo. El establecimiento de socio estratégico también ocurrió en un gran ajuste del sistema internacional después del "9.11". En el periodo actual y futuro, como la crisis financiera mundial continuaba expandiéndose, los factores que afectaron a la economía mundial tendrán más incertidumbre. La estructura política internacional y la reforma del sistema financiero internacional están experimentando el mayor ajuste desde la Segunda Guerra Mundial. En este contexto histórico, se alentó la importancia y la necesidad de intensificar las cooperaciones estratégicas entre los principales países en desarrollo y economías emergentes, tales como China y México.

En segundo lugar, la cooperación política entre China y México podía impulsar los intercambios económicos y comerciales bilaterales. De las relaciones entre China y México, los periodos en que el comercio bilateral y el desarrollo económico tuvieron una velocidad relativamente rápida, la relación política bilateral se encontró en condiciones armoniosas. Cuando en 1986, el presidente mexicano De La Madrid, visitó a China, los dos países firmaron una serie de acuerdos económicos y técnicos, los acuerdos de crédito bancario de beneficio mutuo, para asentar la base sólida de relaciones bilaterales en la década 1980. En 1997, Jiang Zemin, Hu Jintao y otros líderes chinos visitaron México, impulsando las relaciones comerciales hacia un nuevo auge. En mismo año, entre China y México se firmó el "Acuerdo de Desarrollo de la Agricultura moderna Integral de la Empresa Xintian", que fue la primera vez que una empresa china efectuaba inversión agrícola a gran escala en México, elevando enormemente el nivel de cooperación económica entre las dos partes. Por lo tanto, bajo las condiciones de falta de complementariedad entre China y México, la interacción política desempeñaba un papel muy importante en la promoción económica.

En tercer lugar, la voluntad política y la capacidad decisiva de líderes de ambas partes pasa a ser un motivo y garantía importante para promover la cooperación política entre China y México. Del establecimiento de relaciones diplomáticas entre China y México, hasta la definición de socio estratégico, se ha reflejado plenamente la perspectiva amplia de los líderes de la vieja y la nueva generación. Fueron el presidente Echeverría y el primer ministro Zhou Enlai quienes en un momento crítico tomaron la decisión política firme de promover las relaciones entre China y México, de "romper el hielo". También el presidente Fox y el presidente Jiang Zemin, en otro momento histórico, con una visión global decidieron el establecimiento de la asociación estratégica hacia un nuevo siglo.

En cuarto lugar, la relación política bilateral todavía tiene una cierta vulnerabilidad. Aunque China y México tienen voluntad política para fortalecer las relaciones bilaterales, están muy lejos, y con las costumbres y los sistemas políticos tan diferentes, económicamente y diplomáticamente. México depende en gran medida de Estados Unidos. También México y China tienen una estructura económica similar y competitiva, pero a las empresas mexicanas, la academia y el pueblo mexicano le 
faltan muchos conocimientos sobre China, por lo tanto, entre China y México existen algunos problemas y dificultades. Por ejemplo, México se ha quejado de que el gran déficit comercial de China, la visita política del Dalai Lama repetida a México y en 2009 el mal entendimiento diplomático sobre la "gripe porcina", han reflejado plenamente que es necesario fortalecer la confianza política mutua.

En resumen, bajo la tendencia predominante de los intereses estratégicos similares y convergentes entre China y México, la cooperación, la solidaridad, la comunicación y el beneficio mutuo son la corriente principal. Por lo tanto, tenemos razones para creer que después de 40 años, la relación política sigue siendo generalmente armoniosa, y en el futuro será la base estratégica de la cooperación más amplia sólida.

\section{Bibliografía}

- Luo Rongqu, 1997, Historia de América, Editorial de la Academia de Ciencias Sociales de China.

-Wang Taiping, 1999, Historia diplomática de la República Popular China, Beijing, Editorial de Asuntos Mundiales.

- Feng Xiuwen, 2007, Relaciones entre China y México - Historia y Realidad, Editorial de la Academia de Ciencias Sociales de China.

-Wang Shengzu, 1996, Historia de Relaciones Internacionales, Volumen 10, Beijing, Editorial de Asuntos Mundiales, 1996.

- Garza Limón, 2001, México y China - Los testigos de la Amistad.

-Xu Shicheng, 1998, Bravos los Mexicanos, Beijing, Editorial de Asuntos Correntes.

-Xu Shicheng, 2003, Reformas Políticas y Económicas de México y Cambio del Modelo, Beijing, Editorial de Asuntos Mundiales.

-Huang Zhiliang, 2004, "Premier Zhou Enlai y la América Latina”, Beijing, Editorial de Asuntos Mundiales. 
Sección 7:

La experiencia de las entidades federativas y ciudades 



\title{
La relación China-México. La experiencia de la Ciudad de México
}

\author{
Tatiana Alcázar Carrasco
}

Los Estados Unidos Mexicanos y la República Popular China cuentan con una larga historia de relaciones amistosas y de intercambios comerciales y culturales. A mediados del siglo XVI iniciaron los intercambios a través de la nueva Ruta Marítima de la Seda que cruzaría el océano Pacífico hasta las costas mexicanas, intercambios que se han mantenido hasta la fecha sin interrupción. En febrero de 1972 México y la República Popular China establecieron formalmente relaciones diplomáticas, el tercer país latinoamericano en hacerlo, después de Cuba y Chile. El presidente Luis Echeverría se convertiría en el primer presidente latinoamericano en visitar Beijing en 1973. La década de los 90 alcanzó un nuevo nivel en la relación entre ambos países cuando en 1997 se logró un consenso para establecer una asociación cooperativa en todos los ámbitos ante la llegada del nuevo siglo, que culminó en 2004 con la formación de la Comisión Binacional Permanente.

A pesar de que las relaciones entre México y China han ido en aumento a lo largo del tiempo y el país asiático ha logrado erigirse como segundo mayor socio comercial de México, persistentes inconsistencias diplomáticas, políticas (retóricas) y económicas han ensombrecido las actuales relaciones con la República Popular China. En 1993, durante el sexenio del presidente Carlos Salinas se impusieron cuotas compensatorias superiores al 1000 por ciento a ciertos productos provenientes del país asiático. México se convirtió en el último miembro de la OMC en dar su visto bueno para el ingreso de China a este organismo. Durante los dos últimos gobiernos mexicanos, las continuas declaraciones sobre la economía de mercado y los derechos humanos en China, así como la recepción del Dalai Lama en todos los niveles de gobierno, generaron grandes molestias al gobierno chino. Las constantes tensiones y los desatinos diplomáticos no han permitido que la relación entre ambos países se consolide, pese a ser estratégica.

\section{La acción internacional de la Ciudad de México}

Desde el 2006 el Gobierno del Distrito Federal ha desplegado una estrategia internacional sin precedentes en la historia de la Ciudad de México. Los gobiernos anteriores contaban con alguna forma de vinculación con el exterior, sin embargo no fue hasta el 2006 que la acción internacional se convirtió en una política prioritaria transversal a todas las áreas de gobierno. La llegada de la globalización subraya la importancia de las interconexiones mundiales y plantea nuevas relaciones de interdependencia entre los procesos internacionales y locales, tomando en cuenta que los entornos urbanos son los principales núcleos de las relaciones humanas, producción de bienes y servicios e intercambio de información. Desde esta perspectiva podemos determinar que la internacionalización es un fenómeno global que se manifiesta localmente. 
Por lo anterior, los gobiernos locales hoy en día comienzan a ejercer un liderazgo que pasa en primer lugar por compartir información, buscar sinergias con otros gobiernos locales y realizar acciones concertadas en la búsqueda de una mayor eficacia y eficiencia en la utilización de los recursos y el impacto real de su acción exterior. En una época de escasez en que los recursos deben estar cada vez mejor gestionados, es necesario que los gobiernos locales sean capaces de diseñar y coordinar mejor sus acciones de política internacional, las ciudades y sus alcaldes ya no limitan su acción de gobierno a los límites comprendidos dentro de fronteras geográficas o administrativas. Los grandes desafíos de la humanidad se conjugan dentro de las ciudades, por lo que hoy en día el área de influencia de la ciudad es el planeta entero.

\section{La República Popular China y la Ciudad de México}

A partir de la visita realizada por el jefe de gobierno electo en 2007 a la República Popular China, la Ciudad de México elaboró una estrategia con el objetivo de fortalecer y profundizar las relaciones de cooperación e intercambio con el país asiático.

En segundo lugar, la firma del Convenio de Hermanamiento con la Ciudad de Beijing en $\mathbf{2 0 0 9}$ marcó otro importante hito en el acercamiento así como el inicio de un intenso intercambio entre ambas ciudades. Las actividades que se han realizado durante los últimos cinco años de gestión incluyen misiones oficiales que han visitado algunas ciudades chinas, especialmente Beijing, participación en foros organizados en ambas ciudades, recepción de numerosas delegaciones de distintas provincias del país asiático, firma de convenios en áreas específicas de cooperación, actividades culturales y becas para estancias de investigación en la República Popular China.

A continuación haremos un breve recorrido y descripción de las principales actividades que se han llevado exitosamente durante la actual administración.

\section{Misiones oficiales}

Durante los años posteriores a la firma del convenio con Beijing, numerosas visitas de altos funcionarios a la República Popular China tuvieron el objetivo de conocer las mejores prácticas en distintas áreas y participar en foros organizados por la capital china. Las más destacadas se enumeran a continuación:

- Encabezados por el titular de la Coordinación de Relaciones Internaciones, la directora general del Instituto de Ciencia y Tecnología y el Secretario de Turismo visitaron la ciudad de Beijing, con el objetivo de acercarse a sus homólogos chinos para compartir experiencias en estas áreas.

- Con el objetivo de inaugurar la participación de la Ciudad de México en el pabellón mexicano de la Expo Shanghai en 2010, una misión encabezada por el secretario de Desarrollo Urbano y Vivienda, la autoridad del Centro Histórico, la autoridad del Espacio Público y la directora general del Fondo Mixto de Promoción Turística 
viajaron a la ciudad de Shanghai. Al mismo tiempo se sostuvieron reuniones con los homólogos de cada una de las áreas en las que se realizó un intercambio de experiencias.

- Durante este mismo viaje, parte de esta delegación, sumando al titular de la Secretaría de Salud, visitaron la Ciudad de Beijing, donde sostuvieron reuniones y acercamientos con sus respectivas contrapartes.

- En julio de 2011, el secretario de Seguridad Pública organizó un visita a las ciudades de Beijing y Shanghai para conocer sus experiencias con respecto a la utilización de cámaras y sus respectivos centros de control, capacitación a través de las academias de policías, centros de investigación criminal.

- En diciembre de 2011 el director General del Zoológico de Chapultepec visitó China con el objetivo de negociar la firma de dos importantes convenios relacionados al Programa de Conservación del Panda Gigante en la Ciudad de México, el más exitoso fuera de la República Popular China.

- Otras visitas incluyen la participación en foros organizados por la Ciudad de Beijing, en temas como el deporte y las ciudades olímpicas, ciencia y tecnología, educación entre otros.

- Convenios específicos

- Derivado de las diversas misiones que visitaron el país asiático, se han firmado o están en proceso de firma convenios en las siguientes áreas:

-Zoológico de Chapultepec/Zoológico de Beijing: ambos zoológicos iniciarán un intercambio de especies, actualmente la Ciudad de México ha obsequiado dos xoloitzcuintles y se buscará generar un pabellón de especies mexicanas en el zoológico de la capital china.

- Se encuentra en proceso de firma un convenio con las autoridades del gobierno central de la República Popular China para el Programa de Conservación del Panda Gigante en la Ciudad de México. Técnicos chinos viajarán a la Ciudad de México para realizar la inseminación de uno de los ejemplares existentes en nuestro zoológico con el objetivo de que la cría producto de ello pueda permanecer en México y dar así continuidad a este programa.

- En materia de salud se encuentra en proceso de firma un convenio sobre medicina tradicional en el que se intercambiarían expertos de ambas ciudades para la capacitación respectiva de médicos chinos y mexicanos.

- Un convenio en materia de capacitación policía está siendo negociado para el intercambio de personal para la realización de estancias en las respectivas academias de policía.

-En el área del deporte existe un convenio en el que ambas ciudades están interesadas en intercambiar entrenadores de las distintas especialidades en las que cada país tiene mayor experiencia.

- La delegación Cuauhtémoc firmó durante el 2011 un convenio de cooperación con el distrito de Chaoyang, uno de los distritos de mayor importancia en Beijing.

-Durante la Cumbre de Alcaldes (CGLU) celebrada en noviembre de 2010, se firmó un memorando de entendimiento entre la Ciudad de México y la ciudad de Guangzhou, tercera ciudad de mayor importancia en China. 


\section{Misiones de la República Popular China a la Ciudad de México}

El acuerdo de los convenios mencionados anteriormente no hubieran sido posibles de no ser por las constantes visitas de delegaciones de nuestra ciudad hermana y de otras provincias chinas que nos han visitado con el objetivo de conocer las experiencias exitosas de la Ciudad de México. A continuación realizaré una breve enumeración de las más importantes visitas.

-Alcalde de Beijing en noviembre del 2009 para la firma del Convenio de Hermanamiento.

-Durante febrero de 2010 el vicealcalde de Beijing, visitó la Ciudad de México con el objetivo de ampliar la cooperación en materia deportiva, razón por la cual se propuso un convenio en esta materia.

- El alcalde de Kunming realizó una misión en marzo de 2010 para realizar intercambios de información en materia de protección civil y prevención de desastres naturales.

- En noviembre la visita del alcalde de Guangzhou hizo posible la firma del memorando de entendimiento entre ambas ciudades.

- Las provincias de Suzhou, Guangzhou, Shanghai, Shanxi, Chongqing, Tsingdao, han realizado visitas al Distrito Federal y se han reunido con numerosos funcionarios del Gobierno del Distrito Federal.

En lo referente a foros, la Ciudad de México, en conjunto con la Ciudad de Beijing organizaron en mayo del 2010 el primer Foro Ciudad de México Beijing "Hacia una Relación de Largo Plazo" con el objetivo de intercambiar información y experiencias para la solución de los desafíos que enfrentan ambas metrópolis. Este foro contó con la participación de más de 50 delegados provenientes de Beijing y con la participación de los titulares de las dependencias del gobierno del Distrito Federal, convirtiéndolo en el primer foro de esta naturaleza en América Latina.

\section{Actividades culturales}

La Ciudad de México ha realizado numerosas actividades culturales durante la administración actual. Numerosas exposición fotográficas, presentaciones artísticas en distintos importantes escenarios de la ciudad han sido promovidas. Asimismo, la Ciudad de México participó en la construcción del Arco Chino, ubicado en la Plaza Santos DegoIlado a espaldas de la SRE y la restauración del Reloj Chino, ubicado en Bucareli, regalo del gobierno chino.

Tal vez la más importante actividad cultural realizada con el apoyo del gobierno capitalino fueron los festejos del Año Nuevo Chino, con un desfile realizado en Avenida Reforma, con la participación de la comunidad local china. Durante tres años consecutivos este desfile promovió el acercamiento y la sensibilización de loa habitantes de la Ciudad de México respecto a este importante festejo chino, que no sólo ocurre en territorio de la República Popular China, sino en las capitales más importantes del mundo. 


\section{Becarios Ciudad de México-Beijing}

El gobierno de la Ciudad de México, en colaboración con el Centro de Estudios ChinaMéxico, instituyó un programa de becas para profesionales y funcionarios que realicen una estancia en China con el objetivo de desarrollar proyectos específicos sobre experiencias exitosas en el país asiático, mismos que son de utilidad en la práctica a la Ciudad de México. Este programa ha reunido a decenas de profesionales en distintos ámbitos que han concluido con éxito sus estancias y retornado a México con propuestas concretas de gran utilidad para la Ciudad.

\section{Conclusiones}

Los lazos de amistad y de cooperación entre la Ciudad de México cuentan hoy con una base en proceso de consolidación, puesto que existen intereses comunes. El gobierno de la Ciudad de México debe continuar enriqueciendo el contenido de la asociación estratégica que permita continuar con los intercambios de personas y de información entre las instituciones gubernamentales, las universidades y los centros de investigación. De igual importancia el fortalecimiento de los intercambios culturales es necesario para promover el conocimiento y el entendimiento mutuo, así como el acercamiento de las nuevas generaciones.

Es fundamental que la estrategia del Gobierno del Distrito Federal mantenga perspectivas amplias y una mirada de mediano y largo plazos con el objetivo de fortalecer la confianza mutua y profundizar la cooperación con la cual se beneficiarán mutuamente. 



\title{
Puerto Chiapas. Puente logístico para China en México y Centroamérica
}

\author{
Flor de María Cañaveral Pedrero
}

En recientes eventos y acontecimientos históricos de la Administración Portuaria Integral en Puerto Chiapas, ésta ha promovido su dinámico desarrollo como puerto multipropósito en el Pacífico Mexicano celebrando su consolidación en los sectores de cruceros y carga, toda vez que los muelles de las terminales de cruceros, contenedores y usos múltiples se encuentran ocupados por embarcaciones que realizan operaciones de descarga, así como maniobras de importación y exportación, las cuales en algunas ocasiones se realizan de manera conjunta gracias a su infraestructura, que le permite desarrollar las actividades turísticas y de carga de una manera simultánea.

Puerto Chiapas tiene características únicas que lo hacen una excelente opción multimodal, está ubicado en el Océano Pacifico a 43 kilómetros de la frontera con Guatemala, el aeropuerto internacional se encuentra a tan sólo 10 kilómetros y la vía del Ferrocarril opera en paralelo a los muelles, lo que lo convierte en un corredor logístico multimodal de gran importancia para el desarrollo del comercio internacional.

Uno de sus objetivos primordiales es consolidarlo en el intercambio comercial con la Cuenca Asia-Pacifico, por lo que se destacan algunos rubros que se desglosan a continuación.

En el sector pesquero han atracado buques camaroneros, así como embarcaciones propiedad de las empresas Herdez del Fuerte y Procesa, las cuales realizan maniobras de descarga de atún, materia prima para el proceso del enlatado que distribuyen a nivel nacional e internacional, etc.

Es importante destacar que en 2011 y como apoyo a este sector en los muelles de pesca, se realizan trabajos de rehabilitación de banquetas, accesos, enmallado perimetral, casetas de vigilancia, así como reforzamiento de pantallas en muelles, bitas, alumbrado y se contará con un almacén de residuos peligrosos que dará servicio a esta zona, priorizando el compromiso de inversión por parte del Gobierno Federal en esta zona y el cuidado al medio ambiente que por muchos años se descuidó.

Estamos preparando el camino, un recorrido largo, pero efectivo, acompañado de una promoción de nuevas inversiones y atracción de nuevos capitales del mundo, pero principalmente de Asia.

Puerto Chiapas no sólo se ha enfocado a la pesca y carga, sino también al tema de cruceros, un sector nuevo que data de 2006: desde el inicio de este sector en la región se han recibido cruceros de los compañías más importantes del mundo y ha tenido un crecimiento de $\mathbf{2 4 0} \%$ en los últimos cinco años; un ejemplo son los navíos, uno procedente de Puerto Caldera, Costa Rica, transportando 605 pasajeros y 402 tripulantes; se trata de un crucero de primera clase, propiedad de la línea naviera Oceanía Cruises de bandera de islas Marshall, con eslora de 180 metros, 28.3 metros de manga y 30,277 toneladas de registro bruto, en su interior hay 342 suites, 4 restaurantes, spa, albercas, 
salones y barras, casino, gimnasio y estética; el segundo de ellos es el buque Seabourn Odyssey, propiedad de la línea naviera Seabourn, procedente de Puerto Quetzal en Guatemala, con el que se concluyó exitosamente la temporada 2011 de cruceros por el Puerto, dando paso al inicio de la temporada 2012, en la cual se mantendrá la tendencia de operaciones en este sector.

Así, se promueve la industria naviera de cruceros de manera coordinada con cinco países centroamericanos en el desarrollo de una nueva ruta denominada Ruta Mesoamericana, la cual pretende desarrollar los destinos de Costa Rica, Nicaragua, El Salvador, Guatemala y México en los puertos de Chiapas y Guatemala.

2010 fue un año histórico para el sector de carga, pues en él se inició el movimiento de 12,000 toneladas de maíz, lo que detonó la oportunidad de promover el desarrollo de una terminal que contará con áreas de almacenamiento especializadas en este sector; es así como el 13 de septiembre se firmó un contrato de Cesión Parcial de Derechos que estima una inversión de 140 mdp dentro del recinto portuario y considera contar con una capacidad inicial para almacenar 25,000 toneladas en silos con un rendimiento de 600 ton/hr. Así también se iniciaron operaciones del buque Patojo de bandera de Panamá, tipo carga general de 1,639 toneladas de registro bruto, que realiza el proyecto de Short Sea Shipping, exportando chatarra con destino a Puerto Quetzal.

Como otro proyecto histórico para Puerto Chiapas está la operación en ruta regular del buque porta-contenedor MV CFS Desiree de la línea naviera Hapag Lloyd, el cual cuenta con 15 mil 636 toneladas de registro bruto (TRB), 161.09 metros de eslora, con capacidad de recepción de 1,304 TEU, programado para exportar 3,960 toneladas (160 contenedores) dentro de lo que destaca mineral de titanio, café y miel; también realizará la importación de un contenedor con cuatro toneladas. Puerto Chiapas, integrado con equipo altamente capacitado y calificado en coordinación con los actores principales en las cadenas logísticas y los tres niveles de gobierno responde a las necesidades de los clientes internacionales demostrando que está preparado para recibir grandes proyectos atendiéndolos con un excelente servicio y estándares de calidad mundial y principalmente de China.

Hoy, Puerto Chiapas, corredor logístico multimodal entre México y Centroamérica hacia el mundo, ha buscado nuevas formas e innovadores mecanismos para el fomento económico, no sólo de Chiapas, sino de todo nuestro país.

Puerto Chiapas logra un volumen de carga comercial contenerizada de más de 17,000 toneladas en lo que fue el año 2011, consolidándose en el movimiento de contenedores a diversos países como EU, Alemania, Holanda, Japón, Austria, Suiza, Nueva Zelanda, Costa Rica, Inglaterra y China, entre otros lugares.

Por lo anterior, Puerto Chiapas continúa trabajando con diversos sectores productivos de la zona y región del soconusco e impulsando con entusiasmo su opción ante China.

En mayo de 2011 se tuvo la visita de cortesía de Yang Mengbin de la Región de Dongying en nuestras instalaciones marítimas. Parte de los trabajos de encuentros e invitaciones a Puerto Chiapas por parte de la Confederación de Asociaciones Chinas CACHIMEX y el Instituto Nacional para el Federalismo Inafed-Secretaría de Gobernación. 
Exactamente al cumplirse un año (mayo 2010) de haberse firmado la primera carta de intención de hermanamiento entre el municipio de Tapachula y Dongying, para quienes suscribieron los acuerdos para dar los primeros pasos de esta relación, ha sido pieza clave Puerto Chiapas para la región de la costa y centro del país, al establecer vínculos que han permitido resultados importantes en la creación de alianzas estratégicas para los municipios mexicanos con los asiáticos. El 5 de mayo de 2011 correspondió al alcalde de Tapachula, Emmanuel Nivón, recibir a su homólogo Yang Mengbin de Dongying, con quien después de estampar la firma donde acredita el acuerdo de hermanamiento por ambos pueblos, establecieron el intercambio en comunicaciones futuras que ayuden el fortalecimiento y el desarrollo económico.

Un detalle positivo más es que Puerto Chiapas tiene ya en sus manos una presentación en idioma chino sobre las actividades y oportunidades que ofrece a China en materia de intercambio cultural, económico, social, financiero, educativo y de transferencia tecnológica, así como para fortalecer la campaña de atracción de inversiones a las bondades de Puerto Chiapas a través del proyecto portuario.

Por ello no puede pasar desapercibido que la Expo China-México, es un espacio en donde las administraciones portuarias nacionales (API) han participado para establecer alianzas estratégicas con contrapartes chinas, lo que les ha permitido ubicar sus productos agrícolas, pesqueros, artesanales, turísticos, automotriz, entre otros.

Es importante mencionar que API-Puerto Chiapas ha participado en las ediciones 2009, 2010 y 2011 de Expo China. Así como en la Expo Asia-Pacífico, donde Rusia ha mostrado buenos ojos hacia México en el tema comercial marítimo, y se han logrado hacer contactos estratégicos para el desarrollo portuario.

Por lo anterior, también Puerto Chiapas ha sido testigo de que empresarios chinos establecen negocios oportunos; uno de esos apoderados es el empresario Julio Yi Qiu, quien estableció junto con el presidente de la Asociación de Productores y Exportadores de Rambután de Chiapas, Alfonso Pérez Romero, la venta de mil quinientas toneladas de rambután, con la posibilidad de adquirir otra cifra similar para el segundo semestre del año, enviados por tierra, con la esperanza de poder enviar mayores cantidades a China vía marítima.

La salida del primer embarque se dio en el marco de la celebración del Encuentro de Hermandad México China: Tapachula-Chiapas y Dongying Shandong, que se celebró el 5 mayo en Tapachula, y a partir de ahí se calcula que mediante esa empresa asiática representada por Qiu, se enviarán a los mercados chinos de Estados Unidos y Canadá, unas 100 toneladas de rambután cada semana.

En los últimos cuatro años Puerto Chiapas ha tenido un crecimiento del $240 \%$ y tan sólo en este año 2012 se espera concretar el arranque de inversiones cercanas a los 500 millones de pesos en diferentes proyectos de carga y turísticos.

En este sentido, hemos recibido 24 cruceros al año (2011), promoviendo la ruta mesoamericana, los destinos de Centroamérica en la costa del Pacífico. Otro de los sectores es el granel agrícola: se licitó una terminal especializada que tendrá dos silos para almacenar hasta 25 mil toneladas de maíz, en especial. Destaca que en la terminal especializada se podrán mover hasta 100 mil toneladas de granos, lo que implicará una inversión privada de 160 millones de pesos. 
China y Venezuela, nuevos socios comerciales en Centroamérica, tendrán un impacto positivo para el mercado mexicano. Aunque Estados Unidos sigue siendo el principal socio comercial de Centroamérica, en la región han surgido nuevos actores comerciales, datos revelados por la Secretaría de Integración Económica Centroamericana SIECA, revelan un intercambio comercial de Centroamérica en 2010 que integra las exportaciones e importaciones por un monto de 49,259 millones de dólares, equivalente a un crecimiento de $4.85 \%$ respecto al 2009.

La SIECA indicó que con excepción de Honduras, en todos los países de la región se incrementó el intercambio comercial y es Nicaragua la nación que registra el mayor crecimiento relativo al 12 por ciento. Las exportaciones totales de 2010 alcanzaron los 22,143 millones, superando en 2,280 millones de dólares las de 2009. Las importaciones totales fueron de 44,247 millones de dólares, superiores en $18.9 \%$ al 2009 y de ellas 8,133 millones de dólares fueron en combustibles, que representa el $18.39 \%$ del total de las mismas.

De acuerdo con dicho intercambio comercial, los principales socios comerciales de esta región son Estados Unidos, Mercado Común Centroamericano (MCCA), Unión Europea (UE), México, Panamá, Hong Kong, Canadá, China y Venezuela.

Es importante resaltar que en 2011 los gobiernos de México, Costa Rica, El Salvador, Guatemala, Honduras y Nicaragua dieron su aval al Tratado de Libre Comercio entre México y Centroamérica, el cual establecerá un mercado potencial de 150 millones de consumidores. Y China no podrá quitar los ojos a esta enorme oportunidad de apertura del mercado mexicano, probablemente entrando por Puerto Chiapas. El pasado 22 de noviembre de 2011 se aprobó el tratado; no obstante, se firmó la declaración presidencial alusiva a la entrada en vigor del TLC. El presidente Felipe Calderón dijo que las seis naciones que conforman el bloque han tenido un intercambio comercial que creció casi cuatro veces en los últimos 10 años y en 2010 alcanzó un valor de 6,554 millones de dólares.

Firmaron la declaración los mandatarios de México, Felipe Calderón; Guatemala, Álvaro Colom, y Honduras, Porfirio Lobo, así como representantes de las otras tres naciones. El secretario de Economía, Bruno Ferrari, destacó en su momento los beneficios del acuerdo comercial y explicó que las importaciones en la región (México y Centroamérica) registraron el año pasado 350,000 millones de dólares y 328,000 millones en cuanto a exportaciones.

Esto facilitará y aumentará el comercio, pues se homologaron las reglas entre los países. Con esto habrá sólo una normatividad, un certificado de origen y una instancia de interlocución, lo cual permitirá acomodar todavía a México como el más cómodo geográficamente con Asia en la relación con Centroamérica.

Puerto Chiapas es un corredor logístico multimodal que potencializará la relación de México con Asia y los nuevos acuerdos, tratados y convenios. Pondrán a la API chiapaneca a la altura de cualquier puerto del planeta.

Derivado del trabajo en conjunto de los tres niveles de gobierno: municipal, estatal y federal, y como resultado del cierre de negociaciones entre la empresa Mazapa Obras y Proyectos con empresarios chinos, Puerto Chiapas se abre camino al mundo del mineral, con los primeros movimientos de operación de este importante recurso, ya 
que desde el 1 de julio de 2011 se recibieron las primeras 16,640 toneladas de titanio, considerándose realizar un primer embarque en la historia del puerto a finales de julio a través de la línea naviera Hapag Lloyd embarcando de manera contenerizada 1,684 toneladas del mineral, con destino final Beijing Xingang en China.

Estas acciones detonarán las operaciones a granel del mineral para su exportación a través de Puerto Chiapas hacia el mundo o viceversa.

Se han expuesto varios proyectos en camino con la naviera Hapag Lloyd y se asegura que se seguirán exportando productos como café y banano desde este recinto portuario, en especial el café de la Asociación Ismam.

Hasta el momento se han movilizado grandes cantidades de contenedores cada catorce días, además existe el interés de otros empresarios por invertir en Puerto Chiapas para crear otras empresas dedicadas al transporte de mercancías: logística de altura.

Como parte de los trabajos coordinados entre el gobierno de Tapachula y del estado de Chiapas, el alcalde Emmanuel Nivón González en compañía de la titular de la Secretaría para el Desarrollo de la Frontera Sur, Andrea Hernández Fitzner, dieron el banderazo de inicio de actividades de la empresa naviera Hapag-Lloyd, misma que permitirá el envío de productos chiapanecos hacia diversos países del continente asiático.

En el marco de las instalaciones del Recinto Fiscalizado de la Administración Portuaria Integral (API), el munícipe tapachulteco calificó de exitosas las políticas del gobernador del estado, Juan Sabines Guerrero. “Nosotros como pueblo y Gobierno de Tapachula, estamos muy contentos porque el lema que dice nuestro señor gobernador que la unidad da buenos resultados, hoy se ve plasmada en los hechos" agregó- Emmanuel Nivòn, en su discurso; el alcalde señaló "agradezco a la empresa Hapag-Lloyd la confianza de invertir en Chiapas, con estas acciones tenemos la plena confianza de que más empresas establecerán sus actividades comerciales en este rincón del estado de Chiapas y continuar posicionando a Puerto Chiapas como un puerto exitoso."

La paz social que se vive en la entidad ha sido factor clave para que empresas de todo el mundo volteen y decidan establecer vínculos comerciales con los productores chiapanecos, esto también le da certidumbre a las nuevas inversiones que pueden darse en el país. Puerto Chiapas, parte de la infraestructura de la Secretaría de Comunicaciones y Transportes SCT, comanda las tareas estrategias implementadas por el presidente Felipe Calderón y el gobernador Juan Sabines Guerrero, dando excelentes resultados; actualmente el clima de seguridad y paz social ha permitido que más empresas volteen a ver a nuestro puerto, como una entidad digna y amigable.

Desde el Puerto Chiapas hemos impulsado la promoción económica y fortalecemos nuestro porvenir, ejemplo de ello es que partió el contenedor de la Naviera Hapag Lloyd con el Barco Dessire, que hará escala y transbordo en Manzanillo para posteriormente pasar por el Canal de Panamá llegando a los puertos europeos de Le Havre. Este primer envío, de cuatro programados a lo largo de un año, en global se cotiza en más de 200 mil euros, siendo un estimado de cuatro millones de pesos, beneficiando a los 250 productores de los municipios chiapanecos de Tuzantán, Huehuetán, Tapachula, Mazatán, Villacomaltitlán, Escuintla y Acapetahua.

La empresa compradora Chocolaterie Cluzeil es una de las industrias más significativas e históricas de Francia y sus productos se distribuyen en todo el mundo; después 
de un arduo y paciente proceso de acreditación y verificación de la calidad, se llegó al compromiso de adquirir un pedido de más de 50 toneladas repartidas en un contenedor cada 6 meses con precios casi al doble de la bolsa de Nueva York, derivado de la calidad del cacao criollo del Soconusco, donde los productores reproducen sus árboles sólo con semillas nativas, que son las que garantizan un mayor sabor y aromas florales.

China es y será un objetivo común de la región y nuestras experiencias exitosas son de suma importancia. Puerto Chiapas cumple con impulsar el desarrollo económico de la región, promoviendo la consolidación de un puerto multipropósito competitivo que ofrezca infraestructura y servicios portuarios, con un equipo de trabajo comprometido en satisfacer las necesidades de los usuarios y el cuidado al medio ambiente. Un dato curioso que ha llamado mucho la atención es que Beijing Hualin, compañía de China, se ha interesado por Puerto Chiapas para negocios posibles este 2012 por dos simples razones: su ubicación estratégica y por su recinto fiscalizado, que llama mucho la atención al estar en un puerto marítimo.

El Grupo Saneamiento Ambiental de Beijing, como un conjunto industrial especializado en la fabricación de equipos de saneamiento, tiene el propósito de fortalecer la inversión estratégica y la ampliación de negocios con México y Centroamérica, así como promover un desarrollo industrial en cada segmento de negocios, especialmente en la llegada de manufactura de equipamientos, teniendo como precursor la mano de obra y la tecnología mexicana para la fabricación de camiones de basura para ciudades diferentes y con necesidades de limpieza diferente.

Es así como se puede entender la relación trascendental y estratégica que existe entre Puerto Chiapas y China, la historia ha permitido observar que existe una estrecha vinculación a través de su cultura, tradiciones y hoy día se ha de fomentar una relación más productiva en el desarrollo industrial y comercial. Demos paso al futuro, en el cual se puede vislumbrar un constante crecimiento y confianza entre las nuevas relaciones comerciales. 


\title{
La experiencia de la AMSDE con el programa de negocios México-China
}

\author{
Gustavo Adrián Carrillo Jiménez y Misael López Vergara
}

En México han existido pocas políticas públicas que estimulen un intercambio de negocios entre México y la pujante República Popular de China, que es uno de los líderes del crecimiento económico mundial y representa un enorme potencial como aliado estratégico para los países, dado el gran tamaño de su economía.

En 2005 el gobierno del estado de Michoacán desarrolló un programa piloto que tenía como objetivo explorar el potencial del mercado chino y detectar oportunidades de negocios de México hacia China.

En 2006 la Asociación Mexicana de Secretarios de Desarrollo Económico (AMSDE) adoptó y mejoró el programa piloto para pasar a ser un programa nacional de negocios con la República Popular de China denominado Programa Formación de Negocios México-China, que tenía como principal objetivo capacitar a profesionistas y líderes mexicanos, formando agentes de cambio que fueran especialistas en negocios MéxicoChina y poder enfrentar este fenómeno mundial, generando oportunidades en el mercado chino y preparando recursos humanos que pudieran ser aprovechados por el sector gubernamental y el sector privado, llevando a México a un contexto global competitivo.

Para cumplir con tal próposito se establecieron alianzas estratégicas de primer nivel con la academia, gobierno y el sector empresarial a nivel nacional, a través de la firma de convenios de colaboración entre AMSDE y la Secretaría de Economía y sobre todo con el Cechimex de la UNAM, dirigido por el prestigiado académico y experto en los temas económicos entre ambas naciones, Enrique Dussel Peters.

De 2005 a 2010 a través de la AMSDE, con recursos del Gobierno Federal, de la Secretaría de Economía, de los gobiernos estatales, se impulsó este programa con las formación de 209 especialistas con la participación de 14 entidades federativas: Michoacán, Colima, Sinaloa, Quintana Roo, Tlaxcala, Nuevo León, Estado de México, Hidalgo, Chihuahua, Tabasco, Yucatán, Distrito Federal, Zacatecas y Chihuahua.

En términos generales, se cumplió con dos objetivos: crear vínculos comerciales para las empresas mexicanas para ampliar sus mercados e investigar las mejores prácticas empresariales y gubernamentales que pudiesen contribuir a la competitividad nacional.

En el tema comercial se llevó a cabo una amplia serie de acciones entre las que encontramos: representación de empresas mexicanas a través de la participación en expos o ferias y como representantes comerciales para negociaciones; se apoyó a ProMéxico en actividades de promoción y atención a delegaciones empresariales mexicanas, además de contribuir en la búsqueda de proveedores de maquinaria y materias primas que pudiesen complementar los procesos de las empresas mexicanas.

La investigación y análisis de mejoras prácticas consistió fundamentalmente en dos acciones: la primera en una serie de visitas a empresas e instituciones para explorar 
áreas tales como procesos productivos, formas de hacer negocios con países asiáticos, logística, planeación y atracción de la inversión. La segunda fue tomar cursos especializados en materia de economía y política china. Los aspectos comerciales y la investigación y análisis de las mejores prácticas no hubieran sido posibles sin que los participantes acudieran a clases intensivas de mandarín y participaran en actividades culturales para tener una mayor comprensión de la idiosincrasia de la población de China.

Actualmente, los egresados del programa poseen una visión más amplia y tienen conciencia del escenario económico global que les toca vivir, en el que ser competitivos es requisito indispensable para la subsistencia. En ese sentido, se desempeñan exitosamente como propietarios de empresas de exportación e importación, gerentes de logística, funcionarios públicos en áreas de comercio exterior y atracción de la inversión, por mencionar algunos.

El desarrollo de este tipo de programas que combinan elementos económicos y educativos son una excelente estrategia que permite complementar el desarrollo económico de un país, y sus beneficios son palpables, además de que se siembran semillas para la creación de generaciones de jóvenes altamente competitivos internacionalmente.

El programa Formación de Negocios México-China sentó un precedente de política pública exitosa, emanado de las entidades federativas, con diversas áreas de oportunidad que deben mejorar y evolucionar conforme se van requirendo y van madurando las relaciones comerciales entre ambos países.

Por tal motivo, en 2010 la AMSDE decidió hacer un paréntesis al programa para hacer una revisión y analisis de los verdaderos alcances que se pretenden, para lo cual se tiene la intención de trabajar coordinadamente con el Cechimex y poder lanzar un nuevo programa, más fortalecido en todos los sentidos, con objetivos claros que lleven a otro nivel la relación de negocios entre ambas naciones y que en un mediano plazo pudiera ser replicada hacia otras naciones tales como India o Corea del Sur, de los que podemos aprender sobre atracción de la inversión y tecnología. 


\section{Las acciones gubernamentales tejen las relaciones comerciales}

Ricardo Chang Gamboa

China o la República Popular de China se abre al mundo bajo el escenario inevitable de ser la referencia de segunda potencia económica. Es la gran fábrica del mundo actual, con enormes posibilidades de desarrollo para el pueblo y sus empresas parasubnacionales.

El concepto "parasubnacional" está enfocado desde lo local, esto quiere decir que China ha mostrado al mundo un nuevo enfoque de hacer negocios, definición única en el planeta y que en México lo vivimos día a día. Los chinos salen a promover sus respectivas empresas a través de agentes gubernamentales de sus mismas localidades.

Dichas delegaciones son recibidas en nuestro país por instituciones como la Confederación de Asociaciones Chinas en México (Cachimex), la Cámara General de Empresarios Chinos en México y el Instituto Nacional para el Federalismo y el Desarrollo Municipal (INAFED), órgano desconcentrado de la Secretaría de Gobernación.

Este ultimo, el INAFED-SEGOB, juega un papel muy importante al ser una instancia sensible a las necesidades de los municipios, los cuales acuden y desean encontrar la herramienta perfecta para atraer inversión y desarrollo a sus regiones.

María del Rosario Castro, directora general del INAFED-SEGOB, ofrece a los gobiernos subnacionales: estados o municipios, la posibilidad de promoverse y poder cumplir básicamente dos metas: una es el objetivo fundamental de su Plan de Desarrollo Municipal y la segunda es la generación de empleos que en cada rincón de las regiones se necesitan para vivir mejor.

Las tareas son enfocadas a que cada gobierno se promueva por sí solo de la mano con los presidentes municipales y los gobernadores. EI INAFED fortalece esta tarea al ser recinto oficial respecto a los encuentros gubernamentales subnacionales, nada más.

Recordaremos que la parte del negocio la ven los empresarios, después del primer acercamiento entre gobernantes. En el INAFED sólo se ve la parte gubernamental entre ambos pueblos, de ambos países.

Sin duda, la Cachimex, en representación de Jimmy Li, quien es el secretario general de la misma, asume el papel de puente entre las delegaciones gubernamentales de China y las contrapartes mexicanas, que comúnmente son los alcaldes, secretarios de Desarrollo Agropecuario, Económico y regidores de distintas comisiones legislativas de los ayuntamientos.

La experiencia revela que a veces ni siquiera la contraparte mexicana o el representante del municipio tiene el pequeño detalle de saber con quién se va a sentar en el INAFED, con qué representantes de China va tratar, a pesar de que se les envía la información y lista de los distinguidos asiáticos, y mucho menos entiende que estas delegaciones vienen de viajes de hasta 30 horas de vuelo y llegan de manera puntual. 
Con este ejemplo deseo ejemplificar que la cultura de la puntualidad sigue siendo como antes y hoy, un problema que no hemos atendido. Pareciera que los funcionarios asistentes tan sólo van por la foto y decir que están cumpliendo con su función de buscar beneficios para su pueblo.

Al llevarse a cabo reuniones de trabajo entre la Cachimex y el INAFED, con delegaciones chinas y mexicanas no se asume un compromiso económico; el asistir o participar en dichas interlocuciones no se cobra. Ambas instituciones no tienen fines de lucro, por tanto estos acercamientos no tienen precio.

\section{Lo que no te cuesta no lo valoras}

China ha buscado una serie de mecanismos para hacer negocios con México y el mundo, pero tan sólo bastaría con hacernos unas preguntas muy importantes para definir con qué mentalidad China sale a buscar amigos. China primero busca amistad, después negocios, razón por la cual primero salen sus agentes gubernamentales y después vienen los empresarios asiáticos.

¿Cómo se percibe a China en el mundo y en México, qué elementos conforman esa percepción? Si desea ser percibida de otra manera, ¿qué hace para lograrlo y con qué elementos?

Durante miles de años China ha querido estar aislado del mundo. Pero ahora China quiere ser percibido como un país que busca cooperación y complementariedad con el mundo.

China no quiere y no puede crecer solo. A diferencia de Estados Unidos, China no tiene una política imperialista. China quiere ser percibido como el país amigo y aliado. A pesar de ser un país rico en cultura e insumos, hay deficiencias, razón por la cual busca la ayuda de otros países.

China quiere aprender del mundo occidental y a su vez obtener los insumos y apoyos necesarios para crecer y volver a representar la cultura prominente que ha sido durante miles de años.

Para poder trabajar con el mundo occidental, China ha realizado intercambios en todos los niveles, culturales, comerciales, académicos, políticos, etc., mediante programas en México, como el Instituto Confucio, plataformas políticas como la Expo China-México e inversiones en sectores de infraestructura en países de África y Sudamérica.

Actualmente, con la crisis financiera, China está contribuyendo positivamente como la segunda potencia económica del mundo manteniendo un crecimiento del $8 \%$ con políticas socialistas certeras y manteniendo políticas monetarias responsables del yuan. Se está trabajando rápidamente para la convertibilidad del yuan para poder solidificar el sistema financiero mundial, ejemplo ya hay operaciones de yuan con Brasil y Nigeria, país que anunció que el $10 \%$ de sus reservas serán en yuanes. A medida que los países del mundo, en especial los BRIC (Brasil, Rusia, India y China) confíen en la política china y la moneda china, el mundo podrá seguir su paso de crecimiento interrumpido por la crisis financiera americana.

China volverá a ser la potencia mundial que contribuirá en forma decisiva al crecimiento mundial como lo fue hasta el siglo XVIII. Actualmente, China ha logrado enseñar 
al mundo el nuevo modelo socialista que separa lo político (socialista) de lo económico (capitalista), que es una fórmula para el crecimiento mundial para países en desarrollo como México.

Además, China está produciendo productos tecnológicos más accesibles para países en desarrollo como maquinarias agrícolas, maquinaria de construcción, equipos de telecomunicaciones, industria automotriz, entre otros.

\section{La forma de hacer negocios con China entre entes gobernantes}

De acuerdo con el sistema socialista chino, los grandes negocios e inversiones son apoyados y avalados por todos los niveles de gobierno, lo que es un esquema diferente al manejo económico en México. Por esa razón no se ha producido un intercambio comercial favorable a México. La Expo México-China ha estado trabajando arduamente para involucrar a los tres niveles de gobierno mexicano para poder concretar las inversiones chinas y así ayudar a mejorar la balanza comercial reciproca.

Muestra de ello son los trabajos y avances en algunas provincias de nuestro país como Veracruz, Chihuahua, Baja California Sur y Chiapas, entre otros. Este último estado del sur de México ha generado una apertura de suma importancia, particularmente entre las autoridades del municipio de Tapachula y la Administración Portuaria Integral API-Puerto Chiapas.

La API-Puerto Chiapas es un esquema de suma importancia, ya que dentro de las mismas instalaciones se localiza un Recinto Fiscalizado Estratégico, el cual es único en nuestro país al estar asentado precisamente en un puerto marítimo.

Dicho Recinto Fiscalizado Estratégico es administrado por el gobierno estatal de Chiapas, en una alianza estratégica oportuna en la cual participan los tres niveles de gobierno: municipal, estatal y federal.

Tales entidades gubernamentales han tenido y generan las ocasiones de poder hacer lazos comerciales con China que representan un enorme potencial para atraer la inversión de Asia por la situación y posición geográfica estratégica.

API-Puerto Chiapas, puerta del sur de América y ventana de vinculación con Estados Unidos, ve con buenos ojos la posibilidad de relacionarse y plantarse como una alternativa viable para la manufactura China en México.

Las políticas públicas juegan un papel muy importante, pero lo que realmente define el aterrizar los acuerdos es la voluntad de hacer las cosas. En el INAFED nos hemos propuesto en conjunto evangelizar a los gobiernos subnacionales con tres cosas: primero si deseamos en verdad atraer inversión China debemos cambiar nuestra mentalidad. Segundo, ser lo más puntuales en las reuniones, los amigos chinos viajan de tan lejos y son siempre los primeros en llegar, mientras las contrapartes mexicanas que están a dos o tres horas de distancia del Distrito Federal, casi siempre llegan tarde. Tercero, hacer reformas locales y generar un ambiente viable para negocios. Lo que se sugiere es que tanto los municipios como los estados modifiquen sus leyes, reglamentos o normas en relación con la atracción empresarial. 


\section{La sugerencia determina el buen camino de los negocios}

El consejo a los municipios y estados es que reformen en el caso de los ayuntamientos su bando de buen gobierno e integren un transitorio en el cual le den certeza jurídica a las inversiones chinas y no chinas y den apertura a horizontes para mercados potenciales.

En el afán de hacer bien las cosas es importante ofrecer a los agentes económicos de China documentos que acrediten que el municipio siempre toma en cuenta a todas aquellas culturas y países como amigos. Muestra de ello es que en el Plan de Desarrollo Municipal se plasme la búsqueda y la cooperación internacional hacia la asistencia técnica y mejora de la localidad.

Para el caso de los gobiernos provinciales o estatales se sugiere enviar permanentemente iniciativas al Congreso Legislativo local reformas y sugerencias para la atracción de capitales financieros chinos. Es necesario que en los estados se aprueben leyes y se tengan apartados específicos México-China con la finalidad de hacerlos sentir que nos interesan sus inversiones, pero que también lo tenemos plasmado, que deseamos ser sus amigos a la buena. La Presidencia de la República a través de Felipe Calderón manda el mensaje exacto para atraer más inversión extrajera y especialmente la China: en marzo de 2009 el Senado de la República aprobó la Ley Recíproca de Inversión Extranjera entre México y China, hecho que marca la nueva relación entre ambos pueblos, con seguridad legislativa y políticas financieras viables. Lo anterior, trae como consecuencia que el esfuerzo de otros organismos o dependencias empresariales se concrete al reconocer a China como un aliado estratégico y no como un competidor desleal.

Se pueden citar muchos ejemplos, sólo por mencionar alguno, el municipio de Tecomán-Colima, trabajó su restructuración jurídica de promoción empresarial y puso en la mira a China como un país miembro de la APEC, donde China y México son países miembros; las autoridades locales comenzaron armar este rompecabezas oportuno. Tecomán se dio cuenta cuenta de que además de pesca y agroindustria, existen otras posibilidades de atracción de inversión y crecimiento, como el turismo hacia sus bellas playas, donde también existe una nutrida comunidad de cocoteros que día a día se esfuerzan en sacar a sus familias adelante. He ahí un ejemplo de suma importancia de análisis e invitación a los demás municipios y estados a que conozcamos más a China y que aquéllos redescubran su vocación productiva.

\section{Crisis es igual a oportunidad}

El Gobierno Municipal de Tecomán se acercó al INAFED para buscar cooperación internacional y atinadamente se le sugirió el tema de China, por lo que recurrió a la Cachimex, que le tendió la mano y lo invitó a que conociera más a China, se le hizo ver el enorme potencial de consumo de básicos y productos que giran alrededor de las necesidades cotidianas de los chinos y sus industrias. Se hizo una serie de procedimientos protocolarios locales, en los cuales se incluyó una firma de posible hermanamiento con Jixian; a partir 
de entonces comenzó el cabildeo y se tienen visitas recíprocas entre autoridades municipales y empresarios de ambos pueblos, con la finalidad de conocerse más.

Lo anterior contrajo "buenas nupcias" entre los gobiernos locales primero y después entre empresarios, de lo cual derivó poder concretar la venta y el envío o el empaque de un convenio de 800 toneladas de fibra de coco colimense hacia China, de las cuales ya se enviaron las primeras 108 toneladas. Sin duda, la vocación productiva del municipio de Tecomán, ahora descubierta, primero por ellos mismos y después por los chinos, está permitiendo colaborar en igualdad de oportunidades de los habitantes de tan importante municipio hermano de China.

Debemos preguntarnos se realmente conocemos a China. Hay muchas consecuencias que aún desconocemos de nuestro amigo el “Dragón”. México y China, pueblos hermanos, empezaron relaciones diplomáticas el 14 de febrero de 1972 y celebran ya 40 años de ese acercamiento.

Definido México como el segundo socio comercial en América Latina y el mayor destino de exportaciones de China en la región, es conveniente reflexionar en qué tanto exploramos a China, sabedores de que existen reglas globales para el comercio, estándares y cuestiones internacionales.

Nos olvidamos de los orígenes básicos de los negocios: las personas y los aspectos culturales. Reitero que los asiáticos, en particular los chinos, son muy exigentes en cumplir ese protocolo.

En nuestro país, el modelo de competitividad es totalmente al revés; quienes abren mercado son los empresarios y después piden apoyo al gobierno. Pero algo está pasando actualmente que está fortaleciendo el esquema de negocios en México en relación a la China comunista.

\section{Pensar global, actuar local}

En China están asentadas 480 de las 500 empresas multinacionales más importantes del planeta. Y en México, algunas firmas de esas de las que están allá, ven el proceso de asentarse en nuestra demarcación con la intención de aprovechar la ventaja de nuestra región y nuestro país, que tiene el mayor número de tratados de libre comercio con el mundo, principalmente con Estados Unidos.

Otro ejemplo es el gobierno estatal de Guanajuato, que está impulsando una fiesta de cifras económicas y empresariales: “Nuestra Empresa es Guanajuato”. El gobernador, Juan Manuel Oliva, no sólo es uno de los gobernadores más cercanos al presidente Felipe Calderón, sino que también es uno de los más activos promotores de inversión privada internacional y nacional en esa entidad. Con una inversión de 5,635 millones de dólares y la generación de 58,239 empleos, ha apoyado 176 proyectos de atracción de inversiones. Guanajuato ha logrado superar su propia meta sexenal de atracción de inversiones en 32 por ciento.

Guanajuato es uno de los principales receptores de inversión extranjera directa (IED); $84 \%$ de las inversiones es internacional, $12 \%$ nacional y $4 \%$ mixto. 
En Guanajuato han invertido Alemania, Brasil, Canadá, China, Corea, España, Estados Unidos, Francia, Holanda, India, Inglaterra, Italia, Japón, México, Suecia, Suiza y Taiwán. Con un aumento de 45\%, Guanajuato ocupa el primer lugar en generación de empleos.

¿Será acaso una forma de gobernar, o simplemente la globalización nos pide ser eficaces ante mercados tan importantes como el asiático? China no se cierra, como lo decía al principio, sólo pide ser entendida y escuchada. Esta postura ha generado un ambiente sano y atractivo para las delegaciones chinas que visitan y exploran posibilidades de comercio con México y sus regiones. El papel del gobierno local es de suma importancia, base del federalismo y célula gubernamental, tanto aquí como en China.

Más municipios y gobiernos locales, también se han preocupado por generar ambientes de atracción. San Pedro Mixtepec, Oaxaca; Tapachula, Chiapas; San Martín de las Pirámides, Estado de México, y muchos más, han modificado su quehacer gubernamental obteniendo beneficios de este esquema sinomexicano planeado por ExpoChina México.

Expo China-México (concepto e iniciativa nacida del Grupo de Amistad México-China en la LX Legislatura Federal 2006-2009, Cámara de Diputados) veló por un oportuno mecanismo que ayudara al desenvolvimiento de los gobiernos locales.

Sabiendo los legisladores que la política exterior la ejecuta el gobierno federal, destacó entonces los ámbitos municipal y estatal de la competitividad, del mismo modo que en China existe una comisión legislativa hermana China-México, que ayuda a los gobiernos regionales chinos a impulsar la capacidad; los diputados mexicanos impulsores de dicha iniciativa lo hicieron también.

Expo China-México es así el "Espacio de Intercambio, Plataforma de Cooperación" que por cuatro años ha mostrado la efectividad del mecanismo de identificación cultural-financiero y tiene como base primordial a los gobiernos subnacionales de China y México.

\section{El cerebro desconoce lo que el ojo no ha visto}

Municipios mexicanos se han ido sumando a este proyecto de la mano con el INAFED, la Cahimex y el mismo Cechimex-UNAM. Se ha confirmado que cuando un gobernante se documenta y abre sus ojos hacia otros horizontes los pueblos crecen.

Regreso al tema de Tapachula-Chiapas, cuna de la comunidad chino-mexicana. Más allá de las enormes tradiciones chinas, los apellidos chinos y la cocina China, en la región del Soconusco se han concretado excelentes lazos comerciales y sociales.

Por ejemplo, el rambután, fruta exótica de origen asiático que crece y se da por naturaleza en estas bellas tierras chiapanecas, fue el enlace comercial estratégico que el Gobierno Municipal de Tapachula impulsó para fortalecer esas raíces con China.

Hoy se ha documentado un intercambio económico muy importante: la compraventa de más de 1,500 toneladas de esta fruta exótica para las comunidades chinas asentadas en Canadá y Estados Unidos. 
El reconocimiento en la actualidad de comunidad china del Soconusco, por parte de la Cachimex, fue determinante, así como la asistencia y participación del mismo en la Expo China-México.

Es importante mencionar que una nutrida delegación de autoridades del Gobierno Municipal de Tapachula viajó a China, se enamoraron de las raíces asiáticas, mismas que fundaron el Soconusco y se detectaron oportunidades reales que al día de hoy están vigentes. Tapachula, pueblo hermano de Dongying, cabildea estrechar más lazos comerciales.

El objetivo de la participación conjunta de los gobiernos locales, manufactura y pymes mexicanos con las contrapartes chinas, es la complementariedad, no sólo traer productos chinos, sino ver en dónde hacemos el match con las inversiones chinas dirigidas a México.

Los gobiernos locales mexicanos en coordinación con el INAFED y la Cachimex, a través de Expo China-México colaboran en la promoción de la hermandad entre municipios, que es la herramienta indispensable entre China y México para la promoción y el desarrollo local para el enfoque gubernamental.

\section{El mensaje}

La complementariedad entre China y México tiene un diferenciador: “La relación política precede a la relación económica; la amistad a los negocios; las acciones gubernamentales a las comerciales".

Los foros y publicaciones del Cechimex son una bisagra hacia lo que en la actualidad se hace y ejecuta en China. Instituciones como el Cechimex, perla de la sabiduría México-China, dados sus vastos trabajos como el seminario en que se presentó esta ponencia, son fundamentales para conocer, desde lo local, a ese "Dragón dormido". 



\title{
Las relaciones internacionales de las entidades federativas mexicanas con las provincias chinas
}

\author{
Carlos Heredia Zubieta, Alexis Rivera y Jing Wang
}

El surgimiento de China como segunda economía mundial ha constituido uno de los cambios más importantes en el escenario global de las últimas décadas.

México fue uno de los primeros países latinoamericanos en establecer relaciones diplomáticas con la República Popular China, en 1972, y la celebración del cuarenta aniversario de este hecho, el 14 de febrero de 2012, representa una oportunidad singular para tomarle el pulso a la relación bilateral desde la perspectiva arriba enunciada.

En un planeta globalizado, los asuntos internacionales han dejado de ser un ámbito exclusivo de los gobiernos nacionales. La Constitución Política de México reserva al titular del poder ejecutivo federal, el presidente de la república, las competencias y atribuciones en materia de relaciones exteriores y tratados internacionales; sin embargo, cada vez más, las regiones se vinculan directamente entre sí y los gobiernos subnacionales -en México, los estados y municipios- establecen lazos con sus homólogos de otros países.

Este activismo internacional por el cual los gobiernos subnacionales se asoman al mundo y lo introducen en su ámbito geográfico se denomina "diplomacia federativa" o "paradiplomacia", mientras que se conoce como "diplomacia ciudadana" el ejercicio por el cual gobiernos locales, organismos civiles, organizaciones no gubernamentales, instituciones académicas, cámaras empresariales y otros grupos establecen contactos directos con sus homólogos y contrapartes más allá de las fronteras nacionales.

Este documento hace referencia a las relaciones entre México y China para mostrar cómo se ha vinculado cada una de las entidades federativas mexicanas con las provincias, regiones autónomas, municipalidades y regiones administrativas especiales de la República Popular China. Una parte significativa de las relaciones bilaterales entre México y la República Popular China tiene lugar más allá de los vínculos entre los gobiernos nacionales. Un creciente número de estados y municipios mexicanos han establecido lazos con sus homólogos chinos en ámbitos como los negocios, las relaciones diplomáticas, la educación, el arte, la cultura, la ciencia y tecnología, el turismo y los deportes.

La información obtenida para realizar este documento proviene de los portales de las respectivas embajadas, así como de publicaciones oficiales de los gobiernos y dependencias estatales. Se trata de un primer intento de compilar y analizar estos datos, de manera sintética y no exhaustiva, que habrá de complementarse a medida que se cuente con mayor información al respecto. 
Un rubro muy importante es el de estudios e investigación sobre China:

Tabla 1. Principales Centros de Investigación sobre China en México

\begin{tabular}{|c|c|}
\hline Enidad federativa & Nombre \\
\hline Distrito federal & $\begin{array}{l}\text { centro de estudios china - méxico (cechimex) de la facultad de economía de la universidad nacional } \\
\text { autónoma de méxico (unam) }\end{array}$ \\
\hline Distrito federal & $\begin{array}{l}\text { centro de estudios de asia y áfrica (ceaa) del colegio de méxico - pionero en estudios sobre china en } \\
\text { méxico }\end{array}$ \\
\hline Distrito federal & $\begin{array}{l}\text { instituto politécnico nacional (ipn) - la escuela nacional de medicina y homeopatía (enmyh) mantiene un } \\
\text { convenio de colaboración con la universidad de beijing }\end{array}$ \\
\hline Distrito federal & programa de estudios asia - pacífico (peap) del instituto tecnológico autónomo de méxico (itam) \\
\hline Distrito federal & programa de estudios méxico-china del centro de investigación y docencia económicas (cide) \\
\hline Jalisco & departamento de estudios del pacífico (dep) de la universidad de guadalajara (udeg) \\
\hline Colima & centro universitario de estudios de la cuenca del pacífico (cuep) de la universidad de colima \\
\hline Michoacán & centro de estudios asia - pacífico (ceap) de la universidad michoacana de san nicolás de hidalgo \\
\hline Nuevo león & centro de estudios asiáticos (cea) de la universidad autónoma de nuevo león (uanl) \\
\hline Nuevo león & $\begin{array}{l}\text { instituto asia-pacifico del instituto tecnológico y de estudios superiores de monterrey (itesm). El itesm } \\
\text { mantiene oficinas de enlace en beijing, guangzhou y shanghai en la república popular china }\end{array}$ \\
\hline Puebla & $\begin{array}{l}\text { universidad de las américas puebla (udlap), que mantiene intercambios académicos y prácticas profesio- } \\
\text { nales con diversas universidades chinas }\end{array}$ \\
\hline Veracruz & centro de estudios china - veracruz de la universidad veracruzana \\
\hline Baja california sur & $\begin{array}{l}\text { cuerpo académico de estudios regionales y del pacífico (caerp), universidad autónoma de baja california } \\
\text { sur }\end{array}$ \\
\hline
\end{tabular}

La Asociación Nacional de Universidades e Instituciones de Educación Superior (ANUIES) promovió la realización del Primer Foro de Rectores México-China, que tuvo lugar los días 4 y 5 de febrero de 2010, en la sede del Instituto Politécnico Nacional (IPN) en la capital mexicana. En el encuentro participaron autoridades educativas de 17 universidades chinas y de 40 instituciones de educación superior mexicanas. El entonces embajador de China, Ying Hengmin, señaló que desde hace 30 años 500 estudiantes chinos han venido a México a perfeccionar sus estudios. A su vez, en 2008 había 1,263 estudiantes mexicanos realizando estudios en China. Las cifras de 30 becas anuales otorgadas por cada gobierno a nacionales del otro país son muy inferiores al potencial que podría alcanzarse. Las autoridades educativas y universitarias de ambas naciones se comprometieron a avanzar en la certificación de conocimientos y el reconocimiento mutuo de estudios, así como a intensificar el intercambio en materia educativa, científica, tecnológica y cultural, impulsando esfuerzos de investigación conjunta, movilidad docente y movilidad estudiantil.

Un esfuerzo pionero del gobernador Lázaro Cárdenas Batel en Michoacán a partir de 2005 dio pie al Programa de Formación de Negocios México-China, impulsado por la Asociación Mexicana de Secretarios de Desarrollo Económico (AMSDE). Este programa 
(o variantes del mismo) ha sido instrumentado por los gobiernos de Aguascalientes, Chihuahua, Coahuila, Colima, Distrito Federal, Durango, Hidalgo, Estado de México, Michoacán, Nuevo León, Quintana Roo, Sinaloa, Tabasco, Tlaxcala, Yucatán y Zacatecas. Cada semestre viajan a China alrededor de 30 jóvenes profesionistas mexicanos a cubrir estancias de uno o dos años, periodo en el cual se estudia el idioma chino, se cursan seminarios de negocios y se analiza la factibilidad de realizar proyectos de inversión. En China, el Programa opera en las ciudades de Hangzhou, Shanghai y Beijing, contando con acuerdos de cooperación con la Universidad de Zhejiang, la Universidad de Fudan y la Universidad de Lengua y Cultura de Beijing (BLCU).

A partir de 2006, con la apertura de sedes del Instituto Confucio en la Universidad Autónoma de Nuevo León, la Universidad Nacional Autónoma de México, la Universidad de Yucatán y la Universidad de Chihuahua, México se perfila como país iberoamericano que cuenta con un mayor número de sedes de dicha institución para la enseñanza del idioma chino.

Aunque parezca que las relaciones económicas tienen primacía, es crucial tener en cuenta que la relación con China es una relación holística liderada por el interés político y no técnico-comercial. Cuando las bases políticas están sentadas, las empresas e instituciones de ambas entidades encuentran una vía óptima para incrementar y profundizar sus inversiones, sus acuerdos de cooperación, su intercambio académico y su participación en eventos culturales.

Hay al menos tres factores que explican la multiplicación de estos vínculos entre gobiernos subnacionales de ambos países:

1. El posicionamiento de China como segunda economía mundial por el tamaño de su Producto Interno Bruto. Nadie quiere quedarse afuera del mercado chino. Los gobernadores de una veintena de entidades federativas mexicanas han realizado visitas a la República Popular China con el fin de promover a sus estados de origen en el que está llamado a ser el mercado más grande del mundo. Los gobernadores mexicanos se hacen acompañar de empresarios, productores, promotores del turismo y de la cultura.

2. El acelerado crecimiento económico chino ha impulsado una creciente demanda de materias primas, "commodities" e insumos para la producción. China está ávida de comprar metales, minerales y alimentos, entre otros bienes y servicios. En el documento de noviembre de 2008 que esboza la política de China hacia América Latina, se ubica a nuestra región del mundo como una importante fuente de suministro de recursos naturales, materias primas y commodities para satisfacer la creciente demanda china.

3. El interés de los gobiernos de los estados y municipios mexicanos por atraer la inversión china en proyectos de infraestructura, de transporte, portuarios, mineros, etc. La inversión extranjera directa procedente de China es aún incipiente pero tiene un potencial muy significativo dado que viene acompañada de financiamiento chino a tasas de interés atractivas. México representa una plataforma 
para empresas transnacionales chinas que buscan abastecer tanto al mercado mexicano como al estadounidense y latinoamericano.

Para propósitos del presente documento, se identificaron los eventos económicos, políticos, educativos y culturales anunciados públicamente en medios de comunicación, así como la información proporcionada por los gobiernos estatales y locales. Por razones de espacio no es posible incluir en detalle en el presente texto la descripción de cada uno de estos contactos.

Algunas de las empresas mexicanas que han invertido en China son las regiomontanas Grupo Alfa y Gruma; asimismo, Bimbo, Grupo Modelo, Softek, El Fogoncito, Grupo Idesa, Quinn México, Canels, Esmaltados Alfher, entre otras.

La inversión más significativa de capital chino en México es la realizada por Hutchison Port Holdings (HPH), consorcio con sede en Hong Kong, que es el mayor operador portuario del mundo. Hutchison opera terminales de contenedores en cuatro de los cinco puertos más importantes de México: Ensenada, Baja California; Manzanillo, Colima; Lázaro Cárdenas, Michoacán; y Veracruz, Veracruz, con la sola excepción de Altamira, Tamaulipas.

Los inversionistas chinos le apostaron a que una buena parte del futuro del comercio internacional entre Asia y América del Norte dependerá del corredor logístico intercontinental que transporta contenedores desde los puertos de Asia-Pacífico hasta el corazón geográfico de Estados Unidos, pasando por el puerto Lázaro Cárdenas, punto de partida del tren del TLCAN, que llega hasta Kansas City, Missouri.

La tabla 2 muestra la intensidad cuantitativa de vínculos que han presentado las entidades federativas mexicanas con las entidades provinciales chinas, donde la intensidad se refiere al número de contactos o de actividades que realiza cada entidad federativa con alguna entidad provincial china. 
Tabla 2. Relaciones económicas, políticas, educativas y culturales entre las entidades federativas mexicanas y las entidades provinciales chinas

\begin{tabular}{|c|c|c|c|c|c|c|c|c|c|c|c|c|c|c|c|c|c|c|c|c|c|c|c|c|c|c|c|}
\hline MEXICO/CHINA & 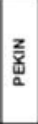 & $\frac{z}{\frac{z}{2}}$ & \begin{tabular}{|l}
$\overline{\underline{\Psi}}$ \\
피
\end{tabular} & 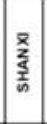 & $\begin{array}{l}0 \\
\frac{2}{2} \\
z \\
0 \\
\leqq\end{array}$ & $\frac{2}{3}$ & 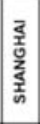 & 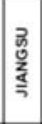 & 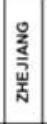 & 章 & $\begin{array}{l}3 \\
\frac{3}{3} \\
3\end{array}$ & $\begin{array}{l}\text { X } \\
0 \\
\frac{3}{2} \\
\frac{3}{7}\end{array}$ & \begin{tabular}{|l|}
0 \\
$z$ \\
0 \\
0 \\
$z$ \\
$z$ \\
s \\
w
\end{tabular} & 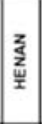 & \begin{tabular}{|l}
$\overline{\underline{w}}$ \\
$\overrightarrow{\underline{\underline{P}}}$
\end{tabular} & $\mid \begin{array}{l}z \\
3 \\
2 \\
2 \\
2 \\
2\end{array}$ & 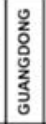 & 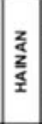 & \begin{tabular}{|l}
0 \\
zz \\
g \\
ż \\
ơ \\
s
\end{tabular} & 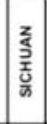 & 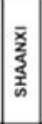 & 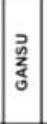 & \begin{tabular}{|l|}
$\frac{\leq}{x}$ \\
$\frac{\partial}{z}$ \\
$\frac{2}{z}$
\end{tabular} & $\mid \begin{array}{l}0 \\
\frac{2}{2} \\
\frac{y}{3} \\
\frac{z}{x} \\
x\end{array}$ & 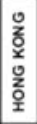 & $\begin{array}{l}3 \\
\frac{3}{4} \\
\frac{3}{4} \\
1\end{array}$ & $\begin{array}{l}\text { 立 } \\
\frac{\mathrm{g}}{\mathrm{w}} \\
\underline{\mathrm{z}} \\
\underline{\underline{z}}\end{array}$ \\
\hline DISTRITO FEDERAL & & & & & & & & & & & & & & & & & & & & & & & & & & & 7 \\
\hline AGUASCALIENTES & & & & & & & & & & & & & & & & & & & & & & & & & & & 6 \\
\hline BANA CALIFORNIA & & & & & & & & & & & & & & & & & & & & & & & & & & & 19 \\
\hline BANA CALIFORNIA SUR & & & & & & & & & & & & & & & & & & & & & & & & & & & 1 \\
\hline CAMPECHE & & & & & & & & & & & & & & & & & & & & & & & & & & & 1 \\
\hline CHIAPAS & & & & & & & & & & & & & & & & & & & & & & & & & & & 2 \\
\hline CHIHUAHUA & & & & & & & & & & & & & & & & & & & & & & & & & & & 10 \\
\hline COAHUILA & & & & & & & & & & & & & & & & & & & & & & & & & & & 3 \\
\hline COLIMA & & & & & & & & & & & & & & & & & & & & & & & & & & & 9 \\
\hline DURANGO & & & & & & & & & & & & & & & & & & & & & & & & & & & 6 \\
\hline GUANAJUATO & & & & & & & & & & & & & & & & & & & & & & & & & & & 3 \\
\hline GUERRERO & & & & & & & & & & & & & & & & & & & & & & & & & & & 2 \\
\hline HIDALGO & & & & & & & & & & & & & & & & & & & & & & & & & & & 3 \\
\hline JALISCO & & & & & & & & & & & & & & & & & & & & & & & & & & & 8 \\
\hline ESTADO DE MÉXICO & & & & & & & & & & & & & & & & & & & & & & & & & & & 12 \\
\hline MICHOACANN & & & & & & & & & & & & & & & & & & & & & & & & & & & 7 \\
\hline NUEVO LEÓN & & & & & & & & & & & & & & & & & & & & & & & & & & & 7 \\
\hline PUEBLA & & & & & & & & & & & & & & & & & & & & & & & & & & & 2 \\
\hline QUERETARO & & & & & & & & & & & & & & & & & & & & & & & & & & & 5 \\
\hline QUINTANA ROO & & & & & & & & & & & & & & & & & & & & & & & & & & & 2 \\
\hline SAN LUIS POTOSI & & & & & & & & & & & & & & & & & & & & & & & & & & & 1 \\
\hline SINALOA & & & & & & & & & & & & & & & & & & & & & & & & & & & 6 \\
\hline SONORA & & & & & & & & & & & & & & & & & & & & & & & & & & & 4 \\
\hline TABASCO & & & & & & & & & & & & & & & & & & & & & & & & & & & 2 \\
\hline TAMAULIPAS & & & & & & & & & & & & & & & & & & & & & & & & & & & 1 \\
\hline TLAXCALA & & & & & & & & & & & & & & & & & & & & & & & & & & & 1 \\
\hline VERACRUZ & & & & & & & & & & & & & & & & & & & & & & & & & & & 7 \\
\hline YUCATAN & & & & & & & & & & & & & & & & & & & & & & & & & & & 4 \\
\hline ZACATECAS & & & & & & & & & & & & & & & & & & & & & & & & & & & 1 \\
\hline INTENSIDAD & 28 & 2 & 6 & 1 & 2 & 2 & 20 & 6 & 14 & 2 & 1 & 2 & 10 & 8 & 2 & 1 & 9 & 2 & 4 & 1 & 3 & 1 & 2 & 1 & 8 & 3 & \\
\hline
\end{tabular}

Fuente: elaboración propia con datos de cada entidad federativa mexicana y de agencias de noticias. Se suprimieron por la parte mexicana los estados de Morelos, Nayarit y Oaxaca, así como por la parte china las entidades provinciales de Mongolia Interior, Heilongjiang, Guangxi, Guizhou, Yunnan, Tibet, Qinghai y Macau, por no contar con información relevante para este análisis.

Indicaciones de la tabla 2

$$
\begin{aligned}
& \text { Vínculos económicos } \\
& \text { Vínculos políticos } \\
& \text { Vínculos educativos } \\
& \text { Vínculos culturales } \\
& 2 \text { vínculos } \\
& 3 \text { vínculos o más }
\end{aligned}
$$

La mayoría de las entidades federativas mexicanas han emprendido acercamientos con China, poniendo énfasis en alguna entidad provincial china específica. Por ejemplo, los estados de Colima y Jalisco han establecido vínculos particulares con la municipalidad de Shanghai. Por otro lado, algunos estados como Baja California han diversificado sus vínculos con más entidades provinciales chinas; ha establecido cinco acuerdos de hermanamiento, teniendo como contrapartes a Shandong y Jiangsu; con esta última ha emprendido proyectos de cooperación académica y de intercambio cultural. En Baja 
California se encuentran instaladas al menos nueve empresas con sede en diferentes entidades provinciales chinas; el estado cuenta con una oficina de representación en Shanghai, ciudad de destino del vuelo de Aeroméxico que parte de Tijuana, único enlace aéreo sin escalas entre ambos países.

Más allá de la medición cuantitativa, el Distrito Federal y Michoacán destacan por la densidad y la continuidad de sus vínculos cualitativos con entidades provinciales chinas. A partir de 2006, Marcelo Ebrard, jefe de gobierno de la Ciudad de México, la capital mexicana, ha llevado a cabo una fructífera relación con las autoridades de Pekín, la capital china, que incluye visitas recíprocas, envío de becarios del Distrito Federal a Pekín e intercambios sobre temas como transporte sustentable y cambio climático. A su vez, como se ha mencionado, Michoacán fue el estado pionero en el Programa de Formación de Negocios México-China. Los egresados de este programa laboran para empleadores michoacanos que sostienen vínculos cotidianos con China, como la Administración Portuaria Integral Lázaro Cárdenas (APILAC) y la Asociación de Agentes Aduanales; para consorcios mexicanos que operan en China, como Grupo Bimbo; para Hutchison Port Holdings, empresa china establecida en Michoacán, y para corporativos que mantienen importantes lazos de negocios con China, como ArcelorMittal Lázaro Cárdenas, DHL, Wal-Mart, entre otros. Michoacán ha sostenido vínculos con la provincia de Zhejiang y un hermanamiento del Puerto Lázaro Cárdenas con el puerto de Ningbo; asimismo, sus productores agropecuarios han participado en la feria agroalimentaria SIAL en Shanghai.

Otros estados como Chihuahua, Colima, Jalisco, Estado de México, Nuevo León y Veracruz, también han entablado numerosos vínculos en diferentes áreas con entidades provinciales chinas.

Gráfica 1. Entidades federativas mexicanas con mayor número de vínculos con entidades provinciales chinas

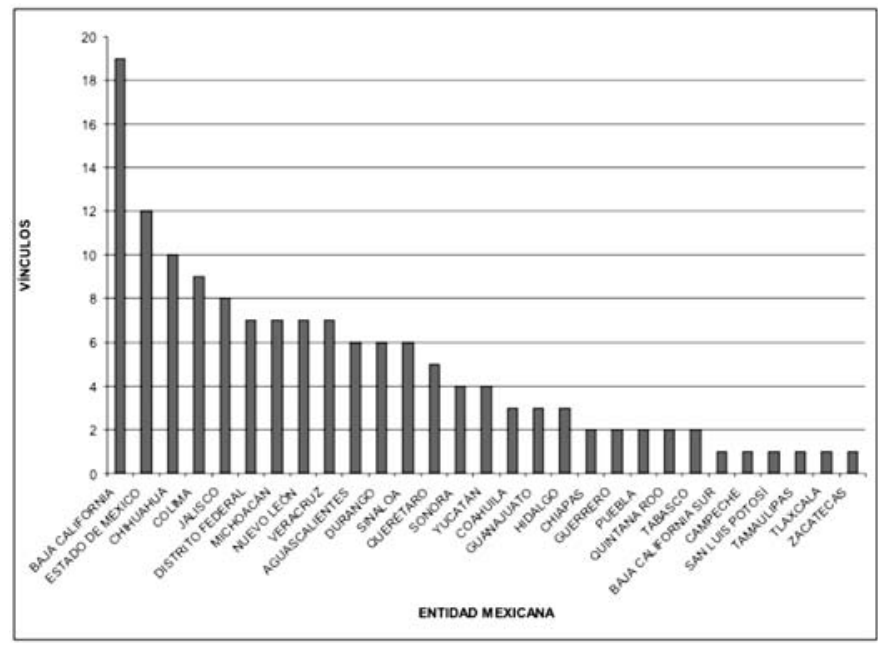

Fuente: elaboración propia con datos de la tabla 2. 
Por la parte china, Pekín y Shanghai encabezan la lista de las entidades con mayores relaciones con entidades federativas mexicanas, seguida de las provincias de Hong Kong, Zhejiang, Shandong y Guangdong (véase la gráfica 2).

\section{Gráfica 2. Entidades provinciales chinas con mayor número de vínculos con entidades federativas mexicanas}

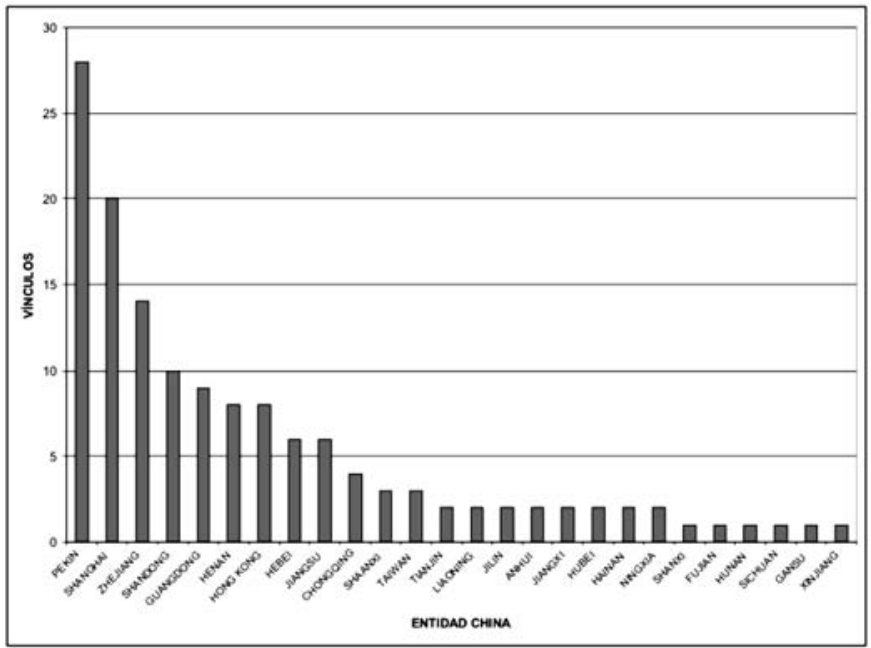

Fuente: elaboración propia con datos de la tabla 1.

La inversión china es más marcada en los estados que cuentan con una base industrial desarrollada y que cuentan con recursos minerales, ubicadas en el norte y el centro de México.

Entre las inversiones industriales, la empresa china Golden Dragon opera una planta para la fabricación de tubería de cobre de alta calidad en Monclova, Coahuila; el fabricante de computadoras Lenovo ha establecido una planta en Monterrey, Nuevo León. El consorcio petrolero chino Sinopec y la compañía mexicana Diavaz formaron la empresa DS Servicios Petroleros en Tampico, Tamaulipas, para evaluar las reservas remanentes y el diseño de alternativas para la explotación eficiente de campos petroleros en la Huasteca. La empresa china de autopartes Minth, proveedora de molduras e interiores automotrices, opera en Aguascalientes. El consorcio chino Giant Engine Company adquirió una planta de ensamble de automóviles en Ciudad Sahagún, Hidalgo; los conglomerados chinos ZTE y Huawei venden equipo a las compañías telefónicas que operan en México. La empresa Foton estableció una planta de tractores agrícolas en Coatzacoalcos, Veracruz.

Por lo que toca a la explotación de recursos naturales y mineros, la pesquera de Dalian, Xinjianghai, montó una planta en San Luis Rio Colorado, Sonora, para exportar mariscos a China; Jinchuan Group, el mayor productor de níquel de China, ha invertido en el yacimiento Bahuerachi, en Chihuahua. A su vez, Huaxi Group compró derechos 
para explotar minas de cobre en Sinaloa. El grupo chino Ayico invirtió en una planta de trituración y preconcentrado de mineral de hierro, que exportará su producción a través de Manzanillo.

En la Gráfica 3, los estados con un color más oscuro muestran un mayor número diversificado de vínculos con entidades provinciales chinas, mientras que los estados con un color más claro, representan una menor actividad.

\section{Gráfica 3. Mapa de distribución de las entidades federativas mexicanas con mayor número de vínculos con entidades provinciales chinas}

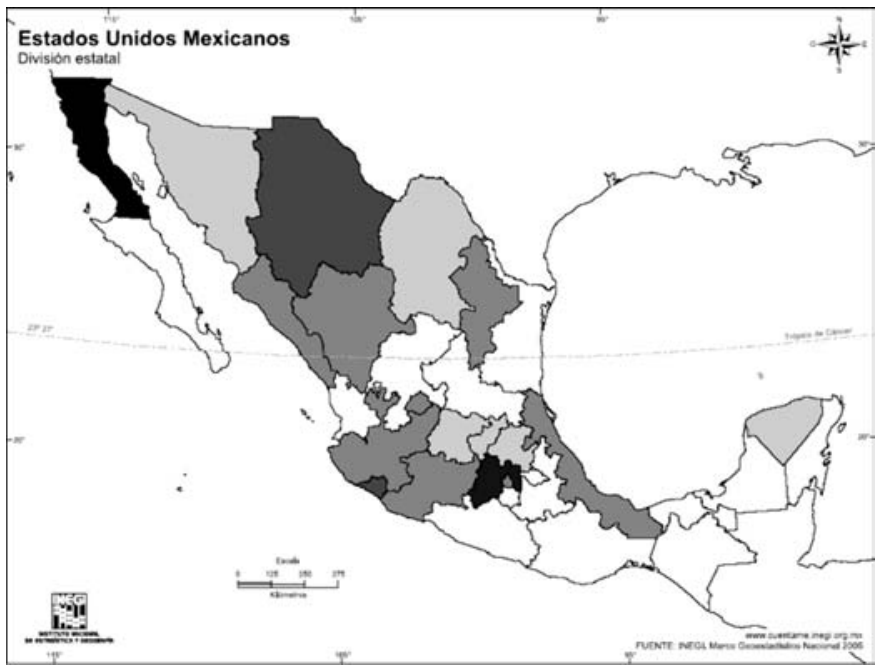

Fuente: elaboración propia con datos de la tabla 2.

La costa este de China es la región con mayor dinamismo de ese país, donde están ubicados sus centros industriales más importantes, con mayor participación en el comercio internacional. Las entidades provinciales chinas donde se localizan los puertos comerciales más importantes del país (Shanghai, Hong Kong, Shenzhen) son las que tienen más vínculos con las entidades federativas mexicanas. En contraste, la región occidental y la región norte de China tienen muy escasos o nulos intercambios con México. En la gráfica 4 se puede observar la concentración de dichas relaciones por estado; se indica con un color más oscuro las entidades provinciales con un mayor número de relaciones con entidades federativas mexicanas. 
Gráfica 4. Mapa de distribución de las entidades provinciales chinas con mayor número de vínculos con entidades federativas mexicanas

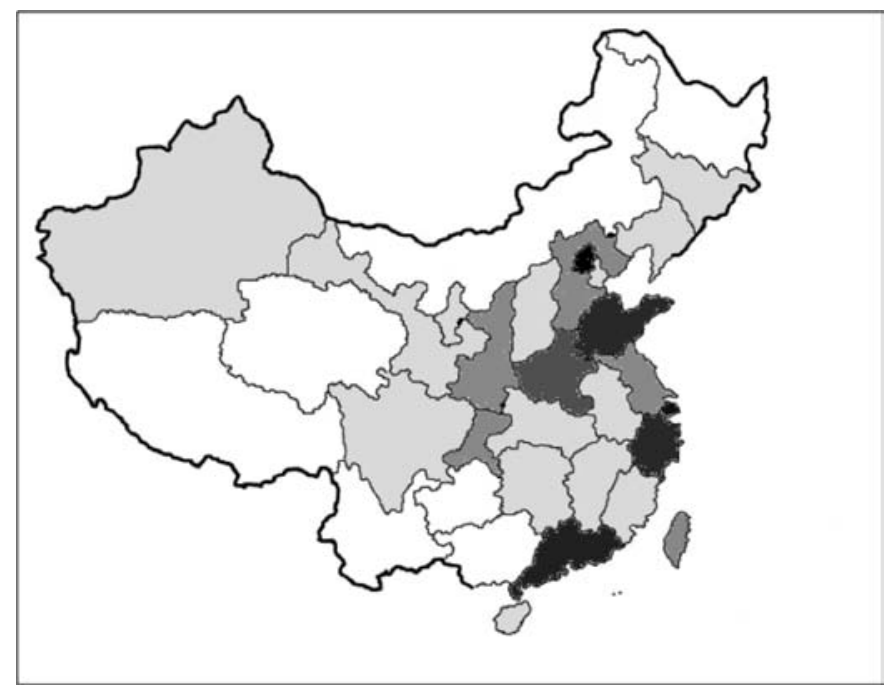

Fuente: Elaboración propia con datos de la tabla 1.

\section{Conclusiones}

La lógica de los vínculos entre las entidades federativas mexicanas y las entidades provinciales chinas se explica por razones geográficas, de peso económico, históricas, culturales y de vecindad con Estados Unidos, el mayor mercado mundial.

China ha tenido una marcada presencia en la industria extractiva en México, explotando los recursos naturales, en particular minerales y petróleo, con el fin de abastecer su creciente demanda.

En suma, las relaciones de las entidades federativas mexicanas con sus contrapartes chinas están marcadas por el corto plazo, y por lo tanto dictadas por los intereses chinos. México interesa a China fundamentalmente por el suministro de materias primas y por su capacidad de absorber exportaciones.

No hay una visión de largo plazo de la parte mexicana. Para dar mayor fuerza y permanencia a las relaciones entre las entidades federativas mexicanas y las entidades provinciales chinas, es necesario un viraje en la relación México-China que incluya los siguientes elementos:

1. La articulación de una estrategia y una agenda integral mexicana con la República Popular China en términos de la relación bilateral y de la respectiva posición en torno a temas globales. 
2. La diversificación de la oferta exportable mexicana y su presentación en términos asequibles a los compradores chinos.

3. La elaboración de una cartera de proyectos de inversión en infraestructura y en otros rubros en las entidades federativas.

4. La complementación de los esfuerzos emprendidos por las entidades federativas mexicanas, que con frecuencia rivalizan entre sí para atraer proyectos de inversión o flujos comerciales procedentes de China, en una especie de "carrera hacia el sótano" que va en detrimento de los propios estados.

5. El conocimiento de las formas de hacer negocios con China, que pasa necesariamente por el estudio de su cultura y de su lengua por parte de los mexicanos.

6. La profesionalización de los cuadros de los gobiernos de las entidades federativas mexicanas que tratan con China. Los contactos coyunturales y ocasionales deben dar paso a una mayor capacidad de seguimiento y continuidad a los vínculos, con visión de largo plazo.

Si logramos avanzar en estos rubros, entonces será posible dotar de contenido a la reiterada consigna de las autoridades mexicanas en el sentido de dejar de ver a China como una amenaza para considerarla como una oportunidad de asociación estratégica. 


\section{China: competencia global en los mercados locales. El caso de la Guitarra Paracho vs. "made in China"}

Eloy Vargas Arreola

En el siglo XVI, los misioneros, entre ellos Fray Juan de San Miguel y el obispo Vasco de Quiroga al evangelizar los pueblos y aldeas de lo que ahora es la meseta purépecha, en su búsqueda de aprovechar las vocaciones productivas de cada región, sin generar competencia directa entre las distintas comunidades, trajeron lauderos de España para que enseñaran a los nativos a fabricar instrumentos musicales y así se beneficiaran de la excelente calidad de las maderas que había en la zona. Es así que desde hace cinco siglos se fabrican en Paracho instrumentos musicales que han llegado a ser reconocidos como "las mejores guitarras del mundo" fabricadas en forma artesanal y que tienen alta demanda dada su calidad, reconocimiento y prestigio internacional.

Al paso de los años en la comunidad se establecieron procesos semiindustriales muy rudimentarios para la elaboración de las guitarras y otros instrumentos musicales, logrando a la fecha que 24,304 de los 34,721 pobladores de Paracho se dediquen a la fabricación de guitarras, lo que representa que más de 700 familias dependan directamente de la producción de este artículo..

Actualmente existen alrededor de 400 artesanos lauderos que fabrican 118 diferentes instrumentos musicales. Los artesanos elaboran 24 tipos de guitarra: barroca, de concierto, flamenca, conchera, de golpe, roquera, romántica, de 7, 8, 9, 10, 11 y 12 cuerdas. También violines, violas, contrabajos, violonchelos, laúd y vihuela, entre otros. Solamente 15 fábricas utilizan en sus procesos tecnología moderna.

En el año 2002, previo a la inauguración del Festival de la Feria de la Guitarra en Paracho, siendo secretario de Desarrollo Económico del Gobierno del Estado de Michoacán me visitó un grupo de productores de guitarra de Paracho para informarme que se celebraría la Feria de la Guitarra, aunque ya nada tenía que ver con su origen, que era difundir y promover la venta de las guitarras que se fabricaban en Paracho.

Ante la sorpresa del entonces gobernador, Lázaro Cárdenas Batel, a la llegada a la comunidad, con sarcasmo algunos liderazgos y periodistas mencionaban que la mayoría de las guitarras que estábamos viendo en los aparadores de los pequeños negocios eran de fabricación china, y que les convenía más comercializar instrumentos chinos para competir, que vender los fabricados en Paracho. Aunado a esto cadenas comercializadoras de guitarras en mayor volumen habían dejado de adquirirlas sustituyéndolas por las fabricadas en China.

El asunto fue alarmante no sólo por las repercusiones económicas que esto tenía para la actividad, los pequeños talleres estaban cerrando, aumentaba la pobreza, la marginación y el desempleo, que ya de por sí era complicado en la zona, sino también por el impacto sociocultural que implicaba. Se contaba con una Casa de las Artesanías con más de 51 años de historia y una Secretaría de Cultura del Gobierno del Estado, en- 
tonces ¿qué podíamos hacer para preservar esta actividad productiva y para no perder este patrimonio cultural e histórico, toda una tradición?

Enfrentábamos una gran paradoja, por lo que el gobernador Lázaro Cárdenas Batel me encomendó atender esta tarea y lo primero que pensé fue que había que conocer al enemigo, por lo que organicé una misión a China, pero al mismo tiempo encargué al área jurídica de la Secretaría de Desarrollo Económico buscar todos los mecanismos posibles para que la Secretaría de Economía implementara una cuota compensatoria a la importación de la guitarra china.

Al respecto me preguntaba ¿cómo podíamos bloquear la entrada de guitarras chinas a México?, acusándolas de dumping, ya que los precios a los que éstas se vendían parecían inferiores a los costos de producción. Buscamos también diferenciar nuestras guitarras de las asiáticas, ya que lo primero que cuestioné era la calidad de las mismas, sin embargo a simple vista para el consumidor común era imperceptible la diferencia.

Mientras nuestros artesanos cortaban pieza por pieza en miniatura para decorar las guitarras, en las chinas ese mismo decorado lo hacen mediante la aplicación de una calcomanía con impresión de alta definición y barnizada, que a simple vista no se notaba la diferencia.

Ante la imposibilidad de poder diferenciarlas físicamente, porque inclusive su calidad parecía mejor, argumenté el sonido, “deberían de sonar diferente" y la respuesta del director de Casa de las Artesanías, experto en el tema, fue que la diferencia no nos favorecía, ya que mientras en nuestras guitarras cada sonido es probado por el oído del artesano y el talento en sus manos le da el toque y el sonido característico a cada una, lo que lo hace diferente en cada instrumento, la guitarra china tenía un proceso de fabricación estandarizado, con un diseño corrido en un modelo que le daba la acústica necesaria para lograr un sonido excepcional.

La reacción inmediata de todos, ciudadanos, funcionarios y productores fue ¿qué podemos hacer para bloquear la entrada de guitarras chinas?, y China se colocaba en primera línea como el principal enemigo de Michoacán, ya que afectaba nuestra economía, dañaba nuestra cultura, nuestra tradición, nos ponía en vergüenza.

Días después se realizó en Michoacán la reunión de la Asociación Mexicana de Secretarios de Desarrollo Económico del país, cuando era presidente y secretario de Desarrollo Económico del Estado de Sinaloa Heriberto Félix Guerra (actual secretario de Desarrollo Social, un extraordinario músico, guitarrista sensible y gran conocedor y amante de las guitarras).

El evento contó con la presencia del presidente de la república, Vicente Fox Quezada. Al término de la reunión, cuya finalidad era tratar el tema del creciente desempleo en México, había una guitarra de Paracho en el centro del salón y el gobernador Cárdenas comentó "Señor presidente, pedí que colocaran una guitarra al centro del salón no sólo para decorar con nuestra artesanía típica el espacio, sino para recordarme tratar el tema y solicitarle al presidente de la república que se implementen medidas para frenar la entrada de guitarras chinas a nuestro país, por las afectaciones que está ocasionando, tendientes a desaparecer la fabricación de guitarras en Paracho" .

Busqué apoyo en Bancomext, pero me informaron que la oficina de México en China había sido cerrada, a petición de los propios fabricantes de calzado en León que 
habían visto arrasado también ese sector y por la visión de que con China nada se tenía que hacer.

Durante mi visita a China me encuentro con un país muy diferente a la visión que yo tenía, lo que percibí durante las actividades de una extraordinaria agenda de trabajo, preparada por el embajador de China y cónsules de Hong Kong y Shanghai, quienes nos manifestaban que fue que desde su visión había un error en el enfoque que como país estábamos teniendo respecto a China.

Al término de mi viaje, que duró cerca de dos semanas y al que fui acompañado por empresarios de distintos sectores, concluimos que China representaba para Michoacán definitivamente una gran amenaza, pero que también significaba una extraordinaria oportunidad y nuestro enfoque cambió, ¿cómo hacemos para venderles algo a estos mil trescientos millones de seres humanos que en un futuro incrementarán su ingreso per cápita?, y ya en ese entonces el $10 \%$ de su población eran ricos, cantidad similar al total de habitantes de nuestro país, si Michoacán es el primer productor mundial de aguacate y de otras frutas, si tenemos vastos recursos minerales y naturales... Ah, pero no me olvidó a lo que íbamos: a bloquear las guitarras chinas, sobre las cuales aprendimos que los chinos no vendían la guitarra, la regalaban, lo que vendían era el método para aprender a tocarla y vendían también un amplificador, ya que tenían la versatilidad de ser electroacústicas.

A mi regreso a Michoacán, mi hijo, de apenas 5 años, me pidió que le comprara una guitarra y me respuesta fue ¿para qué la quieres si tú no sabes tocar? Él me contestó que en su escuela el director había invitado un grupo de niños que quisiera aprender a tocar guitarra.

Al día siguiente presenté al gobernador Lázaro Cárdenas un informe sobre mi viaje a China, él no entendía mi entusiasmo y optimismo, pero en el documento anexé una estrategia completa para hacer más competitiva e incrementar el mercado interno de la guitarra de Paracho, ello sin renunciar a los procedimientos legales que estábamos siguiendo. Dicha estrategia incluía organizar a los productores, estandarizar sus procesos, dotarlos de mejores herramientas, diferenciar el proceso artesanal del proceso semiindustrializado, buscar una especie de certificación o denominación de origen y un método de enseñanza diseñado por Luis Josué Soto para sustituir la flauta de pan, la flauta japonesa o china con la que se enseña a los niños en las escuelas secundarias, por la enseñanza de guitarra, agregando al método y a la enseñanza una pequeña semblanza sobre la importancia del proceso y la calidad de la guitarra de Paracho.

Nueve años después, en el pasado 2011, leí una nota en el periódico La amenaza de la guitarra China sobre la de Paracho es historia, donde los productores de guitarra decían "no nos hace nada ni nos hará nada; no nos damos abasto para cumplir la demanda". Actualmente en Michoacán cada año se dota a las escuelas secundarias de más de 20 mil guitarras para que los niños aprendan a tocarla. Si bien no se ha implementado el proceso de enseñanza de guitarra como un programa obligatorio, la mayoría de éstas lo toman y Luis Josué Soto, a quien le encargué el programa, llegó a mi casa con una invitación a la que acudí puntualmente, para apreciar el concierto que rompía récord de más de mil niños de diferentes escuelas del estado; al centro y al frente como solistas unos niños de Paracho tocando diferentes melodías, incluidas notas de canciones purépechas como la Flor de la Canela, que es casi el himno musical de los purépechas. 
La marca colectiva "Guitarra de Paracho" fue una de las primeras marcas colectivas otorgadas por el Instituto Mexicano de la Propiedad Industrial (IMPI) a un producto artesanal (Michoacán es líder en marcas colectivas), no fue necesario ni se aplicó la cuota compensatoria a la importación de guitarra china, las cadenas comerciales compran hoy las guitarras de Paracho porque compiten en precio y calidad, los artesanos cambiaron el reclamo, la crítica y el cuestionamiento de hace 10 años por un reconocimiento al gobernador y otro a Heriberto Félix, secretario de Desarrollo Social, quien visitó esta comunidad el año pasado.

La guitarra de Paracho logró vencer a la guitarra china. No ha cambiado mucho el proceso semiindustrializado que se lleva, falta mucho por hacer, pero el tiempo de entrega de uno de los mejores artesanos lauderos de Paracho es de tres meses hasta un año por los pedidos, la gran demanda que tiene hoy en día.

La guitarra de Paracho nos enseñó que debemos tomar la globalización y la competencia como un fenómeno del cual no podemos excluirnos, pero el ser víctima de este proceso o verdaderos beneficiarios y participantes activos es una decisión, y ése fue el papel que decidimos jugar y ése fue el enfoque que aprendí al conocer China.

\section{Programa de formación de negocios México/China}

La estrategia para resolver el problema de la guitarra china funcionó, pero nuestro enfoque había cambiado totalmente y nuestro reto también, ¿cómo hacemos ahora para venderle algo a los chinos?, me preguntaba todos los días y siempre decía que importar algo de China, cualquier tarugo lo hace, pero venderle algo a los chinos, eso sí era interesante: otro idioma, otras formas de consumo y gustos, reglas complicadas. En esos momentos yo tenía una nueva tarea encomendada, promover la redinamización del puerto Lázaro Cárdenas.

Meses después de nuestra visita regresamos a China con motivo del foro APEC en Bangkok, del cual soy delegado de México desde el año 2002, y en los pasillos de la sede, previo al registro, me encontré un joven con rasgos árabes, al cual, sin embargo, al oírlo hablar le escuché acento norteño, lo cual llamó mi atención... no había duda, era de Monterrey; al preguntarle qué hacía allá me informó que estaba en Asia por parte de un programa de una institución académica mexicana que llevaba jóvenes a visitar el país asiático en una especie de tour académico, de inmediato lo abordé, tenía ansias saber más al respecto.

Mi primer pregunta a Alfonso Araujo fue: ¿cómo le hacemos para venderle aguacates a los chinos?, ¿cómo le hacemos para que los chinos envíen mercancías a través del puerto de Lázaro Cárdenas que en ese momento se encontraba estancado y paralizado?, él me contestó: “Nunca les podrás vender productos a los chinos, si no conoces a fondo sus leyes, las modificaciones tras la reforma, sus reglas del juego, si no tropicalizas tus productos a los gustos de ellos y sobre todo si no tienes quien hable su idioma. Ante su contestación ese mismo día o al día siguiente, yo ya le estaba proponiendo desarrollar un programa, le pregunté que en cuánto tiempo se podía aprender a hablar chino y él me comentó que llevaba más de dos años viviendo ahí y apenas comenzaba 
a hablarlo, de ahí que desarrollamos el Programa de Negocios México-China, que iniciamos en Michoacán y después se reprodujo en todo el país.

\section{Puerto de Lázaro Cárdenas}

En 1938, gracias a que el general Lázaro Cárdenas promoviera el aprovechamiento de los yacimientos ferríferos de Las Truchas y los de carbón en Coahuila, se planteó la posibilidad de construir una siderúrgica con posibilidades de instalarse en Guanajuato, Querétaro o Michoacán. Sin embargo, tras el estallamiento de la Segunda Guerra Mundial, el proyecto del presidente Lázaro Cárdenas se suspendió debido a que los proveedores de los insumos necesarios eran europeos.

Es en 1958 cuando se retoma el proyecto, después de que la Comisión del Tepalcatepec determinó la ubicación del mismo en las cercanías de los yacimientos, teniendo en cuenta la próxima construcción de la planta hidroeléctrica Morelos, que le proporcionaría energía a bajo costo.

En 1959 la Secretaría de la Marina complementó los estudios realizados en 1951 y 1954, definiendo así la ubicación aproximada del puerto, que coadyuvaría al desarrollo económico de la zona del bajo Río Balsas y lugares circundantes. Estos estudios abarcaron una amplia zona comprendida entre la desembocadura del Río Acalpican y la ensenada de Petacalco, que incluyó el estero del Pichi y la propia ensenada de Petacalco.

Dos años más tarde, la empresa alemana Krupp entregó el proyecto de la siderúrgica solicitado por la Comisión del Tepalcatepec y presidida por el general Cárdenas. En 1962, la Comisión del Río Balsas aceptó el proyecto, dictando el decreto que autorizaba la construcción del complejo siderúrgico durante el sexenio de Gustavo Díaz Ordaz, para lo cual se integró una comisión intersecretarial que realizaría los estudios y se ocuparía de la organización de dicha construcción.

En 1963 se levantaron estudios topográficos en la zona del río con el fin de localizar el canal teórico y estudiar en el terreno la viabilidad de su construcción. Con estos resultados finalmente se acordó establecer el puerto justamente en el delta del Balsas, para aprovechar el conjunto de sus ventajosas características fisiográficas, la cercanía de los yacimientos ferríferos de Las Truchas y su estratégica ubicación geográfica para el comercio marítimo. Ya a finales de los 60 se concluyeron los estudios para la construcción del puerto y se puso en marcha con el dragado del canal acceso lo que sería el puerto más grande de México.

En el año 2002 el puerto Lázaro Cárdenas se encontraba estancado y las empresas lejos de abrir estaban cerrando, derivado de las crisis económicas. Construido con esta visión, se había planteado como un puerto industrial y la tarea era redinamizarlo.

Durante mi visita a China visité Shanghai; cuál fue mi sorpresa que aun siendo un puerto enorme, en el Museo de la Planeación en Shanghai, ya los chinos presentaban lo que sería en los siguientes diez años su nuevo puerto, por lo que me quedó claro que la tendencia en el crecimiento del movimiento de mercancías de Asia, principalmente China a América era exponencial. 
Lo que en un tiempo fue Europa para América ahora era Asia, por lo que consideré que el tiempo de los puertos del Pacífico mexicano había llegado, la respuesta a mi pregunta de por qué la visión del general Lázaro Cárdenas de construir un puerto tan grande estaba ahí: el puerto michoacano podría reactivarse, dinamizarse y convertirse en factor de desarrollo económico regional, sólo había que aprovechar su ubicación estratégica y darlo a conocer al mundo, principalmente a Asia.

La región Asia-Pacífico representa un reto y una oportunidad para Michoacán: el primero por su competitividad y el segundo por el mercado potencial para realizar negocios.

El 21 de octubre de 2002 Michoacán se integra oficialmente al corredor multimodal transpacífico APEC, el cual va de Singapur a Kansas City. Tras un desempeño competente y satisfactorio se logró la primera certificación y valoración de la prueba de descarga, carga y transportación, realizada el 7 de octubre en el puerto por parte de autoridades aduanales, policía fiscal, sanidad, migración y miembros de APEC, la cual permite al puerto Lázaro Cárdenas integrarse en el Corredor Multimodal Transpacífico, lo que abrió un sinnúmero de oportunidades para la reactivación internacional del puerto michoacano.

En dicha prueba se cronometró, desde el arribo a las 9:00 horas del navío "Santa Giuliana" de la línea MARUBA, procedente de Asia, solamente cuatro horas y treinta minutos, de las cinco programadas, para las labores de descarga de contenedores, de trasbordo a plataforma de ferrocarril y arribo a su destino en la frontera con Estados Unidos en un tiempo competitivo. Se trata de una ruta sin costuras que conecta con la empresa ferroviaria norteamericana Union Pacific Railroad.

En términos de creación de capacidades, el proyecto busca generar la infraestructura necesaria para que México desarrolle enlaces multimodales. El transporte multimodal resulta de utilizar dos o más modos de transporte desde el origen de la carga hasta su destino final. Las partes intensificarán la cooperación económica y técnica entre Asia, México y Estados Unidos y dicha cooperación incrementará el comercio en toda la región, permitiendo la participación de pymes locales en la economía global con una competitividad relativa mayor.

El 4 de abril de 2003 gracias a la extraordinaria gestión del consejo de administración de API y de la visión de su director, el entusiasta Juan Paratore, se emitió el fallo correspondiente a la convocatoria para adjudicar la Terminal de Contenedores del puerto de Lázaro Cárdenas a favor de la empresa Controladora y Operadora de Terminales, SA de CV.

Dicho concurso contó con la entusiasta participación de 15 empresas, entre las que figuraban varias de las más grandes e importantes del mundo en el área del comercio marítimo internacional, las cuales definieron su interés en el puerto de Lázaro Cárdenas considerando sus ventajas y su estratégica ubicación geográfica.

La operación de la Terminal de Contenedores da igualmente vigencia a la utilización de logísticas y transporte multimodal dentro de la ruta más corta y rápida entre dos océanos, establecida entre el puerto de Lázaro Cárdenas, en el Pacífico, y Altamira, en el Golfo de México. Es también la ruta ideal entre el puerto michoacano y la frontera con Estados Unidos, lo que convierte a Lázaro Cárdenas en el puerto de recepción más conveniente para cargas transpacíficas provenientes de Asia, y la puerta de entrada al primer corredor terrestre interoceánico del país. 
A la fecha, la Coordinación General de Puerto sigue impulsando su desarrollo, se maneja una terminal de 800 mil contenedores operada por Hutchinson, la principal operadora de puertos de China; Rubén Medina, actual director, ha anunciado la construcción de una nueva terminal de contenedores y otros proyectos están en desarrollo.

Nueve años han pasado y el puerto Lázaro Cárdenas es considerado actualmente como el más conveniente para ser la puerta de entrada del Pacífico, gracias a la profundidad de 16.50 metros de su canal principal de acceso; dispone también de más de 4 mil 806 hectáreas para industrias y terminales portuarias y cuenta además con la capacidad para construir 18 mil 155 metros de muelles.

Gracias a su estratégica ubicación marítima y terrestre es el puerto más viable para convertirse en el puente terrestre que conecte los océanos Pacífico y Atlántico.

Desde 2003 he venido planteando la importancia de que en los puertos se establezcan zonas francas, zonas especiales de inversión, que se dediquen más que a promover el libre tránsito de mercancías, que su finalidad sea promover la inversión para desarrollar procesos que generen valor agregado, atraigan inversiones productivas y ayuden a hacer más competitivos a ciertos sectores de nuestra economía que se dedican a la exportación de productos.

Hoy las mercancías no se fabrican en un solo lugar, hoy se integran, los chinos copiaron muy bien y mejoraron el modelo maquilador de México instalado en la zona franca de la frontera mexicana y han instalado zonas especiales de comercio y seguramente tienen puestos sus ojos muy cerca de nuestro país.

Cuba, una isla con más de 11 millones de habitantes bien capacitados, con una gran hambre de triunfo y un enorme potencial, en mi visión personal, tarde o temprano se va a abrir, ya ha ido dando los primeros pasos y muestras para ello, y seguramente se abrirá con un modelo que coincida política e ideológicamente con el modelo chino y éstos podrían ser sus socios. Esto generaría que tuviésemos frente a nosotros una competencia en una zona especial de comercio, donde entrarían empresas de todo el mundo que quisieran integrar procesos de fabricación con insumos de China y de otras partes del mundo, para entrar a todo el mercado americano, economías que una vez pasadas las crisis económicas representarán una gran oportunidad; es más, llego a pensar que en este sentido la crisis mundial ha jugado a nuestro favor, creo que es lo único que ha detenido que esto no esté sucediendo antes, pero estoy seguro que tarde o temprano sucederá y sectores en los que México es campeón como el automovilístico, podrían ver enfrente una gran competencia si no hacemos algo.

Tenemos que competir en condiciones iguales que ellos. México debe mejorar el modelo de recintos fiscalizados estratégicos para convertirlos en instrumento que permita a las empresas exportadoras, con reglas que no afecten a la industria nacional, poder crecer, desarrollarse y asociarse para ser más competitivos en nuestros sectores estratégicos y aprovechar las vocaciones productivas y las ventajas que México tiene, como es su extraordinaria ubicación estratégica en la cuenca del Pacífico. 

Sección 8:

Las experiencias de las empresas 



\section{Oportunidades comerciales y de inversión entre México y China}

ProMéxico

\section{Panorama de la relación comercial}

Durante 40 años de relación diplomática es esencial subrayar la relevancia de la relación comercial México-China. Este documento analiza la dimensión de dicha balanza comercial y subraya las oportunidades de inversión y comercio existentes en la actualidad.

La economía china ocupa el segundo lugar entre los países de Asia y en escala mundial se sitúa en la tercera posición. De acuerdo con el ranking de Libertad Económica, ${ }^{1}$ China ocupa la posición 26 de la región asiática y la posición 135 a nivel internacional. La composición comercial de este posicionamiento se desagrega de la siguiente forma: el principal destino para las exportaciones de China en 2010 fue EU $(17.94 \%)$, Hong Kong $(13.8 \%)$, Japón (7.6\%), Corea (4.36\%) y Alemania (4.31\%). Por su parte, las importaciones de China provienen principalmente de Japón (12.65\%), Corea del Sur (9.9\%), Taiwán $(8.3 \%)$ y EU $(7.2 \%)$.

China representa un mercado importante tanto para México como para el mundo. De acuerdo con datos del FMI en 2010 el PIB de China sumó 5,878 mdd. Las estimaciones de Global Insight calculan que el PIB de China creció 9.2\% en 2011, y en 2012 su crecimiento esperado es del 8.7 por ciento.

Esta desaceleración en las proyecciones de crecimiento de la economía china responde a una disminución en las exportaciones por la situación económica de EU y la Unión Europea. Destaca que China cuenta con 1.16 billones de dólares en bonos del Departamento del Tesoro de EU, lo que lo convierte en el mayor poseedor de deuda de EU, que representa una inquietud por la influencia que podría tener el país asiático en la deuda estadounidense.

\section{Fortaleciendo una relación comercial más balanceada con China}

México busca que la relación entre ambos países fluya en un esquema de mayor beneficio mutuo para ambas partes. En la actualidad es válido afirmar que la relación entre estas dos naciones se ha fortalecido. Hoy, China es el segundo socio comercial de México a escala mundial. ${ }^{2}$ El intercambio comercial entre México y China creció más de 1000\% entre 2001 y 2010. Pasó de 4,300 mdd en 2001 a 49,800 mdd en 2010. Por su parte, las exportaciones al país asiático registraron un crecimiento histórico al lograr la cifra de

1 Para la elaboración del ranking se miden 10 factores: libertad para los negocio, libertad comercial, fiscal, monetaria, de inversión, financiera, laboral, tamaño de gobierno, derechos de propiedad y corrupción.

2 EU ocupa el primer lugar como socio comercial de China. 
$1300 \%$ entre 2001 y 2010. En 2010, sus exportaciones alcanzaron cerca de 4,200 mdd, lo que representó un crecimiento de $90 \%$ con respecto al año anterior.

Durante los 40 años de relación comercial México-China, la composición de dicha balanza comercial ha cambiado de acuerdo a tendencias históricas y económicas, como es evidente. En el 2011 la composición de las exportaciones mexicanas a China está agregada por tres grandes grupos de artículos ${ }^{3}$ :

1. Las manufacturas, que conforman tres cuartas partes de las exportaciones, y son:

a) Automóviles y sus partes

b) Aparatos eléctricos de telefonía

c) Motores y generadores eléctricos

d) Partes destinadas a televisores y reproductores de sonido

2. Materias primas, tales como cobre y hierro

3. Sector de bienes de consumo como cerveza, jugos y sus concentrados, papel y cartón

\section{Perspectiva actual de inversión y comercio}

Durante los últimos veinte años, el comercio ha sido el eje de los lazos económicos entre México y China. En la actualidad, el impulso en la inversión es la siguiente tarea a intensificar.

La brecha que brinda la oportunidad para fortalecer el intercambio comercial entre México y China es el déficit registrado en la balanza comercial, que para México equivale a 41 mil millones de dólares. ${ }^{4}$ La clave para impulsar una mayor integración económica entre ambos países está en la búsqueda de oportunidades de inversión.

\section{Fortalecer la inversión competitiva es el primer paso}

Si bien la información disponible parece indicar que la inversión total de empresas mexicanas en China es modesta, varias corporaciones reconocidas del país tienen presencia en ese mercado. Es común la inversión de dichas firmas, a través de asociaciones u operaciones de distribución y comercialización, como: Grupo Televisa (transmisión de programas de radio y televisión), Interceramic (pisos y azulejos), Tamsa (tubos de acero), Softek, Grupo Alfa, IDEAL (análisis de proyectos de infraestructura), Aeroméxico, Femsa Cerveza, Bimbo y La Costeña. 
Por su parte, actualmente China impulsa a las compañías de su país a invertir en el extranjero, a través de su "política de internacionalización de las empresas chinas"5 El gobierno chino ha impulsado a las compañías nacionales para que la inversión extranjera fructifique. Ésta es una coyuntura idónea para lograr un mayor acercamiento de México a las empresas chinas y presentarles las ventajas que ofrecen las cámaras de comercio y ProMéxico, por ejemplo. A la par, es una excelente oportunidad para promover oportunidades de negocio e inversión en nuestro país y, derivado de esto, las alianzas que podemos hacer con los empresarios chinos.

\section{IED de China en México}

(Millones de dólares)

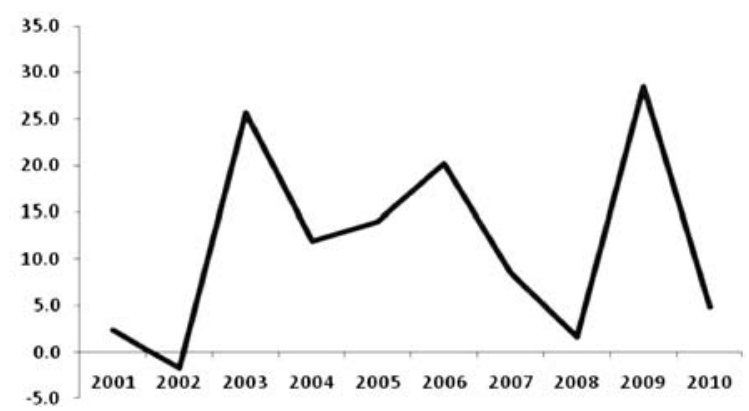

Fuente: ProMéxico con datos reporteador de flujos de IED en México de la DGIE de la SE

En 2010 China ocupó la posición número 28 como inversionista en México a escala mundial. En el lapso comprendido entre enero de 1999 y diciembre de 2010, las empresas con inversión china establecidas en México realizaron inversiones por 133 mdd.

Durante 2010, las empresas chinas con presencia en México realizaron inversiones por 6.1 mdd, lo que significó una disminución de $79 \%$ con respecto al mismo periodo del año anterior (28.5 mdd).

En diciembre de 2010, se registraron 611 empresas con participación china en su capital social. En cuanto a la inversión china en México, las cifras no reflejan fielmente el monto total, ya que muchas de las inversiones provenientes de dicha nación se realizan a través de subsidiarias en otros países, lo que impide tener un registro puntual de las inversiones. Al tercer trimestre de 2010, las empresas chinas con presencia en México realizaron inversiones por 3.5 millones de dólares, lo que significó una disminución del

5 Esfuerzo iniciado en 1999 por el gobierno chino para promover las inversiones chinas en el extranjero. El gobierno, junto con el Consejo Chino para el Fomento del Comercio Internacional (CCPIT), ha introducido iniciativas para ayudar a las empresas chinas a desarrollar una estrategia global y aprovechar oportunidades en la expansión de los mercados locales e internacionales.

Los programas puestos en marcha por el gobierno chino tienen los siguientes objetivos:

1. Incrementar la inversión de compañías chinas en el extranjero

2. Buscar la diversificación de productos

3. Mejorar el nivel y la calidad de los proyectos

4. Promover las empresas chinas en Europa y EU. 
$85 \%$ con respecto al mismo periodo del año anterior (24.1 mdd). La mayor parte de la inversión del dicho trimestre en 2010 fue canalizada en el sector comercial en el Distrito Federal, sucedido por la inversión en el sector de minería y extracción del petróleo en el estado de Nuevo León.

A pesar de la similitud entre ambas economías, México ofrece ventajas competitivas.

México es una excelente oportunidad para los negocios chinos. México tiene una ventaja estratégica en logística dado que es la puerta de entrada para el comercio, la inversión y la transformación de materias primas e insumos que tienen por destino el mercado más grande del mundo, que es, hoy por hoy, el mercado estadounidense. Igualmente, México es una importante puerta de acceso a Latinoamérica, mercado que es de gran interés para las empresas chinas.

México tiene un Acuerdo para la Promoción y Protección Recíproca de las Inversiones (APPRI), suscrito entre México y China, promulgado en 2009 y que protege jurídicamente los flujos de capital y brinda mayor certeza y seguridad para las empresas. De forma recíproca, las empresas chinas pueden invertir en México, producir sus productos o bienes, a costos competitivos y colocarlos en el mercado latinoamericano o norteamericano con tasas arancelarias preferenciales, dada la red de Tratados de Libre Comercio con la que cuenta el país. Uno de los ejemplos más tangibles es la industria automotriz, cuyo crecimiento ha sido notable durante los dos últimos años de esta década.

Existen sectores estratégicos que han impulsado la relación comercial bilateral.

En la industria manufacturera: China tiene la oportunidad de trasladar parte de sus manufacturas a México, con el objeto de abastecer su mercado local e intensificar sus exportaciones dentro del continente americano. Esto facilita la entrada de las empresas que ofrecen servicios de manufactura (EMS) que se han convertido en un elemento indispensable en las cadenas productivas de la industria electrónica. De lo anterior se deriva que las empresas chinas tienen una amplia posibilidad de encontrar en México un destino de inversión para expandir operaciones internacionalmente.

En tanto la industria automotriz: México es un destino ideal para los fabricantes chinos que quieran entrar a los mercados de Latinoamérica y Norteamérica, gracias a sus costos competitivos, su industria automotriz consolidada y su acceso privilegiado a estos mercados, a través de su red de Tratados de Libre Comercio. Las compañías más importantes del mundo en este sector están invirtiendo en el México. Se han registrado inversiones cuantiosas en los últimos años, que provienen de armadoras como Mazda, VW, Chrysler, General Motors y Ford. Estas inversiones hacen de México uno de los principales productores de automóviles en el continente americano. ${ }^{6}$

6 México ocupa el tercer puesto en el continente americano tras Brasil y EU, de acuerdo con cifras de la OICA, 2010. 
A la par, China es el primer productor mundial de vehículos, con un nivel de producción de 13 millones de unidades. ${ }^{7}$ Las empresas automotrices de China (SAIC ${ }^{8}$, Chang'an, Dongfeng, Chery, entre otras) producen modelos propios y están impulsando su ingreso al mercado latinoamericano, con el objetivo de introducirse en un futuro en el mercado estadounidense. Ergo, México es su puerta de entrada tanto a América del Norte como del Sur.

En relación con el uso de energías renovables: México tiene grandes beneficios para este sector, ya que el gobierno de México impulsa fuertemente la reducción de emisiones de dióxido de carbono y la transición a la generación de energía limpia. Igualmente, la nación posee una riqueza natural en recursos limpios, que le permiten ser competitivo a nivel mundial. Por su parte, China busca emerger como el principal exportador de tecnología solar y eólica en el mundo. La producción de China de tecnologías verdes creció más de $70 \%$ en $2010 .^{9}$ Para las empresas chinas, México es una plataforma interesante para la manufactura y diseño de estos productos, tanto para el mercado interno del país, como para su exportación a Latinoamérica y EU. Asimismo, México posee recursos naturales que permiten:

a) Se sitúe dentro del "cinturón solar", lo cual ubica a México dentro de las 6 naciones con mayor radiación solar a nivel mundial. ${ }^{10}$

b) Es 1 de los 5 principales países del mundo en la producción de energía a partir de recursos geotérmicos. ${ }^{11}$

c) En potencial eólico, el estado de Oaxaca es uno de los más privilegiados del mundo. ${ }^{12}$

México cuenta con la base más amplia para manufactura de módulos fotovoltaicos dentro de la región de Latinoamérica, por encima de Brasil, Chile y Argentina. ${ }^{13}$ En 2010, México fue el líder en inversiones de energías renovables en Latinoamérica, con un incremento cercano al $350 \%$, con respecto al año anterior. ${ }^{14}$

En tanto a inversión en turismo: México es un destino turístico indiscutible y de libre tránsito y acceso para los ciudadanos chinos. En noviembre de 2010, México y China firmaron un acuerdo para fortalecer la actividad turística. Actualmente viajan 49 millones de turistas chinos a distintas partes del mundo. Según un pronóstico de la Organización Mundial de Turismo, el número de turistas chinos que salen al exterior podría alcanzar las 100 millones de personas en 2020. Esta cifra convertiría a ese país en una de las mayores fuentes de visitantes, a pesar de que hoy en día China no representa una fuente significativa de visitantes para México. En 2010 arribaron al país más de 28 mil turistas

7 Cifras de OICA, 2010.

8 Shanghai Automotive Industry Corporation

9 Fuente: World Wildlife Fund for Nature, 2010

10 Fuente: Unlocking the sunbelt, EPIA.

11 Fuente: Asociación Mexicana de Geotermia.

12 Atlas de Recursos Eólicos de Oaxaca/ AMDEE

13 Fuente: Unlocking de Sunbelt, EPIA.

14 Global Trends in Renewable Energy Investments 2011, UNEP 
chinos, cifra $67 \%$ mayor al año anterior, ${ }^{15}$ lo que significa una mejora y el umbral para apostar por la inversión en este sector, dado que el potencial de ese mercado es innegable. Por ello es vital promocionar a México y establecer los convenios necesarios para aumentar los vínculos directos entre ambas naciones.

\section{México en Expo Shanghái 2010, un ejemplo de promoción sin precedente}

Este esfuerzo de promoción sienta un precedente inédito en las relaciones chino-mexicanas. Los elementos que marcaron el éxito de la participación de México en la Expo Shanghái 2010 fueron:

1. El diseño del pabellón de México

2. La herencia cultural presentada en el pabellón

3. La diversidad de actividades de negocios y eventos culturales desarrollados

El Programa de Promoción de Negocios del Centro de Negocios del Pabellón, llevado a cabo por la oficina de ProMéxico en Shanghái realizó diversas actividades, para atender a las delegaciones mexicanas y a los empresarios chinos que participaron en los diversos eventos, entre las que destacan los siguiente:

- Atención a delegaciones de gobierno, organismos y empresas mexicanas

- Organización de seminarios de atracción de inversión extranjera

- Atención a delegaciones federales y estatales

- Atención a delegaciones de organismos públicos y privados

- Celebración de semanas temáticas

- Organización de encuentros individuales de negocios

- Celebración de conferencias y pláticas sobre oportunidades de negocios en China y México como destino para invertir.

- Exposición de productos y muestras temporales

- Organización de degustaciones de platillos típicos de las entidades participantes

Para lograr un impacto positivo entre la comunidad empresarial China, ProMéxico realiza de forma permanente una importante difusión del Programa de Negocios, ante los organismos públicos y privados locales, detallando las actividades que realizarían las delegaciones mexicanas participantes en el Pabellón.

Una vez alcanzadas estas oportunidades de comercio e inversión, así como el esfuerzo del gobierno mexicano para fortalecer la relación comercial bilateral, a través del Programa de Promoción de Negocios llevado a cabo en el Centro de Negocios del Pabellón de México en Expo Shanghái 2010, ProMéxico considera de vital importancia fortalecer la presencia de México y sus oportunidades en China. Lo anterior se plantea al fortalecer el mercado existente y

15 Al año arriban a México más de 22 millones de turistas. 17,200 turistas chinos visitaron México en 2009. 
buscar mayor penetración en relación a cultura y tradiciones, así como, un aumento sustancial en intercambio de productos y búsqueda de oportunidades de negocio.

Es prioritario acentuar las semejanzas a las que aluden las hipótesis de Zhen He para aprovechar las oportunidades comerciales e intensificar nuestro comercio. Por ello, en ProMéxico exhortamos a que juntos sector privado, gobierno federal, cámaras, asociaciones y centros de estudios especializados, sumemos esfuerzos para seguir fortaleciendo las oportunidades comerciales y de inversión entre ambos países, así como para cimentar la imagen de México en Asia.

México confirma su voluntad para intensificar la relación comercial con China, en búsqueda de un comercio más balanceado, bajo esquemas que ofrezcan beneficios comerciales para ambos países. 



\section{La experiencia de la Expo China-México 2009- 2011 y Expo Asia-Pacífico-México 2011. Misiones mexicanas a China 2012}

Kuan Tai

\section{Resumen ejecutivo}

La comunidad china en México en conjunto con las instituciones gubernamentales y no gubernamentales, así como representantes del sector empresarial de ambos países realiza la plataforma única de la Expo China-México para buscar una mayor sinergia en la relación binacional.

A pesar de todos los problemas no anticipados, como el brote de AH1N1 y la falta de colaboración del consejero económico de China en México, se han logrado resultados positivos en el hermanamiento entre municipios de ambos países: San Luis, Río Colorado-Pindinshang; Acámbaro-Suzhou; Empalme-Dongying; Tecomán-Gulou; ZapopanChengdu, etcétera.

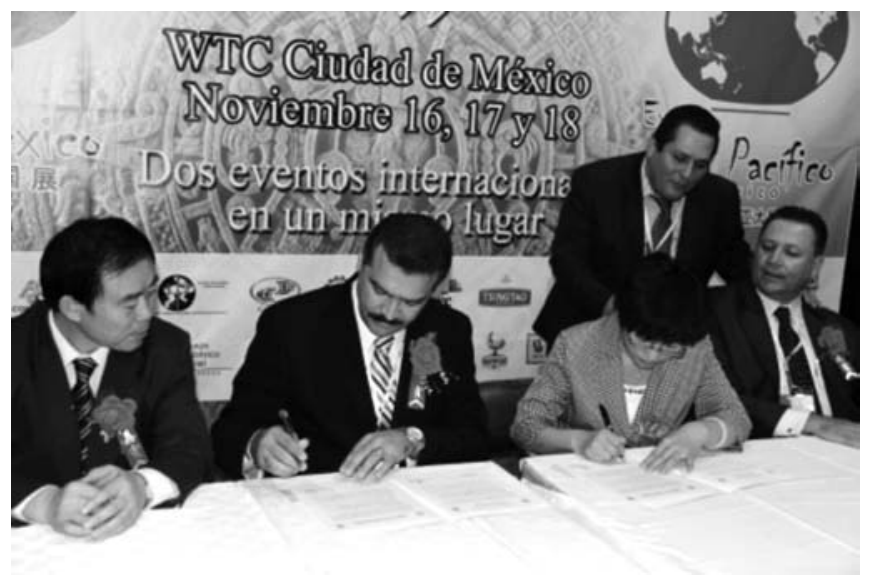

Firma de Intención de Hermanamiento del municipio de Empalme, Sonora con Dongying.

También se ha logrado la exportación de varios productos mexicanos a China y a la comunidad China en el mundo: fibra de agave y de coco, ónix, rambután, lichee, malanga, agua mala, calamar, PET, Hierro, Cobre, etcétera. 


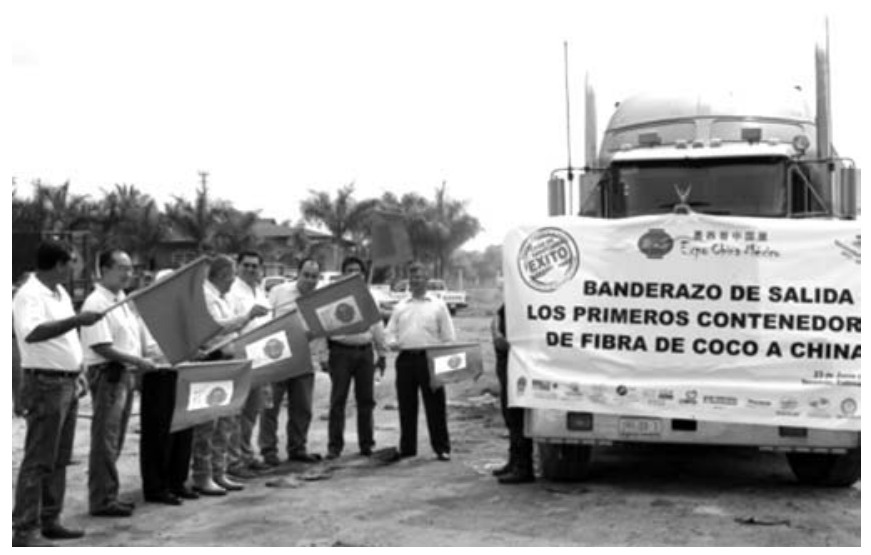

Banderazo de salida de los primeros contenedores de fibra de coco a China.

Durante las primeras tres ediciones, se contó con el apoyo de las instituciones de los gobiernos de ambos países (CCPIT, INAFED, Fondo Pyme, etcétera.).

A diferencia de otros países latinoamericanos como Brasil, Argentina, Perú y Chile, los proyectos de inversión de China en México siguen estancados por falta de garantía gubernamental mexicana.

La relación China-México es accidentada debido a diversos factores políticos y económicos, no hay un interés específico por parte de ninguno de los dos gobiernos para mejorar la relación binacional. Más aún, nuestro esfuerzo en aportar constructivamente con la plataforma de Expo China-México ha sufrido oposición por algunas instancias gubernamentales de ambas partes. Finalmente, el avance obtenido durante los tres años de la Expo China-México es un primer catalizador en el siglo XXI para fortalecer la relación binacional en forma constructiva cubriendo todos los aspectos políticos, económicos y culturales.

Para Expo China-México es importante el reconocimiento del sector empresarial y social como impulsores de la generación de empleo e inversión en México, a través de las exportaciones y proyectos de inversión concretados en estos tres años.

\section{Antecedentes}

A pesar de ser uno de los primeros países latinoamericanos en establecer relaciones diplomáticas con China, México no ha podido aprovechar el crecimiento de China en el siglo XXI para su propio beneficio, aunque la firma de ocho convenios de cooperación en julio del 2008 entre ambos países pareciera indicar un atractivo avance en la relación binacional. 


\section{Problemática China-México}

A pesar de las grandes diferencias culturales entre China y México, hay una gran diferencia política así como económica en los modelos empleados.

México tiene un sistema político capitalista, democrático y fragmentado (tres partidos políticos fuertes), mientras que China tiene un sistema socialista unificado, razón por la cual no se puede hablar de un alineamiento político como otros países latinoamericanos que ya son socialistas, con la excepción de Colombia y México. Por otra parte, la influencia de Estados Unidos no ha facilitado la entrada de inversión china a México, más bien lo ha complicado con el impedimento del visado a empresarios chinos a México.

México no ha podido lograr un intercambio comercial balanceado con China, debido a diversos factores como la falta de apoyo gubernamental efectiva para vender a China y el gran interés de comprar de China por parte de los empresarios mexicanos, hay una relación comercial de 10 a 1 en favor de China.

Las peculiaridades y diferencias culturales entre China y México no ayuda a la relación binacional, las negociaciones y encuentros entre representantes de ambos gobiernos y empresarios, que no han logrado resultados palpables hasta el día de hoy. Algunas de esas peculiaridades que dificultan la relación binacional son:

- El chino no paga y el mexicano no entrega

- El mexicano cambia de parecer todos los días y el chino cambia de parecer cada minuto

- El mexicano no habla claro y el chino tampoco

\section{Oportunidad China-México}

La comunidad china en México junto con algunas instituciones empresariales mexicanas creemos que puede ser el momento de empezar una iniciativa para llevar la relación binacional a otro nivel aprovechando las oportunidades de la crisis financiera de 2009. En ese sentido, la plataforma única de Expo China-México permite formar las cadenas de valores necesarios en busca del equilibrio de la relación entre China y México.

La crisis financiera ha obligado a que gobiernos y empresarios busquen otras fuentes de fondeo, así como proveeduría en China. Por otra parte, la apreciación del RMB, así como la depreciación del dólar ha creado un margen de ganancia nunca visto para las exportaciones a China. Adicionalmente, China anuncia su estrategia de invertir en Latinoamérica con un paquete de 100 mil millones de dólares, la plataforma de Expo China-México podría ser el catalizador para el aterrizaje de algunos de esos millones de inversión china en Latinoamérica. 


\section{Una exposición binacional como plataforma de cooperación}

La Expo China-México tiene como objetivo llevar la relación México-China a un mayor nivel de cooperación reuniendo a todos los integrantes del escenario político, económico y cultural de ambas naciones. Nunca ha habido una plataforma similar que permita el encuentro de las instituciones más importantes de los dos países bajo el mismo techo para explorar las sinergias existentes.

\section{Primera edición Expo China-México 2009}

Durante la primera edición de la Expo China-México 2009 se concentró en la exportación de productos mexicanos a China y a la comunidad china en el mundo; a pesar de no contar con ningún apoyo de los representantes de la embajada china en México, se logró un apoyo contundente del Fondo Pyme de la SE para concretar varias exportaciones de rambután, hortalizas, lichee, etc., a la comunidad china en Toronto y Nueva York. También se establecieron contactos para el inicio de las negociaciones de varios productos alimenticios de México como: tequila y mezcal, pescado y mariscos, patitas de pollo y carne de cerdo.

Esta primera edición fue sumamente exitosa a pesar de la falta de apoyo de la oficina comercial de China en México y de la influenza AH1N1.

Se logró reunir a varias instituciones gubernamentales y no gubernamentales de la parte mexicana como Coparmex, Fondo Pyme, Inafed, Cechimex, Cachimex, Gobierno del Estado de Durango, Gobierno del Estado de Baja California Sur, Gobierno del DF, ChinaChamberMexico, etcétera.

El único punto deficiente que hubo fue la poca presencia de empresas chinas debido al bloqueo por parte de la oficina comercial de China en México, aunado al difícil proceso de obtención de visas para México impuesto por el gobierno americano: se presentó menos de $50 \%$ de las empresas chinas estimadas en la feria.

\section{Segunda edición Expo China-México 2010}

La segunda edición del evento fue realizada con mucho éxito debido al gran apoyo por parte del Fondo Pyme de la SE. La intención era obtener apoyo de la oficina comercial de China en México para incrementar la participación china; sin embargo, nos fue negado, y por iniciativa del consejero chino en México, se retiró la ChinaChamberMexico, así como la Cámara de Empresarios de Zhejian de la Expo China-México 2010 para formar otro evento similar.

Esta vez hubo una mayor participación de los municipios mexicanos interesados en hermanamientos con sus contrapartes chinas.

A pesar de todo se lograron negociar varias intenciones de exportación de agua mala, lichee, rambután, ónix y mármol, calamar, madera pino, PET, etcétera. Como resultado palpable se estima una exportación de cerca de 50 millones de dólares. 
En cuanto a proyectos de inversión china en México, no hubo resultados fehacientes. Debido a la nueva mayoría de la oposición en el Congreso mexicano, se tuvieron que cancelar todos los proyectos de inversión china en México por la falta de garantía gubernamental. El Congreso no aprobó las garantías ofrecidas por el gobierno federal a través de FONADIN, razón por la cual no era posible fondear los proyectos de infraestructura en México que se venían negociando previamente.

Tercera edición Expo China-México 2011. Expo Asia-Pacífico-México 2011

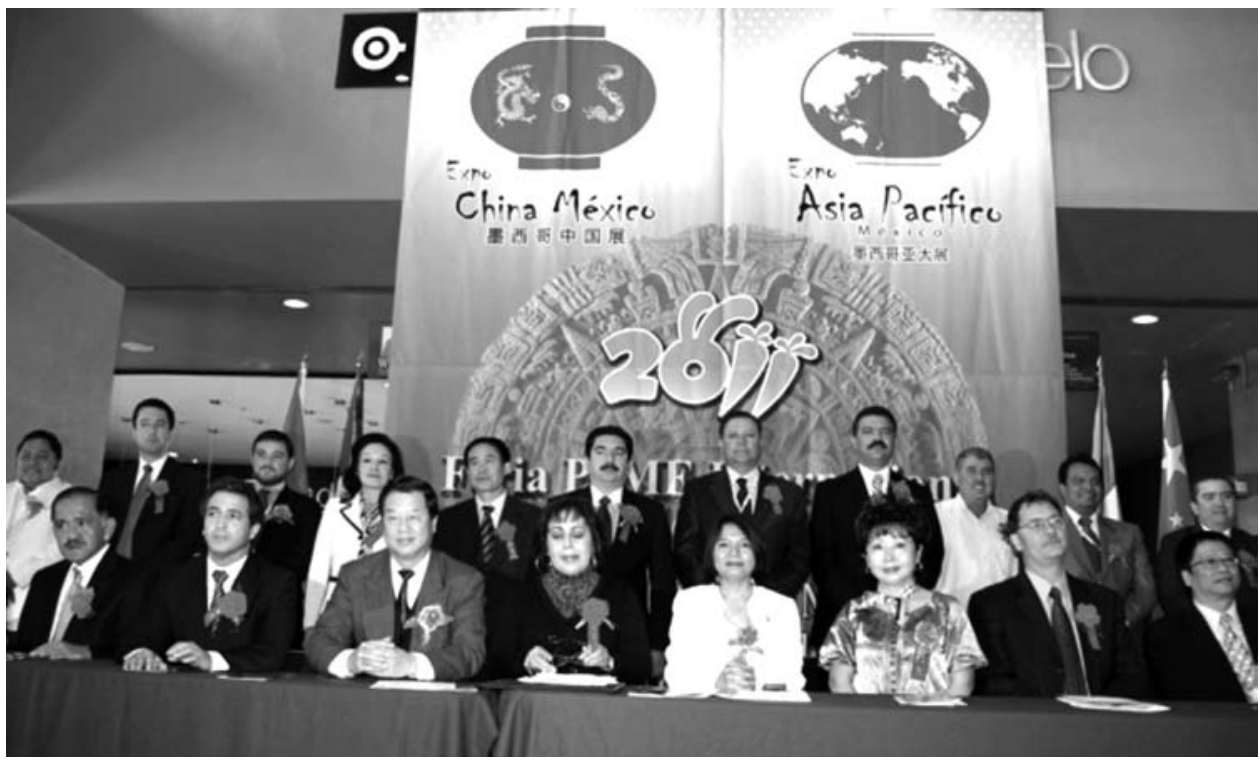

En este tercer año, decidimos incluir a varios países de la región Asia-Pacifico para incrementar las posibilidades de negocios. Varios representantes de las embajadas de Perú, Indonesia, Filipinas, Tailandia y Japón habían indicado interés en la edición anterior, y consecuentemente se lanzó la primera edición de la Expo Asia-Pacífico-México 2011 en las mismas fechas de la Expo China-México 2011. Finalmente se contó con la participación de Filipinas, Corea, Tailandia y Perú en la Expo Asia-Pacífico-México 2011.

Como un gran avance, el Subconsejo de Comercio de CCPIT tomó la organización de la parte china a partir de esta edición. Se obtuvo un menor apoyo del Fondo Pyme para convocar 100 pymes mexicanas a la expo. Destacó el apoyo incondicional a la expo por el nuevo embajador de la República Popular China en México. A pesar de todos los obstáculos, se realizaron con éxito las tres exposiciones y se lograron nuevas intenciones de exportación de miel de agave, aceite de aguacate, así como madera preciosa mexicana. 
Nueva estrategia: misiones comerciales a China-Chengdu y Fuzhou 2012

Durante las tres ediciones anteriores, las instancias gubernamentales mexicanas (Promexico, Fondo Pyme y Sagarpa) nos han propuesto llevar las pymes mexicanas a China para su internacionalización, razón por la cual hemos decidido llevar a las pymes más interesadas a dos ferias estratégicas: la feria de alimentos y bebidas de Chengdu en marzo de 2012 y la feria de mayo 18 de Fuzhou en mayo de 2012.
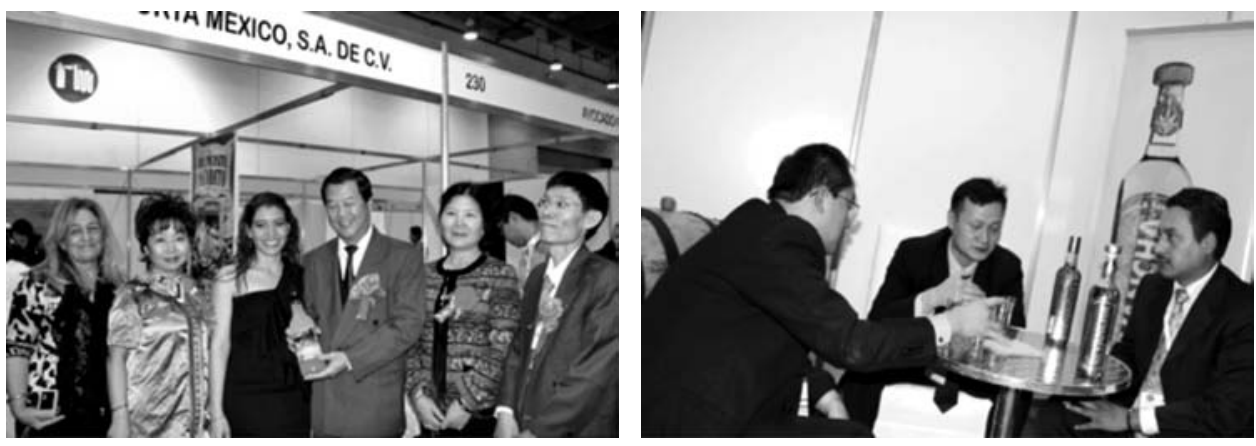

Se obtendrá apoyo por parte del Fondo Pyme para la realización de estas dos misiones. El objetivo es ayudar a las pymes a entender la mecánica de negociación y penetración de sus productos en China. Se establecerán citas de negocios con los contactos previamente obtenidos en las primeras tres ediciones de la Expo China-México y se espera obtener resultados con las primeras exportaciones de tequila $100 \%$ agave, miel de agave, aceite de aguacate y arte mexicano a China.

\section{墨西哥亭 100 \\ los Mejores Productos
de México para}
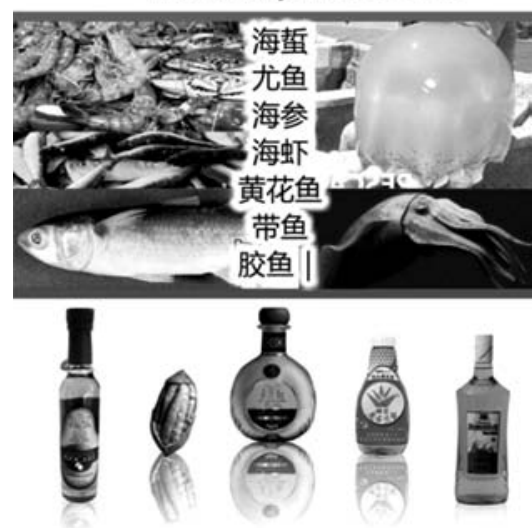


\title{
El impulso de las empresas de pueblo y aldea (EPA) al desarrollo económico de China
}

\author{
Enrique Tejeda Canobbio
}

\section{Introducción}

Durante las reformas económicas de los últimos 30 años, China adoptó una gran gama de políticas diseñadas para incrementar su capacidad tecnológica y fomentar el crecimiento industrial. Como ideológicamente no era posible ejecutarlas a través de empresas privadas, lo hizo creando un híbrido: las empresas no-estatales o minying qiye.

El proceso de crear empresas no-estatales como medio para fomentar el desarrollo tecnológico ha sido variado y adaptado a las condiciones regionales. Sin embargo, este proceso fue ayudado a nivel nacional por dos políticas: la descentralización de la autoridad para administrar empresas y centros de investigación, desarrollo y producción a los niveles locales, y la creación de empresas derivadas con un sistema híbrido de propiedad. El gobierno, impedido de instrumentar la filosofía de mercado, creó la categoría de minying qiye, pero nunca realmente definió sus particularidades, y usualmente llegó a incluir a empresas estatales, colectivas, individuales e incluso algunas privadas (Segal 2003).

Las empresas minying han tenido resultados mixtos, pero han logrado en conjunto el objetivo de crear un núcleo innovador de tecnología en China. Los resultados han variado dependiendo de las políticas gubernamentales en cuanto a inversión, regulación de derechos de propiedad y supervisión oficial.

Las empresas estatales antes de las reformas económicas aportaban el grueso de los insumos industriales y las aportaciones fiscales para el Estado; sin embargo, la economía china cambió. La aportación de la producción industrial de las empresas estatales descendió paulatinamente de 78\% en 1978 a 35\% en 1995. Ya en 2001, tal aportación era de sólo $20 \%$. El empleo y el Factor de Productividad Total ${ }^{1}$ han crecido mucho más en el sector no-estatal.

En el centro de esta ola de cambios estuvieron las Empresas de Pueblo y Aldea (EPA) rurales que fabricaban primero productos para el mercado interno y luego evolucionaron hacia todo el mercado nacional y la exportación. Estas pequeñas pero flexibles empresas con una orientación de mercado fueron uno de los principales motores del crecimiento chino en los últimos 30 años.

En esta investigación estamos tratando de comprender el desarrollo chino en las últimas décadas a partir del debate internacional que busca explicar las fuentes del crecimiento a largo plazo. El debate es intenso y existe una forma interesante e innovadora de verlo, el cual se origina en el institucionalismo y se materializa en el concepto de instituciones transicionales.

1 Total Factor Productivity: cualquier variable o efecto que incide en la producción total y que no es causada por los insumos o la productividad (clima, adelantos tecnológicos, eficiencia). 
La cuestión de la propiedad bien definida es una pregunta y preocupación de la economía ortodoxa, pero al parecer irrelevante en el entorno chino, que contrasta con los fundamentos del institucionalismo y de la lógica occidental. La propiedad como una institución transicional pareciera tener motivaciones de carácter económicamente coyuntural y estructuralmente culturales y políticas, dando pie a que su efectividad esté relacionada más a su capacidad de flexibilidad y experimentación que a su definición teórica.

Las EPA y otras formas de propiedad comenzaron a demostrar el potencial de los incentivos del mercado para el establecimiento de una base industrial pujante, a pesar de los riesgos internos que representaba el incierto contexto institucional. Si le agregamos las políticas depredadoras que algunas agencias gubernamentales y autoridades aplicaban a las empresas exitosas, podremos entender el porqué de la evolución de las formas de propiedad en China. Si bien se podría pensar que esta evolución obedeció simplemente a principios de preservación -de la empresa, del empleo y del capital invertido-, es justo afirmar que el mismo gobierno fue el que al parecer incentivó el lanzamiento de emprendimientos fuera del ámbito estrictamente estatal, y que las adecuaciones institucionales informales fueron un reflejo de una política estratégica que buscaba mejorar la economía en su totalidad.

Las predecesoras de las EPA fueron las empresas comunales y de brigada, y operaban bajo el principio de los tres locales: obtener materia prima local, procesarla localmente y vender los productos terminados en la localidad, confinando sus operaciones a su espacio geográfico inmediato. Por estas características, las empresas comunales y de brigada pertenecían a la economía natural tradicional, de acuerdo a la teoría de la economía del desarrollo.

Por el contrario, las EPA se originaron y desarrollaron cuando el sistema de contratos ya estaba aplicado, por lo que comulgaron inmediatamente con el principio de desarrollar mercados alternos al estatal.

Durante la etapa del Gran Salto Adelante de 1958 y la descentralización de 1970, las comunas populares se dedicaban usualmente a la producción y reparación de maquinaria agrícola, así como a la fabricación de productos de primera necesidad. De manera general, estas empresas redujeron la presión hacia las empresas urbanas y sus empleos, por lo que no se buscó modificarlas en ningún sentido en etapas posteriores.

Sin embargo, las EPA junto con el sistema de contratos individuales, permitieron un desarrollo más amplio del sector rural al motivar a los agricultores a utilizar la producción excedente del plan como medio de inversión para emprendimientos no-agrícolas. Esto a su vez generó un mercado local para productos básicos de consumo e incrementó sensiblemente sus condiciones de vida.

El desarrollo de estas EPA se dio de dos maneras distintas; el factor decisivo fue su localización geográfica. En las zonas internas las EPA estaban dispersas y con su fuerza laboral condicionada a los tiempos agrícolas de cultivo y cosecha. De esta manera, aunque temporalmente, los agricultores dejaban la granja pero no su villa, y entraban a la fábrica, pero no a la ciudad. En las zonas costeras, en cambio, las EPA estaban fuertemente ligadas a los planes gubernamentales locales de promoción industrial, tanto para efectos de desarrollo económico y exportación, como para posicionamiento político. 
Ambas posiciones tuvieron beneficios, ya que por un lado la industria rural absorbía fuerza laboral que no hubiera podido ser adoptada por las zonas urbanas, mientras que los gobiernos locales de las zonas costeras fueron guiando el desarrollo de EPA cada vez más grandes y complejas que se convertirían después en el motor del crecimiento exportador y en la base industrial y de alta tecnología del país.

\section{Reforma legal de las empresas estatales}

El componente principal del sector colectivo eran las EPA. Éstas no eran realmente colectivas en el sentido de que pertenecían y eran administradas por sus empleados (Byrd y Lin 1990; Oi y Walden 1999), pero tenían fuertes vínculos o eran efectivamente controladas por los gobiernos locales donde estaban localizadas. En una simbiosis provechosa, estos gobiernos locales les proveían servicios esenciales y a cambio recibían una parte significativa de sus ganancias. Entre estos servicios estaban la protección contra la depredación, acceso a capital de instituciones crediticias gubernamentales y el apoyo para las negociaciones con instancias gubernamentales más altas. Las empresas que efectivamente fueran de propiedad individual se consideraban oficialmente como colectivas, de manera que no perdieran estos servicios y las conexiones (guanxi) que pudieran aprovecharse de dicha clasificación.

El éxito de estas empresas comunitarias dependía de aspectos como la liberalización gradual de los precios y de la producción y el anonimato de las transacciones comerciales que reducían el riesgo de exportación y del federalismo fiscal (Qian, 2001). Sin embargo, el crecimiento de las empresas comunitarias se desaceleró al intensificarse la liberalización y la apertura de la economía china. La inquietud derivada del subempleo se tradujo en una constante liberalización de las normas que regulaban la formación de estas empresas, que a su vez comenzaron a avanzar hacia formas más complejas de propiedad, gracias a su conversión en cooperativas de acciones o a su transformación en empresas privadas o incluso conjuntas.

Fue entonces que se hizo evidente que era necesario un cambio legal para darles un segundo impulso a las EPA. El gobierno comenzó el proceso de reforma con la entrada en vigor de la Ley de Empresas Industriales Propiedad del Pueblo de 1988. Esta ley consideraba que las empresas son personas legales bajo la Ley Civil, con la misma capacidad y estatus para tomar obligaciones, como cualquier otra persona legal. También les asigna a los administradores la responsabilidad de tomar las decisiones importantes de las empresas. El rol del Partido Comunista se relega a garantizar y supervisar que los principios y políticas del gobierno sean aplicados en las empresas. 


\section{Cronograma de la primera etapa del proceso de reformas al sistema de propiedad}

\begin{tabular}{|c|c|}
\hline Fecha & Accionbes realizadas \\
\hline $\begin{array}{c}20 \text { de octubre de } \\
1984\end{array}$ & $\begin{array}{l}\text { Se acordó que -de acuerdo con el principio de que los derechos de propiedad y operación deben ser apropia- } \\
\text { damente separados y con el apoyo del Estado en la planeación y la administración- las empresas tuvieran más } \\
\text { derechos en las áreas de producción, procuración de materias primas, mercadotecnia, retención de capital, } \\
\text { empleo, bonos, precios, entre otras. }\end{array}$ \\
\hline $\begin{array}{l}12 \text { de julio } \\
\text { de } 1986\end{array}$ & $\begin{array}{l}\text { Para entonces se dio un cambio conceptual en el proceso de asignación de derechos y formas de propiedad, } \\
\text { que se reflejaba en la legislación en torno al tema. El artículo } 41 \text { del Reglamento General para la Ley Civil de la } \\
\text { República Popular de China, con vigencia efectiva desde el } 1 \text { de enero de 1987, especificaba que las empresas } \\
\text { estatales tienen derechos operativos sobre la propiedad estatal, y esta propiedad es protegida por la ley. }\end{array}$ \\
\hline $\begin{array}{c}2 \text { de diciembre de } \\
1986\end{array}$ & $\begin{array}{l}\text { La Ley de Bancarrota Empresarial de la República Popular de China, adoptada en la 18a Reunión del Sexto Con- } \\
\text { greso Nacional Popular, especificaba que cuando una empresa se declare en bancarrota, toda su propiedad se } \\
\text { convierte en propiedad en bancarrota, y la empresa debe pagar sus deudas de acuerdo a la ley. }\end{array}$ \\
\hline 13 de abril de 1988 & $\begin{array}{l}\text { La Ley sobre Empresas Estatales Industriales de la República Popular de China se adoptó en la 1a Reunión del } \\
\text { Séptimo Congreso Nacional Popular. Siendo la primera ley empresarial en el país, definía la naturaleza, derechos } \\
\text { y obligaciones de las empresas estatales de manera sistemática: Las empresas estatales son productoras y } \\
\text { operadoras de commodities socialistas, que operan por sí solas, asumen la responsabilidad sobre sus pérdidas } \\
\text { o ganancias, y adoptan sistemas contables independientes, de acuerdo a la ley. Las propiedades de la empresa } \\
\text { pertenecen a la colectividad, y el Estado le da las empresas los derechos sobre la operación y la administración, } \\
\text { bajo el principio de la separación de la propiedad sobre el poder operativo. Las empresas tienen el derecho de } \\
\text { ocupar, usar y manejar la propiedad del Estado con su aprobación. }\end{array}$ \\
\hline 23 de julio de 1992 & $\begin{array}{l}\text { El Consejo Estatal promulgó las Regulaciones sobre el Cambio Operativo de las Empresas Estatales Industriales, } \\
\text { que buscaban llevar las empresas estatales al régimen de mercado. Bajo los principios generales de la ley em- } \\
\text { presarial, las regulaciones modificaban el régimen operacional de las empresas de acuerdo a las demandas del } \\
\text { mercado y convirtió los derechos dados a las empresas en la Ley sobre Empresas Estatales en } 14 \text { autonomías } \\
\text { operativas. Como resultado, } 29 \text { provincias, regiones autónomas y municipalidades bajo control gubernamental } \\
\text { central adoptaron las nuevas regulaciones de acuerdo a sus intereses, reduciendo formalmente las interferencias } \\
\text { gubernamentales en los precios, planes de producción, margen de operación de la empresa y sistema de distri- } \\
\text { bución, entre otros aspectos. }\end{array}$ \\
\hline $\begin{array}{l}30 \text { de noviembre } \\
\text { de } 1992\end{array}$ & $\begin{array}{l}\text { El Ministerio de Finanzas publicó las Reglas Generales sobre los Asuntos Financieros de las Empresas y los Están- } \\
\text { dares de la Contabilidad Empresarial, con la aprobación del Consejo Estatal. Estas reglas y estándares, con vigen- } \\
\text { cia efectiva desde el } 1 \text { de julio de 1993, afectaron el estatus de las empresas estatales como unidades financieras } \\
\text { del gobierno central, y acercando el sistema financiero chino al ámbito de las empresas modernas y eficientes. }\end{array}$ \\
\hline Mayo de 1993 & $\begin{array}{l}\text { Después del } 14^{\circ} \text { Congreso Nacional del Partido Comunista de China, se hicieron una serie de encuestas sobre } \\
\text { cómo sería mejor establecer las bases generales para una economía socialista de mercado. Fue entonces que } \\
\text { en la 1a Reunión del Octavo Congreso Nacional Popular se hizo una enmienda a la Constitución, que cambiaba } \\
\text { el principio de una economía operada por el Estado por el de economía propiedad del Estado y convertía a las } \\
\text { empresas operadas por el Estado en empresas propiedad del Estado. }\end{array}$ \\
\hline $\begin{array}{l}14 \text { de noviembre } \\
\text { de } 1993\end{array}$ & $\begin{array}{l}\text { Medio año después, en la } 3^{\text {a }} \text { Sesión Plenaria del } 14^{\circ} \text { Congreso Nacional del Partido Comunista de China, se } \\
\text { estableció formalmente la economía socialista de mercado, donde el sistema empresarial moderno de propiedad } \\
\text { pública es la base de este nuevo sistema económico. }\end{array}$ \\
\hline
\end{tabular}




\begin{tabular}{|c|l|}
\hline $\begin{array}{c}29 \text { de diciembre } \\
\text { de } 1993\end{array}$ & $\begin{array}{l}\text { Un mes después, el Comité Permanente del } 8^{\circ} \text { Congreso Nacional Popular adoptó la Ley de Sociedades Mercan- } \\
\text { tiles -Company Law-, con vigencia efectiva el } 1 \text { de julio de } 1994 .\end{array}$ \\
\hline $\begin{array}{c}10 \text { de agosto } \\
\text { de } 1994\end{array}$ & $\begin{array}{l}\text { El Premier Li Peng afirmaba en el Reporte Gubernamental de Trabajo de la } 2^{\text {a }} \text { Sesión del } 8^{\circ} \text { Congreso Nacional } \\
\text { Popular: El Estado organizará varias empresas estatales grandes y medianas, para realizar experimentos que } \\
\text { ayuden a fundar las bases para un sistema empresarial moderno, de acuerdo a la Ley de Sociedades Mercantiles. }\end{array}$ \\
\hline
\end{tabular}

Fuente: Shangquan y Fulin 1997

Básicamente, aparecieron cinco tipos de propiedad que van desde la empresa estatal tradicional a la privatización total:

1. Empresa estatal o colectiva: es la clásica empresa socialista donde el gobierno decide qué producir y a quién, supervisa sus actividades, toma las decisiones de inversión, contrata, despide o promueve a sus empleados y administradores, y se hace responsable por las ganancias o pérdidas. Se localiza usualmente en centros urbanos.

En China, de acuerdo con la Constitución, las empresas estatales son propiedad de toda la gente. En la práctica, cada empresa estatal está afiliada a alguno de los siguientes cuatro órdenes de gobierno: 1) central, 2) provincial (centros urbanos con decenas de millones de personas), 3) prefecturas (ciudades con algunos millones de personas), 4) municipios (con población en el orden de cientos de miles de personas). Al nivel que fuera, usualmente los gobiernos delegan la responsabilidad del seguimiento de las empresas estatales a sus ministerios industriales u órganos económicos. Por lo que el control no se puede considerar de manera homogénea en todos los órdenes de gobierno.

2. Empresa estatal o colectiva reformada (contratos de incentivos a administradores): difiere de las anteriores en que una parte de los derechos de control y sobre los ingresos se reasignan a la empresa y sus administradores. Siguen siendo empleados pagados por el gobierno pero con mayor participación en las decisiones. Los contratos estipulan ex ante la obligación de las aportaciones de impuestos y ganancias al gobierno y la retención de las ganancias marginales -si es que existen.

3. Asociaciones gobierno-administradores: proliferaron desde mediados de los 80 más en el entorno rural, donde las empresas eran típicamente pequeñas y la cantidad de capital invertido por el gobierno era modesto, por lo que sus administradores tenían un margen más amplio que los de las empresas estatales o colectivas reformadas. El trato en el esquema más liberal de este tipo de propiedad podría parecer como de dueño a dueño (gobierno y administradores) donde los riesgos son compartidos y los acuerdos de la repartición de las ganancias duran de 3 a 5 años (y no se renegocian anualmente, como en las empresas reformadas).

4. Arrendamiento de activos públicos: el arrendatario asume todo los derechos de control y sobre ingresos, a cambio de pagos fijos al gobierno, durante un periodo específico. En los tipos de propiedad anteriores, el riesgo es compartido 
(los ingresos del gobierno y los administradores varía de acuerdo a la actividad económica) mientras que en el arrendamiento el pago al gobierno es fijo, independientemente de los resultados.

No se le puede llamar privatización como tal, ya que la inversión inicial es propiedad del gobierno, por lo que este tipo de propiedad produce conflictos cuando el arrendador utiliza las ganancias para inversión de capital. Utilizado más en el entorno local, donde el gobierno buscaba deshacerse de activos no interesantes pero donde no ha encontrado un comprador fuerte para la totalidad de la empresa.

5. Privatización: el gobierno no tiene ningún derecho de propiedad sobre la empresa, aunque la regula y le asigna obligaciones fiscales. Aplicaba principalmente para empresas iniciadas por familias y para empresas públicas que luego son vendidas a emprendedores.

Estos tipos de propiedad se englobaban básicamente en dos regímenes de propiedad: enfocados al gobierno o enfocados al emprendedor. Pero poco a poco, el sector no-estatal (que consistía en las empresas que no están en el sector gubernamental e incluye a las privadas como subsector) comenzó un segundo proceso de evolución.

De acuerdo con su localización había empresas no-estatales urbanas y rurales. Para 1991, había tres categorías para designar a estas empresas en términos de propiedad: colectivas, individuales y otro tipo de propiedad.

En los anuarios oficiales, el espectro de clasificación de empresas no-estatales es el siguiente:

\section{Clasificación oficial del sector no-estatal}

\begin{tabular}{|c|c|c|c|c|c|}
\hline $\begin{array}{c}\text { Clasificación } \\
\text { primaria }\end{array}$ & Colectivas & Individuales & Otros \\
\hline Urbanas & $\begin{array}{c}\text { Empresas } \\
\text { distritales }\end{array}$ & $\begin{array}{c}\text { Empresas de } \\
\text { vecindad }\end{array}$ & $\begin{array}{c}\text { Cooperativas } \\
\text { urbanas }\end{array}$ & $\begin{array}{c}\text { Individuales } \\
\text { urbanas }\end{array}$ & $\begin{array}{c}\text { Privadas } \\
\text { joint ventures } \\
\text { con extranjeras }\end{array}$ \\
\hline Rurales & $\begin{array}{c}\text { Empresas } \\
\text { de sindicaturas }\end{array}$ & $\begin{array}{c}\text { Empresas } \\
\text { de comunidades }\end{array}$ & $\begin{array}{c}\text { Cooperativas } \\
\text { rurales }\end{array}$ & $\begin{array}{c}\text { Individuales } \\
\text { rurales }\end{array}$ & \\
\hline
\end{tabular}

Fuente: Qian y Xu, 1993.

Empresas colectivas (jiti). Las colectivas urbanas incluían a las empresas afiliadas a un gobierno distrital o municipal (grandes colectivas o dajiti), a empresas afiliadas a un vecindario dentro de un distrito o municipio (pequeñas colectivas o xiaojiti) y a las cooperativas urbanas (chengzhen hezuo). Muchas colectivas urbanas eran subsidiarias de empresas estatales y recibían activos transferidos de sus matrices o contrataban al exceso de personal. La ventaja de transferir su control a un orden de gobierno local radicaba en más flexibilidad de negocio y menos vigilancia oficial. ${ }^{2}$

2 Esto se conoce como "una fábrica, dos sistemas" (yichang liangzhi), refiriéndose a que la parte estatal opera en un ámbito de planeación estatal y la parte colectiva en el sistema de mercado abierto. 
Empresas rurales colectivas: seguían la misma lógica, es decir, empresas afiliadas a una sindicatura (xiang o zhen), a una villa (cun) y las cooperativas rurales (nongcun hezuo). Las predecesoras de estas EPA fueron las empresas comunales y de brigada (CBE) que nacieron durante la etapa del Gran Salto Adelante.

Empresas individuales (geti): eran negocios pequeños constituidos por máximo siete personas. Estas empresas han operado desde 1978.

La categoría de otros tipos de propiedad (qita leixing) incluye empresas privadas con más de 7 empleados (siying), empresas extranjeras o asociaciones con extranjeras (sanzi qiye) y otros tipos de asociaciones (como una joint venture entre una empresa estatal y una privada) y las empresas accionarias. Estos tipos de propiedad emergieron hasta bien entrados los 80 y principios de los 90 .

\section{Cierre}

Por casi tres décadas, China aplicó ambiciosos programas de transformación económica, los cuales no han estado exentos de situaciones conflictivas en torno a los derechos de propiedad. La confusión es más pronunciada en torno a las EPA, un sector alguna vez marginal que ha sido uno de los principales responsables del alto crecimiento chino desde finales de los 70 . El valor agregado bruto de estas empresas creció de $9.8 \%$ del total en 1980 a 44\% en 1994, mientras que su participación en el empleo creció de 9.4\% a $33 \%$ de la fuerza total de trabajo rural (Chen 1999).

¿Qué podría explicar el rápido crecimiento de estas empresas? La respuesta yace en el proceso gradual de reformas impulsado por Deng Xiaoping, que se compuso de cuatro grandes etapas.

La primera etapa (1978-1984) fue desarrollada en las áreas rurales bajo el sistema de responsabilidad familiar a través del cual los hogares rurales se encargaban ahora de la producción agrícola y podían vender sus excedentes en el mercado libre.

La segunda etapa (1985-1988) se concentró en las áreas urbanas. Se introdujo un sistema de precios de dos niveles, en que las empresas estatales también vendían su producción marginal a precios de mercado. Los mecanismos de mercado evolucionaron a nuevas dimensiones y alcances. Se le dio autonomía a las empresas para que fijaran los salarios y el Premier Zhao Ziyang sugirió la división entre las autoridades del PCC y los administradores de las empresas en 1987.

La tercera etapa (1989-1991) se caracterizó por el esfuerzo gubernamental para clarificar el entorno económico en el país, rectificar las actividades económicas y preparar el camino para más reformas.

La cuarta etapa comenzó en 1992 con los discursos que Deng Xiaoping emitió durante sus viajes al sur de China. Los discursos abrieron una brecha ideológica en el sistema económico chino y reavivaron las actividades comerciales produciendo un nuevo patrón de crecimiento sostenido. 
La aceleración de la economía china comenzó en la segunda mitad de los 80. La producción agrícola creció de 1978 a 1980, probablemente por el éxito del sistema de responsabilidad familiar. El consecuente incremento en el ingreso aumentó la tasa de crecimiento del consumo. Las ventas finales crecieron más de $20 \%$ entre 1978 y 1985. La inflación se mantuvo estable en menos de 5\%. La economía estaba obviamente expandiéndose bajo el marco institucional de ese entonces, con los recursos y capacidades existentes.

El impacto de las visitas de Deng Xiaoping al sur de China en 1992 creó una nueva forma de pensar que hizo que las autoridades examinaran la estructura económica de aquel entonces y buscaran nuevas estrategias de negocios.

La reforma a las empresas estatales se convirtió entonces en el foco de atención del gobierno chino. Junto con la decisión del gobierno sobre las empresas que implicaba tomar a las grandes para dejar ir las pequeñas y someterlas a la competencia internacional, China comenzó a introducir cambios sobre la estructura de los derechos de propiedad, su definición y el grado de énfasis sobre las diferentes formas que tomarían.

Las empresas estatales se encargaron de proveer recursos esenciales a las nacientes empresas que abastecían el mercado interno del país. Ya fuera a través de la venta de equipo de segunda mano, con ingeniería en reversa, ${ }^{3}$ o con la provisión de servicio técnico, este sector fue un importante conducto para la difusión de procesos y tecnología industriales. Además de proveer apoyo continuo a la industria rural, las empresas estatales contribuyeron a la creación y expansión de nuevos tipos de empresa, que operaban con niveles más altos de sofisticación tecnológica. Por otra parte, muchas de las empresas estatales se han modernizado y convertido en empresas accionarias, cotizando en las Bolsas de Valores de Shanghai, Shenzhen, Hong Kong, Singapur y Nueva York.

No hay que olvidar que las empresas estatales siguen siendo una fuente importante de ingresos fiscales para el gobierno chino. Durante las dos décadas anteriores a las reformas, la industria estatal fue la principal vía de ingresos gubernamentales. Sin embargo, favorecidas por el gobierno y acostumbradas al control monopolístico de los mercados, las empresas estatales se vieron enfrentadas -en un ambiente de relajación de las restricciones competitivas- por un cada vez mayor número de empresas colectivas, que en 1978 representaban 265 mil empresas (tres veces el número de empresas estatales). 30 de las 500 empresas más grandes de China en términos de ventas, provienen de este sector (Jefferson y Singh 1999).

\section{Bibliografía}

-Byrd, William A. y Qingsong Lin, 1990, China's Rural Industry: Structure, Development and Reform, Oxford University Press.

- Chen, Chih-jou Jay, 1999, Property Rights in Southern Fujian, en Jean C. Oi y Andrew G. Walder: Property Rights and Economic Reform in China, Stanford University Press.

3 Reverse engineering 
- Jefferson, Gary H. e Inderjit Singh, 1999, Enterprise Reform in China: Ownership, Transition and Performance, Washington, Oxford University Press.

- Oi, Jean C. y Andrew G., 1999, Walder. Property Rights and Economic Reform in China, Stanford University Press.

- Qian, Yingyi, 2001, How Reform Worked in China, University of California, Berkeley.

- Qian, Yingyi y Chenggang Xu, 1993, Why China's Economic Reforms Differ: The M-Form Hierarchy and Entry/Expansion of the Non-State Sector en The Economics of Transition, $\mathrm{N}^{\circ} 1$ (2).

-Segal, Adam, 2003, Digital Dragon: High-Technology Enterprises in China, Cornell University Press, Nueva York.

-Shangquan, Gao y Chi Fulin, 1997, Reforming China's State-Owned Enterprises, Beijing, Foreign Languages Press. 



\title{
Huawei. Apoyo global y su participación en México
}

\author{
Oscar Eduardo Toulet Lazos y Rosalba Delgado Alvarado
}

Todo inició en un pueblo de pescadores llamado Shenzhen localizado al sur de la República Popular de China junto a Hong Kong. En la década de los años 70, con miras a mejorar la situación económica del país, el gobierno chino decidió establecer algunas zonas específicas que motivaran el desarrollo económico. Se ofrecieron bajos o nulos impuestos para atraer la inversión extranjera, la cual creció de manera acelerada dando pauta a nuevas oportunidades y a la creación de miles de empresas. En este contexto, Ren Zhengfei, fundador de Huawei Technologies, reunió a siete colegas para que entre ellos reunieran con un capital inicial de 2,500 dólares e iniciaron la fabricación de tarjetas de conmutadoras dada la creciente demanda por dichos productos. Con esta primera inversión, en 1987 fundaron entonces la empresa Huawei Technologies Co. LTD (Huawei).

Conforme creció el mercado, crecieron el negocio y la empresa, teniendo desde su fundación dos objetivos claves por alcanzar. El primero fue conocer, apoyar y asegurar un valor agregado para sus clientes. El segundo, reinvertir sus ingresos para desarrollar productos y soluciones innovadoras con tecnología de punta. Como complemento de los anteriores, se daría atención prioritaria a un mercado abandonado: dar acceso a las comunicaciones en las zonas rurales. Al hacerlo, Ren Zhengfei se dio cuenta de que cada zona rural que lograba comunicarse con las urbes en un corto tiempo mejoraba considerablemente su economía y enriquecía la vida de sus pobladores. Fue entonces que adoptó la visión de Huawei: enriquecer la vida de las personas a través de la comunicación.

Hoy, veinticinco años después, Huawei se ha convertido en el segundo proveedor más grande de tecnologías de información y comunicaciones (TIC) del mundo. Sus ventas globales registradas en 2011 alcanzaron 31 mil millones de dólares, mismas que la colocan en el lugar 352 de la revista Global 500 el mismo año. Su crecimiento exponencial ha sido de tal magnitud, que una tercera parte de la población mundial utiliza soluciones o infraestructura de redes de telecomunicaciones que Huawei ha desarrollado; en muchos casos sin ser de conocimiento de sus propios usuarios.

Con presencia en más de 140 países y más de 130,000 empleados, de los cuales $44 \%$ se dedican a continuar generando innovación tecnológica, Huawei apoya a 45 de los 50 operadores de servicios de telefonía más importantes a nivel mundial. Para ellos es críticamente importante proveer a sus clientes de servicios avanzados que también agreguen valor a sus vidas. Ofrecer una red altamente confiable y con una extensa cobertura ya no son ventajas competitivas de la industria, pues los usuarios cuentan con mayor información y necesidades que les hacen suponer que las redes de telecomunicaciones tienen dichas características de facto. Entonces, para crear valor a largo plazo, Huawei debe asegurar que su crecimiento es sólido y que mantiene su liderazgo en otorgar soluciones y apoyo a redes de telecomunicaciones e informática. 
De los más de 20 centros de investigación y desarrollo a nivel mundial, Huawei somete a aprobación más de 3,000 patentes ante el Tratado de Cooperación de Patentes (PCT por sus siglas en inglés), de las cuales un promedio de 280 son concedidas mensualmente, contribuyendo significativamente al número total de patentes otorgadas a la República Popular de China que lo ubican en la posición 4 a nivel mundial, de acuerdo con la Organización Mundial de Propiedad Intelectual. Cabe hacer aquí una pequeña reflexión, ¿cuántas patentes son otorgadas anualmente a todos los centros de investigación y desarrollo de Mexico?

En los últimos seis años, Huawei ha logrado mantener un crecimiento sostenido promedio año con año de $29 \%$. Con ello se puede asegurar que Huawei es una empresa sólida y preparada con respaldo que le permite establecer alianzas tecnológicas con sus clientes y continuar apoyando el crecimiento de las telecomunicaciones de México y del mundo.

En la región norte de América Latina, que para Huawei representa a los principales 13 países latinoamericanos que incluyen al Caribe y parte de los países andinos, se alcanzaron ventas en 2011 cercanas a los 2 mil millones de dólares con una plantilla superior a los de 4,600 empleados. Esto contribuyó a que Huawei se convirtiera en el segundo proveedor más importante de la región, con $29 \%$ del mercado considerando las ventas registradas y auditadas del 2010. En materia de competencia, arriba de Huawei se ubica la empresa sueca Ericsson con $31 \%$ del mercado, y debajo de ambos la firma finlandesa Nokia-Siemens con $16 \%$ del mercado, Alcatel-Lucent con $14.6 \%$ y Cisco con $8.9 \%$ del mercado.

En México, Huawei también ha logrado un crecimiento impresionante. Durante el último lustro logró captar $17 \%$ del mercado de telecomunicaciones, teniendo por encima únicamente a Ericsson (35\%) y seguida por Nokia-Siemens (16\%), Cisco (15\%) y Alcatel-Lucent (15\%). Otros proveedores menores poseen $2 \%$. La plantilla de empleados superó los 1,600 empleados, distribuidos en sus oficinas de la Ciudad de México, Monterrey y un centro de manufactura en Guadalajara. Al cierre de 2011, las ventas de Huawei México superaron los 700 millones de dólares.

En este país, Huawei ha logrado posicionarse como socio tecnológico de los principales operadores, proporcionando soluciones, equipamiento y servicios a redes fijas y móviles, teniendo siempre en mente mejorar la experiencia de los usuarios.

Además de ayudar a establecer, optimizar y crecer las redes de telecomunicaciones, que nos permiten levantar o activar un teléfono y siempre contar con "el tono de servicio" en el caso de redes fijas, o con una buena "disponibilidad de señal" en el caso de redes móviles, Huawei también abrió un centro de investigación y desarrollo en la Ciudad de México. Este centro desarrolla proyectos y soluciones de software que agregan valor a nuestras vidas con aplicaciones y novedosas formas de instalar dichas aplicaciones a los teléfonos inteligentes en forma de contenido que adecue los teléfonos a la particular forma de vida de cada usuario.

Otro aspecto importante que Huawei toma con seriedad e importancia es la responsabilidad social. En apoyo a la sociedad y la calidad de vida de los ciudadanos, los siguientes cuatro aspectos son pilares importantes en la filosofía de trabajo de Huawei: educación, catástrofes, reducción de la brecha digital y salud. 
En materia de apoyo a la educación, durante 2011 Huawei apoyó donando un switch de núcleo de red, equivalente al corazón de la conmutación de información de una red. Su interés fue asegurar que los estudiantes practicaran con equipos con tecnologías de punta para que llegado el momento de participar al mercado laboral, cuenten con el conocimiento actualizado de la tecnología que se utiliza en la realidad.

Otra forma de apoyo a la educación también se alcanzó gracias a la participación que Fundación Telefónica le concedió a Huawei en su programa "Proniño". Este noble e importante programa hace frente a la problemática que enfrentan algunos niños en zonas rurales al ser obligados por sus padres a trabajar. Proniño parte del derecho primordial de los niños a estudiar y jugar. Para garantizar estos derechos, el programa lleva tecnología avanzada a comunidades rurales en donde se educa primero a padres y maestros para que éstos aprecien el valor de la educación a sus hijos y alumnos, y posteriormente les den estas herramientas que posibiliten su crecimiento en la vida.

Durante la emergencia nacional sanitaria ocasionada por el virus de la influenza AH1N1, Huawei colaboró con Patrimonio de la Beneficencia Pública donando mascarillas para su distribución entre la población. Tras dicha colaboración, en 2011 se apoyó nuevamente a la Secretaría de Salud mediante el ofrecimiento de una donación constituida por prótesis y terapias de rehabilitación para un número determinado de personas que cuentan con Seguro Popular y que requieran estos implantes y servicios para recuperar el movimiento de su parte motriz dañada y se reincorporen a la sociedad.

Recientemente, Huawei comenzó a dirigir esfuerzos hacia el mercado empresarial y de gobierno mediante el ofrecimiento de una amplia gama de servicios profesionales de alta calidad que le permitirá a ambos sectores contar con la experiencia y el apoyo de los expertos de Huawei que administran, monitorean y mantienen las redes más complejas y eficientes de telecomunicaciones e informática a nivel mundial, permitiendo a dichos sectores abocarse a su área de competencia y dejar los aspectos de comunicación en manos confiables y expertas.

La economía de un país se ve beneficiada cuando el balance de importaciones y exportaciones es favorable. Para contribuir al comercio internacional y a la mejora del citado balance, Huawei estableció un centro de manufactura, almacenaje y distribución en Guadalajara. De acuerdo con las cifras del tercer trimestre de 2011, este centro colocó importaciones por un valor de 9.8 millones de dólares y exportaciones por 1.2 millones de dólares. Asimismo generó productos que se utilizaron para incrementar la infraestructura de telecomunicaciones en México y otras regiones de América Latina donde también se destinan estas exportaciones.

En resumen, Huawei desarrolla y produce bienes con tecnología de punta y soluciones que facilitan la operación de redes de telecomunicación e informática en el mundo. Adicionalmente asesora a empresas, sectores de gobierno y proveedores de servicios de telecomunicaciones, y contribuye en los procesos de planeación de dichos sectores para contar con antelación o de manera inmediata con los nuevos servicios o aplicaciones requeridos por los clientes o el mercado.

El mundo evoluciona rápidamente y también las tecnologías que facilitan nuestra vida diaria. En un futuro cercano, el mercado de las TIC experimentará cuatro migraciones importantes que cambiarán el mundo. En primer lugar, los servicios de voz pasarán 
a segundo plano, y serán sustituidos por servicios de datos. Veremos crecer rápidamente la demanda de los usuarios de contar con servicios de banda ancha que les permitan transferir grandes cantidades de datos a sus dispositivos, fijos o móviles, en lugar de contar con el tradicional servicio de voz que fue motivo por el que usamos teléfonos.

El segundo cambio importante es el que experimentarán los proveedores de servicios de telefonía. Se han convertido en proveedores de ductos de transmisión de voz y datos y necesitan cambiar su enfoque para que sean proveedores de contenidos e información.

En tercer lugar, veremos cómo las redes de comunicaciones tendrán otro componente crítico que será la informática. El control de la seguridad de la información, su almacenamiento y la disponibilidad de la misma son aspectos que hoy día se instrumentan alrededor del mundo con la aparición del concepto de la red "nube".

Finalmente, el último cambio revolucionario e importante es que la comunicación dará un salto cuántico. En otras palabras, en lugar de que el mayor volumen de comunicación que circula en las redes sea de humanos entre humanos, se experimentará ahora la comunicación de máquinas a máquinas. De hecho, en la actualidad las tecnologías como bluetooth y Wi-Fi permiten que dos o más equipos se identifiquen e inicien comunicación inmediata de manera automática cuando están cerca unos de otros sin necesidad de recibir instrucción alguna por parte de seres humanos. Lo más impactante, sin embargo, es que mientras para las generaciones del fin del siglo pasado esto sería posible únicamente en películas de ciencia ficción, para las generaciones actuales no representa más que una lista de características imprescindibles y básicas de los productos que deben estar disponibles en el mercado.

Tecnológicamente hablando, para que las cuatro migraciones convivan adecuadamente, el mercado verá cómo los aspectos convergen en una plataforma que asegura una perfecta convivencia entre señales y protocolos digitales que viajan a velocidades de millones de millones de bytes por segundo gracias a la supercarretera de ancho de banda que se despliega para mejorar el servicio de todos los usuarios y que se conoce como "Broad Band", contemplada en los planes de gobierno y de operadores líderes del mercado.

Sabemos que el proceso es acelerado y con cambios muy fuertes. Sin embargo, gracias a la vasta experiencia que Huawei tiene a nivel mundial y al compromiso que hemos adquirido con México, nos aseguraremos de que todos los involucrados cuenten con la infraestructura, los servicios, los dispositivos necesarios y que el contenido que utilicen se logre integrar en una red que sea más fácil de operar, generando mayores oportunidades de comunicación para toda la sociedad. 
Sección 9:

Hacia una historia compartida 



\section{Encuentros y desencuentros. México y la República Popular China antes del establecimiento de relaciones diplomáticas \\ (1949-1972)}

Jorge Octavio Fernández Montes

Desde la fundación de la República Popular China (RPCH) el 1 de octubre de 1949 hasta el establecimiento de relaciones diplomáticas el 14 de febrero de 1972, todos los gobiernos mexicanos, salvo la gestión de Díaz Ordaz, manifestaron un claro interés por estrechar las relaciones con el gobierno popular central de la $\mathrm{RPCH}$. El interés económico y la idea de diversificar los mercados para los excedentes mexicanos fueron variables que prevalecieron en la mayoría de los casos. El interés político, emanado de los ideales que rigen el comportamiento diplomático de México, también surgió periódicamente a lo largo de cinco periodos presidenciales. Poco se pudo concretar de esos deseos. Todos los gobiernos, incluida la gestión del presidente Luis Echeverría, cejaron al miedo de afectar su relación con Washington. En poco más de dos décadas, el interés por preservar la relación México-EU prevaleció sobre el deseo de estrechar la relación con la RPCH.

El trabajo que aquí se expone concentra documentos que dan cuenta de periodos concretos de la relación México-RPCH a lo largo de cinco periodos presidenciales. Presenta información inédita de archivos del Ministerio de Asuntos Exteriores de la RPCH, del Departamento de Estado de EU y de la Secretaría de Relaciones Exteriores de México, desde la gestión del presidente Miguel Alemán hasta la gestión de Luis Echeverría, a fin de estimular el interés para ampliar el conocimiento de un periodo histórico poco conocido entre México y China. Finalmente concluye que para el estudio de este periodo histórico, que se inserta en la llamada Guerra Fría, la valoración que las distintas gestiones presidenciales hicieron de la relación México-EU, determinó el grado de acercamiento o alejamiento entre México y la RPCH.

Miguel Alemán: pasos frustrados para el establecimiento de relaciones diplomáticas con la RPCH

Los primeros días de julio de 1950, funcionarios del gobierno de México comenzaron a gestionar informalmente un acercamiento con la RPCH por medio de la embajada de Polonia acreditada en México. El secretario de Relaciones Exteriores, Manuel Tello, solicitó una reunión con el embajador polaco en México para pedir al gobierno de Polonia que fungiera como interlocutor entre México y la RPCH. Tello pidió el embajador polaco extender a las autoridades del gobierno popular central dos mensajes del presidente 
Miguel Alemán: anunciar el deseo del presidente Alemán de establecer relaciones diplomáticas con la Nueva China y aclarar que para el gobierno de México los diplomáticos del Guomindang eran ciudadanos extranjeros y que no representaban al gobierno legítimo del pueblo chino. ${ }^{1}$

El gobierno de Polonia aceptó la solicitud para fungir como enlace entre México y la $\mathrm{RPCH}$, y encomendó al embajador polaco en la RPCH, Juliuz Burgin, transmitir al primer ministro Zhou Enlai el mensaje del canciller mexicano. El 11 de julio de 1950, Burgin presentó a Zhou Enlai el mensaje de Tello y la posición del gobierno de México en relación al Guomindang. El 20 de julio, el primer ministro Zhou Enlai explicó a Burgin que si el gobierno de México reconocía al gobierno popular central de la RPCH como el único representante legítimo del pueblo chino, y que si el gobierno de México estaba dispuesto a establecer una relación regida por principios de igualdad, beneficio compartido y respeto mutuo, entonces ambas partes podrían iniciar a la brevedad posible gestiones para el establecimiento de relaciones diplomáticas. Zhou Enlai sugirió dos canales para el inicio de conversaciones: el envío de una notificación formal al gobierno central de la $\mathrm{RPCH}$, o el establecimiento de una ronda de conversaciones informales en la embajada de Polonia acreditada en México. ${ }^{2}$

El 9 de agosto, el embajador Burgin transmitió al primer ministro Zhou Enlai la postura del gobierno mexicano para el asunto de "las dos Chinas". Tras pedir al gobierno comunista guardar absoluta discreción, Tello explicó que la política del presidente Miguel Alemán era mantener la posición de México en secreto cuando la polémica prevalecía en las Naciones Unidas. En el caso de China, el canciller aclaró que mientras el gobierno comunista generara controversia, México se reservaba el derecho de intercambiar o repatriar a sus diplomáticos de la isla de Taiwán. El diplomático mexicano explicó que si bien el gobierno de México no había hasta el momento tomado acciones para reconocer a la $\mathrm{RPCH}$, optaba por repatriar a todas sus misiones diplomáticas de territorio controlado por el gobierno del Guomindang y aseguraba que el gobierno de México no enviaría a ninguna representación a la isla de Taiwán. ${ }^{3}$

El 20 de septiembre, el primer ministro Zhou Enlai anunció por conducto del embajador Burgin que el gobierno popular central de la RPCH recibía con beneplácito la posición del gobierno de México en torno a sus relaciones con el Guomindang. Las conversaciones para el establecimiento de relaciones diplomáticas, ahora que México había hecho explícita su posición, podían entrar sin problemas en una fase inicial. Zhou Enlai sugirió que funcionarios de la cancillería mexicana asistieran a la embajada de

1 Pei Jianzhang, Zhonghua renmin gongheguo waijiaoshi (Historia Diplomática de la República Popular China), vol. 1, Beijing, Shijie zhishi, 1994, p. 352. Hay una errata en el documento original en relación al cargo de Manuel Tello. La historia oficial de la RPCH dice que fungía como ministro de la Suprema Corte de Justicia. Esto probablemente se debe a un error de traducción: El cargo de "Oficial Mayor" se tradujo primero del español al polaco y después del polaco al chino. Tello tenía en ese entonces cargo de secretario de Relaciones Exteriores.

2 "Zhou Enlai waizhang wei moxige zhengfu yu wo jianjiaoshi zhi bolan zhengfu de fuhan" (Respuesta del ministro del Exterior Zhou Enlai al gobierno de Polonia sobre el asunto del establecimiento de relaciones diplomáticas entre México y la RPCH) Departamento de Archivos del Ministerio de Asuntos Exteriores de la RPCH(PRCFMA) 111-00002-02.

3 "Bolan dashi zhuanda moxige zhengfu yu wo jianjiaoshi fuhanzhihuida" (El embajador de Polonia transmite al gobierno de México la respuesta a la carta sobre el establecimiento de relaciones diplomáticas entre México y la RPCH) PRCFMA: 111-00002-03. 
Polonia acreditada en México para que afinaran junto con sus homólogos polacos los detalles de las conversaciones posteriores entre México y la RPCH. ${ }^{4}$

Las primeras gestiones del gobierno mexicano para establecer un contacto con la $\mathrm{RPCH}$ ocurrieron a la par de los primeros meses de la guerra de Corea. Las autoridades mexicanas aparentemente desvincularon a la RPCH de la conflagración en la península coreana. La intervención del Ejército Popular de Voluntarios Chinos el 19 de octubre de 1950; no obstante, cambió la percepción del gobierno del presidente Alemán y demandó que México adoptara una posición coherente con las políticas que la administración del presidente de Estados Unidos, Harry S. Truman, dictaba para México y para la RPCH.

La última semana de noviembre de 1950, tras numerosas presiones del Departamento de Estado de EU, para convencer a México de enviar tropas a Corea, ${ }^{5}$ el recién investido embajador de EU, en México, William O’Dwyer, solicitó una reunión con Manuel Tello para tratar el asunto de los comunistas chinos en Corea y la colaboración de México en un comando unificado. O’Dwyer quería conocer la opinión de México en caso de que se presentara en la Asamblea General de las Naciones Unidas un proyecto para declarar agresora a la RPCH y, consecuentemente, coordinar un ataque con soldados mexicanos y latinoamericanos contra el estado comunista chino. Tello indicó que México no estaba en posibilidad de proporcionar soldados para una acción conjunta contra la RPCH, pero explicó que si quedaba plenamente aclarado que México no tenía obligación de participar con tropas en contra de China comunista, entonces el gobierno de México estaba en condiciones de votar favorablemente por ese tipo de resolución. El 1 de febrero de 1951, tras apenas unos meses de haber buscado un contacto con funcionarios chinos para establecer relaciones diplomáticas con la Nueva China, México giraba instrucciones a su delegado permanente ante la ONU, Padilla Nervo, para que votara por la resolución en la que se declaraba agresora a la RPCH (Tello, pp. 37-38).

\section{Ruiz Cortines: el miedo a establecer relaciones comerciales con la RPCH}

En el verano de 1955, Ricardo Zevada, director del Banco Nacional de Comercio Exterior, y Rodrigo Gómez, director del Banco de México, discutieron con el presidente de México, Ruiz Cortines, la posibilidad de iniciar relaciones comerciales con la República Popular China. La inquietud respondía a una ola de presiones emanadas de la izquierda mexicana que, al tiempo que demandaba el establecimiento de relaciones diplomáticas con la China Popular, argumentaba los efectos económicos adversos que el embargo de Estados Unidos a la RPC tenía sobre la economía mexicana. En opinión de los grupos mexicanos de izquierda, China constituía un mercado para los excedentes mexicanos y podía ser fuente de mercancías por las que México pagaba a revendedores internacionales que, paradójicamente, eran los mismos que bloqueaban a la RPCH y prohibían a México el establecimiento de relaciones comerciales (Boletín SMACHP).

4 "Zhou enlai buzhang jiu youguan moxige yu wo jianjiaoshi fu bolandashi de han" (Respuesta del Ministro Zhou Enlai al embajador de Polonia en relación al establecimiento de relaciones diplomáticas entre México y la RPCH) PRCFMA: 111-00002-04

5 "El secretario de Estado al secretario de Defensa (Marshall)", Washington, 23 de febrero de 1951, Foreign Relations of the United States (FRUS), Korea and China1951, vol.VI I: 194. 
El proyecto que los funcionaros del comercio mexicano plantearon al presidente Ruiz Cortines giraba en torno a la venta de petróleo, zinc y algodón. En aquel entonces, México intentaba sortear los problemas derivados de la innovación tecnológica de países industrializados. La aplicación de nuevas tecnologías para la elaboración de productos sintéticos impactaba negativamente en países como México, cuyas materias primas de origen natural tenían un costo comparativo más alto al de los productos fabricados por países industrializados. Así, mientras la diversificación del comercio era, por un lado, una opción y un incentivo, el temor al conflicto que podría provocar con los Estados Unidos el hecho de que México vendiera productos estratégicos a la RPCH, por otro lado obstaculizaba las conversaciones con el presidente.

Finalmente, aprovechando la celebración de la décima reunión de la Junta de Gobernadores del Banco Internacional para la Reconstrucción y el Desarrollo, celebrada del 12 al 16 de septiembre en Estambul, Turquía, el presidente Ruiz Cortines autorizó a Zevada a designar a una delegación para ir a Hong Kong, establecer contacto con funcionarios de comercio de la RPCH e iniciar conversaciones para el establecimiento de relaciones comerciales. Entre las condiciones estaba que ningún producto estratégico entraría en la negociación, no se revelaría a la prensa información alguna sobre las negociaciones y el presidente seguiría de cerca todas las actividades de la delegación. ${ }^{6}$

Zevada nombró a Adrián Lajous y a Adolfo Crespo como los encargados de iniciar las gestiones para establecer relaciones comerciales con China Popular. El 8 de noviembre de 1955, Lajous y Crespo iniciaron conversaciones en Hong Kong con representantes de la compañía Huarun, intermediaria para asuntos comerciales entre la RPCH y el resto del mundo. Los funcionarios mexicanos explicaron a los directivos de Huarun el interés del gobierno de México por diversificar el comercio, revertir la dependencia del comercio mexicano en EU y encontrar productos y mecanismos concretos de negociación con la RPCH. Ambas partes observaron que las restricciones legales para el comercio de productos restringidos, el problema del transporte y la moneda de pago eran obstáculos gestionables y que las posibilidades de establecer relaciones comerciales entre México y la RPCH eran viables y redundaban en el beneficio de los dos países. ${ }^{7}$

Los directivos de la empresa Huarun en Hong Kong aclararon a los funcionarios mexicanos que las conversaciones podrían girar en torno a dos temas: el establecimiento de relaciones comerciales formales o el acuerdo de negocios en concreto. Indicaron que para el establecimiento de relaciones comerciales oficiales, sería necesario primero definir los principios de la relación y que esto sólo podría hacerse entre funcionarios mexicanos y chinos en alguna embajada de la RPCH acreditada en el extranjero o en la parte continental de China. Y agregaron que para el establecimiento de negocios

6 "Sulian zhu huashiguan jiaowo guanyu moxige waimaoyinhang daibiaochu ni fangwen xianggang bing wo zhu xianggang daibiao jianli lianxishi de beiwanglu " (Memorando de la Embajada de la RPCH en la URSS en relación a la delegación del Banco Nacional de Comercio Exterior que desea visitar Hong Kong y establecer contacto con la representación de la RPCH en Hong Kong.) PRCFMA: 111-00105-08.

7 "Guanyu moxige waimao yinhang daibiao ni yu wo zhu xianggang daibiao jianli lianxishi de chuli yijian (Sugerencia para la gestión del asunto de la delegación del Banco Nacional de Comercio Exterior que desea establecer contacto con la representación de la RPCH en Hong Kong) PRCFMA: 111-00105-09. 
en concreto, podrían hacerlo directamente con la empresa Huarun, que tenía un gran interés por comprar o trocar algodón mexicano. ${ }^{8}$

El 14 de noviembre, a escasos días de haber comenzado las conversaciones, Lajous y Crespo partieron súbitamente de Hong Kong rumbo a México sin un acuerdo de fondo en torno al intercambio o al establecimiento formal de relaciones comerciales entre los dos países. Escuetamente aclararon a sus contrapartes chinas que en el futuro, cualquier asunto comercial entre México y China podría ser discutido con Zevada en el Banco Mexicano de Comercio Exterior. Y sugirieron, antes de marcharse, que el comerciante español nacionalizado mexicano, Josué de Benito, fuera el intermediario para la venta de algodón y otros productos entre México y la RPCH. ${ }^{9}$

Varias décadas después, Adrián Lajous aclara en sus memorias que el abandono de las conversaciones mantenidas con directivos de Huarun respondía a órdenes directas del presidente Ruiz Cortines. El mandatario mexicano temía que las indagaciones de la delegación mexicana con la RPCH salieran a la luz y que fueran interpretadas como irreverencias a la administración del presidente Eisenhower. Lajous explica que el presidente Ruiz Cortines tenía un gran temor a las represalias de EU, al punto de pensar que la salida de divisas de México en 1954 respondía a una maquinación de la CIA para castigarlo por la negativa a apoyar a EU contra el gobierno de Jacobo Arbenz en Guatemala. No es fortuito que el argumento que prevaleció para repatriar a la misión negociadora de Hong Kong fuera, entonces, el miedo a la represalia si la administración de Eisenhower se enteraba de que funcionarios mexicanos mantenían conversaciones con funcionarios de China comunista para el establecimiento de relaciones comerciales. Lajous lo explica de la siguiente forma: "Concluidas satisfactoriamente las negociaciones, tuve que echarme para atrás porque don Adolfo había cambiado de opinión. Me contó don Rodrigo Gómez [director del Banco de México] que [el presidente] Ruiz Cortines le había dicho: 'Siempre no. Allá espantan'. Pero estaba pensando en Washington, más que en Pekín" (Lajous, p.170).

\section{Adolfo López Mateos: a un paso de la apertura de oficinas comerciales en México y} en la RPCH

El 8 de enero de 1963, el secretario de Industria y Comercio de México, Raúl Salinas Lozano, recibió en la Ciudad de México a Ji Chaoding, vicepresidente del Consejo Chino para el Fomento del Comercio Internacional, con quien habló sobre la solicitud de la $\mathrm{RPCH}$ para montar una exhibición de productos industriales y comerciales en México. ${ }^{10}$ Salinas Lozano no sólo transmitió la anuencia del presidente Adolfo López Mateos para materializar la propuesta de su gobierno, sino que aconsejó para tal fin, dada la inexistencia de relaciones diplomáticas entre México y la RPCH, la formación de un comité no

8 “Huarun gongsi yu moxige waimao yinhang daibiao qiaotan maoyi qingkuang de qingshi chuli yijian 9 Idem

10 “Wo jingji maoyi daibiaotuan fangwen moxige zongjie baogao ji fujian" (Informe y archivo adjunto de la delegación comercial y económica de la RPCH que visitó México) PRCFMA: 111-00477-01.

(Instrucciones para las conversaciones entre el Banco Nacional de Comercio Exterior y la empresa Huarun) PRCFMA: 111-00105-10. 
gubernamental para apoyar a los funcionarios de la RPCH en las gestiones necesarias para la exhibición. ${ }^{11}$

Así, por iniciativa del secretario de Industria y Comercio, Salinas Lozano, quedó establecido el Comité Mexicano de Fomento para las Relaciones Económicas con China Popular, encabezado por los economistas José Luis Ceceña, Félix Espejel, y por el comerciante mexicano de origen libanés, Guillermo Nasser Quiñones. A lo largo de casi un año, el Comité fungió como intermediario entre funcionarios del gobierno mexicano y de la RPCH para gestionar todos los trámites necesarios de la exhibición. Además de contribuir a la realización de la Exposición Económica y Comercial China, misma a la que asistió el presidente López Mateos y en la que Salinas cortó el 7 de diciembre la cinta en la ceremonia inaugural, el Comité consiguió la rúbrica de contratos con intervención de la Secretaría de Agricultura, del Banco Nacional de Crédito Ejidal, del Banco Nacional de Comercio Exterior y del Banco de China (Comercio Exterior, p. 900).

El 26 de diciembre, tres días antes de la clausura de la Exposición Económica y Comercial, el Comité Mexicano de Fomento para las Relaciones Económicas arregló una reunión con el presidente López Mateos a fin de que el jefe de la delegación china a cargo de la Exposición Económica, Zhang Guangdou, presentara al presidente sus respetos antes de partir de regreso a China. En la conversación, Félix Espejel y José Luis Ceceña aprovecharon la ocasión para proponer al presidente López Mateos y a Zhang el establecimiento de oficinas de representación comercial permanentes ante la falta de relaciones diplomáticas. López Mateos apoyó la idea argumentando que el establecimiento de una oficina representativa de la RPCH en México era necesaria y que facilitaría el intercambio comercial. Para sorpresa de Espejel y de Ceceña, Zhang Guangdou aclaró que él no estaba en posición de aceptar o rechazar la invitación, pero indicó que consultaría con las autoridades de la RPCH y que una vez que tuviera respuesta, de ser positiva, lo comunicaría al Comité para que ambas partes iniciaran a la brevedad posible las negociaciones correspondientes. ${ }^{12}$

Zhang Guangdou recibió el 8 de enero de 1964 autorización de la Oficina de Asuntos Exteriores del Consejo de Estado para iniciar las gestiones necesarias e iniciar la apertura de una oficina de representación comercial de la RPCH en México. Guillermo Nasser Quiñones acudió en representación de Zhang a las oficinas de la Secretaría de Gobernación que, ya con la venia del presidente, informó de las condiciones que la RPCH debía cumplir en México para acreditar su oficina comercial: “Un máximo de cinco personas, ninguno titular de pasaporte diplomático, puede permanecer en México hasta por un periodo de dos años como representante de la oficina o representación de la RPCH en México. Bajo ningún motivo la oficina comercial está autorizada a colgar a la entrada de sus instalaciones la bandera nacional de la RPCH." 13

11 Entrevista con Félix Espejel, presidente del Comité Mexicano de Fomento para las Relaciones Económicas con China Popular, 2 de octubre de 2010.

12 "Guanyu wo zai moxige shezhi shangwu jigou de qingshi" (Instrucciones para el establecimiento de una oficina comercial en México) PRCFMA: 111-00526-01; entrevista con Félix Espejel, op.cit

13 "1963 nian wo fu moxige juban jingji maoyi zhanlanhui you guan wendian ji qingkuangbaogao" (Informe y telegramas en relación a la Exposición Económica y Comercial que la RPCH montó en México en 1963) PRCFMA: 111-00477-06. 
El Comité Mexicano de Fomento, por su parte, aprovechó el momentum para discutir con funcionarios del Banco de Comercio Exterior la apertura de una oficina comercial de México en la RPCH. Tras conversaciones con Zevada, director del Banco Nacional de Comercio Exterior, el Comité solicitó a las autoridades de comercio chinas una invitación para que en abril una delegación de funcionarios y empresarios mexicanos visitara la RPCH. Zevada decidió que la misión se enmarcara en el Plan de Acción Conjunta, impulsado por el Banco de Comercio Exterior, y que quedara presidida por Gustavo Solórzano, gerente de la Impulsora y Exportadora Nacional, y que contara entre sus miembros con Enrique Soto Izquierdo, del Banco Nacional de Comercio Exterior, José Luis Ceceña, representante de la Empresa Compensación Internacional, Mario Antonio Durán, jefe del Departamento Técnico de la Cía. Nacional de Subsistencias Populares y Carlos Barraza de la Cía. Confecciones Internacionales S.A de Tijuana, B.C. ${ }^{14}$

En Beijing, el primer ministro Zhou Enlai recibió el 1 de mayo a la misión mexicana, que ya llevaba en la nación china 15 días de conversaciones con altos funcionarios. Zhou Enlai indicó que había escuchado con agrado las declaraciones de Zevada a la prensa mexicana, en la que anunciaba la inminente apertura de una oficina comercial de la RPCH en México, y declaró que si México deseaba abrir una oficina comercial en Beijing, el gobierno central otorgaría todas las facilidades y garantías al personal para su funcionamiento (Gómez Bulnes). Las declaraciones del primer ministro no eran más que la repetición de las conversaciones que Ceceña había tenido el 20 de abril con funcionarios del Ministerio de Comercio, a quienes informaba que México enviaría a tres funcionarios a su oficina comercial en la RPCH. Únicamente quedaba pendiente en la negociación la redacción de un documento que rubricara la intención de ambas partes. ${ }^{15}$

Las conversaciones para la apertura de oficinas comerciales quedaron suspendidas el 29 de abril por indicaciones de Guillermo Nasser, del Comité Mexicano de Fomento. El presidente López Mateos había cambiado de opinión y ordenaba la cancelación de toda negociación para la apertura de oficinas comerciales. López Mateos había seguido de cerca los primeros días de abril el golpe militar contra el presidente de Brasil, Joao Goulart, y el arresto el día 3 de periodistas y funcionarios de comercio chinos, quienes en México habían colaborado en la Exposición Económica y Comercial, y a quienes ahora se les acusaba de espionaje. En una conversación con Ricardo J. Zevada, el presidente López Mateos explicó que el golpe militar contra Joao Goulart había cambiado la estructura en el sistema de países latinoamericanos y que, por ello, el gobierno mexicano se quedaba solo y en una posición desfavorable frente a las presiones de EU. El volumen comercial podía aumentarse, pero la apertura de una oficina comercial permanente de china comunista en México quedaba fuera de toda negociación. ${ }^{16}$

14 "Guanyu tongyi moxige maoyi daibiaotuan fanghua he qing zhouenlai zongli jiejian de qingshi" (Sobre la aceptación para que la delegación comercial de México visite a la RPCH y sobre la solicitud para que los reciba el primer ministro Zhou Enlai) PRCFMA: 111-00372-07.

15 "Guanyu tongyi moxige maoyi daibiaotuan fanghua he qing zhouenlai zongli jiejian de qingshi" (Sobre la aceptación para que la delegación comercial de México visite a la RPCH y sobre la solicitud para que los reciba el primer ministro Zhou Enlai), op. cit.

16 "Moxige guoji buchang gongsi nasaier gei maocuhui laixin gao moxige zongtong bu tongyi wo zai mo sheshangwu daibiaochu" (El director de la Compañía Compensación Internacional, Guillermo Nasser, envía una carta al Comité para la Promoción Internacional del Pueblo Chino para decir que el presidente de México no autoriza el establecimiento de una oficina comercial) PRCFMA: 111-00526-02. 


\section{Díaz Ordaz: el complot contra los corresponsales de la agencia Xinhua}

La autorización del presidente López Mateos para establecer en enero de 1964 una corresponsalía de la agencia de noticias Xinhua en México causó preocupación en la embajada de la República de China en México. El embajador Feng Shang Ho argumentaba que Beijing operaba sistemáticamente en todo el mundo para infiltrarse y conseguir el establecimiento de relaciones diplomáticas. Bajo esa premisa, el establecimiento permanente de una sucursal de Xinhua respondía, según Feng, a los esquemas calculados de Beijing: Xinhua minaba la legitimidad de la China Nacionalista en México y tentaba al gobierno de Díaz Ordaz a que estrechara relaciones con China Popular. El embajador Feng estaba convencido de que la diplomacia de Taiwán debía librar una lucha sin cuartel para erradicar de México a los comunistas chinos (Feng Shan Ho, p. 597).

Feng usó todos los medios a su alcance para desvirtuar el trabajo de los comunistas chinos en México. En una recepción en México, Feng conoció al periodista estadounidense Jack Anderson, investigador de la revista Parade, con quien trabó amistad y a quien pasó información sobre el perfil de los corresponsales de Xinhua. ${ }^{17}$ La información parcial de Feng codificada al lenguaje mediático de Anderson, salió a la luz el 7 de febrero: Anderson señalaba a Wu Chu, corresponsal de Xinhua, como coronel al servicio del buró de inteligencia comunista chino y jefe de una organización espía en México. Parade decía que los comunistas chinos habían sido trasladados de la Habana a la Ciudad de México para ampliar la red de espionaje de la RPCH. Anderson aseguraba que Wu Chu tenía un centro de operaciones en la ciudad fronteriza de Mexicali y que desde ahí obtenía secretos de la defensa nacional de los EU (Anderson, pp. 362-367).

La vinculación que Anderson hacía entre el robo de secretos de EU y los corresponsales de la agencia Xinhua generó inquietud entre funcionarios y ciudadanos estadounideneses. El Departamento de Estado de EU ordenó al embajador acreditado en México, Fulton Freeman, a que solicitara al gobierno de Díaz Ordaz información sobre las actividades de los periodistas chinos. Freeman transmitió la preocupación del gobierno de EU al secretario de Gobernación, Luis Echeverría, quien a su vez giró el 17 de febrero instrucciones a la Dirección Federal de Seguridad para investigar las actividades de los chinos en México. ${ }^{18}$

En los diarios mexicanos, la información de Parade comenzaba a adoptar un nuevo tono. El diario El Universal publicó el 10 de marzo un editorial anónimo en la que abundaba sobre la red de espionaje comunista chino. A la información de Anderson añadía que Wu Chu y el director de la agencia, Bian Cheng, habían planeado la infiltración de espías chinos en Brasil, a quienes las autoridades habían descubierto y expulsado de Sao Paulo. El editorial recomendaba al gobierno federal seguir el ejemplo de las

17 De la embajada estadounidense (Ciudad de México) al secretario de Estado, "Following information is submitted regarding article Parade February 7", 8 de febrero de 1965, National Archives and Records Administration (NARA), RG 59, China. February 1963-1966 (Documentos Microfilmados), carrete 31- 311.

18 De embajador estadounidense Freeman al secretario de Estado, "Report from Mexican Federal Security Agent", NARA, RG 59, China. February 1963-1966 (Documentos Microfilmados), carrete 31-310. 
autoridades brasileñas y clausurar permanentemente la agencia de noticias Xinhua en México. ${ }^{19}$

Mientras, la Dirección Federal de Seguridad desplegaba operativos para espiar a los periodistas de Xinhua y a sus simpatizantes mexicanos, la Sociedad Mexicana de Amistad con China Popular. El capitán Fernando Gutiérrez Barrios, jefe de la Dirección, rubricó el 27 de febrero el primero de una serie de inumerables informes sobre las actividades de la RPCH en México. Entre ellos se leía que los corresponsales de Xinhua eran agentes encubiertos y que Wu Chu era teniente coronel al servicio del buró de inteligencia de China Popular. Gutiérrez Barrios afirmaba que Xinhua era el disfraz de un centro de operaciones de donde emanaba el trabajo de los agentes para infiltrar el comunismo de China Popular en México y en América Latina (AGN, folios 76-88).

Agentes de la Dirección aseguraban que el gobierno del presidente Días Ordaz ya había comenzado a estudiar la expulsión de los corresponsales chinos de México. ${ }^{20} \mathrm{El}$ proyecto se vio interrumpido, curiosamente, por la salida repentina y voluntaria de los corresponsales de Xinhua del país. Respondiendo al llamado a participar en la Revolución Cultural, todos los corresponsales partieron de México el 4 de noviembre de 1966 rumbo a la RPCH. Una versión dice que los periodistas regresaron sin autorización y que por ello, desde junio de 1967, Xinhua comenzó a gestionar el regreso de sus periodistas a México. ${ }^{21}$

La noticia del intento de regreso de los periodistas de Xinhua llegó rápidamente a Taiwán. En una extensa carta, el nuevo embajador, Chen Chih-Ping, argumentaba al secretario de Relaciones Exteriores, Carrillo Flores, el daño que causaría a México que Xinhua reanudara sus operaciones. El embajador Chen explicaba que los corresponsales de Xinhua no eran periodistas sino agentes del comunismo que buscaban involucrarse en actividades guerrilleras y precipitar una revolución a gran escala en América Latina. El diplomático afirmaba que Bian Cheng y compañía habían sido adoctrinados en tácticas usadas por los guardias rojos y que buscarían usarlas para incitar rebeliones entre estudiantes universitarios y entre la comunidad chino-mexicana. ${ }^{22}$

Entre el 5 y el 12 de julio de 1967, el embajador Chen buscó al embajador de EU, Fulton Freeman, para alertarlo del peligro que la admisión de chinos comunistas representaba para la seguridad de los EU. El representante de Taiwán sugería que el reingreso de chinos comunistas en México, dada la vasta frontera con EU, agudizaría la infiltración comunista en EU. Una vez terminada la exposición de Chen, Freeman pidió instrucciones al secretario del Departamento, Dean Rusk, para conocer qué posición tomaría Washington en torno a la reapertura de Xinhua. ${ }^{23}$ El 13 de julio, Dean Rusk, indicaba a su embajador en México la estrategía a adoptar: Freeman debía comunicar verbalmente al canciller Carrillo Flores el interés de EU para que México no emitiera visas ni permitiera la apertura

19 Anónimo "Espionaje chinocomunista en México", El Universal, 10 de marzo de 1965, p. 2.

20 De embajador estadounidense Freeman al secretario de Estado, "Report from Mexican Federal Security Agent", NARA, op. cit.

21 Entrevista con informante anónimo de la agencia de noticias Xinhua, 4 de abril de 2010.

22 “1965. Informe sobre comunistas chinos que desean visitar México" Legajo III-2990-30, Archivo Histórico de la Secretaría de Relaciones Exteriores de México (AHSRE).

23 De embajada estadounidense a secretario de Estado "Information from GRC ambassador Chen Chih-Ping" 12 de julio de 1967, NARA, RG 59 Central Foreign Policy Files 1967-1969, Political and Defense, caja 2343. 
de la corresponsalía de Xinhua. El embajador debía poner en duda la autenticidad de las actividades periodísticas de los chinos, pero sin adoptar una actitud activa que despertara sospechas entre los funcionarios mexicanos. La inquietud de Rusk se debía a que durante las conversaciones a nivel embajada entre EU y la RPCH en Varsovia, Washington había invitado sin condiciones a periodistas comunistas chinos a trabajar en los EU24.

Las presiones de Washington y de Taipei terminaron finalmente seis días después de las indicaciones de Dean Rusk a Freeman. El 19 de julio la Procuraduría General de la República acusaba al director de la agencia Xinhua, Bian Cheng, de complicidad en un complot para derrocar al gobierno de Díaz Ordaz y establecer un sistema político de tipo popular socialista. Julio Sánchez Vargas, subprocurador de la República, afirmaba en conferencia de prensa que la RPCH financiaba con libras esterlinas a individuos que buscaban la organización de movimientos populares en el país. Indicaba que por medio de Bian Cheng, la RPCH suministraba dinero y regalaba libros y revistas a Javier Fuentes Gutiérrez, dueño de la Distribuidora Interamericana de publicaciones chinas en México, quien colaboraba con trece personas que buscaban organizar guerrillas rurales y reclutar a jóvenes para orientarlos a la línea marxista proChina (Ravelo).

La petición de los corresponsales chinos de regresar a México fue naturalmente rechazada. No sólo eso. A partir de julio de 1967 la Dirección Federal de Seguridad desplegó extensos operativos para espiar a todos aquellos que pudieran tener relación con la $\mathrm{RPCH}_{.}{ }^{25}$ Comenzaba una etapa de desarticulación acelerada de los vínculos políticos y económicos establecidos con la RPCH en el periodo del presidente López Mateos, al tiempo que se estrechaban las relaciones políticas y económicas con el gobierno de Taiwán.

\section{Luis Echeverría: ¿la soberanía es indivisible?}

El 5 de octubre de 1971, el presidente Echeverría pronunció un discurso que irrumpió no sólo en la XXVI Asamblea General de la ONU sino también en el Departamento de Estado de EU. México anunciaba al mundo, al menos en principio, la posición que adoptaría en la cuestión de las "dos Chinas". ${ }^{26}$ Por un lado, apoyado en el principio de la universalidad, México se pronunciaba por la admisión de la RPCH en el seno de la ONU. Por otro lado, apoyado en el principio jurídico de la indivisibilidad de la soberanía, México confrontaba la tesis de "las dos Chinas" defendida por los EU. El jefe del Estado -y no el canciller- subía a la tribuna a rubricar tácitamente que los intereses de México y de EU en el tema de las dos Chinas entraban en total oposición.

24 Del secretario Rusk a embajada estadounidense “Desirability of maintaining status quo on closure of

25 AGN, grupo documental Dirección General de Investigaciones Políticas y Sociales, Caja 2958-B, 1967.

NCNA" 13 de Julio de 1967, NARA, RG 59 Central Foreign Policy Files 1967-1969, Political and Defense, caja 2343.

26 "Voz de México en la Organización de las Naciones Unidas" en El Gobierno Mexicano, Vol. 11, 1-31 de octubre de 1971, México: Secretaría de la Presidencia, 1971, pp. 185-199. 
Minutos después de haberse pronunciado el discurso, el embajador de EU acreditado en México, Robert H. McBride, envió un telegrama al secretario de Estado, William P. Rogers, en el que lo exhortaba a hablar personalmente con el presidente Echeverría para aclarar el tema de China en la ONU. La posición de México, que durante años había coincidido con la de EU ahora cambiaba sin un proceso gradual o evidente de reajuste. Habían pasado sólo unos días de que el Departamento de Estado pensara que México no sólo lo apoyaría sino que copatrocinaría la propuesta para evitar la expulsión de Taiwán y para impulsar la doble representación ante la ONU. McBride notaba en el discurso de Echeverría que la incongruencia con la posición pretérita únicamente reflejaba indefinición en la postura mexicana, y por ello, la indefinición podría definirse favorablemente si el secretario Rogers conversaba personalmente con el presidente Echeverría. ${ }^{27}$

La tarde del 5 de octubre el secretario de Estado hizo una visita de cortesía al presidente Echeverría en la suite que ocupaba en el hotel Waldorf Astoria de Nueva York. Al diálogo protocolario siguió un acalorado debate en el que el secretario William P. Rogers y el secretario de Relaciones Exteriores, Emilio Rabasa, presentaron sus posiciones. Rogers explicaba que la existencia simultánea de la RPCH y de Taiwán era una realidad y que, sobre la base de esa realidad, EU impulsaba la integración de la RPCH al tiempo que defendía la permanencia de Taiwán en la ONU. Por su parte, Rabasa rebatía que la tesis de las "dos Chinas" carecía de un principio legal porque no se trataba de la admisión de un nuevo miembro sino de quién era el representante verdadero del pueblo chino en la ONU. El canciller mexicano alegaba que EU al impulsar la doble representación, se atribuía derechos que contrariaban las posiciones de Taipei y de Beijing. Si en algo coincidían las dos partes, decía, es que en el mundo sólo existe una China (Rabasa, pp. 48-49).

En una breve síntesis hecha al presidente de EU Richard Nixon, el secretario William P. Rogers indicó el 17 de octubre que el presidente Echeverría había reconocido en la conversación del hotel Waldorf que su conocimiento del problema había sido inexacto (I didn't have a clear understanding of it before) y que Echeverría había indicado que México no emitiría un voto desfavorable para los EU. Faltaban 11 días para la votación, programada originalmente para el 28 de octubre, y el presidente Nixon y el secretario Rogers estudiaban la estrategia para evitar la expulsión de Taiwán del seno de la ONU. Notaban que mientras los presidentes de otros países apoyaban la propuesta de EU sus ministros del exterior manifestaban una notable reticencia. Emilio Rabasa -decía Rogerses un "hombrecillo insípido", pero Echeverría no deja de ser un "buen sujeto". "Tengo a [Echeverría] de nuestro lado y no creo que vote en nuestra contra. Creo que se abstendrán. Pero necesitamos los votos para la Cuestión Importante. Ese es el voto clave."28

La postura jurídica del canciller Rabasa había pasado a ser un obstáculo para que México y EU cerraran filas en las votaciones de la ONU. Aprovechando que Rabasa estaba en Ottawa, Canadá, el secretario Rogers giró el 18 de octubre instrucciones al embajador McBride para que concertara a la brevedad posible una cita con el presidente

27 De embajador McBride a secretario de Estado “Echeverría's ambiguous but from our point of view negative reference to China Question", 5 de octubre de 1971, NARA, RG59, Subject Numeric Files 1970-1973, caja 3214, carpeta 10-05-71.

28 NARA, Nixon Tapes, Cassette 1166, 17 de octubre de 1971. 
Echeverría. ${ }^{29}$ Había que evitar que Rabasa estuviera presente en la conversación entre McBride y Echeverría. El 19 de octubre, el presidente Echeverría recibió al embajador en la residencia oficial de Los Pinos. McBride leyó un mensaje del secretario Rogers que extendía el agradecimiento del presidente Nixon por la indicación hecha el día 5 de octubre en Nueva York de que México no votaría por la expulsión de Taiwán de la ONU. En una clara alusión a Rabasa, Rogers decía que sabía que en el gabinete del presidente había personas a quienes les preocupaban los aspectos legales, pero que la permanencia de Taiwán debía valorarse desde un marco de "sabiduría y juicio político." Ahora, Rogers pedía específicamente al presidente Echeverría que México votara por la Cuestión Importante a fin de evitar la expulsión de Taiwán. El mensaje de Rogers concluía con la advertencia de que el presidente Nixon prestaba especial atención a la posición de Echeverría en este tema. ${ }^{30}$

Según el informe del embajador McBride al secretario Rogers, Echeverría contestó que no veía ningún inconveniente en votar favorablemente por la Cuestión Importante ya que respondía coherentemente a la posición mexicana en la ONU. El presidente Echeverría, no obstante, aclaró que en cuanto al resto de las propuestas (la propuesta de Albania de expulsar a Taiwán para admitir a la RPCH y la propuesta de la Doble Representación) tendría que esperar a que Rabasa regresara de Canadá para consultarlo y tomar una decisión. El embajador debía esperar hasta la tarde del sábado 23 de octubre para conocer la decisión final del presidente. McBride estaba seguro de que Echeverría votaría para evitar la expulsión de Taiwán de la ONU. No obstante, el diplomático alertaba al secretario Rogers de la actitud desfavorable del canciller Rabasa y aconsejaba que el presidente Nixon se involucrara directamente en el asunto. ${ }^{31}$

El 23 de octubre por la mañana, sin previo aviso y antes de que Echeverría y Rabasa pudieran llegar a un acuerdo, el presidente Richard Nixon llamó por teléfono al presidente Echeverría. En un tono amigable y cordial, el presidente Nixon apelaba a la amistad entre los dos mandatarios para que México votara por la Cuestión Importante a fin de evitar la expulsión de Taiwán. El presidente estadounidense aclaraba que defendía la posición de que la RPCH entrara en la organización mundial, al tiempo que enfatizaba que la expulsión de Taiwán impactaría negativamente en la vitalidad y la supervivencia de la ONU. El presidente Echeverría en respuesta indicó que su gabinete estudiaba el asunto y solicitó a Nixon que concertara una cita para el 24 o el 25 de octubre entre Rogers y Rabasa para volver a tratar cara a cara el asunto. El presidente Echeverría prometía a Nixon que comunicaría su respuesta por medio del canciller mexicano. ${ }^{32}$

29 De secretario Rogers a embajador McBride, "You should seek an early meeting with President Echeverría for the purpose of delivering an oral message of the greatest importance", 18 de octubre de 1971, NARA, RG59, Subject Numeric Files 1970-1973, caja 3215, carpeta 10-18-71.

30 De embajador McBride a secretario del Departamento "I presented message to president Echeverría regarding vital significance which we attached to the position of Mexico", 20 de octubre de 1971, NARA, RG59, Subject Numeric Files 1970-1973, caja 3215, carpeta 10-18-71.

31 De embajador McBride a secretario del Departamento, "I have just had further brief talk with President Echeverría on subject of Chinese representation at UN", 20 de octubre de 1971, NARA, RG59, Subject Numeric Files 1970-1973, caja 3215, carpeta 10-18-71.

32 NARA, Nixon Tapes, Cassette 1176, 23 de octubre de 1971. 
El 25 de octubre por la mañana Rogers y Rabasa conversaron una vez más en Washington D.C. ${ }^{33}$ Los ánimos, no obstante, ya estaban caldeados. No había para los funcionarios de EU una explicación a la inflexibilidad del canciller mexicano. El embajador McBride pensaba que Rabasa tenía "un complejo de inferioridad por ser mitad estadounidense". ${ }^{34} \mathrm{Y}$ para el secretario Rogers, Rabasa era un sujeto "terriblemente agobiante". En ese contexto, las conversaciones entre los dos funcionarios no podían llegar a un buen acuerdo. Ya en un acto de franca amenaza, el secretario Rogers indicó a Rabasa que el presidente Nixon seguía de cerca el voto de Echeverría en la ONU y le advirtió que, con esa actitud, la buena amistad entre Echeverría y Nixon se perdería. ${ }^{35}$

La actitud amenazante del secretario Rogers sólo reafirmó la posición del canciller mexicano. Al salir de la entrevista, llamó al presidente Echeverría y recomendó que México emitiera una abstención a la Cuestión Importante (que exigía una mayoría de dos tercios para decidir si Taiwán debía ser expulsada) y que votara favorablemente por la propuesta albana de admitir a la RPCH. El presidente no dio una instrucción definitiva. Asumía que faltaban varios días para la votación. Pero la fecha de la votación cambió y la Cuestión Importante se tendría que decidir la noche del 25 de octubre. Al llegar a Nueva York tras la entrevista con Rogers en Washington, el canciller Rabasa se enteró por mediación de Alfonso García Robles de las instrucciones finales del presidente Echeverría: la Cuestión Importante debía votarse favorablemente para EU y la propuesta albana de admitir a la RPCH debía votarse como abstención. Rabasa recuerda ese momento con las siguientes palabras: “La decisión del Presidente contradecía, en el fondo, lo que él mismo había sostenido en su discurso 20 días antes, el 5 de octubre. Es la primera vez que pensé en renunciar y así se lo hice saber a mis compañeros de delegación" (Rabasa, p. 53).

La sesión votó primero el proyecto de Estados Unidos. México cerró filas con Washington y votó a favor de la Cuestión Importante que perdió por una diferencia de cuatro votos. El nuevo escenario urgió a Rabasa a llamar al presidente para pedirle que reconsiderara su posición. El proyecto de Albania secundaría al de EU y México debía ajustarse inmediatamente al hecho de que Taiwán estaba virtualmente fuera de la ONU. Echeverría accedió. Rabasa votó finalmente a favor de la propuesta de Albania que ganó con un total de 76 votos a favor, 35 en contra y 17 abstenciones. ${ }^{36}$

El 26 de octubre, el presidente Nixon envió al presidente Echeverría una carta de agradecimiento por el incondicional apoyo de México a EU para mantener a Taiwán en la ONU. ${ }^{37}$ El presidente Echeverría envió en respuesta un mensaje por duplicado. Al presidente Nixon explicaba que como la Cuestión Importante era de "indudable interés" para los dos países y que como México y EEU “se solidarizaban en todo asunto

33 Del Departamento de Estado a embajada estadounidense "Rabasa saw Secretary early afternoon 25th", NARA, RG59, Subject Numeric Files 1970-1973, caja 3215, carpeta 10-23-71.

34 De McBride a secretario del Departamento "Foreign secretary Rabasa departed to New York on eastern flight at 1:15pm" 24 de octubre de 1971, NARA, RG59, Subject Numeric Files 1970-1973, caja 3216, carpeta 10-24-71.

35 NARA, Nixon Tapes, Cassette 1177, 25 de octubre de 1971

36 Idem.

37 De Departamento de Estado a embajador McBride "Following is the text of a letter from the President to President Echeverría", 26 de octubre de 1971, NARA, RG59, Subject Numeric Files 1970-1973, caja 3216, carpeta 10-28-71. 
que fuera esencial", México había votado para que Taiwán tuviera una oportunidad de quedarse en la ONU. ${ }^{38} \mathrm{Y}$ al embajador McBride decía que lamentaba la derrota de la Cuestión Importante, pero que le quedaba "la satisfacción del fortalecimiento inédito de las relaciones entre EU y México tras esta dura prueba". ${ }^{39} \mathrm{Al}$ igual que en los sexenios anteriores, la relación México-EU había salido airosa del escabroso tema de las "dos Chinas". Esta vez, sin embargo, había triunfado sobre los ideales que el mismo Echeverría había defendido el 5 de octubre en la ONU.

\section{Bibliografía}

- "Exposición Industrial y Comercial China” en Comercio Exterior, tomo XIII, núm 12, diciembre de 1963.

-Anderson, Jack Washington Exposé, Washington: Public Affairs Press, pp. 362-367.

-Archivo General de la Nación (AGN), grupo documental Dirección Federal de Seguridad (DFS), legajo 1, expediente 11-150-65, folios 76-88.

-Boletín de la Sociedad Mexicana de Amistad con China Popular (SMACHP), núm. 3, México, D.F., agosto de 1955.

- Feng Shan Ho, Wai jiao shengya sishinian (Mis cuarenta años como diplomático), Hong Kong: Zhongwen daxue, 1990, pp. 597.

- Gómez Bulnes, Hugo, “Recibió Chou En-lai a la misión comercial mexicana”, El Día, 2 de mayo de 1964.

- Lajous, Adrián, Mi Cuarto a Espadas, México, Ed. Edamex, 1985.

- Rabasa, Emilio O. canciller de México. Mis memorias como secretario de Relaciones Exteriores 1970-1975, México: Secretaría de Relaciones Exteriores, 2010.

-Ravelo, Carlos, "13 Arrestados por conducta subversiva. Planeaban crear guerrillas y preparaban un atraco bancario" Excélsior, 20 de julio de 1967, p. 1.

- Tello, Manuel, México: Una posición internacional, México, Cuadernos de Joaquín Mortiz, 1972.

38 De presidente Echeverría a presidente Nixon "Estimado señor presidente" 29 de octubre de 1971, NARA, RG59, Subject Numeric Files 1970-1973, caja 3216, carpeta 11-15-71

39 De embajador McBride a secretario del Departamento "I talked with president this morning and indicated I believed that US officials were well pleased with his decision to vote for Important Question" 27 de octubre de 1971, NARA, RG59, Subject Numeric Files 1970-1973, caja 3216, carpeta 10-27-71. 


\section{La hostilidad racista de México contra el ser chino}

Jorge Gómez Izquierdo

La hostilidad racista contra el ser chino no es nueva en nuestro país. La historia de la inmigración china desde fines del siglo XIX y principios del XX nos hace comprensibles las imágenes estigmatizantes, racistas con las que se descalificaba a los ciudadanos chinos para pintarlos como seres naturalmente sucios, portadores de temibles enfermedades, débiles, feos, viciosos, amorales, crueles, pervertidos, sangrientos, refractarios e inasimilables a la cultura occidental, de la cual México, se decía, formaba parte.

La historia triste y desgraciada de los ciudadanos chinos en México representa, a no dudarlo, uno de los episodios del más claro desencuentro habido entre nuestro país y China. Si alguna de las corrientes migratorias ha revelado los límites auténticos de nuestra tolerancia ante el "otro-extranjero", ésa ha sido la que llegó de la lejana China. Su presencia desencadenó fenómenos ligados al odio racial y a la envidia económica que desembocaron en actitudes de persecución y violencia asesina. La autoimagen de la sociedad mestiza libre de racismo y amistoso con todos los pueblos de la humanidad quedó hecha añicos a lo largo del movimiento antichino (1871-1934) mostrando la dimensión omnipresente del racismo en la sociedad mexicana.

Recordemos que ya en la segunda mitad del siglo XIX la imagen de china como una sociedad inmóvil, atrasada y refractaria a los valores de la moderna cristiandad se había difundido por todo el mundo en la obra de reconocidos pensadores europeos, que desde los primeros encuentros de España y Portugal con el imperio chino en el siglo XVI, hasta filósofos como Hegel (1770-1831), Gobineau (1816-1882) y algunos positivistas franceses habían pintado a China como el prototipo de una civilización degenerada, viciosa, abyecta, amoral y atrasada. ${ }^{1}$

La llegada en la década de los 70 del siglo XIX de jornaleros chinos dio origen a uno de los episodios más significativos y ejemplares del fenómeno racista mexicano que se prolongó durante casi seis décadas: 1871-1934 (Gómez). Los primeros trabajadores chinos fueron mandados traer para satisfacer las necesidades de los grandes propietarios de haciendas y minas que se quejaban de una supuesta carencia de mano de obra atribuible a la sempiterna actitud negativa del indio ante el trabajo. El trabajo del chino

1 Hegel (Filosofía de la Historia) aporta una nueva característica al estereotipo del chino: su abyección moral ocasionada por la falta absoluta de respecto a la dignidad personal. Gobineau en su Ensayo sobre la desigualdad de las razas humanas, termina con la reputación de sabio que el chino gozaba todavía en el siglo XVIII en Europa, para presentarla como "raza" de poco vigor físico, apática, mediocre, partidaria de los goces materiales, y poco profunda intelectualmente. Uno de los positivistas franceses que más influyó la visión de las elites mexicanas sobre China fue el filósofo Pierre Laffitte (Considerations génerales sur l'ensamble de la civilisation chinoise" (1861) , a quien José Covarrubias, autor de "La inmigración china considerada desde los puntos de vista intelectual y moral", Revista Positiva, tomo VI, México, noviembre-diciembre de 1904, atribuye el mérito de haber ubicado a China, de acuerdo a las leyes intelectuales descubiertas por Comte, en el estado primitivo o fetichista, es decir, en el nivel más bajo de la evolución humana. 
se había convertido en una alternativa mundial de acceso a trabajadores dóciles, aplicados, resistentes y fácilmente manipulables:

Los chinos se distinguen sobre todo por su inteligencia (...) son sumisos y tranquilos (...) para la mecánica son muy aptos y tienen especial predilección por los ferrocarriles (...) hasta el presente, el inconveniente mayor que han tenido los chinos es su afición a fumar opio. Y además por 3 ó 4 pesos al mes trabaja el chino en la construcción de cualquier camino o edificio (Gómez). ${ }^{2}$

La abolición de la trata de esclavos africanos acordada entre Inglaterra y España en 1817 (aunque en Cuba, posesión española, ese medida se hizo efectiva solo hasta 1845), ocasionó que los grandes terratenientes de las islas caribeñas (inglesas y españolas), así como de las plantaciones algodoneras del sur de Estados Unidos y de las empresas del guano en Perú, buscaran en China la mano de obra que sustituyera a los esclavos africanos. La inmigración china daba satisfacción a las necesidades de las clases propietarias por resarcirse de los perjuicios que les ocasionaba tanto la abolición de la trata de esclavos africanos, como la "negligencia" atribuida a los operarios indígenas. Por eso fueron los países y regiones cuyas economías dependían del trabajo esclavo los primeros beneficiarios del tráfico de culis (1847-1874): Cuba, Perú, las Antillas Británicas, Panamá, Jamaica y el sur de Estados Unidos. La economía mexicana ciertamente no se basaba en el trabajo africano; no obstante, las élites mexicanas decidieron no quedarse al margen de esta nueva moda de importar trabajadores asiáticos.

Aun antes de su llegada, la sola idea de la presencia de chinos en territorio nacional suscitó una enconada polémica en la prensa a partir del año $1871^{3}$. Los intelectuales, políticos y periodistas advertían acerca de los problemas que la inmigración china podría ocasionar en cuanto a una eventual miscegenación ahondando la degeneración de la raza mexicana, lo mismo que a conflictos políticos debido al seguro desplazamiento en el mercado laboral. Aprovechaban la ocasión estos próceres para mostrar su preocupación paternalista y decisión de proteger a los "inválidos inditos", tanto como a las "pobrecitas mujeres mexicanas" de la invasión china, percibida como "verdadero peligro nacional":

Los trabajadores y operarios indígenas poseen individual y colectivamente aquellas eminentes cualidades (de los trabajadores chinos), unidas a severa moral pública y privada (...) he admirado la moral estricta, la increíble sobriedad y extraordinaria resistencia corporal que caracterizan a los trabajadores indígenas de México (...) defender a nuestro gremio trabajador de una competencia desastrosa y del contagio de depravadas costumbres; ya que por el estado de ignorancia y miseria en que las agrupaciones indígenas se encuentran, el contacto chino puede producir grave degeneración, supuesto que para conjurar este peligro aquellas no poseen la fuerza moral que el bienestar económico y la cultura intelectual de las masas proporciona (Romero).

2 Diario Oficial. México, 18 de octubre de 1871.

3 Dicha polémica se suscitó en los siguientes periódicos en sus ediciones de octubre y noviembre de 1871: Diario Oficial, El Federalista en pro de la inmigración china. , mientras que El Siglo XIX, La Iberia, se oponía al proyecto de importar jornaleros chinos. 
Deslumbradas por el dinero (...) que les dan los chinos, viven en descarado concubinato con hombres de ojos atravesados. Sabemos que hay también chinos que se dedican a explotar la prostitución y para ello hacen frecuentes excursiones a Sinaloa y de allá traen mujerzuelas para especular con ellas (EI Toro del Once).

En el contexto marcado por las ideas acerca de la importación de extranjeros como panacea del problema étnico de México (blanquear la población), se delinearon dos grandes bandos: 1) el de los que estaban a favor de la importación de chinos, pero limitando de antemano su papel en la sociedad sólo como fuerza de trabajo y limitado a los años que duraran sus contratos, y 2) los que estaban radicalmente en contra de dicha inmigración, sin importar la función que se les asignara a los chinos, pues temían que éstos, como lo habían hecho en otros países, se quedaran a radicar después de terminado su contrato abriendo así la posibilidad a enlaces sexuales con las mujeres nativas (que no podrían ser otras que las pobres y las indias), con lo que se daría al traste al plan elitista de "mejorar la raza".

Prochinos y antichinos compartían, sin embargo, la misma visión estereotipada sobre el hombre chino y su civilización:

El pueblo chino, el más antiguo del mundo y a su vez el menos civilizado: acostumbrado a la miseria y dominado por la avaricia, niega a su cuerpo todas las ventajas no ya de una vida cómoda, sino medianamente higiénica (...) sus alimentos favoritos son el té, el arroz, las ratas y muchas especies de reptiles, sus vicios predilectos, el juego y la embriaguez; sus habitaciones, desamuebladas y pequeñas sirven para dar albergue a un número considerable de huéspedes de ambos sexos que viven en familia, convirtiendo en inmundas pocilgas aquellas casas ahumadas y grasientas, donde se anida todo lo que pueda haber de más repugnante en el desenfreno de sus costumbres; siendo fatalistas, les preocupa muy poco la vida humana, que a menudo sacrifican (...) la poligamia que es permitida en su país natal, ha destruido casi por completo el amor a la familia (...) emplean la agudeza de su ingenio en inventar los medios más hábiles para adquirir la propiedad ajena; son dóciles no por virtud, sino por abyección y cobardía (El Economista Mexicano).

En la caracterización racista antichina típica del XIX podemos encontrar otras muestras con evidentes ecos en la situación actual:

Forman el carácter de los hijos de Confucio la redomada astucia, la perseverancia casi sin límites y una moral (si es que tienen alguna) enteramente heterogénea de las más elementales nociones de la nuestra (...) el compatriotismo predomina entre los miembros de esta raza (...) es gente muy unida por lo que llega a ser tan formidable y perjudicial a la causa pública de los pueblos que incautamente admiten en su seno a tales extraños elementos. $\mathrm{Si}$ se añade lo antipático y repulsivo que en su totalidad es este mongol, ética y estéticamente considerado en su físico, en su moral, sus hábitos, su monstruosa lengua, verdadera matraca de monosílabos, se comprende (...) la animadversión general e instintiva en contra suya (EI Siglo XIX). 
Sin embargo, con tal de satisfacer la necesidad de contar con fuerza de trabajo barata, las élites mexicanas dejaron de lado el asco y la repulsa que les ocasionaba la presencia china.

El odio antichino en México se nutrió de las ideas del pensamiento racial euroamericano, que ya había estigmatizado al chino junto a las razas indias mexicanas como "razas inferiores", colocándolas en los escalones más bajos de la progresión evolutiva y estética de la humanidad. El prejuicio racial antichino en México también recibió la influencia del movimiento antichino norteamericano que había logrado presionar lo suficiente para lograr de su gobierno la expedición en 1882 de una legislación discriminatoria en la forma de una Acta de Exclusión que prohibió el acceso de trabajadores chinos a Estados Unidos. Y se puede distinguir otra corriente que alimentó las fobias racistas contra los trabajadores chinos, me refiero a la tradición de pensamiento de conquista heredado del sistema colonial racial de castas con su idea sobre la "limpieza de sangre" y el miedo a la degeneración a causa del previsible intercambio sexual entre los "amarillos" (fumador de opio) y las "indias" mexicanas (bebedoras de pulque) de cuya unión, se pensaba de acuerdo a los clichés eugenésico-raciales en boga, no podía esperarse más que la procreación de seres degenerados.

La matanza de la colonia china de Torreón en 1911 por tropas revolucionarias conducidas por Emilio Madero es uno de los episodios más conocidos del nacionalismo revolucionario. El repudio al extranjero "perverso" reforzó la identidad nacional de los mexicanos, quienes en el odio antichino encontraban la placentera sensación de pertenecer a una "raza superior", por lo menos en relación al degradado chino. A esta historia se refiere el informe de un testigo presencial de esos hechos relacionados con la destrucción de vidas y propiedades de los súbditos chinos:

Todos esperaban que dadas las condiciones de paz [el ejército federal había evacuado ya la ciudad], la del ningún peligro que había ya para sus vidas, hicieran [los maderistas] su entrada ordenadamente y sin ejercer actos reprobables. Pero desgraciadamente no fue así; cual irrupción de salvajes, cual desbordamiento de indios bárbaros, se precipitaron sobre Torreón los cuatro mil hombres, al frente de seis plebes..., todas dispuestas al saqueo.

Llegaban a las tiendas, algunas muy costosas de los chinos, y después de robarles hasta los armazones, los maderistas les dispararon una lluvia de balazos, y eran muertos de diez a doce. Al dirigirse al banco de esa nacionalidad [china], dos dependientes que habían visto lo anterior, se propusieron defenderse disparando sus armas. Aquello fue motivo para que rodearan la casa, y descargaran por cientos sus carabinas, acribillando a balazos a los dos y a todos los que ahí se encontraban y siguieron furiosos descuartizando a todos los de esa nacionalidad, sin escaparse los niños de cinco o menos años. Aquello era el día del juicio. Se presentaron cuadros que horrorizarían a los cafres y a los hotentotes.

Aquellos hombres cubiertos los sombreros con estampas del Santo Niño de Tongo, de Nuestra Señora de Guadalupe, del Señor Misericordioso y del Santo de su devoción, no tenían compasión de nadie, antes bien, se extasiaban en su obra. iiA trescientos tres llegaron los asesinados!! 
Las calles de Torreón a las tres de la tarde estaban cubiertas de cadáveres, hasta de mexicanos que tenían semejanza con los chinos. Los vecinos estaban aterrorizados y las familias lloraban a grito abierto. La matanza cesó gracias a la llegada de Don Emilio Madero, el que inmediatamente mandó a la fuerza que lo acompañó, cáigase a sable contra las plebes ${ }^{4}$.

Concuerda con lo anterior Francisco L. Urquizo, otro testigo presencial de los hechos, que en su novela Tropa vieja (1931) nos regala una pintura exacta, realista, pintoresca de la vida de cuartel en la época de la Revolución y en ella encontramos el breve relato de la matanza de chinos:

(...) han hecho una matazón que da horror. Los pobres chinos son los que han pagado el pato. Tienen (los revolucionarios) la creencia de que todos ellos, los que tenían hortalizas en las afueras, estaban armados para defender el pueblo, y en ese cuento se pusieron a matar a los pobres chales. Los sacaban, arrastrando de las trenzas, de sus hortalizas o de sus lavanderías, y en la mitad de la calle los mataban a tiros y a puñaladas. ¿Se acuerdan del Banco Chino? Tiene tres pisos; pues cuando los pobres que estaban allí dentro se dieron cuenta de la furia de los maderistas, se escondieron a toda prisa en el último piso, y hasta allá subieron a buscarlos una turba de desalmados; los agarraron de los cabellos y los aventaron por las ventanas hasta la calle. Hay ahorita en Torreón más chinos muertos que soldados federales. En mi vida hubiera yo podido pensar en tanto horror. Algunos corrían desesperados por las calles, tratando de escapar y gritando en su idioma quién sabe qué cosas raras; detrás de ellos todo el peladaje, eso sí, muy llenos de escapularios y de santos, los doblaban a tiros. Dicen que los españoles están muy temerosos, con miedo a que les pueda pasar una cosa igual (Urquizo, pp.454-455).

Francisco León de la Barra, presidente provisional de la República nombró una comisión especial encabezada por el diputado Francisco Ramos Pedrueza para investigar lo ocurrido, la resolución consistió en ofrecer al Ministro de China la cantidad de tres millones de pesos como indemnización por las pérdidas sufridas por los chinos. Posteriormente, siendo ya Francisco Madero presidente del país, no sólo se ratificó dicho pago sino que también se brindaron cien mil pesos adicionales para amparar todas las reclamaciones de los súbditos chinos afectados por pérdida de vidas y destrucción de bienes durante la revolución maderista. La oferta fue aceptada por el Ministro de China y el 16 de diciembre de 1911 se firmó un protocolo en el que México se obligaba a pagar a su similar de China tres millones y cien mil pesos como desagravio por lo ocurrido. Así el gobierno de China eximió al de México de toda responsabilidad de la salvaje matanza y se fijó el día primero de julio de 1912 para verificar dicho pago. De esta manera ambos gobiernos de manera amistosa y cordial arreglaron asunto tan desagradable. ${ }^{5}$

El odio antichino en México es un caso histórico, no inventado, que documenta que el racismo no es algo accidental, atribuible solamente a la acción de grupos señalados, sino que es una ideología que fundamenta al Estado en su tarea de proteger a la "raza"

4 Memoria. Hechos relativos a la matanza de chinos en Torreón el día 15 de mayo de 1911, y el protocolo de 16 de diciembre de 1911, prometiendo indemnización por la matanza.

5 Memoria. Hechos relativos a la matanza de chinos en Torreón el día 15 de mayo de 1911, y el protocolo de 16 de diciembre de 1911, prometiendo indemnización por la matanza. 
verdadera que debe sobrevivir y excluir a aquella que la amenazaba con la degeneración. Demuestra también la forma en que se pudieron manipular los prejuicios raciales por grupos de ideología nacionalista y xenófoba en la consecución de ciertas metas económicas (apropiarse de la riqueza generada por los chinos) y políticas (movilizar a la población promoviendo el nacionalismo de defensa de la patria ante la amenaza racial). El relativo éxito de la colonia china en las actividades económicas y comerciales suscitó odio, frustración y envidias en ciertos sectores fuertemente nacionalistas. Se crearon organizaciones en 17 estados de la república para defender la "integridad racial" de la nación mexicana ante el "peligro amarillo". En su propaganda nacionalista, esas organizaciones responsabilizaban a los chinos de todos los males (el desempleo, los bajos salarios, la prostitución) padecidos por los mexicanos pobres. Se nublaban las verdaderas causas del problema para encontrar en la población china un "chivo expiatorio" al que, por representar a un ser de tan bajo valor y carente de un real apoyo diplomático de su gobierno, se podía agredir sin ocasionar conflicto en la conciencia social.

La eliminación del chino se convirtió en una prioridad nacional. La animadversión antichina alcanzó tal nivel, que hizo de legislaturas locales y gobiernos estatales, específicamente Sonora, precursores de los nazis en cuanto a la aplicación de una auténtica política de "higiene racial": en la década de los 20 se prohibieron legalmente los matrimonios entre hombres chinos y mujeres mexicanas, a quienes se privó incluso de su nacionalidad y sus derechos ciudadanos por hacer vida conyugal con chinos. Al concluir la campaña antichina en 1934 con la expulsión de familias enteras chinomexicanas de Sonora, Sinaloa, Baja California, Chihuahua, Tamaulipas y Veracruz, nadie podía extrañarse de la animadversión en China contra México. El cónsul mexicano en Hong Kong, Mauricio Fresco, advertía que la Secretaría de Relaciones Exteriores debía recomendar a las mexicanas casadas con chinos se abstuvieran de hacer el viaje con sus maridos a China, ya que muchos de ellos tenían esposa en China antes de haber estado en México, por lo que de acuerdo con las leyes de aquel país el matrimonio con mexicanas quedaría anulado. En algunos casos, el hombre chino llevaba a su mujer mexicana a casa de su primera esposa, convirtiéndola así en concubina. Abandonada por la ley mexicana que le había retirado su nacionalidad, las mexicanas que llegaron a China en estas condiciones recibieron un trato discriminatorio. Ellas pagaron los platos rotos. El cónsul Fresco hablaba de 250 chinos expulsados de México “(...) y había una enorme cantidad de mexicanas y desgraciadamente de niños. Salieron rumbo a Cantón y también será otro grupo de mujeres de quien jamás se sabrá de ellas" (Pardiñas, pp. 478-479).

En esta serie de medidas racistas se emitieron además disposiciones para recluir a los chinos en barrios especiales y se les impidió el ejercicio de sus negocios con el fin de proteger la salud pública de las repugnantes enfermedades que, supuestamente, el chino portaba y transmitía. Estas acciones llevaron a sus últimas consecuencias los ideales del movimiento eugenésico, pues para proteger a la "raza" verdadera, se decidió eliminar física y políticamente, por medio del acoso, el asesinato y la expulsión, a los portadores de la amenaza de envilecimiento racial.

El racismo de Estado se ejerció, aunque sólo fuese en regiones determinadas, sin cortapisas y abiertamente. Así lo exigía el interés mayor de la nación. Es muy importan- 
te tener presente que beneficiarios directos del racismo antichino fueron grupos como el de los sonorenses liderados por Plutarco Elías Calles, eventual presidente del país (1924-1928) y líder máximo de la revolución institucionalizada (1929-1933), personaje que hizo sus pinitos políticos en organizaciones antichinas en su natal Sonora. En esta región ha sido inobjetable la trascendencia del odio antichino, tal como lo muestra el hecho de que aún en 1965 se celebraba el 50 aniversario de la campaña antichina en Sonora como un triunfo en la defensa de la nacionalidad y de la raza. ${ }^{6}$ La campaña antichina proporcionó las armas ideológicas a los sectores medios que se sintieron amenazados por la activa presencia de los chinos. El uso de los odios raciales alimentó el proyecto de movilización nacionalista de la población durante los años de la Revolución Mexicana.

Otras etnias extranjeras (norteamericanos, españoles, alemanes o franceses) disponían de mayor poderío sobre la población nativa, pero mientras a éstas se les temía, respetaba y aun admiraba, a los chinos se les podía agredir fácilmente pues su nación en esos momentos era incapaz de otorgarles la protección debida, además de representar un estereotipo de degradación e inferioridad mundialmente difundido, lo que facilitaba su elección como el chivo expiatorio en el que se descargaran envidias y frustraciones. La idea de amenaza racial permitía a amplios sectores participar del heroísmo glorioso de "defensa de la patria" ante un grupo victimizado que no estaba en condiciones de responder eficazmente a la agresión. Los mexicanos llegaron a convencerse de que era incomprensible tolerar la existencia de una minoría china que progresaba en sus negocios y, peor todavía, que envilecía a la "raza de bronce" prostituyendo a las mujeres nativas. El historiador puede constatar que la presencia china fue reducida en los medios de comunicación a problemas de nota roja, de criminalidad y de salud pública; típicas estrategias racistas para justificar el acoso, el despojo y la violencia.

El odio organizado contra los chinos de ninguna manera debe considerarse como la reacción espontánea contra su importancia demográfica o su poder económico. La población china crecía ininterrumpidamente entre 1895 y 1910 en todo el país: pasó de 907 hombres y 22 mujeres de nacionalidad china (aunque éstas fuesen de origen mexicano) 13 mil 203 hombres y 80 mujeres para 1910. La masa de población china nunca pudo ser considerada como una amenaza para la "integridad racial" de la nación mexicana. Por ejemplo, en Sonora, centro por antonomasia del antichinismo, la población china representaba entre el 4 al $6 \%$ de la población total. Mientras la colonia china en todo el país crecía hasta alcanzar la cifra de 14,498 personas según el censo de 1921, pero en Sonora la disminución causada por la violencia nacionalista fue evidente en este periodo de 1910 a 1921: de más de 6 mil chinos que había registrados en 1919 cayó la cifra a menos de 3,600 en 1921. Al finalizar la presidencia de Plutarco Elías Calles se contaba con el dispositivo legal necesario para hacer efectivo el ideal de los defensores de la "pureza racial" mexicana: excluir a los chinos del proyecto de construcción nacional. Eso se refleja en las cifras censales: en 1927 se registraban 24,218 hombres y 1772 mujeres; para 1930, en medio de lo más álgido de la campaña "unidos deschinatizaremos México" se redujo a 17,865 hombres y el número de "chineras" se incrementó

6 Apología del 50 aniversario de la Campaña Nacionalista. 26 de mayo de 1915. 1915-1965. Sonora, México, 1965. 
levemente a 2,522; el censo de 1940 registra las consecuencias de la ya entonces concluida campaña nacionalista: 4,856 hombres por sólo 110 mujeres.

La antipatía social hacia los chinos se convirtió en una forma de discriminación racial. A causa de su "ilegal" situación migratoria, pero sobre todo por los hechos delictuosos en que algunos se involucraron (la guerra de los Tongs, por ejemplo), el chino quedó estigmatizado por siempre como un ser de "idiosincrasia criminal" y, por tanto, se le vio como la representación del asocial. Éstos fueron los argumentos éticos y morales con los que la violencia antichina habría de justificar la apropiación de la riqueza generada por estos inmigrantes como una acción justa y legal. De esta manera, los comités antichinos establecidos en 17 estados del país, autodenominados también Comités de Salud Pública Pro-raza y orgánicamente integrados a la estructura del oficialista Partido Nacional Revolucionario, pugnaban por la satisfacción de 4 demandas básicas: 1) que las autoridades fijaran el porcentaje de chinos que podían residir en cada pueblo y ciudad, ordenando establecerlos en lugares especiales (guetos) para evitar el contacto y segregarlos del resto de la población; 2) que se expulsara del país (aplicar el artículo 33 de la Constitución) a los chinos sorprendidos en los juegos de azar, a los que traficaran o consumieran drogas e incluso a aquellos que padecieran enfermedades incurables y contagiosas (sarna, beri-beri, tracoma); 3) que se evitara la entrada clandestina de chinos al país y se expulsara a los que no pudieran comprobar su estancia legal, y 4) que se prohibieran los matrimonios o la simple vida conyugal entre chinos y mexicanas, esto a fin de proteger a la "raza" mexicana de seguras degeneraciones.

La importancia del prejuicio racial contra el extranjero "perverso" se dejó sentir como un reforzamiento de la identidad nacional de los mexicanos, quienes se "hermanaron" gracias a la placentera sensación de pertenecer a una "raza superior", por lo menos, respecto al degradado chino. La perversidad, la maldad, la avaricia, la sensualidad incontrolada, todos ellos rasgos con los que se identificaba al chino (lo mismo que al indio, al negro, al judío) y que ocasionaban la repulsa, el asco, el pavor y otros miedos sociales, pudieron ser fijados por la iconografía de la época en una fisonomía temblorosa y débil. Los chinos fueron representados como seres agotados a causa de conductas depravadas, lo que contrastaba aún más negativamente con el "vigor racial" que una sociedad, como la mexicana, glorificaba y necesitaba para su expansión progresista. La percepción social hacia los chinos dio forma, en imágenes, al prejuicio racista de que la fealdad física de las personas revela su maldad espiritual (Gómez). ${ }^{7}$ Los prejuicios racistas nunca son inofensivos.

La manipulación de la xenofobia y del racismo antichinos exigía a los chinos también un alto grado de incorporación socio-cultural y la ruptura con su origen. Pero a la vez, se tomaban las medidas que impedían en realidad tal incorporación. El proyecto nacional al incluir elementos xenofóbicos y racistas se hizo inviable y estrecho, pues tal como gusta decir Knauth, en vez de sumar se privaba a sí mismo de valiosos recursos.

En años más recientes, la nueva versión sobre China como el "reino del mal" ha sido difundida por los noticieros de la televisión mexicana, por lo menos desde 2004. Según la visión que transmiten esos medios, resulta que la "mano de obra barata de

7 En este trabajo se reproducen algunas muestras de la iconografía aludida. 
china" es la responsable de la pobre situación de los artesanos mexicanos por hacerles una competencia desleal. Se habla incluso de una "clonación" de artesanías mexicanas (cerámica, canastas de fibras naturales e imágenes de la Virgen de Guadalupe), que los malévolos chinos venden a precios bajísimos, lo cual amenaza mortalmente no sólo la economía de esos artesanos, sino también a todo un conglomerado de la población mexicana que vive de la industria maquiladora y de la ensambladora. Se difunde, pues, una imagen satanizada contra los trabajadores chinos a través de una serie de imágenes, entrevistas, cifras de personas que pierden el poco ingreso que tenían, y todo esto debido a "la malvada mano de obra china".

En el caso de Zhenli Ye Gong los medios de comunicación también han sido protagonistas centrales de difusión de fobias torpes y verdaderos prejuicios racistas, a las cuales se presenta como manifestaciones de simples mofas o burlas. Fallan sin embrago en su intento, pues esas bromas racistas no pueden considerarse como muestras de humor inofensivo. Dichos prejuicios nos llegan de épocas pasadas en que la comunidad china en México fue objeto de resentimientos, recelos y acoso violento, ejercido por grupos nacionalistas respaldados por diversas instancias estatales. En el linchamiento mediático a Ye Gong reaparecen una serie de percepciones sociales que los mexicanos tenemos de China y sus habitantes. Prejuicio e ignorancia, como siempre, van de la mano cuando se trata de movilizar a partir de fomentar fobias racistas y xenófobas:

No sabíamos el origen de los 205 millones de dólares, pero sabíamos el origen nacional de quien los resguardaba. Eso bastó. Nos faltó información pero nos sobran atajos mentales. Ye Gon, sin consideración de su ciudadanía mexicana, se convirtió de inmediato en el 'chino', de ahí al comentario agrio y la burla pueril el paso fue automático... es que los chinos serán ininteligibles, pero innegablemente turbios. pasivos y ausentes, los chinos nos son... ajenos... Agotados los refranes de la sinofobia nacional, bienvenida la burla de pastelazo. Cambiar la ' $r$ ' por la 'l', la declaración del 'cooperas o cuello' mutó en 'coopelas o cuelo', porque en el chiste se pierde toda credibilidad (y capacidad de análisis). Las culpas se asignan por opinión. La PGR no ha concluido realmente nada, pero para nosotros Ye Gon es el rey de las tachas, el emperador de los sicotrópicos; y su abogado (también chino) el maestro de las 'bombas' mediáticas. Aquí no se discute la inocencia de Ye Gon, esa es tarea de la PGR. Se discute el tratamiento del caso que se dio en algunos medios y artículos de opinión (Merino).

Ciertamente la sinofobia de los mexicanos es muy rancia, con el caso Ye Gon volvieron a tocarse algunos temas de los prejuicios más comunes sobre la naturaleza criminal atribuida a los "hijos del Celeste Imperio" y de su capacidad para corromper autoridades y funcionarios mexicanos de diversa índole. Ello ha quedado plasmado en chistes generalizados que hacen escarnio de los chinos. Cuando algo es difícil de hacer decimos que 'está en chino'. Las situaciones que implican obligatoriedad son así, 'aquí y en China'; un trabajo cuya minuciosidad nos desespera es 'trabajo de chino'; el que es sumiso y aguanta todo, tiene 'paciencia china'; un acreedor que no se tienta el corazón, 'se cobra a lo chino'; el mero espectador está 'como el chinito, nomás milando'; un lugar lleno de aire viciado es 'un fumadero de opio' y 'me engañaron como a un chino', suelen decir los que pecan de crédulos (Botana). 
También en el resto del mundo se vive una ola antichina, agudizada por las denuncias de mal trato a la fuerza laboral por parte de poderosas empresas transnacionales que maquilan por intermedio de empresarios chinos artículos deportivos para las olimpiadas de 2008 (Mergier, pp. 76-79). Aunque el resurgimiento en el mundo del temor a la "amenaza amarilla" tiene que ser explicado por el enorme éxito chino en la economía mundial. El antichinismo, sin tener la virulencia de las épocas de la revolución mexicana, se encuentra ahí latente, esperando para ser puesto en marcha por los demagogos de turno en situaciones de competencia o de crisis laboral. La historia del odio antichino nos debe advertir de sus eventuales explosiones y hacernos conscientes de las dificultadas que ello genera para tener con China relaciones sanas y benéficas.

\section{Bibliografía}

-Botana Montenegro, Evelia, “Cuentos chinos ó de cómo los chinos en México pasaron de "hijos del Celeste Imperio a jijos del máiz", Desacatos, 4, CIESAS verano 2000.

- El Economista Mexicano. México, 16 de diciembre de 1891.

- El Siglo XIX. México, 24 de octubre de 1871.

- El Toro del Once, periódico de Guaymas, Sonora, 23 de marzo de 1916.

- Gómez Izquierdo, José Jorge, El movimiento antichino en México (1871-1934). Problemas del racismo y del nacionalismo durante la Revolución Mexicana. INAH, col. Divulgación, México, 1991.

- Hegel, J.G.F. Filosofía de la Historia. Ed. Zeus, Barcelona, 1979.

- Mergier, Ana Marie Esclavismo "Made in China", en Proceso, No. 1605, México 5 de agosto 2007, pp.76-79.

- Merino, José, Contra esquina. El Chino.

http://www.nuevoexcelsior.com.mx/ 27 1786.htm, 11 de julio 2007.

- Pardiñas, Felipe, Relaciones diplomáticas entre México y China, 1898-1948. SRE México, 1982, Tomo I.

- Romero, José María, Comisión de Inmigración, encargada de estudiar la influencia social y económica de la inmigración asiática en México. México, Imp. de A. Carranza e Hijos, 1911.

- Urquizo, Francisco L. Tropa Vieja [1931], en La Novela de la Revolución Mexicana (selección, introducción..., por Antonio Castro Leal), Tomo II, Aguilar, México, 1971. 


\title{
Reflexiones sobre la etnicidad del estado-nación de China y de México
}

\author{
Natividad Gutiérrez Chong
}

¿Qué tienen en común la etnicidad de China y la de México? En el aula de clases, con frecuencia, expongo a mis alumnos el caso de China y su similitud con México, por supuesto, que mi cuestionamiento genera en los alumnos perplejidad e interés ¿cómo es que un país tan lejano y desconocido, una emergente potencia económica, tenga algo en común y no con países con etnicidad indígena más conocida, como Guatemala, Perú o Bolivia? La explicación no es sencilla y necesita abordarse por partes. En esta presentación, esbozaré algunas reflexiones que podrán ser más elaboradas y refinadas con estudios posteriores. La primera parte de este escrito iniciará con la definición de etnicidad. Aquí encontraremos contextos históricos muy diferentes; no obstante, la definición es susceptible de ser aplicable. A continuación encontremos que en términos de política de regulación y administración de las etnicidades, los dos Estados soberanos llevan a cabo políticas muy diferentes. No obstante, ambos incluyen en sus constituciones el derecho a la autonomía y libre determinación. Otro concepto en común es el de colonialismo interno. En la parte final veremos que el caso chino ayuda a explicar qué es la autonomía y qué es la libre determinación en términos reales e históricos, mientras que en México no hay ejecución en términos de política pública sino incipiente conceptualización y abundante ideología.

\section{Etnicidad}

Etnicidad y cultura significan lo mismo, etnicidad es cultura. Mientras que los grupos o naciones dominantes tienen cultura, a los grupos minoritarios o no privilegiados, les corresponde una etnicidad. Etnicidad y cultura son lo mismo, porque ambos integran los siguientes factores en su definición de identidad: memoria, pasado, historia, lengua, mitos y leyendas, símbolos, territorio... La gran diferencia es que la nación tiene su propio Estado y la etnia carece de Estado propio, aunque todas las etnias del mundo están asentadas en territorio soberano de algún Estado, por lo general, la explicación étnica adquiere relevancia cuando la relación de estos grupos con el Estado es de falta de representación, falta de acceso al Estado de bienestar, oportunidades, derechos, ciudadanía, etc. La nación dominante y su Estado son el modelo bajo el cual se han puesto en práctica medidas homogeneizantes por la vía de la asimilación, aculturación o extinción de minorías. De ahí emergen y se consolidan las relaciones asimétricas entre nación y etnias en un mismo Estado y que están sustentadas por la explotación laboral, la superioridad cultural y lingüística de la nación dominante versus la inferioridad de las minorías, la discriminación, y el racismo y la puesta en práctica de modelos dicotómicos basados en lo atrasado versus avanzado, exclusión-inclusión, etc. Además, 
tanto naciones como etnias tienen identidad construida, inventada, reconstruida, amalgamada, pero su imaginario colectivo responde a las mismas interrogantes de mitos originarios, fundacionales o de destino: ¿quiénes somos?, ¿a dónde vamos?

\section{Datos étnicos de México}

México reconoce a 62 pueblos indígenas según criterios lingüísticos. La población indígena se calcula en más de 6 millones de personas. Cada pueblo indígena presenta variaciones de entorno geográfico y coexistencia; por ejemplo, los nahua habitan en 10 estados de la república. El estado de Oaxaca es el hábitat de más de 12 pueblos distintos, mientras que los tres estados de la península de Yucatán forman el territorio de un amplio grupo lingüísticamente compacto: los mayas (hay más de 1,490 hablantes de lengua maya). Otras diferencias entre pueblos están determinadas por su densidad demográfica. Mientras que los kiliwa en el norte del país son 80 personas, se contabilizan más de 5 millones de nahuas por todo el país. La dispersión y fragmentación de las etnias-pueblo marca la ausencia de una identidad supracomunitaria capaz de cohesionar a un grupo. Por otro lado, muy pocos analistas cuestionan la generalización del término "indígena", el cual ha desplazado a las identidades con nombre propio, mixteca, maya o zapoteca. En las reivindicaciones de los años 70, los intelectuales indígenas clamaban "Nadie quiere ser indio, queremos volver a ser mixtecos, zapotecos, rarámuri" (Gutiérrez, 1999). Hoy dicen: "si en indígenas nos convirtieron, como indígenas nos liberaremos".

\section{Datos étnicos de China}

El Estado chino reconoce a 56 nacionalidades minoritarias o minorías étnicas, que representan el $8.04 \%$, es decir, 108 mil 460 millones de personas. Los han, la nacionalidad dominante conocida como china, representa el $91.96 \%$ de la población nacional. 18 minorías de las 56 se caracterizan por tener más de un millón de personas, 15 contabilizan menos de un millón y las 23 restantes cuentan de miles a varias decenas de miles. Esta gran diversidad étnica es en buena parte resultado de la historia imperial de expansiones territoriales en las que China conquistó y absorbió diversos territorios habitados por poblaciones con identidades diferentes a la china o han, que han quedado establecidos en las actuales fronteras. Tan sólo 47 de las 56 minorías habitan entre 50\% y $60 \%$ de los 9.6 millones de km2 que abarca la superficie total del país. Los territorios autónomos ocupan $92 \%$ de las fronteras continentales (China. Hechos y cifras 2000, 2000). 


\section{Nación y etnicidad}

México

Con el nation-building al estilo latinoamericano y, México en particular, siguiendo modelos y estrategias europeas, por ejemplo la educación masiva, los medios de comunicación y los rituales cívicos (Gellner, 1983, Hobsbawm, 1983), los Estados han construido sus naciones. Sin embargo, las naciones que emergieron en el siglo XIX fueron distantes de su realidad, no se buscaba que un Estado liberal pudiera satisfacer los reclamos y demandas de sus grupos culturales o lingüísticos, tampoco surgieron para responder a la diversidad (para un argumento opuesto, véase, Mallon, 1995). Por eso, los Estados-nación construidos a partir de la segunda mitad del siglo $\mathrm{XX}$ se han forzado para aparentar ser homogéneos, monoétnicos, monoculturales (Ibarra, 1992) y, por lo tanto, en claro antagonismo con la diversidad de toda índole, intolerante y amenazante, en constante atropello y violación de los derechos humanos y culturales. En la agenda del nation-building no había lugar ni conciencia por el respeto ni la diversidad, la tolerancia ni la coexistencia. La fórmula para fabricar naciones estaba basada en formar grandes comunidades con un idioma, lengua e identidad común que pudiesen ser gobernadas en un estado unitario y con corresponsalía entre cultura y territorio. Así, se idealizaba a la nación moderna (Safran, 1995).

Los efectos de este constructo de la modernidad, es decir, la nación, tumbaron con más fuerza los últimos reductos de la etnicidad. Para que existiera la nación se buscó desparecer la etnicidad, o bien emplearla selectivamente como fue el caso del indigenismo mexicano. Por lo tanto, la etnicidad en la era del nation building ha tenido una doble función, por un lado la asociación de la etnicidad con el pasado ancestral hace de ésta un componente genuino y legítimo de identidad nacional, pero por otro lado la etnicidad en la vida cotidiana ha sido debilitada en muchos ángulos, desde la extinción y negación de lenguas, hasta la dificultad de que los indígenas de hoy puedan localizar información sobre los núcleos de su identidad, tales como los mitos de origen y descendencia (Gutiérrez, 2006). Esta contradicción de la etnicidad se explica por la falta de condiciones objetivas o de la confianza necesaria para ser reproducida con libertad ante la explícita hostilidad y discriminación de la cultura dominante. Esta etnicidad que parece ser mejor explicada en función de la vigencia de un pasado que ya nadie es capaz de reproducir, ha cobrado mucha nostalgia entre la escuela de científicos sociales y humanistas (véase Jenkins, 1999) que han observado y teorizado, con acento, la desaparición y el desgaste de la tradición por el empuje de la modernidad y el consumo. La etnicidad asociada ficticiamente al pasado, diversa por sus variaciones lingüísticas y de prácticas culturales $y$, por ende, desconocedora de la lengua oficial y de la cultura dominante ha sido, como repetidamente sabemos, atribuida a la pobreza, la marginalidad y el atraso.

Sin duda, el Estado-nación causó daños y desgastes a la etnicidad ya sea porque la persiguió, la amenazó o la redujo a la pobreza; la nación moderna es obra del Estado, y como parte de esta obra, no había lugar para la diversidad ni comprensión alguna a la etnicidad. 
China

Nación, unidad nacional y nacionalismo configuran la etapa de desenvolvimiento y expresión de la era moderna y, como tales, eran ideas todavía ausentes del pensamiento político de China de principios del siglo XX. En contraste con esta relativa ausencia de ideas modernas de Estado-nación, es decir, la industrialización, la movilidad social y la estandarización (Gellner, 1983) China, ha acumulado un poderoso recurso nacionalista, el etnocentrismo de los han (Smith, 1986). Este etnocentrismo nutre el núcleo duro de la identidad china y está anclado en su larga historicidad, con su complejo repertorio de mitos, tradiciones, leyendas, símbolos, sin los cuales es impensable trazar los contornos de nación; asimismo, el etnocentrismo es el marcador para delimitar las fronteras propias de identidad con respecto a las naciones de Occidente y a los pueblos vecinos anexados. El naciente Estado chino del siglo XX habría de enfrentar la monumental tarea de construir una nación (una ciudadanía unificada con objetivos en común) y de unir la diversidad étnica de sus fronteras. La unidad nacional (o frente unificado) capaz de responder tanto a las presiones extranjeras como a la multietnicidad interna empezaba su lento proceso de construcción.

En China, la fórmula de cómo construir la nación (nation-building) incluyó la propagación de una ideología nacionalista con fines de unificación y en el fomento a la integración, equivalente a la homogeneidad étnica, sinizacion, asimilación a la cultura y lengua chinas, homogeneidad que hoy día es cuestionada desde distintas trincheras de cara a las políticas de reconocimiento de etnicidades otrora dominadas. En la medida en que se promueve la homogeneidad, en esa medida también crecen, en forma unilateral, los privilegios a una mayoría o a un grupo étnico dominante que se identifica con la nación del Estado (Stavenhagen, 1984: 143). El énfasis puesto en la nacionalidad han como centro aglutinador de la unidad, era la respuesta nacionalista al dominio de la dinastía manchú, la cual nunca dejó de ser para el grueso de la población china, aun con su marcada hanización, una dinastía extranjera. De esta manera, la "gran nacionalidad china" forjadora de la unidad de la nueva república, anulaba la presencia omnipresente del poder manchú en la tradición política cultural de China y de su territorio; ésta era una necesidad histórica de los han por recuperar su posición política y presencia social largamente usurpadas por la dinastía manchú. La manera de obtener nuevamente su lugar en su propia sociedad, era derrumbando las viejas estructuras dinásticas y convocando a la formación de una república nacionalista en 1911. Las repercusiones de esta autorrecuperación de identidad, condujeron a que el resto de las minorías fueran concebidas simples "derivaciones" y ubicadas en una segunda o tercera ciudadanía y lo que es más, en un proceso interminable de alcanzar la cultura y civilización de la nacionalidad han. El antiguo temor de invasiones externas se convirtió en posibles amenazas de desunión fronteriza al surgir proyectos de independencia de pueblos étnicos solidarios entre sí. De ahí que el ejército y el partido comunista, habrían de desplegar una estrategia a fin de ganar la adhesión y consenso de los grupos minoritarios en su proyecto político nacional. 


\section{Política étnica}

México

Los pueblos indígenas de México no siempre están en el centro del debate nacional. En 1993 como resultado de la amenaza de guerra del EZLN al Estado mexicano, los indígenas lograron una visibilidad política sin precedente. La sociedad civil fue la primera en dejar atrás su indiferencia habitual. Tras un recorrido legislativo con numerosos escollos, se aprobó por primera vez en la historia nacional una ley indígena. Esta ley, sin embargo, ha quedado congelada en la palabra "incumplimiento" de ahí su cuestionable efecto social. Por una parte, prevalece la opinión generalizada de que la ley aprobada no cumplió con las negociaciones previas en San Andrés Larráinzar. De ahí que esta legislación sea subestimada. Por otra parte, el nuevo indigenismo institucional, es decir, el que remplaza a partir de 2003 con la creación de la Comisión Nacional para el Desarrollo de los Pueblos Indígenas, la tradición indigenista enfocada a procurar la asimilación y aculturación de los indígenas, no ha registrado avances visibles que permitan afirmar la creación de políticas en apoyo a la introducción del derecho a la autonomía y la libre determinación.

El resultado de una negociación entre asesores y representantes tanto del EZLN como del gobierno federal, tuvo por objetivo acordar un pacto para poner fin al conflicto chiapaneco, su título legal es "Pronunciamiento conjunto que el Gobierno Federal y el Ejército Zapatista de Liberación Nacional enviaran a las instancias de debate y decisión nacional" más conocido como los Acuerdos de San Andrés (ASA) (16 de febrero de 1996).

Algunas organizaciones indígenas y el EZLN en Chiapas han comenzado el proceso de construcción autonómica "desde abajo". Existe un amplio espectro de visiones y conceptos de autonomía, pero aún incipientes y apenas algunos casos concretos. Un posible cambio a esta falta de movilidad propiciada por el "incumplimiento" podría ser destrabado por las organizaciones indígenas independientes, es decir, las agrupaciones formadas para proponer y resolver asuntos y demandas indígenas que incluyan una ideología en favor de sus intereses y que pueden transformarse en vehículos de representación y negociación a escala territorial mas amplia y de mayor interrelación con otros actores políticos indígenas y no-indígenas. Serán los mismos integrantes de pueblos indígenas, sean funcionarios, líderes o intelectuales, quienes tendrán que construir su otra agenda, la propia, para defender sus demandas y oponerse a todo aquello que continúe posponiendo la urgencia de rehabilitar a sus propios pueblos.

De cara a las múltiples vetas que presenta la autonomía en las regiones indígenas de México. Partimos de la premisa de que no hay suficiente investigación empírica que aporte al conocimiento sobre las formas en las que sé esta construyendo el derecho de autonomía para los pueblos indígenas (Art. $2^{\circ}$ ) y cómo esta experiencia de organización podría estar influyendo en los conceptos de territorio según la perspectiva de negociación indígena, territorio que es fundamental para erigir autogobiernos y ejercer autonomía. 
Propuestas del EZLN de autonomía "desde abajo". En el estado de Chiapas se han desarrollado las siguientes modalidades de autonomía: 1. La concepción zapatista de poder y gobierno en regiones autónomas: el que mande, mande obedeciendo. 2. Las Regiones Autónomas Pluriétnicas (con jurisdicción diferente a comunidades y municipios). 3. Los Caracoles o Juntas de Buen Gobierno ( 5 organizaciones que abarcan más de 30 “Municipios Autónomos Rebeldes Zapatistas (véase, Burguete, Sánchez y DíazPolanco).

El Municipio Autónomo Ricardo Flores Magón. En la Junta de Buen Gobierno Selva Tzeltal, del municipio de Ocosingo, se ubica el Municipio Autónomo Ricardo Flores Magón. Esta demarcación de autonomía esta integrada por 44 comunidades zapatistas. "Por compartir el municipio con el ayuntamiento constitucional, que es priista, la situación en la región es complicada. El impacto y la respuesta de la sociedad civil suele cambiar con respecto a la acción de las autoridades zapatistas o con la presión del ayuntamiento priista y de los grupos paramilitares. No obstante, la aceptación es enorme, ya que cuentan con 44 comunidades de base y un constante flujo de visitantes y promotores nacionales y extranjeros" (ORGINDAL). Sus autoridades expresan tener objetivos de organización en torno a la democracia, la igualdad y la justicia así como la autonomía local y regional. Buscan consolidar un desarrollo autónomo sustentable y mantener su gobierno autónomo a través de los consejos tradicionales y las asambleas comunitarias. Hacen valer la norma de "mandar obedeciendo" en todos los aspectos de su vida comunitaria. En tanto municipio autónomo existe delimitación territorial con respecto a los otros municipios, esto permite ejercer algunas funciones de control y sanción, como la prohibición del tráfico de drogas, de narcotraficantes e indocumentados. Para este modelo de autonomía, el control político de un territorio es una estrategia central.

La autonomía se pone en práctica bajo las siguientes formas: tener una forma propia de hacer las cosas y de solucionar sus problemas, conocer y revivir la cultura y la memoria histórica, tener la posibilidad de elegir las formas propias de gobierno y actuar para el beneficio colectivo en un territorio específico. Sus formas de representación política son la Junta de Buen Gobierno, el Comité Clandestino Revolucionario Indígena y la Asamblea Municipal Autónoma. Operan sus propios reglamentos, por ejemplo los sistemas normativos que son aplicados y vigilados por la Junta de Buen Gobierno; la opinión y las decisiones vienen "desde abajo". En estos municipios otras formas de establecer vínculos con el EZLN, es la estructura militar en la organización (i.e. rigurosa jerarquía y discreción), la vestimenta de las autoridades municipales (i.e. pasamontañas y paliacate rojo al cuello) y los rituales que recuerdan el ambiente cívico de imponer lealtad a un personaje dominante, establecido por la burocracia soviética y china en las regiones autónomas de esas naciones (i.e. autoridades presidiendo un escritorio, en la pared de madera un retrato pintado a mano del subcomandante Marcos, lemas alusivos). Otros símbolos de la autonomía zapatista son las banderas rojinegras y el himno zapatista. Más vínculos de interacción importantes son la radio comunitaria y el programa radial la "Voz Zapatista" que transmite algunas noticias muy locales y, sobre todo, sones cubanos, así como el cancionero popular latinoamericano de protesta de los años 70 (Observación y entrevista Municipio Autónomo Flores Magón y Junta de 
Buen Gobierno, mayo de 2005, sin identificación de entrevistado. ORGINDAL). Este municipio ha recibido apoyo y simpatía de los centros de derechos humanos, grupos de artistas, intelectuales y académicos.

La autonomía se entiende y se lleva a cabo de distintas formas y se adapta a las necesidades de las organizaciones. Sin embargo, aún no se conoce ningún tipo de resultados institucionales, accesible y confiable, que dé muestra de la trascendencia de los preceptos constitucionales (Artículo $2^{\circ}$ ). Esto es como traducir en formas prácticas y, sobretodo, en políticas públicas, el funcionamiento y puesta en marcha de los derechos de libre determinación o la administración de los pueblos indios de sus propios asuntos en las autonomías territoriales.

\section{China}

Desde 1949 hasta la actualidad, el gobierno central enfatiza una rotunda condena a la desunión entre nacionalidades, como resultado de la práctica de la autodeterminación, es decir, crear Estados propios, por ello sólo se permitiría la autonomía regional nacional, que incluía garantías y derechos para la libre existencia cultural de las minorías pero en el estricto marco de la unidad del Estado; interés celosamente resguardado por las fuerzas políticas y militares de la administración. Este proceso de integración por medio de autonomías regionales ocurrió de manera forzada en aquellos territorios que fueron anexados durante la expansión imperial de China.

En territorio chino se han establecido, desde 1947 hasta hoy día, más de mil quinientas categorías de autonomía: cinco regiones autónomas, 30 prefecturas autónomas y ciento 21 distritos autónomos así como 1256 cantones étnicos, cuya especificidad censal y territorial generalmente no se encuentran disponibles. De manera que 160 millones de ciudadanos viven bajo regímenes autonómicos, de éstos, 72 millones son de minorías. Mientras que 44 de las 56 nacionalidades tienen derechos autonómicos regionales, es decir, derechos para ser ejercidos dentro de territorios (China. Hechos y cifras 2000, 2000).

Un gran número de estos grupos minoritarios que pueblan las fronteras mantienen $y$, en cierta forma, desarrollan sus propias identidades, sean culturales, religiosas o lingüísticas con las cuales se diferencian de la actual mayoría han. En varios casos, estas identidades colectivas ejercidas por el lado de la frontera china, constituyen o mantienen afinidad con la identidad de una mayoría dominante en un estado vecino, por ejemplo: tadjikes (iraníes), coreanos, vietnamitas (jing), mongoles y rusos. La diversidad aumenta significativamente de frontera norte a frontera sur, tan sólo si consideramos el conjunto de los límites territoriales de China: la exURSS, la república de Mongolia, Pakistán, Afganistán, Corea del Norte, Tailandia, Vietnam, India y Birmania (Myanmar desde 1989).

Una característica notable en las zonas de autonomía es la convivencia de diversas minorías en un solo territorio autónomo. Un ejemplo de convivencia multiétnica lo constituye la región autónoma uigur de Xinjiang, en este territorio que ocupa una sexta parte de la superficie total del país, o tres veces el tamaño de Francia, conviven más de 47 minorías con diversas identificaciones de tipo cultural y lingüístico, de éstas, 17 
nacionalidades habitan permanentemente en la región y constituyen grupos mayores a las mil personas (Comisión de asuntos de nacionalidades de la región autónoma uigur de Xinjiang, Urumuqui, 21/6/1980). Otras minorías no tienen un territorio autónomo de ninguna categoría, tal es el caso de los manchú (Gutiérrez 2001:33).

La gama de resultados hacia las minorías mediante la ejecución de la autonomía es amplia; éstos, por supuesto, no son finales o definitivos, antes bien han tomado cauces distintos como el posible proyecto independentista de Tíbet y, por tanto, la insuficiencia de la autonomía regional, así como las manifestaciones en apoyo a la unidad religiosa que comparten uigurs, kazaks y tartars de Xinjiang con Estados y poblaciones islámicas del globo. La explosividad y radicalismo de esas etnicidades han demostrado su carácter impredecible y han sido, por tanto, combatidas y reprimidas. Todavía hoy en día son escasas las noticias a disposición de la opinión pública sobre el dominio y represión de minorías por las fuerzas militares del país, por tratarse de asuntos estrechamente ligados a la seguridad del Estado. Hemos mencionado la ocurrencia de frecuentes conflictos que han surgido en las regiones autónomas de Tíbet, de Xinjiang, de Mongolia Interior, entre otros lugares autónomos, por apego y tradición a sus propias instituciones culturales, sobre todo, las religiosas. A esto se suma que las principales regiones autónomas están, como sabemos, situadas en las fronteras del territorio que ocupa la República Popular, lo cual sigue planteando conflictos entre las minorías y el estado sobre la seguridad, la estabilidad y la unificación del país.

\section{Discusión}

Tanto China como México tienen minorías étnicas y una mayoría dominante que es demográficamente mayoritaria y se encuentra en todos los espacios urbanos y rurales de ambos territorios. La población étnica no-china, en la óptica oficial, se caracteriza por lo siguiente: no ha asimilado la cultura china, en tanto, su acceso a la educación es limitado, es inferior e incompetente para alcanzar la modernización, y existen profundas brechas en educación y movilidad social con respecto a la población han. Para lo cual el gobierno comunista ha aplicado durante más de medio siglo dos estrategias de integración étnica: una política de autonomía regional y otra política multicultural de tipo afirmativo, basada, esta última, en la distribución de privilegios, cuotas de acceso preferencial, por etnicidad y género, a la educación y el empleo, principalmente. Un acercamiento entre China y México se refiere a la existencia de una mayoría asociada con el Estado, en el caso mexicano, la población mestiza equivale a la han. En México, el mestizo es un poderosos mito nacionalista, la pareja idealizada formada por un hombre español y una mujer indígena cuyo discurso ideológico ha guiado las políticas de construcción de la nación a la largo del siglo XX y lo que corre del XXI. La población mestiza se localiza a lo largo de todo el territorio mexicano, es el estándar de asimilación para las minorías indígenas y se espera, como en China, que los indígenas por la vía de la aculturación lleguen a ser mestizos. Aquí radica un elemento importante para mantener la inferiorización y dominación de los indígenas tanto de China como de México. 
Otro aspecto a considerar es el del colonialismo interno. Aunque China no experimenta en su historia un colonialismo prolongado y cuasi total como el de la Nueva España, puede plantearse que ambos Estados y sus naciones dominantes -han y mestiza- llevan a cabo formal o informalmente una colonización demográfica en territorios de minorías y ejercen formas de discriminación. Cabe precisar que no todos los han como tampoco todos los mestizos son afluentes o prósperos. Hay pobreza en estos amplios grupos de población. En China diversas fuentes han documentado una creciente colonización de población han hacia territorios de minorías, colonización que ha provocado diversos conflictos sobre la distribución y administración de recursos entre etnias distintas. Por ejemplo, en la Región Autónoma de Mongolia Interior, se estima que la población han representa el $80 \%$, de manera que la etnia de Mongolia es minoritaria en su propio territorio, 17 por ciento.

El asunto de la sobrevivencia cultural de las etnias es un fenómeno globalmente compartido y no es exclusivo de China. Mientras que algunos Estados han impuesto francas políticas asimilacionistas o excluyentes desde las primeras décadas del siglo $\mathrm{XX}$, China ha optado por una política que permite un cierto desarrollo pluricultural que ha tenido más de 50 años. Los resultados de la política China no pueden medirse por igual, mientras que ha contribuido a la revitalización de grupos al borde de la extinción como los yi, ewenka, pumi y elunchun, por otro se muestra reacia a favorecer las aspiraciones político-culturales de tibetanos, dai, uigur o mongoles en la búsqueda de mayor independencia.

China ilustra de manera muy objetiva cómo se aplica la autonomía y la libre determinación. La autodeterminación es sancionada. Primero se trata de una delimitación de territorio; segundo, es una política oficial porque es un asunto de Estado y debe regularse y normarse; tercero, deben ser las minorías que deben ocuparse de sus propios asuntos; finalmente, el Estado debe formar prioritariamente cuadros y profesionales de minorías para intervenir en la administración pública con respecto a la construcción y desarrollo de sus autonomías o modelos de autogobierno local. El financiamiento proviene del Estado y debe ser prioritario.

Por ultimo, China ha hecho un gran esfuerzo en una dirección: los Juegos Olímpicos le dieron la oportunidad de ser parte del mundo global por ellos mismos y han dejado atrás una larga historia de temor y desconfianza al extranjero. Falta otro gran esfuerzo en política interna: abocarse a la construcción de una cultura de respeto a los derechos humanos. La anexión territorial dio lugar a la multietnicidad, sólo respetando los derechos humanos de las minorías se podrá pagar la factura que significó la conquista y colonización interna de territorios y pueblos desde la historia dinástica del imperio y que ha continuado intensamente desde la fundación de la Republica Popular China en 1949 hasta hoy día.

México, en esta dirección, ha perdido la mira. La celebración bicentenaria del Estado en 2010, es un acto irrepetible para celebrar un Estado, es un acto de unidad territorial, de solidaridad y de lealtad. Así como no hay Estados-nación que sean homogéneos en cultura y lengua en el mundo, tampoco es acertado siquiera sugerir que los Estados son étnicamente neutrales, de ahí que debe cobrar gran significado el acto de involucrar políticamente a la diversidad étnica. Así lo entendió y llevó a cabo, por 
ejemplo, el Partido Comunista de la República Popular China, en la ceremonia inaugural de los Juegos Olímpicos de Beijing, en 2008. En contraste con la indiferencia del Estado mexicano, en ese inmenso país asiático se aprovechó la oportunidad para emitir un claro mensaje de multietnicidad y de unidad con el Estado: un conjunto de 56 parejas en edad infantil, ataviados con la indumentaria que caracteriza a cada una de las etnias, enmarcaron el ritual cívico-militar al momento de izar la bandera en el estadio nacional de Beijing, un poderoso simbolismo se presentó ente los ojos del mundo: el Estado chino es multinacional y unitario y fue fundado en conjunto por todas las nacionalidades del país.

En México, con la celebración del bicentenario comprobamos que los pueblos indígenas han sido excluidos de la simbología nacionalista que conmemora el surgimiento del Estado y la construcción de la nación, por las élites políticas e intelectuales que han organizado los festejos. La inexistencia de una política indígena, o bien, su falta de claridad, en el gobierno actual se manifiesta en la exclusión de los indígenas en el programa y en la agenda de las conmemoraciones de la independencia celebradas en 2010. Y esta exclusión simbólica sigue soportando la exclusión estructural y cultural de los pueblos indígenas.

\section{Bibliografía}

-Benson Linda, 2040, “Education and social mobility among minority populations in Xinjiang" Xinjiang China's Muslim Borderland, S. Frederick Starr (ed) M.E. Sharpe, London.

-Bulag Uradyn E., 1998, Nationalism and Hybridity in Mongolia, foreword by Caroline Humphrey Clarendon Press, Oxford.

- Connor Walker, , 1978, "A nation is a nation is a state is an ethnic group is a..." en; Ethnic and Racial Studies, (4) Vol. 1.

- __ 1984, The National Question in Marxist-Leninist Theory and Estrategy, Princeton University Press.

- Constitución de la República Popular China, Ediciones en Lenguas Extranjeras, Beijing, 1982.

- Cotton James, Asian Frontier Nationalism, 1989, Owen Lattimore and the American Policy Debate, Manchester University Press.

- China. Hechos y Cifras 2000, 2000, Editorial Nueva Estrella, Beijing.

- Dalai Lama, 1990, Freedom in Exile. The Autobiography of the Dalai Lama, Harper Collins, Nueva York.

- Cornejo Bustamante, Romer, 2006, China: perspectivas sobre su cultura e historia, Centro de Estudios de Asia y África, El Colegio de México.

- Deng Xiaoping, 1960, La gran unidad del Pueblo Chino y la gran unidad de los pueb/os, Ediciones en Lenguas Extranjeras, Beijing.

-Dillon Michael Xinjiang, 2004, China's Muslim Far Northwest, Routledge Curzon, London and New York. 
-Dudley L Poston jr y Yaukey David (eds), 1992, The Population of Modern China, Plenum Press, Nueva York y London.

-Etxeberria Xavier, 2008, “La plural, conflictiva y procesual autonomía vasca, en; Estados y autonomías en democracias contemporáneas, Natividad Gutiérrez Chong (coordinadora) IISUNAM, Unión Europea y Plaza y Valdés, México.

- "Estadísticas culturales y educacionales de las minorías nacionales" y "Las minorías nacionales de China" en; Beijing Informa (21) 25 de mayo de 1983.

- Gellner Ernest, 1983, Nations and Nationalism, Cornell University Press, Ithaca.

- Guibernau Montserrat, 1998, “El futuro del nacionalismo en las naciones sin Estado", Revista Mexicana de Sociología, (1) enero-marzo:115-130.

- Organización Internacional del Trabajo, Convenio 169 sobre Pueblos Indígenas y Tribales en Países Independientes, 1989, Ginebra.

- Gutiérrez Chong Natividad, 2001, Autonomía étnica en China (29) Cuaderno de Investigación, Instituto de Investigaciones Sociales y Plaza y Valdés.

2006, "China: ¿integración o desintegración territorial?" China en el Siglo XXI. Economía, política y sociedad de una potencia emergente, José Luis Estrada, José Luis León y Ricardo Buzo (coordinadores) Miguel Angel Porrúa y UAM-Iztapalapa.

$\bullet$ 2009, Conflictos étnicos y etno nacionalismos en las Américas. Reportes de Investigación, Quito, Abya-Yala.

-Harrell Stevan (ed), 1995, Cultural Encounters on China's Ethnic Frontiers, University of Washington Press, Seattle y Londres.

- Jones Sian, 1997, The Archeology of Ethnicity. Constructing Identities in the Past and Present, Routledge, Londres y Nueva York.

-Iver, Pico, 2008, The Open Road. The Global Journey of the Fourteenth Dalai Lama, Bloomsbury, London.

- Kedourie Elie, 1970, Nationalism in Asia and Africa, Meridian Books, Cleveland.

-Patterson N. George, 1968 , "Trato dado a las minorías" en; El modelo chino, Werner Klatt (ed), Minerva, México.

- Lattimore Owen, 1950, Pivot of Asia; Sinkiang and the Inner Asian Frontiers of China and Russia, Little Brown, Boston.

- Nuevos avances de los derechos humanos en la región autónoma de Tibet, Oficina de información del Consejo de Estado de la República Popular China, Beijing,1998. - Libertad de creencia religiosa en China, Oficina de Información del Consejo de Estado de la República Popular China, Beijing, 1997.

- Ley de Matrimonio de la República Popular China, Ediciones en Lenguas Extranjeras, Beijing, 1983.

-Mao Tse-tung, 1977, “La relación entre la nacionalidad han y las minorías nacionales" en; Obras escogidas, Ediciones en Lenguas Extranjeras, Beijing.

-ONU, 2007 "Declaración de las Naciones Unidas sobre los derechos de los pueblos indígenas.".

-Pye W. Lucian, 1975, “China: Ethnic Minorities and National Security” en; Ethincity; Theory an Experience, Glazer Nathan y Mohnihan Daniels Eds., Harvard University Press, Cambridge y Londres. 
- Rex John, 1996, Ethnic Minorities in the Modern Nation-State, Macmillan, Londres y Nueva York.

-40 años de la Región Autónoma de la etnia Zhuang de Guangxi, Editorial Nueva Estrella, Beijing, 1998.

-Región Autónoma de Mongolia Interior: 50 años, Editorial Nueva Estrella, Beijing, 1997.

-Sechin Jagchid, "Discrimination agaisnt minorities in China” en; Case Studies on Human Rights and Fundamental Freedom, Martinuos Nijhoff (ed), La Haya, 1975.

-Schurman Franz y Schell Orville, 1980, China Republicana, Fondo de Cultural Económica, México.

-Smith D. Anthony, 1986, The Ethnic Origins of Nations, Basil Blackwell, Oxford.

-Stavenhagen Rodolfo, 1996, Ethnic Conflicts and the Nation-State, Macmillan and St. Martin's Press, Hampshire and New York.

- _ 2008, “La Importancia de la declaración de las Naciones Unidas sobre los derechos de los Pueblos Indígenas", "Suplemento "Mundo Indígena", de Milenio Diario, 3.

-Yi Lin, 2009, Cultural Exclusión in China. State Education, Social mobility and Cultural Difference, Comparative Development and Policy in Asia, Routledge.

-Zang Xiaowei, 2007, Ethnicty and Urban Life in China. A Comparative Study of Hui Muslims and Han Chinese, London and New York, Routledge.

\section{Sitios consultados}

- Lhttp://spanish.peopledaily.com y http://news.bbc.co.uk/2/hi/asia-pacific)

- http://www.globalresearch.ca/index.php?context=va\&aid =9735

- http://www.archive.org/details/uyghurs 


\section{Sobre los autores}

Jenny Acosta Trujillo

Estudió la carrera de Química Farmacéutica-Bióloga en la Facultad de Química de la UNAM. Desde 1997 comenzó sus estudios de idioma chino en el CELE de la UNAM. Terminó sus estudios de idioma chino en 2001, en ese año hizo el curso de Formación de Profesores en el CELE de la UNAM, obtuvo varias becas de actualización y perfeccionamiento. En el año 2011 obtuvo una plaza de Tiempo Completo como Profesor Asociado B en el CELE de la UNAM. Desde enero de 2009 a la fecha es Directora del Instituto Confucio de la UNAM, ubicado en la Antigua Escuela de Economía, en el Centro Histórico de la Ciudad de México, es miembro del Centro de Estudios China-México de la Facultad de Economía y en el 2010 fue nombrada Presidenta de la Asociación Mexicana de Profesores de Chino.

\section{Tatiana Alcázar Carrasco}

Es licenciada en Ciencia Política y Administración Pública por la Universidad Iberoamericana de la Ciudad de México, con una especialidad en comunicación y marketing. En 2003 realizó la Maestría en Estudios Asiáticos en la Universidad de Barcelona, España, especializándose en China. Posteriormente cursó un posgrado en Estudios de Lengua y Cultura China en la Universidad de Lengua y Cultura de Beijing. Participó en varias investigaciones del Centro de Investigación y Estudios Superiores en Antropología social (CIESAS). En 2007 publicó: Los Pueblos Indígenas y los Censos en México y América Latina: la Cultura en la Definición de su Identidad. En Derecho Demográfico. Actualmente se desempeña como directora para Asia y África, en la Coordinación General de Relaciones Internacionales del Gobierno del Distrito Federal.

\section{Eugenio Anguiano Roch}

Es licenciado en economía de la UNAM, estudios de posgrado en las universidades británicas de Leeds y Sussex. Fellow del Centro de Estudios Internacionales de la Universidad de Harvard. Trabajó en las secretarías de Hacienda y Crédito Público y de Relaciones Exteriores (1961-1994). Embajador de México en Costa Rica, China (2 veces), Argentina, Austria y Brasil. Representante permanente de México en Naciones Unidas-Viena; miembro de la Junta de Gobernadores de la Organización Internacional de Energía Atómica; representante suplente de México en el Consejo de Seguridad de la ONU. Profesor e investigador de El Colegio de México (1994-2008), donde también fue director del Centro de Estudios de Asia y África, y coordinador del Programa de Estudios APEC. A partir de enero de 2009 es profesor asociado al Centro de Investigación y Docencia Económicas. Coautor de varios libros, el más reciente: 
La huella global de China: interacciones de una potencia mundial, Colección Prospectiva Global, ElICH-UNAM, 2011.

\section{Liljana Arsovska}

Es licenciada por parte de la Universidad de Idiomas de Beijing (1981-1985), maestra por el Colegio de México (1985-1988) y cuenta con estudios de doctorado por la Universidad de Idiomas de Beijing (desde 2007). Es actualmente profesora-investigadora del Centro de Estudios de Asia y África de El Colegio de México. Cuenta con un grupo de publicaciones, incluyendo el libro de texto Gramática práctica del chino, Colegio de México, 2011, y varias traducciones, incluyendo la de Hui Wei, Shanghai Baby, Planeta (2006); Zhang Ailing, Amor en la ciudad en ruinas, El Colegio de México (2007) y Antología de cuentos contemporáneos de China, el Colegio de México (en proceso de publicación).

\section{Edgardo Bermejo Mora}

Es escritor, periodista y promotor cultural. Es licenciado en Historia por la Universidad Nacional Autónoma de México (1991) y tiene una especialización en Gestión Cultural y Políticas Culturales por la UAM Iztapalapa/OEI. Obtuvo el Premio Nacional de Novela Política, de la Universidad de Guadalajara (1997). Textos suyos forman parte de las antologías Dispersión multitudinaria (Joaquín Mortiz, Ciudad de México, 1997), y Líneas aéreas (Lengua de Trapo, Madrid, 1999). Desde 2002 y hasta 2008 fue agregado cultural de la Embajada de México en la República Popular China. De 2008 a 2010 ocupó el mismo cargo en la Embajada de México en el Reino de Dinamarca. Desde junio de 2011 fue nombrado Director General de Asuntos Internacionales del Consejo Nacional para la Cultura y las Artes. Sus publicaciones más recientes en coautoría son los libros Diplomacia Cultural, un acercamiento, editado por la Universidad de Nuevo León en 2009; y Cuentos a la Mesa, una antología de literatura y gastronomía coordinada por Sara Poot, publicada en 2010 por la Dirección de Difusión Cultural de la UNAM.

\section{Edmundo Borja Navarro}

Tiene estudios de Licenciatura en Administración y de perfeccionamiento del idioma chino mandarín. Obtuvo en 2008-2009 una beca por parte del Gobierno de la República Popular China para realizar estudios de idioma chino mandarín en la Universidad Normal de Shenyang, provincia de Liaoning. Actualmente es profesor de idioma chino en el Centro de Enseñanza de Lenguas Extranjeras (CELE) de la UNAM y secretario técnico del Departamento de Ruso, Lenguas Asiáticas y Griego Moderno del CELE de la UNAM. Ha participado en la elaboración de planes y programas de estudio de los 10 niveles de idioma chino en el Instituto Confucio de la UNAM y ha impartido múltiples cursos del idioma chino en la UNAM.

\section{Flora Botton Beja}

Es profesora-investigadora del Centro de Estudios de Asia y África de El Colegio de México. Tiene una maestría en Filosofía del México City College, una maestría en 
Estudios Orientales de El Colegio de México, estudios de posgrado en la School of Oriental and African Studies de la Universidad de Londres y completó estudios de doctorado en la Universidad de Michigan. En todos los casos se especializó en el área de China. De 1978 a 1980 fue agregada cultural en la Embajada de México en China (1978-1980), directora de la Revista Estudios de Asia y África (1981-1987) y directora del Centro de Estudios de Asia y África de El Colegio de México (1991-1997). Es autora de: China: su historia y cultura hasta 1800 (que se encuentra en la segunda impresión de la segunda edición ), Bajo un mismo techo: la familia tradicional en China y sus crisis (con Romer Cornejo) y coautora de La dinastía Han.

\section{Diego Cándano Laris}

Es actualmente director general adjunto de Asuntos Internacionales de la Coordinación de Asesores de Presidencia de la República. Anteriormente trabajó en la Subsecretaría para América del Norte de la Cancillería. Es licenciado en Relaciones Internacionales por el ITAM y maestro en Política Exterior China en el St Antony's College de la Universidad de Oxford. Además cuenta con estudios en las Universidades de Pekín y de Viena. Fue delegado en el Harvard Project for Asian International Relations en Pekín 2007. Sus áreas de especialización son política exterior, política y gobierno en China y cambio climático.

\section{Flor de María Cañaveral Pedrero}

Es directora general de la Administración Portuaria Integral en Puerto Chiapas. Es la primera y la única mujer a cargo de un Puerto Federal a nivel nacional. Licenciada en Administración Turística egresada de la Universidad Autónoma de Chiapas, Maestría en Administración de Organizaciones por la Universidad Autónoma de México. En Puerto Chiapas, como gerente de Comercialización, logró ingresar por primera vez el arribo de Cruceros en 2006, en febrero de 2007 ingresa al Puerto de Dos Bocas como gerente de Comercialización, donde participa en la promoción del mantenimiento a plataformas petroleras, el arribo por primera vez de cruceros turísticos y fomenta la inversión privada dentro del Recinto Portuario. En septiembre de 2009 regresa a Puerto Chiapas como directora general logrando posicionar nuevos sectores en arribos históricos como son carga contenerizada, granel agrícola, mineral, carga general, cesiones parciales de derechos, entre otros.

\section{Gustavo Adrián Carrillo Jiménez}

Es licenciado en Mercadotecnia por el Instituto Tecnológico y de Estudios Superiores de Monterrey Campus Ciudad de México y está por terminar la maestría en Administración Empresarial en el ITESM. Actualmente se desempeña como jefe del Departamento de Promoción de la Secretaría de Fomento Económico del Gobierno del Estado de Colima y como profesor por asignatura en el área de Mercadotecnia en las Facultades de Contabilidad y Administración y la de Economía de la Universidad de Colima. También se ha desempeñado en el área de investigación de mercados en la empresa Proyecta Mercadotecnia Aplicada y como profesor por asignatura en el Instituto Tecnológico de Colima. Entre las principales distinciones que ha al- 
canzado son mención honorífica por Promedio y Diploma de Desarrollo Estudiantil durante sus estudios de educación superior; asimismo, en el año 2008 participó en el Programa Formación de Negocios México-China.

\section{Romer Cornejo}

Es profesor-investigador en el Centro de Estudios de Asia y África de El Colegio de México. Imparte la cátedra de Historia Contemporánea de China, así como los seminarios Sistema Político de China y Relaciones Internacionales de China. Ha publicado extensamente libros, artículos arbitrados y capítulos de libros sobre sus temas de estudio y participado en diversas conferencias nacionales e internacionales.

\section{María de Lourdes Cuéllar Valcárcel}

Estudió chino en el Instituto de Lenguas Extranjeras de Beijing y ha sido profesora de este idioma desde 1999, laborando en diferentes centros educativos de la Ciudad de México. Es trabajadora social y desde 1989 participa en la corriente Humanismo Universalista donde se ha desempeñado como tallerista, conferencista y organizadora de múltiples eventos sobre humanismo, no violencia y desarrollo humano, tanto en México como en diversas partes de Latinoamérica. Desde 2004 y hasta la fecha se desempeña como profesora definitiva de chino en el CELE de la UNAM, donde además de su actividad docente, es asesora en la modalidad de aprendizaje autónomo. Actualmente está a cargo del proyecto "Introducción del aprendizaje del idioma chino en la Mediateca" y participa en las líneas de Investigación "Aprendizaje Autodirigido" y "Lengua, Cultura y Literatura" del Departamento de Lingüística Aplicada del mismo centro.

\section{Ricardo Román Chang Gamboa}

Es politólogo egresado de la UNAM, conferencista gubernamental entre México y China. Coordinador de la "Expo China-México 2009, 2010 y 2011", organizador de la "Expo Asia-Pacífico" 2011. Asesor en Asuntos Internacionales, Senado de la Republica LVIII y LIX Legislatura 2000-2006. Asesor en la Cámara de Diputados LX Legislatura, Comisión de la Función Pública 2006-2007. Asesor en la Cámara de Diputados LX Legislatura, Comisión de Presupuesto y Cuenta Pública 2007-2008. Secretario Técnico en la Cámara de Diputados LX Legislatura, Comisión de Seguridad Social 2009. Asesor en la Cámara de Diputados LX Legislatura, Grupo de Amistad MéxicoChina 2009. Columnista del Grupo Editorial Milenio, revista Infochannel, Semanario de Negocios para la Industria TIC; Comunidad Portuaria, publicación especializada del sector marítimo y en la revista Manufactura del Grupo Expansión, romanchang@ yahoo.com.mx

\section{Rosalba Delgado Alvarado}

Se incorporó en septiembre de 2011 a Huawei Technologies de México tras una estancia escolar de cuatro meses en la Universidad del Lenguaje de Beijing, China. Es licenciada en Relaciones Internacionales y cuenta con una especialidad en Estudios Internacionales, ambos en el Tecnológico de Monterrey, Campus Ciudad 
de México. Cuenta con siete años de experiencia en asuntos internacionales de la administración pública en dependencias como la Secretaría de Educación Pública, la Secretaría del Trabajo y Previsión Social y la Secretaría de Relaciones Exteriores. Colaboró en instituciones académicas como el Tecnológico de Monterrey y el Centro de Investigación y Docencia Económicas. Actualmente, se desempeña como gerente de Relaciones Públicas de Huawei Technologies de México y es responsable de la relación con dependencias e instituciones del gobierno mexicano.

\section{Enrique Dussel Peters}

Es maestro por la Universidad Libre de Berlín y doctor en Economía por la Universidad de Notre Dame. Desde 1993 trabaja como profesor Tiempo Completo en la División de Estudios de Posgrado (DEP) de la Facultad de Economía de la Universidad Nacional Autónoma de México (UNAM). Coordinador del Campo de Conocimiento de Economía Política (2004-2008) y del Centro de Estudios China-México (2006-) de la Facultad de Economía de la UNAM. Miembro de Sistema Nacional de Investigadores (SNI), nivel 3. Desde su ingreso a la DEP ha impartido numerosos cursos a nivel de licenciatura, maestría y doctorado en México y en el extranjero. Su investigación, docencia, publicaciones y trabajo de consultoría se concentra en organización industrial, economía política, teoría del desarrollo, comercial y regional; análisis de la estructura productiva en México y América Latina; estudios sectoriales (electrónica, hilo-textil-confección, autopartes y automotriz, agroindustria y farmoquímica, entre otros) y territoriales (en México y América Latina); China y la relación socioeconómica con México y América Latina, http://www.dusselpeters.com.

\section{Patricia Espinosa Cantellano}

Es Secretaria de Relaciones Exteriores desde el primero de diciembre de 2006 y miembro del Servicio Exterior Mexicano desde el 16 de septiembre de 1981. Se ha desempeñado como Embajadora de México en la República de Austria, concurrente ante la República Eslovaca y la República de Eslovenia y Representante Permanente de México ante los Organismos Internacionales con sede en Viena; Embajadora de México ante la República Federal de Alemania. Fue Directora de Organismos Internacionales de la Secretaría de Relaciones Exteriores (1989-1991) y responsable de los temas económicos en la Misión Permanente de México ante las Naciones Unidas con sede en Ginebra, entre otros cargos. Licenciada en Relaciones Internacionales por El Colegio de México y estudios de Posgrado en Derecho Internacional por el Instituto Universitario de Altos Estudios Internacionales en Ginebra.

\section{Rafael Fernández de Castro}

Es fundador y jefe y del Departamento de Estudios Internacionales del ITAM. De 2008 a 2011 fue asesor de Asuntos Internacionales de la Oficina de la Presidencia de la República. Ha sido profesor invitado de la Universidad de Harvard y como investigador de The Brookings Institution. Es licenciado en Ciencia Política del ITAM, maestro en Políticas Públicas de la Escuela Lyndon B. Johnson de la Universidad de Texas en Austin y doctor en Ciencia Política por la Universidad de Georgetown. Ha 
publicado y coeditado más de 20 libros sobre política exterior de México y sobre la relación México-Estados Unidos.

\section{Jorge Octavio Fernández Montes}

Es licenciado en Ciencias de la Comunicación por la UNAM. En la República Popular China (RPC), maestro en Política Internacional y doctor en Historia de las Relaciones Diplomáticas de la República Popular China por la Escuela de Relaciones Internacionales de la Universidad de Beijing. Ha participado como ponente en la Associaction of Chinese Political Studies, USA, y ha dado cátedras en la China Youth University for Political Sciences. Su campo de investigación gira en torno a las relaciones internacionales de la RPC en la Guerra Fría, con especial atención a la relación entre México y la RPC. Actualmente labora como asesor para el servicio de noticias internacionales de la Televisión Central de China.

\section{Cecilio Garza Limón}

Es abogado egresado de la Universidad Iberoamericana (1971-75) (mención) con estudios de posgrado en Relaciones Internacionales del Instituto de Estudios Políticos de París, de doctorado de tercer ciclo en la Universidad de la Sorbona y de MBA en Saint Michael's College de Vermont, EU. Ha sido embajador de México ante la República Popular China (1998/2002), la República de Corea (1995/1998) y la República de Mongolia. Representante comercial de México en Francia, Túnez, Argelia y Marruecos (1990/1995); secretario ejecutivo de Fértica S.A., con sede en San José, Costa Rica, para Centroamérica y Panamá; vicepresidente de la Cámara Franco-Mexicana de Comercio e Industria y director general de la empresa paraestatal pesquera Pescado de Colima. Conferencista en temas de negocios en Europa, Asia y América Latina. En 2010 fue nombrado por el Fondo de Población de la ONU coordinador general de la Conferencia Mundial de la Juventud. Actualmente es CFO Namuh, empresa mayorista en decoración y administrador de la empresa Trinational Technogenetics, especializada en biogenética.

\section{José Jorge Gómez Izquierdo}

Es licenciado (UNAM) y doctor (U. Libre de Berlín) en sociología y profesor/investigador del ICSyH de la BUAP y miembro del SNI, nivel II. Con su trabajo de investigación ha demostrado la presencia, importancia y efectos de dominación del racismo en la construcción de la identidad colectiva de México. Tiene un trabajo pionero sobre el racismo antichino en México.

\section{Natividad Gutiérrez Chong}

Es profesora e investigadora titular del Instituto de Investigaciones Sociales, Universidad Nacional Autónoma de México. Pertenece al Sistema Nacional de Investigadores, nivel II. Obtuvo el grado de maestra (MSc) y doctora (PhD) en sociología por la London School of Economics and Political Science, Universidad de Londres. Sus publicaciones sobre etnicidad y nacionalismo incluyen a la República Popular China, México, Guatemala, Inglaterra, Bolivia y Ecuador. Es fundadora y coordinadora del 
banco de datos, Sistema de Consulta de las Organizaciones Indígenas y Conflictos Étnicos en las Américas (SICETNO). Algunas de sus publicaciones son: Conflictos étnicos y etnonacionalismos en las Américas, Abya-Yala, 2009. Estados y autonomías en democracias contemporáneas: Bolivia, Ecuador, España y México, IIS, Plaza y Valdés, Unión Europea en México. Mujeres y nacionalismos en América Latina, UNAM, 2007. Autonomía étnica en China (29) Cuaderno de Investigación, Instituto de Investigaciones Sociales y Plaza y Valdés, 2001.

\section{Carlos Heredia Zubieta}

Es economista egresado del ITAM con maestría en la Universidad McGill de Montreal, Canadá y estudios de doctorado en la Facultad de Economía de la UNAM. Actualmente es director de la División de Estudios Internacionales del Centro de Investigación y Docencia Económicas (CIDE). Fue Profesor Asociado del Programa de Estudios México-China en el propio CIDE. De 2003 a 2008 fue asesor para Asuntos Internacionales y Económicos del gobernador de Michoacán, Lázaro Cárdenas Batel. De 2000 a 2003 fue funcionario en el Gobierno del Distrito Federal. De 1997 a 2000 fue diputado federal de la 57 Legislatura del Congreso de la Unión. Es fundador asociado del Consejo Mexicano de Asuntos Internacionales (COMEXI) y forma parte del Consejo Consultivo del Instituto de México en el Centro Woodrow Wilson en Washington DC.

\section{Carlos Jiménez Macías}

Es senador de la República por el estado de San Luis Potosí en la LX y LXI Legislatura. Presidente de la Comisión de Relaciones Exteriores, Asia-Pacífico y secretario de la Comisión de Relaciones Exteriores, Europa. Como representante del Congreso de la Unión ha participado permanentemente en los trabajos de la Unión Interparlamentaria, presidente del Grupo Latinoamericano y de El Caribe para el periodo (2009-2012), integrante de la mesa de trabajo en materia migratoria, al interior de la Comisión de Población y Desarrollo del Senado de la República, presidente de la Delegación del Congreso de la Unión ante el Foro de Diálogo Parlamentario MéxicoChina, presidente de la Delegación del Congreso de la Unión que participa en las reuniones anuales del Foro Parlamentario Asia-Pacífico.

\section{Simón Levy-Dabbah}

Es presidente de Latinasia Group, empresa donde ha realizado inversiones y exportaciones entre Asia y América Latina. Vicepresidente de China Business Intelligence y de Hebei Boda Investment Group. Representante del Consejo Consultivo de la UPCI de la Secretaría de Economía de México. Es miembro de Agendasia, el primer think-tank entre México y China. Especialista en derecho chino por la Universidad Popular de China. Colaboró en la United States Agency for International Development. Fue el primer abogado mexicano con permiso de trabajo en la República Popular China (2005). Maestro en Administración y Dirección Internacional en el ITAM y la EGADE del ITESM. Abogado con especialidad en comercio exterior, egresado de la Facultad de Derecho de la UNAM. Columnista y autor de 6 libros, entre ellos China 
la nueva fábrica del mundo, La era microglobal y la novela Neonao y catedrático de la UNAM, ITESM, profesor visitante de la UIBE en China. @simonlevyd

Sergio Ley López es arquitecto egresado de la Escuela Nacional de Arquitectura de la UNAM y realizó estudios de posgrado en Historia del Arte en la Universidad de París; Maestría en Restauración de Edificios Históricos en el Instituto de Arqueología de la Universidad de Londres. Director general de Obras Públicas del Ayuntamiento de Culiacán (1969-1973) y director general, gerente y miembro del consejo de administración de varias empresas. Miembro del Servicio Exterior de Carrera a partir de 1984 como agregado cultural a la Embajada de México en la República Popular China (1984-1990) y en diversas funciones en Singapur y la República de Indonesia, cónsul general de México en Shanghai (1993-1994), director general para el Pacífico y Asia de la Secretaría de Relaciones Exteriores (1994-1997). Embajador de México ante la República Popular China (2001-2007). En enero de 2008 fue nombrado presidente del Instituto Asia-Pacífico del ITESM. En marzo de 2009 se le designó presidente de la Sección Empresarial para la Región Asia y Oceanía del COMCE y asesor de la Cámara de Comercio México-China.

Jing Zhou Li Yu (conocido como Jimmy Li en México). Licenciado en Relaciones Internacionales y Comercio Exterior por parte de la Universidad de Estudios Internacionales de Shanghai (1988). Trabajó en el Ministerio de Comercio Exterior y Cooperación Económica de la República Popular China (1988-1989), en Sinochem (China National Chemicals Import \& Export Corporation) (1989-1994) como director de Exportación, asesor de diversos ayuntamientos de México en temas vinculados a asuntos internacionales y China (2000-2011) y asesor de asuntos generales de la Oficina Económica-Comercial de la Embajada China en México (2003-2008). Ha participado activamente con la comunidad china en México durante los últimos 23 años y es miembro del Centro de Estudios China-México de la UNAM. Desde 2001 ha colaborado en diversas funciones con la Confederación General de Asociaciones Chinas en México; actualmente es su secretario general.

\section{Sun Xuedong Liu}

Es egresado de Licenciatura en Economía por la Universidad Popular de China, maestría en la misma carrera por el Centro de Investigación y Docencia Económicas, doctorado por la Facultad de Economía, Universidad Nacional Autónoma de México (UNAM). Actualmente es profesor de Carrera de la Facultad de Estudios Superiores, Aragón, UNAM y miembro del Centro de Estudios China-México de la Facultad de Economía de la UNAM.

\section{Raúl Lomelí Rodríguez}

Estudió las licenciaturas de Ciencias y Técnicas de la Información (Ciencias de la Comunicación) en la Universidad Iberoamericana y Derecho en la UNAM. Trabajó en televisión 25 años: tanto en el manejo de noticias como a nivel de alta dirección. Posteriormente se proyectó como empresario internacional, consultor y estudioso de China. En México y el extranjero ha participado en numerosos foros internacionales: tanto comunicacionales como empresariales. Fundó el Colegio Nacional de 
la Comunicación y es autor del libro Libertad de Difusión Masiva que distingue la libertad de expresión de la libertad en el uso de los medios de comunicación. Escritor, periodista y comentarista en temas de comunicación y China.

\section{Misael López Vergara}

Es licenciado en Economía por la Universidad Autónoma de Guadalajara. Cuenta con un Diplomado en Políticas Públicas por la Universidad de California Berkeley y ha participado en diversos diplomados y cursos en el ITESM, ITESO y el ITAM. Fue director comercial de la Empresa RPK dedicada a proveer insumos a el sector automotriz y electrónico. Fue director de Estadística y asesor del secretario de Desarrollo Económico, secretario técnico de la Asociación Mexicana de Secretarios de Desarrollo Económico (AMSDE). Participa, en representación de la AMSDE, como consejero en diferentes comités relevantes como: Fondo PYME, Comité Intersecretarial de Innovación del Conacyt, Focir, Nafin y Proméxico.

\section{José Ignacio Martínez Cortés}

Tiene estudios de doctorado en Economía Internacional en la Universidad Complutense de Madrid, tienen maestría y licenciatura en Relaciones Internacionales en la Universidad Nacional Autónoma de México (UNAM). Es analista de la economía internacional, comercio internacional y de negocios internacionales. Ha publicado diversos artículos sobre comercio internacional en libros y revistas especializadas. Profesor adscrito al Centro de Relaciones Internacionales de la Facultad de Ciencias Políticas y Sociales de la UNAM. Es profesor del Seminario sobre Competitividad Internacional en el posgrado de la Facultad de Ciencias Políticas y Sociales de la UNAM. También imparte el Seminario de Economía Internacional en la maestría en Negocios Internacionales de la Facultad de Contaduría y Administración en la UNAM. Ocupó el cargo de coordinador del Centro de Relaciones Internacionales de la FCPyS-UNAM. Fue director de Investigación Económica en la Asociación Nacional de Importadores y Exportadores de la República Mexicana.

\section{Omar Martínez Legorreta}

Es licenciado en Ciencias Políticas por la Facultad de Ciencias Políticas y Sociales de la UNAM, maestro en Estudios Internacionales por SAIS, The Johns Hopkins University. Cuenta con estudios de Doctorado en Relaciones Internacionales. Su área de especialización es el Este de Asia y Pacífico. Ha publicado varios libros y artículos académicos. Fue profesor-investigador fundador de la Sección de Estudios Orientales (actualmente Centro de Estudios de Asia y África) de El Colegio de México, del que también fue director. Fue fundador y primer presidente de El Colegio Mexiquense. En el Servicio Exterior Mexicano fue embajador de México en la República Popular China, concurrente ante Vietnam y Camboya; posteriormente ante la República Socialista Federativa de Yugoslavia y Albania. Participó también en la Conferencia General de la UNESCO en 1974. Actualmente es profesor e investigador en El Colegio Mexiquense, donde es coordinador del Programa Interdisciplinario de Estudios sobre Asia-Pacífico. 


\section{Sergio E. Martínez Rivera}

Es doctor en Economía, con la especialidad de Economía de los Recursos Naturales y Desarrollo Sustentable por la División de Estudios de Posgrado de la Facultad de Economía de la UNAM. Profesor investigador del Centro de Estudios China-México (Cechimex) de la misma institución y editor de la revista Cuadernos de Trabajo del Cechimex. Ha sido tutor de proyectos para mejorar la competitividad de la Ciudad de México en el programa de becas "Ciudad de México-China" auspiciado por el Instituto de Ciencia y Tecnología del Distrito Federal. Miembro de la primera generación del Programa Formación de Expertos en Suelo Urbano patrocinado por el Institute Lincoln of Land Policy de Estados Unidos y el Programa Universitario de Estudios sobre la Ciudad de la UNAM. Líneas de investigación: patrón de consumo alimentario y medio ambiente; procesos de urbanización y medio ambiente; procesos de urbanización en China: implicaciones ambientales y sociales.

\section{Jorge Eduardo Navarrete}

Es economista y diplomático mexicano, fue embajador en China de 1989 a 1993. Embajador ahora retirado, sirvió también en Venezuela, Austria, Yugoslavia, Reino Unido, Chile, Brasil y Alemania y en las misiones ante el OIEA, la ONUDI y la ONU. Fue subsecretario de Relaciones Exteriores y de Energía. Es miembro de la Comisión del Sur e investigador en el Centro de Investigaciones Interdisciplinarias en Ciencias y Humanidades de la Universidad Nacional Autónoma de México.

\section{Jorge Nuño Jiménez}

Fue ayudante del presidente de la República, Luis Echeverría Álvarez (1970-1976), agregado militar y aéreo en la Embajada de Francia, República Federal de Alemania y Países Bajos, así como director jurídico del Instituto Nacional de Estadística Geografía e Informática (INEGI) (1992-1994). Actualmente se desempeña como director general del Centro de Estudios Económicos y Sociales del Tercer Mundo (CEESTEM), institución no gubernamental con estatus consultivo de las Naciones Unidas. Ha asistido y participado como conferencista en múltiples institucionales nacionales e internacionales y es representante no gubernamental ante instituciones como la CEPAL, la Comisión Económica para África y el Consejo Económico y Social de las Naciones Unidas, entre otras.

\section{Arturo Oropeza García}

Es doctor en Derecho Económico por la Universidad Nacional Autónoma de México (UNAM), e investigador en el Instituto de Investigaciones Jurídicas de la UNAM. Árbitro no nacional por parte de Brasil dentro del mecanismo de solución de controversias del Mercosur. Autor y coordinador de diversas obras sobre derecho comercial internacional e integración económica, entre las que destacan: BRICS: el difícil camino entre el escepticismo y el asombro, editado en 2011, América del Norte en el Siglo XXI, editado en 2010, El Comercio Internacional y la Gestión Aduanera en el Siglo XXI, editado en 2009; México-China: Culturas y Sistemas Jurídicos Comparados, editado en 2008; China-Latinoamérica: una visión sobre el nuevo papel de 
China en la Región, editado en 2008; China, entre el reto y la oportunidad, editado en 2006; México-Mercosur: un Nuevo Diálogo para la Integración, 2003, etc. Ha impartido conferencias en diversas universidades de China, España, Sudáfrica, Brasil, Argentina, Chile, Perú, Guatemala, etc.

\section{Alexis Rivera Ballesteros}

Es licenciado en economía con mención honorífica por la Universidad Nacional Autónoma de México. Realizó una estancia de investigación en China de agosto a diciembre del 2010 como parte del Programa de Becas México-China del Gobierno del Distrito Federal. Ha colaborado con el Centro de Estudios China-México de la Facultad de Economía de la UNAM y completó el curso del idioma mandarín impartido por el Centro de Lenguas Extranjeras de la UNAM. Actualmente es asistente de investigación en la División de Estudios Internacionales del Centro de Investigación y Docencia Económicas (CIDE). Sus principales líneas de investigación son las relaciones de China con el mundo y en particular con México, y la migración MéxicoEstados Unidos.

\section{Yanfeng Sun}

Es investigador y profesor asociado del Instituto de América Latina del Instituto de Relaciones Internacionales Contemporáneas de China (CICIR). Se dedica principalmente a los estudios de América Latina, y las relaciones sino-latinoamericanas, particularmente los países sudamericanos. Ha visitado, estudiado e investigado en varios países latinoamericanos (Brasil, Argentina, Chile y Venezuela, entre otros). Ha publicado artículos académicos en diarios y revistas chinos..

\section{María Teresa Rodríguez y Rodríguez}

Es investigadora de tiempo completo del Instituto de Investigaciones Económicas (IIEc) de la Universidad Nacional Autónoma de México (UNAM) (1994-) y profesora de la materia de Teoría Económica en la Facultad de Ciencias Políticas y Sociales, UNAM. La línea de investigación en la que se desenvuelve desde su ingreso al instituto cubre una gran diversidad de temas en conexión con la reforma económica en China. Es licenciada en economía por la UNAM; maestra en economía por el Colegio de México (COLMEX) y doctora en economía por la UNAM. Entre sus trabajos de investigación está el libro Agricultura, Industria y Desarrollo Económico. El caso de China, publicado en junio de 2007 por el Instituto Matías Romero, México. Entre sus artículos recientes están: “Búsqueda de un nuevo tipo de desarrollo en China: propósitos del último plan quinquenal de desarrollo" en la revista Dimensión Económica de octubre 2011 del IIEc, UNAM. Tiene además el Cuaderno de Trabajo de Cechimex denominado "El sistema financiero de China: heterodoxia política" de junio de 2011.

\section{Kuan Tai}

Estudió ingeniería eléctrica en Florida Institute of Technology (Estados Unidos) y obtuvo la Maestría en Negocios por la University of Michigan. Fundador del restau- 
rante Oriental Omei en el Hotel Nikko en México, se dedica a la organización de la Feria Internacional Expo China-México desde el 2009 (posteriormente la Expo Asia Pacífico-México). Actualmente también asesora a empresas chinas que desean invertir en proyectos de ingeniería en Latinoamérica, así como en el reciclaje de basura, construcción de centrales hidroeléctricas y la explotación y exploración minera de hierro y cobre, entre otras actividades.

\section{Enrique Tejeda Canobbio}

Es administrador de empresas y economista, con Maestría en Prospectiva Estratégica (ITESM) y Doctorado en Economía Política (UNAM). Ha laborado en los sectores académico, privado y público. Actualmente se desempeña como Coordinador de Asesores de uno de los cuatro consejeros independientes en el Consejo de Administración de Pemex, donde maneja, entre otros, temas de estrategia de negocios e inversiones.

\section{Oscar Eduardo Toulet Lazos}

Ha colaborado en Huawei Technologies de México por 6 años. Durante este tiempo ha fungido como director de cuenta, director de control interno, director de asuntos con gobierno y actualmente como vicepresidente de asuntos Públicos y comunicaciones. Es responsable de transmitir la imagen corporativa de Huawei en México. Se desempeñó en otras empresas líderes del ramo de la tecnología y las telecomunicaciones como Ciena, NET y AT\&T. Es ingeniero en electrónica por la Universidad Metropolitana de la Ciudad de México y cuenta con estudios de posgrado en Alta Dirección por la Universidad Anáhuac en México.

\section{Yolanda Trápaga Delfín}

Es doctora en economía por la Universidad de París VIII y profesora titular de tiempo completo de la División de Estudios de Posgrado de la Facultad de Economía de la UNAM. Responsable del Centro de Estudios China-México y actualmente coordinadora del Campo de Conocimiento de Economía Política del Posgrado en Economía de la UNAM. Sus líneas de investigación y docencia: políticas agrícolas, sistema de producción agrícolas alternativos y agroindustriales, comercio internacional, desarrollo sustentable y China.

\section{Rafael Valdez Mingramm}

Es fundador y expresidente de la Cámara de Comercio de México en China (Mexcham). Empresario y banquero en Shanghai, fundó y dirige Hyperlink "http://www. laREDchina.com" www.laREDchina.com, la red social más importante que conecta a China con Iberoamérica. Fue socio fundador y es miembro del Consejo Asesor de SinoLatin Capital, firma que promueve inversiones chinas en América Latina. Anteriormente trabajó en ChinaVest, el primer fondo de capital de riesgo en China Continental. De 2004 al 2006, en la Ciudad de Nueva York, asesoró a ProVentures, un fondo de capital privado y al Instituto Synergos. En su ciudad natal, estuvo al frente del área de negocios de la Casa de Moneda de México y presidió Fundación EDUCA 
México. Es licenciado en Economía del ITAM, estudió una Maestría en Economía y Políticas Públicas en la Universidad de Columbia y un MBA en China Europe International Business School (CEIBS).

\section{Eloy Vargas Arreola.}

Licenciado en administración y Postgraduado en planeación y promoción de inversion; postulante de la maestría en administración. Socio fundador y presidente de un grupo de pequeñas y medianas empresas de diferentes giros. Productor de limón persa y aguacate. Consultor asociado de empresas de consultoría política y de administración pública. Presidente de la Cámara de Comercio de Morelia, Michoacán y vicepresidente del Consejo Coordinador Empresarial, coordinador del equipo de transición en el gobierno de Lázaro Cárdenas Batel,

secretario de Desarrollo Económico del estado de Michoacán durante dos administraciones. Presidente de la Asociación de Secretarios de Desarrollo Económico (AMSDE) por un periodo de 3 años. Candidato a la presidencia municipal de Morelia y delegado de México en el foro económico Asia-Pacífico APEC desde 2002 y consejero de la Administración Portuaria Integral del Puerto de Lázaro Cárdenas.

Jing Wang (王静)

Tiene licenciatura en lengua española por la Universidad de Qingdao, en la ciudad de Qingdao, provincia de Shandong, República Popular China (agosto 2006-agosto de 2009). Tiene maestría en Política Pública y Administración por la Universidad Carnegie Mellon, de Pittsburgh, Pennsylvania, Estados Unidos; fue estudiante de intercambio en el CIDE en México DF.

\section{Yongheng Wu}

Es periodista de carrera graduado con honores de la Universidad de la Habana, Cuba, en la Facultad de Humanidades. Inició su carrera como periodista en 1970 en la Agencia de Noticias Xinhua y ocupó puestos redactor, corresponsal en jefe del Departamento Internacional de la Agencia en Beijing, después como director general de la Oficina Regional para América Latina en México y subdirector del Departamento Internacional de la Agencia (1997-1998). De 2001 al 2004 fue subdirector del Departamento de Asuntos Internacionales y subdirector Ejecutivo de la Comisión de Oficinas Sucursales en Ultramar de Xinhua. Conferencista en universidades públicas y privadas en América Latina y México. Actualmente es director general para América Latina de la Revista China Hoy, edición en lengua española, con sede en la Ciudad de México.

\section{Shouguo Yang}

Es doctor en Relaciones Internacionales, subdirector del Instituto de Estudios de América Latina del China, Instituto de Relaciones Contemporáneas Internacionales (CICIR, por sus siglas en inglés). Su investigación se concentra en relaciones entre China y América Latina, relaciones entre Estados Unidos y América Latina, estudios de México y Cuba, entre otros. 


\section{Zhimin Yang}

Obtuvo su doctorado en Economía Mundial de la Escuela de Posgrado de la Academia China de Ciencias Sociales (CASS) en 2006. Ha trabajado en el Instituto de Estudios de América Latina (ILAS) del CASS desde 1998. Es investigador titular y director ejecutivo del Departamento de Economía del ILAS. Su investigación se concentra en las relaciones económicas China-América Latina, la integración regional en el hemisferio occidental y los vínculos económicos bilaterales entre China y México en particular. También es autor (o coautor) de muchos libros, artículos y documentos en estas áreas de investigación. Fue investigador visitante en KIEP (Corea, 2006), BA (UK, 2006), UCSD (EU, 2007) y Cechimex/UNAM (México, 2010), respectivamente. Ha impartido conferencias y presentaciones internacionales de alto nivel: Conferencia Wilton Park, Londres (2006), Universidad de Oxford (2006), World Economic Forum (2007), Fundación Rosa Luxemburg (2009) y LASAK (2011).

\section{Lingyan Zhou Li}

Es médica cirujana por la Facultad de Medicina de la UNAM. Tiene maestría y doctorado en Ciencias Fisiológicas, Instituto de Investigaciones Biológicas de la UNAM. Presidenta y fundadora del Instituto Cultural Chino Huaxia. Directora del Instituto Confucio de la Ciudad de México. 

Universidad Nacional Autónoma de México

"40 años de la relación entre México y China. Acuerdos, desencuentros y fututro"

Esta edición se terminó de imprimir en el mes de febrero de 2012 en los talleres de Editores Buena Onda, S.A. de C.V.

Suiza 14, Col. Portales Oriente, México 03570, D.F.

Su composición se realizó con las familias tipográficas:

Zurich Bt 6.5:8; 7:9; 8:12; 9:12; 10:12; 15:15

El tiraje consta de 1,000 ejemplares

El cuidado de la edición estuvo a cargo de

Dr. Ricardo Arriaga Campos 